.
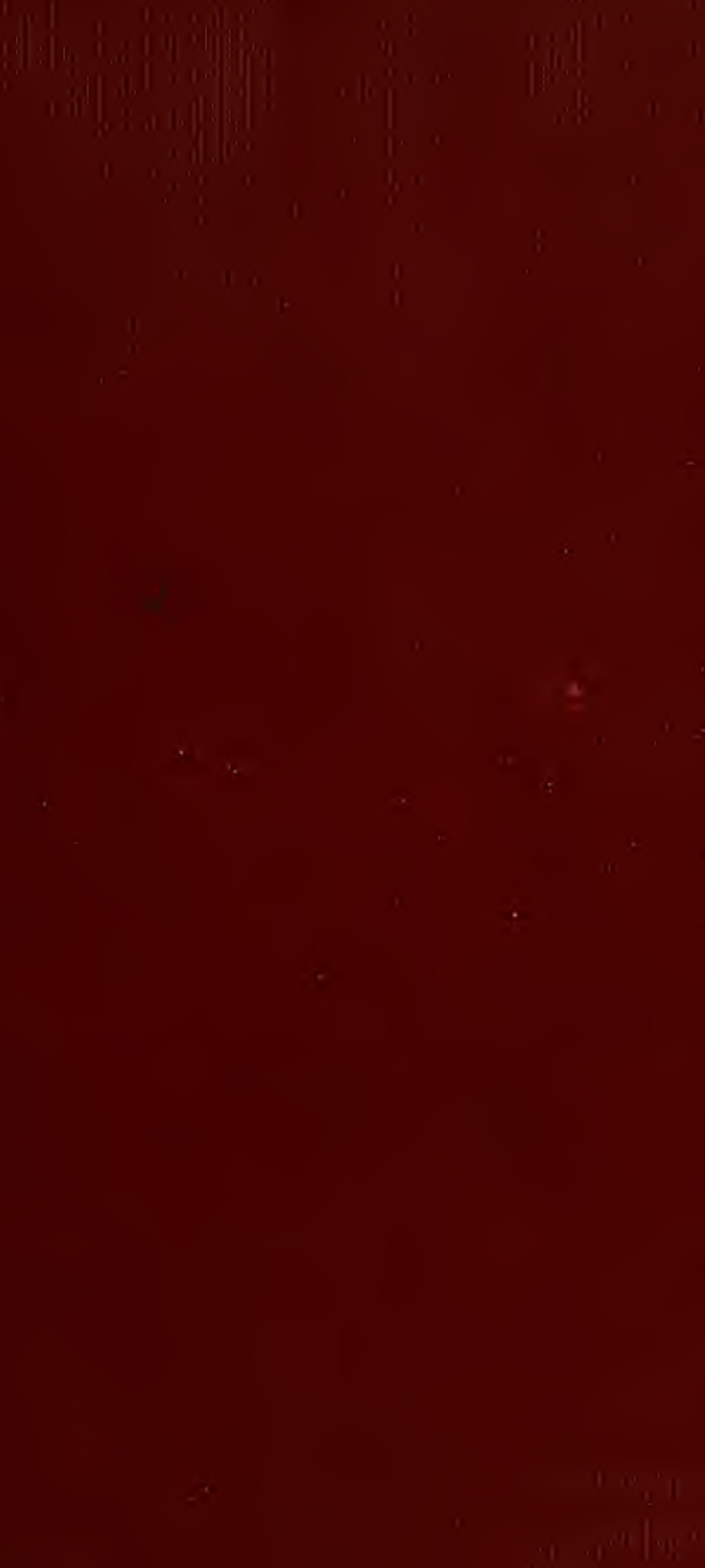
Vebostor Family LIUI di y Ui Velerinary Modicing

Cummings Schoo! or '/eterinary Modicine of?

Tults Unwersity

200 Westboro Road

North Grafton, MA 01530 


$$
\begin{aligned}
& \text { HLlíasm } \\
& \text { 6/15. Litu", 4 Can- }
\end{aligned}
$$





\title{
VETERINARY \\ STATE BOARD QUESTIONS \\ AND ANSWERS
}

\author{
BY \\ V. G. KIMBALL, D.V.M.
}

ASSISTANT PROFESSOR, VETERINARY MEDICINE, UNIVERSITY OF PENNSYLVANIA

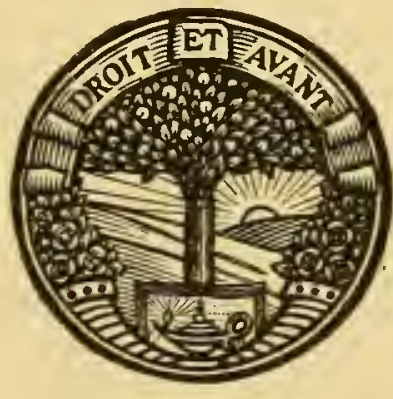

PHILADELPHIA AND LONDON

J. B. LIPPINCOTT COMPANY 
COPYRight, I9I 4

BY J. B. LIPPINCOTT COMPANY

Electrotyped and Printed by J. B. Lippincott Company The Washington Square Press, Philadelphia, U.S.A. 


\section{PREFACE}

BeING intimately associated with veterinary students, the author is fully aware of the feelings of fear and mysticism with which they are possessed when confronted with the ordeal of taking a State Board examination. Partly to dispel these fears, but more to provide a means of selfquizzing, this work was undertaken.

A large number of State Board questions from ten of the more representative eastern and a few of the middle and western States have been sorted over. Those contained herein represent what was left after eliminating hundreds of duplicates. The few duplications which remain serve to illustrate the close relationship of the various subjects to one another. The overlapping and the necessary process of elimination resulted in the abbreviation of some subjects, especially Sanitary Science, Pathology and Zoötechnics, to a considerable degree. Many topics, considered elsewhere, might rightly have been inserted under these headings.

The author lays no claim to literary genius or bombastic propensities. The aim has been to supply brief, accurate answers, and this has been done many times at the expense of grammatical precision.

The extensive library of the Veterinary School of the University of Pennsylvania, being at my disposal, has been thoroughly perused and the highest authorities on the different phases of veterinary science have been carefully consulted and compared. It would be impossible to make acknowledgment to all in the space allotted.

To my colleagues, with whom it is a privilege to associate, and who have endeared themselves by their valuable suggestions and advice, my heartfelt thanks are due.

It is the author's hope that this humble beginning will meet the student's demand for a means of self-interrogation in preparing for State Board and Civil Service examinations. Incidentally, by reason of the complete index, it may, in a measure, satisfy the need of a convenient, complete, reliable reference book on veterinary science. To the end that this may be accomplished, criticisms and suggestions will be cheerfully rcceived.

MAY, 1914.

V. G. Kimball. 



\section{CONTENTS}

CHEMISTRY

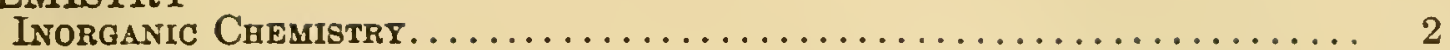

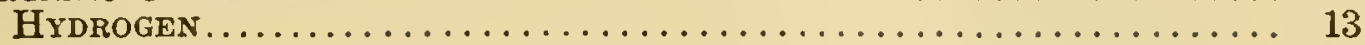

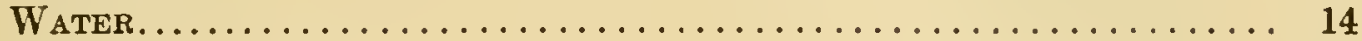

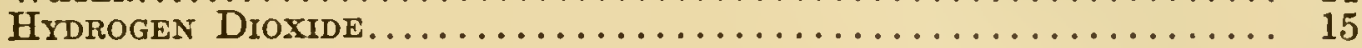

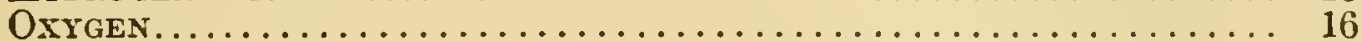

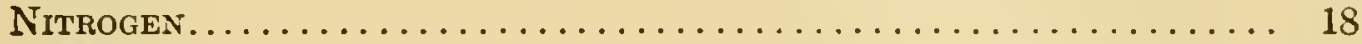

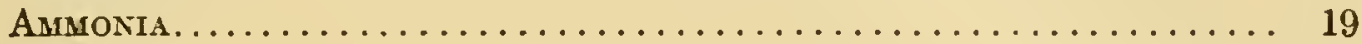

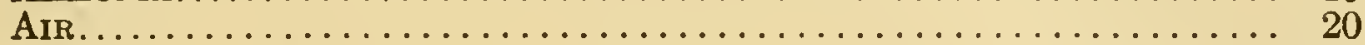

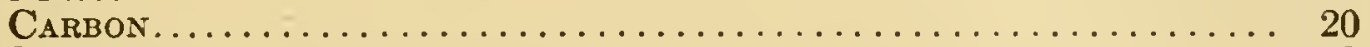

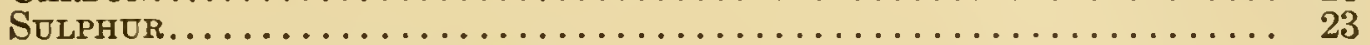

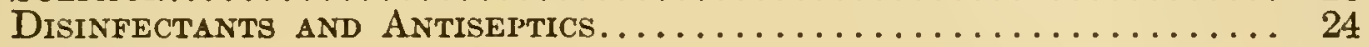

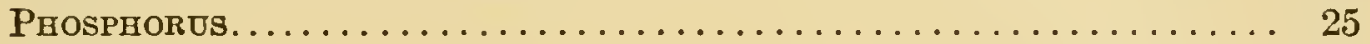

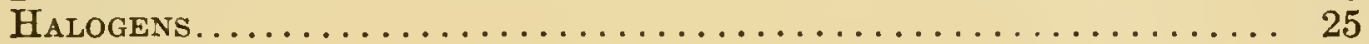

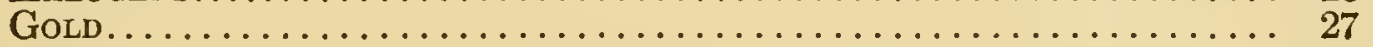

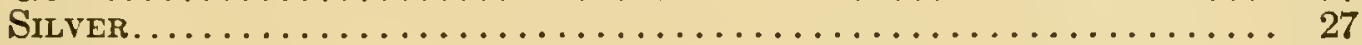

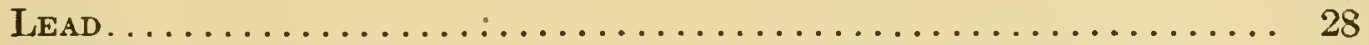

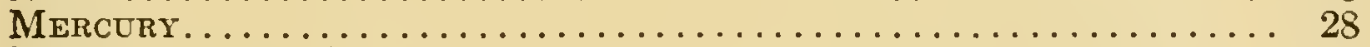

Metals of the Alkalies........................... 29

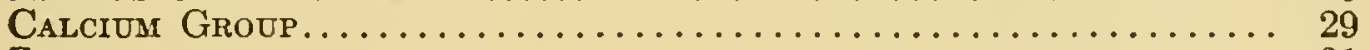

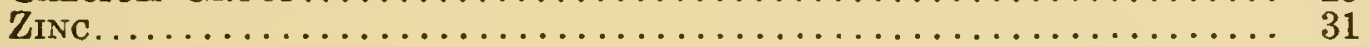

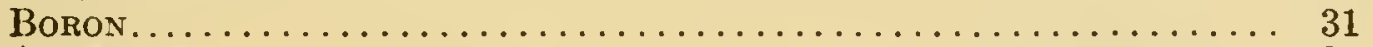

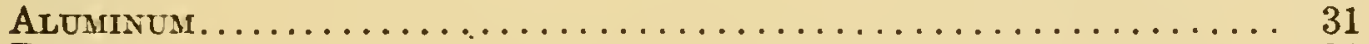

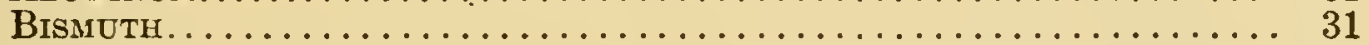

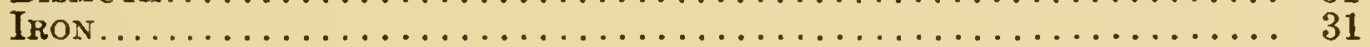

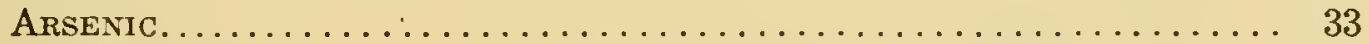

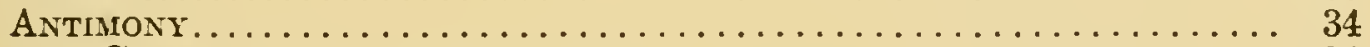

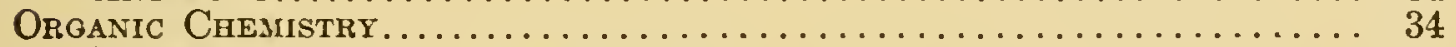

Fermentation and Putrefaction. ................... 34

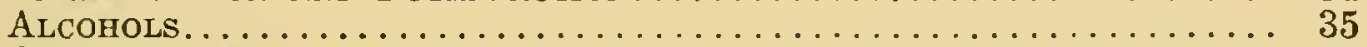

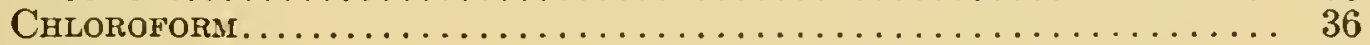

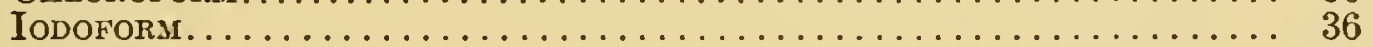

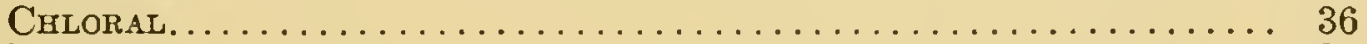

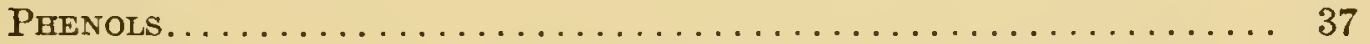

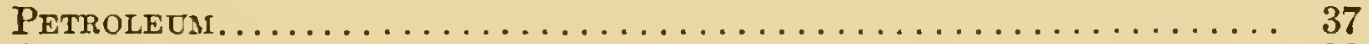

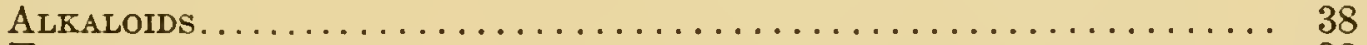

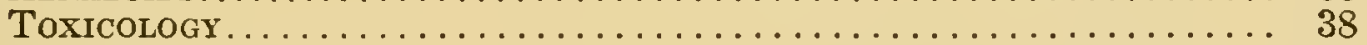

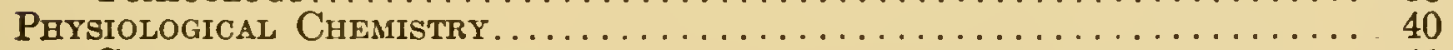

Carbohydrates.............................. 41

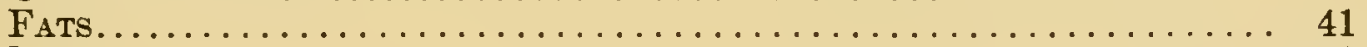

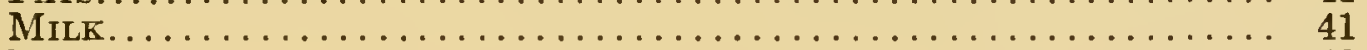

URINE. . . . . . . . . . . . . . . . . . . . . . . 42

ANATOMY

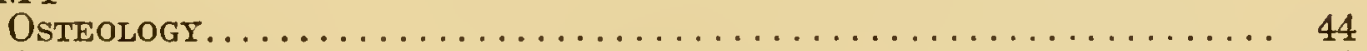

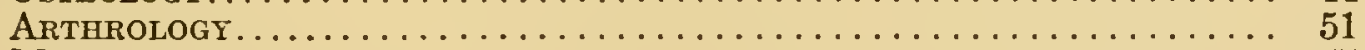

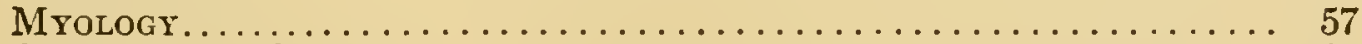

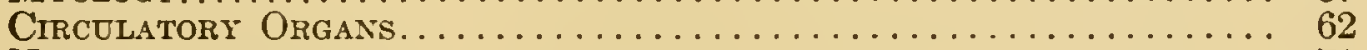

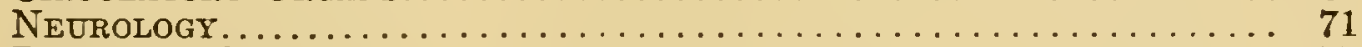

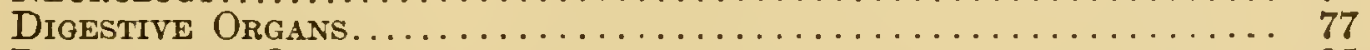

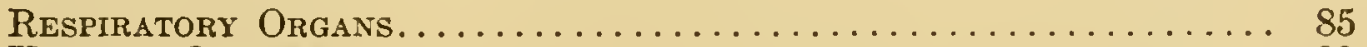

URINARY Organs................................ 89

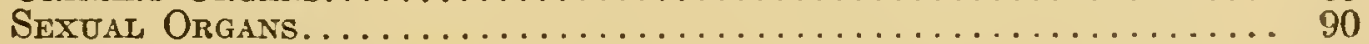

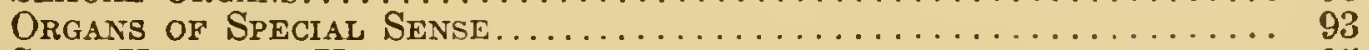

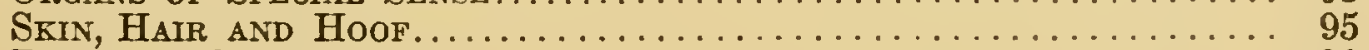

Ductless Glands................................ 96

ToPOGRAPHICAL ANATOMY............................... 98

Histological ANAtomy. . . . . . . . . . . . . . . . . . . . 99 
PHYSIOLOGY

BLOOD. . . . . . . . . . . . . . . . . . . . . . . . . . . . . . . . 106

Heart. . . . . . . . . . . . . . . . . . . . . . . . . . . . . . 109

Blood-VEsSELS. . . . . . . . . . . . . . . . . . . . . . . . . . 110

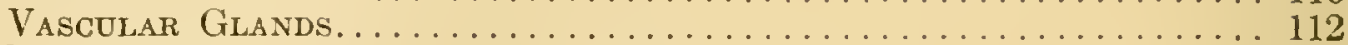

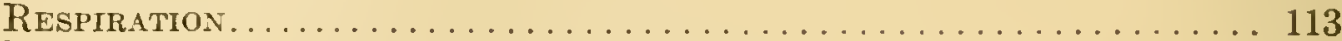

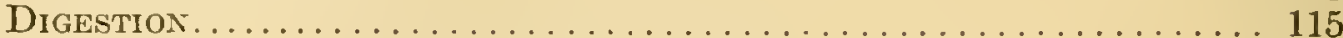

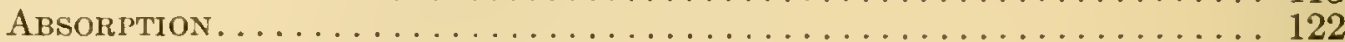

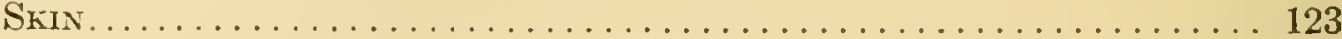

URINE....................................... 125

Nutrition. . . . . . . . . . . . . . . . . . . . . . . . 126

Animal Heat..................................... 128

Muscular System................................. 130

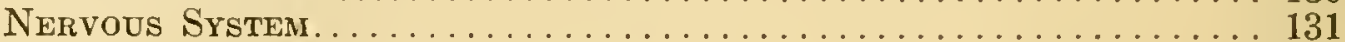

SENSES................................... 136

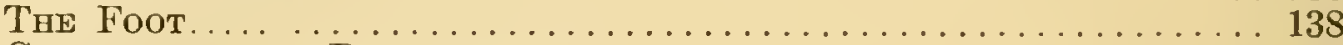

Generation and Development......................... 139

PATHOLOGY

HYPERTROPHY AND ATROPHY............................ 143

Degenerations.................................. 143

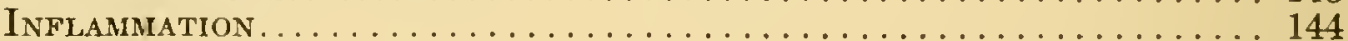

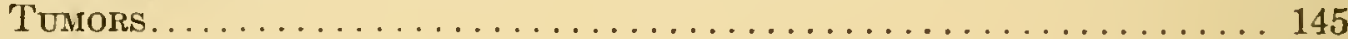

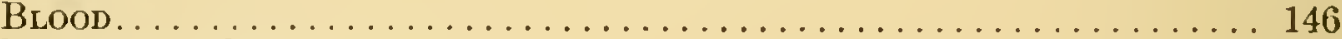

BONES AND JOINTS.................................... 147

Heart and Blood-vessels . . . . . . . . . . . . . . . . . . . . 148

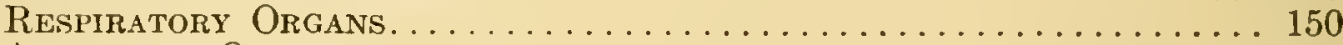

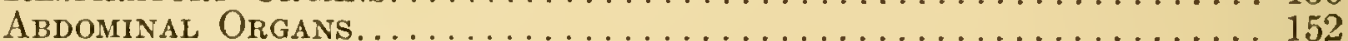

Genito-URinary Organs........................... 153

Nervous System............................. 155

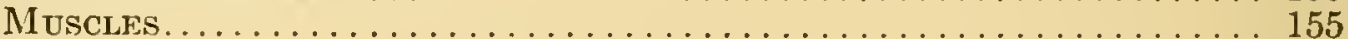

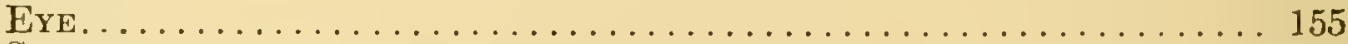

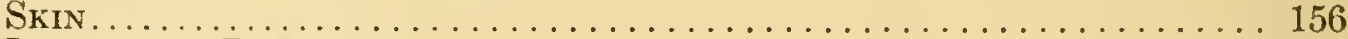

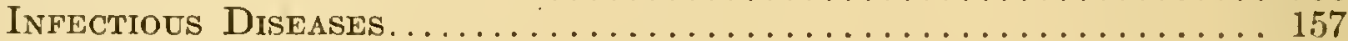

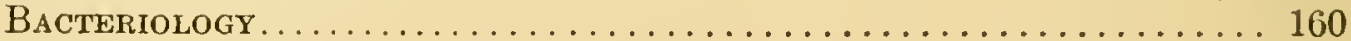

THEORY AND PRACTICE OF MEDICINE

General and Differential Diagnosis................... 165

Acute General Infectious Diseases.......................... 172

Chronic Infectious Diseases......................... 179

Disfases of Blood and Blood-forming Organs............. 182

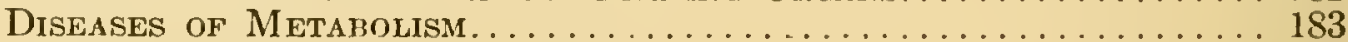

Diseases of the Urinary Organs..................... 184

Diseases of the Circulatory Organs................. 186

Diseases of the Respiratory Organs........................ 188

Diseases of the Digestive Organs...................... 191

Diseases of the Nervous System........................ 199

Diseases of the Organs of Locomotion ................... 201

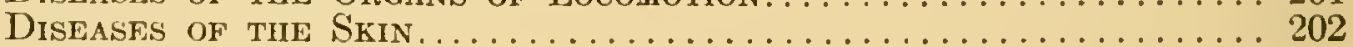

\section{SURGERY}

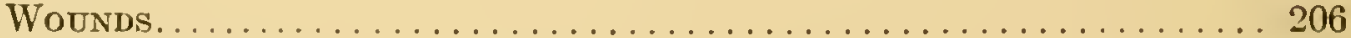

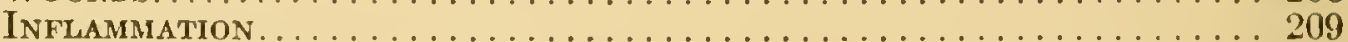

Ulcer, Fistula and Gangrene...................... 210

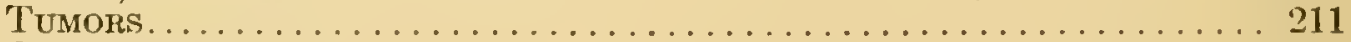

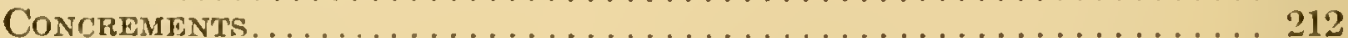

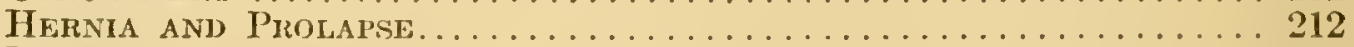

BONES...................................... 212

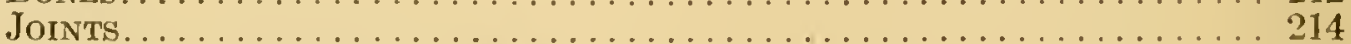

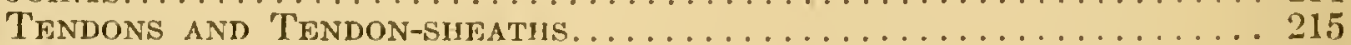

Muscles and Nerves.............................. 216

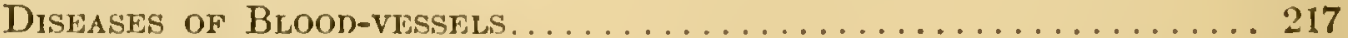

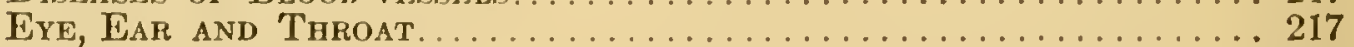

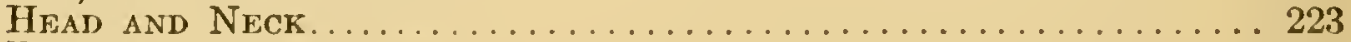

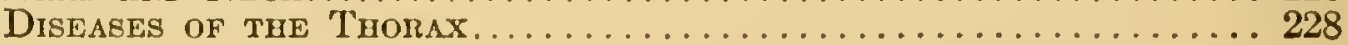


Diseases of the Abdomen.......................... 229

Diseases of The' Urinary Organs..................... 232

Diseases of the Generative Organs.................. 234

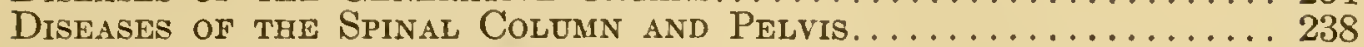

Diseases of the Fore Limb......................... 239

Diseases of the Hind Linib........................ 245

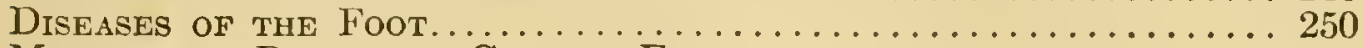

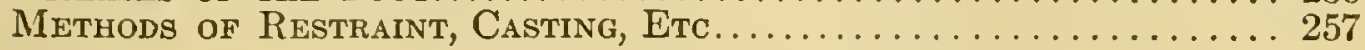

OBSTETRICS

Obstetrical Anatomy............................ 259

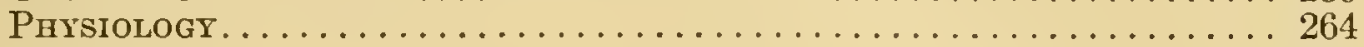

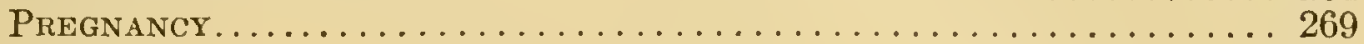

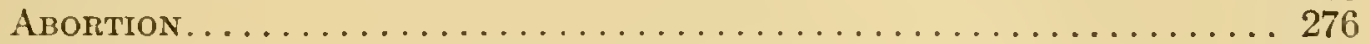

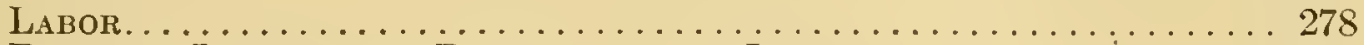

Diseases Incident to Pregnancy and Labor.................... 284

Diseases of the New-Born. . . . . . . . . . . . . . . . . . . 294

MATERIA MEDICA AND THERAPEUTICS

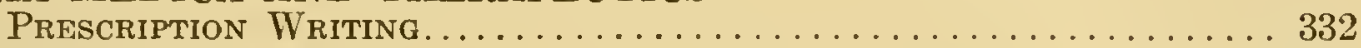

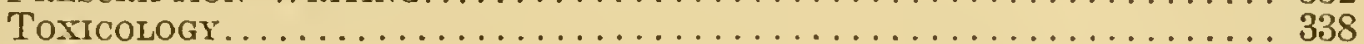

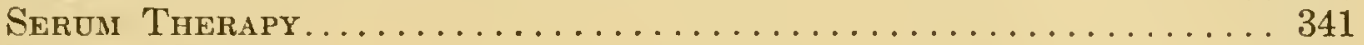

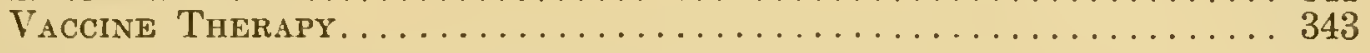

SANITARY SCIENCE-MEAT AND MILK HYGIENE

Air and Ventilation............................. 346

Infectious Diseases . . . . . . . . . . . . . . . . . . . . . . 347

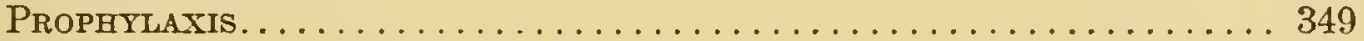

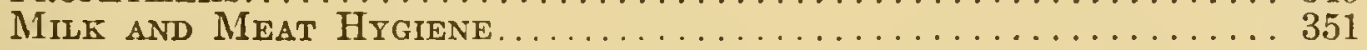

ZOÖTECHNICS................................... 360

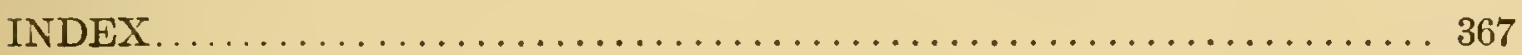





\section{VETERINARY STATE BOARD QUESTIONS AND ANSWERS}

\section{CHEMISTRY}

Distinguish between chemistry and physics.

Physics is the science of matter and energy. It deals with those changes in matter which do not involve a change in composition. It also deals with the doctrine of equilibrium and with that of motions. The latter are visible, as those of mass, in fall, projection, rotation, propagation in a plane, etc.; or invisible, and only perceptible by their results, as sound, heat, light and electricity.

Chemistry reveals to us the composition of matter, and in the formation of new compounds, acquaints us with the rules and laws by which its various forms act upon one another. It deals with those changes in matter which do involve a change in composition.

Define specific gravity. If the specific gravity of a substance is I.5,

how many c.c. of distilled water will ten grammes represent?

The specific gravity of a substance is the ratio between the weight of any volume of the substance and the weight of a like volume of some other substance taken as a standard. For solids and liquids, the standard is distilled water at its temperature of maximum density; for gases and vapors, the standards are hydrogen and air at a temperature of $0^{\circ} \mathrm{C}$. and a barometric pressure of 76 centimetres of mercury.

If the specific gravity of the substance in question is $1.5,10$ grammes would equal 15 grammes of water; 1 gramme of water equals 1 c.c., hence 15 grammes would equal 15 c.c.

How is the specific gravity of a liquid determined?

There are several ways. The hydrometer is usually employed, or comparisons can be made of the weights of equal volumes of the liquid and water.

What effect on the volume of a gas has (a) change of pressure, (b) change of temperature?

(a) The volume of a gas varies inversely as the pressure upon it (Boyle's law).

(b) All gases approximately expand equally for equal rises of 
temperature. Theoretically, at 273 degrees below zero (absolute zero) the gas becomes nothing, and for each degree of rise in temperature it expands $\frac{1}{273}$ of the volume which it occupied at $0^{\circ} \mathrm{C}$.; hence 273 volumes of air at $0^{\circ} \mathrm{C}$. becomes 274 volumes at $1^{\circ} \mathrm{C}$., 275 at $2^{\circ}$ C., etc.

\section{Describe the process of electro-plating.}

This process depends upon electrolysis, that is, the decomposition of a chemical compound, the electrolyte, into its constituent parts, called ions, by an electric current. In a battery or in an electrolytic bath, the metallic, or electropositive ion is carried with the current through the electrolyte. Similarly, when a chemical salt is electrolysed, the metallic base is carried to the cathode (the negative pole of the battery). Therefore, by attaching the object to be plated at the cathode in a bath composed of a silver, gold or copper solution, it will become coated, or plated, with silver, gold or copper.

\section{Define evaporation, electrolysis, amorphism, dialysis.}

Evaporation is the process of converting a substance, especially a liquid, into a vapor.

Electrolysis-see answer to preceding question.

Amorphism relates to the non-crystalline character of some substances, such as starch and glue.

Dialysis is the passing of a dissolved substance through a diaphragm of parchment into another liquid.

Convert (a) $104^{\circ} \mathrm{F}$. to its equivalent in Centigrade degrees, (b) $38^{\circ} \mathrm{C}$. to Fahrenheit scale.

(a) $\left(104^{\circ} \mathrm{F} .-32\right) \times \frac{5}{8}=40^{\circ} \mathrm{C}$.

(b) $\left(38^{\circ} \mathrm{C} . \times \frac{9}{5}\right)+32=100.4^{\circ} \mathrm{F}$.

\section{INORGANIC CHEMISTRY}

Define chemistry.

Chemistry is the science which treats of the properties and composition of substances, their changes in composition and the phenomena attending such changes. The subject of chemistry is divided for convenience into inorganic, organic and physiologic.

State the difference between a chemical and a physical change, with an example of each.

A chemical change is one occurring in the molecules of matter in which the substance or substances lose their identity by the formation of new substances. Example: Paper, when burned, yields carbon dioxide, water and some charcoal.

A physical change is one occurring in a mass of matter in which 
the substance retains its original composition. Example: Water, changing into ice or steam.

Define the following terms : analysis, synthesis, atom, molecule, combustion, chemical affinity, compound.

Analysis is the process of determining the composition of a substance. There are two kinds, qualitative and quantitative.

Synthesis is the artificial building up of a chemic compound, by the union of its elements.

An atom is, theoretically, the smallest particle of an element which can exist.

A molecule is, theoretically, the smallest particle of a compound that can exist.

Combustion is oxidation accompanied by the development of heat and light.

Chemical affinity is the affinity or attraction which exists between the atoms of certain substances.

A compound is a substance made up of two or more elements, united to each other in definite proportions:

\section{Define and illustrate acid, base, salt, alkali.}

An acid is a compound having electronegative, or anionic, properties and containing hydrogen which is replaceable by metals to form salts. It produces hydrogen ions when dissolved in water or other dissociating liquids. Acids change blue litmus to red. Example: hydrochloric acid, $\mathrm{HCl}$.

A base is a substance which unites with an acid to form a salt. Bases produce hydroxyl ions when dissolved in water or other dissociating liquids. Example: Zinc unites with sulphuric acid to form zinc sulphate.

A salt is a compound formed by the union of a base with an acid. Example: Iron sulphate is formed by the action of sulphuric acid on iron.

An alkali is a soluble substance having strong basic (electropositive) properties, usually applied to the oxides and hydroxides of the alkali metals and metals of the alkali earths. Such substances are very soluble in water, change red litmus to blue, unite with and neutralize acids, forming salts, and emulsify fats. Example: potassium and sodium.

Define efflorescent substance, deliquescent substance. Give an example of each.

An efflorescent substance is one which is converted from a crystalline solid to an amorphous powder on exposure to the air, 
due to the loss of its water of crystallization. Example: crystalline sodium sulphate, exposed to the air, becomes a white powder.

A deliquescent substance is one which can be converted from a solid salt into a liquid form by the absorption of moisture from the air. Example: calcium chloride left in an open vessel for a few days will become wet and in time will even liquefy.

Define acid salt, amalgam, molecular repulsion, neutralization.

An acid salt is one in which only part of the hydrogen of an acid is replaced by a metal or basic radical. Example: $\mathrm{NaHSO}_{4}$.

An amalgam is an alloy containing mercury, as tin and mercury.

Molecular repulsion is the term applied to the tendency of molecules to separate. According to the theory of the constitution of matter, the molecules of every mass are in ceaseless motion, hitting and rebounding from one another. In gaseous masses, the molecules move without restraint; hence gases always tend to expand.

Neutralization is the term applied to the interaction between acids and bases with the result that both acid and basic properties disappear, i.e., are neutralized. It consists in the union of the hydrogen ion of an acid with the hydroxyl ion of a base to form water.

Define valence and write formulas of four compounds containing elements having different valences, indicating the valence in each case.

Valence is the definite capacity which every elementary atom has for uniting with other atoms. Hydrogen is taken as the standard and its valency is assumed to be unity. In $\mathrm{HCl}, \mathrm{Cl}$ is univalent because it combines with one atom of $\mathrm{H}$; in $\mathrm{H}_{2} \mathrm{O}, \mathrm{O}$ is bivalent; in $\mathrm{NH}_{3}, \mathrm{~N}$ is trivalent; in $\mathrm{CH}_{4}, \mathrm{C}$ is quadrivalent.

Define monad, diad, triad, tetrad, pentad. Give an example of each.

Monad is an element having a valency of one; diad, a valency of two; triad, three; tetrad, four; pentad, five.

Examples: see preceding answer; pentad, phosphorus as in $\mathrm{PCl}_{5}$.

Define monobasic acid, dibasic acid, tribasic acid. Give an example of each.

A monobasic acid is one containing in its molecule one replaceable atom of hydrogen, as nitric acid, $\mathrm{HNO}_{3}$.

A dibasic acid is one having two replaceable atoms of hydrogen in its molecule, as sulphuric acid, $\mathrm{H}_{2} \mathrm{SO}_{4}$. 
A tribasic acid is one having three replaceable atoms of hydrogen in its molecule, as phosphoric acid, $\mathrm{H}_{3} \mathrm{PO}_{4}$.

Define crith, atomic weight, and molecular weight.

$A$ crith is the unit of weight for gases, it being the weight, in a vacuum, of a litre of hydrogen gas at $0^{\circ} \mathrm{C}$. A crith $=0.0899$ gramme.

Atomic weight is the weight of an atom of a substance compared with the weight of an atom of hydrogen which is taken as unity. (In scientific work, oxygen is taken as the standard, but the U.S.P. takes hydrogen.)

Molecular weight is the sum of the atomic weights of the element or elements contained in a molecule of a substance.

\section{Define allotropism and reduction.}

Allotropism is the property possessed by certain elements of presenting themselves in two or more different forms, as the allotropic forms of carbon, seen in the diamond, charcoal and graphite.

Reduction is the process of abstracting oxygen from an oxide. (This is a generally accepted definition, although the subject of reduction has a deeper significance, as may be instanced in the reduction of calomel with stannous chloride, which also involves the subject of valence. $\mathrm{SnCl}_{2}+2 \mathrm{HgCl}=\mathrm{SnCl}_{4}+\mathrm{Hg}_{2}$. See oxidation, p. 16.)

\section{What is a metal?}

A metal is an element which is predominantly basic in its chemi. cal behavior. Metals are solid at ordinary temperature, except mercury, usually opaque, have a more or less metallic lustre, are malleable, ductile, tenacious, good conductors of heat and electricity, and are capable of forming basic substances and salts.

\section{What is meant by isomerism?}

Two or more compounds which contain the same elements in the same relative proportions by weight in the molecule, but differ more or less widely in their physical, chemical and physiological properties, are called isomeric, e.g., $\mathrm{C}_{3} \mathrm{H}_{6} \mathrm{O}_{3}$, lactic acid, and $\mathrm{C}_{6} \mathrm{H}_{12} \mathrm{O}_{6}$, grape sugar.

Define chemical action. Name three kinds and give an example of each.

Chemical action refers to the changes taking place in two or more elements when brought in contact or disintegrated.

Light: Silver chloride decomposes in the presence of light.

Heat: Heat decomposes red oxide of mercury into mercury and oxygen. 
Electricity: By electrolysis, water is split into hydrogen and oxygen.

How many elements are there?

There are about eighty known elements.

Give the symbol and atomic weight of each of the following elements: chlorine, hydrogen, nitrogen, oxygen, potassium and sodium.

Chlorine, $\mathrm{Cl}, 35.2$; hydrogen, $\mathrm{H}, 1$; nitrogen, $\mathrm{N}, 14$; oxygen, O, 16 ; potassium, K, 39; sodium, Na, 23.

Name five elements. Give the symbol and one principal use of each element named.

Carbon, C, is the chief element of coal.

Phosphorus, $\mathrm{P}$, is used in matches.

Arsenic, As, is used in medicine.

Copper, $\mathrm{Cu}$, is used in the arts.

Chlorine, $\mathrm{Cl}$, is used as a bleaching agent.

Define incompatibility. Name three forms and give an example of each.

Incompatibility is that relation between medicines which renders their admixture unsuitable. There are three forms, viz., chemical, physical or pharmaceutical, and physiological or therapeutic.

A chemical incompatibility exists when a new compound is formed, as silver nitrate and sodium chloride form silver chloride; a physical, when an unsightly appearance is produced, as when resinous tinctures are added to aqueous solutions, the resins separate; a physiological, when there is an antagonistic action between the drugs, as atropine, which checks secretion, and pilocarpine, which stimulates glandular activity.

Write the chemical formula for (a) sulphuric acid, (b) nitric acid, (c) potassium iodide, (d) copperas, (e) epsom salts. $7 \mathrm{H}_{2} \mathrm{O}$.

(a) $\mathrm{H}_{2} \mathrm{SO}_{4}$, (b) $\mathrm{HNO}_{3}$, (c) $\mathrm{KI}$, (d) $\mathrm{FeSO}_{4}, 7 \mathrm{H}_{2} \mathrm{O}$, (e) $\mathrm{MgSO}_{4}$,

What is meant by synthesis? Name two products that can be made this way.

Synthesis is the artificial building up of a chemic compound by the union of its elements.

Water can be made by uniting hydrogen and oxygen. Cupric oxide can be made by heating metallic copper in the air.

What is meant by diffusion of gases? Describe an experiment to illustrate diffusion of gases.

A diffusion, similar to that of liquids, takes place when two 
different gases are separated from each other by some porous substance, such as burned clay, gypsum, etc.

In the open end of an unglazed clay cylinder (such as is used in galvanic experiments) there is fixed a glass tube about one metre long, its open end terminating in a dish containing water; the cylinder and tube are filled with air. Over the porous cylinder is placed a wider vessel filled with hydrogen. The latter presses faster into the cylinder than the air escapes from it; the air in the cylinder and tube is displaced and rises in the water in bubbles. When the escape of gas ceases, the tube and cylinder are almost filled with pure hydrogen.

State which of the following gases are (a) lighter than air, (b) heavier than air: oxygen, nitrogen, hydrogen, ammonia gas, sulphur dioxide, chlorine.

(a) Hydrogen, ammonia gas, nitrogen.

(b) Sulphur dioxide, chlorine, oxygen.

Distinguish in meaning between the following suffixes when used in names of chemical compounds: (a) ous and ic, (b) ate and ite. Give examples.

(a) ous indicates that a compound contains less, and ic that it contains more, of the other, or electronegative, element. An explanation of these terms involves the subject of valence. Frequently, two elements unite to form two or more compounds, for instance, mercury and chlorine unite to form mercurous chloride, $\mathrm{Hg}_{2} \mathrm{Cl}_{2}$, and also, mercuric chloride, $\mathrm{HgCl}_{2}$. The electropositive atom (mercury) terminates in ous, indicating the lower valence (or a valence of 2 for two atoms), while ic indicates the higher valence (or a valence of 2 for one atom).

(b) The suffix ite indicates that a salt is derived from an acid, terminating in ous (as $\mathrm{Na}_{2} \mathrm{SO}_{3}$, sodium sulphite), and the suffix ate that it is derived from an acid terminating in ic (as $\mathrm{Na}_{2} \mathrm{SO}_{4}$, sodium sulphate).

Give the formula and the chemical name of each of the following: (a) washing soda, (b) saltpetre, (c) blue vitriol, (d) corrosive sublimate, (e) Glauber's salt, (f) Rochelle salt.

(a) Sodium carbonate, $\mathrm{Na}_{2} \mathrm{CO}_{3}, 10 \mathrm{H}_{2} \mathrm{O}$. (b) Potassium nitrate, $\mathrm{KNO}_{3}$. (c) Copper sulphate, $\mathrm{CuSO}_{4}$. (d) Mercuric chloride, $\mathrm{HgCl}_{2}$. (e) Sodium sulphate, $\mathrm{Na}_{2} \mathrm{SO}_{4}$. (f) Potassium sodium tartrate, $\mathrm{KNaC}_{4} \mathrm{H}_{4} \mathrm{O}_{6}$.

Distinguish between organic and inorganic compounds.

Organic compounds contain carbon and therefore, upon burn- 
ing, char. When pure they are completely consumed under continned heat; any residue remaining after the disappearance of the char indicates the presence of mineral matter. They are the essential compounds of plant and animal structures and their molecular composition may be very complex, but includes only a few elements.

An inorganic compound is any one of the large series of compounds (minerals, metals, etc.) which are not directly connected with vital processes, either in origin or nature, and which are broadly and relatively contrasted with organic compounds.

\section{Distinguish between solution and emulsion.}

The term solution is applied to any clear and homogeneous liquid obtained by causing the transformation of matter from a solid or gaseous state to the liquid state, by means of a liquid called the solvent or menstruum. Solutions may be made by uniting two liquids, as when we dissolve oil in ether.

The term emulsion is used to designate a more or less homogeneous liquid, rendered opaque or milky by the suspension in it of finely divided particles of fat, oil or resin.

Distinguish in meaning between the following when used in names of chemical compounds : hypo and per. Give examples to illustrate the differences.

Hypo is prefixed to a compound containing less of the negative element, oxygen, than the ous compound in that series, as hypochlorous acid, $\mathrm{HClO}$, and chlorous acid, $\mathrm{HClO}_{2}$.

Per or hyper indicates that the compound contains a greater amount of oxygen than the ic compound in the series, as perchloric acid, $\mathrm{HClO}_{4}$, and chloric acid, $\mathrm{HClO}_{3}$. We have the term peroxide, applied to compounds very rich in oxygen.

Name a substance used as a bleaching powder and explain chemically its bleaching properties.

Hypochlorite of lime, $\mathrm{CaOCl}_{2}$. The element chlorine has a strong affinity for hydrogen. In the presence of moisture, it unites with the hydrogen and thus liberates oxygen, which acts upon the coloring matter and bleaches it.

Write the equation to show the reaction between (a) sulphuric acid and zinc, (b) hydrochloric acid and calcium carbonate, (c) sodium carbonate and calcium hydroxide.

(a) $\mathrm{H}_{2} \mathrm{SO}_{4}+\mathrm{Zn}=\mathrm{ZnSO} \mathrm{nO}_{4}+\mathrm{H}_{2}$.

(b) $2 \mathrm{HCl}+\mathrm{CaCO}_{3}=\mathrm{CaCl}_{2}+\mathrm{H}_{2} \mathrm{O}+\mathrm{CO}_{2}$.

(c) $\mathrm{Na}_{2} \mathrm{CO}_{3}+\mathrm{Ca}(\mathrm{OH})_{2}=2 \mathrm{NaOH}+\mathrm{CaCO}_{3}$. 
Distinguish between a mixture and a compound.

A mixture consists of a combination of two or more substances each of which retains its individual characteristics and may be separated from each other by mechanical means, no matter how thoroughly mixed and finely commingled. Example: Iron filings and sulphur may be mixed and if no heat is added, the iron can be removed from the mixture with an electromagnet; if heat had been added to the mixture, a compound, ferrous sulphide (FeS) would have been formed, which would require chemical means to separate.

\section{Distinguish between a metal and a non-metal.}

See "metals," p. 5. Non-metals do not possess a metallic appearance and are known as metalloids. To these belong sulphur, carbon, phosphorus, oxygen, etc. The line between metals and nonmetals is not very marked. Thus, mercury, despite the fact that it is liquid at ordinary temperature, must be included among the metals because of its chemical properties.

Mention (a) three light metals and (b) three heavy metals. Give the symbol and atomic weight of each.

(a) Aluminum, Al, 26.9; sodium, Na, 23; potassium, K, 39.

(b) Gold, Au, 195.7; lead, Pb, 205; iron, Fe, 56.

Name ten non-metallic elements and write the symbol of each.

Hydrogen, $\mathrm{H}$; oxygen, $\mathrm{O}$; nitrogen, $\mathrm{N}$; sulphur, $\mathrm{S}$; carbon, $\mathrm{C}$; phosphorus, $\mathrm{P}$; chlorine, $\mathrm{Cl}$; bromine, $\mathrm{Br}$; iodine, $\mathrm{I}$; fluorine, $\mathrm{F}$.

Complete the following equations:

1. $\mathrm{HCl}+\mathrm{AgNO}_{3}=$

2. $2 \mathrm{NH}_{4} \mathrm{OH}+\mathrm{H}_{2} \mathrm{SO}_{4}=$

3. $\mathrm{H}_{2} \mathrm{O}+\mathrm{Na}=$

1. $\mathrm{HCl}+\mathrm{AgNO}_{3}=\mathrm{AgCl}+\mathrm{HNO}_{3}$.

2. $2 \mathrm{NH}_{4} \mathrm{OH}+\mathrm{H}_{2} \mathrm{SO}_{4}=\left(\mathrm{NH}_{4}\right)_{2} \mathrm{SO}_{4}+2 \mathrm{H}_{2} \mathrm{O}$.

3. $\mathrm{H}_{2} \mathrm{O}+\mathrm{Na}=\mathrm{NaOH}+\mathrm{H}$.

Complete the following equations:

1. $\mathrm{AgNO}_{3}+\mathrm{KCl}=$

2. $\mathrm{ZnCl}_{2}+2 \mathrm{KOH}=$

3. $\mathrm{CaF}_{2}+\mathrm{H}_{2} \mathrm{SO}_{4}=$

4. $3 \mathrm{HCl}+\mathrm{HNO}_{3}=$

5. $\mathrm{Ca}(\mathrm{OH})_{2}+2 \mathrm{NH}_{4} \mathrm{Cl}=$

1. $\mathrm{AgNO}_{3}+\mathrm{KCl}=\mathrm{AgCl}+\mathrm{KNO}_{3}$.

2. $\mathrm{ZnCl}_{2}+2 \mathrm{KOH}=2 \mathrm{KCl}+\mathrm{Zn}(\mathrm{OH})_{2}$.

3. $\mathrm{CaF}_{2}+\mathrm{H}_{2} \mathrm{SO}_{4}=2 \mathrm{HF}+\mathrm{CaSO}_{4}$.

4. $3 \mathrm{HCl}+\mathrm{HNO}_{3}=2 \mathrm{H}_{2} \mathrm{O}+\mathrm{NO}+3 \mathrm{Cl}$.

5. $\mathrm{Ca}(\mathrm{OH})_{2}+2 \mathrm{NH}_{4} \mathrm{Cl}=\mathrm{CaCl}_{2}+2\left(\mathrm{NH}_{4} \mathrm{OH}\right)$. 
Complete the following equations:
1. $\mathrm{AgNO}_{3}+\mathrm{NaCl}=$
2. $\mathrm{CuSO}_{4}+\mathrm{H}_{2} \mathrm{~S}=$
3. $2 \mathrm{NaCl}+\mathrm{H}_{2} \mathrm{SO}_{4}=$
1. $\mathrm{AgNO}_{3}+\mathrm{NaCl}=\mathrm{AgCl}+\mathrm{NaNO}_{3}$.
2. $\mathrm{CuSO}_{4}+\mathrm{H}_{2} \mathrm{~S}=\mathrm{H}_{2} \mathrm{SO}_{4}+\mathrm{CuS}$.
3. $2 \mathrm{NaCl}+\mathrm{H}_{2} \mathrm{SO}_{4}=\mathrm{Na}_{2} \mathrm{SO}_{4}+2 \mathrm{HCl}$.

Complete the following equations:

1. $\mathrm{NaNO}_{3}+\mathrm{H}_{2} \mathrm{SO}_{4}=$

2. $\mathrm{CaCO}_{3}+2 \mathrm{HCl}=$

3. $2 \mathrm{NaCl}+2 \mathrm{H}_{2} \mathrm{SO}_{4}+\mathrm{MnO}_{2}=$

4. $\mathrm{Cu}+2 \mathrm{H}_{2} \mathrm{SO}_{4}=$

1. $\mathrm{NaNO}_{3}+\mathrm{H}_{2} \mathrm{SO}_{4}=\mathrm{NaHSO}_{4}+\mathrm{HNO}_{3}$.

2. $\mathrm{CaCO}_{3}+2 \mathrm{HCl}=\mathrm{CaCl}_{2}+\mathrm{H}_{2} \mathrm{O}+\mathrm{CO}_{2}$.

3. $2 \mathrm{NaCl}+2 \mathrm{H}_{2} \mathrm{SO}_{4}+\mathrm{MnO}_{2}=\mathrm{Cl}_{2}+\mathrm{Na}_{2} \mathrm{SO}_{4}+\mathrm{MnSO}_{4}+$ $2 \mathrm{H}_{2} \mathrm{O}$.

4. $\mathrm{Cu}+2 \mathrm{H}_{2} \mathrm{SO}_{4}=\mathrm{CuSO}_{4}+2 \mathrm{H}_{2} \mathrm{O}+\mathrm{SO}_{2}$.

Complete the following equations:

1. $\mathrm{Pb}\left(\mathrm{NO}_{3}\right)_{2}+\mathrm{H}_{2} \mathrm{~S}=$

2. $\mathrm{Ca}(\mathrm{OH})_{2}+2 \mathrm{HCl}=$

3. $2 \mathrm{NaOH}+\mathrm{H}_{2} \mathrm{SO}_{4}=$

1. $\mathrm{Pb}\left(\mathrm{NO}_{3}\right)_{2}+\mathrm{H}_{2} \mathrm{~S}=2 \mathrm{HNO}_{3}+\mathrm{PbS}$.

2. $\mathrm{Ca}(\mathrm{OH})_{2}+2 \mathrm{HCl}=\mathrm{CaCl}_{2}+2 \mathrm{H}_{2} \mathrm{O}$.

3. $2 \mathrm{NaOH}+\mathrm{H}_{2} \mathrm{SO}_{4}=\mathrm{Na}_{2} \mathrm{SO}_{4}+2 \mathrm{H}_{2} \mathrm{O}$.

Complete the following chemical equation. Give the name of the new compound formed.

$\mathrm{Zn}+2 \mathrm{HCl}=$

$\mathrm{Zn}+2 \mathrm{HCl}=\mathrm{ZnCl}_{2}+2 \mathrm{H} . \quad \mathrm{ZnCl}_{2}=$ Zinc chloride.

Write the equation to express the reaction that takes place between sulphuric acid and sodium carbonate. Name the compounds formed.

$\mathrm{H}_{2} \mathrm{SO}_{4}+\mathrm{Na}_{2} \mathrm{CO}_{3}=\mathrm{Na}_{2} \mathrm{SO}_{4}$ (sodium sulphate) $+\mathrm{H}_{2} \mathrm{O}$ (water) + $\mathrm{CO}_{2}$ (carbon dioxide).

Write the equation to express the reaction between (a) potassium chloride and sodium nitrate, (b) ammonium chloride and calcium hydroxide, (c) ferrous sulphide and hydrochloric acid.

(a) $\mathrm{KCl}+\mathrm{NaNO}_{3}=\mathrm{NaCl}+\mathrm{KNO}_{3}$.

(b) $2 \mathrm{NH}_{4} \mathrm{Cl}+\mathrm{Ca}(\mathrm{OH})_{2}=\mathrm{CaCl}_{2}+2\left(\mathrm{NI}_{4} \mathrm{OH}\right)$.

(c) $\mathrm{FeS}+2 \mathrm{HCl}=\mathrm{FeCl}_{2}+\mathrm{H}_{2} \mathrm{~S}$. 
Give the chemical symbol and the atomic weight of each of the following: (a) hydrogen, (b) chlorine, (c) iron, (d) mercury, (e) oxygen.

(a) $\mathrm{H}, 1$; (b) $\mathrm{Cl}, 35$; (c) Fe, 56; (d) $\mathrm{Hg}, 198.5$; (e) $\mathrm{O}, 16$.

Give the chemical name of each of the following: (a) $\mathrm{FeCl}_{2}$, (b) $\mathrm{NaHCO}_{3}$, (c) $\mathrm{CO}_{2}$, (d) $\mathrm{As}_{2} \mathrm{O}_{3}$, (e) $\mathrm{H}_{3} \mathrm{PO}_{4}$.

(a) Ferrous chloride, (b) sodium bicarbonate, (c) carbon dioxide, (d) arsenic trioxide, (e) phosphoric acid.

Write the chemical names of the substances whose formulas are as follows: (a) $\mathrm{Ca}(\mathrm{OH})_{2}$, (b) $\mathrm{KClO}_{3}$, (c) $\mathrm{PH}_{3}$, (d) $\mathrm{KNO}_{3}$, (e) $\mathrm{HgCl}$, (f) $\mathrm{SnCl}_{2}$, (g) $\mathrm{KMnO}_{4}$, (h) NO, (i) CO, (j) $\mathrm{AgNO}_{3}$.

(a) Calcium lyydroxide, (b) potassium chlorate, (c) phosphine, (d) potassium nitrate, (e) mercurous chloride, (f) stannous chloride, (g) potassium permanganate, (h) nitric oxide, (i) carbon monoxide, $(j)$ silver nitrate.

Write the graphic formula of (a) sulphuric acid, (b) ammonia, (c) potassium chlorate.

(a) $\mathrm{H}-\mathrm{O}$<smiles></smiles>

(b) $\mathrm{H}-\mathrm{N} / \mathrm{H}$

(c) $\mathrm{Cl}-\mathrm{O}-\mathrm{O}-\mathrm{O}-\mathrm{K}$

Give two laws relating to chemical combinations.

1. Law of constant or definite proportions. The same compound is always composed of the same elements in constant proportions by weight.

2. Law of multiple proportions. When two elements unite to form several compounds the higher proportions of each are even multiples of the lowest.

Explain fully how the percentage composition of any compound is determined.

Obtain the molecular weight of the compound by adding together the atomic weights of the elements it contains. Then, the percentage of any one element is obtained by dividing its atomic weight by the molecular weight. For instance, the molecular weight of $\mathrm{KNO}_{3}$ is, $38.82+13.93+47.64=100.39$. The percentage composition of $\mathrm{K}$ is $38.82 \div 100.39$, or 38.66 per cent.

Define and illustrate the law of definite proportions.

Definition given above.

Sodium chloride, $\mathrm{NaCl}$, is always composed of 23 parts by weight of $\mathrm{Na}$ and 35.5 parts of $\mathrm{Cl}$. 
State Avogadro's law.

Equal volumes of gases, compared under identical conditions of temperature and pressure, contain equal numbers of molecules.

Name the elements that enter into the composition of each of the following alloys: (a) brass, (b) German silver, (c) soft solder, (d) bell metal.

(a) Copper and zinc, (b) copper, zine and nickel, (c) tin and lead, (d) copper and tin.

Is glass a compound or a mixture? To what does green glass owe its color?

Glass is a mixture. Green glass owes its color to silicates of iron derived from the impure materials of which it is made.

What element occurs in all acid compounds?

Hydrogen.

Name two classes of salts and distinguish between the classes named.

Acid salts are acids in which only a portion of their replaceable hydrogen atoms have been replaced, e.g., $\mathrm{KHSO}_{4}$, potassium hydrogen sulphate. Acid salts are generally acid in reaction to litmus.

Basic salts are salts containing a higher proportion of a base than is necessary for the formation of a salt, e.g., $\mathrm{Pb}(\mathrm{OH}) \mathrm{NO}_{3}$, basic lead nitrate.

What gas is evolved when copper acts on nitric acid? Account for the formation of this gas.

Nitric oxide, NO.

$$
3 \mathrm{Cu}+8 \mathrm{HNO}_{3}=3 \mathrm{Cu}\left(\mathrm{NO}_{3}\right)_{2}+2 \mathrm{NO}+4 \mathrm{H}_{2} \mathrm{O} \text {. }
$$

Determine how much sulphuric acid and how much copper will be needed to produce I,000 grammes of copper sulphate by the reaction $\mathrm{Cu}+{ }_{2} \mathrm{H}_{2} \mathrm{SO}_{4}=\mathrm{CuSO}_{4}+\mathrm{SO}_{2}+{ }_{2} \mathrm{H}_{2} \mathrm{O}$. [Atomic weight of $S=32$, of copper $=63$, of $O=16$.]

Sce p. 11 regarding determination of percentage composition.

Molecular weight of $\mathrm{Cu}=63$, of sulphuric acid $=196$, of copper sulphate $=159$; it takes $63+196$ or 259 parts of copper and sulphuric acid to make 159 parts of copper sulphate, So, $259: 159=$ $X: 1000 ; \mathrm{X}=1629$. $63 / 259$ of $1629=396$, and $196 / 259$ of $1629=$ 1233. Substituting grammes for parts, we have 396 grammes of copper and 1233 grammes of sulphuric acid necessary to make 1000 grammes of copper sulphate.

Find the number of grammes of oxygen that can be prepared from Io grammes of $\mathrm{KClO}_{3}$. [Atomic weight of $\mathrm{K}=39$, of $\mathrm{Cl}=35$, of $\mathrm{O}=\mathrm{I} 6$. 
$39+35+48=122$, the molecular weight of $\mathrm{KClO}_{3}$.

$48 \div 122=.393$, the percentage composition of oxygen.

10 grammes of $\mathrm{KClO}_{3}$ would contain 3.93 grammes of oxygen.

Calculate the weight of carbonic acid gas that can be obtained from one pound of marble. Write the equation. [Atomic wt. of $\mathrm{Ca}=40$, of $\mathrm{O}=\mathrm{I} 6$, of $\mathrm{C}=\mathrm{I2}$.]

$\mathrm{CaCO}_{3}+$ leat $=\mathrm{CaO}+\mathrm{CO}_{2}$.

$40+12+48=100$, the molecular weight of calcium carbonate (marble). $12+32=44$, the molecular weight of carbon dioxide (carbonic acid gas). Therefore .44 is the percentage composition of $\mathrm{CO}_{2}$. From one pound of marble, .44 of a pound of $\mathrm{CO}_{2}$ could be obtained.

Under standard conditions how many litres of hydrochloric acid will result from the action of sulphuric acid on 117 grammes of common salt? $\quad[\mathrm{Na}=23, \mathrm{Cl}=35.5 \cdot]$

$2 \mathrm{NaCl}+\mathrm{H}_{2} \mathrm{SO}_{4}=\mathrm{Na}_{2} \mathrm{SO}_{4}+2 \mathrm{HCl}$. The molecular weight of $\mathrm{NaCl}=58.5$. The molecular weight of $\mathrm{HCl}=36.5$. $58.5: 36.5=$ $117: X . \quad X=73 \mathrm{~g}$. One litre of hydrogen weighs 0.0899 gramme under standard conditions. $73 \div 0.0899=812$ litres.

How much chlorine can be derived from 50 grammes of $\mathrm{NaCl}$ ? [Atomic weight of $\mathrm{Na}=23$, of $\mathrm{Cl}=35.5$.]

$23+35.5=58.5$, the molecular weight of $\mathrm{NaCl}$. $35.5: 58.5=$ $X: 50 . \quad X=30.34$ grammes.

\section{HYDROGEN}

What are the physical and chemical properties of hydrogen?

Hydrogen, the lightest of all elements, is a colorless, odorless, tasteless gas; combustible, burning with a colorless flame, but is not a supporter of combustion. The resulting compound of its combustion in air is water. It is only slightly soluble in water, is electropositive and capable of combining with many elements.

Give details of the preparation of hydrogen by the action of an acid on a metal. Write the equation.

Place a quantity of granulated zine in a glass flask and cover it with dilute hydrochloric acid. Adjust a piece of glass tubing in the stopper of the flask and after the air of the flask is expelled, hydrogen will pass from the tubing. $\mathrm{Zn}+2 \mathrm{HCl}=\mathrm{ZnCl}_{2}+2 \mathrm{H}$.

Give (a) the symbol, (b) valence, (c) atomic weight, and (d) a method of preparation of hydrogen.

(a) $\mathrm{H}$, (b) 1 , (c) 1 , (d) see answer to preceding question (Iron 
filings may be substituted for the zine, and sulphuric acid for the hydrochloric acid).

What element occurs in all acid compounds? Describe the element. Hydrogen. See description given above.

Find how many grammes of $\mathrm{H}$ may be released from $\mathrm{HCl}$ by 260 grammes of $\mathrm{Zn}$. How many grammes of $\mathrm{HCl}$ are necessary? [Atomic weight of $\mathrm{Zn}=65$, of $\mathrm{Cl}=35 \cdot 5$.]

$65: 2=260: I . \quad X=8$ grammes of $\mathrm{H}$.

$73: 2=X: 8 . \quad X=292$ grammes of $\mathrm{HCl}$.

WATER

Give the composition of water (a) by volume, (b) by weight, and (c) give its molecular weight.

(a) Two volumes hydrogen and one volume of oxygen.

(b) Two parts of hydrogen and sixteen parts of oxygen.

(c) 18 .

If six volumes of hydrogen and two volumes of oxygen are placed together and the electric spark passed through them, will the volume be increased or diminished, and to what extent?

The volume will be diminished from 8 to 2 , because four volumes of hydrogen would unite with the two of oxygen and form 2 molecules of water, leaving two volumes of hydrogen free. The volume of the water formed is so small that it may be disregarded in the ealculations.

Describe one way in which water can be decomposed and two ways in which it can be formed.

Decompose by acidulating slightly with sulphuric acid and pass an electric current through it. Water can be formed by passing an electric spark through a receptacle containing two volumes of hydrogen and one volume of oxygen; also by burning hydrogen in the presence of oxygen, as in the air.

State the means by which water may be purified. Describe one of these ways.

Filtration, distillation and precipitation.

Filtration is accomplished by allowing the water to pereolate through layers of eharcoal and sand, or by forcing it through a very thick porcelain material with small pores.

Describe a test to show the presence of each of the following in water:

(a) chlorides, (b) nitrates, (c) lead.

(a) Add silver nitrate: a white, curdy precipitate is produced 
which is soluble in even very dilute ammonia water, but insoluble in nitric acid.

(b) Add a few drops of 1 part of brucine in 300 parts of 5 per cent. dilute sulphuric acid, then add some concentrated sulphuric acid by pouring carefully down the side of the test tube and a red color, changing to yellow, is produced at the line of contact.

(c) Add hydrogen sulphide or ammonium sulphide to the solution and a black precipitate of lead sulphide, which is insoluble in dilute acids or alkalies, results.

Distinguish between hard water and soft water. Under what conditions and how may hard water be made soft?

Hardness of water is due to the presence of mineral salts (calcium, magnesium). Hard water does not readily produce a lather with soap. Soft water contains very little or no inorganic matter and readily produces a lather with soap.

By boiling hard water, carbon dioxide escapes, the carbonates of the metals are precipitated, and the water is rendered soft. By distillation, hard water may be made soft.

\section{Describe a test to determine the hardness of water.}

For calcium: Pass a small amount of $\mathrm{CO}_{2}$ into the water, $\mathrm{CaHCO}_{3}$ will be thrown down, but is redissolved in an excess of $\mathrm{CO}_{2}$. Upon boiling the clear solution, the excess of $\mathrm{CO}_{2}$ will be driven off and $\mathrm{CaHCO}_{3}$ will be precipitated.

For magnesium: The addition of an alkali carbonate solution causes a white precipitate of basic magnesium carbonate.

Hard water does not readily produce a lather with soap, as does soft water.

\section{Describe the oxyhydrogen blow-pipe.}

In this apparatus the oxygen and hydrogen are contained in two separate receptacles. They are mixed just at the tip of the burner, which consists of two tubes, one within the other. Through the inner tube, oxygen is passed, and the outer one is connected with the hydrogen reservoir. The hydrogen is first turned on and ignited, then the oxygen is admitted. The resultant flame is intensely hot.

\section{HYDROGEN DIOXIDE}

\section{What is hydrogen dioxide? Write the formula.}

It is a colorless liquid with an odor resembling weak chlorine solution, a bitter astringent taste, and is unstable in concentrated solutions, being easily decomposed with the liberation of oxygen. 
It is composed of two parts by weight of hydrogen and thirty-two of oxygen. Formula $\mathrm{H}_{2} \mathrm{O}_{2}$.

Write the equation for the preparation of hydrogen dioxide. $\mathrm{BaO}_{2}+\mathrm{H}_{2} \mathrm{SO}_{4}+\mathrm{H}_{2} \mathrm{O}=\mathrm{BaSO}_{4}+\mathrm{H}_{2} \mathrm{O}_{2}+\mathrm{H}_{2} \mathrm{O}$.

Mention the important properties and the uses of peroxide of hydrogen.

It is an active oxidizing agent and is used preëminently as a disinfectant, bleaching agent, antisuppurant, and deodorant.

Give the chemical explanation of the uses of hydrogen peroxide.

It acts as an oxidizing agent because it is readily decomposed into water, $\mathrm{H}_{2} \mathrm{O}$, and nascent oxygen, $\mathrm{O}$.

\section{OXYGEN}

Describe oxygen as to (a) occurrence, (b) physical properties, (c) chemical properties.

(a) Most abundant of all the elements. Uncombined, but mixed with nitrogen, it constitutes one-fifth of the atmosphere; combined, it forms eight-ninths of the material composing water, and nearly half the weight of all the rocks. It is a very important constituent of animal and vegetable matter.

(b) A colorless, tasteless, odorless gas, nearly sixteen times heavier than hydrogen, and somewhat heavier than air. It may be made liquid or even solidified by great cold and pressure.

(c) It supports combustion, but is non-combustible and is one of the most powerful electronegative elements; capable of uniting with all elements except fluorine, bromine and the helium group.

Describe a method of preparing oxygen. Give the symbol, atomic weight and specific gravity of oxygen.

Mix potassium chlorate and manganese dioxide, equal parts, and apply heat, carefully; oxygen will be givell off copiously. Symbol, 0 . Atomic weight, 16. Specific gravity, compared with hydrogen, is 16 , compared with air, 1.1056 .

How much oxygen can be obtained from 50 grammes of potassium chlorate? [Atomic weight of potassium $=39$, of chlorine $=35.5$, of oxygen $=\mathrm{I} 6$.]

$39+35.5+48=122.5$, the molecular weight of $\mathrm{KClO}_{3}$. The molecular weight of 3 atoms of oxygen $=48$. 122.5:48 $=50: X$. $X=19.5$ grammes.

What is oxidation? Give an example.

Oxidation is the union of oxygen with other elements, the products formed are oxides. Example: iron and oxygen unite to form ferrous oxide. See reduction, p. 5. 
What is combustion?

Combustion is rapid oxidation and is accompanied by heat and light.

Distinguish between an oxidizing and a reducing agent and give an example of each.

An oxidizing agent is one which readily parts with its oxygen when brought in contact with substances having a greater affinity for it. Example : $\mathrm{KClO}_{3}$.

A reducing agent is one which has the power to abstract oxygen from an oxide. Example: hydrogen.

What is meant by (a) slow oxidation, (b) rapid oxidation? Give an example of each.

(a) A process of oxidation evolving no light. Example: oxidation of the different organic substances in the living body.

(b) When the heat generated by oxidation is sufficient to cause the emission of light and perhaps a loud report, the process is called rapid oxidation, or combustion. Example: gunpowder is a mixture of sulphur, carbon and potassium, $\mathrm{KNO}_{3}$. Upon heating or igniting this mixture, the sulphur and carbon are oxidized, and various gases ( $\mathrm{CO}, \mathrm{CO}_{2}, \mathrm{~N}, \mathrm{SO}_{2}$, etc.) are formed, the sudden generation and expansion of which cause the explosion.

Describe a method of preparing oxygen on a commercial scale. Write the equation to express the reaction.

Heat to redness in an iron vessel manganese dioxide $\left(\mathrm{MnO}_{2}\right)$, causing it to decompose into manganous manganic oxide and oxygen.

$3 \mathrm{MnO}_{2}=\mathrm{Nnn}_{3} \mathrm{O}_{4}+2 \mathrm{O}$.

Compare the physical and chemical properties of oxygen with those of hydrogen.

Both gases are colorless, odorless and tasteless. Oxygen is 16 times heavier than hydrogen. Oxygen supports combustion but is non-combustible, whereas hydrogen is combustible but not a supporter of combustion.

What is ozone? Describe the preparation of ozone.

Ozone is an allotropic modification of oxygen. It possesses a peculiar odor and is a stronger oxidizing agent than common oxygen. Its symbol is $\mathrm{O}_{3}$.

Ozone is prepared by passing non-luminous electric discharges through atmospheric air or through oxygen. 
Give (a) the symbol, (b) atomic weight, (c) molecular weight, and (d) describe the properties of nitrogen.

(a) N. (b) 14 . (c) 28. (d) Nitrogen is an odorless, colorless, tasteless gas, neither combustible nor a supporter of combustion. It is distinguished by having very little affinity for any other element. Nitrogen is not poisonous, but, being mable to support combustion, cannot sustain animal life. In compounds it is unstable.

What is the function of nitrogen in the air? Describe a process of preparing nitrogen from the air.

It serves to dilute the oxygen and has some important function in regard to plant life.

By burning phosphorus in a confined portion of air, the oxygen of the air unites with the phosphorus and forms phosphorus pentoxide, $\mathrm{P}_{2} \mathrm{O}_{5}$. If the experiment is conducted over water, $\mathrm{P}_{2} \mathrm{O}_{5}$ unites with the water, forming phosphoric acid, leaving nitrogen in the container.

Name a preparation of nitrogen. Mention the properties of nitrogen. Ammonia, $\mathrm{NH}_{3}$. Properties described above.

Describe the usual method of preparing laughing gas. Write the equation to show the reaction.

By heating ammonium nitrate, it breaks down directly into water and nitrous oxide.

$\mathrm{NH}_{4} \mathrm{NO}_{3}=\mathrm{N}_{2} \mathrm{O}+2 \mathrm{H}_{2} \mathrm{O}$.

Name the oxides of nitrogen.

Nitrogen monoxide, $\mathrm{N}_{2} \mathrm{O}$; nitrogen dioxide, $\mathrm{N}_{2} \mathrm{O}_{2}$; nitrogen trioxide, $\mathrm{N}_{2} \mathrm{O}_{3}$; nitrogen tetroxide, $\mathrm{N}_{2} \mathrm{O}_{4}$; nitrogen pentoxide, $\mathrm{N}_{2 .} \mathrm{O}_{5}$.

Calculate the percentage composition of $\mathrm{HNO}_{3}$. [Atomic weight of $\mathrm{N}=\mathrm{I}$. $]$

$1+14+48=63$, the molecular weight of $\mathrm{HNO}_{3}$.

$1 \div 63=0.0158$, or 1.58 per cent. hydrogen.

$14 \div 63=0.222$, or 22.2 per cent. nitrogen.

$48 \div 63=0.761$, or 76.1 per cent. oxygen.

Mention two nitrates and give two uses of each.

Silver nitrate, used in medicine and electro-plating.

Sodium nitrate, used in fertilizers and in the preparation of saltpetre. 
Describe a method of preparing nitrogen. Compare the properties of nitrogen with those of oxygen.

By passing a current of air over copper, leated to redness, copper oxide will be formed and nitrogen isolated.

Nitrogen and oxygen are both colorless, odorless, tasteless gases. Oxygen has a great affinity for other elements and supports combustion; nitrogen unites with very few elements and does not support life nor combustion.

Describe the commercial préparation of nitric acid and write the reaction. Mention important uses of nitric acid.

Sodium nitrate is distilled with sulphuric acid.

$2 \mathrm{NaNO}_{3}+\mathrm{H}_{2} \mathrm{SO}_{4}=\mathrm{Na}_{2} \mathrm{SO}_{4}+2 \mathrm{HNO}_{3}$.

Nitric acid is used in medicine as a caustic and is employed in etching copper plates for engraving; it is also important in the refining of precious metals and in the making of nitroglycerine, gun cotton, aniline dyes, etc.

What element constitutes four-fifths of the air?

Nitrogen.

AMMONIA

What is ammonia? Give the source and uses of ammonia.

Ammonia is a colorless gas, of a peculiar, characteristic and very pungent odor. It is neither combustible nor a supporter of combustion. By weight it is composed of 13.93 parts of nitrogen and 3 parts of hydrogen. It is very soluble in water; caustic and readily blisters the skin; strongly alkaline in reaction. Formula, $\mathrm{NH}_{3}$.

Sources: Decomposition of organic matter (meat, urine, blood, etc.). Decomposition of ammonium salts by the hydroxides of sodium, potassium and calcium, $2\left(\mathrm{NH}_{4} \mathrm{Cl}\right)+\mathrm{Ca}(\mathrm{OH})_{2}=\mathrm{CaCl}_{2}+$ $2 \mathrm{H}_{2} \mathrm{O}+2 \mathrm{NH}_{3}$. Ammonia is obtained, commercially, from gas liquor, a by-product of gas plants.

Uses: It is used in medicine as a cardiac stimulant and general stimulant, also to increase secretions. In the household it is used as a general cleaning agent in the aqueous form (hartshorn).

Explain why the presence of free ammonia in drinking water is a sign of danger.

Because it is indicative of contamination with decomposing organic matter.

Give the composition and method of preparation of ammonium chloride.

It is composed of nitrogen, hydrogen and chlorine, $\mathrm{NH}_{4} \mathrm{Cl}$. Pre- 
pared by neutralizing hydrochloric acid with ammonia water. The solution is evaporated and the crystalline mass remaining is ammonium chloride. $\mathrm{HCl}+\mathrm{NH}_{4} \mathrm{OH}=\mathrm{NH}_{4} \mathrm{Cl}+\mathrm{H}_{2} \mathrm{O}$.

Give the chemical name and formula of two compounds of ammonia. Ammonium chloride, $\mathrm{NH}_{4} \mathrm{Cl}$, ammonium nitrate, $\mathrm{NH}_{4} \mathrm{NO}_{3}$.

Name the important constituents of air and give the approximate percentages of each constituent.

\begin{tabular}{|c|c|c|}
\hline Nitrogen & $\begin{array}{l}\text { By weight } \\
. \quad 76\end{array}$ & $\begin{array}{c}\text { By volume } \\
7 \tau\end{array}$ \\
\hline Oxygen . & .. 23 & 21 \\
\hline $\mathrm{Co}_{2}, \mathrm{amm}$ & . 1 & 2 \\
\hline
\end{tabular}

State three facts tending to show that air is a mixture and not a compound.

1. By artificially mixing oxygen and nitrogen in the proportions found in the air, no energy change (heat) that indicates chemical union takes place.

2. Analysis shows air taken from different heights to be slightly variable.

3. By passing air through water it is changed, oxygen being more soluble than nitrogen.

Mention the injurious substances added to the air in breathing. What per cent. of carbon dioxide is fatal to the animal breathing it?

Carbon dioxide and disease germs are added to the air in breathing.

It is not advisable to allow animals to breathe for any length of time air containing more than 1 per cent. $\mathrm{CO}_{2} ; 5$ per cent. produces insensibility, and 8 per cent. causes death in a few minutes.

What element constitutes four-fifths of the air?

Nitrogen.

\section{CARBON}

Give (a) the symbol, (b) specific gravity, (c) the physical and chemical properties of carbon.

(a) C. (b) In its purest form, 3.5; graphite, 2.15; amorphous forms, 1.5 to 2 . (c) One of the most common elements, tasteless, odorless, non-volatile, infusible and insoluble in all its forms; black in color, except in the form of the diamond, and is combustible, yielding $\mathrm{CO}_{2}$. It unites readily with a great many elements, forming important compounds. 
Discuss the use of carbon as a reducing agent.

Carbon is a very active reducing agent, because of its great affinity for oxygen. By leating carbon in the presence of any oxide, the latter is rapidly reduced, its oxygen forming $\mathrm{CO}$ or $\mathrm{CO}_{2}$ with carbon.

Mention and describe three allotropic forms of carbon.

1. Diamond is the purest form of carbon, and is the hardest substance known. It occurs in erystals, octahedral in shape. It is a very brilliant gem, owing to its great refractive power.

2. Graphite, also known as plumbago, or black lead, is a black, greasy substance with a specific gravity of 2.15. It is a good conductor of heat and electricity. Used as a lubricant for machinery, and in the manufacture of lead pencils, stove polish, crucibles, etc.

3. Amorphous carbon is always a black solid, but the different kinds vary in hardness and specific gravity. It is seen as the principal part of the various kinds of coal; in the form of lamp-black it is used in printer's ink; and occurs in bone-black, which serves as a decolorizing agent in the making of sugar, syrups and other liquids.

Describe how each of the following may be prepared: (a) lamp-black,

(b) bone-black. Mention the important uses of each.

(a) Lamp-black is made by burning tar, rosin, turpentine or petroleum, with a deficient supply of air, and passing the smoke into large chambers where the carbon is deposited. It is used in making printer's ink.

(b) Bone-black is made by carbonization of bones of animals and is used as a decolorizing agent.

Give the important physical and chemical properties of carbon dioxide.

Carbon dioxide is a colorless, odorless gas which by cold and pressure may be easily condensed to a liquid. Its specific gravity is 1.529, and its symbol, $\mathrm{CO}_{2}$, being composed of one volume of carbon and two of oxygen. It is not combustible and is not a good supporter of combustion, in fact it has a decided tendency to extinguish flames. It unites with water to form carbonic acid, $\mathrm{H}_{2} \mathrm{CO}_{3}$.

Describe the method of preparing carbon dioxide from marble and write the equation.

By heating marble $\left(\mathrm{CaCO}_{3}\right)$ or by adding hydrochloric acid, carbon dioxide is liberated.

$\mathrm{CaCO}_{3}+$ heat $=\mathrm{CaO}+\mathrm{CO}_{2}$.

$\mathrm{CaCo}_{3}+2 \mathrm{HCl}=\mathrm{CaCl}_{2}+\mathrm{H}_{2} \mathrm{O}+\mathrm{CO}_{2}$ 
Describe a simple test for carbon dioxide and write the reaction.

Pass the gas through lime water and the solution becomes turbid.

$$
\mathrm{Ca}(\mathrm{OH})_{2}+\mathrm{CO}_{2}=\mathrm{CaCO}_{3}+\mathrm{H}_{2} \mathrm{O} \text {. }
$$

Compare as to weight, carbon dioxide with air.

Carbon dioxide is one and one-half times heavier than air.

Describe the manufacture of some carbide and mention its common use.

Calcium carbide $\left(\mathrm{CaC}_{2}\right)$ is manufactured on a commercial scale by heating, in an electric furnace, a mixture of lime and coal, or coal tar $\left(\mathrm{CaO}+3 \mathrm{C}=\mathrm{CaC}_{2}+\mathrm{CO}\right)$. It is used for generating acetylene gas, which is formed by the action of calcium carbide and water $\left(\mathrm{CaC}_{2}+\mathrm{H}_{2} \mathrm{O}=\mathrm{C}_{2} \mathrm{H}_{2}+\mathrm{CaO}\right)$.

What is marsh gas? Give its formula and chemical importance with a method of preparation.

Marsh gas $\left(\mathrm{CH}_{4}\right)$ is a colorless gas which burns readily with a bluish-yellow flame, emitting much heat but little light. In nature it is produced by the decay of dead leaves in the bottom of stagnant pools. It also accumulates in coal mines as the dreaded "fire damp" and mixing with the oxygen of the air forms deadly explosions. In impure form it is obtained from wells in some localities and is used for lighting and heating. It can be prepared by mixing aluminum carbide and water $\left[\mathrm{Al}_{4} \mathrm{C}_{3}+12 \mathrm{H}_{2} \mathrm{O}=3 \mathrm{CH}_{4}+4 \mathrm{Al}(\mathrm{OH})_{3}\right]$.

Find the weight of each of the products formed by the complete combustion of 20 grammes of marsh gas $\left(\mathrm{CH}_{4}\right)$. [Atomic weight of $\mathrm{C}=\mathrm{I} 2$, of $\mathrm{O}=\mathrm{I6}$.]

$\mathrm{CH}_{4}+2 \mathrm{O}_{2}=\mathrm{CO}_{2}+2 \mathrm{H}_{2} \mathrm{O}$.

$16: 44=20: X, X=55$ grammes of $\mathrm{CO}_{2}$.

16:36 $=20: X, X=45$ grammes of $\mathrm{H}_{2} \mathrm{O}$.

Describe the manufacture of illuminating gas.

Bituminous or cannel coal is heated in clay or brick retorts and the products of distillation pass out into a series of pipes in which water, coal-tar, ammonia, etc., are deposited. The gas still contains impurities, which are removed by passing it over some absorbent substance, such as slaked lime.

Describe the construction and operation of the Bunsen burner.

In a gas flame, if the air is excluded, soot and smoke will form copiously. But if the combustion is rendered more perfect, no carbon is deposited and the flame becomes hotter, but less brilliant. In the Bunsen burner, this is arranged for by allowing air to enter at the bottom of the burner and become thoroughly mixed with the gas before the latter is ignited. If the openings through which 
the air enters are stopped up, the flame becomes more luminous and less hot.

Give proof of the fact that a diamond is composed of carbon.

A diamond, when heated intensely in the presence of oxygen, burns and forms carbon dioxide.

\section{SULPHUR}

Mention the properties and important uses of sulphur.

Sulphur is ordinarily a yellow, brittle solid, without taste or odor. It dissolves in carbon disulphide, but not in water, and combines easily with most of the other elements. Allotropic forms: prismatic or monoclinic, rhombic octahedra, and plastic. Uses: Used in the manufacture of gunpowder, matehes, sulphuric acid, bleaching agents, in medicine, etc.

Discuss the behavior of sulphur at different temperatures.

At $115^{\circ} \mathrm{C}$. it melts to a clear, amber-colored liquid which becomes viscid as the temperature rises to $230^{\circ} \mathrm{C}$. Above $250^{\circ} \mathrm{C}$. it becomes fiuid again and if poured into cold water it becomes plastic or ductile, but after standing a few days it returns to its primary condition, original sulphur.

Describe the use of sulphur in disinfecting. Explain its efficiency.

Remove animals from premises. All openings to outside air should be closed. Three pounds of flowers of sulphur, mixed with two ounces of alcohol and ignited, should be employed for every 1000 cubic feet of air space to be disinfected. Keep premises closed for six hours. Steam introduced into the apartment together with the sulphur fumes is more efficient, the water unites with the sulphurous anhydride to make the more potent sulphurous acid $\left(\mathrm{H}_{2} \mathrm{SO}_{3}\right)$. Sulphur fumigation is of little worth to destroy disease germs. Formaldehyde or chlorine gas is to be preferred.

Write the formula of hydrogen sulphide. Describe its properties.

$\mathrm{H}_{2} \mathrm{~S}$. A colorless gas with the peculiar odor of rotten eggs and a disgusting taste. It is soluble in water and highly combustible in the air, burning with a blue flame and forming sulphur dioxide and water. This gas is poisonous when inhaled.

Describe a method of preparing hydrogen sulphide.

Prepared by the action of dilute sulphuric acid upon iron sulphide. $\quad\left(\mathrm{FeS}+\mathrm{H}_{2} \mathrm{SO}_{4}=\mathrm{FeSO}_{4}+\mathrm{H}_{2} \mathrm{~S}\right.$. $)$

Describe a process of preparing sulphuric acid on a commercial scale. Mention the important uses of sulphuric acid.

"Lead chamber process." Sulphur dioxide, generated by the 
combustion of sulphur or by roasting iron pyrites in a suitable furnace, is passed into a large chamber, or series of chambers, lined with sheet lead. Nitrous fumes, produced by heating sodinm nitrate with a little sulphuric acid, enter the chamber at the same time; jets of steam are blown in at several points and a draft of air is kept up throughout. The sulphur dioxide meeting the nitrous fumes is oxidized by them and with the water of the steam forms sulphuric acid.

Uses: Very extensively used in the arts, in the manufacture of all the other strong acids, and fertilizers; refining sugar, fats and oils; in galvanic batteries, etc.

Write the graphic formula and calculate the percentage composition of sulphuric acid. [Atomic weight of $\mathrm{S}=$ 32.]<smiles></smiles>

$2+32+64=98$, the molecular weight of sulphuric acid.

$2 / 98$ or 2.04 per cent. hydrogen.

$32 / 98$ or 32.65 per cent. sulphur.

$64 / 98$ or 65.30 per cent. oxygen.

\section{What is 'copper sulphate? How prepared?}

Copper sulphate, blue vitriol, or blue stone, is the most important compound of copper. It is formed in large, transparent, deep-blue crystals which are easily soluble in water and have a nauseous, metallic taste. Formula, $\mathrm{CuSO}_{4}$.

It is prepared by dissolving eupric oxide in sulphuric acid, evaporating and erystallizing the solution.

\section{DISINFECTANTS AND ANTISEPTICS}

Differentiate between disinfectants and antiseptics.

Disinfectants are agents that destroy the mieroörganisms which cause infectious and contagious diseases, fermentation and putrefaction.

Antiseptics are agents which prevent the growth and development of the micloörganisms occasioning fermentation but more especially the pus-producing variety.

\section{What is a deodorant?}

Deodorants are agents which destroy or counteract a foul odor, e.g., phenol, zinc chloride and charcoal. 
Describe an efficient method of disinfecting by the use of formaldehyde.

For every 1000 cubic feet of air space, mix in a deep vessel $16 \%$ ounces of potassium permanganate with 20 ounces of formalin (a 40 per cent. aqueous solution of formaldehyde). Close all openings and leave this mixture in the room for 3 hours before opening.

PHOSPHORUS

Give a description of phosphorus as to (a) occurrence, (b) physical properties, (c) source.

(a) Never found free in nature, but as phosphates is an important constituent of plants, animals and the earth's crust.

(b) Phosphorus exists in several allotropic varieties, the more important of which are the yellow and red. The yellow variety is a yellowish-white, waxy solid of specific gravity 1.837. It melts at $44.2^{\circ} \mathrm{C}$. and boils at $263^{\circ} \mathrm{C}$; is highly inflammable and oxidizes readily in the air at ordinary temperature. It has a faint odor, resembling garlic, is very poisonous, is soluble in carbon disulphide and insoluble in water. The red variety is not easily inflammable in air, has a density of 2.2 , is insoluble in carbon disulphide and is not poisonous.

(c) Prepared from bone-ash or from sombrerite, an impure calcium phosphate found in the West Indian guano.

Mention the principal uses of phosphorus.

Used in matches, vermin poison, medicine and fertilizers.

Give (a) the symbol, (b) the valence, (c) atomic weight, (d) molecular weight, of phosphorus.

(a) P, (b) 3 and 5, (c) 31, (d) 124.

Name the allotropic forms of phosphorus.

Yellow, red, white and black.

\section{HALOGENS}

Name the elements of the halogen group and write the symbol of each. Fluorine, $\mathrm{F}$; chlorine, $\mathrm{Cl}$; bromine, $\mathrm{Br}$; iodine, $\mathrm{I}$.

Give the physical and chemical properties of iodine. Describe a test for iodine.

Iodine is a bluish-black crystalline substance, with a metallic luster and an odor faintly resembling that of chlorine. Its specific gravity is 4.95 and its atomic weight is 125.89 . Its vapor has a violet color. Iodine is almost insoluble in water but forms several important compounds with other elements. 
Test: Add a solution of starch paste, when an intensely blue color is produced.

Give the source and the preparation of iodine.

Iodine was previously obtained from the ashes of sea-weeds which are treated with water and the solution thus obtained is heated with manganese dioxide and sulpluuric acid. Iodine is set free by distillation.

At present, it is obtained from $\mathrm{NaIO}_{3}$, a by-product in the manufacture of Chili saltpetre.

\section{Mention the important uses of iodine.}

Used in medicine, photography and in the preparation of aniline dyes.

Give the method of making potassium iodide. Write the equation involved.

Add iodine crystals to an aqueous solution of caustic potash until saturated, then evaporate to dryness; the residue, which consists of potassium iodide and iodate, is then strongly heated to decompose the iodate, thus forming iodide with the liberation of oxygen. Dissolve the mass in water and evaporate, when crystals of potassium iodide will be left.

$$
\begin{aligned}
& 6 \mathrm{KOH}+3 \mathrm{I}_{2}=5 \mathrm{KI}+\mathrm{KIO}_{3}+3 \mathrm{H}_{2} \mathrm{O} . \\
& 2 \mathrm{KIO}_{3}+\text { heat }=2 \mathrm{KI}+3 \mathrm{O}_{2} .
\end{aligned}
$$

What are the phyical and chemical properties of chlorine. Mention the uses and important compounds of chlorine.

Chlorine is a greenish-yellow gas, two and one-half times heavier than air, and having a highly irritating odor; soluble in water and convertible into a liquid by cold and pressure. It has a strong affinity for other elements and forms a number of important compounds. Its atomic weight is 35.18 .

Uses: Strong disinfecting, deodorizing and bleaching agent and its compounds are valuable medicinal agents.

Among its important compounds are: sodium chloride, hydrochloric acid, chloral hydrate, calcium chloride, etc.

Describe a method of preparing chlorine and write the reaction.

Mix manganese dioxide with hydrochloric acid in a large flask provided with a delivery tube and heat gently; chlorine gas will be evolved.

$$
\mathrm{MnO}_{2}+4 \mathrm{HHCl}=\mathrm{MnCl}_{2}+\mathrm{Cl}_{2}+2 \mathrm{H}_{2} \mathrm{O} .
$$

Describe the preparation of hydrochloric acid.

It is prepared by the action of sulphuric aeid on sodium chloride in the presence of heat.

$2 \mathrm{NaCl}+\mathrm{H}_{2} \mathrm{SO}_{4}=\mathrm{Na}_{2} \mathrm{SO}_{4}+2 \mathrm{IICl}$. 
Mention a compound of each of the halogens.

Sodium chloride, potassium iodide, sodium bromide and hydro. fluoric acid.

Describe the properties of bromine and give a method for its preparation.

At ordinary temperature, bromine is a heavy, dark, reddishbrown liquid, giving off yellowish-red fumes of an exceedingly suffocating and irritating odor ; it is very volatile and has a specific gravity of 2.99. It is soluble in water, is a strong disinfecting and bleaching agent and acts as a corrosive poison.

Bromine is prepared by treating magnesium bromide with chlorine.

$\mathrm{IgBr}_{2}+2 \mathrm{Cl}=\mathrm{MgCl}_{2}+2 \mathrm{Br}$.

Give the properties and uses in medicine of bromine.

Properties given above. Sodium and potassium bromide are used in medicine as antispasmodies, nareotics and nerve sedatives.

\section{GOLD}

Give a test for gold and gold compounds.

Most reducing agents, as oxalic acid, ferrous sulphate, etc., precipitate gold from its solutions as a dark-brown powder.

\section{SILVER}

Describe silver, giving names of its most important compounds used in medicine.

Silver is a pure, white brilliant metal, a good conductor of heat and electricity, and is malleable and ductile. It is univalent and forms but one series of salts. It is not affected by the oxygen of the air, but is readily affected by traces of hydrogen sulphide, which forms a black film of sulphide upon the surface. Its atomic weight is 107 , its specific gravity is 10.5 and its symbol is Ag. Compounds used in medicine are: silver nitrate, protargol, argyrol, collargol.

What is lunar caustic? How is lunar caustic prepared and what is its medicinal use?

Lunar caustic is nitrate of silver, fused into round sticks, or pencils. It is prepared by adding 4 per cent. hydrochloric acid to silver nitrate, fusing and pouring into suitable moulds. It is used for cauterizing inflamed surfaces, warts, etc.

Give a chemical test for silver.

Add to a solution of silver a solution of hydrogen sulphide or ammonium sulphide, and a dark-brown precipitate of silver sulphide will be produced. 


\section{LEAD}

Give (a) the symbol, (b) atomic weight, (c) valence, and (d) the physical properties of lead.

(a) Pb. (b) 205. (c) 2 and 4. (d) Lead is a soft, bluishwhite metal; specific gravity, 11.38. When freshly cut, it has a bright metallic luster, but quickly tarnishes on the surface and becomes dull. It is malleable and ductile.

What is sugar of lead? Give its pharmaceutical name.

Sugar of lead is a salt formed by the action of acetic acid on lead oxide. It forms colorless, shining, transparent erystals, easily soluble in water, and has a sweetish, astringent, afterwards metallic taste. Formula, $\left(\mathrm{C}_{2} \mathrm{H}_{3} \mathrm{O}_{2}\right)_{2} \mathrm{~Pb}$.

Pharmaceutical name is plumbi acetate.

\section{MERCURY}

Describe mercury as to physical and chemical properties and occurrence in nature.

Mercury is the only metal which is liquid at ordinary temperature; it is almost silver-white and has a bright metallic lustre ; specific gravity, 13.56. Pure mercury does not tarnish in the air until heated above $300^{\circ} \mathrm{C}$., when it unites with the oxygen to form the red oxide. It combines directly with chlorine, bromine, iodine and sulphur and dissolves in nitric acid and hot sulphuric acid. Its atomic weight is 198.5 .

Mercury occurs in nature in a free state, but generally as mercuric sulphide (cinnabar), a dark-red mineral.

\section{Name the compounds of mercury used in medicine.}

Mercuric oxide, mercuric and mercurous chloride, mereuric iodide, massa hydrargyri, unguentum hydrargyri, hydrargyri cum creta.

Write the formula of each of the following: (a) mercurous chloride, (b) mercuric chloride. Mention the common name and important properties of each.

(a) $\mathrm{HIg}_{2} \mathrm{Cl}_{2}$, calomel, is a cholagogue cathartic, intestinal antiseptic and diuretic. The formula is commonly written, FigCl.

(b) $\mathrm{HgCl}_{2}$, corrosive sublimate, is a violent poison, antiseptic, and alterative.

Write the chemical equation representing the preparation of calomel. $\mathrm{HgSO}_{4}+\mathrm{Hg}+2 \mathrm{NaCl}=\mathrm{Na}_{2} \mathrm{SO}_{4}+2 \mathrm{HgCl}$. 
METALS OF THE ALKALIES

Name three important elements of the alkali group of metals.

Potassium, sodium, lithium.

Name three important potassium salts. Give in regard to each salt named: (a) its formula, (b) its principal uses in medicine.

Potassium chlorate, $\mathrm{KClO}_{3}$, antiseptic, refrigerant, sialogogue, and diuretic.

Potassium nitrate, $\mathrm{KNO}_{3}$, diuretic and antipyretic.

Potassium bicarbonate, $\mathrm{KHCO}_{3}$, antacid and sedative in gastric disorders.

Name five sodium salts used in medicine and write the chemical formula of each.

Sodium bicarbonate, $\mathrm{NaHCO}_{3}$; sodium chloride, $\mathrm{NaCl}$; sodium sulphate, $\mathrm{Na}_{2} \mathrm{SO}_{4}, 10 \mathrm{H}_{2} \mathrm{O}$; sodium phosphate, $\mathrm{Na}_{2} \mathrm{HPO}_{4}, 12 \mathrm{H}_{2} \mathrm{O}$; sodium carbonate, $\mathrm{Na}_{2} \mathrm{CO}_{3}, 10 \mathrm{H}_{2} \mathrm{O}$.

Describe the chemical action of liquid caustics on the tissues of the body.

The liquid caustics (sodium hydroxide, potassium hydroxide) have a great affinity for water and in abstracting same from the tissues, a great amount of heat is produced, which coagulates the albumin.

Mention the metals of the sodium group and describe the process of manufacturing sodium carbonate.

Potassium, sodium, lithium, rubidium and cæsium.

The Solvay process for manufacturing sodium carbonate depends upon the fact that when carbon dioxide is passed into a solution of common salt, in aqueous ammonia, sodium bicarbonate is formed, thus:

$$
\mathrm{NH}_{3}+\mathrm{CO}_{2}+\mathrm{NaCl}+\mathrm{H}_{2} \mathrm{O}=\mathrm{NaHCO}_{3}+\mathrm{NH}_{4} \mathrm{Cl} \text {. }
$$

The bicarbonate of soda $\left(\mathrm{NaHCO}_{3}\right)$, being slightly soluble, is deposited in large quantities and is converted into ordinary carbonate by heating.

\section{CALCIUM GROUP}

Name the elements of the calcium group and give their general characteristics.

Magnesium, calcium, strontium, barium and radium. They are alkaline in character and form oxides and salts whose properties somewhat resemble the metals of the alkalies. They are white in color and fusible only above a red heat; all oxidize readily in the air; all are malleable and ductile. 
Describe the process of preparing lime water from lime stone. Write the reactions.

By heating lime stone, $\mathrm{CO}_{2}$ is driven off and calcium oxide obtained. One part of calcium oxide is slaked and agitated occasionally during half an hour with 30 parts of water. The mixture is then allowed to settle and the liquid, containing, besides calcium hydroxide, the salts of the alkali metals which may have been present in the lime, is decanted and thrown away. To the calcium hydroxide left, and thus purified, 300 parts of water are added and occasionally shaken in a well-stoppered bottle, from which the clear liquid may be poured off for use.

$\mathrm{CaCO}_{3}+$ heat $=\mathrm{CaO}+\mathrm{CO}_{2}$, etc.

$\mathrm{CaO}+\mathrm{H}_{2} \mathrm{O}=\mathrm{Ca}(\mathrm{OH})_{2}$.

$\mathrm{Ca}(\mathrm{OH})_{2}+300 \mathrm{H}_{2} \mathrm{O}=$ lime water.

Describe with explanation the manufacture of plaster of Paris.

Plaster of Paris is made by heating native calcium sulphate (gypsum) and depriving it of part of its water.

$2\left(\mathrm{CaSO}_{4}, 2 \mathrm{H}_{2} \mathrm{O}\right)+$ heat $=2 \mathrm{CaSO}_{4} \cdot \mathrm{H}_{2} \mathrm{O}$ (plaster of Paris) and $3 \mathrm{H}_{2} \mathrm{O}$.

\section{What is gypsum?}

It is native calcium sulphate, $\mathrm{CaSO}_{4}, 2 \mathrm{H}_{2} \mathrm{O}$, and occurs abundantly in nature in white translncent masses.

Describe magnesium. Name its principal compounds used in medicine and write the chemical formula of each compound named.

Magnesium is a brilliant, almost silver-white alkaline metal with a specific gravity of 1.74 . It is tenacious and dnctile; dissolves readily in dilute acids, forming salts. It is easily combustible and burns with an intensely brilliant light, and is used in photography for flashlight purposes.

Compounds used in medicine: oxide, $\mathrm{MgO}$, known as magnesia; carbonate, $\mathrm{MgCO}_{3}$; sulphate (Epsom salts), $\mathrm{MgSO}_{4}, 7 \mathrm{I}_{2} \mathrm{O}$.

Describe the method of preparing Epom salts. Write the formula of Epsom salts.

Prepared by treating magnesium carbonate witl sulphuric acid and evaporating the solution to the erystallizing point. $\mathrm{IgCO}_{3}+$ $\mathrm{H}_{2} \mathrm{SO}_{4}=\mathrm{MgSO}_{4}+\mathrm{H}_{2} \mathrm{O}+\mathrm{CO}_{2}$. Formula of Epsom salts, $\mathrm{MgSO}_{4}$,$7 \mathrm{H}_{2} \mathrm{O}$.

Name and give the formula of a compound of barium used in medicine.

Barinm chloride, $\mathrm{BaCl}_{\text {. }}$. 
ZINC

Name three preparations of zinc that are used in medicine and write the chemical formula of each.

Zine sulphate, $\mathrm{ZnSO}_{4}$; zine chloride, $\mathrm{ZnCl}_{2}$; zinc oxide, $\mathrm{ZnO}$.

Describe a method of preparing zinc sulphate.

Dissolve zinc in dilute sulphuric acid.

$\mathrm{H}_{2} \mathrm{SO}_{4}+\mathrm{Zn}=\mathrm{ZnSO}_{4}+2 \mathrm{H}$.

How can Epsom salts be distinguished from zinc sulphate?

By testing with potassium ferrocyanide. Zine ferrocyanide will be thrown down as a white precipitate. No precipitate is formed with magnesium.

BORON

Give the names of the principal compounds and the chemical importance in medicine of boron.

Boric acid, $\mathrm{H}_{3} \mathrm{BO}_{3}$.

Sodium borate, $\mathrm{Na}_{2} \mathrm{~B}_{4} \mathrm{O}_{7}, 10 \mathrm{H}_{2} \mathrm{O}$ (borax).

Boric acid and borax are mild, harmless, non-irritating antiseptics and are very serviceable in surgery.

\section{ALUMINUM}

Give the properties of aluminum and mention its important salts.

Aluminum is a bluish-white, brilliant metal; malleable and ductile; specific gravity, 2.583. It is an excellent conductor of heat and electricity. It oxidizes superficially in the air and has the valuable properties of strength and lightness combined.

Aluminum sulphate is its most important salt. This combines with the sulphates of the alkaline metals to form a class of double salts, known as alums. Potassium alum is the commonest example.

\section{BISMUTH}

Give (a) the symbol, (b) atomic weight, (c) occurrence in nature, and (d) the compounds used in medicine of bismuth.

(a) Bi. (b) 206.5. (c) Rare, occurs as an oxide and sulphide. (d) Bismuth subnitrate, subgallate, subcarbonate, subsalicylate and citrate.

IRON

How does iron occur in nature?

Iron is found in small quantities in nearly all forms of rocks, clay, sand and earth, and in plants and blood. Rarely found free 
in nature except in meteoric masses, but is very abundant in certain ores, viz., magnetite, hematite and siderite.

Give the physical and chemical difference between cast iron and wrought iron.

Cast iron is brittle and eannot be welded or forged. It contains two, three or more per cent. of carbon. Wrought iron fuses with difficulty and is tough, fibrous and ean be welded. It eontains 1.6 per cent. or less of earbon.

\section{Describe briefly the Bessemer process.}

The Bessemer process of making steel from cast iron, which is accomplished by removing the carbon from the latter, is as follows : melted pig iron (cast iron) is poured into an egg-shaped vessel, called a "converter," through which a powerful blast of air can be blown. The converter is made of the strongest wrought iron and is lined with an infusible layer of fire clay. As the air bubbles through the molten iron, being forced in from below, the temperature rises and silicon and carbon are burned away. Spiegeleisen is added to supply the proper amount of earbon for good steel. The molten mass is then poured into moulds.

Mention three important ores of iron.

Magnetic oxide, $\mathrm{Fe}_{3} \mathrm{O}_{4}$; hematite, $\mathrm{Fe}_{2} \mathrm{O}_{3}$; and siderite, $\mathrm{FeCO}_{3}$.

Give the common name, the chemical name and the chemical formula of three compounds of iron.

1. Copperas, or green vitriol, ferrous sulphate, $\mathrm{FeSO}_{4}$.

2. Chloride of iron, ferric chloride, $\mathrm{Fe}_{2} \mathrm{Cl}_{6}$.

3. Carbonate of iron, ferrous earbonate, $\mathrm{FeCO}_{3}$.

Give the chemical equation showing the preparation of ferrous sulphate. Give the common names of ferrous sulphate and state its uses in medicine.

$\mathrm{Fe}_{2}+2 \mathrm{H}_{2} \mathrm{SO}_{4}=2 \mathrm{FeSO}_{4}+2 \mathrm{H}_{2} . \mathrm{Fe}_{2} \mathrm{SO}_{4}, 7 \mathrm{H}_{2} \mathrm{O}$, copperas, green vitriol or ferrous sulphate, is used in medicine as a hematinie, astringent, vermicide and disinfectant.

What is reduced iron and how is it made?

It is a very fine, grayish-black, lusterless powder, without odor or taste; permanent in dry air, insoluble in water or aleohol.

Made by passing hydrogen gas over freshly made, and earefully washed, ferric oxide, in a hot and closed tube. 


\section{ARSENIC}

Give the properties of arsenic and name some of the compounds of arsenic used in medicine.

Arsenic is an odorless, tasteless, steel-black non-metal with a metallic appearance. It is very brittle and volatilizes unchanged and without melting when heated to $180^{\circ} \mathrm{C}$. without access of air. In the air it burns with a bluish-white light and gives forth an odor which resembles that of garlic; insoluble in water; occurs as an opaque powder or in irregular masses.

Compounds of arsenic used in medicine: Fowler's solution, arsenious acid, arsenious iodide and sodium arsenate.

Write the chemical formula of white arsenic. State the occurrence of arsenic in nature.

White arsenic, or arsenious acid, $\mathrm{As}_{2} \mathrm{O}_{3}$.

Arsenic sometimes occurs in nature in the native state, but generally as a sulphide or oxide.

Describe the making of one preparation of arsenic that is used in medicine.

Fowler's solution, liquor potassii arsenitis. Dissolve one part arsenious oxide and two parts of potassium bicarbonate in ten parts of distilled water by boiling. Add enough distilled water to make ninety-seven parts and then add three parts of compound tincture of lavender. Filter through paper.

Give Marsh's test for arsenic. What other element gives a similar reaction? How may these two be distinguished?

Make a hydrogen generator with a flask containing zine and hydrochloric acid. Ignite the hydrogen escaping through the tube. Pour into the generating flask a few drops of any compound of arsenic. Hold a piece of cold porcelain against the flame, and a black, mirror-like stain of metallic arsenic will be deposited upon it.

Antimony compounds give a similar reaction. The arsenic stain is soluble in a solution of sodium hypochlorite, whereas, the antimony stain is not.

Mention a common substance containing arsenic.

Paris green. Arsenic is also found in lead shot, it being used to harden the same.

How should the contents of the stomach be examined for the presence of arsenic?

Examine under the microscope for solid arsenious oxide. Then apply MIarsh's test given above. 


\section{ANTIMONY}

Name the preparation of antimony used in medicine.

Antimonyl-potassinm tartrate, commonly called tartar emetic.

\section{ORGaNic ChEMISTRY}

What is organic chemistry?

Organic chemistry is the chemistry of the carbon compounds or the chemistry of the hydrocarbons and their derivatives.

Differentiate between hydrocarbons and carbohydrates.

Hydrocarbons are compounds of hydrogen and carbon, as methane, $\mathrm{CH}_{4}$.

Carbohydrates are compounds composed of carbon, hydrogen and oxygen, the two latter elements being present in the same relative atomic proportion as in water, e.g., grape sugar, $\mathrm{C}_{6} \mathrm{H}_{12} \mathrm{O}_{6}$.

Name four elements that enter into the formation of most organic bodies.

Carbon, hydrogen, oxygen and nitrogen.

Give the difference between essential oils and fixed oils.

Essential oils are derived from plants and belong to the class of compounds known as terpenes. They generally bear the empirical formula $\mathrm{C}_{10} \mathrm{H}_{6}$ and are volatile liquids. They do not form glycerine when treated with an alkali.

Fixed oils are the true fats and are composed of the glyceryl radical combined with a fat acid radical. They form soap when treated with an alkali.

How does gallic acid differ from tannic acid? What are the tests for differentiating the same?

Gallic acid does not eoagulate albumin, nor precipitate alkaloids, gelatin or starch; whereas, tannic acid does.

To a dilute solution (1-100) of tannic acid add a small quantity of lime water. A pale, bluish-white, flocenlent precipitate is formed, which is not dissolved on shaking (differenee from gallic acid), but becomes more copious and of a deeper blue than pinkish by the addition of an excess of lime water.

\section{FERMENTATION AND PU'REFACTION}

Why are organic substances liable to decay?

Because they are composed of combustible elements (carbon and hydrogen) which readily oxidize, forming earbon dioxide and water. Organic substanees offer the proper enviromment for the inenbation of bacteria. 
Name the principal salts of acetic acid and state which of the salts named are used in veterinary medicine.

The acetates of potassium, lead, ammonium, sodium, zinc and copper. The first five named are used in veterinary medicine.

\section{What is vinegar? How made?}

Vinegar is dilute acetic acid (about 6 per cent.). It is made by the oxidation of fermented juices (wine, cider). This oxidation is greatly facilitated by the enzyme "Mycodermie aceti." Vinegar is also made artificially by adding coloring and odoriferous substances to dilute acetic acid.

\section{ALCOHOLS}

State briefly the method of preparation of alcohol. Give the properties and the principal uses of alcohol.

Ethyl alcohol is prepared by the fermentation of grape sugar (glucose). To a solution of grape sugar, a certain yeast (ferment) is added which causes the decomposition of the sugar, yielding carbon dioxide and ethyl alcohol. Alcohol boils at a much lower temperature than water and therefore it can be readily separated by distillation.

$\mathrm{C}_{6} \mathrm{H}_{12} \mathrm{O}_{6}=2 \mathrm{CO}_{2}+2 \mathrm{C}_{2} \mathrm{H}_{5} \mathrm{OH}$ (ethyl alcohol).

Methyl alcohol $\left(\mathrm{CH}_{3} \mathrm{OH}\right)$ is obtained by the distillation of wood.

Pure ethyl alcohol is a transparent, colorless, volatile liquid, of a characteristic, rather agreeable odor, and a burning taste. It is very soluble in water, for which it has a great affinity. It is used in medicine in the preparation of tinctures, extracts and fluidextracts, and widely used in the arts.

What is the difference between an alcohol and an aldehyde?

An aldehyde is derived from an alcohol by dehydrating the latter, hence it contains less hydrogen than an alcohol. Aldehydes are unstable (except formaldehyde), very volatile liquids having a peculiar odor, e.g., liquor formaldehydi.

Give the formula for (a) ethyl alcohol, (b) methyl alcohol. Which is used for internal purposes?

(a) $\mathrm{C}_{2} \mathrm{H}_{5} \mathrm{OH}$, used internally.

(b) $\mathrm{CH}_{3} \mathrm{OH}$.

What is absolute alcohol?

Alcohol containing not more than one per cent. of water.

Compare wine and brandy in respect to composition.

Wine, according to the variety, contains from 6 to 22 per cent. alcohol. Brandy contains from 40 to 50 per cent. of alcohol. 


\section{CHLOROFORMI}

How is chloroform prepared? Write the formula of chloroform.

Cliloroform is prepared by the action of chlorinated lime on alcohol, or the purest from chloral. Formula, $\mathrm{CHCl}_{3}$.

Give the properties of chloroform.

Chloroform is a heavy, colorless liquid of a characteristic ethereal odor, a burning, sweet taste, and a meutral reaction; it is but sparingly soluble in water, but miscible with alcohol and ether in all proportions. It evaporates rapidly at all temperatures. Specific gravity, about 1.48 .

IODOFORM

\section{State the derivation of iodoform.}

Iodoform is a derivative of methane, $\mathrm{CH}_{4}$, in which three atoms of hydrogen have been replaced by three atoms of iodine. It is made by heating together an aqueous solution of an alkali carbonate, iodine and alcohol, until the brown color of iodine has disappeared; on cooling, iodoform is deposited in yellow scales, which are washed and dried between filter paper.

Give the chemical formula and uses of iodoform.

$\mathrm{CHI}_{3}$. It is used in surgery as an antiseptie for wound dressings, also for its slight local anæsthetic effect.

\section{Describe chloral.}

\section{CHLORAL}

Chloral is a colorless, oily liquid, with a penctrating odor and an acrid taste; soluble in water; specific gravity, 1.5. Formula, $\mathrm{C}_{2} \mathrm{HCl}_{3} \mathrm{O}$.

How is chloral hydrate made? Mention its principal uses in medicine.

Chloral hydrate is made by adding chloral to water, forming crystals. It is used in medicine for its hypnotic effect.

What is the difference between chloral hydrate and chloroform?

Chloral hydrate, $\mathrm{C}_{2} \mathrm{HCl}_{3} \mathrm{O}$.

Chloroform, $\mathrm{CHCl}_{3}$.

Chloral hydrate is frcely soluble in water; chloroform is only sparingly so. Chloral hydrate is a erystalline mass and volatilizes slowly at ordinary temperatures, whereas chloroform is a liquid and volatizes rapidly at all temperatures. 
PHENOLS

Give the composition and the properties of phenol.

Pure phenol, $\mathrm{C}_{6} \mathrm{H}_{5} \mathrm{OH}$, occurs in colorless crystals which are deliquescent and soluble in fixed oils, glycerine and water. It has a characteristic, aromatic odor; when diluted, it has a sweetish and afterward burning, caustic taste and produces a benumbing and caustic effect and even blisters on the skin. It is strongly poisonous and a powerful disinfectant.

What is phenol? For what is it used and from what is it obtained? See answer to preceding question.

Phenol is used in surgery for its germicidal, antiseptic and slight anæsthetic effects. Used as a disinfectant and deodorant in cesspools, stables, etc. It is obtained by fractional distillation of crude carbolic acid which is obtained during the distillation of coal-tar.

\section{What is salol? Give its properties and uses.}

Salol, a compound of salicylic acid and phenol, is a white, crystalline, almost tasteless powder, with a faintly aromatic odor; nearly insoluble in water, but readily soluble in alcohol and ether. It is made by the action of suitable dehydrating agents upon a mixture of phenol and salicylic acid. It is used as an antirheumatic, antipyretic and intestinal antiseptic.

\section{PETROLEUM}

What is petroleum? Name the important derivatives of petroleum used in medicine.

Petroleum is a product of the decomposition of organic matter, mostly of the fats and oils of fish and other aquatic animals. It is a mixture of the various liquid and solid paraffins, often containing in solution the gaseous and solid members of this group and also small quantities of coloring and other matters.

Derivatives used in medicine : petrolatum (cosmoline, vaseline) and liquid petrolatum.

Mention the source and important properties of vaseline.

Vaseline is obtained from petroleum by distilling off the lighter and more volatile portion and purifying the residue. It is a fatlike mass, varying in color from yellowish-white to light amber, slightly fluorescent, odorless and tasteless; when heated it gives 
off a faint odor of petroleum. Used principally as a base for ointments.

What is glycerine? How is glycerine prepared? Give its chemical formula.

Glycerine, a trihydroxyl alcohol, is a colorless, syrupy liquid, with a specifie gravity of 1.28. It is prepared by the action of superheated steam and an alkali upon fats, causing a splitting of the fats into fatty acids and glycerine. Formula, $\mathrm{C}_{3} \mathrm{H}_{5}(\mathrm{OH})_{3}$.

Mention the sources from which each of the following is obtained: (a) acetic acid, (b) lactic acid, (c) tartaric acid.

(a) From the destructive distillation of wood and the fermentation of alcohol.

(b) From lactic fermentation of sugar; certain bacteria in milk produce the enzyme.

(c) Obtained from the deposit occurring in the fermentation of wine.

\section{ALKALOIDS}

What is an alkaloid? State the properties of a vegetable alkaloid. Mention three alkaloids.

An alkaloid is an alkaline or basic principle of vegetable or animal origin. Alkaloids combine with acids to form salts. Vegetable alkaloids show the characteristic physiologic properties of the substance from which they are derived. They are usually crystalline, white, with a bitter taste, and odorless, except those which are volatile. They are insoluble in alkalies, sparingly soluble in water, but readily soluble in alcohol, ether and chloroform. They are all more or less toxic.

Strychnia, from nux vomica; morphia, from opium; atropia, from belladonna.

Mention a chemical antidote for alkaloids and explain why it acts as an antidote.

Tannin forms an insoluble tannate with nearly all alkaloids.

\section{What is a poison?}

TOXICOLOGY

A poison is any substance applied to the body, ingested, or developed within the body, which causes or may cause disease.

Give a classification of poisons and an example of each class named.

1. Irritant poisons, as caustic potash, phenol and caustic acids.

2. Neurotic poisons, as opium, belladouna and stryehnine. 
Define ptomaines and state how they are produced.

Ptomaines are the alkaloidal or basic products of the putrefaction of animal or vegetable matter. They are produced by the action of bacteria on nitrogenous matter.

Distinguish between physiological, chemical and mechanical antidotes and give an example of each.

A physiological antidote does not act directly upon the poison but produces physiological efiects opposite to that of the poison. Example: strychnine as an antidote to opium poisoning.

A chemical antidote is one which changes the chemical nature of the poison, rendering it inert. Example: sulphates in lead poisoning form insoluble lead sulphate.

A mechanical antidote is one that prevents the absorption of the poison. Example: stomach pump, mucilaginous drinks.

Name three metallic poisons and mention an antidote for each.

Lead: antidote, magnesium sulphate.

Nercury: antidote, albumin.

Copper: antidote, potassium ferrocyanide.

Name the antidotes that should be prescribed in case of poisoning by (a) caustic alkalies, (b) mineral acids, (c) mercuric chloride.

(a) Vinegar, olive oil, demulcent drinks, lemon juice.

(b) Sodium bicarbonate, lime water, soap.

(c) Egg albumin, flour and water.

Give the treatment for strychnine poisoning in the dog.

Produce vomiting at once; give tannin; place patient under ether, chloral or potassium bromide for a few hours.

Name the antidotes for phosphorous poisoning.

Copper sulphate, turpentine, peroxide of hydrogen, potassium permanganate. Never use oils.

Mention a chemical antidote for arsenic and explain its action.

Freshly prepared hydrated oxide of iron forms the insoluble ferric arsenite or arsenate.

Give treatment in case of poisoning by Paris green.

Same as arsenic. See preceding answer. Empty stomach; give oils and mucilaginous drinks as well as stimulants.

Give the chemical antidotes for (a) zinc salts, (b) lead salts.

(a) Solution of tannin (or strong tea) forms the insoluble tannate of zine. 
(b) Magnesium sulphate forms the insoluble sulphate of lead. In chronic lead poisoning, give potassium iodide liberally.

Mention precautions to be observed in case of poisoning by mineral acids.

Avoid stomach tube, as it might perforate the softened œsophagus. Neutralize the acids before producing vomiting.

What is the treatment for carbolic acid poisoning?

Give Epsom salts, or neutralize with alcohol, and produce vomiting with apomorphine or use the stomach pump. Opiates relieve pain.

\section{Physiological Chemistry}

\section{Define physiological chemistry.}

Physiological chemistry is that part of chemistry which has more especially for its object the various chemical changes which take place in the living organism of either plants or animals.

\section{Define the terms metabolism, catabolism and anabolism.}

Metabolism refers to the various chemical changes occurring in the living body, due to the action of enzymes, bacteria, and the living cell activity.

Catabolism is destructive metabolism, or the conversion of matter, especially protoplasm, into a lower state of organization and ultimately into waste products.

Anabolism is constructive metabolism, or the change of matter from a lower to a higher state of organization; especially the conversion of matter into protoplasm.

Define isotonic, hypo-isotonic and hyperisotonic solutions.

Isotonic is a condition in which the tension in two substances, or solutions, is the same, that is, the osmotic pressure is equal, e.g., physiologic salt solution is isotonic with blood.

Hypo-isotonic refers to a solution having a lesser osmotic power than another.

Hyperisotonic refers to a solution having a greater osmotic power than another. A solution of salt in greater proportion than is present in a physiological salt solution would be hyperisotonic to blood. Such a solution if mixed with blood would eause hæmolysis and other changes.

\section{What is a physiologic salt solution?}

It is a solution of sodium chloride of a certain strength ( 0.6 to 0.9 per cent.) which is isotonic with blood. 
Define (a) osmosis, (b) diffusion.

(a) Osmosis is the phenomenon of the passage of certain fluids through a porous substance, usually an animal membrane.

(b) Diffusion is the gradual interchange of the particles of miscible liquids when brought together.

\section{CARBOHYDRATES}

Define carbohydrates. How do they differ from hydrocarbons? Give an example of each.

Carbohydrates are organic compounds composed of hydrogen, carbon and oxygen; hydrogen and oxygen usually being present in the same proportion as in water. Example: glucose, $\mathrm{C}_{6} \mathrm{H}_{12} \mathrm{O}_{6}$.

A hydrocarbon is an organic compound composed of carbon and hydrogen. Example: methane, $\mathrm{CH}_{4}$.

Mention carbohydrates that are common food for horses and cattle.

Starches, sugars and gums which are present in large proportions in nearly all the common feeding-stuffs.

\section{FATS}

Define fats. 'Give the names of three fats.

Fats are compounds of the glyceryl radical and a fat acid radical. They are formed by glycerine and a fat acid, and consist of carbon, hydrogen and oxygen, are insoluble in water, slightly soluble in cold alcohol, easily soluble in ether. In a pure state, all fats are odorless, colorless, tasteless substances, and stain paper permanently.

Palmitin, stearin and olein are the principal animal fats.

\section{What is soap? Describe a laboratory method of preparing soap.}

Soap is a compound of one or more fatty acids with an alkali. It is usually prepared by the direct action of caustic soda or potash upon fats.

\section{MILK}

What is the composition of normal cow's milk?

The average composition may be given as follows:

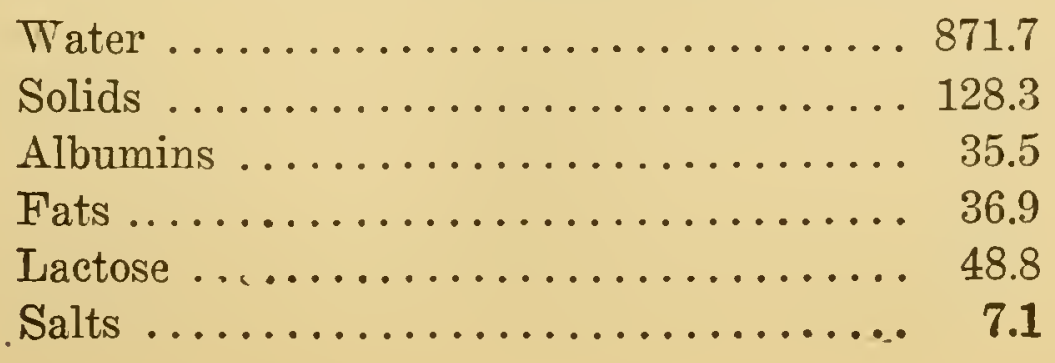


Describe the process of determining the per cent. of butter fat in a specimen of milk.

Take 20 c.c. of milk and add to it a small amount of a sodium hydrate solution. Extract the fat by adding 80 c.c. of ether which has been saturated with water. This is done by shaking in a tightly closed bottle. After the ethereal extract has entirely separated, 60 c.c. are placed in a weighed beaker, and the ether allowed to evaporate; the residue is dried and weighed. The result is calculated out for 80 c.c. of the ethereal extract, corresponding to 20 c.c. of milk.

Describe briefly the cause of the souring of milk and the changes thereby produced.

The lactic acid bacteria act upon the lactose, forming lactic acid which renders the milk sour and coagulates the caseinogen, the curd. The milk becomes acid in reaction, the curd settles as a thick, jellylike mass, leaving a watery fluid, the whey, above.

Give the requirements of the State of New York in regard to milk composition.

Milk must contain twelve per cent. solids, of which three per cent. must be butter fat.

Give the Pennsylvania State requirements for milk composition.

Milk must contain not less than 12.5 per cent. solids, of which 3 per cent. must be fat.

\section{URINE}

Describe a test for sugar in the urine.

Place some Fehling's solution in a test tube and boil it. If no discoloration takes place, it is suitable for the test. Add a few drops of the suspected urine and boil. If the mixture suddenly turns to an opaque yellow or red color, the presence of sugar is indicated.

\section{Give a test for albumin in the urine.}

To a small amount of nitric acid in a test tube, gently pour upon the surface some of the suspected urine. If albumin is present, a ring of white coagulum oceurs at the junction of the two fluids.

Describe a method of detecting the presence of bile in the urine.

Agitate a few drops of chloroform with the suspected urine in a test tube. If bile be present, the chloroform becomes turbid 
and acquires a yellowish hue, the depth of which depends upon the amount of bile present.

What is Fehling's solution and for what is it employed?

Fehling's solution is an aqueous solution of cupric sulphate mixed with potassio-sodic tartrate solution. It is used as a test for sugar. See answer to preceding question.

State the specific gravity of normal urine.

The specific gravity of horse urine ranges from 1020 to 1050 , the average being about 1035 .

\section{What is urea? Give its chemical formula.}

Urea is an end-product of metabolism. It is produced by the metabolism of the albuminous foods ingested and the albuminous substances in the body. It is a white, crystallizable substance and the chief nitrogenous constituent of urine. Formula, $\mathrm{CON}_{2} \mathrm{H}_{4}$. 


\section{ANATOMY*}

\section{OSTEOLOGY}

Give the properties and describe the development of the growth of bone.

Bone is composed of one-third animal matter and two-thirds mineral matter, principally phosphates and carbonates of lime.

Externally, bones are covered by a very vascular and nervous, fibrous membrane, except over the articular surfaces and insertion of tendons and ligaments. Bone proper consists of lamellæ, traversed by "Haversian eanals." These eanals are very minute and are part of the vascular system. The medulla, or marrow, is a pulpy, fatty substance which fills the interior and the areolæ of the spongy tissue of bones. Blood-vessels and nerves enter by way of the nutrient eanal. Flat bones (found in the head) do not have a medullary cavity.

Bones are developed from cartilages and fibrous tissue. The bones of the face and eranium are the only ones formed from the latter. Cartilage, undergoing calcifieation and being ramified with blood-vessels which carry the osteoblasts (bone-producing cells), eventually becomes hard, dense bone. Fibrous tissue is transformed very much the same except that the blood-vessels and other directing lines do not arrange themselves in parallel as in the long bones and, as a result, the medullary canal is absent, it being replaeed by irregular, eommunieating cavities, ealled medullary spaces.

\section{How many bones are there in the skeleton of the horse?}

The number is subject to slight variation in different skeletous. Considering the sacrum as a single bone, the os hyoides as one and 16 as the average number of eoceygeal vertebra, there are 191 bones in the horse's skeleton.

Name the bones of the cranium.

Occipital, parietal, frontal, sphenoid and ethmoid, and two temporal-seven in all.

Name the bones of the head.

Besides those of the eranium, above mentioned, there are the following pairs: superior maxillary, premaxillary, palatine, pterygoid, malar, lachrymal, nasal, supcrior and inferior turbinated, and three single bones-vomer, inferior maxillary and hyoid. 


\section{Describe the frontal bone of the ox.}

A very large, flat bone, occupying nearly one-half the anterior surface of the head and forming the front part of the roof of the craniun and part of the face. Quadrilateral in shape, it presents an external and internal face and four borders. The external face, slightly convex, is extended laterally by the processes which form the orbital arches and rest on the malar bone. Its middle region is covered by the skin and constitutes the base of the forehead. In the upper third, the supra-orbital foramen opens into a vasculonervous groove which ascends toward the base of the horns, and descends to near the lower border of the bone. The internal face is concave and divided into two unequal parts by a transverse ridge. The superior, the more extensive, is covered with digital impressions and belongs to the cranial cavity. The inferior part, articulating in the median line with the ethmoid, shows, between the external and internal plates of the bone, the frontal sinuses, two spaces which form part of the roof of the nasal cavities. Projecting from each side of the superior border are the osseous conical cores which support the horns (absent in hornless breeds). These projections are long and curved, very rugged, perforated by foramina and grooved by small vascular channels. The inferior border is deeply notched in its middle to receive the nasal bones. Laterally, the bone articulates with the sphenoid, parietal, lachrymal and malar. The orbital foramen, in the ox, belongs entirely to the frontal bone.

\section{Describe the superior maxillary bone.}

This bone, the most extensive in the upper jaw, is situated on the side of the face; it is bordered above by the frontal, palatine, zygomatic and lachrymal bones, below by the premaxillary, in front by the nasal, behind and within by that of the opposite side. It is elongated vertically and is irregularly triangular.

The external face shows a convex surface ending below in the supermaxillary spine; the infra-orbital foramen. The internal face shows a flat surface which forms the outer wall of the nasal fossa; the maxillary sinus, the palatine canal; a ridge for the attachment of the inferior turbinated; the inferior opening of the lachrymal canal.

The external border is very thick and hollowed into six large quadrilateral cavities, alveoli, which hold the molar teeth. Above the last alveolus is the alveolar tuberosity, and, below the first, the interdental space. 
The superior extremity is large and rounded and shows: a large cavity, the maxillary sinus; the infra-orbital eanal; and the palatine canal.

The inferior extremity presents a eavity which forms the alveolus of the tusk, and unites with a similar space in the premaxillary bone.

\section{Describe the inferior maxilla.}

The inferior maxillary is a very large bone, situated behind the upper jaw, and is composed of two symmetrieal branehes, joined at their lower extremities to form the intermaxillary space. It consists of two extremities, an inferior and superior, two faces, external and internal, and two borders, a superior and inferior.

The inferior extremity shows the body of the bone which is formed by the union of the two lateral halves. The inferior face is smooth and eonvex, and shows the inferior opening of the maxillodental canal-the mental foramen; on a level with this foramen, the bone markedly contracts to form the neek. The superior face is smooth and eoncave; it supports the free extremity of the tongue. The circumference is convex anteriorly and contains six sockets for the ineisors, and behind these-in the male only-on either side is an additional socket for the tusks. The space between the lateral incisors and tusks is called the bars, or inferior interdental space.

The superior extremity shows the condyloid proeess which articulates with the glenoid cavity of the temporal bone; the neek, a constriction below the condyle; the coronoid process, in front of the condyle and separated from it by the sigmoid noteh, is flattened on its sides and receives the terminal insertion of the temporalis muscle.

The external face is smooth and rounded in its inferior twothirds and roughened above for the insertion of the masseter muscle. The internal face presents in its upper one-third the superior orifice of the inferior maxillodental canal which runs down under the molar teeth, between the two plates of the bone, to the mental foramen; in its inferior two-thirds the internal face is smooth. Near the alveolar border and running parallel therewith is the myloid ridge. At the junction of the two sides is a roughened exeavation-the genial surface.

The superior, or alveolar border, shows a straight or inferior' portion which is hollowed by six alveoli to receive the inferior molar teeth, and a curved or superior portion for muscular insertion. The inferior border shows a sharp, straight portion and a more rounded portion above. The union of these two portions forms the angle of the jaw. 
Name the bones of the fore limbs of the horse and state how they differ from those of the ox.

In the horse: Scapula, humerus, radius, nlna, scaphoid, lunar, cuneiform, pisiform, trapezoid, magnum, unciform, principal metacarpus, two rudimentary metacarpi, suffraginis, corone, pedis, two sesamoids and one naviculare.

In the ox: Scapula, humerus, radius, ulna, six carpal bones (the os magnum and trapezoid are fused together), two metacarpi (one principal and one rudimentary, situated outwardly), four digitstwo with three phalanges and three sesamoids (as in the single digit of the horse), and two mdimentary ones, composed of two small bones.

\section{Describe the scapula and name the bone with which it articulates.}

The scapula is a flat, triangular-shaped bone which is applied against the anterior and outer plane of the thorax in an oblique direction downward and forward.

It has two faces, external and internal; three angles, anterior or cervical, posterior or dorsal, and inferior or humeral, and three borders, anterior, posterior, and superior.

The external surface is divided by a marked crest, the acromian spine, which runs parallel to the long axis of the bone, into two unequal depressed surfaces, the supra- and infraspinous fossie. The internal face is concave, forming the subscapular fossa, and is roughened for muscular insertion.

The anterior or eervical angle is comparatively thin, the posterior or dorsal is thick. The inferior or humeral is separated from the rest of the bone by a slight constriction, the neck of the scapula. It presents a glenoid cavity, a round, shallow depression, which receives the head of the humerus, and in front, a coracoid process, with a base and a summit which curves inwardly.

The superior border is sharp and thin, while the posterior is thick and slightly concave, and the superior is irregular and is prolonged by a thin cartilage, the cartilage of prolongation.

The scapula articulates with the humerus.

\section{Describe the ulna.}

The ulna is an elongated, triangular-shaped bone which is applied against the posterior and upper three-fourths of the radius and strongly united with the same. It presents for study a middle portion and two extremities.

The middle portion shows an external smooth, an internal concave, and an anterior rough surface which unites with the radius. In the middle third of the anterior surface is seen the ulnar groove 
which aids in forming the radio-ulnar arch. The posterior border is concave and thick.

On the superior extremity is an enormous process, the olecranon, which provides place for the attachment of the extensors of the forearm. It shows anteriorly an articular surface, the sigmoid cavity, which terminates above in a beak. The inferior extremity terminates in a sharp point, and sometimes by a small knob, the capitellum, which sometimes extends to the inferior extremity of the radius.

The ulna articulates with the humerus and radius.

\section{Name the bones of the carpus.}

Seaphoid, lunar, euneiform, pisiform or superearpal, trapezoid, magnum and unciform.

\section{Describe the pedal bone.}

The pedal bone, os pedis, third phalanx or coffin bone as it is variously known, supports the hoof and anterior limb. It is a short bone, somewhat pyramidal in shape, and is divided into three faces, three borders, and two lateral angles.

The anterior face is perforated by vaseular openings and shows laterally the preplantar fissure, a horizontal groove between the basilar and retrossal processes; between this fissure and the inferior border of the bone is a roughened projeeting surface, the patilobe eminence. The superior face shows two articular surfaces, glenoid cavities, which are divided by a median ridge. The inferior (or solar) face is somewhat eoneave and divided into two regions by the semilunar erest; just behind this erest and on either side the plantar fissures which open into a eavity in the interior, the semilunar sinus, may be seen.

The superior border is convex forward and shows the pyramidal eminence. The inferior border is convex and perforated by from five to ten large foramina. The posterior border is slightly eoneave and shows a diarthrodial facet for the navicular bone.

The lateral angles are two projections which are direeted backward. They show a superior, the basilar, and an inferior, the retrossal, process.

\section{What bones enter into the formation of the foot?}

Seven carpals, three metacarpals, three phalanges and three sesamoids, before mentioned.

Describe the first two cervical vertebræ.

The first or atlas has no head but instead two deep concave facets which articulate with the occipital ; posteriorly, is an articular surface for the odontoid process of the axis ; the transverse processes 
are large, flattened and incline forward and downward; there is no spinous process, but a roughened surface instead. At the base of each transverse process are two foramina which traverse it from below upward.

The second or axis is the longest of all the cervical vertebræ. It terminates anteriorly in a conical proccss, the odontoid, which is convex, smooth below and concave above to articulate with the atlas. The spinous process is very prominent and elongated anteroposteriorly. The transverse processes are only slightly developed.

Describe the common characteristics of vertebræ.

Each vertebra has a body, and an arch enclosing the spinal canal. The superior face of the body forms the lower boundary of the spinal canal. The anterior extremity of the body is convex and the posterior is concave. The arch projects upward from the body and is composed of pedicles, laminæ, transverse, spinous and articular processes. The articular processes, four in number, are distributed two anteriorly and two posteriorly. The anterior pair look upward, the posterior look downward.

What are true vertebræ? Give the number in the horse, ox and dog.

True vertebra are those constituting the cervical, dorsal and lumbar regions of the spinal column. There are 30 in the horse, 26 in the ox, and 27 in the dog.

Describe the sternum of the horse and compare it with the sternum of the ox and dog.

The sternum is the osteocartilaginous body which forms the inferior boundary of the thoracic cavity. It shows on either side articulations for the first eight ribs; anteriorly, it shows a cartilaginous mass, flattened on each side and curved upward, the cervical prolongation or presternum; posteriorly it is flattened above and below to form the xiphoid or ensiform cartilage. It is flattened, laterally, in its anterior two-thirds, and from above downward in its posterior one-third.

The sternum never undergoes complete ossification. It is developed, in the horse, from six single nuclei which never coalesce to form a single piece.

In the ox, the sternum is made up of seven parts; they are much more compact than those in the horse, and are united to each other, with the exception of the first. There is no cervical prolongation and the xiphoid cartilage is feebly developed.

In the sternum of the dog, eight component parts are noted. They are hollowed in their middle part and thick at their ends. They are never ossified to each other. 
Describe the sacrum.

The sacrum is formed by the consolidation of five vertebra which are closely fused. It articulates, anteriorly, with the last lumbar vertebra, posteriorly, with the first coccygcal bone, aud, latcrally, with the os innominata.

The bone is triangular in shape with a base anteriorly, articulating with the last lumbar vertebra through its body, articular and transverse processes; posteriorly, the apex articulates with the coccyx; and laterally, the first segment shows a sort of transverse process which has an auricular facet to furnish articulation with the os innominata. The inferior surface is smooth and shows four intervertebral foramina, and the superior surface shows in its middle the spinous processes which together constitute the sacral spine. On each side of the sacral spine is a groove which is pierced between each segment by the supersacral foramina.

\section{Name the bones of the pelvis.}

The os innominatum, made up of the ilium, pubis and ischium, and the sacrum.

\section{Describe the cotyloid cavity.}

The cotyloid cavity is a deep excavation which is formed in the middle of the os innominata at the junction of the ilium, pubis and ischium. It is circumscribed by a narrow rim which is notched on the inner side to communicate with the subpubic notch. 'The decper portion is roughened for ligamentous insertion. The cavity receives the articulating head of the femur.

Describe the pelvis. State the difference between the pelvis of the horse and that of the ox.

The pelvis is a bony cavity in the posterior part of the body, which prolongs the abdominal cavity between the sacrum and the coccygeal vertebrx. It is formed above by the sacrum, laterally by the ilia, but mostly by the sacrosciatic ligannent, and below by the ischia and pubes. The inlet is bounded by the sacrum, pubes and ilia and has four diameters, vertical, horizontal and two oblique; the ontlet, through which pass the rectum and genital organs, is bounded by the sacrum, ischia and sacrosciatic ligament, and has two dianeters, vertical and horizontal.

In the ox, the os innominatum is nearly horizontal, the transverse diameter is relatively less extensive, and the ilinm is more oblique.

Name the bones of the hind limb.

The os innominatum or coxa (composed of ilium, pubis and ischium), femur, tibia, fibula, the tilrsus (composed of six bones, 
viz., astragalus, calcaneum, cuneiform magnun, cuneiform medium, cuneiform parvum, and cuboid), one principal and two rudimentary metatarsi, two sesamoids, suffraginis, coronx, pedis, and naviculare.

Give the number of ribs, sternal and asternal, in the horse, the ox and the dog respectively.

Sternal: horse, 8 ; ox, 8 ; dog, 9.

Asternal: horse, 10 ; ox, 5 ; dog, 4 .

Define trochanter, condyle, trochlea, foramen, sinus, tuberosity, spinous process, glenoid cavity.

Trochanter is a large, bony eminence on the superior extremity of the femur, below the neck.

A condyle is an articular eminence on the extremity of a bone which represents an ovoid segment cut parallel to its larger axis (e.g., the condyles of the femur).

A trochlea is a pulley-like articular surface on the extremities of bones, as seen on the os astragalus or tibial-tarsal bone.

A foramen is an opening into or surrounded by bone, through which blood-vessels and nerves pass.

A sinus is a recess, cavity or hollow space surrounded by bone, found chiefly within the cranium.

A tuberosity is a large, round, and slightly detached nonarticular eminence on a bone (the great tuberosity of the humerus).

A spinous process is a bony projection on the dorsal face of a vertebra.

A glenoid cavity is an oval, shallow, diarthrodial eavity in a bone (the glemoid cavity of the scapula).

\section{Arthrology}

Name the different classes of articulations and give an example of each class.

Synarthroses, e.g., the occipitotemporal articulation.

Amphiarthroses, e.g., the intervertebral articulations.

Diarthroses, e.g., the coxofemoral articulation.

Define (a) synarthrosis, (b) amphiarthrosis, (c) diarthrosis.

Synarthrosis is an immovable articulation as seen in the bones of the skull.

Amphiarthrosis is a joint with limited movement, being intermediate between a synarthrosis and a diarthrosis; e.g., the sacro-iliac joint.

Diarthrosis is a freely movable joint, as the atlo-axoid. 
What structures may enter into the construction of the following different kinds of joints: (a) synarthrodial, (b) amphiarthrodial, and (c) diarthrodial?

(a) Bone, fibrous tissue and periosteum.

(b) Bone, fibrocartilage, ligaments.

(c) Bone, cartilage, ligaments, synovial capsule and synovia.

\section{Describe the atlo-axoid articulation.}

This is an example of a diarthrodial joint. It is made up of the odontoid and articular processes of the axis and the corresponding depressions on the atlas.

Ligaments: Odontoid, from the odontoid to the inferior areh of the atlas; the superior atlo-axoid, between the spines; the inferior atlo-axoid below the bodies; the eapsular ligaments (two) between the articular processes; synovial membrane.

Action: Lateral rotation.

\section{Describe the articulating surfaces of the axis.}

Anteriorly, is a conical process, termed the odontoid, which is flattened above and below, convex and smooth on its inferior surface to fit the corresponding surface on the atlas. The anterior artienlating processes (prezygopophyses) are carried to the base and to each side of the odontoid in the shape of two undulating facets and are eonfounded with the gliding surface of the latter. Posteriorly, is a wide and deep cavity to receive the head of the sueeeding: vertebra; above and on each side of this cavity are the posterior artieulating processes (post-zygopophyses) inclined dowuward.

Describe the joints that, back of the dentata, connect the vertebræ.

Ligaments: 1. The common superior vertebral ligament which lies above the bodies of the vertebræ and is attached to them from the axis to the saerum.

2. The common inferior vertebral ligament which lies below the bodies and is attaehed to them from the sixth or eighth dorsal to the sacrum.

3. An interartieular fibroeartilage which is found between the bodies of the vertebra.

4. A capsular ligament, between the artienlar proeesses.

5. An intertransverse, between the transverse processes.

6. An interlamellar, between the laminx.

7. An interspinous, between the spinons proeesses.

8. A supraspinous, between the summits of the spinous processes.

The ligamentum nuchx extends from the first dorsal to the oeciput. In the sacral and eoceygeal regions the artieulations are more or less fused and rudimentary. 
The fibrocartilage in the lumbosacral articulation is very thick and the transverse processes of the last lumbar articulates with the external angles of the sacrum. The fifth and sixth lumbar also articulate between their transverse processes.

The movements of the spinal column are those of flexion, extension and lateral. These movements are quite free in the cervical region but restricted elsewhere.

Describe the ligamentum nuchæ, particularly as to its origin, distribution and function.

The ligamentum nuchæ is composed of two portions, viz., a funicular portion, from the first dorsal spinous process to the summit of the head, and a lamellar portion which extends between the spinous processes of the second dorsal and the last six cervical vertebræ.

Function: It acts as a stay and support to the head and maintains the head and neck in a natural position during repose.

What forms and kinds of costochondral and costosternal joints in the horse and the ox hinder or favor free breathing in the recumbent position?

The costochondral in the horse are synarthrodial and hinder, but in the ox they are true gingymoid diarthroses and hence favor free breathing. The costosternal in both the horse and the ox are diarthrodial, but have a gliding movement only, hence they hinder free breathing in the recumbent position.

Describe the shoulder-joint.

The scapulohumeral articulation is an enarthrodial, or ball-andsocket joint, which is formed by the head of the humerus and the glenoid cavity of the scapula.

Ligaments: A rudimentary glenoid ligament which deepens the cavity; a capsular ligament, extending from the margins of the cavity to the neck of the humerus; two supporting fasciculi from the coracoid process to the head of the humerus.

The muscles in relation to the joint are:

1. In front, coracoradial.

2. Behind, large extensor of the forearm and teres minor.

3. Outside, short abductor of the arm and postea spinatus.

4. Inside, subscapularis.

Action: Abduction, adduction, flexion, extension, rotation and circumduction.

Name and describe the ligaments of the elbow-joint.

An anterior, from the humerus above the articuiar surface to the anterior part of the radius. 
An external lateral, from the eavity ontside of the humerus to the external portion of the radius.

An internal lateral, from the inner tuberosity of the inferior extremity of the humerus to the radial tuberosity and to interosseous fibres.

\section{Describe the radiocarpal articulation.}

The radiocarpal articulation is an imperfect ginglymoid which is made up of the lower articular surface of the radius and the four upper carpal bones.

Three ligaments: an internal from the radius to the fourth bone, a superficial external from the radius to the supercarpal bone, and a deep external from the radius to the second bone and interosseous ligament.

\section{Name the structures composing the carpus.}

1. The articulations uniting the carpal bones of the first row to each other.

2. The analogous articulations of the second row.

3. The radiocarpal articulation.

4. The articulation of the two rows with each other.

5. The carpometacarpal articulation.

\section{Describe the ligaments of the knee-joint.}

Besides those mentioned above in describing the radiocarpal joint are three anterior and three interosseous in front or and between the first row of carpal bones; two anterior and two interosseous in front of and between the second row; an external posterior, from the first bone of the upper to the second bone of the lower row; an internal posterior, from the internal bone of the upper row to the second and third of the lower row ; an external, from the superearpal bone to the first bone of the second row and head of the external metacarpal.

Between the lower row and the metacarpal bones are two anterior, one between the second bone and the principal metacarpal, the other from the first to the external metaearpal ; two interosseous from the articulation between the metacarpi to the interosseous ligaments of the seeond row.

Common earpal ligaments are:

1. Anterior, from the radius to the prineipal metacarpus.

2. Posterior, from the posterior part of the radial surface to the carpus and the prineipal metaearpus.

3. External lateral, from the outer side of the radius to the 
first bones of the upper and lower rows and the outer metacarpal bone.

4. Internal lateral, from the inner side of the radius to the principal and inner metacarpi, as well as to the capsular ligament.

Name the bones and ligaments of the fetlock joint.

Bones: Metacarpus, first phalanx, and two sesamoids.

Ligaments: Intersesamoid, between the two sesamoids; lateral sesamoid, between the sides of the sesamoid and the upper extremity of the first phalanx; inferior sesamoid, of three fasciculi from the posterior surface of the first phalanx to the sesamoid bones; external and internal lateral, from the metacarpus to the sides of the first phalanx; an anterior, between the anterior surfaces of both bones; a posterior, or suspensory ligament of the fetlock, from the first and second bone of the inferior carpal row and posterior face of the principal metacarpus to the top of the sesamoids, where it divides into two fasciculi which pass forward and are inserted into the anterior extensor of the phalanges.

\section{What is the function of the suspensory ligament?}

It acts as a mainstay or brace to the foot, and assists in preventing jar from concussion when the fore limbs are brought to the ground in locomotion.

\section{Describe the first interphalangeal articulation.}

This is an imperfect ginglymus, between the os suffraginis and os coronæ. Ligaments: two lateral ligaments between the sides of the bones; one posterior ligament, or glenoidal fibrocartilage attached to the first and second phalanges by six bands, increases the articular surface below and forms a sheath for the passage of the perforans tendon.

IIovements : Flexion, extension and some lateral motion.

\section{Describe and discuss the functions of the lateral cartilages.}

The lateral cartilages, two in number, are composed of fibrous and cartilaginous tissue, and are the shape of an oblique parallelogram. They are prolonged behind the third phalanx and are attached in front to the anterior lateral ligament, behind, to the basilar and retrossal processes and plantar cushion. They are thin above with a notch posteriorly for vessels; thick below, concave internally, with vascular foramina, and convex externally, with foramina for vessels.

In association with the plantar cushion they act as cushions in preventing jar and allowing for expansion when the foot is brought in contact with the ground. 
Describe the hip-joint.

The coxofemoral articulation is an enarthrodial, or ball-andsocket, joint between the cotyloid eavity of the os innominata and the head of the femur.

Ligaments: Capsular, extending from the margins of the cotyloid cavity to the neck of the femur; a transverse, converting the notch into a foramen; a cotyloid which deepens the cavity; a coxofemoral (ligamentum teres), from the bottom of the cotyloid cavity to the depression in the head of the femur; a pubiofemoral, from the inferior face of the pelvis to the cotyloid cavity; a synovial membrane which is very extensive.

Muscles in relation to the joint are, anteriorly, the gracilis and rectus; posteriorly, the gemelli, internal obturator and pyramidalis; inferiorly, the external obturator; and superiorly, the small gluteus.

State the difference between the hip-joint of the horse and that of the ox.

See answer to preceding question.

The pubiofemoral ligament is absent in the ox, which permits of greater freedom to movements of abduction.

\section{Describe the femorotibial articulation.}

A diarthrodial type of joint, between the femur, tibia and patella.

Ligaments: An anterior, made of three strong fasciculi from the patella to the anterior surface of the tibia; the antepatellar aponeurosis, which is an expansion of the fascia lata, binds the patella to the femur by two lateral fasciculi; an external lateral, from the external condyle to the head of the fibula; an internal latcral, from the inner condyle to the inner tibial tuberosity; a posterior, from the posterior face of the femur to the tibia ; two crucial, or interosseous, from the intercondyloid notch to the tibial spine, crossing in the centre, forming an $\mathrm{X}$; two interarticular fibrocartilages (menisci), attached to the tibial spine and by fasciculi to the femur and tibia; a synovial membrane in two portions, one under the patella and the other under the lateral ligaments.

Action: Flexion, extension and rotation.

Name the various articulations of the tarsal joint.

Tibiotarsal, calcaneo-astragaloid, sccond row of tarsus with each other, two rows of tarsus with each other, and tarsometatarsal.

Describe the calcaneocuboid ligament.

A strong fibrous brace which unites the posterior border of the ealcis to the cuboides and to the head of the external ruclimentary 
metatarsal bone. It blends, outwardly, with the external and superficial, tibiotarsal ligament, and inwardly, with the posterior tarsometatarsal band. Strains of this ligament give rise to "curb."

\section{MYOLOGY}

Dcscribe aponeuroses.

Aponeuroses are flattened bands of white fibrous tissue which envelop, in common, all the muscles of one or several adjoining regions, and by one extremity are attached to the bones. They maintain the muscles in their position and sustain them during their contraction.

Describe the masseter muscle.

A short, wide and very thick muscle, irregularly quadrilateral, applied against the external face of the mandible. Origin: the zygomatic process of the temporal bone. Insertion: the outer surface of the ramus of the jaw. Action: elevator of the jaw. Nerve: inferior maxillary branch of the fifth.

Name the muscles that close the jaw and give the attachments of each.

Masseter, see above. Temporal, from the temporal fossa, the temporal fascia and the outer border of the orbit to the coronoid process and ramus of the inferior maxilla; pterygoid internus, from the palatine crest and subsphenoidal process to the hollow on the inner face of the inferior maxilla; pterygoid externus, from the inferior face of the sphenoid and the pterygoid process to the neck of the condyle of the lower maxilla.

Name the muscles of the globe of the eye.

Retractor oculi; superior, inferior, external and internal recti; superior oblique and inferior oblique.

Describe the mastoidohumeralis muscle.

It extends from the summit of the head to the inferior part of the arm. It consists of two portions, viz., an anterior portion which originates on the mastoid process and crest, and is inserted in the furrow of torsion of the humerus, below the deltoid imprint; a posterior portion which originates on the transverse processes of the first four cervical vertebræ and is inserted with the anterior portion. It carries the limb forward or inclines the head to the side.

Name the muscle separating the carotid artery from the jugular vein. What is the function of this muscle?

The subscapulohyoideus. It is a depressor of the hyoid bone and its appendages. 
Name the muscles that aid in flexing the shoulder-joint.

Teres externus (long abductor of the arm) and teres internus (adductor of the arm).

Name the muscles of the brachial region.

Anterior region: the flexor brachii and humeralis obliquus.

Posterior brachial region : the triceps, viz., caput magnum, caput medium and caput parvum, and the anconeus.

Name the muscles of the forearm.

Four anteriorly, viz., anterior extensor of the metacarpus, oblique extensor of the metacarpus, extensor pedis and extensor suffraginis.

Five posteriorly, viz., external flexor of the metacarpus, oblique flexor of the metacarpus, flexor pedis perforatus, flexor pedis perforans and internal flexor of the metacarpus.

\section{Describe the flexor pedis perforans.}

Situated immediately behind the radius and is composed of three portions which unite at the carpus to continue to the inferior extremity of the digit by a long and powerful tendon.

Origin: The summit of the epitrochlea, summit and posterior border of the olecranon, and posterior surface of the radius, by the three portions, respectively. Above the carpus, these three unite and pass through the carpal sheath and between the two terminal branches of the perforatus tendon to its insertion, the semilunar crest of the os pedis.

Name all the muscles that would be severed in amputating the fore limb just above the knee.

All those of the forearm mentioned above.

Name the muscles that flex the carpus. Give their attachments.

1. External flexor of the metacarpus, from the external condyle of the humerus to the supercarpal and external metacarpal bones.

2. Oblique flexor of the metacarpus from the base of the epitrochlea and olecranon to the supercarpal.

3. Internal flexor of the metacarpus from the base of the epitrochlea to the head of the internal metacarpal bone.

4. Flexor pedis perforatus arises on the summit of the epitrochlea and extends to the second phalanx; in contracting shortly, it flexes the carpus.

5. Flexor pedis perforans, described above.

Give the origin, insertion and action of the flexor brachii.

Origin: Coracoid process of the scapula. 
Insertion: Superior and internal tuberosity of the radius, the capsular and internal lateral ligament.

Action: Flexes the forearm.

Give the origin, insertion and action of the flexor metacarpi medius.

This is the same as the oblique flexor of the metacarpus given above.

Name the muscles of the gluteal region, or croup.

Three: superficial, middle and deep glutei.

Name the muscles attached to the upper third of the femur.

Great psoas, iliopsoas, superficial, middle and deep glutei, tensor fascia lata, vastus externus, vastus intermus, pectineus, small adductor of the thigh, great adductor of the thigh, quadratus femoris, obturator externus, internal obturator, and gemelli.

Give the origin and the insertion of the vastus externus muscle.

Origin: Outer and anterior surfaces of the superior extremity of the femur.

Insertion: Superior face and external side of the patella.

Give the origin, insertion and action of the popliteus.

Origin: Outside the external condyle of the femur.

Insertion: Into the triangular surface on the posterior surface of the tibia in its superior parts.

Action: Flexes the tibia and rotates it outward.

Describe the origin, insertion and action of the gastrocnemius.

Origin: The external head from above and behind the external condyle of the femur; the internal head from the internal condyle.

Insertion: Into the posterior part of the summit of the os calcis after passing into a bursa.

Action: Extends the foot on the tibia.

Give the origin, insertion and action of the sartorius.

Origin: The iliac aponeurosis near the tendon of the psoas parvus.

Insertion: The internal patellar ligament.

Action: Adducts the leg and flexes the femur.

Name and give the attachments of the muscles that flex the tarsus.

1. Flexor metatarsi: the tendinous portion orginates from the front of the femur between the trochlea and the external condyle and is inserted in front of the superior extremity of the principal metatarsus and to the cuboid bone; the muscular portion originates from the tibia on the sides of the groove through which the tendon 
passes, and is inserted in front of the superior extremity of the principal metatarsus and the second cuneiform bone.

2. Anterior extensor of the phalanges: originates in the digital fossa above the external condyle of the femur; and is inserted in the capsular ligament of the metatarsophalangeal articulation, the anterior surfaces of the first two phalanges, and the pyramidal eminence of the os pedis.

3. Lateral extensor of the phalanges: originates along the external femorotibial ligament and the whole extent of the fibula, and terminates in the tendon of the anterior extensor.

Give the origin, course, relations and termination of the lateral extensor of the phalanges (peroneus).

Origin and termination given above.

The muscular portion extends in the direction of the tibia on the external side from the superior to its inferior extremity. The tendinous portion, succeeding the muscular portion, passes to the external side of the tarsus through the tibial sheath and passes forward to join the tendon of the anterior extensor, near the middle of the metatarsal region.

The muscular body is enveloped in a special containing aponeurosis which separates it in front from the anterior extensor and behind from the perforans. The tendon covers the tibia and margins the external and superficial ligament of the tibiotarsal articulation.

\section{Name the muscles of the tail.}

Six sacrococcygeal muscles, viz., two superior, two inferior and two lateral; two ischiococcygeal muscles.

\section{Describe the panniculus carnosus muscle.}

An immense wide muscle on the inner surface of the skin, covering the sides of the thorax and abdomen. It is irregularly triangular, thin at its borders and thicker in its middle.

Origin: From the flank to the posterior border of the nlnar mass of muscles and pectoralis major.

Insertion: One layer to the anterior limb and one to the small trochanter; aponeurotic fibres attach it to the internal surface of the skin and fascia of the superficial muscles.

Action: In contracting, the whole entancous integument is shaken, thus preventing insects from alighting.

Give the origin, insertion and action of the longissimus dorsi.

Origin: The lumbar border, external angle and internal surface of the ilium, and the spinous proeesses of all the lumbar, dorsal and last four cervical vertebre. 
Insertion: The transverse processes of the lumbar vertebræ and the outer surfaces of the fifteen or sixteen last ribs.

Action: Extends the vertebral column and pulls the ribs forward in expiration.

Give the origin, insertion and action of the longus colli muscle.

Origin: Posterior portion arises from the inferior face of the bodies of the first six dorsal vertebra. The middle portion, from the transverse processes of the last six cervical vertebre. The anterior portion, from the anterior three or four fasciculi of the middle portion.

Insertion: The posterior portion is inserted on the tubercle of the sixth cervical vertebra. The middle portion, on the inferior ridge of the bodies of the first six cervical vertebræ. The anterior portion, on the inferior tuberele of the atlas.

Action: Flexes the neck.

Give the origin, insertion and action of the serratus magnus.

Origin: The external surface of the first eight ribs.

Insertion: The anterior and posterior triangular surfaces of the scapula and the subscapularis.

Action: Supports the body as a girdle, or depresses the scapula.

Describe the diaphragm. What important structures pass through the diaphragm?

The diaphragm is the muscular partition between the thoracic and abdominal cavities.

Originates by right and left pillars from the lumbar vertebræ and is confounded with the inferior common ligament of the spine; also from the xiphoid appendage of the sternum, and the anterior extremities of the last twelve ribs.

Insertion: Phrenic centre, dividing into right and left leaflets.

The diaphragm is related anteriorly with the pleura and lungs; posteriorly, with the peritoneum, stomach, liver, colon and spleen.

The aorta, thoracic duct, vena cava and œsophagus pass through the diaphragm.

How does the diaphragm of the ox differ from that of the horse? Of what surgical importance is this difference?

The attachments of the muscular portion are much farther distant from the cartilaginous circle than in the horse.

This arrangement permits puncture of the rumen through the last intercostal space, whereas a puncture at this point in the horse would enter the thoracic cavity. 
Name the muscles of respiration.

Inspiratory: External and internal intercostals, levatores costarum, serratus anticus, serratus magnus, latissimus dorsi, diaphragm.

Expiratory: External and internal intercostals, serratus posticus, triangularis sterni, great and small oblique muscles of the abdomen, longissimus dorsi, and the retractor of the last rib.

Describe the inguinal canal, stating the structures which it contains.

A canal, two to two and one-half inches in length, on each side and in front of the pubic bone, running downward, backward and inward, comprised between Poupart's ligament of the great oblique muscle, posteriorly, and the small oblique muscle anteriorly. Its inferior orifice (external or cutaneous orifice, inguinal or external abdominal ring) is much larger than the superior (internal) ring.

The spermatic eord and vessels in the male, and the external mammary vessels in the female pass through the inguinal canal.

\section{Describe the navicular sheath.}

The navicular sheath is a fibrous membrane which covers the os naviculare and the single ligament of the pedal articulation. It is reflected on the plantar aponeurosis of the flexor pedis tendon, in front of this ligament and ascends to the inferior sac of the sesamoid sheath, where it is reflected upon itself, thereby forming two culs-desac, one superior and one inferior. It is lined by a synovial membrane which aids the aponeurosis of the tendon in gliding over the navicular bone.

\section{Circulatory Organg}

State the position of the heart and show its relation to the right and left walls of the chest and to the sternum in the horse and dog.

In the horse, the heart occupies a position in the middle line of the chest, corresponding to the third, fourth, fifth and sixth ribs, being enclosed in a sac and suspended from the spine by its aortic vessels. Its base is uppermost, its apex nearly touches the sternum but does not rest on the ribs. The diaphragm lies just behind the apex. The heart is separated from the right wall of the ehest by the right lobe of the lung. There is a triangular notch in the left lung which exposes the left ventricle and allows it to make its impulse felt against the chest wall.

In the dog, the heart oceupies a more nearly median position, resting almost entirely on the upper face of the sternum and about equidistant from the right and left chest wall. 
Describe the right and left heart, noting the size of the different cavities, the thickness of the walls at different points, the nature, position and dependencies of the four sets of valves and the source and distribution of the vascular and nervous supply.

The heart is divided by a vertical septum into two parts, which are further divided into four by a transverse septum. The cavities above the transverse septum are called right and left auricles, those below, the right and left ventricles, the two latter constituting the largest portion of the heart.

The right auricle: The walls are about one-fourth of an inch in thickness. It receives the anterior vena cava, posterior vena cava, vena azygos, and the large coronary veins. It opens, in its floor, into the right ventricle through the auriculoventricular opening.

The right ventricle: Its walls are on an average six-tenths of an inch thick. It has two openings, the auriculoventricular, and the pulmonary opening into the pulmonary artery.

The left auricle: Similar to the right. The walls are irregular in thickness, varying from one-third of an inch in some places to a very thin membranous wall in others. It receives the pulmonary veins and empties through the auriculoventricular opening in its floor into the left ventricle.

The left ventricle: Its walls are on an average one and one-fifth to one and five-eighths inches in thickness. Two openings, the auriculoventricular and aortic.

The valves of the heart are made of fibrous segments. The right auriculoventricular is composed of three segments (tricuspid) attached by their free edges to the ventricular wall by tendinous cords, chordæ tendinæ. The left auriculoventricular is composed of two segments (bicuspid) and is similarly attached. The pulmonary and aortic openings of the ventricles are closed by the semilunar valves made up of three segments which are also attached by tendinous cords.

The blood supply of the heart is by the two coronary arteries, branches from the trunk of the aorta at the sigmoid valves. Each divides into two principal branches, one passing along the horizontal, the other in the vertical furrow of the heart. The venous blood is returned to the right auricle by the coronary vein.

The nerves of the heart, furnished by the cardiac plexus, come from the pneumogastric and sympathetic.

Mention all the arteries given off from the posterior aorta.

Intercostals, phrenic, lumbar, middle sacral, broncho-œsophageal, cœliac axis, anterior mesenteric, posterior mesenteric, renal, sper- 
matic, small testicular (uterine in females), external and internal iliacs.

Name the terminal branches of the anterior aorta.

The two axillary arteries.

Name in regular order the important blood-vessels through which the blood moves in passing from the left ventricle to the right front foot.

Common aorta, anterior aorta, axillary, humeral, posterior radial, collateral artery of the cannon, digital.

Describe the posterior radial artery and give its branches.

It arises from the humeral artery near the inferior extremity of the humerus, passes along the internal ligament of the elbow-joint, along the inner side of the radius to the inferior extremity of the same, where it divides into the common interosseous, metacarpal and collateral artery of the cannon, giving off branches in its course to the elbow and muscles of the forearm.

\section{Describe the digital arteries and their branches.}

The digital arteries originate just above the fetlock, from the terminal extremity of the collateral artery of the eannon, and descend one to the right, the other to the left, along the margin of the flexor tendons to the basilar process of the pedal bone, where they bifurcate to form the plantar and preplantar ungual arteries.

Several small branches are given off at the fetlock to the articulation, sesamoid sheath and tendons. Near the middle of the os suffraginis, the perpendicular artery, with anterior and posterior branches, encircles the limb, and by anastomosing both before and behind, supplies the neighboring tissues. Small branches are given off to the plantar cushion and coronary eircle. The preplantar ungual enters foramina in the os pedis. The plantar ungual passes into the plantar fissure, plantar canal and semilunar sinus and unites with the opposite to form the semilunar anastomosis.

Give the origin and the distribution of the brachial artery.

The brachial, or axillary, arteries, two in number, are the terminal branches of the anterior aorta. 'They give off the following branches: dorsal, superior cervical, vertebral, internal thoracic, external thoracic, superior cervical, suprascapular and subscapular; after giving off these branches, the brachial artery is continued as the humeral artery. In addition to those named, the right axillary gives off, near its origin, the common trunk of the two carotid arteries. 
Name the branches of the external carotid artery.

Glossofacial, maxillomuscular, posterior auricular, superficial temporal and internal maxillary.

State the anatomic relations of the external carotid artery.

From its origin to the hyoid bone, it is related inwardly to the guttural pouch and the glossopharyngeal and superior laryngeal nerves; outwardly, to the outer belly of the digastric muscle and the hypoglossal nerve; throughout the rest of its course, it is comprised between the guttural pouch, the parotid gland, the great cornu of the hyoid bone, and the inner side of the posterior border of the inferior maxilla.

Give the course and the termination of the vertebral artery.

It arises from the axillary at the first intercostal space. It passes beneath the transverse process of the seventh and through the foramina of the upper six cervical vertebræ, anastomosing with the retrograde branch of the occipital and giving off muscular and spinal branches at each intervertebral space.

Give the blood supply of the larynx.

The laryngeal artery, which arises from the common carotid at a short distance from its termination, just behind the larynx.

Give the blood supply of the salivary glands.

Small branches from the external carotid supply the parotid and submaxillary glands. The sublingual is supplied by the sublingual artery.

Trace the course of the blood from the left ventricle to the left hind foot, naming in regular order all the important vessels through which the blood passes.

The common aorta, posterior aorta, external iliac, femoral, popliteal, anterior tibial, collateral artery of the cannon, digital, plantar and preplantar. A collateral stream from the popliteal passes through the posterior tibial region and gives off an interosseous branch which unites with the collateral artery of the cannon just above the fetlock.

Describe the origin and distribution of the external iliac artery.

Originates in common with the internal iliac from the posterior extremity of the posterior aorta and gives off the small testicular, or artery of the cord in the male, or the uterine in the femalc, and the circumflex iliac; then it is continued as the femoral upon leaving the anterior border of the pubis. 
Describe the cœliac axis and name its branches.

The coliac axis is a short trunk which arises from the posterior aorta immediately upon the entrance of that vessel into the abdominal cavity. After a course of three-fourths inch, it separates into three large branches, the gastric, splenic and hepatic arteries.

Describe the origin and the distribution of the internal iliac artery.

The internal iliac artery arises from the posterior extremity of the posterior artery and terminates near the insertion of the small psoas muscle by dividing into the obturator and iliofemoral arteries. It gives off the following branches: umbilical, internal pudic, iliolumbar, lateral sacral and gluteal.

Give the course and the termination of the femoral artery.

It arises at the anterior border of the pubis as a continuation of the external iliac and descends to the superior extremity of the gastrocnemius, where it is continued as the popliteal. The following branches are given off: prepubic, femoris profunda, superficial femoris, small muscular, and saphena.

Give the blood supply of the stomach.

Supplied by the gastric artery, a branch of the cœliac axis.

Give the blood supply of the spleen.

Supplied by the splenic artery, a branch of the cœliac axis.

Give the blood supply of the uterus.

The uterine artery which arises from the posterior aorta or from the external iliac near its origin; the utero-ovarian which arises from the posterior mesenteric.

Give the functional and nutritive blood supply of the liver and lungs.

Liver: Functional supply, the portal vein; nutritive, the hepatic artery, a branch of the cœlic axis.

Lungs: Functional, pulmonary artery; nutritive, bronchial artery which is given off from the posterior aorta near the first pair of intereostals.

\section{Give the blood supply of bone.}

The arteries of bones belong to three orders, viz.:

Those of the first order penetrate to the interior of the medullary canal of long bones, by a particular orifice, the mutrient foramen. They soon divide into a network that lines the walls of the eanal and enters the medulla. This network communicates with the arteries of the second order which go to the spongy tissue of the extremitics of the long bones. The arteries of the third order are branclies 
of the periostic network that enters the superficial Haversian canals. In the flat and short bones, there are no arteries of the first order.

\section{Describe the systemic circulation.}

The blood enters the left auricle from the lungs through the pulmonary vein, passes through the bicuspid valve into the left ventricle, through the semilunar valve into the common aorta, anterior and posterior aorta, from thence it is distributed to all parts of the body, passing through arteries, capillaries and into the veins back to the right auricle, through the anterior and posterior vena cava. At the right auricle, the pulmonary circulation begins.

\section{Describe the pulmonary circulation.}

The blood reaches the right auricle through the anterior and posterior vena cava and passes through the tricuspid valve into the right ventricle, thence through the semilunar valve into the pulmonary artery, through which it is carried to the lungs. In the lungs it goes through a fine network of capillaries and returns through the pulmonary vein to the left auricle, here to begin the systemic circulation.

\section{Describe the fetal circulation of the blood.}

The blood, after interchanging gases in the placenta, enters the umbilical vein and is carried to the liver. In the substance of the liver, it is mixed with the venous blood from the intestines and posterior parts, through the medium of the ductus venosus, and at last arrives at the right auricle. From here it passes into the left auricle through the foramen ovale, thence into the left ventricle and aorta. The greater portion is driven into the vessels that supply the head, neck and fore limbs, the remainder passes backward in the posterior aorta. After the fluid has circulated in the anterior part of the body, it is returned to the right auricle by the anterior vena cava. From the right auricle, it passes to the right ventricle, and from this cavity it is pumped into the pulmonary artery, thence through the ductus arteriosus into the posterior aorta, which earries it to the hinder parts of the body. The veins of the hind parts unite in forming the umbilical artery, which conveys the blood to the placenta. The umbilical artery is practically a continuation of the internal iliacs. (The ductus venosus only exists in ruminants.)

Describe the umbilical arteries of the fotus.

The umbilical arteries arise from the internal iliacs and pass along the sides of the bladder. Escaping at the umbilicus, they arrive at the terminal extremity of the amniotic portion of the cord, and, giving off some branches to the amnion, they are continued 
to the extremity of the allantoid portion, where they end in an expansion of placental ramifications.

Describe the ductus arteriosus and the foramen ovale in the fœtus. Give their uses and state what remnants of these can be found in mature life.

The ductus arteriosus is a short vessel which connects the pulmonary artery, near its origin, to the posterior aorta. In fetal life, the lungs do not functionate, hence the blood is not carried to them but takes this short course to the aorta. This duct remains, but in mature life is represented by a yellow elastic fibrous cord (the ligamentum arteriosum).

The foramen ovale is the opening between the right and left auricles, through which the blood passes in fetal life. It is provided with a valve, the Eustachian valve (absent in horse and pig), that stretches from the mouth of the posterior vena cava to the annulus, or thickened border of the foramen. The function of this valve is to direet the blood-stream into the left auricle, from whence it goes into the systemic circulation. In mature life, the foramen ovale is represented by a depression of a thin membrane, surrounded by the ring of Vieussens, or annulus ovalis. Occasionally the opening persists throughout adult life.

\section{Describe the anterior vena cava.}

A large trunk extending from the entrance of the chest to the right auricle. It is formed by the union of the two axillary and the two jugular veins. It receives in its course: the internal thoracic, vertebral, superior cervical and dorsal veins, and the great vena azygos.

Give the origin of the vena azygos and name its tributaries.

Oriminates at the first lumbar vertebra and extends forward to the sixth dorsal, where it terminates in the anterior vena cava. Its tributaries are the satellite veins of the first lumbar and all of the aortic intereostal arteries, right and left.

\section{Describe the pulmonary veins.}

The pulmonary veins, four to eight in number, arise from the substance of the lung, emerging immediately above the origin of the bronchi. They terminate in the left auricle, which they enter by way of four to eight orifices. They have no valves. Their function is to earry the blood from the lungs, where it has been purified, to the left auricle to begin the systemic cireulation. 
Give the course and relations of the jugular vein.

Formed by the union of the superficial temporal and internal maxillary veins, behind the inferior maxilla. It passes downward and backward, lodged at first in the substance of the parotid gland, afterward in the jugular furrow (the muscular interspace between the mastoidohumeralis and the sternomaxillaris). At the inferior extremity of the neck, it unites with its mate to form the confluent of the jugulars. After leaving the parotid gland, the jugular is covered externally by the cervical panniculus. Inwardly and above, it is related to the subscapulohyoideus muscle, which separates it from the carotid, but in its inferior part it is in direct relation with that vessel, the trachea and the œsophagus.

Branches: maxillomuscular, posterior auricular, occipital, glossofacial, thyroid, cephalic, parotidean and many small muscular veins.

\section{Describe the course and the function of the portal vein.}

It begins in the sublumbar region, by the union of the anterior and posterior mesenterics and the splenic veins; it is then directed forward, traversing the pancreatic ring, below the vena cava, and is afterward lodged in the great fissure of the liver, where it ramifies by forming the interlobular veins. It receives on its course the right gastro-omental and anterior gastric veins. Its function is to carry the blood which comes from the intestinal walls, charged with assimilable substances, that are absorbed by the veins of the villi, to the liver.

\section{Give a general description of the lymphatics.}

The lymphaties are vessels with very thin and transparent walls, found all over the body, except in blood-vessels, nervous tissue, bone, muscles, eyeball, cartilage, tendons, the membranes of the ovum, placenta, umbilical cord, cuticle and hair. They possess nutrient vessels, no nerves, have valves, and carry lymph or chyle into the vascular system. Like the veins, the lymphatics terminate in two principal trunks, resembling the vena cava; and, like the veins, have three tunics. The lymphatics originate from capillaries which form networks or terminal culs-de-sac. They terminate, as before stated, by emptying into the vascular system; the union of the blood with the lymphatic system takes place at the origin of the anterior vena cava.

Give the course and the termination of the thoracic duct.

The thoracic duct receives all the lymphatics except those of the right side of the head, neck and thorax and the right anterior limb. It originates beneath the vertebral column, near the first lumbar vertebra, where it is marked by a very irregular dila- 
tation (reeptaculum chyli), passes forward through the pillars of the diaphragm to the sixth dorsal vertebra, where it passes to the left and empties, after a dilatation, into the anterior vena cava at the junction of the jugulars.

\section{Describe the lymphatic glands.}

The lymphatic glands are ovoid, spherical or diseoid bodies of medium consisteney, which intercept the course of lymphatic vessels at several points. Their number is eonsiderable, and they are rarely single, but most frequently are eollected in groups along the bloodvessels. All the vessels of the lymphatic system are provided with one or more of these glands on their course. The branch of the vessel, entering the gland, is called the afferent, and that leaving, the efferent. The capsule of the gland sends fibrous strands into its substance, dividing it into very minute spaces (lymph simuses) which are filled with lymph corpuscles. The afferent vessels take a tortuous course and, communicating with the sinuses, become charged with lymph-cells.

Lymph-glands are richly supplied with blood-vessels which penetrate the gland through the eapsule, or enter at the hilum and break up into a fine-meshed capillary network, branches of which pass through the lymph sinuses.

The lymph-glands act as filters for the lymphatic system and are important as a source of leucocytes.

\section{In what part of the intestinal tract is lymphoid tissue found?}

At certain places in the walls of the ileum there are collections of solitary follicles, known as Peyer's patehes.

\section{Give the situation of the lymphatic glands of the thorax.}

1. Posterior mediastinal, a series of small granular masses on the course of the osophagus.

2. The bronchial, in the angle of the bifurcation of the trachea.

3. Two long strings of lobules which extend on the sides of the inferior face of the trachea, from the base of the heart to near the first rib.

Mention the location of the following lymphatic glands: posterior cervical, prescapular, posterior mediastinal, inguinal, popliteal, precrural, iliac, axillary and bronchial.

Posterior eervieal, situated on the side of the terminal extremity of the jugular, within the inferior border of the sealenus musele, extends into the ehest by passing beneath the axillary vessels and ascends to the inner face of the first rib.

Preseapular, situated on the aseending branch of the inferior 
cervical artery, beneath the internal face of the mastoidohumeralis muscle and extends close to the attachment of the sternomaxillaris muscle.

Posterior mediastinal (see preceding question).

Inguinal, the deep inguinal situated beneath the crural aponeurosis and arch in the interstice between the adductor museles of the leg, along with the iliac vessels. The superficial inguinal are located in front of the inguinal ring at the side of the sheath on the track of the subcutaneous abdominal artery.

Popliteal, located behind the great sciatic nerve and gastrocnemius muscle, between the biceps femoris and the semitendinosus muscles, and near the femoropopliteal artery.

Precrural, located within the anterior border of the tensor fascia lata, on the course of the circumflex iliac artery.

Iliac, situated in the triangular space between the two branches of the circumflex iliac artery.

Axillary, beneath the anterior limb, inside the arm; one group is near the ulnar articulation, the other, behind the brachial vessels, near the common insertion of the teres major and latissimus dorsi muscles.

Bronchial (see preceding question).

\section{State the approximate number of mesenteric lymph-glands.}

About thirty in number.

\section{Neurology}

The nervous system is divided into two great parts, the cerebrospinal and the sympathetic. The cerebrospinal system consists of the brain, spinal cord, ganglia and nerves. The brain is the central portion of the nervous system and is situated in the cranial cavity; the spinal cord is, in reality, a great extension of the brain throughout the length of the spinal canal, from which emerge, at numerous points, branches, nerves, upon which are noted enlargements, called ganglia. The sympathetic system will be described in answer to a question below.

Name the membranes that cover the brain and describe the outer one.

From within outward, pia mater, arachnoid and dura mater.

The dura mater is a strong, fibrous membrane, adherent to the bony walls. It gives off prolongations into the brain, forms depressions for the venous sinuses and is prolonged on the nerves and spinal cord. 
Name the principal parts of the brain.

Cerebrum, cerebellum, the isthmus, and medulla oblongata.

Describe the island of Reil.

The island of Reil is a very small lobule of brain in the fissure of Sylvius, found in man but not in the horse.

\section{Describe the optic thalami.}

The optic thalami are two masses of gray matter, placed above the crura cerebri; they are separated by a deep groove, and form the sides of the third ventricle. At their posterior border are found two projections, the external and internal geniculate bodies.

\section{Describe the cerebellum.}

The cerebellum is that part of the brain, situated behind and beneath the cerebrum, above the isthmus and separated from the cerebrum by a fold of the dura mater.

It is globular in form and is divided by two fissures into three lobes, two lateral and a middle. The lateral lobes are convex and show many convolutions or depressions. The middle lobe is disposed in a vermicular manner, which gives rise to the names of the twc divisions, anterior vermiform and superior vermiform processes.

The strueture is gray externally and white internally with a tree-like arrangement called the arbor vitos.

\section{Describe the corpora quadrigemina.}

These are four round eminences, placed in pairs, which lie above the cerebral peduncles. The two posterior, the smallest, are also named the tubercula testes, and the anterior pair, the tubercula nates. The nates are gray and the testes are white.

\section{Describe the spinal cord, using a diagram.}

The spinal cord is the portion of the nervous system which is enelosed in the spinal canal from the oceipital foramen to the upper third of the saeral eanal. Its average weight in the horse is $101 / 2$ ounces. It is slightly flattened above and below, and has two enlargements in its course, one between the fifth eervieal and second dorsal vertebra, the brachial bulb, the other, near the middle of the loins, the lumbar enlargement.

The structure of the cord is, externally, white matter, internally, gray. 'The gray matter is arranged like two horns, the larger ends of which point down and out, but do not reach the surface, the smaller look upward and outward, reaching the surface. 'The two horns are connected by a transverse band (similar to the letter 
" $\mathrm{H}$ "), called the commissure, which shows in its middle the central canal of the cord.

The cord is traversed throughout its length by two fissures, the superior of which is narrower and shallower than the inferior, which is only separated from the gray commissure by a white band, the white commissure.

The white matter is divided on each side into three columns. The superior column lies between the superior fissure and the superior or sensory nerve root. The inferior, between the inferior fissure and the inferior or motor root. The lateral lies between the two. The cord is covered by membranes similar to the brain, viz., dura mater, arachnoid and pia mater. The posterior end of the cord is marked by a narrow prolongation, the filum terminale.

\section{Describe the spinal nerves.}

The spinal nerves emanate from the spinal cord and leave the vertebral canal by the intervertebral foramina to proceed to the various organs. They proceed from the lateral aspects of the cord by two orders of roots: one motor, the other sensitive. These two roots unite into a very short trunk in passing through the intervertebral foramen and this mixed nerve divides almost immediately into two terminal branches. On the superior root, before its union with the inferior, a ganglion is found. Passing out with the inferior root of the spinal nerve, but indistinguishable from it, is a branch of nerve known as the white ramus communicans which leaves the main trunk after the mixed nerve has been formed, and runs to a distinct system known as the sympathetic.

How many pairs of spinal nerves are there in the horse? State the relative number in the cervical, dorsal, lumbar, sacral and coccygeal regions, respectively.

There are 42 or 43 pairs of spinal nerves as follows: cervical, 8 pairs; dorsal, 17 pairs; lumbar, 6 pairs; sacral, 5 pairs; and coccygeal, 6 to 7 pairs.

\section{Name the cranial nerves.}

Olfactory, optic, motor oculi, patheticum, trifacial, abducens, facial, auditory, glossopharyngeal, pneumogastric, spinal accessory and hypoglossal.

\section{Describe the first pair of cranial nerves.}

The olfactory nerves originate, superficially, in the olfactory lobe of the brain, deeply, from the corpus striatum and transverse fibres of the pons. Pass through the cribriform plate of the ethmoid bone and are widely distributed over the nasal septum and ethmoidal 
cells in the upper third of the nasal fossie. Function: preside over the sense of smell.

Give the origin and the distribution of the optic nerve.

Origin: From the commissure and optic tracts which arise from the thalamus and corpora quadrigemina.

Distribution: To the retina.

Describe the third pair of cranial nerves, the oculomotor.

Originates superficially from the crura near the interpeduncular fissure, deeply, from the anterior border of the pons. Passes through the smallest suprasphenoidal foramen of the orbit. Distributed to all the muscles of the eye except the external rectus, the great oblique and part of the posterior rectus, and by the ophthalmic ganglion to the iris.

\section{Give the origin and the distribution of the fourth pair of cranial nerves.}

The patheticum originates in the band of Reil, behind the corpora quadrigemina and, deeply, from the interior of the isthmus. It is distributed to the great oblique muscle of the eye.

\section{Describe the fifth pair of cranial nerves, the trifacial.}

This nerve originates by two roots, motor and sensory, in the pons varolii. On the sensory branch, in the region of the occipitosphenotemporal hiatus, is a large ganglion, the Gasserian, which gives rise to the three branches of the nerve, viz., the superior maxillary, the inferior maxillary and the ophthalmic. The motor root passes along, but outside of, the ganglion and unites with the fibres of the inferior maxillary branch. So, although the fifth pair is called a mixed nerve, in reality only the inferior maxillary branch is composed of sensory and motor fibres.

The branches emerge from the cranial cavity as follows: the first braneh (ophthalmic) passes through the smallest of the large suprasphenoidal foramina to the orbit and is distributed to the skin of the forehead and eyelids, lachrymal gland and nasal fossa. The second, superior maxillary, passes through the foramen rotundum to the orbit and along the infra-orbital canal, where it ends in small branches to the face and upper lip. It sends branches to the eycball, palate, nose and teeth of the upper jaw. The third, inferior maxillary, passes through the foramen ovale to the temporomaxillary articulation and then passes downward to enter the inferior dental canal; it supplies the inuseles of mastication and the teeth of the lower jaw.

On the course of the fifth pair of nerves, the following ganglia 
from the sympathetic system are seen : the ophthalmic or ciliary, the sphenopalatine or Meckel's, and the otic or Arnold's.

Describe the sixth pair of cranial nerves.

The abducens originates superficially from the medulla behind the pons and, deeply, from the inferior pyramid and lateral tract of the medulla.

It leaves the cranial cavity with the ophthalmic branch of the fifth, and is distributed to the external rectus muscle of the eye.

Describe the seventh pair of cranial nerves, the facial.

Originates superficially from the medulla behind the pons and, deeply, in the floor of the fourth ventricle. It escapes from the cranial cavity through the internal auditory meatus with the eighth pair, enters the aqueduct of Fallopins, has the geniculate ganglion developed on it and passes out through the stylomastoid foramen to the muscles of the face, ears, lips, nostrils and eyelids.

Branches: great petrossal, to Meckel's ganglion; small petrossal, to otic ganglion; tympanitic, to stapedius ; chorda tympani, to tongue and mouth; muscular, to occipitostyloid, digastric, stylohyoid and cervical muscles; auricular, to the ear and face.

\section{Describe the auditory nerve (eighth pair).}

Originates in the medulla, below the seventh pair. Leaves the cranial cavity with the seventh pair and is distributed to the internal ear by two branches, the cochlear and the vestibular.

\section{Describe the ninth pair of cranial nerves, glossopharyngeal.}

Originates in the medulla and more deeply in the floor of the fourth ventricle. Leaves the cranial cavity by the posterior foramen lacerum and is distributed to the back part of the tongue, and pharynx.

Branches: Jacobson's nerve to the tympanum; filaments communicating with the superior cervical ganglion; carotid and pharyngeal.

Give the origin and the distribution of the pneumogastric nerve.

The pneumogastric, vagus or tenth pair, originates in the medulla and passes through the posterior lacerated foramen to be distributed to the esophagus, pharynx, lungs, bronchi, trachea, heart, stomach and intestines. Its principal branches are: 1, superior laryngeal to the mucous membrane of the larynx and cricothyroid muscle; 2 , inferior laryngeal to all the muscles of the larynx except the cricothyroid; 3 , bronchial to the bronchi and lungs; 4, œsophageal to the œsophagus, stomach, liver and solar plexus. 
Describe the spinal accessory nerve.

The eleventh pair of cranial nerves, spinal accessory, originate along the whole cervical region of the eord, and from the fourth ventricle. It enters the eranium through the foramen magnum and escapes through the foramen lacerum to be distributed to the muscles of the neck and thorax. It gives off the following branches: to the cervical sympathetic, sternomaxillaris, mastoidohumeralis, cervical and dorsal trapezius muscles and motor fibres to the vagus.

Describe the hypoglossal or twelfth pair of cranial nerves.

Originates in the medulla and leaves the eranium through the condyloid foramen to be distributed to the muscles of the tongue and depressor museles of the larynx.

Describe the formation of the brachial plexus.

Formed from the inferior branches of the sixth, seventh and eighth cervical and first and second dorsal spinal nerves.

Give the nerve supply of the extensors of the forearm.

Radial.

What is the nerve supply of the flexors of the forearm?

Median.

Describe the median nerve.

The median nerve arises from the posterior part of the brachial plexus and a branch from the musculocutaneous. It passes down in front of the humeral artery, along the inner side of the radius to the lower one-third of the same, where it bifureates into the external and internal plantar.

It gives rise to the following branches: To the fiexors of the forearm and subcutaneous region of the forearm; the plantars which give off the anterior, middle and posterior digitals at the fetlock and supply the phalangeal region.

Give the origin and the distribution of the posterior digital nerve.

See answer to preceding question. Originates from the plantars at the fetlock and is distributed to the podophyllous and osseous structures of the foot.

Of what is the lumbosacral plexus formed?

Last two lumbar and first three sacral spinal nerves.

What nerve supplies the following named muscles of the hind limb: gastrocnemius, flexor pedis perforans and flexor pedis perforatus?

Branches of the great sciatic. 
Give the nerve supply of the salivary glands.

Parotid: from the facial and inferior maxillary nerves.

Submaxillary: from the carotid plexus.

Sublingual: from the lingual and carotid plexus.

Give the nerve supply of the larynx.

Inferior and superior laryngeal from the pneumogastric.

Give the nerve supply of the spleen.

Brauches from the solar plexus.

Give the nerve supply of the stomach.

Pneumogastric and solar plexus.

What is the nerve supply of the uterus?

Branches from the small mesenteric and pelvic plexuses.

Describe briefly the sympathetic nervous system.

This extensive system, composed of nerves and ganglia, is derived from the spinal cord and brain. It consists of two long cords lying under the spinal column, from the head to the tail. From the great number of ganglia along its course, there arise very fine nerves which are distributed to the blood-vessels, viscera and glands. The system is divided into cephalic, cervical, dorsal, lumbar and sacral portions.

Ganglia are distributed as follows: cephalic, three on the fifth nerve (see above); cervical region, two, superior and inferior carotid; dorsal, seventeen below the vertebrocostal articulations (most important is the solar plexus); lumbar, six on the psoas parvus muscle; sacral, four beneath the sacrum.

The function of the sympathetic system may be summarized thus: 1, supplies the blood-vessels with constrictor and dilator fibres; 2, supplies the viscera with motor and inhibitory fibres; 3 , accelerator fibres to the heart; 4 , dilator fibres for the pupil; 5 , secretory fibres for sweat, salivary and sebaceous glands; 6 , motor fibres to the muscles of the hair; 7, trophic fibres which exercise an effect on the nutrition of a part.

\section{Digestive Organs}

Name the organs of prehension, deglutition and digestion.

Prehension: lips, tongue and incisor teeth.

Deglutition: hard palate, tongue, pharynx and œesophagus.

Digestion: salivary glands, stomach, intestines, liver, pancreas and teeth. 
Give the permanent dental formula of (a) the horse, (b) the ox, (c) the dog.

(a) $\frac{3-3}{3-3} \quad \frac{1-1}{1-1} \frac{3-3}{3-3} \quad \frac{3-3}{3-3}$. Total 40 .

(b) $\frac{0-0}{4-4} \quad \frac{0-0}{0-0} \quad \frac{3-3}{3-3} \quad \frac{3-3}{3-3}$. Total 32 .

(c) $\frac{3-3}{3-3} \quad \frac{1-1}{1-1} \quad \frac{3-3}{3-3} \quad \frac{3-3}{4-4}$. Total 42 .

\section{Describe an incisor tooth.}

Pyramidal, flattened from before, backward, with a single fang. Three surfaces, anterior, indented by a slight longitudinal furrow, which is prolonged to the root; a posterior face, rounded from side to side and coneave from above downward, and two borders, of which the internal is always thicker than the external; last, a surface of friction, the table.

In composition, there are three fundamental substances: the dentin envelops the pulp eavity, the enamel covers the dentin. The enamel is doubled in the external dental cavity, lining it throughout, and when the surface of friction is in wear, a ring of enamel surrounds that surface and an internal ring of the same surrounds the infundibulum. The first circle forms what is called the encircling enamel; the second, the central enamel. Over the enamel is a protecting substance, the eementum or crusta petrosa, which disappears soon after the tooth becomes in wear.

Give the general arrangement of dentin, enamel and cementum from without, inward, in the following teeth: (a) incisor, (b) canine, (c) molar.

(a) Cementum, enamel and dentin.

(b) Cement, enamel and dentin.

(c) External cement, external enamel, dentin, internal enamel and internal cement.

State the difference between the incisors of the horse and those of the ox.

(See deseription of horse's incisor above.)

In the ox, the incisor's are eight in number, all in the lower jaw. They are not fixed in the alveoli, as in the horse, but have a certain degree of mobility. The root is more eonieal in shape, giving the tooth a shovel-like appearance, the root being the handle. On the middle of the internal face, is a conical eminenee, the base of which widens and terminates near the free extremity of the tooth. As age and wear advance, the teeth seem to separate from one another, and in youth they only toneh by their extremities. 
Describe the appearance of the incisors of the horse at the age of (a) 5 years, (b) Io years.

(a) In the lower jaw, the nipper's are worn more or less completely. The intermediates are on a level with the nippers and their posterior border is level with the anterior. The corners are lower than the intermediates. There is a notch on the posterior which is lower than the anterior border; sometimes this notch is very deep and extends down on the posterior face of the tooth. The corners are fresh and well grown out. The dental arches form a regular semicircle from above, downward, and from one side to the other.

(b) In the lower jaw, the nippers are rounded. The central enamel is round and small and very near the posterior border. The intermediates are nearly round, while the corners still remain oval. In profile, the arch of the upper and lower teeth from above, downward, becomes more angular.

Give the dental formula of (a) a six-year-old mare, (b) a seven-year-old cow, (c) a one-year-old dog.

At the ages stated, these animals would have all their permanent teeth.
(a) $\frac{3-3}{3-3} \quad \frac{0-0}{0-0} \quad \frac{3-3}{3-3} \quad \frac{3-3}{3-3}$. Total 36 .
(b) $\frac{0-0}{\overline{4}-4} \quad \frac{0-0}{0-0} \quad \frac{3-3}{3-3} \quad \frac{3-3}{3-3}$. Total 32 .
(c) $\frac{3-3}{3-3} \quad \frac{1-1}{1-1} \quad \frac{3-3}{3-3} \quad \frac{3-3}{4-4}$. Total 42 .

What modifications are seen in the upper and lower molars of the horse and how do these modifications affect decay?

The inferior molars are somewhat longer and much more flattened than the superior. Their enamel is but a single organ and is not divided into internal and external parts as in the superior molars. In the superior, the two central rings of enamel completely enclose the infundibula. This arrangement renders the upper molars slightly more susceptible to decay because there is greater possibility of the enamel being broken and an opening for microorganisms being produced, resulting in caries.

\section{Describe the tongue.}

The tongue is a fleshy organ, elongated anteroposteriorly, flattened on each side, and fixed to the os hyoides and inferior maxilla by the muscles forming the basis of its structure, or by the membrane covering it. It lies in the intermaxillary space, extending from the back part of the mouth to the incisor teeth, and rests on a kind of wide sling formed by the two mylohyoidean muscles. The anterior 
extremity of the tongue, the free portion, is quite free from the middle of the interdental space to the tip; by its inferior face, it is fixed to the body of the inferior maxilla by a fold of mucous membrane, the frænum linguæ.

The superior surface of the tongue is not smooth but is covered with innumerable papillæ, which, according to their shape, are termed filiform, fungiform and calciform.

The blood supply to the tongue is by the lingual and sublingual arteries and the nerve supply by the lingual, ninth and twelfth pairs.

Function: coneerned in prehension, mastication, deglutition and taste.

Name the three principal salivary glands and the duct or ducts of each.

Parotid, Steno's duct; submaxillary, Wharton's duct; sublingual, 15 or 20 ducts (of Rivinus).

Describe the pharynx, giving particular attention to its connection with the mouth, nose and ears.

The pharynx is a membranous vestibule common to the digestive and air passages, situated behind the soft palate; attached above to the base of the cranium and below to the laryngeal apparatus.

It communicates with the mouth through the isthmus of the fauces, with the nose through the posterior nares, and with the middle ear through the guttural pouch and eustachian tube.

Describe the œsophagus and give its relations.

The œsophagus is an elongated, muscular eanal extending from the pharynx to the stomach. It is made up of superficial longitudinal and deep circular museular fibres and is lined internally by mucous membrane. At its upper extremity it is comprised between the guttural pouch and the posterior erico-arytenoid muscles. In the ecrvical region, superiorly, it lies between the trachea and the longus colli muscles, bordered on the side by the carotid artery, the great sympathetic, pneumogastric and inferior laryngeal nerves; inferiorly, it is related to the trachea, internally, the inferior sealenus muscle and the jugular vein, externally. In its thoracic portion, it lies along the trachea, passes above the left bronchus, to the right of the thoracic aorta, against the internal face of the lungs. Passing through the diaphragm, it is lodged in a fissure of the liver and terminates in the cardiac opening of the stomach.

Name the organs contained in the abdominal cavity.

Stomach, large and small intestines, liver, panereas, spleen, kidneys, ovaries and uterus. 
Describe the stomach.

The stomach is a muscular sac, situated in the diaphragmatic region between the esophagus and the duodenum, in which the principal acts of digestion take place. It has a capacity of 3 to $31 / 2$ gallons and weighs from 3 to 4 pounds. It is elongated, often constricted in its middle, and presents an anterior and a posterior face, a great curvature below, to which the great omentum is attached, a lesser curvature above, to which the œsophagus and gastrohepatic ligament are attached. In the left extremity is an opening continuous with the cesophagus, and the right extremity communicates with the duodenum through the pyloric orifice.

Externally, the stomach is covered with a serous coat, the peritoneum; internally, it is lined with mucous membrane in which are innumerable peptic and mucous glands. The middle coat is muscular, the fibres of which run in various directions.

Blood supply: gastric, splenic, pyloric, œsophageal, right and left gastro-epiploic vessels.

Nerves: pneumogastric and solar plexus.

Give the relative capacity of the gastric cavities and intestines in (a) horse, (b) the ox, (c) the sheep, (d) the pig, (e) the dog.

(a) Stomach small, intestines large.

(b) Stomach large, intestines small.

(c) Stomach large, intestines small.

(d) Stomach small, intestines large.

(e) Stomach small, intestines large.

\section{Describe the rumen of the ox.}

The rumen is a large reservoir which occupies nearly threefourths of the abdominal cavity. It has a capacity of 45 to 50 gallons. Elongated from before, behind, it presents two surfaces, superior and inferior, an anterior and posterior extremity and a right and left border.

By its superior surface, it is in contact with the intestines and its opposite face lies on the inferior abdominal wall. Its left border, supporting the spleen, extends to the highest part of the flank and sublumbar region. The right border lies against the abomasum. The anterior extremity lies close to the diaphragm and receives the insertion of the csophagus. The posterior extremity occupies the entrance to the pelvic cavity. Interiorly, the rumen is divided by two septa, muscular pillars, into a right and left sac.

The rumen has three coats: outer serous, middle muscular and inner mucous. The mucous coat has innumerable papillæ similar 6 
to those on the tongue. Two openings, one into the osophagus, the other into the reticulum, are close together.

Describe the internal surface of the recticulum of the ox.

It is divided by ridges of the mucous membrane into polyhedral cells which look like honeycomb. In the centres of the cells and deeply situated are conical papillie.

Name some of the synonyms for the omasum and give the reason for these names.

Manyplus, manyplies, many-leaves and psalterium.

So named because of the peculiar arrangement of the mucous membrane, which is disposed into 25 to 30 unequally' developed leaves, arranged longitudinally, adherent to the great curvature and free on the border turned toward the lesser curvature. This arrangement gives the opened organ an appearance not unlike that of an open book.

Describe the arrangement of the mucous membrane in the first, second, third and fourth stomachs of the ox.

See answers to three preceding questions. The mucous membrane of the fourth stomach is practically the same as in the horse, q.v.

Give the length of the intestines of (a) the horse, (b) the cow, (c) the dog.

(a) 100 feet; (b) 180 feet; (c) 14 feet.

Describe the small intestine and name its divisions.

The small intestine, a tube 75 feet in length, begins at the pyloric orifice of the stomach, turns transversely to the left, forms numerous folds, being suspended in the mesentery (a fold of the peritoneum), and terminates in the cæenm in the right hypochondriac region. The diameter of the tube is variable in different portions and in all portions depends upon the contraction of the muscular tunic, but averages 1 to $13 / 4$ inches.

Three eoats: outer serous, middle muscular, and inner mucous. Blood supply by the great mesenteric and cœliac axis. Nerves from the solar plexus.

Divisions: duodenum, jejunum and ileum.

Describe the double (fixed) colon.

The double colon begins at the cxemm, passes forward, then bends backward and to the left, forming the suprasternal eurvature, lying above the sternum, then backward and turning again to form the pelvic flexure, then runs forward to the diaphragm, forming 
the diaphragmatic flexure, then passes back with the first portion to terminate in the small (floating) colon.

Throughout its length, it is traversed by from 1 to 4 longitudinal, muscular bands which hold the transverse folds in position. It is made up of three coats: outer serous, middle muscular and inner mucous. Lengtl, 10-13 feet. Capacity, 18 gallons. Blood supply, two colic arteries. Nerves, sympathetic.

What is the difference between the cæcum of the horse and that of the ox?

In the horse, there are four longitudinal muscular bands which are absent in the ox, hence in the latter the bulgings seen in the horse do not appear.

Describe the ileocæcal valve and give its function.

It is formed by the projection of the ileum into the cxcum and is formed by a circular mucous fold, strengthened externally by muscular fibres. Situated on the inferior face of the cæcum.

Function: by acting as a sort of check-valve, probably aids the onward movements of the intestinal contents.

\section{What is the capacity of the cæcum?}

Seven and a half gallons.

\section{Describe the liver.}

The liver is a glandular viscus, situated in the abdominal cavity to the right of the diaphragmatic region. Its average weight is eleven pounds. Flattened before and behind and indented at its borders, the organ is divided into three principal lobes and presents two surfaces and a border for study.

The anterior face, applied against the diaphragm, is channelled by a deep fissure for the posterior cava. The posterior surface also has a fissure for the passage of the portal vein and vessels. In the superior border is a notch for the œsophagus. Several smaller fissures are observed, one dividing the right and left lobes and small ones dividing the middle lobe into lobules.

The four lobes are: left (the largest), right, spigelian or caudate, and middle.

The liver is held in place by five ligaments, viz.:

1. Anterior or coronary, from the fissure for the cava to the phrenic centre.

2. One from the left lobe to the sides of the cesophageal orifice.

3. One from the right lobe to the sublumbar wall.

4. Broad or suspensory, from the middle lobe to the inferior abdominal wall and lower part of the diaphragm. 
5. Round, a fetal remuant, from the middle lobe to the umbilicus. The external serous coat covers the true capsule (Glisson's) which is of fibrous tissue.

Hepatic ducts, originating within the liver parenchyma, unite to form the ductus choledochus, or great bile duct, which cmpties into the duodenum.

Blood supply: functional, portal vein; nutritive, hepatic artery.

Nerve supply: sympathetic, vagus and phrenic.

Name the lobes of the liver.

Three principal lobes are right, left and middle. The right lobe has a small secondary lobe attached to it, the lobus Spigelii, or caudate lobe.

Describe and give the relations of the pancreas.

This organ, sometimes called the abdominal salivary gland, because of its resemblance to the salivary glands in structure, is situated in the sublumbar region, across the aorta and post cava, in front of the kidneys and behind the liver and stomach. Its weight is seventeen ounces. In form, it is elongated, triangular and curved on itself. It has two surfaces, superior and inferior, two border's, anterior and posterior, and two extremities, a right or head and a left or tail. The posterior border is notched for the portal vein to pass through.

Two ducts, duct of Wirsung, the principal, runs along the anterior border from the left to the right side and opens into the duodenum in eommon with the bile duct; an accessory duct opens alone after receiving several branches.

Blood supply: hepatic and great mesenteric.

Nerve supply: solar plexus.

State the difference in the relation of the biliary and pancreatic ducts in (a) the horse, (b) the ox, (c) the sheep, (d) the goat, and (e) the pig.

(a) Open in common into the duodenum.

(b) 'Two separate openings into the duodenum.

(c) Open in common into the duodenum.

(d) Open in eommon into the duodenum.

(e) Two separate openings into the duodenum.

Describe the peritoneum and give its relation.

The peritoneum is a serous membrane composed of a parictal and a visceral layer which together form a elosed sac, so arranged that the organs contained in the abdominal eavity are enveloped by, but are external to, it. 
In its rarious folds and duplicatures, it forms ligaments, mesenteries and omenta as follows : falciform ligament from the umbilicus to the middle lobe of the liver; the common ligament of the liver which surrounds the posterior vena cava; the cardiac ligament that envelops the termination of the osophagus; the gastrohepatic ligament or omentum attaches the stomach to the posterior fissure of the liver and separates at the lesser curvature of the stomach to envelop the same, joining again at its greater curvature. This fold is called the great omentum and also the gastrocolic omentum, because by its posterior border it is extended around the termination of the large colon. A reflection from the stomach to the splecn is called the gastrosplenic omentum. Behind the stomach, there is a small opening in the great omentum, which communicates with the peritoneal cavity, called the foramen of Winslow. Posteriorly, the great omentum is continued as the mesentery proper, being reflected orer the small and large intestines, forming their mesenteries, the ligaments of the bladder, broad ligaments of the uterus, and then from the rectum and front of the bladder is reflected to the superior and inferior abdominal wall, forming the parietal layers. The inferior parietal layer continues forward, descends into the scrotum through the inguinal canal to envelop the testicles, and is continued forward to form the suspensory ligament of the liver. The superior parietal layer passes beneath the kidney, forms the mesenteries and is continued to the diaphragm.

\section{RESPIRATORY ORGANS}

Name the sinuses of the head.

The sinuses of the head are arranged in pairs, five on each side as follows: the frontal, supermaxillary, sphenoidal, ethmoidal and inferior maxillary.

Compare the frontal sinus of the ox with that of the horse as regards position, structure and size.

In the ox, the frontal sinuses are prolonged into the horn cores and into the parietal and occipital bones. They envelop the anterior and superior part of the cranium and form a double wall to this cavity. They are, therefore, much larger and situated more superiorly than in the horse. In the horse, the sinus communicates with the superior maxillary sinus by a vast opening in the thin bony partition, but in the ox, no such communication exists.

\section{Describe the larynx.}

The larynx is a cartilaginous box, situated in the intermaxillary space between the two corona of the os hyoides and fixed to these 
appendages by one of its constituent pieces, the thyroid eartilage. Its anterior opening is at the bottom of the pharynx, its posterior is continuous with the trachea.

In structure, it is comprised of five cartilages, viz., three single, ericoid, thyroid and epiglottis, and one pair, the arytenoids. The museles which either move the whole organ or its eartilages upon one another are: three extrinsic, the sternothyroideus, hyothyroideus and the hyo-epiglottideus; five intrinsic, cricothyroid, posterior crico-arytenoideus, lateral crico-arytenoid, thyro-arytenoid and arytenoideus. All of these muscles are pairs, except the hyoepiglottideus and arytenoideus.

Internally, the larynx is lined with mucous membrane and is marked on each side by the elastic structure known as the vocal cords.

Blood supply: laryngeal arteries.

Nerve supply: superior and inferior laryngeal.

Function : an air passage and organ of phonation.

\section{Name the cartilages of the larynx.}

See answer to preceding question.

\section{Describe the guttural pouch and give its function.}

Two in number, one on each side, the guttural pouches are elongated cavities, communicating with the pharynx and lying on its sides. In reality, a dilatation of the eustachian tube, these two pouches lie against each other in the median plane; externally, they are related to the carotid artery and parotid gland. Before and behind, they extend from the anterior part of the pharynx to the inferior face of the atlas. Capacity, about three-quarters of a pint. Function: probably connected with hearing and plonation in some way.

\section{Describe the trachea and give its relations.}

The trachea is a long, flexible, elastic, cylindrical tube, composed of a series of about fifty incomplete cartilaginous rings that succeed the ericoid cartilage of the larynx and terminate above the base of the heart by bifureating into the two bronehi. The rings are mited by fibrous tissue.

Relations: In its cervical portion, surrounded by museles of this region-sternohyoid and sternothyroid, in front; the sternomaxillaris muscles are situated in front in the inferior part but on the sides near their termination; the subseapulohyoideii are placed above and in the middle of the lateral parts; the sealeni are below and at the sides; the longus colli, behind. The osoplagus deseends 
at first in the middle of the posterior face, then to the left side of the trachea. The carotid arteries, the pneumogastric, great sympathetic and recurrent nerves pass along both sides of the tube.

In the thoracic portion, the trachea is related superiorly to the longus colli muscle and the œsophagus; below to the brachial vessels, the anterior aorta, anterior vena cava, the cardiac and recurrent nerves, and to the left auricle of the heart; laterally it is in contact with the inferior cervical ganglia of the great sympathetic, the vertebral vessels and the two layers of the anterior mediastinum, vena azygos, aorta and thoracic duct.

Describe the thoracic cavity. Name the organs that are contained in this cavity.

The thoracic cavity is a bony cage, representing a hollow cone placed horizontally, depressed on its sides, apex forward and base formed by the diaphragm, posteriorly.

Boundaries: in front, the first ribs and longus colli muscle; behind, the diaphragm; superiorly, the vertebræ, ribs and longus colli muscle; inferiorly, the sternum, costal cartilages and the triangularis sterni muscle; laterally, the ribs and deep intercostal muscles. Its internal face is covered with a serous membrane, the pleura.

It contains the following organs : heart and great vessels, lungs, trachea, osophagus, thoracic duct and lymphatic glands.

Function: Receptacle for the contained organs; its movements are of primary importance in the act of respiration.

Compare the thoracic cavity of the horse with that of the ox.

In the ox, the thorax is not so long, particularly in its superior part, as in the horse, because the diaphragm is situated less obliquely and its attachment to the ribs is more anterior. Its total capacity is less than in the horse.

Give the number of pulmonary lobes in (a) the horse, (b) the ox, (c) the sheep, (d) the pig, (e) the dog.
(a) 5
(b) 6
(c) 6 ;
(d) 6 ; (e) 7 .

Describe the lungs of the horse.

The lungs, the essential organs of respiration, are situated in the thoracic cavity, surrounding the heart, and enveloped by a serous membrane, the pleura.

Divided into two lateral halves, the lungs are considered as two parts, right and left, which, in contour, correspond to the thoracic cavity which they practically fill. Each half is cone-shaped and has: an external face lying against the ribs; an internal face, forming the side of the mediastinum which presents an excavation 
in which the heart is lodged, and behind this is the root of the lung, formed by the bronchi, blood-vessels and nerves entering the structure, also a fold of the pleura, ligamentum latum pulmonalis, which is attached to the mediastinum and posterior face of the diaphragm; a base or diaphragmatic face, concave and in contact with the diaphragm, showing a notch for the posterior vena cava; an apex or summit, situated behind the first rib, forms the anterior lobe; a superior border, thick and convex, rests in the vertebrocostal channel or concavity; an inferior, shorter and thinner, is notched deeply for the heart.

The right lung has three lobes, an anterior, middle and posterior; the left, two, an anterior and posterior.

The lung substance is pink-colored, soft, spongy and elastic tissue; it is divided into lobules which are further subdivided into alveoli and air-cells that communicate with bronchioles, the subdivisions of bronchii.

Blood supply: nutrient, bronchial arteries; functional, pulmonary arteries. Nerve supply: pneumogastric and sympathetic.

Describe the different reflections of the pleura and state the different structures to which they are respectively applied.

1. Costal pleura is applied to the internal face of the ribs and internal intercostal muscles.

2. Diaphragmatic pleura, a continuation of the costal, is adherent to the diaphragm.

3. Mediastinal pleura separates the two lateral halves of the Iungs. It is applied against the interual face of each half and comprises between its two layers the heart. The portion in front of the heart is called the anterior mediastinum, and that behind, the posterior mediastinum.

The anterior mediastinum contains the trachea, osophagus, anterior aorta and its divisions, anterior vena cava, thoracic duct, and the cardiac, pneumogastric, recurrent and phrenic nerves. In the fœtus and very young animals, it also contains the thymus glands.

The posterior mediastinum is traversed by the posterior aorta, vena azygos, thoracic duct, osophagus and nerves.

4. Pulmonary or viseeral pleura, a continuation of the mediastinal, completely envelops the lung-tissue proper.

Give the relative thickness of the mediastinum in horses and in cattle, and state how this affects conditions in unilateral pleurisy.

In its inferior part, the posterior mediastinum of the horse is very thin and perforated by small openings; whereas, in cattle, it is 
not open but is thick and solid there as elsewhere. A case of unilateral pleurisy in the horse tends to become bilateral because the effusion, and hence the infection, can readily pass from one side to the other. In cattle, localization of the disease in one side is possible.

\section{Describe the kidney.}

\section{URINARY ORgans}

The kidneys, two in number, are situated in the right and left sublumbar region, against the psoas muscles, usually imbedded in fat, and supported beneath by the peritoneum. The right kidney is heart-shaped and more anterior than the left, which is beanshaped. Each kidney has a superior and inferior flattened surface, an external convex border and an internal concave one which is deeply notched, the hilum. In the hilum, the blood-vessels, nerves and beginning of the ureter are lodged. Inside, at the hilum, is a cavity, the pelvis, into which the uriniferous tubules empty and which is the beginning of the ureter.

The kidney is encapsulated by a fibrous coat which sends prolongations into its substance. The tissue proper of the kidney is divided into an external or cortical layer and an internal or medullary layer. The cortical layer contains the malpighian corpuscles and the medullary layer contains the uriniferous tubules.

Blood supply: renal artery.

Nerve supply: branches from the solar plexus.

Function: secretion of urine.

Compare the kidney of the horse with that of the ox.

In the ox, the kidneys are more elongated from before to behind, and are divided into 15 to 20 lobules, the structures of which are comported like so many separate kidneys.

\section{Describe the ureters.}

The ureters, two in number, are membranous canals, beginning at the pelvis of the kidney and running backward and downward to the upper face of the bladder, which they enter in an oblique direction. Size, about $1 / 4$ inch in diameter. Structure consists of an external fibrous coat, a middle muscular and an internal mucous.

Function: to convey urine from the kidneys to the bladder.

\section{Describe the urinary bladder.}

The bladder is a muscular bag, situated in the inferior part of the pelvic cavity, and has three openings, viz., the openings of the two ureters and the beginning of the urethra. Its structure is 
principally muscular tissue and is lined with mucous membrane made up of stratified epithelinm. Its anterior half is covered with peritoneum. Related above to the uterus and vagina in the female, and to the seminal vesicles and rectum in the male.

Blood supply: internal pudic and umbilical arteries.

Nerve supply: pelvic plexus.

Funetion: receptacle for urine until conditions are satisfactory for its expulsion.

\section{Compare the urethra of the horse with that of the ox.}

In the ox, the urethra conforms with the bend of the penis in front of the pubis, by making an S-shaped curve. Its diameter diminishes from its commencement to its termination. The latter is not prolonged by an urethral tube, as in the horse. Near the ischial arch, the urethra of the ox shows a valve which covers a cul-de-sac about one inch deep. This is not present in the horse. The walls of the urethra in the ox are thicker than in the horse and are provided with a sphincter muscle and erectile tissue.

What is the length of the urethra in the mare?

It is very short, less than one inch.

\section{Sexual Organs}

Describe the ovaries of the mare and state how they differ from those of the cow.

The ovaries, two in number, situated in the right and left sublumbar regions, are small, ovoid bodies with a deep notch or hilus on their upper surface, which gives attachment to the pavilion of the oviduct. Each ovary floats at the anterior border of the broad ligament and is attached to the uterus by vessels and the utero-ovarian ligament. Externally, they are covered by serous membrane, underneath which is the tunica albuginea, a fibrous covering.

In the cow, the ovaries are relatively much smaller than in the mare, but in form and structure are the same.

Describe the uterus of the mare. Give distinctive features of the uterus of the cow and bitch.

The uterus of the mare is a hollow, muscular sac, situated in the abdominal cavity in the sublumbar region. Its posterior extremity extends to or within the anterior opening of the pelvic cavity. It is comprised of a body, constituting the greater bulk, which is continned anteriorly by a slight bifurcation into the two cornua. 
Posteriorly, it is separated from the vagina by a constriction, the cervix or neck.

Relations: Above, to the rectum; below, with the bladder; anteriorly and laterally with the intestines; behind, with the vagina.

Attachments: Two broad ligaments, descending from the sublumbar region to the sides of the uterus and cornua; two rudimentary, round ligaments, from the sides of the uterus to the upper inguinal ring.

Openings: One small opening in each cornua, from the oviducts; os uteri, opening into the vagina.

Structure: Outer serous coat, middle muscular, and inner mucous.

Blood supply: Uterine and utero-ovarian vessels.

Nerve supply: Mesenteric and pelvic plexuses.

Function: The sac in which the embryo is developed.

In the cow, the concave curvature of the cornua looks downward, instead of upward, as in the mare. The body is shorter and narrower and the cornua are thinner and more tapering than in the mare. The interior is studded with numerous tubercles, cotyledons. The cervix is longer and the muscular coat thicker.

In the bitch, the body of the uterus is short and the cornua are very long and folded, floating amongst the intestines. Its cervix projects into the vagina and is even more voluminous than the body.

\section{Mention the ligaments of the uterus.}

Broad ligament, round ligament, and utero-ovarian ligament.

\section{Describe the vagina.}

The vagina is a long, membranous canal, situated in the pelvic cavity, succeeding the uterus and terminating in the vulva. It is made up of an inner mucous coat, a middle muscular, and its anterior part is covered with peritoneum. It is related above with the rectum; laterally, with the ureters and connective tissue; below with the bladder.

Blood supply: Internal pudic artery.

Nerve supply: Pelvic plexus.

Function: Copulation and passage of the fœtus.

\section{Describe the mammary gland of the cow.}

The mammary gland of the cow, situated in the inguinal region, is made up of two lateral halves, each of which is composed of two distinct glands. The whole mass is enclosed by a fibrous capsule. 
In the centre of eaeh quarter is a prolongation, the teat or nipple, which is piereed at its extremity by a small orifice, the opening of the teat duct. The teat duct or eanal traverses the teat and opens superiorly into the galaetophorus sinus or reservoir at the base of the teat.

Externally, the organ is covered with skin which, together with ligamentous, elastic bands attaehed to the abdominal tunie, fixes it in position. Internally, the organ is made up of glandular, adipose and connective tissue.

Blood supply: External pudic.

Nerve supply: First lumbar pair.

\section{Describe the mammary glands of the bitch.}

The mammary glands of the bitch are ten in number, five on each side, situated along the ventral surface of the body from the inguinal to the axillary region. Each teat has from eight to ten orifices.

\section{Describe the genital organs of the cow.}

The genital organs of the cow inelude the ovaries, Fallopian tubes, uterus, vagina and mammary gland. For deseription of same, see preceding questions.

Name the coverings of the testicles.

From without, inward: serotum, dartos, eremaster, fibrous tunie and tunica vaginalis.

\section{Of what structures is the spermatic cord composed?}

Vas deferens, spermatie artery, spermatic vein, nerves of sympathetic origin, cremaster muscle and peritoneum.

Define the following: epididymis, vas deferens, globus major, vesiculæ seminales, prostate gland, clitoris and vulva.

Epididymis is an elongated duct, placed against the upper border and outside of the testicle, arising from the vas efferentia and also ealled the head of the epididymis.

Vas deferens is an elongated canal, beginning at the epididymis and ending at the seminal vesicles, through which spermatozoa pass.

Globus major is the enlarged anterior part of the epididymis; also ealled the head of the epididymis.

Vesienlæ seminales are two elongated ponches in which the semen is stored, situated above the neek of the bladder.

The prostate gland is situated at the commeneement of the urethra around the neck of the bladder. It secretes a viscid fluid, which it pours forth into the urethra through several orifiees. 
The clitoris is a small body, two to three inches long, situated in the inferior commissure of the vulva. It is composed of erectile tissue.

The vulva is the slit-like orifice of the female genitalia and is situated in the perineal region below the anus.

\section{Describe the eyeball.}

\section{Organs of Special Sense}

The eyeball, which lies in the fat of the orbit, is a sphericalshaped shell, consisting of three tunics surrounding the humors. It is slightly bulged in front (the cornea), making the anteroposterior, the longest diameter.

The tunics of the eye are, outer sclerotic and cornea, middle choroid and iris, and inner retina.

The sclerotic is a white, dense membrane, forming about fourfifths of the external shell, into which the muscles are inserted. It is continued in front as the cornea, a transparent membrane which constitutes the remaining one-fifth of the outer tunic. Posteriorly, the sclera has an opening for the passage of the optic and ciliary nerves and the central artery.

The choroid, the middle layer, is a thin, brownish, vascular membrane. It is continued anteriorly as the iris, a circular curtain with a central opening, the pupil. This curtain is governed by the eiliary muscle which unites the iris to the sclera.

The retina, or internal layer, is the thinnest and most delicate. It is the expansion of the optic nerve and adheres closely to the choroid, ending anteriorly in a number of folds, the zone of Zinn. Although very thin, the retina is composed of connective tissue and nerve elements, arranged in nine or ten superposed layers.

The crystalline lens is a double convex lens of concentric layers, with an external capsule. It is situated in the anterior one-third of the eye, behind the pupil. Back of the lens, filling the space bounded by the retina, is a gelatinous fluid, the vitreous humor, and anterior to the lens is the aqueous humor, which entirely fills the anterior and posterior chamber, the space between the cornea, pupil and iris.

The eyeball is freely movable in various directions, the movements being controlled by seven muscles: five recti and two oblique, all of which attach to the sclera.

\section{Describe the cornea.}

The cornea is a transparent membrane which constitutes the anterior one-fifth of the outer covering of the eyeball. It is shaped like a watch glass with its convexity forward, and is composed of 
three layers. The anterior layer is epithelial in character and is a contimuation of the eonjunetiva. The middle is composed of eonnective tissne and the internal layer, elastic in structure, is called Descemet's membrane.

Name the tunics of the eyeball. Describe one.

See answer to preceding questions.

Describe the membrana nictitans and give its use.

The membrana nictitans, also called the third eyelid, is placed at the greater angle of the eye, whence it extends over the eyeball to remove foreign bodies from the cornea. It is made up of fibrocartilage, triangnlar in shape, thiek anteriorly and thick at its base, where it is continued by an adipose cushion which is insinuated between the muscles of the eye. It moves, almost instantaneonsly and in a mechanical manner, over the eye, whenever the eyeball is retracted in the orbit.

\section{Describe the lachrymal apparatus of the horse and compare it with that of the ox.}

The lachrymal apparatus consists of the lachrymal gland, puncta lachrymalia, lachrymal sac and laehrymal eanal.

The lachrymal gland is conglomerate, situated between the orbital process and the upper part of the eyeball. It secretes the tears which empty on the inner surface of the upper lid. After lubricating the cornea and conjunctiva, the exeess of tears enter the puncta lachrymalia, two small canals in the npper and lower lids, which carry the tears into the lachrymal sac, a small reservoir, the beginning of the lachrymal canal. The latter runs down in the laehrymal bone as a membranons canal, ending on the upper side of the nostril.

In the ox, the laehrymal gland is mueh more voluminous than in the horse; it has two large and several small ducts, and the nasal opening is situated higher in the nostril than in the horse.

\section{Describe the humors of the eye.}

'The vitreous humor occupies all the cavity' of the eye, behind the lens, surrounded by the retina. It is a eolorless, transparent, jellylike tissue which coneurs in refracting the rays of light and at the same time aets as a supporting substance by maintaining the rotundity of the eyeball.

The aqueons humor is more fluid than the vitreous, containing only 2 per cent. solids. It oecupies the anterior and posterior chamber of the eye in front of the lens and is secreted by Descemet's 
membrane. It serves to maintain the convexity of the cornea and assists in refracting the rays of light.

\section{Describe the Eustachian tube and state its function.}

The Eustachian tube is a fibrocartilaginous canal, about four inches long, extending from the middle ear to the pharynx. Its upper orifice is narrow, but the inferior is widened by a great slit, the borders of which are cartilaginous in structure. Its inferior border is cleft, allowing the mucous membrane to escape in the form of a large sac, known as the guttural pouch. It is bordered by the stylopharyngeus muscle.

Function: maintains the equilibrium of air within the cavity of the tympanum.

\section{Describe the membrana tympani.}

The membrani tympani, or ear-drum, is a thin membrane which separates the middle ear from the auditory canal; oval in shape and is attached by its circumference to a bony frame, the tympanitic circle. Its inner face is slightly convex and is adherent to the handle of the malleus. Although very thin, it consists of three layers, a middle fibrous and muscular, an external of skin, and an Internal of mucous membrane.

The function of this drum-like membrane is to receive the vibrations of the sound waves and transmit them to the internal ear.

\section{SkIN, HaIr aNd Hoof}

\section{Name the appendages of the skin.}

Hair, sweat-glands, sebaceous glands and horny parts (chestnut, ergot and hoof and, in ruminants, horns).

Describe the different structures that make up the elastic cushion of the heel.

These consist of two fibrocartilages and the plantar cushion.

The cartilages, two in number, are flattened plates, shaped like an oblique-angled parallelogram. They are attached in front to the anterior lateral ligament, behind to the basilar and retrossal processes and plantar cushion; they have a thin upper border and a thick lower. The upper border is notched for the passage of ressels and nerves.

The plantar cushion is a wedge-shaped mass, situated between the lateral cartilages, the perforans tendon and the lower part of the hoof. Superiorly, it lies against the expansion of the perforans tendon and is attached by ligamentous bands to the ergot, metacarpus and os pedis. Inferiorly, it is covered by the keratogenous 
membrane and presents at its middle the pyramidal body which corresponds to the frog. Its base terminates in two lateral masses, the bulbs of the plantar cushion. Its summit attaches to the plantar surface of the os pedis and on each side it is attached to the lateral cartilages. In structure, it is composed of fibrous, elastic and adipose tissue, and contains vessels and nerves.

\section{Describe the coronary cushion.}

The coronary cushion is the matrix of the wall of the hoof. It is lodged in a cavity at the upper border of this horny case. Its inferior border is separated from the upper extremity of the laminæe by a white ring. Its superior border is limited by the perioplic ring. The extremities are narrow and end in the velvety tissue of the płantar cushion. In sirueture it is a modified skin made up of a fibrous framework.

\section{What is the keratogenous membrane?}

This is the seereting strueture of the horny foot. It envelops the extremity of the digit and is covered by the hoof. It consists of the coronary cushion (see preceding question), velvety and laminal tissue. The velvety tissue covers the plantar surface of the os pedis and plantar cushion. The laminal tissue eonsists of 500 to 600 leaves, on the front and siajes of the os pedis, which dovetail with the leaves on the inside of the hoof wall.

Describe minutely the mode of connection of the hoof wall with the pedal bone and state how the weight of the animal is supported by the hoof.

The os pedis is covered on the front and side by the laminal tissue (see preceding question). This tissue consists of five to six hundred parallel leaves, running from above, downward. On the inner side of the hoof wall, there are analogous leaves, keraphyllous tissue, which dovetail with these.

The weight of the body is supported by the hoof wall and bars through the intimate union of the horny and sensitive lamine. The sole of the foot is slightly convex upward, thus making an areh-like support. The frog, through the medium of the plantar eushion and lateral eartilages, receives a share of the weight and the wall the balanee.

\section{Ductliess Glands}

Mention the ductless glands and state where they are located.

Splcen, adrenals, pituitary gland, thyroid and thymus.

The adrenals, two in number, lie on the under and inner side of the kidneys, in front of the hilus. 
The spleen is situated in the diaphragmatic and left hypochondriac regions, and suspended from the sublumbar.

The pituitary gland is situated near the third ventricle of the brain, being attached to the interpeduncular fissure by the pituitary stem.

The thyroid gland lies in the neck beside the first two tracheal rings.

The thymus lies under the lower face of the trachea, partly without and partly within the chest in the fœtus and very young animals.

\section{Describe the spleen.}

The spleen is a falciform-shaped organ, situated in the diaphragmatic and left hyponchondriac region. It has an external convex and an internal concave face; a convex posterior border and a concave and sharp anterior border. The superior extremity, the base, is broad, and the inferior extremity is pointed. It is held in position by a suspensory ligament from the sublumbar region and kidney to its base, and the gastrosplenic omentum which envelops the whole organ.

It is covered with peritoneum and has a thick, strong, fibrous coat which sends prolongations, or trabeculæ, into the interior. The tissue of the spleen is made up of pulp, a reddish material, composed of pigment, broken-down corpuscles and Malpighian corpuscles, small rounded bodies of lymphoid structure which are covered by the outer tunic of the small arteries.

Blood supply: Splenic artery.

Nerve supply: Solar plexus.

State the difference between the spleen of the horse and that of the ox.

(See answer to preceding question.)

In the ox, the spleen is not supported by the great omentum, but adheres to the left side of the rumen and diaphragm. It is not falciform, and the breadth is the same throughout its extent.

Apart from the disease microbe, what anatomic arrangement favors the sanguineous engorgement of the spleen in anthrax and Texas fever of animals and in malaria in man?

The capsule, the sheaths of the vessels and the trabeculæ consist of a dense mesh of white and yellow elastic fibrous tissue which gives it a great amount of elasticity.

Describe the thyroid gland.

The thyroid gland lies on the sides of the first two tracheal rings. It is composed of two lateral lobes and a median portion, the isthmus. 
Its fibrous coat sends prolongations into its structure, as in the spleen. Its parenehyma is divided into lobules which eontain vesieles, lined with polygonal cells, and contains albuminous matter. It is a very vascular organ, reeeiving its supply from the thyrolaryngeal branch of the carotid artery. Nerve supply from the first and second cervical and sympathetic.

\section{What is the thymus gland? Where is it found?}

It is a transitory organ whieh is found only in the foetus and very young animals, and disappears a few months after birth. In structure, it elosely resembles the thyroid gland. It is situated beneath the trachea, partly without and partly within the thoracic cavity.

\section{What are the adrenals? Give location.}

The adrenals, or suprarenals, are two small bodies which resemble somewhat the kidney in structure. They are applied to the lower face of the kidney in front of the hilus and close to their inner border. They have no exeretory duct but have an internal secretiun.

\section{TOPOGRAPHical ANATOMY}

\section{What structures are severed in tracheotomy?}

The skin, connective tissue, the cervieal panniculus and sternothyrohyoideus muscles and the trachea.

State the difference between the foramen ovale and the foramen magnum.

The foramen ovale is the opening between the auricles of the heart, seen in the fotus.

The foramen magnum is the large orifice that passes through the occipital bone and establishes a communication between the cranial cavity and the spinal canal.

Name the structures that would be severed in amputating the hind limb just below the tarsus.

Skin, subcutaneous faseia, flexor pedis perforans and flexor pedis perforatus tendons, the tendon of the oblique flexor of the metatarsus, the anterior extensor of the phalanges, the lateral extensor of the phalanges, the sheaths of these tendons, the plantar arteries, the perforating pedal artery, the internal and external plantar interosseous arteries, the accompanying veins of these arteries, two rudimentary and one principal metatarsal bones. 
Name the regions into which the abdominal cavity is divided for study.

Sublumbar, right and left lumbar, suprasternal, umbilical, prepubic, right and left inguinal, hypochondriac, flank, diaphragmatic and pelvic regions.

At what point in the head would you trephine to open (a) the frontal sinus, (b) the lower maxillary sinus?

(a) At the point of intersection of a line connecting the superior borders of the orbital cavities and one parallel to, but about one-half inch from, the median line.

(b) Just above the inferior extremity of the zygomatic ridge.

Through what tissues do you cut in the operation of median neurectomy?

Skin, sterno-aponeuroticus muscle and antibrachial fascia.

\section{Histological Anatomy}

\section{Describe (a) arteries, (b) veins, (c) nerves.}

(a) The arteries are cylindrical tubes which carry the blood from the heart to the various organs of the body. All arteries carry pure blood with one exception, the pulmonary artery. 'They originate at the heart by two great trunks which divide and subdivide until their size is almost imperceptible (capillaries).

Arteries are more or less rigid and elastic and have three tunies, viz., an external fibrous (tunica adventitia), a middle (tunica media), and an internal (tunica intima).

The outer coat is nourished by small blood-vessels, called vasovasorum, which are quite voluminous in the large arteries. Nerves, vasomotor, from the sympathetic system accompany these vessels.

(b) The veins are likewise eylindrical tubes which accompany the arteries and carry the impure blood from the distant parts to the heart; with one exception, the pulmonary veins which carry pure blood from the lungs to the left auricle. They have two distinct coats, an internal serous and an external of elastic and muscular fibres. The walls of veins are thin, semitransparent and elastic and collapse when empty. Nourishment is provided by vasovasorum.

The interior of veins is remarkable for the presence of valves which favor the flow of blood. No valves are found in the pulmonary and portal veins and vena cava.

(c) The nerves are the peripheral portions of the nervous system. They originate in the brain or cord and are distributed to every part of the body. Their structure is made up of a collection 
of nerve cells bound together by a delicate connective-tissue network; a number of these collections, united together and covered by neurilemma, constitute a nerve. Blood-vessels traverse the connective tissue. On the upper root of all the spinal and on the track of certain other nerves are masses of nerve cells, ganglia. The function of nerves is to conduct impulses to and from the brain and spinal cord.

\section{Describe the structure of voluntary muscle.}

Voluntary muscle is made up of a great number of fibres which are marked by transverse furrows or striæ, giving rise to the term striated or striped muscle. Each fibre is made up of fibrils and these in turn can be subdivided into fibrillæ or sarcous elements, attached to eacli other end to end. The muscle fibres unite to form secondary fasciculi which are covered by a connective sheath, the internal perimysium. The secondary fasciculi unite to form more voluminous fasciculi which form the entire muscle. The muscle is covered by a connective sheath, called the external perimysium or sarcolemma. The nuclei are flat or oval and can be seen on the inner face of the sarcolemma.

State the difference in structure between striped muscular tissue and unstriped muscular tissue.

(See answer to preceding question.) Unstriped muscular tissue has no transverse strix and is found in the viscera. It is not under control of the will, hence is called involuntary. Its structure consists of fusiform cells, each with a distinct nucleus and bound together by connective tissue.

\section{Illustrate the difference between mucous membrane and serous mem-} brane as to (a) structure and (b) location. ..

(a) Both membranes have two layers, the deeper of which are quite analogous. In mucous membrane, the superficial layer may consist of epithelial eells only one layer deep, but usually there are several layers (stratified). Cilia, hair-like appendages, are seen on the surface of mucous membranes in some parts of the body, as well as depressions in the decper layer, giving rise to follieles and papillæ. In serous membranes, the superficial layer always consists of flat polygonal epithelial cells, one layer decp. 'The free surface is always smootli.

(b) Mucous membrane is found throughout the inner walls of the alimentary canal, respiratory ehannels, bladder, urethra and vagina. Serous membrane is found within the thoracic eavity, 
lining the same and covering the enclosed viscera, as well as in the abdominal cavity, where it is disposed in a similar manner.

Mention the varieties of connective tissue.

Fibrous, elastic, cartilaginous and bone.

Describe the composition of blood.

Blood contains: liquor sanguinis or plasma, containing in solution proteids (serum-albumin, serum-globulin, fibrinogen), extractives, mineral matter and gases; corpuscles, red and white.

Name the structures and coverings of the kidneys, from without inward to the pelvis and the opening of the ureter.

1, Capsule; 2, cortex, composed of Malpighian bodies, supporting connective tissue, vessels and tubules, etc.; 3 , medulla, composed of uriniferous tubules (loop of Henle, convoluted and straight tubules); 4 , crest of the pelvis, pelvis ; 5 , infundibulum of the pelvis and ureter.

Where is elastic fibrous tissue found?

It is found closely packed in certain organs such as the ligamentum nuchæ and abdominal tunic, or forming a network in the midst of connective tissue, as in the walls of arteries. It is also found in the framework of bone.

Name the different kinds of epithelium. State where ciliated epithelium is found and give its special function.

Kinds: squamous, columnar, modified and specialized.

Columnar and squamous varieties are polyhedral, pavement, or tessellated and may be either simple or stratified. Modified epithelium includes the ciliated, goblet and pigmented varieties. Specialized includes glandular and neuro-epithelium.

Ciliated epithelium is found in the Eustachian tube and parts of the tympanic cavity; laclirymal passages; respiratory part of the nasal fossæ, with the communicating sinuses; ventricles of the larynx; trachea and bronchi; epididymis and first part of the vas deferens. 


\section{PHYSIOLOGY*}

What does the study of physiology comprise?

The sum of the knowledge concerning the function of living things.

Explain the force of the following: "Physiology is the study of the properties of cells."

All animal and vegetable life is composed of minute structural elements, ealled "cells." Every living organism is derived from a parent cell, the ovum, which, through endless division and subdivision, develops into a mature body. Since physiology treats of the structure and function of living things, it may be truly said that "physiology is the study of the properties of cells."

What properties does a cell possess?

A cell wall, cell body of protoplasm which includes a nucleus and a nucleolus. The vital manifestations of a cell embrace metabolism, growth, reproduction and irritability.

Describe cell division.

Direct cell division, the simplest form, consists of a direct cleavage of the cell body and nucleus into two parts.

Karyokinesis, mitosis or indirect cell division, is more complex and includes a series of changes involving the nucleus, the centrosomes and the cytoplasm. In this form, the chromatin of the nucleus arranges itself in a star-shaped skein, the bars of which compose themselves symmetrically. The two symmetrical parts separate, followed by a cleavage of the cell body, making two distinct cells in which the ehromatin granules are more or less seattered. The latter then assume a normal appearance and soon each new cell prepares itself for division.

Name the eliminative organs of the body and state what each eliminates.

Skin: Eliminates water, urea, uric acid, fatty acids, carbon dioxide, serum albumin, serum globulin, fat, and sodium and potassium salts.

Kidneys: Eliminate water, urea, urie acid, hippurie acid, benzoic acid, phenol, sulphates, phosphates, and chlorides of sodium, potassium, calcium and magnesium.

* Unless otherwise stated all questions relate to the horse. 
Lungs: Eliminate carbon dioxide and water.

Frces consist of the undigested portion of the food which is indigestible, together with that which though digestible has escaped absorption; mixed with these are water, coloring substances, mucin, organic matter's, inorganic salts, bile pigment, volatile fatty acids, remains of digestive fluids, microörganisms, etc.

Define excretion. Mention four ways in which waste matter of the body is eliminated.

Excretion refers to the throwing off or ejection of waste matter, formed in the body, which is not intended to be retained in the body and if retained would be harmful.

Waste matter is eliminated by the urine, frecs, skin and expired air.

Explain the meaning of four of the following: chordæ tendinæ, hæmatin, Goll's column, bile salts, accommodation.

Chordx tendinx are the small tendinous cords, attached to the free border of the heart valves, which unite the latter to the walls.

Hæmatin is the iron-containing substance of the hæmoglobin.

Goll's column is the superior median tract or column of the spinal cord.

Bile salts, two in number, glycocholate and taurocholate, are formed in the liver by the union of cholalic acid with glycin and taurin.

Accommodation refers to the power which the eye possesses of focusing itself for near and distant objects.

Define and illustrate five of the following terms: absorption, chyle, excretion, ferment, tidal air, phagocytosis, alimentation.

Absorption is the process of taking up fluids or other substances by the skin, mucous surfaces or absorbent vessels, e.g., absorption of chyle by the lacteals.

Chyle is the milky fluid taken up by the lacteals from the digested food in the intestines.

Excretion is the act or process of eliminating waste matter from the body, e.g., urea is excreted by the kidneys.

Ferment is a substance which decomposes or causes fermentation in other substances with which it comes in contact, e.g., pepsin changes proteids into peptones.

Tidal air is the quantity of air taken in and expelled by an ordinary respiration. In the horse it amounts to about 250 cubic inches. 
Phagocytosis is the destruction of microörganisms and injurious substances by the phagocytes, e.g., leucocytes envelop and digest bacteria.

Alimentation is the act or process of affording nourishment, e.g., food in the alimentary canal.

Define the following terms : excretion, secretion, exosmose, decussation, reflex action.

Excretion: see preceding question.

Secretion is the process of separating from the blood and cells a substance intended, eventually, to be utilized in the body.

Exosmose is the act of liquids and gases in passing outward through a membrane.

Decussation refers to the erossing of the fibres of the pyramids of the medulla from one pyramid to another.

Reflex action is an involuntary movement produced by stimulation of a peripheral nerve.

State the kind of epithelium (a) in the lungs, (b) in the stomach, (c) in the larynx.

(a) Single layer of polygonal plates, mostly without nuclei and including groups of small and round cells.

(b) Tall columnar, some of which are the goblet-cell variety.

(c) Stratified, ciliated, columnar and stratified squamous.

Describe the function of the blood, gland cells and nerves in secretion. How does secretion differ from (a) transudation, (b) œdema, (c) exudation?

Secretion is the result of the activity of the protoplasm of the secreting cell. The inorganic constituents of a secretion are derived from the blood by osmosis; the organic constituents are the results of active manufacturing processes occurring within the protoplasmic cell-contents. Through the impulse conveyed by the nerve, the glandular blood-vessels dilate and secretion is stimulated.

Secretion differs from transudation, cedema and exudation, in that the latter are merely acts of filtration or osmosis and no glandular activity is concerned.

Which organ, liver or kidney, receives the greater amount of blood, and what conditions, anatomic, hydrostatic and circulatory, contribute to the difference?

The liver receives the greater amount because of its greater size, more dependent position and greater blood supply; besides the hepatic artery, the portal vein, draining the whole splanchnic area, empties into it. 
What are the physical properties of bone? How does the chemical composition of bone vary with age?

Bones are composed of an outer layer of compact tissue and of a spongy, reticular tissue which forms the interior (marrow). The compact tissue is traversed by channels called "Haversian canals," from which radiate numerous canaliculi; the latter are surrounded by concentric lamellæ of bone, separated by spaces (lacunæ) containing the bone cells, corpuscles. These lacunæ communicate with the Haversian canals through the canaliculi. The inner spongy tissue contains large marrow cavities. The exterior of bone is covered by a thin, tough, protective membrane, the periosteum.

As age advances, the bones contain less organic matter and more of the inorganic constituents.

Give the composition of bone. State how bone is nourished and give the function of long bones.

See answer to preceding question.

Bones consist of connective tissue, the substratum of which is osseine (an animal matter which yields gelatin upon boiling), impregnated with lime salts, chiefly calcium phosphate. Bone is composed of one-third animal matter and two-thirds mineral matter. Nourishment is supplied to bone by a nutrient artery which sends branches into the medullary and Haversian canals.

Long bones serve an important part in locomotion by imparting rigidity to the limbs and furnishing muscular attachments, as well as by entering into the formation of joints.

Mention the functions of the articular cartilages.

1. Favor, by their smoothness, the gliding and displacement of bones.

2. By their suppleness and elasticity, they lessen the violent shocks to which the articulations are exposed.

3. They resist the wear and deformations of the articular surfaces.

Mention with regard to the body (a) the principal secreting organs,

(b) the excreting organs, (c) the vital organs.

(a) Salivary glands, gastric glands, liver, pancreas, sebaceous glands, synovial, mucous and serous membranes, lachrymal glands. The spleen, thymus, thyroid and adrenals have an internal secretion.

(b) Skin, kidneys, bowels and lungs.

(c) Heart, lungs, brain, intestines, liver, kidneys. 
Mention the elements composing proteids.

Nitrogen, carbon, hydrogen, oxygen and varying amounts of sulphur.

Mention the inorganic constituents of the animal body.

1. Water.

2. Salts, viz., salts of sodium, potassium, calcium, magnesium and iron in the form of chlorides, sulphates, phosphates and carbonates.

3. Gases, viz., oxygen, nitrogen, hydrogen, carbon dioxide, sulphuretted hydrogen and marsh gas.

\section{What is blood?}

\section{BLOOD}

The blood is the fluid that circulates through the heart, arteries and veins, carrying nutriment and oxygen to the tissues of the body. It is a red, opaque, rather viscous fluid with an alkaline reaction, characteristic odor and saltish taste; specific gravity 1060.

\section{What is the chemical composition of the blood?}

Water 81 parts.

Solids 19 parts.

Hæmoglobin (0.4 per cent. iron) 13 parts.

Proteids 4 parts.

Fibrinogen

Serum globulin

Serum albumin

Fibrin ferment

Fibrin globulin

Salts 1 part.

Sodium chloride

Potassium chloride

Sodium carbonate

Calcium phosphate

Magnesium phosphate

Sodium phosphate

Potassium phosphate

Extractives 0.6 part.

Fats

Cholesterin

Lecithin

Creatin

Urea 


\section{Hippuric acid}

Uric acid

Grape sugar.

Nitrogen, oxygen and carbon dioxide gases are also present.

Describe the composition of the blood with reference to the nature and the purpose of each component part.

It consists of a colorless liquid, the plasma, containing red blood-corpuscles (erythrocytes), yellowish, circular, biconeave dises, containing hæmoglobin which earries the oxygen; white blood-corpuscles (leucocytes), white spherical amœboid masses of protoplasm, having phagocytic powers; blood platelets, small bodies, onequarter the size of a red cell, function unknown.

Mention the proteids of the blood.

Fibrinogen, serum albumin, serum globulin, fibrin ferment and fibrin globulin.

Mention three gases found in the blood. Indicate the relative amount of each of these gases in arterial blood and in venous blood, respectively.

Oxygen, earbon dioxide and nitrogen. In the arteries, oxygen is present in a greater amount and carbon dioxide in a lesser amount than in the veins. The amount of nitrogen is practically the same in both cases.

State the average amount of blood in the horse.

6.6 per cent. of the body weight. About 66 pounds or 55 pints in the average horse.

Describe the function of (a) red blood-corpuscles, (b) leucocytes.

(a) Carriers of oxygen.

(b) Take up and digest bacteria and other injurious substances (phagocytosis).

State how the red blood-corpuscles vary in size and shape in the different animals.

Horse: non-nucleated, biconcave dises, 4 to 5 microns in diameter. Ox: non-nucleated, biconcave dises, 3 to 5 microns in diameter. Sheep: non-nucleated, biconcave dises, 2 to 4 microns in diameter. Dog: non-nucleated, biconcave dises, 5 to 7 microns in diameter. Cat: non-nucleated, biconcave dises, 5 to 6 microns in diameter. Camel : non-nucleated, oval bodies, 7 microns long, 4 microns broad. Fowls: nucleated, oval bodies, 12 microns long, 7.5 microns broad. 
What are the principal differences between arterial blood and venous blood?

Arterial blood contains more oxygen and less carbon dioxide, more water, fibrinogen, extractives, salts and sugar, fewer bloodcorpuscles and less urea; its temperature is, on the average, $1^{\circ} \mathrm{C}$. lower. Venous blood is darker in color, due to the diminution in the oxygen-content.

What is the color of the blood in the renal veins? Why?

Dark-blue, same as all venous blood. In its passage through the kidney, the blood loses oxygen and takes up carbon dioxide, therefore, it is venous in character as it leaves this organ.

What salts render the blood alkaline?

The phosphate and bicarbonate of soda.

Describe the process of coagulation of the blood.

The blood first becomes a jelly and then a firm clot. The clot contracts and squeezes out a fluid, serum. As this serum accumulates, the clot sinks. The substance which brings abont coagulation is fibrinogen, which, being acted upon by the ferment, thrombin, produces fibrin.

Of what does a blood clot consist? How would you demonstrate the presence of fibrin in freshly drawn blood?

A blood clot consists of fibrin and blood-corpuscles. Fibrin may be demonstrated by defibrinating freshly drawn blood. This is accomplished by whipping the blood with a rod or bunch of twigs; the fibrin separates rapidly and collects on the rod.

What influences the combination of hæmoglobin with oxygen?

The atmospheric pressure of oxygen being higher than the pressure of the oxygen in the venous blood as it arrives at the heart may play a very small part in influeneing the taking up of oxygen by the blood; but the strong affinity of hæmoglobin and oxygen for each other is of grcater influence. This subject has not been satisfactorily explained.

How is oxygen carried in the blood and where is it exchanged for carbon dioxide?

It is carried in the blood united with the hamoglobin, as oxyhæmoglobin. It is exchanged for carbon dioxide in the tissues.

When serum is used subcutem for therapeutic purposes, what danger attends its transfer from one genus to another?

Hrmolysis, breaking down of red blood-corpuscles and liberation of hæmoglobin, occurs. 
What morbid and dangerous states of the blood may be connected with the suspension of biliary secretion?

Jaundice, intoxication with the waste products of the biliary secretion (cholesterin and lecithin) and the poisonous products in the alimentary canal, due to constipation following a lack of the stimulating action of bile on peristalsis.

What is (a) oxyhæmoglobin, (b) methæmoglobin, (c) hæmatoidin?

(a) Hrmoglobin charged with oxygen.

(b) A modification of oxyhæmoglobin in which the oxygen is more firmly united than in ordinary oxyhæmoglobin. It occurs pathologically whenever there is a sudden breaking down of the red blood-corpuscles, e.g., as in azoturia.

(c) A yellow-brown, crystalline, iron-free product, derived from hæmatin. It is found in old blood clots.

\section{HeART}

What is the influence of the vagus nerve on the heart? What would be the effect on the heart if the vagi nerves were cut?

The vagus (pneumogastric) has a restraining or, as it is termed, an inhibitory effect on the heart movements. If cut, the inhibitory action is removed, the heart rate is greatly increased, and the blood-pressure rises.

\section{Describe the cardiac sounds.}

There are really four cardiac sounds, but, as they occur in pairs, we recognize only two. The first sound is dull, deep, prolonged and louder than the second, which is short, not so deep and not so loud. The two sounds are best reproduced by pronouncing the words "lubb dupp."

\section{What are the cardiac sounds? What causes these sounds?}

See answer to preceding question.

The first sound is caused by the closing of the auriculoventricular valves and the contraction of the muscular fibres. The second sound is due to the closure of the semilunar valves.

Explain the action of digitalis on the heart.

It reduces the frequency of the heart-beat and later excites the cardiac muscle to a stronger and prolonged systole. It is a cardiac tonic.

Define (a) systole, (b) diastole, (c) cardiac cycle.

(a) Systole is the term applied to the heart's contraction. It occurs synchronously with the first heart sound; by it, the blood is driven into the aorta and pulmonary artery. 
(b) The dilatation or stage of dilatation of the heart.

(c) A cardiac cycle is a complete cardiae movement or heartbeat. It includes the period from the beginning of one heart-beat to the end of another, i.e., the systolic and diastolic movements with the interval between.

\section{BLOOD-VESSELS}

How do arteries and veins differ in (a) structure, (b) function? What arteries carry venous blood and what veins carry arterial blood?

(a) The walls of veins are thinner than those of arteries and they collapse when empty. They contain less elastic and muscular material and more fibrous tissue than arteries. Veins are provided with valves which are not present in arteries.

(b) Veins carry impure blood from the tissues to the heart. Arteries carry pure blood from the heart to the various parts of the body. There are two exceptions, viz., the pulmonary artery carries venous blood from the heart to the lungs and the pulmonary vein carries pure blood from the lungs to the heart.

How does the internal coat of an artery differ from that of a vein?

Arteries have no valves as do the veins.

Discuss the forces that cause the blood to circulate in (a) the arteries, (b) the capillaries, (c) the veins.

(a) Force of the heart's contraction, and the elasticity of the arterial walls.

(b) Pressure from arteries and elasticity of the walls.

(c) Muscular contractions, valves, gravity, and negative pressure in veins leading directly into the right heart.

Describe the course of the blood from the right auricle back to the same point. What part of this circulation is called the systemic circulation?

From the right amricle, blood flows through the trieuspid valve into the pulmonary artery, to the lungs, returning to the left auricle through the pulmonary veins, completing the pulmonary eireulation. From the left auriele, the blood begins the systemic eireulation, passing through the bienspid valve into the left ventricle, thenee through the aortie semilunar valve into the aorta, which divides and subdivides until every part of the body is supplied. Collecting in the veins, it is carried through the anterior and posterior vena eava to the right auricle, whenee it started, thus completing the systemic eireulation. 
Describe the circulation of the blood.

See answer to preceding question.

Discuss the relative velocity of the blood in the arteries, capillaries and veins.

Greatest velocity is in the arteries, least in the eapillaries, and rising again in the veins.

Define blood-pressure. Mention (a) factors that increase bloodpressure, (b) factors that decrease blood-pressure.

Blood-pressure is the tension on the walls of the blood-vessels derived from the blood current.

(a) Increase in force of the heart-beat and contraction of the arterioles.

(b) Decrease in the force of the heart-beat and dilatation of the arterioles.

Where is blood-pressure (a) the highest, (b) the lowest? How is blood-pressure governed?

(a) In the region of the aorta.

(b) In the region of the periphery.

Blood-pressure is governed by the contraction of the heart and the resistance offered by the peripheral vessels; all being regulated by the vasomotor centre in the brain.

Describe the flow of blood in the arteries.

The centre of the vessel is occupied by a column of rapidly moving red cells, while between them and the vessel wall is a clear layer in which the white corpuscles move slowly along, occasionally stopping along the sides, then moving forward once more.

What is meant by the velocity of the blood? State where this velocity is (a) the greatest, (b) the least.

Velocity refers to the rate at which the blood flows through the blood-vessels. The velocity varies inversely as the sectional area of the tubes. Since the total sectional area of the capillaries is greater than that of the arteries or veins, the velocity is least in the capillaries and greatest in the arteries.

What causes the flow of blood in the veins?

Muscular contractions, valves, gravity and the negative pressure in the veins leading directly into the right auricle.

Why is blood-pressure highest at the beginning of an expiration and lowest at the beginning of an inspiration?

At the beginning of expiration, which is really the height of inspiration, the intrathoracic pressure is greatest, more blood is 
forced into the aorta and, therefore, the blood-pressure is highest. At the beginning of an inspiration, which is really the end of an expiration, there is a negative intrathoracic pressure, the blood is aspirated into the right auricle and the blood-pressure is lowest.

\section{Describe the circulation of the blood in the brain.}

Supplied by the cerebrospinal branch of the external carotid, which divides into two branches, the median spinal and basilar, and the internal carotid, which divides into the posterior communicating and the common trunk of the anterior and middle cerebral arteries.

The venous arrangement is very remarkable; the walls of the veins are composed of the dura mater and portions of the cranial bones. The veins, or sinuses of the brain, are large cavities which, because of their unyielding walls, allow the venous blood to return freely. The cerebral circulation is assisted by the fluid in the ventricles of the brain. This fluid passes from one ventricle to another and to the spinal cord; therefore, when the external pressure becomes greater, the internal becomes less, thereby avoiding any compression of the brain substance.

\section{Describe the portal circulation.}

The portal circulation begins in the small mesenteric, the great mesenteric and splenic veins, all of which unite to form the portal vein. The latter, beginning near the great mesenteric artery, passes through the pancreatic ring and divides in the great posterior fissure of the liver to enter its structure, carrying the venous blood, which, after circulating through the liver, leaves it by the hepatic vein.

\section{Describe the circulation of the blood in the kidney.}

The blood enters at the hilus by the renal artery, which breaks up, after entering the organ, into a large number of branches; these branches run in a nearly parallel direction through the medullary portion until the cortex is reached, where they diverge in varions directions to enter the Malpighian corpuscles. In these bodies there is a plexus of capillaries, the glomeruli, and leading from them are small vessels, arranged similar to the arterial branches, which unite to form the renal vein.

Give the normal pulse of (a) the horse, (b) the ox, (c) the dog, (d) the sheep, (e) the cat.
(a) $36-40$;
(b) $45-50$
(c) $90-120$;
(d) $70-80$
(e) $90-120$.

\section{Vascular Glands}

Mention the vascular glands.

Spleen, thymus, thyroid, adrenals, pituitary and pineal bodies. 
Name two vascular glands. Give the function of each.

Spleen: Red blood-corpuscles are formed in the spleen during intra-uterine life, but after birth they are destroyed in it. This organ is thought by some to produce an enzyme which converts trypsinogen into trypsin and also to produce uric acid. It serves as a reservoir for the abdominal circulation.

Thyroid: This gland has an internal secretion which is directed to the mutrition of the body. The nature of this secretion is not well understood.

\section{RESPIRATION}

Describe the process of respiration. Describe the changes that take place in inspired air during the process of respiration.

The act of respiration is divided into two parts, inspiration and expiration. The former, by which the chest is filled with air, is a purely muscular act; the diaphragm contracts and therefore recedes, the ribs are rotated, being drawn forward and outward, their posterior edges everted, and the intercostal space widened. By' these means the capacity of the chest is increased and the lungs expand to fill the space, thus causing air to rush in. Expiration is effected by the recoil of the lungs and the displaced abdominal organs, the contraction of the abdominal muscles and the internal intercostals. Through these movements the air is expelled from the lungs.

During respiration, part of the oxygen of the air is taken up by the blood in exchange for carbon dioxide which is thrown off.

How are the diameters of the chest enlarged during inspiration?

By the recession of the diaphragm, the anteroposterior diameter of the chest is lengthened from four to five inches and by the outward rotation of the ribs, the transverse diameter, between the eleventh and twelfth ribs, is increased one and one-half inches.

Compare inspired air with expired air as to relative quantity of oxygen, nitrogen and carbon dioxide.

Inspired air contains more oxygen and less carbon dioxide than expired air ; the amount of nitrogen is the same in both.

\begin{tabular}{|c|c|c|c|}
\hline jired air & $\begin{array}{r}\text { Oxygen. } \\
. \quad 20.96\end{array}$ & $\begin{array}{c}\text { Nitrogen } \\
79.01\end{array}$ & $\begin{array}{c}\text { Carbon dioxide } \\
0.03\end{array}$ \\
\hline Expired air & 16.02 & 79.01 & 4.38 \\
\hline
\end{tabular}

Mention the functions of respiration.

Supplies oxygen to the blood and excretes carbon dioxide, solids, moisture, etc. 
Give in full the functions of the lungs.

Medium of interchange of earbon dioxide and oxygen between the air and blood.

Name (a) two inspiratory muscles, (b) two expiratory muscles. What is the normal stimulus to the action of these muscles?

(a) Diaphragm and external intereostals.

(b) Abdominal and internal intercostals.

Inspiration is presided over by a centre in the medulla. Expiration is thought to be a purely passive act.

Discuss the absorption of gas by fluids.

If the atmosphere, containing a mixture of gases, be exposed over a fluid containing some of these gases dissolved in it, it is found that if the proportion of dissolved gases in the fluid is less than their proportion in the atmosphere, the latter pass into the fluid until the amounts in air and fluid are equal. Likewise, if the fluid eontains more dissolved gas than the atmosphere, gas will pass from the fluid to the air above until the amounts are equal. This is a process of diffusion.

Define tidal air and residual air.

Tidal air is the air breathed in and out in an ordinary respiration. Residual air is that which always remains after a foreed expiration.

Give the normal number of respirations per minute in (a) the horse, (b) the ox, (c) the sheep, (d) the hog, (e) the dog.

(a) $8-16$; (b) $12-15$; (c) $12-20$; (d) $10-15$; (e) $15-20$.

What is the ratio of respirations to the pulse beats?

About 1:4.

Describe the lining of the bronchial tubes, touching on epithelium and glands.

The bronehi are lined with mucous membrane composed of ciliated epithelium and containing mucous glands.

What is the meaning of each of the following: (a) eupnœa, (b) hyperpnœa, (c) dyspnœa, (d) apnœa?

(a) Easy or normal respiration.

(b) Moderate inerease in the respiratory movements.

(c) Diffieult or labored breathing.

(d) Transient cessation of breathing following a forced respiration. 
Describe the different stages of asphyxia. How does asphyxia cause death?

First stage: labored breathing, all muscles of respiration being brought into play; convulsions; blood-pressure rises.

Second stage: inspiratory muscles less active; expiratory muscles still powerful; convulsions cease.

Third stage: unconsciousness, occasional inspiratory gaspings, mouth open, the pupils dilated, pulse imperceptible, blood-pressure falls. Death occurs from five to six minutes after the beginning of the first stage.

Asphyxia causes death by creating a deficiency of oxygen and an excess of carbon dioxide in the blood. Carbon dioxide is a poison and affects the cardiac centre in the brain, causing death.

Give the composition of normal air and state how it supports life.

\begin{tabular}{|c|c|}
\hline Oxygen & $\begin{array}{l}\text { By volume. } \\
20.96\end{array}$ \\
\hline Nitrogen & 79.01 \\
\hline dioxide & .03 \\
\hline
\end{tabular}

Normal air supports life by supplying oxygen which it contains in an uncombined state.

What animals may, with effort, breathe through a broken long bone? Why?

Birds, because they have a system of air sacs in the bones which communicate with the lungs.

\section{DigESTION}

Give the different steps in the process of digestion.

Prehension, mastication, salivation, deglutition, gastric digestion, intestinal digestion, absorption and defecation.

Give the dental formula for the horse and the ox.

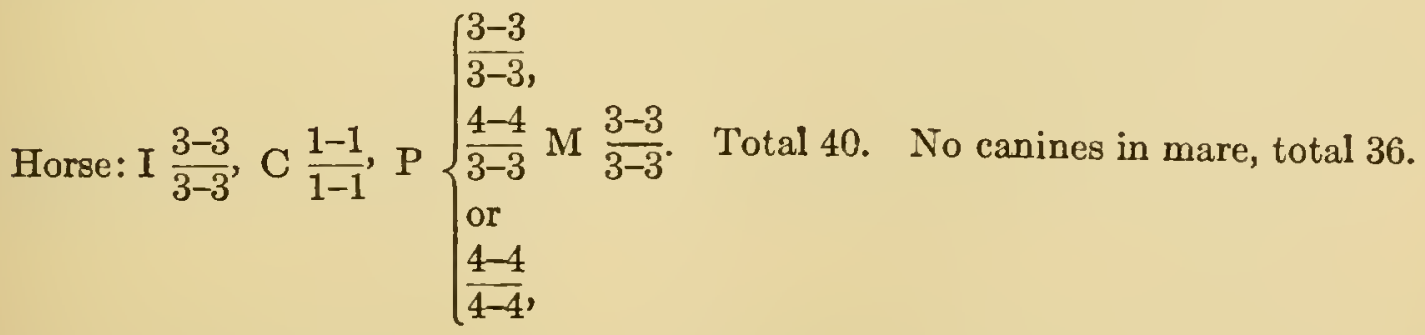

Ox: I $\frac{\mathrm{O}-\mathrm{O}}{4-4}, \mathrm{C} \frac{\mathrm{O}-0}{\mathrm{O}-0}, \mathrm{P} \frac{3-3}{3-3}, \mathrm{M} \frac{3-3}{3-3}$. Total 32 . 
How do horses, cattle and sheep, respectively, take in their food? Have these methods any bearing on swallowing non-alimentary and harmful bodies?

Horses prehend the food mainly with the lips and thoroughly masticate it. Because of this thorough mastication, any foreign body is quite sure to be detected and rejected.

Cattle use their long tongue to convey food into the mouth, whence it passes directly to the rumen through a thin, distensible csophagus, hence foreign bodies are frequently swallowed.

Sheep have a cleft upper lip which enables them to graze closely and pick up very small objects. They have a delicate manner of eating and are less liable to swallow foreign bodies than cattle, but, owing to their method of swallowing their food with little or no mastication, foreign bodies are more commonly found in their stomachs than is the case with the horse.

Name the digestive ferments. What digestive ferments act on (a) fat, (b) starch, (c) proteid?

Ptyalin, pepsin, rennin, trypsin, steapsin, amylopsin, enterokinase, erepsin, maltase, invertase and lactase.

(a) Steapsin; (b) ptyalin and amylopsin; (c) pepsin and trypsin.

\section{What are the physical and chemical properties of saliva?}

An alkaline, opalescent, or slightly turbid fluid which readily froths when shaken. On exposure to the air it throws down a deposit of calcium carbonate due to the loss of carbon dioxide. It has a specific gravity of 1005 . Microscopically, it consists of epithelial scales and salivary corpuseles. Saliva consists of a 0.6 per cent. mineral matter and 0.2 per cent. organic matter, the latter consisting of mucin and small amounts of proteid matter. The salts are: calcium earbonate, calcium chloride, ealcium phosphate, magnesium chloride and magnesium phosphate. It contains a ferment known as ptyalin which converts starches into sugar. The gases of saliva are: carbon dioxide, oxygen and nitrogen.

Name four uses of saliva.

Assists in mastication and swallowing; stimulates the nerves of taste and has an amylytic action. In ruminants, it assists in rumination.

Describe the cells of the parotid gland when actively secreting.

The granular material passes toward the eentre of the acinus or lumen, leaving each cell with a clear outer edge and the edge next 
the lumen is granular; when the cells are exhausted, they are smaller and remarkably clear, only a few granules being left on the inner edge, whilst the lumen is now distinct and large and the nuclei become large and rounded, showing the mucleoli.

Compare the amount of saliva in the horse with that in the ox. On what conditions does the amount secreted depend?

It has been estimated that the horse secretes 84 pounds and the ox 112 pounds of saliva in 24 hours. The amount depends on the dryness of the food, more being secreted when eating dry than moist foods.

How is food when swallowed prevented from getting into the posterior nares and the larynx?

The soft palate prevents food entering the posterior nares and the epiglottis protects the larynx.

\section{Describe the phenomena of regurgitation in ruminants.}

Rumination is a reflex, nervous act and can only be performed by means of the united action of the diaphragm, stomach walls and abdominal muscles. It is performed as follows: The churning movement of the rumen throws the food gently against the osophageal groove, when a spasmodic contraction of the diaphragm and abdominal muscles forces some of the liquid content of the reticulum and the solid matter from the rumen into the resophagus. The funnelshaped extremity of the latter contracts and euts off the bolus, which, by a reverse peristaltic action, is conveyed to the mouth. After a thorough mastication, the bolus is reswallowed and passes directly into the third compartment of the stomach.

Explain fully why a normal horse can rarely vomit.

1. The cardiac extremity of the oesophagus is thickened and contracted.

2. The œsophagus enters the stomach in an oblique direction.

3. The dilated pylorus lies close to the contracted cardia, so that compression of the stomach contents forces them into the duodenum.

4. The mucous coat is thrown into folds over the cardiac opening.

5. Encircling the cardia are muscular loops the contractions of which keeps the opening tightly closed.

6. The stomach is not in contact with the abdominal wall.

State the function of the stomach.

It thoroughly mixes the food and through the action of the enzymes, secreted by its walls, converts proteid matter into peptone, thereby rendering it absorbable. In young animals, there is 
another enzyme, remmin, which curdles milk. In the stomach of dogs, free hydrochloric acid is present; it aids in the digesting of bone.

Give the composition of gastric juice. From what is the hydrochloric acid derived?

Water, hydrochloric acid, lactic acid, pepsin, rennin, chlorides, phosphates and iron.

The hydrochloric acid of the gastric juice is thought to be derived from the gastric glands which form it from the chlorides, which the mucous membrane takes up from the blood.

Describe the digestion of proteids in the stomach.

Pepsin converts proteids into peptones. This change is effected through several stages. The intermediate products in the order in which they occur are:

1. The proteid as consumed, or native albumin.

2. Acid albumin, or syntonin.

3. Primary proteoses.

4. Secondary proteoses.

5. Peptones.

How many stomachs has (a) the horse, (b) the ox, (c) the goat, (d) the camel?

(a) One; (b), (c) and (d) one stomach divided into four compartments, which gives rise to the common statement that they have four stomachs. The fourth compartment, the abomasum, is the true stomach and is practically the same as the stomach of other animals.

State the condition of food as it leaves the abomasum.

It is a soft, pasty mass with a sour odor and alkaline reaction; the proteids have been converted into peptones and the starch is said to have been digested. In the young, the milk has been eurdled.

State the extent of the secreting (peptic) mucosa, as compared with the non-peptic, in the stomach of the horse, hog and dog and in the fourth stomach of the ox.

In the horse, the peptic mueosa constitutes about two-thirds of the whole lining of the stomach, the non-peptic the remainder.

In the hog, the peptic mucosa constitutes about one-third, the remainder being non-peptic.

In the dog, the peptic mucosa extends over the whole extent of the stomach wall. 
In the ox, about the same relation exists between the two as in the horse, but the glands of the pylorus are poorer in pepsin than those of the fundus.

Name the different digestive ferments in the gastric secretion of the mature horse and the different proximate food principles that they digest. State how this action is affected in each case by acidity and alkalinity, respectively.

Pepsin acts on proteid matter and can only do so in an acid medium. The gastric secretion is said by some to contain an amylolytic ferment; at any rate, the saliva swallowed with the food, this ferment, or both convert starch into sugar in the stomach and can only act during the early part of stomach digestion while the reaction is alkaline.

What produces the sensation of (a) hunger, (b) thirst?

(a) Hunger is referred to the stomach, but the reason why is not known. The pneumogastric nerves may be divided but the sensation of hunger remains. The stomach may be full or empty and hunger still exist.

(b) Thirst is referred to the pharynx. A deficiency of moisture in the system is always shown by a dryness of the pharynx and palate. Nothing is known of the nervous apparatus involved in thirst.

\section{Describe peristaltic action. How is it accomplished?}

Peristaltic action is the worm-like movement by which the alimentary canal propels its contents. It consists of a wave of contraction passing along the tube, anteroposteriorly. It is accomplished by the contraction of its circular and longitudinal muscular fibres.

Mention the glands of the intestinal canal and state their function.

Lieberkühn's and Brünner's glands secrete a mucous fluid which contains enzymes as follows: succus entericus, enterokinase, erepsin, inverting ferments (invertase, maltase, lactase). These enzymes have very important digestive actions.

State the difference between chyme and chyle.

Chyme is the liquid mass into which the food is converted by gastric digestion. It is a yellow, frothy, precipitated, slimy fluid, which in the anterior part of the intestinal canal possesses a peculiar, mawkish smell, and in the ileum, a distinctly fecal odor. In the ileum, the contents are considerably less fluid.

Chyle is the milky fluid taken up by the lacteals from the chyme in the intestines. It is a turbid, alkaline fluid, containing fat 
globules. In starving animals it is transparent, owing to the absence of fat, and in herbivora it is said to be yellowish or yellowish-green, owing to the chlorophyll in the food.

How does chyle differ from lymph?

Chemically they are very much alike, but chyle contains fat, which gives it a milky appearance. Lymph contains lymph corpuscles and possesses the power of spontaneous clotting.

State the function of the double colon in digestion.

In the colon, bacteria attack the unabsorbed products of proteid digestion, reducing them to simpler end-products. These endproducts are partly absorbed, but mostly passed out with the frees.

What constitutes the bulk of the fæces? Compare the fæces of herbivora with the fæces of carnivora.

The fæces consist principally of that portion of the food which is undigestible, together with that part which though digestible has escaped absorption.

The fæces of herbivora consist mainly of inorganic mattel (58 per cent.), and they are acid in reaction. In carnivora, there is less inorganic matter (20 to 25 per cent.), and they are alkaline in reaction. The fæces of carnivora contain a large amount of lime salts.

\section{What relation has the portal vein to absorption from the intestines?}

The portal vein drains the whole splanchnic area, hence the blood it carries is charged with substances, absorbed from the intestinal canal, that are by-products formed during the gradual breakingdown of the food substances. These substances are those which are soluble in water, such as salts, sugar, soaps, and peptone. Peptone is probably changed to serum-albumin during absorption, for peptone in the blood is a poison.

Give the function of the liver.

Secretion of bile, glycogenic function, formation of urea and a protective function (neutralizes poisons).

Give the blood supply of the liver.

The hepatic artery supplies the nutritive blood. The functional blood is supplied by the portal vein.

What are the functions of the bile? Show how the secretion of bile in the equine differs from that in the bovine.

Functions of the bile: Emulsifies fat, stimulates peristalsis and has slight antiseptic action on the intestinal contents. 
Equines have no gall-bladder, hence the bile is poured into the intestines as fast as it is secreted. Bovines have a gall-bladder and in this capacious receptacle the bile is stored until required. It has been computed that a horse secretes 10 ounces of bile, hourly, and the ox only 4 ounces in the same time.

\section{What is glycogen?}

Glycogen is commonly called "animal starch." It is a carbohydrate from the liver, leucocytes, cartilage and other tissues. It is formed in the liver from carbohydrates and proteids, being converted into sugar as the needs of the system require, and is carried away in the hepatic vein.

State the function of the pancreas.

The pancreas secretes a digestive fluid and also has an internal secretion which, in some way not well understood, governs the amount of sugar in the body.

Give the composition of the secretion of the pancreas.

The pancreatic fluid is an alkaline, clear, colorless fluid with a saltish, unpleasant taste and a specific gravity of 1010 (in the dog, it is viscid). It contains over 98 per cent. water, the balance being salts, of which sodium chloride is the most important, and organic matter which contains the active principles of the fluid. These enzymes are amylopsin, steapsin, trypsin and rennin.

Give the ferments of the pancreatic juice and state the function of each.

1. Trypsin is a proteolytic enzyme which converts proteids into pepsin.

2. Amylopsin is a diastatic enzyme which converts starch into sugar.

3. Steapsin is a lipolytic enzyme which acts on fats.

4. Rennin is a milk-curdling enzyme.

What is the action of the pancreas on the production of glucose in the urine and how is this action understood to be brought about?

If the pancreas be removed, glucose appears in the blood and is separated by the kidneys, causing glycosuria. If only partly removed, glycosuria occurs but to a lesser extent. It is not known how this action occurs, but it is considered that the internal secretion of the pancreas acts upon a ferment in the muscles and makes the decomposition of sugar possible. 


\section{Describe the action of salt in digestion.}

Salt increases thirst and causes the animal to drink more water, which increases the fluidity of the food and thereby aids digestion and absorption. In the stomach, it forms hydrochloric acid, which is so essential to gastric digestion.

\section{Describe several conditions that retard digestion.}

Improper teeth cause improper mastication of the food, which hinders the action of the digestive fluids. Improper foods (too hot, too bulky, too cold, too dry, etc.) retard digestion. Feeding hay before grain causes a retention of the latter in the stomach, and disease conditions of any part of the alimentary canal retard or entirely prevent digestion.

\section{ABSORPTION}

Describe the lymph as to (a) appearance, (b) source, (c) function.

(a) A transparent, slightly yellow-colored fluid, alkaline in reaction; occasionally it is a light rose color from the presence of red blood-corpuscles, and it is often opalescent from the presence of fat globules.

(b) There are two theories advanced to account for the formation of lymph. The more generally accepted one is the physical theory. According to this, the lymph is formed from the blood by the process of filtration and osmosis. The second or secretory theory is based on the secretory activity of the endothelial lining of the capillary walls.

(c) Lymph is a sort of mediary material between the tissues and the blood, by which nourishment is carried from the blood to the tissues and effete material taken back to the blood. Generally speaking, the lymphatic system is the drainage system of the body as contrasted with the blood, the irrigating system.

Describe the lymph-spaces, the lymph-capillaries and the general arrangement of the lymphatic vessels.

The lymph-spaces are irregular cavities, lined by epithelioid plates, found in the connective tissue outside of the blood-vessel walls, into which the lymph passes from the blood. From these spaces, the lymph reaches the lymph-capillaries. The latter are the most minute branches of the lymphatic vessels and their lining is composed of the same epithelioid plates as found in the spaces. Between these plates, ereviees are supposed to exist throngh which the lymph transudes.

The lymphatie vessels follow the eapillaries. They have, in addition to the epithelioid lining, a muscular coat and a connective-tissue 
covering. Valves, similar to the ones found in veins, are seen in their interior. All the lymphatic vessels of the left side of the head and neck, the left fore limb, the chest, the abdominal cavity and hind limbs converge toward and empty into a central vessel, the thoracic duct, which empties into the anterior vena cava; the lymphatic vessels of the right side of the head and neck and the right fore limb collect and pour their contents by a separate duct into the same vein.

What medicinal and other agencies may be employed as lymphagogues?

Ingestion of large quantities of water assists in increasing the amount of lymph. Certain agents, when injected into the circulation, increase the flow of lymph, such as peptone, decoctions of intestinal wall, liver, etc., crystalline bodies such as sugar and neutral salts. The administration of sodium citrate by the mouth increases the general lymphatic circulation.

In what diseases of connective tissue is the lymph specially involved? In infected wounds and suppurative inflammations.

\section{What forces assist the flow of lymph?}

Contraction of vessel walls, aspiration by the diaphragm, contraction of the abdominal muscles, peristalsis, and valves in the lymph-vessels.

\section{State the function of the skin.}

\section{SkIN}

Protective covering for the body; sense of touch; excretion of waste matter and regulation of temperature.

Describe the glands found in the skin of domestic animals, noting the relative number and complexity of these in the different genera, and the attendant variation of the product in amount and facility of secretion.

The sweat-glands in the ox are rudimentary, consisting merely of oval sacs found principally on the muzzle. In the horse, dog, cat, sheep and hog they are more highly developed, being long convoluted tubes which pass through the entire thickness of the skin. The sweat-glands of the horse are quite generally distributed, but there are certain parts of the skin which sweat more freely than others, for instance, the base of the ears, the neck, sides of the chest and the inside of the thighs. Mules and donkeys sweat with difficulty and then principally at the base of the ears. Dogs and cats 
perspire freely on the foot-pads and but very little elsewhere. The sweating of pigs is confined to the snout. Sheep are said to perspire very little or not at all.

The sebaceous glands, racemose in type, are scattered quite generally over the body, but are more especially developed where there is an abundant supply of hair, also in the prepuce, ears and eyelids. The ducts of the sebaceous glands, as a rule, empty into the hair follicles. These glands are very numerous in sheep and secrete the oily substance known as wool-fat or lanolin.

What is the difference between sebaceous and sudoriparous glands?

Sebaceous glands are racemose in type; their secretion, sebum, an oily substance, is formed principally by a fatty degeneration and breaking down of the cell-content.

Sudoriparous glands secrete sweat by a true secretory activity of the cells composing them. The nerve supply to sweat-glands is more acutely developed than is the case with sebaceous glands. This is demonstrated by the effect of emotion on the production of sweat.

\section{What is sebum? State where and how it is secreted and give its func- tions.}

Sebum is the secretion of the sebaceous glands; it is a thick, semifluid substance, composed of fat and epithelial débris from the cells of the Malpighian layer. For manner of secretion, see answer to preceding question.

Sebum saves the epithelium from the disintegrating influence of water, protects the animal from the elements, especially rain storms; keeps the skin moist and pliable and maintains a glossy hair coat.

State the effect of a complete compulsory suppression of cutaneous perspiration.

A loss of body heat followed by death in a few days is produeed by varnishing the skin. Formerly, it was thought that this lesult was due to the retention of poisonous products.

\section{Of what does dandruff consist?}

Epithelial scales, fat, coloring matters, salts, silica and dirt.

State the difference in structure of hair, fur and wool.

Fur is very fine, closely set hair, and is distinguished from ordinary hair, which is longer and coarser and generally more or less present with it. Woal is a modified form of hair, distinguished by its slender, soft and wavy or curly structure and by the highly imbricated or serrated surface of its filaments. 
Mention the conditions that favor the growth of wool or of improvement in its quality.

Good feeding of a rather high nitrogenous diet; neither too hot nor too cold temperature; dry surroundings. Salt and sulphur are thought to aid the growth of wool; at any rate, the former is indispensable as a part of the diet and should be given regularly; the latter is valuable as a mild laxative and, by its general tonic action, may improve the fleece.

What precautions may be taken to limit the growth of an injuriously long, thick coat of hair?

Warm quarters and blanketing will cause shedding. Clipping may be resorted to.

URINE

Give in full the functions of the kidneys.

They are the filtering organs of the body. They excrete urine, which consists of nitrogenous waste products, salts and other excrementitious substances.

What is the structure of the capsule of the kidney and how does this capsule affect the progress of the urine through the uriniferous tubules, pelvis and ureter?

It is composed largely of fibrous tissue and is rigid and unyielding. The internal pressure, therefore, tends to force the urine through the various canals.

Describe the cortical layer of the kidney and state where the secretion of the liquid and solid elements of the urine takes place.

The cortical layer is the essential secreting region. It contains the Malpighian bodies and convoluted tubules, as well as the beginning of the straight collecting tubules. Beneath the capsule, also between the cortex and medulla, is a narrow layer in which no glomeruli are found, otherwise the cortex is filled with them.

In the glomeruli, the water and perhaps the salts are passed out, while in the tubules the organic matter is excreted.

Give the composition of urine.

Water.

Organic matter: Urea, uric acid, hippuric acid, creatine, creatinine, benzoic acid, ethereal sulphates of phenol and cresol, coloring matter and mucus.

Salts: Sulphates, phosphates and chlorides of sodium, potassium, calcium and magnesium. 
Compare the urine of herbivora with the urine of carnivora as to its chemical reaction and give the cause for the difference.

The urine of herbivora is alkaline, owing to the excess of alkaline salts of organic acids contained in their food, such as malic, citric, tartaric and succinic. These salts are converted into carbonates during their passage through the body and appear as such in the urine. The urine of carnivora is acid in reaction, due to the presence of the acid phosphate of soda.

Give the reaction and specific gravity of the urine of (a) the horse, (b) the ox, (c) the sheep, (d) the dog.

(a) Alkaline, 1035; (b) alkaline, 1020; (c) alkaline, 1010; (d) acid, 1050.

What is the average amount, by weight, of excreta and of urine passed in 24 hours by (a) the horse, (b) the cow?

(a) Excreta, 24 lbs.; urine, 81/2 pints.

(b) Excreta, 75 lbs.; urine, 25 pints.

What are the sources of urea?

Urea is a nitrogenous end-product, derived from proteid -food and proteid tissues. These substances, after destruction, are discharged into the blood in the form of ammonia compounds and are then converted into urea in the liver.

State the causes, racial, dietetic and pathologic, that tend to cause acidity of the urine.

The urine of carnivora is acid, due to the acid phosphate of soda. A flesh diet or starvation, when the animal is living on its own tissue, produces acidity of the urine. If a horse is fed exclusively on oats, its urine becomes acid, because the acidity increases with the nitrogen contents of the food; oats are very rich in nitrogen. The urine of herbivora is acid in fevers when the appetite is lost or impaired, also in catarrh of the intestinal tract.

\section{NUTRITION}

Define (a) metabolism, (b) anabolism, (c) catabolism. What is meant by the metabolism of nutrition?

(a) The changes occurring in living tissues; the building up and breaking down of the body tissues.

(b) The building up process or the conversion of matter into protoplasm.

(c) The breaking down process or the conversion of protoplasm into a lower state of organization and ultimately into waste products.

By the term "metabolism of nutrition" is meant the constructive or anabolic metabolism, i.e., the process of assimilation. 
Name some of the important food proteids. What do green vegetables contain?

Oats, rye, wheat, corn, barley, brewers' grains, clover and grass.

Green vegetables contain a large proportion of protein. The color is due to a green coloring matter, chlorophyll.

Name the classes of non-nitrogenous foods. Give a list of the foods that come under each class named.

1. Carbohydrates: starch, sugar, gum and cellulose.

2. Fat: the fat part of milk and meat.

3. Inorganic matter: chlorine, potassium, sodium and iron.

Mention the effete materials in the body produced from nitrogenous foods.

Urea, uric acid, hippuric acid, creatine and creatinine.

What are the ultimate results of proteid foods in the body?

See answer to preceding question.

What is the chief function of fat in the body?

By its oxidation, it supplies heat and energy.

What would constitute a proper diet for a horse weighing $1500 \mathrm{lbs}$. and working every day?

Timothy hay $\ldots \ldots \ldots \ldots \ldots \ldots \ldots \ldots \ldots$ pounds

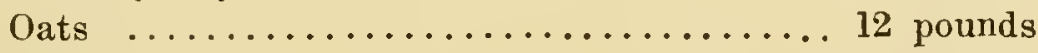

Wheat bran ................... 4 pounds

Corn ...................... 4 pounds

Give the origin and the destination of glycogen.

Glycogen is derived from the starch in the food. It is stored in the liver and dispensed to the tissues in the form of glucose.

Discuss briefly the nature and value of a balanced ration.

A balanced ration is one containing all of the food elements in the proper proportions for the animal's requirements without incurring a loss in weight. The tissues require all of the food elements but in different proportions. This proportion is approximately one part of proteid to six parts of carbohydrate and fat.

Give a daily ration containing the proper relative amount of dry matter, proteids, fats and carbohydrates for a dairy cow that weighs 900 pounds.

Clover hay $\ldots \ldots \ldots \ldots \ldots \ldots \ldots \ldots \ldots \ldots 10$ pounds

Corn silage $\ldots \ldots \ldots \ldots \ldots \ldots \ldots \ldots \ldots . \ldots . \ldots . \ldots$ pounds

Hominy chops .................. 2 pounds

Wheat bran $\ldots \ldots \ldots \ldots \ldots \ldots \ldots \ldots \ldots .4 .5$ pounds

Linseed meal ................. 2.5 pounds 
Give the effects of starvation on the tissue.

The animal lives on its own tissues. The urine of herbivora beeomes acid. Nitrogen is eliminated rapidly at first, but soon only a small amount is lost daily. The amount of earbon dioxide exereted falls in amount and the absorption of oxygen is redueed. The fat suffers the greatest loss, being nearly all consumed before death oeeurs. The eentral nervons system suffers no loss.

Animal Heat

How is the heat of the body (a) maintained, (b) regulated?

(a) By muscular contraction and tension, glandular activity and tissue oxidation.

(b) By the heat centres in the brain, which preside over and maintain an equality in heat production and heat loss.

What is animal heat? What conditions influence the temperature of the body?

Animal heat is the heat produced in the body by the ehemieal changes oeeurring in the tissues. Four-fifths of the daily heat production is generated in the skeletal museles.

Exereise, feeding, changes in the atmospheric temperature, variations in the amount of humidity, sweating, defeeation, urination and respiration influence the body temperature.

Give the average normal temperature of the (a) horse, (b) ox, (c) dog, (d) sheep, (e) swine, (f) cat.
(a) $100.4^{\circ}$ F. $\left(38.0^{\circ}\right.$ C. $)$.

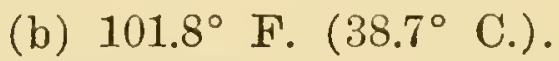
(c) $101.5^{\circ} \mathrm{F} .\left(38.6^{\circ} \mathrm{C}.\right)$.
(d) $104.0^{\circ} \mathrm{F} .\left(40.0^{\circ}\right.$ C. $)$.
(e) $103.3^{\circ} \mathrm{F} .\left(39.0^{\circ}\right.$ C. $)$.
(f) $101.5^{\circ} \mathrm{F} .\left(38.6^{\circ}\right.$ C. $)$.

Why does the temperature vary with external conditions in coldblooded animals and remain constant in spite of external conditions in warm-blooded animals?

Beeause of the differenee in the energy of tissue ehanges. In cold-blooded animals the development of heat is so slight that it is quickly dissipated in a cold atmosphere, whereas, in warmblooded animals the amount of heat, on aeeount of the greater energy of tissue ehange, is so much greater that it gives up only a part to the surrounding medium. Furthermore, in warm-blooded animals, the heat-regulating meehanism is undoubtedly more highly developed, in fact, there would seen to be no sueh meehanisin in the cold-blooded animals. 
Explain why the temperature does not rise unduly as a result of severe exercise.

Because the heat-regulating mechanism causes the excess of heat to be lost through radiation, sweating, etc., and thus a balance is maintained.

Mention the causes of the variations in the average temperature of the horse and of the dog.

A rise in temperature may be due to a contraction of the capillaries in the skin, following a cooling of the exterior, thus sending more blood to the deeper internal parts. Exereise and oxidation of food increase the body heat, therefore there is a daily variation corresponding to periods of activity and rest. When the peripheral vessels dilate, a greater radiation occurs and the internal temperature falls. The body temperature is lowest in the early morning when the vital processes are at lowest ebb.

Describe the chief factors in the regulation of the temperature of the body.

The heat centres in the brain preside over the heat-regulating mechanism. Heat loss occurs through radiation and conduction, evaporation of sweat, evaporation from the mouth and nostrils, vaporizing of water from the lungs, warming of inspired air, feces and urine. Heat production occurs through oxidation of tissues, glandular activity, and muscular contraction and tension.

What is a calorie or heat unit?

A large calorie is the amount of heat needed to raise one kilogramme of water from $0^{\circ}$ to $1^{\circ} \mathrm{C}$. A small calorie is the amount of heat needed to raise one gramme of water $1^{\circ} \mathrm{C}$. in temperature. (A horse produces 2.1 large calories per hour for every 2.2 pounds of body weight and it is estimated that a 1100 pound horse loses 20,684 large calories per diem when at rest, 24,500 at moderate work and 37,200 at hard work.)

What tissues produce the greatest amount of heat?

The skeletal muscles; four-fifths of the daily heat production originating in them.

Compare the natural means by which the body of the horse is cooled in summer with the means by which the body of the dog is cooled. Explain.

The horse loses heat to a great extent by the evaporation of perspiration from the skin. The dog sweats but little and that only on the foot-pads, but by panting, the mouth cavity and respiratory passages are supplied with a rapidly changing current of air. This 
causes a rapid evaporation of moisture from these parts, thereby cooling the body.

Give arguments for and against clipping horses in winter.

For

Less sweating and loss of condition.

Less liability to effects of cold.

Easier to groom.
Against

Require blanketing and warmer quarters.

\section{Muscular System}

Define: voluntary muscle, involuntary muscle. Give an example of each.

Voluntary muscle is one the movements of which are under the control of the will; nearly always striated; e.g., any skeletal muscle, such as the masseter, biceps, etc.

Involuntary muscle is one the movements of which are not under the control of the will; nearly always non-striated, e.g., muscles of the intestinal walls, bladder, etc.

\section{What peculiarities has the heart muscle?}

Heart muscle is striated but is involuntary. Its fibres are formed by branched, nucleated, quadrilateral cells and it has no sarcolemma.

What are the functions of muscle? How many kinds of muscle are there?

Functions: movements of the skeleton, contraction of the heart, regulation of the blood supply, transportation of ingesta along the alimentary canal.

Varieties: 1, voluntary, skeletal, striped or red muscle; 2, involuntary, unstriated or pale muscle; 3 , heart muscle.

Discuss the phases of a muscular contraction. What chemical changes accompany muscular contraction?

1. The latent period, which lasts about one one-hundredth part of a second, is the time occupied by the stimulus to traverse the nerve and by the muscle in preparing itself.

2. The period of contraction occupies about one-twentieth of a second, during which time the muscle shortens.

3. The period of relaxation which follows the maximum of contraction and has a duration of about one one-hundredth of a second longer than the period of contraction.

Chemical changes accompanying muscular contraction are: increased output of creatine, urea, carbon dioxide, sarcolactic acid; 
production of heat by the oxidation of the carbohydrates, glycogen and sugar.

Define muscular excitability. What conditions tend to (a) impair muscular excitability, (b) enhance muscular excitability?

Muscular excitability is the power possessed by muscles to respond to stimuli. This excitability is independent of the motor nerve, as may be shown by injecting curare into the muscle, when stimulation of the motor nerve will not produce muscular contraction, but if the same stimulus is applied directly to the muscle, contraction follows.

(a) Fatigue and lessened blood supply.

(b) By training and "conditioning" the voluntary muscles are educated to work in the best and most economical manner; their response increases in rapidity and power and their relaxation is quickened to prevent loss of time.

\section{What changes take place in a muscle as a result of rigor mortis?}

The muscle becomes firm and solid, loses its elasticity and does not respond to electrical stimuli. Its reaction is no longer alkaline, but becomes acid owing to the sarcolactic acid formed. The proteids coagulate, carbon dioxide is produced and heat is evolved.

\section{Nervous System}

Describe (a) an efferent nerve, (b) an afferent nerve. Give the function of each.

(a) One conveying impulses from a centre to the periphery. This impulse may cause contractions and movements of muscles, blood-vessels and viscera, or, it may be inhibitory in character and thus slow the heart, retard peristaltic action, etc.

(b) One conveying impulses from the periphery to a centre. The impulse may be one of the special senses, sight, hearing, smell, etc., one of pain, heat, cold, etc.

Classify nerves according to function and state the function of each class named.

1. Afferent or sensory.

2. Efferent or motor.

See answer to preceding question.

Describe the functions of the spinal cord.

1. Conducts impulses from the periphery to the brain and vice versa.

2. Seat of numerous reflex actions.

3. Takes some part in coördination. 
What are the functions of the spinal nerves?

The superior roots convey sensory impulses from the whole body, except certain parts of the face. The inferior roots convey motor impulses to all of the voluntary museles, also to the bladder, uterus, intestines, other hollow viscera, blood-vessels, and sweatglands.

What would be the effect of division of one of the inferior nerve roots of the spinal nerves?

Motor paralysis would follow in the parts supplied by the nerve.

What would be the effect if both nerve roots of the spinal nerves were cut?

Sensory and motor paralysis would follow in the parts supplied by these branehes.

What is reflex action? Describe an experiment illustrating reflex action.

Any involuntary action produced by a stimulus that is conveyed to the central nervous system and reflected to the periphery. If the foot of a frog, with its brain destroyed, is pinched, the leg will be drawn away from the irritant.

Discuss the reflex functions of the spinal cord.

In the spinal cord, there are a great number of reflex nerve centres which are capable of acting independently to a greater or less extent. Each centre has an afferent and an efferent root and is able to generate impulses which are earried to the periphery without any assistance from the brain. This is shown by experiments conducted on a frog with the brain destroyed as described in the preceding answer.

What is the difference in function between the superior and the inferior columns of the spinal cord?

Through the superior column, impressions, such as temperature, pressure and muscular sense, are conveyed to the cerebrum. The inferior column eonveys motor impulses to the body. The respiratory and vasomotor fibres also pass through the inferior columu. So it may be said that the superior column is an afferent ehannel and the inferior column an efferent channel.

What is the difference between a motor nerve and a sensory nerve?

A motor nerve carries motor impulses from a eentre to the periphery (efferent).

A sensory nerve carries impulses from the periphery to a centre (afferent). 
State the function of the phrenic nerve.

It is the motor nerve to the diaphragm.

Describe the effect of electric stimulation on a motor nerve.

Muscular contraction follows.

Name and describe the membranes of the brain. Give the function of each.

The outer membrane, the dura mater, is dense and fibrous and serves a very valuable protective function. The arachnoid is a serous membrane applied against the inner face of the dura. It contains the subarachnoid fluid which equalizes pressure on the brain and saves it from jar and concussion. The pia mater, the most internal, is a thin but very vascular structure. It passes into all the convolutions of the surface of the brain and supplies it with blood.

State the function of the cerebellum and describe the effect of its removal.

The cerebellum presides over the coördination of body movements and equilibrium. If removed, the power of coördination is lost, muscular weakness ensues and disturbances in equilibrium follow.

Locate the medulla oblongata. Mention four centres located in it.

The medulla is located at the upper end of the spinal cord, between it and the cerebrum, and rests on the basilar process.

Centres located in the medulla are: the respiratory, vasomotor, deglutition and vomiting.

Discuss the functions of the medulla oblongata.

Serves as a medium of transmission of motor and sensory impulses and contains centres for mastication and suckling, secretion of saliva, deglutition, vomiting, dilatation of the pupil, coughing, sneezing, closure of eyelids, contraction and relaxation of the bloodvessel walls, cardiac inhibition and respiration. There is also a centre which controls the glycogenic function of the liver.

State the function of the cerebrum.

The cerebrum is the seat of sensation, reasoning and will. It contains motor and sensory areas and the centres for sight, hearing and taste are located in it.

Define (a) cö̈rdination, (b) augmentation, (c) inhibition, (d) automatism.

(a) Harmony and rhythm in muscular movements.

(b) The increasing of the action of nerve centres by afferent impulses. 
(c) Arrest or restraint of a process effected by nervous influence.

(d) The powrer possessed by nerve centres to originate nervous impulses.

How does the nervous system influence secretion?

Through reflex action, as shown by the secretion of saliva produced by the presence of food in the month, or of the gastric juice by food in the stomach.

What are (a) voluntary movements, (b) reflex movements?

(a) Movements under control of the will.

(b) Involuntary movements produced by stimulation of a peripheral nerve.

How many pairs of cranial nerves are there? Give the name and the function of any one pair.

There are twelve pairs of cranial nerves. The first pair, olfactory, is concerned in the sense of smell.

Give the function of the optic nerve.

(The second pair of cranial nerves.) The nerve of sight.

Give the function of the third pair of cranial nerves. What muscles does it supply?

(The oculomotor.) The motor nerve to the eyeball. It supplies all the muscles of the eye, except the external rectus and superior oblique; it also supplies the muscle of the upper lid and sends fibres to the iris and ciliary muscle.

State the function of the fourth pair of cranial nerves.

(Patheticum.) The motor nerve of the superior oblique muscle of the eyeball.

\section{State the function of the fifth pair of cranial nerves.}

(Trifacial.) This is a mixed nerve, i.e., both motor and sensory. It supplies motor power to the muscles of mastication, sensation to the side of the face, lips, mouth, temple, part of the ear, cornea, conjunctiva, nasal mucous membrane and anterior two-thirds of the tongue. It also sends trophic fibres to the eyeball.

What is the function of the sixth pair of cranial nerves?

(Abducens.) Supplies motor power to the external rectus muscle of the eyeball.

\section{State the function of the seventh pair of cranial nerves.}

(Facial.) Motor nerve to the muscles of the middle ear, external ear, cheeks, lips, nostrils and orbicular muscles of the eye. Through its chorda tympani branch, it supplies the anterior portion of the tongue with taste and sends secretory fibres to the maxillary gland, and dilator fibres to the blood-vessels. 
State the function of the eighth pair of cranial nerves.

(Auditory.) Sense of hearing and maintenance of equilibrium through its connection with the semicircular canals.

What is the function of the glossopharyngeal nerve?

(Ninth pair of cranial nerves.) This is a mixed nerve; it supplies motor power to the muscles of the pharynx and sensory fibres to the posterior third of the tongue, the soft palate, part of the pharynx, and the anterior surface of the epiglottis. It is principally concerned in deglutition and the sense of taste on the posterior third of the tongue.

State the function of the pneumogastric, or vagus, nerve.

(Tenth pair of cranial nerves.) It supplies sensation to the external ear, pharynx, œsophagus, stomach and respiratory passages ; and motor power to the muscles of the pharynx, larynx, trachea, bronchi, œsophagus, stomach and intestines.

It is the inhibitory nerve of the heart and contains vasomotor fibres for the lungs and trophic fibres for the lungs and heart.

What is the function of the eleventh pair of cranial nerves?

(Spinal accessory.) Motor nerve to the sternomaxillaris, mastoidohumeralis, and the cervical and dorsal trapezius muscles. By giving notor fibres to the vagus, it has some control over the larynx and voice.

State the function of the great hypoglossal nerve.

(Twelfth cranial pair.) Motor nerve to the tongue.

What nerves, afferent and motor, supply the larynx?

Superior laryngeal branch of the vagus is the afferent or sensory nerve. It also supplies motor fibres to the cricothyroid muscle. The inferior laryngeal, or recurrent, branch of the vagus supplies all the muscles of the larynx, except the cricothyroid, with motor power.

What symptoms would ensue in case of a transverse section of the motor nerve supplying the arytenoid muscles on one side?

Inspiratory dyspnœa, accompanied by a roaring or whistling sound due to paralysis of the muscles moving the vocal cord. The cord would hang free in the larynx obstructing the air current. Paralysis of this kind produces the disease called "roaring."

What are the functions of the sympathetic nervous system?

The sympathetic nervous system supplies vasodilator and vasoconstrictor fibres to the blood-vessels, the viscera with motor and inhibitory fibres, accelerator fibres to the heart, dilator fibres to the 
pupil, secretory fibres to the sweat, salivary and sebaceous glands, motor fibres to the muscles of the hair, and influences the process of nutrition in general.

Mention the three classes of sympathetic nerve ganglia, giving the function of each.

1. Vertebral ganglia, afford connection with the cerebrospinal system.

2. Collateral ganglia, including the cardiac, solar and mesenteric plexuses which send branches to the various organs, supplying them with accelerator, vasomotor and secretory fibres, and carrying from them afferent impulses.

3. Terminal ganglia, fibres originating in the collateral ganglia and terminating in the tissues, control certain reflexes.

\section{SENSES}

Name the appendages of the eye and state the function of each.

Eyelashes: protective function; they give warnings of danger. Eyelids: two in number, protective covering.

Membrana nictitans: third eyelid, removes foreign bodies.

Meibomian glands: secrete an oily liquid to lubricate the edges of the lids and prevent the overflow of tears.

Conjunctiva : a mucous membrane which provides a smooth gliding surface between the lids and the cornea.

Caruncle: small, red elevation at the inner canthus, which directs the tears toward the puncta.

Lachrymal apparatus: secrete and carry away the tears which lubricate the cornea and inner side of the lids.

Ocular sheath: binds the structures of the orbit together.

What is the function of the iris? Describe the innervation of the iris.

The iris regulates the amount of light passing into the eye. Its circular fibres are supplied by the third pair of cranial nerves and its dilator fibres are innervated by the sympathetic.

What structures in the horse's eye serves the purpose of the human eyebrow? Describe clearly the position, attachments and movements of this structure.

The membrana nictitans. It is situated in the inner angle of the eye, and is continued posteriorly by a strong, adipose cushion which insinuates itself between all the muscles of the eyeball. When the recti muscles retract the eye in the orbit, this fatty eushion is forced outwardly and the membrana nictitans is forced forward over the eye. 
State the function of the corpora nigra (pigmentary bodies of the iris). Assist in absorbing rays of light.

Describe the process of focal accommodation.

The crystalline lens becomes more convex for near objects because the rays are more divergent. This convexity is brought about by the bulging of the lens when the tension on the capsule is lessened by the action of the ciliary muscle which contracts and draws forward the choroid coat and with it the ciliary processes. A reversal of this process will produce a lesser convexity of the lens and thus properly focus distant objects.

What are the functions of the lachrymal secretion?

It lubricates the conjunctiva, keeps the cornea brilliantly polished and washes away foreign bodies.

Describe fully the function of the auditory nerve.

Special sense of hearing and through its connection with the semicircular canals assists in maintaining the equilibrium of the body.

\section{How do the auditory sensations reach the brain?}

The tympanum receives the sound wave and transmits it through the chain of bones (malleus, incus and stapes) to the fenestra ovalis which imparts an impulse to the perilymph of the labyrinth; the perilymph carries the impulse through the vestibule and from here it is carried into the scala vestibuli of the cochlea. The vibrations pass through the spiral-shaped cochlea and set in motion the membrane of Reissner; this causes the lymph in the cochlear canal to vibrate and reach the scala tympani. The lymph in this canal is now set in motion and affects the basilar membrane on which the organ of Corti rests. The auditory nerve ends in the organ of Corti, so the impressions are carried from this organ to the brain.

What is the function of the Eustachian tube?

It allows an equalization of pressure on both sides of the membrani tympani.

Name the four primary taste sensations.

Sweet, bitter, acid and salt.

\section{What nerves are concerned in the sensation of taste?}

The gustatory branch of the fifth pair of cranial nerves, which receives fibres from the chorda tympani of the seventh pair, supplies the taste buds on the anterior two-thirds of the tongue. The posterior one-third is supplied by the glossopharyngeal. 
What three sorts of impressions are obtained through the cutaneous nerves?

Temperature, pain and pressure.

\section{The Foot}

What are the provisions for preventing concussion in the foot?

1. The yielding artieulation of the pedal joint.

2. Expansion of the heels when in contact with the ground.

3. The foot-pad, or frog.

4. The slight deseent of the pedal bone and sole, when weight is placed on the foot.

\section{What are the uses of the lateral cartilages?}

1. They form an elastic wall to the sensitive foot, and afford attaehment to the vaseular laminæ.

2. They carry the sensitive laminx outward when the hoof expands and so prevent any disturbance of the union of the insensitive and sensitive laminæ.

3. They provide passage for the blood-vessels and their movements assist the venous eirculation.

4. They admit of expansion under the influenee of the body weight.

How does secretion occur from horny structures and what provisions are made for a freer secretion at given points? Name such points.

From the lower edge of the eoronary substanee, white, protoplasmic cells are poured out between the papillæ; these cells are carried down and pressed between the sensitive leaves. As the horny leaves pass through the sensitive leaves, the vaseular layer of the latter furnishes them with horny lamellæ.

The wall is thicker and longer at the toe and quarters than at the heels because it is at these regions that the greatest wear and tear oceurs. The thinness at the heel eorresponds to the yielding power it possesses, and whieh is an essential part of the anticoncussion mechanism.

Mention the keratogenous tissues of the foot, giving the function of each.

1. The coronary eushion seeretes the wall.

2. The velvety tissue seeretes the sole and foot-pad (frog).

3. The laminal tissue seeretes the horny lamellie. 
State the functions of the sensitive laminæ or podophyllous tissue.

It is the seat of tactile sense, secretes horny lamella and the horny lamine to cover the pedal bone, thus providing support for the body weight.

Define physiologic shoeing.

Shoeing of the normal, or healthy foot, as contrasted with the special shoeing necessary when pathological conditions exist. It comprises the proper paring of the foot and careful adjustment of the shoe so that the bearing surface is the same as in the unshod foot, or in other words, as nature intended.

\section{Generation and Development}

State the function of the testicle.

The production of semen, especially the generative element of the same, viz., spermatozoa.

Describe fully the development and maturation of a Graafian follicle.

The germinal epithelium covering the ovary grows into the body of the latter as a long cylinder of cells. These cells become cut off from any connection with the outside, and one cell (occasionally two) takes on the appearance of an ovum and the remaining cells become the membrana granulosa, enclosing it. A connective-tissue capsule, the tunica fibrosa, forms around this structure, and between it and the membrana granulosa a fluid, the liquor folliculi, appears. This whole structure continues to grow and approach the surface where it remains until ovulation occurs.

\section{Describe the placenta and state its function.}

The placenta is a membranous structure within the uterus which establishes communication between the mother and fœtus by means of the umbilical cord. In the mare, it is diffuse, i.e., the villi which intimately unite the chorion and uterus are scattered over the whole surface of the chorion. In the cow, the placenta is cotyledonary, i.e., the villi are gathered into tufts upon the surface of the chorion, and these tufts correspond to elevations of the mucous membrane of the uterus. In the dog and cat, the villi are arranged in a bandlike manner over the chorion with a considerable space on either side free from villi. This form of placenta is called "zonary."

\section{Describe the decidua vera of the cat and state its function.}

Zonary type (see preceding answer). It establishes communication between the mother and fotus through the umbilical cord.

Give the source and character of uterine milk.

This fluid is secreted by the uterine glands and lies between the villi of the chorion and the uterine mucous membrane. It is of a 
white, or rosy-white, creamy consistency and contains proteids, fat and a small proportion of ash. It takes part in providing nourishment for the fotus.

Describe the mammary glands of the mare.

The mammary glands of the mare are two hemispherical-shaped bodies, lying together on the median line in the posterior and inferior abdominal region, in the position of the scrotum in the male. They terminate below in a small prominence, the nipple, or teat, which is traversed by several sinuses that communicate above with the milk reservoir and open on their free extremity by two, three or four canals. The gland is covered externally by a fibrous coat which sends prolongations into its interior and over this coat is the skin. The body of the gland proper is made up of a highly developed type of sebaceous glands.

Give the average percentage composition of (a) cow's milk, (b) mare's milk.

\begin{tabular}{|c|c|c|}
\hline Water & $\begin{array}{l}\text { Cow } \\
87.00\end{array}$ & $\begin{array}{l}\text { Mare } \\
91.8\end{array}$ \\
\hline Solids & 13.00 & 8.2 \\
\hline Proteids & 3.30 & 2.6 \\
\hline Fat & 4.00 & .6 \\
\hline Lactose & 4.95 & 4.7 \\
\hline Salts & .75 & .3 \\
\hline
\end{tabular}




\section{PATHOLOGY*}

Define pathology.

Pathology is that branch of medical science which treats of the essential nature of disease, especially of the structural and functional changes caused by disease.

Special pathology deals with the pathologic processes in certain diseases, organs, or parts.

How do infection, poison and nervous disorder, respectively, cause a rise of temperature?

Infection by bacteria produces toxins which, being carried through the blood to the brain, stimulate the heat centres. Poisons are taken up by the blood and act the same way. Nervous disorders, by disturbing the process of metabolism, cause toxic products, such as albumoses, peptones, or ferments to be found. These products are carried in the blood to the heat centres.

Define the following terms: infection, disinfection, atrophy, œdema, immunity, anæmia, hyperæmia, cystitis, orchitis.

Infection refers to the entrance into the system of a diseaseproducing microörganism capable of self-multiplication.

Disinfection is the process of freeing from, or neutralizing, pathogenic germs or agents.

Atrophy is a wasting or diminution in the size of a part.

CEdema is a swollen condition of tissue caused by an excessive accumulation of the tissue fluid, lymph.

Immunity is a condition of an animal or person in which there is an insensitiveness or insusceptibility to a certain disease.

Anæmia is a reduction in the quantity or quality of the blood, affecting the cellular elements or hæmoglobin or both.

Hyperæmia is a condition in which there is an excess of blood in a part of the body.

Cystitis is the term applied to an inflammatory condition of the urinary bladder.

Orchitis: inflammation of the testicles.

Define primary and secondary lesion and illustrate by example.

A primary lesion is a pathological condition produced at the point of attack by the causative agent (bacteria, trauma, etc.). If from this point pathogenic material is carried to other parts of

* Unless otherwise stated all questions relate to the horse. 
the body and ehanges are produced there, the later formed lesions are secondary. For example, from an abscess on the leg (primary lesion) infection may be carried to the lungs, liver, etc., and produce abscesses in these parts (secondary lesions).

State what value you would give to each of the following agents in the development of an infectious disease: microbes, chill, electric tension, imperfect ventilation, impure water, decayed or indigestible foods, emanations from sewers, cesspools or heaps of manure, impaired health or vigor from previous illness, fatigue, overwork, damp soils, exposure to hot summer sun.

The first named agent, microbes, and it only, can produce the disease alone. The other agents can only act as accessory factors in lessening the resisting powers but none of them alone, or together, can produce an infectious disease without the causative factor, the microbe.

What lesions and conditions would indicate that an animal had been killed by lightning?

Blood is dark and uncoagulated, the muscles dark brownish-red, the endocardium stained by the altered blood and the heart muscle shows hemorrhagic infarets in death by lightning. The tissues may be lacerated, showing hemorrhages. Branching, tree-like lines of singeing along the course of the current. Rapid decomposition with slight rigor mortis.

Conditions aiding diagnosis are: fact of lightning storm; animal being found under a tree which shows the effects of the current.

\section{What is meant by auto-intoxication?}

Auto-intoxication is a poisoning of the organism by substances which arise in the body itself through its own activity, that is, it is a self-poisoning. The poisoning is the result of the absorption of the waste products of metabolism or of the products of decomposition within the intestines.

Define metastasis. Give examples.

Metastasis is the transportation through the blood- or lymphstream of a disease-producing agent and the production of disease at the point of deposit of such agent, e.g., living cells of tumors may be carried to distant parts and produce daughter tumors at the site of lodgement. Vegetable or animal parasites are carried in the blood-stream from one part to another, producing disease at their point of lodgement. The movement of emboli in the blood-vessels is an example of metastasis. 
What is anaphylaxis?

Increased susceptibility to an infection or to the action of any foreign protein introduced into the body following a primary infection. The opposite of immunity.

\section{IIYPERTROPHY AND ATROPHY}

Describe (a) atrophy, (b) hypertrophy. Give the causes of each of these conditions.

(a) Atrophy is a diminution in the size of an organ due to a diminution in size or disappearance of its individual elements. Causes: senility, impaired nutrition, pressure, disuse, and neuropathic.

(b) Hypertrophy is an increase in the size of an organ, due either to an increase in the size or in the number of the individual elements. Causes: compensatory (overwork), lessened use (as in hoof or horn), congenital, neuropathic, lessened pressure, inflammatory.

\section{Degenerations}

\section{Differentiate fatty degeneration from fatty infiltration.}

Fatty degeneration is characterized by the degeneration of tissue cells and the presence therein of fat droplets, whereas in fatty infiltration no change occurs in the substance of the cell except it be from pressure of the fat globules without or inside of the cells.

\section{What is necrosis? Name and define three kinds.}

Necrosis is the death of individual cells or groups of cells, as a result of which their function is forever lost. Coagulation-necrosis is characterized by the occurrence of coagulation of the fluids about the cells or of the cells themselves, due to the infiltration of bloodor fibrin-containing lymph. Liquefaction-necrosis is due to the necrotic parts becoming dissolved in the fluids present in the tissues. Gangrene is a form of necrosis in which the tissue is putrefied, showing an appearanee similar to that occurring in burned tissues. There are two forms, dry and moist, depending upon the presence or absence of moisture.

\section{What is caseation-necrosis? Where does it occur?}

Caseation-necrosis is a form of necrosis closely resembling coagulation-necrosis. It is characterized by either a hard or soft cheesy appearance in the necrotic area. It occurs most frequently in tubercular nodules. It is also seen in very cellular tumors and inflammatory exudates. 
Define œdema and give its causes.

Edema is an infiltration of the tissues and serous cavities with a serous fluid, lymph. Causes: obstructions to the eirculation of the blood or lymph, anxmia, changes in blood-vessel walls, disturbances of metabolism.

Define (a) anasarca, and (b) calcification.

(a) Anasarca is a serous infiltration (œdema) of the superficial portions of the body.

(b) Calcification is a hardening of the tissues due to the deposits therein of granular masses of lime salts, particularly phosphates.

\section{Define inflammation.}

\section{INFLAMMATION}

Inflammation is the phenomena of tissue-reaction to injury.

Describe the process of inflammation. Give the four cardinal symptoms of inflammation.

Following injury to the tissue, there is an increased flow of blood to the part; then occurs changes in the vascular walls, exudation of serum, diapedesis of leucocytes, and proliferation of the comnectivetissue cells. This may be followed by subsidence of the hyperimia, regeneration, suppuration, necrosis or some other form of degeneration.

Cardinal symptoms of inflammation are: redness, heat, pain and swelling.

State the pathologic blood and tissue changes in inflammation.

See answer to preceding question.

What is productive inflammation?

Productive inflammation is a hyperplastic formation of connective tissue occurring in chronic inflammation. It is seen on serous surfaces and in certain organs as bone, liver, kidney, lung, etc.

Define (a) abscess, (b) ulcer, (c) fistula.

(a) A circumscribed collection of pus in the substance of a part or organ, usually formed by the disintegration of tissue.

(b) An open suppurating wound accompanied by tissue destruction.

(c) A suppurating duct-like eavity extending into the tissues.

Name four inflammatory exudates.

Serum, fibrin, pus and blood. 


\section{Tumors}

Classify tumors and give an example of each class.

Connective-tissue tumors, as fibroma and sarcoma.

Specialized tissue tumors, as epithelioma and adenoma.

Mixed tissue tumors, as dermoid cysts.

\section{Describe the pathologic difference between a malignant tumor and a non-mailignant tumor.}

Malignant Tumors.

Non-cireumscribed.

Infiltrate neighboring tissues.

Rapid growth.

Spread by metastasis.

Undergo degenerative changes.

Cachexia present.
Non-Malignant Tumors.

Circumscribed.

Do not infiltrate neighboring tissues.

Develop slowly.

Non-metastatic.

Seldom degenerate.

Cachexia absent.

What is cancer? Name the varieties.

Cancer or carcinoma is a malignant tumor made up chieflyof epithelial cells. It is characterized by an infiltrative growth and the formation of metastases. Three varieties: squamous epitheliomata, cylindrical epitheliomata, and glandular-cell cancers.

\section{What is melanosis? Give the cause of melanosis.}

Melanosis is an abnormal deposit of black matter in various parts of the body. The color is due to the pigment melanin. This condition, which is seen almost exclusively in old gray horses, is usually associated with tumor formation. It is thought to be due to the breaking down of red blood-corpuscles in the spleen and liver, thus liberating melanin from the hæmoglobin.

In what animals are melanosarcomata most commonly found? Describe the gross appearance of melanosarcomata.

Horses, especially gray-colored ones. The tumors usually develop in the region of the root of the tail and the anus, although no tissue seems to be exempt. They appear as small nodules of a soft or hard consistency and vary in size from that of a walnut to a man's fist or larger. The cut surface is uniformly black or dark-brown and soils the hands similar to shoe-blacking.

Name the different types of sarcoma. What tissue does sarcoma resemble?

1. Round-celled sarcoma, a. Small round-celled. 
b. Large round-celled.

c. Lymphosarcoma.

d. Alveolar sarcoma.

2. Spindle-celled sareoma,
a. Small.
b. Large.

3. Giant-celled sareoma.

4. Melanosarcoma.

Sarcomata resemble embryonal connective tissue.

Define (a) neuroma, (b) angioma, (c) myoma.

(a) A tumor composed largely of nerve substance.

(b) A tumor made up of blood-vessels.

(c) A tumor made up of muscular elements.

Classify cysts and give an example of each class.

1. Retention cyst, as seen in the kidney, sebaceous glands, mucous glands, etc., due to obstruction of the excretory duct.

2. Degeneration cyst, due to liquefaction of the tissues as in the brain, thyroids and tumors.

3. Parasitic cysts, as the ecchinococcic variety.

4. Foreign-body cyst, seen when a bullet or other foreign body is encapsulated by connective tissue.

\section{Define cysts and name the varieties.}

A cyst is a circumscribed cavity, shut off from the surrounding tissues, by a connective-tissue membrane or by tissue of a more complex structure, the contents of which differ in nature from the capsule. (See answer to preceding question.)

\section{BLOOD}

Define leucocythæmia, polycythæmia, phagocytosis.

Leucocythæmia, or leukæmia, is a fatal disease, characterized by a marked inerease in the number of leweocytes in the blood, together with enlargement and proliferation of the lymphoid tissue of the spleen, lymphatic glands and bone-marrow.

Polycythrmia is an increase in the number of red blood-corpuscles in the blood.

Phagocytosis is the term applied to the destruction of bacteria in the body by the phagocytes. (Phagocytes are certain cells, chiefly leneocytes, which possess the power of taking up and destroying bacteria by intracellular digestion.) 
What is leucocytosis? Enumerate the diseases with their stages in which leucocytosis may be expected.

Leucocytosis is a temporary increase in the number of leucocytes in the blood. It oceurs in:

Pneumonia, variola (suppurative stage), pyæmia, septicæmia, actinomycosis, trichinosis, glanders, articular rheumatism (acute), cerebrospinal meningitis (suppurative stage), endometritis, pericarditis, peritonitis, pleurisy, erysipelas, dermatitis, gangrenous conditions, abscesses of all kinds and situations, ete.

State the relation of leucocytosis to phagocytosis. How may phagocytosis be stimulated?

Phagocytosis is accomplished principally by leucocytes, therefore leucocytosis greatly augments phagocytic activity.

Phagocytosis may be stimulated by injecting products of bacterial growth into an animal.

Define leukæmia and ischæmia.

Leukæmia, same as leucocythæmia. See above.

Ischæmia is a local anæmia.

State the difference between an ante-mortem and a post-mortem bloodclot such as is found in the blood.

An ante-mortem clot is a yellowish translucent mass resembling chicken fat, clotting occurred slowly. A post-mortem clot is a dark-red, homogeneous, gelatinous mass; the blood coagulated quickly before the red blood-corpuscles had time to settle.

\section{BONES AND JOINTS}

Describe the reparative process of a fractured long bone.

At first hemorrhage occurs in the marrow and at the line of fracture, then occurs hyperæmia and cellular infiltration of the periosteum, marrow and bone; cell division and proliferation of the marrow, periosteum and vascular endothelium; deposition of calcium salts and formation of bone and cartilage. The name callus is applied to the new-formed tissue, and is distinguished as periosteal and myelogenous.

Give the pathology of osteoporosis.

The bones, especially those of the lower jaw, are thickened. The bones of the extremities and articulations are often enlarged. In some cases the articular cartilages become ulcerated. The bony cortex is thin, spongy, brittle and easily fractured. There is an increase in the vascular and fibrous tissues without any increase 
in bone substance. If cachexia is present, the bone-marrow is pale, gelatinous, and even watery. Anæmia, cachexia and æedematous infiltration of the body is present. Atrophy and fatty degeneration of the muscles attached to the affected bones. Recent or old fractures, showing callous formation, may be present.

What are the lesions of arthritis chronica deformans tarsi (spavin)?

The lesions, confined usually to the articular cartilage of the cuneiform and of the upper part of the metatarsus, though sometimes the scaphoid and other bones of the hock are involved, consist of ulceration, abrasions, and at the borders of the articular surfaces, rugged, uneven swellings produced by the thickening of the articular cartilage which is ossified. Under the microscope, the intercellular substance is seen to be fibrillated and the cartilage cells to be undergoing multiplication. The synovial membrane is thickened and vascular. Partial or complete ankylosis of the articular surfaces and ossification of the ligaments are seen.

\section{What is caries?}

The molecular decay or death of bone (teeth) in which it becomes softened, discolored and porous. It corresponds to ulceration in soft tissues.

\section{Give the causes of dental caries.}

By the fermentation of starchy foods in the mouth, brought about through the action of bacteria, acids are produced which soften the enamel and permit the entrance of other bacteria into the dentin, producing caries.

Define (a) periostitis, (b) periarthritis, (c) arthritis.

(a) Inflammation of the covering of bone (periosteum).

(b) Inflammation of the struetures surrounding a joint.

(c) Inflammation of a joint, characterized by great pain, heat, redness and swelling.

\section{HeArt ANd BLOOd-vessels}

Name lesions that may be found in chronic heart disease.

Thickening of the endocardium, borders of valves, and of the chordæ tendinæ. Insufficiency of the valves. Heart wall thickened, solid, and contains grayish-white spots or streaks (scars). Fatty degeneration of muscle fibres.

Give the causes and lesions of cardiac hypertrophy.

Causes: severe work, disturbance in circulation requiring more force in the heart action, as chronic interstitial nephritis, lung dis- 
eases, valvular diseases, etc., tumors or adherent pericardium creating pressure from without, disease of the heart muscle itsclf.

Lesions: increased volume and weight of the heart; walls thickened, hard and firm.

What pathological changes may follow mitral stenosis?

Hypertrophy of the left auricle, pulmonary congestion, hypertrophy of the right ventricle and right auricle; pulmonary oedema, bronchial catarrh and hepatic congestion.

Describe the lesions of pericarditis.

Acute form: fibrinous membranes on the pericardium; fluid exudate, clear (or cloudy from pus), in varying amounts distends the pericardial sac. Passive hyperæmia of the lungs and liver and œdematous infiltrations may occur.

Chronic form: connective-tissue proliferation, thickening and adhesions of the pericardial sac.

What is the difference between active and passive congestion?

Active congestion arises from an increase in the arterial supply on account of the dilatation of the lumen of the blood-vessels to the part. Passive congestion arises through a retardation or obstruction of the flow of blood from the veins and a passive yielding of the vessel-walls to intravascular pressure.

\section{Define (a) embolism, (b) aneurism, (c) lymphangioma, (d) myocar- ditis.}

(a) The plugging of a blood-vessel by a clot or obstruction which has been brought to its place by the blood-current.

(b) A sac formed by the dilatation of the walls of an artery and filled with blood. It may be a true aneurism which contains one or more of the coats of the artery, or a false aneurism in which all of the coats are absent, the blood being retained by the surrounding tissues.

(c) A tumor composed of dilated lymphatic vessels.

(d) Inflammation of the heart muscle.

Discuss verminous aneurisms of the cœliac or mesenteric arteries of the horse.

They are due to the larvæ of the sclerostoma equinum which enter the blood-stream from the intestines, are carried to the coliac artery and enter the vasa vasorum of the same and cause infarction in the media of the vessel, and then meso-arteritis, or peri- and endarteritis. This leads to formation of a thrombus and narrowing of the lumen of the vessel, providing dilatation is not commensurate with the diminution in calibre. The inflamed vessel-wall, losing its 
tone, yields more readily to the internal tension and as a result an enormous distention and thickening of the wall occurs.

\section{Respiratory ORgans}

What pathologic changes occur in the air-cells during pulmonary hepatization?

Hyperæmia, smaller or larger hemorrhagic foci, extravasation of blood-serum with white and red blood-corpuscles into the alveoli.

Describe the post-mortem appearance of each stage of pneumonia.

First stage (congestive): Capillaries distended and the alveoli filled with serous fluid containing endothelial and red blood-cells.

Second stage (red hepatization): Fibrinous exudate and red blood-cells in the air saes, coagulation of same; lung is consolidated, dark-red and friable, does not collapse when thorax is opened and shows the imprint of the ribs; sinks in water; the cut surface appears granular from the projection of fibrin plugs.

'Third stage (gray hepatization): The red cells are gradually destroyed and absorbed, and leucocytes predominate, giving the cut surface a gray appearance.

Fourth stage (resolution): The exudate has undergone fatty degeneration and liquefaction; the cut surface is smooth and exudes a whitish fluid; the lung is approaching normal color and condition.

Give the post-mortem appearance of gangrene of the lungs.

In the anterior and inferior portions of the lungs, gangrenous foei are found, which appear dirty-brown, red or yellowish-brown, and consist of a soft mass of a very disagreeable, sweetish, foul odor. The bronchi contain liquefied or soft masses of a similar color and smell. The mucosa of the bronchi is slate-gray in color. The internal surface of the eavities formed is ragged and eovered with a friable, stinking, mushy mass. If the eavity is near the pleura or breaks through the same, purulent pleurisy may be present. Between the foci the pulmonary tissue shows a catarrhal or fibrinous pneumonia.

Describe the post-mortem lesions of pulmonary emphysema (heaves).

The lungs are enlarged, soft, less elastic and paler in color. Their surface often shows the imprint of the ribs. Air vesieles ean be seen with the naked eye. Between the vesieles are large air spaces due to rupture of the walls. These air spaces often produee bulging of the serous coat in various places when beneath the pleura. 
Give the post-mortem appearance of acute diffused pleuritis.

Hyperæmia, surface of the pleura is rough, lustreless and dry. The exudate composed of blood-corpuscles and fibrin covers the surface of the pleura like a veil. In some cases a serofibrinous exudate covers the surface with a thicker, friable, moist, loose membrane. Purulent and hemorrhagic exudates may be present. The pleuritic cavity may contain a considerable amount of a serous fluid which compresses the lungs.

Describe the post-mortem appearance of the lungs in pleuropneumonia.

(It is taken for granted that the interrogator is referring to contagious pleuropneumonia.) This disease is characterized by interstitial pneumonia with secondary hepatization of the lungs and an exudative pleuritis. The cut surface shows a pale yellow network formed by an increase in the interlobular connective tissue; a clear serous fluid oozes from the cut surface. Between the network of connective tissue the lung tissue is hepatized. The bronchial walls show serous infiltration and their lumen contains a fibrinous exudate. The pleura is lustreless, injected and covered with a veil-like exudate of fibrin; a large amount of exudate in the pleural eavity.

Give the symptoms and post-mortem lesions of hydrothorax.

For symptoms, see diseases of the respiratory organs, page 191.

Lesions: A large amount of a clear, light yellow, or slightly turbid fluid in the thoracic cavity. The lungs show compression to an extent dependent upon the amount of the fluid present. The pleura may be normal or thickened and cloudy. More or less congestion present.

What is atelectasis?

An airless condition of the lungs seen in the fœtus; also seen in later life due to pressure of a pleural effusion or blocking of the smaller bronchial tubes with mucus.

Describe the structural changes in the nervous and muscular tissue in a case of roaring.

The recurrent nerve is reduced in size and gray in color, indicating degeneration. The posterior crico-arytenoid, the lateral cricoarytenoid and the transverse arytenoid muscles show pale yellow streaks and degeneration of their fibres.

Describe the appearance of the lungs in bronchopneumonia.

This is a lobular affection, with scattered areas of consolidation. These areas are not as firm as in croupous pneumonia. The cut surface is grayish-red or grayish-yellow and not granular, but 
smooth and moist; on pressure a frothy serum exudes from the healthy portion and a grayish-yellow fluid from the diseased areas. The lobules stand out prominently and may contain pus foci.

\section{Abdominat Organs}

Describe the post-mortem appearance of the intestines in catarrhal enteritis.

Acute form: The intestinal mucosa is reddened, swollen and covered with slimy mucus mixed with dead epithelial cells. Small hemorrhages may be present. The submucosa is infiltrated with serum. The villi are swollen and crowded together giving a velvety appearance. Peyer's patches are swollen and may discharge pus and even become nlcerated.

Chronic form: The mueosa is darkly pigmented (sometimes pale), thickened and covered with an excess of mucus; the thickening may extend into the submucosa, giving a firm leathery feeling to the part. The villi are hypertrophied and Peyer's patehes congested and ulcerated.

\section{Describe enteroliths.}

These are hard, dense, stony coneretions found in the intestines and range in weight from one ounce to 25 pounds. They resemble billiard balls, or sometimes are pyramidal in shape from being worn off on the sides. Their principal constitnent is ammoniomagnesium phosphate which is largely derived from wheat and rye bran feeds. Enteroliths are important beeause of obstruetions and erosions which they produce in the intestines.

\section{Give the pathology of peritonitis.}

The peritoneum is congested, dull and opaque; fibrinous membranes cover the surface. Serous fluid may be present in large amounts (40 litres) in the peritoneal cavity; later this fluid may be mixed with fibrin floceuli and pus. Acute peritonitis may become chronic with the development of connective tissue under the fibrinous membrane. In this ease the peritoneum becomes thickened and the surface of the organs is covered with thick layers of connective tissue.

\section{Describe the appearance of a cirrhotic liver.}

In atrophic cirrhosis there is an inerease in connective tissue with compression of the parenchyma. The tissue is of a tough, leather-like consisteney and grates when eut. The organ is reduced in size, the surface irregular and granular or nodular; the serous covering is thickened. 
In hypertrophic cirrhosis, the liver is enlarged, the cut surface as well as the outer surface appears smooth or slightly granular and greenish-yellow in color; the consistency is hard, due to the increase in the interlobular connective tissue; there is no tendency toward contraction.

\section{Give the pathology of icterus.}

There is a yellow discoloration of the skin and mucous membranes, particularly noticeable in the conjunctiva; the urine is brownish or greenish in color and all of the organs of the body, except nerve tissne, may be stained yellow. The bile capillaries of the liver are distended with bile, and pigmentation of the livercells is noted. Constipation is present and the stools are dry, hard, pale and fetid.

In what diseases does enlargement of the spleen occur?

Anthrax, Texas fever, piroplasmosis of dogs, and leukæmia.

Differentiate an ante-mortem from a post-mortem tympanites in bovines at autopsy.

In ante-mortem tympanites, the lungs are compressed, dark-red and full of blood. The veins of the subcutaneous connective tissue are filled to their utmost with dark-red, possibly uncoagulated blood. Signs of death from suffocation, such as striate and punctate hemorrhages into the serous membranes, especially in the pleura and pericardium, are seen. In post-mortem tympanites, none of these conditions are found. The blood is evenly distributed, except perhaps a hypostatic congestion in the side on which the cadaver lies.

\section{Genito-URinary Organs}

Define (a) hæmaturia, (b) hæmoglobinuria.

(a) Blood in the urine.

(b) Hæmoglobin in the urine without blood-corpuscles.

Name the different varieties of urinary casts and state the conditions in which each is found.

Casts are albuminous exudates from the blood, with the addition of transformed or destroyed epithelium. There are six varieties of true casts: 1 , hyaline; 2, epithelial; 3, blood; 4, granular; 5 , fatty; 6 , waxy.

The first three are found in acute parenchymatous nephritis. Granular casts are found in chronic parenchymatous nephritis. Fatty and waxy casts are secondary products and only found in nephritis of long standing (chronic interstitial). 
Describe the gross pathology of (a) acute parenchymatous nephritis, (b) chronic interstitial nephritis.

(a) Kidneys are soft, friable and the capsule strips easily. The cut surface is streaked with hyperamic vessels, especially in the medulla; in the cortex the Malpighian corpuscles stand out prominently.

(b) The kidney is small and its surface irregular; the capsule is thickened and strips with difficulty, owing to the productive growth and extension of same into the substance of the gland. On section the substance is firm and pale in color.

\section{Give the pathology of a cystic ovary.}

In a large majority of cases, cystic ovaries follow peri-oöphoritis, which thickens the capsule and prevents the ovisac from rupturing. The peri-oöphoritis may be caused by extension of infection or inflammation in cases of endometritis, granular venereal disease, etc. A small number of cases may be attributed to a persistent corpus luteum. The enlarged ovary is uniformly rounded and smooth or it may be marked by irregular bulgings, giving it a lobulated appearance. The organ is very vascular and covered by the thickened peritoneum. One or more closely adherent cysts of various sizes, containing a clear, yellow or brownish-red liquid, may be seen.

\section{What is your idea of the pathology of azoturia?}

This disease is due to an auto-intoxication. The lesions are characterized by the following conditions: The lumbar, psoas and gluteus muscles appear swollen and gray or grayish-yellow in color like fish-meat or boiled meat. Occasionally, these muscles are ruptured and contain hemorrhages. They are friable and tear easily. The kidneys show cloudy swelling and even severe parenchymatous degeneration. The heart muscle shows the same changes as the muscles but in a lesser degree. The bladder contains brownish-red or coffee-colored urine. In cases of long standing, lesions of septicæmia, due to decubital gangrene, are seen.

Name five diseases that may affect the udder of the cow.

Mastitis, tuberculosis, actinomycosis, carcinoma, cezema.

Define (a) oophoritis, (b) orchitis, (c) metritis.

(a) Infiammation of the ovary.

(b) Inflammation of the testicle.

(c) Inflammation of the uterus. 
Nervous System

Define (a) phrenitis, (b) meningitis, (c) pachymeningitis, (d) leptomeningitis, (e) apoplexy.

(a) Infiammation of the brain.

(b) Inflammation of the meninges, the covering of the brain and cord.

(c) Inflammation of the dura mater, the outer covering of the brain and cord.

(d) Inflammation of the pia and arachnoid membranes.

(e) Paralysis resulting from rupture of a cerebral blood-vessel.

Give the pathologic changes in the brain of a horse suffering with chronic hydrocephalus (dummy).

There is a dilatation of the lateral ventricles and anterior part of the third ventricle by an excessive amount of fluid. The base of the cerebrum and the olfactory lobes have their internal cavity distended so that they appear like bladders of fluid. The cerebral hemispheres are flattened and their convolutions nearly effaced. There is degeneration and softening of the compressed nervous tissue and anæmia of the brain.

What are the post-mortem appearances of anæmia of the brain?

Meninges are pale and their vessels collapsed. The cortex is pale and the line of demarcation between it and the white matter is indistinct. On section, minute points of blood are seen.

What faulty conditions in the food tend to produce paralysis?

Moulds, rusts, smuts and fermentation.

\section{MIUSCLES}

What parasite affects the muscles of hogs? Name the disease and state the lesions produced.

Trichina spiralis produces trichinosis. The parasites invade the muscles and become encysted therein in the shape of an oval which is grayish-white in appearance. Within this oval body, which is only one-twenty-fifth of an inch in length, the parasite is coiled up in a spiral shape. The muscle fibres lose their diagonal striation; the sarcolemma is dilated, covering the cyst; the connective tissue is infiltrated and the capillaries are distended. The cut surface of the muscle is cloudy, a pale-gray color and transparent.

\section{Eye}

Describe the pathologic changes occurring in an attack of periodic ophthalmia.

The conjunctiva is injected. The injected blood-vessels of the 
cornea have an aborescent appearance. Back of the cornea and in the lower part of the anterior part of the eye is a fibrinopurulent exudate. The iris is swollen and adherent to the lens or cornea, constituting synechia. There is swelling and tenderness of the outer rim of the cornea (cyclitis). Infiltration of the lens with lymph renders it opaque. Exudates beneath the retina detach it from the choroid. The whole condition is often spoken of as "iridocyclochoroiditis."

SKIN

Give the pathology of acne.

Acne is an inflammation of the sebaceous glands and hair follicles. It appears as small nodules varying in size from a millet seed to a pea. These nodules may contain serum or pus and the hair covering them falls out. Scabs may cover the nodules which upon being removed leave a raw ulcerating spot beneath. Chronic indurative dermatitis often follows or accompanies this condition.

\section{What is dandruff?}

Dandruff is an exudation product, seen as small bran-like scales, occurring in superficial inflammation of the skin with an excessive sebaceous secretion.

Name the stages of eczema.

Erythematous, papular, vesicular, moist, pustular and scaly.

\section{Name the pathologic conditions that may affect the equine foot.}

Pododermatitis, including corns and canker, navicular bursitis, fracture of the navicular bone, ossification of the lateral cartilage (side-bone), necrosis of the lateral cartilage (quittor), laminitis, inflammation of the ligaments of the coronet joint, ringbone, ete.

\section{Give the pathology of acute and chronic laminitis.}

Acute: Hyperæmia of the sensitive laminæ; exudation, loosening the hoof from the matrix; the exudate may consist of serum, or serum and pus. The sole may be "dropped" owing to descent of the os pedis. Separation of the hoof from the coronary band may occur and allow the exudate to escape.

Chronic: The hoof wall shows a number of concentric rings, producing irregularities of same; the sole is "dropped" and the os pedis displaced downward ; the coronet joint shows abnormal dorsal flexion. The white line is greatly thickened and a thin purulent exudate covers its surface. The laminx are not as hyperemic as in the acute form. 


\section{INFECTIOUS DISEASES}

What tissue changes may be found in chronic glanders and farcy?

Lesions are most frequently found on the respiratory mucous membrane, in the lungs, lymph-glands, spleen and skin, and occur in two forms, (1) as circumscribed nodules with the formation of ulcers and cicatrices; and (2) as diffuse or infiltrated lesions.

The nodules resemble somewhat the neoplasms of tuberculosis; they show cell proliferation in nests in a fibrous stroma, varying in size from a grain of sand upward; have a central degeneration containing fatty debris; open on the surface forming ulcers, showing a grayish necrotic centre and surrounded by a ragged border; cicatrices may form. In the lungs the nodules give rise to a lobular pneumonia, interlobular and peribronchial inflammation; the central mass becomes yellowish and caseated from glandular and fatty degeneration; the periphery may be bounded by a dense fibroid envelope or show only an area of congestion. In the skin there is an infiltration and proliferation of lymphoid cells which cause an eruption of rounded papules that degenerate and soften and form superficial ulcers (farcy). Sometimes the nodules undergo fibroid degeneration and fail to ulcerate; diffuse engorgements and extensive swellings occur in the subcutaneous connective tissue, due to infiltration of lymph; hyperplasia of lymph-vessels.

The regional lymphatic glands are always involved, showing hypertrophy, congestion, serous infiltration and cell proliferation, and often caseated centres. The spleen and liver may be the seat of nodules.

\section{Describe the appearance of a typical nasal ulcer in glanders.}

At the first the ulcers are round, regular and smoothly bordered, but later, as a result of progressive tissue destruction, they become irregular with raised borders, ragged edges, pale-yellow, with a lardaceous base covered with pus and detritus or, eventually, a brownish crust. Larger ulcers are formed by the coalescence of small ones. The shallow ulcers may heal without any visible changes, but the deeper ones, after granulating, leave a radiating, star-shaped cicatrix.

\section{What are the known lesions of rabies?}

Congestion of fauces, pharynx and larynx; cyanosis of the mucous membrane of the mouth; foreign bodies, but no food in the stomach, and the mucous membrane of the latter is congested or actively inflamed. The foregoing conditions are usually found in all cases of rabies, but cannot be called specific of the disease. The 
following are specific: brain congestion; Negri bodies in the ganglion cells of the hippocampus, and other brain cells; proliferation of the endothelial cells in the eapsules of the Gasserian and plexiform ganglia.

\section{What is the pathology of foot and mouth disease?}

In mild cases the lesions are slight and may be overlooked. In more severe cases, hyperæmia and odema are noted. Catarrhal rhinitis and pneumonia, and dilatation of the heart; the heart musele may show degeneration and hemorrhagic infarets. In some eases hemorrhagie gastro-enteritis is a prominent lesion; ulcer's in the stomachs of eattle; these ulcers rarely extend deeper than the mueosa. Vesicles are seen on the feet, between the digits, and may extend into the deeper structures, causing sloughing of the hoof and necrosis of the bone.

\section{Describe the appearance of a case of infectious lymphangitis.}

(All cases of lymphangitis are probably of infectious origin. Presuming that the interrogator refers to the so-called "epizoütic lymphangitis," the following answer is given.)

It is characterized by red exuberant skin nodules (buttons, boils) which burst and diseharge a thiek, creamy, yellowish or bloody pus. The neighboring lymph plexus swells into corded lines, with nodules or abseesses at irregular intervals. The infection extends to, and implicates the lymph-glands of the region affected and pyæmia may follow. The disease is eaused by a yeast fungus, cryptococeus fareiminosus, also known as saccharomyces fareiminosus.

A disease, caused by a sporothrix, called "sporothricosis," presents practically the same pieture and is frequently mistaken for the former disease. Epizoötic lymphangitis is unknown in this country.

\section{Give the post-mortem lesions of Texas fever.}

Putrefaction of careass occurs rapidly. Icteric coloration of mucous membranes and tissnes due to hæmoglobinxmia. 'Tieks may be found on the body and oceasionally tufts of hair matted with blood. IIemorrhages beneath the skin and into the endocardium. The right ventriele is distended with blood and the left ventricle contracted. Liver enlarged from congestion; the spleen engorged with blood; the kidneys œdematous and blood-stained. 'The bladder is petechiated and contains bloody urine. Congestion of the mueosa of the digestive tract. The blood thin and watery with hamoglobinæmia present. 
Describe the post-mortem lesions of anthrax.

In rapidly fatal cases, changes in the blood and tissues are often so little marked, that, after the engorged spleen and infiltrated internal organs are removed, the carcass appears fit for consumption as food. In more protracted cases, the blood is dark, tissues brown or yellow, the heart muscle pale; liver enlarged, soft, pale and hemorrhagic; spleen greatly enlarged or ruptured; lymphglands hyper:mic; serosa petechiated; the bacterium anthrax is readily demonstrated in blood smears.

\section{Describe the post-mortem lesions of hemorrhagic septicæmia.}

Widely distributed areas of hemorrhage, varying in size from a pin point to several inches in diameter. Blood extravasations in the subcutem and intramuscular tissues, in the lungs, stomach and intestinal walls, lymph-glands, endocardium, myocardium, and pericardial sac. The spleen is usually normal except, perhaps, a few hemorrhagic areas on its surface. The central nervous system may occasionally show hemorrhages, especially in the dura. In animals recently dead, the blood is lighter in color than normal. When decomposition occurs, the blood is black and tarry, but reddens after exposure to the air. Cultures from the tissues reveal the causative factor, bacterium bovisepticus.

\section{What tissues are most commonly affected by tuberculosis?}

Lungs, liver, intestines, generative organs and the lymphatic glands adjoining these organs, especially the mesenteric, portal, mediastinal and those about the head; serous membranes-peritoneum, pleura, meninges and synovial.

\section{Describe a miliary tubercle.}

The term "miliary tubercle" was originally applied to tubercles which approximated in size a millet seed, but now is applied to various sizes of new-formed tuberculous nodules, larger or smaller, which show a central necrotic mass of one or more giant-cells surrounded by a proliferation of epitheloid cells and outside of this a collection of lymphocytes. It appears as a gray, translucent body and, in properly stained specimens, the tubercle bacillus may be seen. As the central necrotic mass increases in size, it becomes caseated or calcified and a connective-tissue stroma of a fibrous nature may encapsulate the lesion; it then becomes an old, yellow, or crude tubercle. 
Name three characteristic lesions of each of the following diseases: hog cholera, anthrax, glanders.

Hog cholera: button ulcers in the intestines, hemorrhagic areas and enlargement of the spleen and lymph-glands.

Anthrax: Enlarged spleen, hemorrhages, black tarry blood, showing little tendency to coagulate.

Glanders: Typical nodules in lungs, ulcers and star-shaped eicatrices on the nasal mucous membrane, hyperplasia of lymph-glands.

BACTERIOLOGY

Classify bacteria and give the name of the classification used. Migula's classification:

I. Lower bacteria.

A. Coccacex.

1. Streptococcus.

2. Micrococcus.

3. Sarcina.

4. Planococcus.

5. Planosarcina.

B. Bacteriaceæ.

1. Bacterium.

2. Bacillus.

3. Pseudomonas.

C. Spirillaceæ.

1. Spirosoma.

2. Microspira.

3. Spirillum.

4. Spirochæta.

II. Higher bacteria.

A. Chlamydobacteriaceæ.

1. Streptothrix.

2. Phragmidothrix.

3. Crenothrix.

4. Cladothrix.

5. Thiothrix.

B. Beggiatocex.

1. Beggiatoa.

Define (a) spore, (b) flagella, (c) complement.

(a) The reproductive element of bacteria. Spores are very resistant to the influence of temperature and the action of ehemical agents.

(b) Whip-like processes attached to the ends of, or all over, certain microörganisms. They impart the power of motility to the bacteria. 
(c) A thermolabile substance present in normal blood-serum, which influences the action of the immune body. (See diagnosis of glanders by the fixation of the complement test, page 167.)

Differentiate the terms anaerobic and aerobic and give an example of each.

Anaërobic is the term applied to bacteria that can live in the absence of air. There are two forms, facultative anaërobic which live best in the absence of air, but can live in its presence, as B. typhoid; and obligative anaërobic which can live only in the absence of air, as B. tetanus. Aërobic refers to bacteria which live in the presence of air. As with the anaërobic, there is a facultative form which grows best in the presence of air but can live in its absence, as B. anthracis ; and an obligative form which can grow only in its presence, as $B$. subtilis.

Define the following terms: (a) saphrophytic, (b) pathogenic, (c) asepsis, (d) sterile, (e) culture, (f) pure culture.

(a) Bacteria that feed on dead organic matter and usually non-pathogenic; (b) capable of producing disease; (c) free from sepsis-producing organisms; (d) absolutely free of all germs; (e) a growtl of microörganisms in suitable fluids or other media; (f) a growth consisting exclusively of one species of bacteria.

Name five common culture-media.

Bouillon, agar, blood-serum, potato, milk.

Define antiseptic and disinfectant and give examples of each.

An antiseptic is an agent which prevents the formation of pus. Examples: corrosive sublimate, phenol.

A disinfectant is an agent which destroys bacteria. Examples: strong solutions of corrosive sublimate, formaldehyde, actual cautery.

Name the pus-producing microorganisms.

Staphylococcus pyogenes aureus, albus and citreous, streptococcus pyogenes, gonococcus and pneumococcus are the most common pus-producing microörganisms, although the bacillus of tuberculosis, typhoid, coli and glanders may form pus, as well as the actinomyces and certain yeast and moulds, e.g., aspergilli.

What disease is produced by (a) Koch's bacillus, (b) Nicolaier's bacillus, (c) bacillus of Bang?

(a) Tuberculosis; (b) tetanus; (c) infectious abortion. 
Name the channels through which the bacillus of tuberculosis may enter the animal's body.

Alimentary tract, respiratory tract, genito-mrinary tract, abraded skin and mucous membranes.

What is an acid-fast organism? Name the organisms belonging to this group.

An acid-fast organism is one that is not decolorized by dilute acids after being stained with the usual aniline dyes.

B. tuberculosis, smegma bacillus, leprosy bacillus and the bacillus of bacterial dysentery of cattle (Johne's bacillus) belong to this group.

Describe the bacillus of (a) tetanus, (b) anthrax, (c) tuberculosis.

(a) A slender rod, from 4 to $5 \mu$ long and generally shows a spore at one end which, being larger than the bacillus, gives it the appearance of a pin or drum-stick. It is anaërobic, stains readily with aniline dyes and produces the most poisonous toxin of any known bacteria.

(b) A non-motile, rod-shaped organism, 5 to $20 \mu$ long; a uniform width of $1 \mu$; square cut ends; grows in long filaments composed of a large number of the organisms joined end to end. It forms very resistant spores and grows best under aërobic conditions.

(c) Straight or slightly curved rods, 1.5 to $3.5 \mu$ long and $\mathrm{J} / 2 \mu$ wide, occurring singly or in bunches; does not produce spores, is acid-fast and difficult to cultivate on culture media until adapted to such conditions.

Describe the fungus of actinomycosis.

This fungus belongs to the type of higher bacteria, known as cladothrix or streptothrix. It is club-shaped and occurs as minute, yellow granules in the lesions; varies from 1 to $10 \mu$ long; can be cultivated on artificial media and stains feebly with the aniline dyes. In some varieties, the clubs show long, thread-like filaments attached to them.

Define (a) mallein, (b) tuberculin.

(a) A liquid extract from cultures of the glanders bacillus used as a diagnostic agent for glanders. It is prepared by growing glanders bacilli in a flask of glyecrinated bonillon for 6 or 8 weeks; the growth is filtered off and the filtrate is concentrated by boiling; a small amount of a preservative, such as phenol, is added.

(b) Tuberculin is a glycerine extract obtained from cultures of the tubercle bacillus and is used as a diagnostic agent for tuberculosis. It is prepared similar to mallein, above deseribed. 


\section{What are agglutinins?}

Substances in the blood-serum which have the property of agglutinating or clumping bacteria. These substances are present in normal serum but are very abundant in the serum of animals immunized to, or suffering from certain diseases. This property is utilized as a diagnostic agent.

If unexpectedly called upon to do so, how could one properly collect tissues in the country for bacteriologic examination?

Procure a fruit-jar with a tight-fitting cover. Boil same for thirty minutes. Open the animal and, with a sterilized knife, cut out and carefully place in the jar, specimens desired to be examined; avoid contaminating with any other objects; seal quickly, using paraffin over the top.

\section{What is the opsonic index? How is it determined?}

The opsonic index is the measure of the power of the blood-serum of an infected individual to prepare bacteria for phagocytosis, compared with the serum of a healthy individual.

It is determined by mixing a known quantity of bacterial suspension with equal quantities of blood serum and an emulsion of healthy leucocytes. After incubating the mixture long enough to permit the opsonins to act on the bacteria and phagocytosis to take place, slides are prepared and stained, and the average number of bacteria in a leucocyte determined. (One hundred or more leucocytes should be examined to obtain average.) If 100 leucocytes take up 400 bacteria when treated with healthy serum, and 100 leucocytes take up only 300 of the same bacteria when treated with the patient's serum, that patient's opsonic index is $(400: 300=$ $1: X) \quad X=0.75$.

What is the cause of the following diseases: (a) surra, (b) Johne's disease, (c) hog cholera, (d) actinomycosis.

(a) Trypanosoma Evansi; (b) bacillus paratuberculosis; (c) filterable virus, associated with B. cholera suis; (d) ray fungus.

What diseases are caused by the bacillus necrophorus?

The necrosis bacillus causes foot rot in sheep and cattle; necrobacillosis of the liver, lips, mouth, vagina, sheath, penis; and various gangrenous processes.

What is (a) an antitoxin, (b) a toxin, (c) a bactericidal serum, (d) bacteriolytic serum, (e) exotoxin, (f) endotoxin?

(a) A substance in the serum which binds and neutralizes toxin; 
(b) a poisonous product elaborated by microörganisms; (c) a serum destructive to bacteria; (d) a serum containing a lysin destructive to a species of bacteria; (e) a toxin excreted by a microörganism, and which can be recovered by filtration from a culture without destruction of the producing agent; ( $f$ ) a toxin elaborated by a microörganism within its substance, and which becomes free only after destruction of the producing agent.

\section{What do you understand by negative phase?}

The temporary lowering of the opsonic index, following an injection of a bacillary vaccine. It is followed by the positive phase in which the opsonic index is raised and a relief from the general symptoms of the disease is observed.

What is meant by the optimum, maximum and minimum of temperature of a germ?

All bacteria grow best at a certain temperature, about $38^{\circ} \mathrm{C}$, called the optimum. Some will grow at a much lower and some at a much higher temperature. The lowest point at which the germ will grow is called the minimum, and the highest point, the maximum temperature of the germ.

\section{What do you understand by Gram-positive and Gram-negative?}

This refers to Gram's differential method of staining bacteria. The specimen is first placed in aniline gentian violet, then rinsed in water and immer'sed in Gram's solution of iodine (iodine 1, potassium iodide 2, water 300 ), again rinsed in water and placed for a few minutes in strong alcohol, washed again and dipped in dilute eosin solution. The bacteria that are stained a deep-violet by this method are called Gram-positive; those that are decolorized and take on the counter-stain are Gram-negative.

How do bacteria produce disease?

By their irritating local action and by the production of toxins.

Define immunity and give varieties.

A state in which the body is resistant to disease. 1. Natural immunity, possessed by all the individuals of a class, by reason of age or racial peculiarity. Cattle are naturally immune to glanders. 2. Acquired immunity, obtained by having overcome an attack of a pathogenic microörganism (active), or as a result of the injection of a serum from an animal which has acquired an active immunity against the organism in question (passive).

What disease is caused by tinea tonsurans?

Ringworm. 


\section{THEORY AND PRACTICE OF MEDICINE*}

\section{General and Differential Diagnosis}

\section{What is meant by (a) diagnosis, (b) prognosis, (c) termination?}

(a) Diagnosis is the recognition of a disease by its symptoms.

(b) Prognosis is the art of foreseeing and predicting the course and outcome of a disease.

(c) Termination refers to the end of a disease, it may be by cure (complete recovery), incomplete recovery or death.

What is the difference between an infectious and a contagious disease? 'Give examples of each.

Some authorities use these terms synonymously. All contagious diseases are infectious, that is, due to infection, but all infectious diseases are not contagious, that is, spread by contact. Tetanus and black-leg are infectious diseases but are not communicable through contact (contagion), arising generally from wound infection; whereas, foot and mouth disease, anthrax and tuberculosis are infectious diseases which are spread by contact.

Describe a hard pulse, a fast pulse, a compressible pulse, a dicrotic pulse and state conditions in which each occur.

A hard pulse is one in which the arterial wall is firmly distended and does not yield readily to pressure. Seen in inflammation of serous membranes (peritonitis, pleurisy), tetanus and acute brain diseases.

A fast pulse is an abnormal increase in the frequency of the pulse. It is seen plyysiologically after exercise, excitement, high atmospheric temperature; pathologically in most all severe diseases.

A compressible pulse is one which yields readily to moderate pressure and does not lift the finger palpating it; seen in diseases associated with cardiac weakness.

A dicrotic pulse is one in which two expansions can be felt in one beat of the artery; seen in cases of lowered arterial tension, associated with weakened heart action, as in long-continued fevers and in all forms of anæmia.

\section{Give the symptoms of internal hemorrhage.}

Sudden paleness of the visible mucous membranes, syncope, rapid heart action, rapid weak pulse, convulsions and death. Depending upon the location, special symptoms may be shown. Gas- 
tric and intestinal hemorrhage may be shown by vomiting of blood and bloody fæces; pulmonary hemorrhage is shown by dyspnœa, coughing and bloody froth from the nostrils. Hæmaturia is present in hemorrhage of the urinary tract.

\section{What is Cheyne-Stokes breathing? When seen?}

A type of breathing characterized by rhythmic variations in intensity, occurring in cycles. Each eycle consists of a gradual decrease in the intensity of the respiratory movements, followed by total cessation for a space of from five to forty seconds; this in turn is followed by a gradual increase of the respiratory movements until they reached a maximum and become dyspnœic in character. This type of breathing is seen in severe cerebral diseases such as uræmic coma and cerebrospinal meningitis.

\section{Differentiate malignant œdema from anthrax.}

Malignant œdema may be differentiated from anthrax by its appearance outside of anthrax districts; by absence of bacillus anthracis from the blood; normal size of the spleen; erepitating swellings; presence of an extensive wound and the characteristic, causative microörganism.

\section{Differentiate heat stroke (thermic fever) from heat exhaustion.}

Heat stroke is manifested by weariness during work, profuse sweating, great rise of temperature, dyspnœa, rapid pulse, dilatation followed by contraction of the pupil, staggering, collapse and death. In heat exhaustion, there is no fever present, in fact the temperature may be subnormal; muscular weakness and collapse.

Name the diagnostic tests for glanders.

1. Animal inoculation (Strauss method).

2. Subcutaneous mallein.

3. Cutaneous mallein.

4. Intradermal mallein.

5. Ophthalmic mallein.

6. Complement-fixation.

7. Agglutination.

8. Precipitin.

9. Autogenous bacterin.

10. Post-mortem.

11. Clinical (physical examination).

State the difference between the agglutination test and the precipitin test for glanders.

The agglutination test is based upon the fact that blood-serum, which normally contains agglutinating substances, but in glanders 
a greater amount, will cause the clumping, or agglutinating of glanders bacilli in suspensions of potato or agar cultures, whereupon these clumps are precipitated to the bottom of the supernatant clear fluid.

The precipitin test is based upon the fact that the serum from a glandered horse produces a flaky precipitate in the filtrate of glanders cultures, when mixed together.

In a test for glanders, state the relative advantages of the mallein and agglutination tests.

The mallein test can only be used on living animals. The agglutination test can be applied to dead animals. The former method is long and tedious and cannot be used when fever is present, whereas the latter is simple for the practitioner, most of the work being done in a laboratory; presence of fever is no hindrance. Mallein is more accurate; agglutination does occur with the serum of healthy animals and the line of distinction is often close. The mallein test necessitates the confinement of the patient, whereas the agglutination test allows the horse to continue at work.

\section{Describe the course to be pursued in testing with mallein.}

Take three preliminary temperatures, at least four hours apart. With antiseptic precautions, inject the mallein subcutaneously. Eight hours later, make a temperature reading and thereafter every two hours until twenty hours after injection. A reaction consists of a gradual rise and fall of temperature of at least $2^{\circ} \mathrm{F}$., and a local reaction shown by an œdematous, painful swelling at the seat of injection, lasting four or five days. Healthy horses are not affected except, perhaps, by a local swelling which disappears in twenty-four hours.

The ophthalmic mallein test depends upon a purulent conjunctivitis following from 4 to 24 hours after the instillation of a few drops of a concentrated mallein solution into the conjunctival sac.

The cutaneous mallein test depends upon a local reaction following an intradermal or endermic inoculation with mallein.

\section{Describe the complement fixation test for glanders.}

The phenomenon of hæmolysis is the fundamental principle of this test. If the blood-serum of a rabbit is treated with the red blood-corpuscles of a sheep, antibodies (hcomolytic amboceptors) will be formed. These antibodies have the power to dissolve sheep red blood-corpuscles in the presence of free complement. This process is called homolysis and depends upon two substances; one of these, the complement, is present in the blood of every animal 
and can be destroyed by heating the serum to $56^{\circ} \mathrm{C}$. for half an hour. (This is called inactivating the serum); the other substance, known as the immune body, hamolytic amboceptor, or antibody. By inactivating the serum, the power of hemolysis is lost, because the complement is destroyed; but this power can be restored by adding fresh serum which always contains complement. Guinea-pig serum is very rich in complement and is used in the test.

In horses affected with glanders, the infectious principle, the toxin, stimulates the production of antibodies. These antibodies, or bacterial amboceptors, are nature's fighters against the invading toxin. For use in this test, this toxin is obtained by making an extract of an artificial growth of glanders bacilli, and is called antigen.

If the serum of a glandered animal which, of course, contains antibodies, is inactivated (complement destroyed by heat) and brought in contact with the antigen in the presence of complement (supplied by adding fresh guinea-pig serum), the complement will become firmly fixed by the combined antibody and antigen. This fixation of the complement is more thoroughly established when the mixture is placed in an incubator for one hour. If to this mixture, red blood-corpuscles of a sheep and rabbit serum, containing hæmolytic amboceptors, are added, no hæmolysis will occur because the complement that was added was previously fixed to the antigen by means of the glanders antibodies.

The serum of a glanders-free horse does not contain antibodies, so if it is mixed with antigen and complement, the latter does not become fixed, but remains free; therefore, when the red bloodcorpuscles and the rabbit serum, containing hæmolytic amboceptors, are added to such a mixture, hæmolysis occurs.

Positive Reaction.

Antigen + serum-containing antibody + complement + hæmolytic amboceptor + sheep red blood-corpuscles = no hæmolysis.

The complement unites with the antigen, through the antibody, hence there is no complement to aet through the homolytic amboceptor on the sheep corpuscles.

\section{Negative Reaction.}

Antigen + normal ser u $m$ + complement + linmolytic amboceptor + sheep red blood-corpuscles $=$ hamolysis.

There is no antibody to unite the complement and antigen, hence the complement is free to act through the hxmolytic amboceptor on the sheep red blood-corpuseles.

This is not a practicable test for the regular practitioner because it requires special laboratory apparatus and very accurate technic. 
How may strangles be differentiated from glanders?

By purulent submaxillary lympliadenitis; by animal inoculation; by any of the various glanders tests; in glanders, typical ulcers are seen in the nasal mucous membranes, similar ulcers are seen in strangles but tend to heal rapidly; strangles occurs in young horses and prevails in sale stables.

Make a differential diagnosis between acute nasal glanders and nasal gleet.

Clinically, it may be difficult to differentiate, a considerable time for observation being necessary. Usually there are no ulcers $\mathrm{ol}^{\circ}$ scars in nasal gleet, and the disease responds to treatment. Special diagnostic tests for glanders are best resorted to at first to avoid danger in handling.

Name two diseases that are frequently mistaken for glanders. Name two laboratory methods frequently employed in diagnosing glanders.

Strangles and nasal gleet (chronic rhinitis). Agglutination test and complement fixation test.

Make a differential diagnosis of acute lymphangitis and farcy.

Lymphangitis is a local affection; farcy is a symptom of generalized glanders. The former progresses very acutely with fever and sometimes formation of abscesses in the lymph-glands; the latter usually progresses slowly, without fever and with but slight participation of the glands. The abscesses of lymphangitis have smooth edges and heal rapidly by granulation, but those of glanders form crateriform, non-healing ulcers. Special diagnostic tests for glander's.

Differentiate azoturia from spinal meningitis.

Differentiate by the sudden onset, hard swollen gluteal muscles, ability to bear weight on the legs, although the fetlocks knuckle; history of idleness and full diet; black, coffee-colored urine.

Differentiate cryptogamic forage poisoning from lead poisoning.

Forage poisoning develops slowly with paralyses, especially of the pharynx, little or no fever. Lead poisoning has a sudden onset (except in the chronic form) ; salivation, convulsions, colics, blue line around gums, coma and collapse.

\section{Differentiate osteoporosis from osteomalacia.}

Osteoporosis is a condition in which the compact bone proliferates and becomes rarefied (porous), or cancellated. Osteomalacia is a morbid softening of bone. The former often occurs with the 
latter and predominates. In fact, the two conditions are so similar that, in view of the lack of information, it is hardly proper to classify them as independent affections. However, osteomalacia occurs more frequently in cattle and clinically, in many ways, is not unlike osteoporosis which is more commonly observed in horses.

Describe the course to be pursued in testing with tuberculin.

Practically the same as the mallein test (subcutaneous), see page 167, except no local reaction occurs as in glanders.

Give an account of the sources of fallacy in testing cattle for tuberculosis and state clearly the precautions that might be taken to avoid them.

Tuberculin may be of inferior quality. Cattle may have been tested recently or had tuberculin injected just previous to test, and therefore do not respond properly. Cattle do not react when in advanced stages of the disease. Cows, within two weeks of parturition, may not react though affected with the disease. Stabling animals when accustomed to pasture may cause a rise in temperature. Administration of antipyretics by unscrupulous owners may cause a mistaken interpretation of results.

Precautions: Use freshly prepared reliable tuberculin; determine, if possible, the date of last test; observe advanced cases by clinical examination and exclude them from test; defer testing pregnant cows near end of term and cows which have recently calved; stable animals a few days before making test.

Differentiate contagious pleuropneumonia from influenza.

Contagious pleuropneumonia is characterized by the typical pleurisy and pneumonia which are transmitted with the same predominating symptoms to other animals. The legs do not swell as in influenza; it is more severe and fatal; influenza may cause a croupous pneumonia; is milder in attack; digestive disorders are common; legs swell; pink-eye is seen.

Give the distinctive symptoms of spasmodic colic and enteritis.

Spasmodic colic shows intervals of ease, no fever, and violent movements when spasms occur; early recovery. Enteritis is accompanied by fever, constant uneasiness, carcful decubitus and rising; gradually grows worse.

What is the difference between septicæmia and pyæmia? Treatment for each.

Septicæmia is a morbid condition due to the presence of nonspecific pathogenic bacteria and their associated poisons (toxins and tox-albumins) in the blood. It is accompanied by chills, fever, 
sweating and great prostration. Pyæmia is a blood-poisoning by pyogenic microörganisms and is shown by fever, chills, icterus and abscess formation in various parts of the body.

Treatment: Is virtually hopeless. Remove necrotic tissue from wounds ; antiseptic treatment ; quinine sulphate in large doses, internally; stimulants to sustain heart action.

Give the differential symptoms of acute pharyngitis and acute laryngitis.

Pharyngitis: difficulty in swallowing; no cough.

Laryngitis: no difficulty in swallowing; cough present.

Often occur together.

How can acute nephritis be distinguished from lumbago and lumbar rheumatism?

By urinary examination and finding casts, indicative of nephritis. By tenderness of the kidneys in nephritis, as shown by palpation per rectum.

\section{What do you understand by diagnostic inoculation?}

Diagnostic inoculations consist of the introduction of certain substances into the bodies of animals for the purpose of determining either the character of the substance or the condition of the animal's health. Hence the substance injected is either a material of known composition (tuberculin, mallein), or tissue from an animal affected with an infectious disease, the nature of which is to be determined.

Name three diseases in which you would expect to find a subnormal temperature.

Parturient paresis, anæmia and chronic gastro-intestinal catarrh in the dog.

Discuss auscultation and palpation.

Auscultation is the act of listening for sounds within the body, especially in determining the condition of the heart, lungs, pleura and abdominal organs.

Palpation is the act of examining an organ by feeling with the hands or finger tips.

How is a positive diagnosis of rabies made?

By miscroscopic examination of the brain and finding Negri bodies; also by inoculating experimental animals with the brain tissue of the suspected animal. More recently, the complementfixation test has been used and is said to be satisfactory in the diagnosis of rabies. 
Give mode of examining a horse for soundness and a certificate for same.

Examine the horse in the stable, outside and at work. Reeord a deseription of the animal for the purpose of identification. Examine thoroughly every accessible part or organ by inspection, palpation and ausenltation. As very few horses are absolntely sound, most examiners employ the phrase "serviceably sound," meaning that the defects present will not interfere with the animal performing the required duty.

\section{EXAMINATION FOR SOUNDNESS}

Philladelphia, Pa., Jan. 5, 1914.

This certifies, that I have this day examined, at the request of Mr. John Doe, a bay gelding, 15.2 hands high, 9 years old, white star and blaze patch between nostrils, elipped foretop, full mane and tail, all black points, saddle and collar marks, slit in the tip of left ear.

Notes: ringbone on near fore, ehronic arthritis deformans of the left hoek.

From above notes, to the best of my judgment and belief, said animal is not sound.

\section{Richard Roe, D.V.M.}

Note.-The above examination does not include such obsenre diseases as staggers (epilepsy and immobility), recurrent ophthalmia, cribbing without evidence on teeth, etc.

\section{Acute General Infectious Disenses}

\section{What are the essential causes of hog cholera and swine plague?}

According to the results of latest investigators, hog cholera is caused by an ultramicroscopie, filtrable virus. Besides the virus, two species of bacteria, the bacillus suipestifer and the bacillus suiseptieus, play an important part in the etiology of hog cholera. The secondary affections of the intestines, lympli-glands and lungs are usually produeed by the pathogenic action of these bacteria.

Swine plague is caused by the bacillus suisepticus.

Give the diagnostic symptoms of hog cholera and swine plague.

Hog cholera: Acute form, fever, variable appetite, vomiting, conjunctivitis, constipation followed by diarrhoea which may be bloody; reddening of skin on nose, ears, abdomen and on the inside of the thighs; die after a few hours or a few days' sickness; simultaneous sickness of several members of the herd; may or may not 
be complicated with the respiratory affection of swine plague. Chronic form, after 1-3 weeks, acute symptoms diminish, appetite improves, diarrhœa ceases; recovery; others, the appetite remains irregular, occasional diarrhœa, anæmia, cachexia, exhaustion and death after several months.

Swine plague: Often appears as a complication of hog cholera. Less commonly as a primary affection. Peracute form: high fever, weakness, anorexia, petechia, symptoms of hemorrhagic septicæmia; die in 12 to 24 hours. Acute form: fever $104^{\circ}-106^{\circ} \mathrm{F}$., nasal discharge, paroxysmal cough, dyspnœa, pneumonia, tenderness of thorax (pleurisy), cyanotic membranes, rapid, throbbing pulse; constipation followed by diarrhœa, anorexia, emaciation, petechiæ, die in 1 to 2 weeks; recovery rare. Chronic form follows subsidence of acute symptoms; coughing and difficult respiration persist; cachexia; polyarthritis; die in 3 to 6 weeks.

What prophylactic measures and means of extinction should be employed in an outbreak of hog cholera or swine plague?

Hog cholera: Separate the well from the affected and divide into small groups; should any of these show symptoms, repeat the procedure. Destroy affected and thoroughly disinfect premises; isolate newly-purchased animals for three weeks before introducing them into herd; quarantine; immunize and treat with serum.

Swine plague: Separate the well from the affected; destroy carcasses, thoroughly disinfect, quarantine and immunize with hog cholera serum. (Hog cholera and swine plague often exist in the same animal.)

\section{State causes of horse-pox and cowpox.}

An ultramicroscopic, filtrable virus, called "virus of variola."

Give the general symptoms, the sequelæ and the best methods of treatment, restriction and extinction of horse- and cowpox.

Horse-pox is very rare and its occurrence is doubted by many good authorities. A vesiculopustular exanthema in the flexor region of the pastern of young animals is considered as horse-pox. This is usually accompanied by a slight elevation of temperature. Treatment consists of antiseptic dressing of affected part.

Cowpox occurs sporadically on the teats and around their base; 5 to 20 nodules, size of a pea, develop into vesicles, pustules and rupture, leaving an ulcer, scab and scar, respectively. Duration, 1 to 2 weeks; slight general disturbance, fever, diminished appetite, irregular rumination, changes in the milk not constant. Scrotum affected in the male. Sequelæ: mastitis, wound infection. 
Treatment: Avoid irritating wound; use milk eatheter; keep udder clean and dry; isolate and vaccinate; Epsom salts internally; sodium hyposulphite, 1 per cent. solution, or oxide of zinc ointment externally.

Give the accessory causes of tetanus.

Essential cause is the bacillus tetani. Accessory causes : traumas, especially punctured wounds, castration, amputation of the tail, pricks in shoeing, parturition, unhealed navel, etc.

\section{What genera are most subject to tetanus? Why?}

Solipeds, because they are more susceptible to the action of the virus and more subject to traumatism.

\section{Give the diagnostic symptoms, prevention and treatment of tetanus.}

Symptoms: generalized tonic spasms, "saw-horse" attitude, head and tail extended, ears rigid, eyes sunken and fixed, protrusion of the membrana nictitans, nostrils dilated, hyperæsthesia, difficult swallowing, temperature normal or slightly elevated, constipation.

Prevention: Avoid traumatism, especially nail wounds of the feet. Treat all wounds antiseptically. Tetanus antitoxin, if given before symptoms appear, in dose of 750 units, will prevent the disease.

Treatment: Nothing specific. Disinfect the seat of infection; provide quiet quarters; feed easily masticated, laxative diet; keep fresh water before patient; empty rectum and bladder at frequent intervals with the hand; antispasmodies may help in controlling spasms; phenol, magnesium sulphate, bromides, hydrocyanic acid, lobelia, tetanus antitoxin, etc., are of disputed therapeutic value.

State the cause of malignant cedema. Name the microbe and give symptoms and course.

Cause: wound infection by bacillus œedematis maligni.

Symptoms: Suddenly appearing and rapidly spreading swelling which is odematous and crepitates on palpation; hot and tender at first but later becomes insensitive; if incised, a reddish-ycllow or colorless serous fluid containing air-bubbles is discharged; dyspnœa, cyanotic membranes, colicky pains, tympanites, high temperature; death may occur in a few hours or, at the longest, three days after appearance of the first symptoms. Recovery exceptional.

Describe the symptoms of hemorrhagic septicæmia in cattle.

Sudden checking in milk secretion, difficult swallowing, anorexia, general dulness, high temperature, diarrhoal discharge dark in color or may be bloody; bloody urine and bloody serous discharge from nostrils; painful œdematous swellings about the legs, shoulders and 
under the throat; convulsions; short duration, often found dead in field.

Describe the symptoms and course of anthrax in cattle.

Peracute cases: May die suddenly with no previous symptoms observed; high fever, bloody discharge from mouth, nostrils and anus, convulsions and death in a few hours.

Acute cases: High fever, restlessness followed later by depression and convulsions; small rapid pulse, dyspncea from odema of the glottis; tympany, diarrhœa, frecs mixed with blood, or clots of blood may be passed; hot, doughy swellings over the surface of the body. Cutaneous form, which is characterized by carbuncles (malignant pustule), rare. Death in 12 to 48 hours.

Subacute cases: Occur in latter end of an epidemic; show rise of temperature and constitutional disturbance; recover in 2 to 7 days.

Give the symptoms, treatment and general termination of epizootic cellulitis.

A form of influenza characterized by fever, depression and inflammatory odema of the eutis and subcutis over the dependent portions of the body, especially the eyelids, nostrils, sheath, ventral surface of the abdomen and the limbs. Appetite may or may not be impaired; pulse rapid and strong; disinclination to move; constipation.

Treatment: Sodium sulphate may be given in bran mashes or in drench. Potassium nitrate in the drinking water. Usually recover uneventfully.

Describe the symptoms of infectious pneumonia (contagious pleuropneumonia) other than the elevation of temperature, increased pulse-rate and respiration.

Icterus, anorexia, dulness, yellow nasal discharge, cough, erepitation, pleuritic friction at first, later a long horizontal line of dulness on percussion due to exudate; pharyngitis which may be followed by inhalation bronchitis and gangrenous pneumonia; pericarditis, endocarditis and myocarditis; dropsical swellings of the legs and elsewhere. The symptom of dulness may be followed by stupor, rolling of eyes, vertigo or paresis of the hind limbs.

Give course, termination and treatment of contagious pleuropneumonia.

See answer to preceding question. Moderate cases in strong, well-nourished horses begin to improve at the end of one week and recover in 2 to 3 weeks, convalescence complete in one month. Severe cases almost invariably succumb in a few days; gangrene 
of the lungs, toxæmia, tendinitis and myocarditis are unfavorable complications.

Treatment: Hygienic and dietetic measures are most important. In very high fever, give antipyretics; likewise, symptomatic treatment in other alarming conditions such as intestinal antisepties in diarrhœa, heart tonics in myocarditis, ete. Nuclein, tallianin, colloidal silver, bacterial endotoxins and serum therapy are of disputed therapeutic value. More recently, salvarsan and neosalvarsan have been advocated as specifics and "sure cures" and the outlook is most encouraging.

Give the symptoms of foot and mouth disease (aphthæ epizooticæ).

Fever, redness and tenderness of the buccal mucous membranes and teats, grinding of teeth, salivation, smacking of tongue, tender feet, shaking of feet backward; blisters on lips, buccal mucous membranes, teats and between digits; these blisters may rupture and leave a raw, inflamed, underlying tissue; separation of horn from coronary band sometimes occurs; diarrhœa in sucklings due to gastro-intestinal eatarrh. Prognosis favorable in adult cattle. Recovery in 2 weeks.

Give the symptoms and course of rabies in dogs.

Two forms, furious and dumb. Furious form: More affectionate, dulness alternating with excitement; peculiar howl, due to paralysis of the throat; depraved appetite, hallucinations, eyes red and fixed; wanders away from lome, biting dogs, persons and all objects in its path; dribbling of saliva and finally paralysis of the lower jaw, pharynx and posterior limbs, followed by death. Course, 2 to 5 days. Dumb form: Usually follows the furious form and represents the paralytic stage. If present from the first, the animal is dull, apathetie, shows little or no inclination to bite; no howling, seeks seclusion and quiet. Paralysis extends and death follows.

Describe the successive symptoms of a very severe case of distemper in the dog eventually ending in death.

Fever, vomiting, coughing, nasal discharge which is first serous but later mucopurulent; catarrhal eonjunctivitis, lieratitis, uleers on the cornea; exanthema; eatarrhal bronchitis and pncumonia, chorea, emaciation and death. May have the nervous form, manifested by chorea, from the first.

Give the causes and symptoms of Texas fever.

Cause: A microörganism belonging to the protozoa, called piroplasma bigeminum, also called Babesia bigeminum bovis. 
Symptoms : Acute form, high fever, rapid pulse and respiration, anorexia, dulness, constipation, icterus, prostration, weakness, delirinm, hæmoglobinuria, blood thin and pale, diarrhœa, emaciation. Course, 1 to 7 days. Mild form: Symptoms similar to those in the acute form, except they are less severe and are prolonged for a greater length of time.

\section{What is influenza? Give causes and symptoms.}

Influenza is an acute, infectious disease of the horse (rarely the ass and mule), occurring enzoötically and epizoötically, and is characterized by a rise of temperature and a catarrhal condition of the unucous membranes of the respiratory and digestive tracts.

Cause: Seems to be a specific infection, the nature of which is, as yet, undetermined. A number of organisms liave been found and described as the specific one, viz., coccobacillus of Lignieres, bacilli, streptococci, etc. A filtrable virus seems to have been proven by recent experimenters who consider the streptococci, bacilli, etc., as secondary invaders.

Symptoms: Various manifestations and forms; viz., catarrhal form, pink eye, abdominal form, infectious cellulitis and any number of combinations of the above. In general, we observe: sudden attack, anorexia, extreme prostration and weakness, high temperature, swelling and watering of the eyes, icterus, cough, accelerated pulse, mucopurulent nasal discharge, pharyngitis, bronchitis, pneumonia, pleurisy, digestive disorders, and an œedematous swelling of the extremities, sheath, etc. Mild cases may show only a high fever and prostration lasting a few days. There is a great variety of internal forms.

Give some of the modern forms of treatment of influenza.

Besides the usual symptomatic treatment followed in pneumonia, pleurisy and enteritis from other causes, nuelein, tallianine, antistreptococcus serum, polyvalent bacterins, mixed infection phyla. cogens and proprietary vaccines are used.

Give causes and symptoms of purpura hemorrhagica.

Cause: Not definitely known; follows debilitating diseases as a secondary affection; probably toxins, especially those causing vasodilatation.

Symptoms: Fever; nasal petechiæ; characteristic, extensive, abruptly-ending swellings of the skin and subcutis of the abdomen, sheath and extremities; oozing of serum from the skin; dyspnœa and suffocation may follow from swelling of the nostrils and pharynx; locomotion is painful; appetite is usually good in the mild and often in the severe cases. 
What is the prognosis and treatment of purpura hemorrhagica?

Prognosis: Depends upon the severity of the attack and the complications. Average mortality 50 per cent.

Treatment: Hygienic attention is very important; potassium chlorate as a diuretic; give vasomotor stimulants as potassium dichromate, quinine sulphate, strychnine sulphate and ergot; internal antiseptics such as sodium salicylate, salol, calomel, turpentine; occasional small doses of linseed oil for its laxative effect, but do not give strong or drastic purgatives; surgical measures such as tracheotomy may be necessary.

Define specific infectious disease. Name five of these diseases.

A specific infectious disease is one that is caused by the multiplication of a single species of microörganism within the animal body. This particular organism, and it only, can produce the disease, e.g., anthrax, Texas fever, tetanus, glanders, tuberculosis.

State the period of incubation of a case of street rabies in the dog.

Varies from two weeks to three months. There are cases recorded with an incubation period of two years (?). Average, 22 days.

Give the causes and treatment of an epizootic of scours in calves (white scours).

Accessory causes: Unclean surroundings; open umbilicus; and hereditary debility. Specific cause: umbilical and intestinal infection with B. coli communis.

Treatment: As a prophylactic measure, disinfect stables and the external genitals of the mother before parturition; provide clean surroundings for parturient animals. Disinfect the umbilical region; sterilize the milk, feeding utensils, or udder before feeding; clear the intestinal tract of irritating matters with castor oil one ounce, or calomel 2 to 5 grains, and follow with subnitrate of bismuth 30 grains; one teaspoonful of a 1 to 4000 solution of formalin, to each pint of milk, is useful to check diarrhœa in artificially fed calves, but it should be preceded by castor oil.

Give the symptoms of rhino-adenitis. Mention the complications that sometimes occur in rhino-adenitis.

Rhino-adenitis or strangles is a discase of young horses, manifested by dulness, anorcxia, mucopurulent nasal discharge, purulent inflammation of the submaxillary lymph-glands which leads to rupture and healing; fever; inereased pulse. Complications: laryn- 
gitis, pharyngitis, bronchopneumonia, pleurisy, metastatis abscess formation in the lungs, liver, kidneys, spleen, pancreas and other parts.

\section{Chronic Infectious Diseases}

What genus of animals is subject to Johne's disease? State the essential cause.

Bovine. Caused by the bacillus of Johne's disease, an acid-fast microörganism which resembles very much the tubercle bacillus.

\section{What are the symptoms of Johne's disease?}

Gradual emaciation and anæmia unattended by fever or pain; a persistent, thin, watery diarrhœa, containing gas bubbles; appetite variable; diminished milk secretion; fatal termination. This disease is also known as "enteritis chronica paratuberculosa" and "chronic bacterial dysentery."

\section{State the prevention and treatment of Johne's disease.}

Isolation and destruction of affected animals; thorough disinfection of premises; raise offspring on new or uninfected pastures. No satisfactory treatment is known.

Describe a case of epizootic lymphangitis, giving the history, symptoms and prognosis.

(This disease is unknown in this country; the cases so diagnosed are probably "sporothricosis," which is caused by a sporothrix and presents similar symptoms.)

History: Wound on the leg; unthrifty for past one or two months ; development of multiple, nodular swellings on the wounded leg; bursting of nodules and a discharge of thick, yellowish, oily pus; nodules vary in size from a pea to a hen's egg; scar formation; disease gradually extended up the leg, along the lymphatic vessels to the inguinal lymph-gands.

Symptoms: Buds, ulcers or sores, characterized by exuberant granulations, fungoid appearance, indurated base and well-defined edges, discharging yellowish, oily pus; nodules of various sizes; induration of inguinal lymph-glands and swelling of the lymphatics; normal temperature and good appetite.

Prognosis: Usually recover with a resultant pachydermatitis of the affected leg. Mortality, 7 to 10 per cent.

What is the treatment for epizootic lymphangitis?

Antiseptics; open abscesses; curette; cauterize. Give potassium iodide internally. 
Give the symptoms and treatment of actinomycosis in the cow.

Symptoms: Deformity of the head or other parts affected by the neoplasms; hard, dense and sometimes suppurating tumors develop on the lips, tongue, maxillary bone, pharynx, skin, lymphglands, lungs and oceasionally in other organs. The symptoms, therefore, are various. Diffieulty in prehension and mastieation of food; teeth loosen; profuse salivation; difficulty in swallowing and breathing; in a pulmonary affection, the symptoms resemble those of tubereulosis of the lungs. The disease progresses slowly; a course of several years in mild cases; die from inanition due to inability to eat.

Treatment: Surgical removal of tumors; cauterize the wound formed and apply tincture of iodine freely. Internally, give potassium iodide in repeated doses until signs of iodism appear, then discontinue for a time and repeat until a eure is effected.

\section{Give the cause, course and symptoms of glanders.}

Cause: Bacterium mallei, also called baeillus mallei.

Course: Aeute form, a few weeks; the chronic form, one or more years.

Symptoms: Variously manifested as nasal, pulmonary and cutaneous (farey) forms. Aeute form starts with a ehill, fever, mucopurulent nasal discharge which is sometimes mixed with blood; one or both nostrils swollen, mueous membrane of a dark-red or violet color; and contains numerous nodules which after a few days become eroded, leaving uleers; submaxillary lymph-glands enlarged, hard and show little heat or tenderness; eutaneous form (farey) may or may not be present; this form is eharacterized by swellings or nodules (farey buds or farey buttons) along the superfieial lymphaties, usually of a lind limb. The throat and lungs may become involved, as shown by a violent cough and dyspnoa. The acute form runs a rapid course to a fatal termination.

Chronic form: Develops insidiously with nasal lesions, ulcers or star-shaped cicatrices, a sticky, blood-streaked nasal discharge; slate-colored mucous membrane; submaxillary lymph-glands hard, indurated and adherent to the adjacent structures. Appetite variable, gradual loss of flesh; intermittent, slight fever; adematous swellings; cough due to involvement of the lungs; farey buds may be present.

What animals suffer from actinobacillosis? Give diagnosis and treatment.

Cattle and sheep.

Diagnosis depends upon the finding of the baeillus which 
arranges itself in the tissues similar to the ray fungus of actinomycosis. The four cases that were observed in Canada, in 1904, are the only ones ever reported in America. It is a very rare disease; symptoms and treatment are the same as in actinomycosis.

\section{Describe the symptoms and course of tuberculosis in cattle.}

The symptoms vary according to the course of the discase. There are two forms, acute or miliary, and chronic. The latter is by far the more common. Acute form : Rapid loss of flesh, anorexia, cough, weakness, dyspnœa, slight fever, increased pulse, enlarged lymph-glands; very rapid course terminating in death in a few months.

Chronic form: Symptoms vary according to location and extent of lesions. Many badly affected cases show no prominent symptoms. In general we observe: emaciation (tubercular cachexia), although the appetite remains good; staring coat; cough, especially if the lungs are involved. The palpable lymph-glands are painless, hard and enlarged. Enlarged mediastinal lymph-glands may press on the œsophagus and bronchi, thereby producing tympany and dyspnœa. Indigestion, shown by diarrhœa and constipation, follows tuberculosis of the stomach and intestines. Enlargement and hardening of the udder, and changes in the milk are observed in advanced cases of udder affection. Nervous derangement indicates involvement of the brain and spinal cord. In tuberculosis of the bones and joints, the parts are enlarged and lameness is shown.

\section{What is dourine?}

Dourine is a chronic, contagious affection of breeding horses, transmitted by copulation, and is characterized first by local lesions on the external genitals, such as swellings, ulcers and scars, which is followed later by an affection of the nervous system, as shown by hyperisthesia and paralysis.

\section{Give the cause and symptoms of dourine.}

Trypanosoma equiperdum, transmitted by contagion and almost exclusively by the act of coition.

Symptoms: In the stallion, from one week to two months after infection a cold painless swelling develops on the glans penis, sheath, scrotum and abdomen; an urethral discharge, vesicles and ulcers may occur, although not constant; paraphymosis, semi-erections, slight fever, strangury, paresis of hind limbs, emaciation, weakness, dementia, decubitus and skin eruption are some of the various symptoms presented. Course: 2 to 3 months to as many years, terminating usually by death. In mares: vulvar swelling, 
leucorrhœa, eruptions on the mucosa of the vagina, erections of the clitoris, straining, inguinal swellings, sterility or abortion, lameness, trembling, anæmia and emaciation, ending the same as in the stallion.

\section{What is the treatment for dourine?}

Local antiseptics; arsenical preparations internally. "Salvarsan" is being strongly advocated. Prevention: isolate, prevent copulation, castrate and use sanitary police measures.

\section{What is infectious abortion?}

Infectious abortion is the premature expulsion of the fœtus, seen in cows, less commonly in mares, due to an infectious catarrh of the uterus transmitted by copulation or contagion. Infectious abortion of cows is due to the bacillus of Bang. Etiology is not fully determined in the mare.

Granular venereal disease, which is quite prevalent, is frequently associated with abortion in cows.

Name some of the more recent methods of diagnosing infectious abortion.

Agglutination test, complement fixation test and the allergic test with "abortin." The allergic test is not reliable at present.

\section{Diseases of the Blood and Blood-Forming Organs}

\section{What is "swamp fever" or infectious anæmia?}

Infectious anæmia is a specific infectious disease of the horse which is manifested sometimes as an acute, at other times as a chronic, septicæmia, and causes a destruction of great numbers of red blood-corpuscles. It is caused by an ultramicroscopic microorganism.

Define anæmia, leukæmia and hæmophilia.

Anæmia is a condition in which the blood is deficient either in quantity (oligemia) or in quality (oligocythæmia).

Leukæmia is a fatal discase in which there is a marked increase in the number of leucocytes in the blood, together with an enlargement and proliferation of the lymphoid tissue of the spleen, lymphatic glands and bone-marrow.

Hæmophilia is a condition marked by a strong and abnormal tendency to bleeding, or hemorrhage, and is usually hereditary.

State the causes of anæmia and give treatment.

Causes: Inanition, unsanitary surroundings, overwork, poisons, lack of exercise, hemorrhage, persistent diarthœa, long-lasting suppuration, copious transudation, chronic discases, parasites, infection, ctc. 
Treatment: Remove cause; correct diet; give tonics such as iron sulphate or reduced iron, arsenic, etc.; transfusion of blood or infusion of normal saline solution.

Where is the filaria immitis found? What condition does it produce?

The embryos of this parasite are found in the circulating blood and the mature worms in the right heart of dogs. Conditions produced are anzmia, emaciation, increased appetite, dropsical swellings due to emboli, heart disturbances, etc. It runs a course of several years.

\section{Discuss briefly the etiology and prevention of hæmoglobinuria.}

Hæmoglobinuria (azoturia) occurs almost invariably in wellconditioned, plethoric horses, accustomed to regular work, after a day of idleness without reduction in the amount of rations. It is rarely seen in poorly nourished horses. Cold is thought to be an etiological factor as more cases are seen in winter than in summer. It is probably an auto-intoxication, the exact nature of which is undetermined.

Prevention: Give regular exercise and reduce rations when idle.

Give the symptoms and treatment of azoturia.

Symptoms: Soon after leaving the stable in apparently perfect condition, the patient sweats, knuckles over on one or both hind, rarely in the fore, fetlocks, falls down and cannot arise except to stand in the knuckled attitude; cerebral excitement may or may not be present; the muscles of the gluteal region are hard and swollen; urine is coffee-colored or black; pulse full and accelerated, temperature normal or slightly elevated.

Treatment: Nothing specific. Quick-acting cathartics such as arecoline and Epsom salts; hot blankets over the loins may help; evacuate the bladder regularly; plenty of bedding should be provided and the patient should be turned over every 4 to 6 hours. Bromides or chloral hydrate may be given per os, or cannabis indica, intravenously if the patient is restless. Slings are used by some but should not be used unless the patient can stand well, in which case they are needless.

\section{Diseases of Metabolism}

Give the symptoms, course and termination of osteoporosis.

Inappetency, lifelessness, stiffness, shifting lameness, "tied-in" gait, stumbling, distortion of the bones of the face and lower jaw, 
polyarthritis, "tucked-up" abdomen, pleuritic ridge, emaciation, fractures, tearing away of ligamentous and tendinous attachments, etc., are among the prominent symptoms of the disease.

Course: Chronic, running several months or years, ending in death. Improvement may follow under proper handling if taken early, but relapses are common.

\section{What is the treatment for osteoporosis?}

Change of feed and environment. Calcium phosphate, in twodrachm doses three times daily, may be useful. Best to turn the horse out in pasture and make him "rough it" for a year.

\section{Give cause, symptoms and treatment for rachitis.}

Causes: Hereditary, lack of lime salts in the food, unhygienic conditions.

Symptoms: Unthrifty appearance, easily fatigued, recumbency, stiffiness ; tender, swollen joints ; enlarged epiphyses, long bones bent; brittleness of bones and loosening of teeth; diarrhœa.

Treatment: Principally hygienic; provide fresh air and sunshine; feed nutritious rations, rich in earthy salts, phosphates, bone dust, lime water, dilute hydrochloric acid, etc.

Name the different forms of diabetes and give the treatment for each.

Diabetes mellitus is characterized by the passing of a large amount of urine, containing an excessive amount of sugar.

Diabetes insipidus is a chronic disease marked by great thirst and the passage of a large amount of urine but no excess of sugar.

Diabetes mellitus is practically incurable; treat by limiting the amount of carbohydrates and feed more fats and proteids. Carnivora may be fed fat meat, eggs, butterinilk. Opium and Carlsbad salts are said to be helpful.

Diabetes insipidus is unsatisfactory to treat. It is usually due to chronic interstitial nephritis. Give vasoconstrictors, as ergot, valerian, etc.

\section{Diseases of the URinary Organs}

\section{Define pyelitis. How diagnosed and treated?}

Inflammation of the pelvis of the kidney. Diagnosed by microscopical examination of the urine and finding epithelial cells from the pelvis, blood-cells and pus. Usual symptoms of nephritis.

Treatment: Abundance of pure water, sodium bicarbonate, urinary antisepties, hot fomentations over loins. 
State the more common causes of urinary cystitis. Give diagnosis and treatment.

Canses: Diuretics, retention of urine, infection, calculi, parasites, unclean catlieter, adjacent inflammation.

Diagnosis: Cloudy urine, containing shreds of mucous membranes, pus eells, blood and triple phosphates and of an alkaline reaction; painful urination; bladder-walls tender and thickened.

Treatment: Disinfect bladder by irrigating with a 3 per cent. solution of boric acid and methylene blue internally. Give an abundance of pure water. Surgically remove calculi.

Give the symptoms and treatment of uræmic poisoning in the dog.

Occurs usually in connection with acute or chronic nephritis; dulness, chill, high fever, vomiting, convulsions, paralysis, CheyneStokes breathing, coma and death. Uriniferous odor to the skin.

Treatment: Venesection followed by infusion of normal saline solution. Withdraw urine and produce sweating with pilocarpus. Move bowels; control convulsions with bromides.

Give the common causes and the treatment for acute nephritis.

Occurs most commonly as a secondary disease. May be caused by cold, drugs, such as arsenic, phosphorus, etc., irritant diureties, toxins from specific fevers, infection, suppression of the urine, calculi, etc.

Treatment: Relieve the kidneys as much as possible by giving diaphoretics and purges. Give urinary antisepties as methylene blue and quiet pain with bromides or chloral hydrate.

\section{What are the causes of polyuria? How treated?}

Chronic interstitial nephritis, tumors of the brain, nervous disorders, mouldy feeds, diuretic drugs, cold, habitual constipation, suppression of perspiration.

Treatment: Remove cause, change food, open bowels; drugs are useless in most cases.

What are the different steps in the examination of the urine?

A. Macroscopical: Determine quantity, color, transparency, consistency, odor and specific gravity.

B. Chemical: Reaction, albumin, indican, bile pigments and sugar.

C. Microseopical : Centrifuge unfiltered urine and examine sediment under the microscope for casts, epithelial cells, blood-cells, pus-cells and unorganized sediments (uric acid crystals, etc.). 
In what conditions do we find albuminuria?

Nephritis, organic heart disease, emphysema, fevers, pneumonia, diabetes, anæmia, leukæmia, hydræmia, hæmaturia, hæmoglobinuria, pregnancy. Often occurs in small amounts in healthy individuals.

\section{Give causes and treatment for hæmaturia.}

Nephritis, injuries to the kidneys, irritant plants with diuretic principle, certain drugs, wounds and inflammation of the bladder, calculi, urethritis and infectious diseases as anthrax and Texas fever are among the common causes.

Treatment: Determine the cause and remove it. Give urinary antiseptics as methylene blue, balsam copaiba, etc.; remove calculi, irrigate bladder with boric acid solution.

\section{Diseases of the Circulatory Organs}

Describe the symptoms of pericarditis in the bovine species.

Usually of traumatic origin. Digestive disturbances, sensitiveness to pressure in the region of the reticulum, tympany of rumen after meals, hurried breathing, groaning, irregular pulse, friction sounds synchronous with the heart-beat followed later by splashing or metallic tinkling sound; dropsical swellings in the dew-lap and sides of sternum; pleurisy and pneumonia may complicate matters.

State the usual causes (dietetic and anatomic) of traumatic pericarditis in cattle and goats. 'Give prevention and treatment.

Anatomically, the reticulum, into which most foreigu bodies are passed, lies against the diaphragm. On expiration and during rumination, the diaphragm is brought in contact with the pericardium and the sharp objects are thus directed into the latter.

Dietetic causes: Ruminants swallow food with little mastication; pins, needles, hay-wire, pieces of tin, etc., if in the feed, are readily swallowed.

Prevention: Avoid the presence of foreign bodies in the feed. Cut hay-wires in the middle instead of near the joints.

Treatment: Generally useless; give laxatives; stand animal with front parts elevated. Surgically remove the offending object through the rumen or chest wall.

Give causes and symptoms of insufficiency of the cardiac valves, auriculoventricular and semilunar.

Insufficiency may be caused by endocarditis which leaves the valves thickened and rigid; cardiac hypertrophy, tumors, parasites, aneurism of aorta near the heart; overexertion may injure the ralves. 
Insufficiency of the right auriculoventricular valve is shown by a systolic murmur, a feeble pulse, distention of the veins, jugular pulse and sedema of the extremities.

Insufficiency of the left auriculoventricular valve is accompanied by a systolic murmur, passive congestion of the lungs, induration of the lung tissue, pulmonary œdema, pulse slightly weaker, dyspnoea on exercise.

Insulficiency of the semilunar valve of the aorta is usually accompanied by hypertrophy, which gives an increased cardiac dulness on percussion, a stronger impulse on palpation and a full, strong, bounding pulse; thrill of the wall of the thorax over the heart; a diastolic murmur which shows its greatest intensity in the left fourth intercostal space below the shoulder line.

Insufficiency of the semilunar valve of the pulmonary artery shows the same as the preceding, except there is no change in the pulse and it is usually accompanied by respiratory disturbances.

\section{Give the treatment for valvular disease of the heart.}

Secure rest for the patient. Give heart tonics as, digitalis, strophanthus, etc. Slaughter meat-producing animals.

\section{What are the usual causes of dropsy of the abdomen, limbs and beneath} the venter?

Valvular heart disease, cirrhosis of the liver, diseases of the kidneys, circulatory obstructions which produce venous congestion as, tumors, aneurisms, etc.

\section{Give the causes, symptoms and treatment of aneurism.}

Causes: Debilitated vascular walls, violence which may rupture the arterial coat, violent exercise, increased blood-pressure, obstruction by embolus and arteritis.

Symptoms: Depends on the location. In general, we note: a soft tumor pulsating with the heart; a double rushing sound, palpitation, cardiac weakness, rapid fatigue, vertigo, and venous congestion.

Treatment: Unsatisfactory. Rest the patient; give a low diet; apply compression or ligature above and below the aneurism. Internal aneurism, which is seldom diagnosed, is irremediable.

\section{In what animals and at what age is cyanosis liable to occur?}

In the new-born animal. It is due to the failure of the foramen ovale to close. 


\section{Diseases of the Respiratory Organs}

Define epistaxis and give its causes.

Bleeding from the nose. It may be due to traumatism, violent exertion, parasites, granulating tumors, uleeration of the nasal passages, anthrax, glanders, purpura hemorrhagica, hæmophilia, etc.

State causes, symptoms and treatment of nasal gleet.

Nasal gleet or chronic rhinitis may follow the acute form or it may be due to diseased teeth; infection or eatarrh of the nasal sinuses. It is also seen in glanders.

Symptoms: A continuous, unilateral or bilateral nasal discharge of a thick, creamy consistency. The submaxillary lymph-glands are hard and enlarged; uleers sometimes form on the mucous membrane; the temperature remains normal and the patient becomes anæmic and emaciated.

Treatment: Locally, apply astringent antisepties, such as nasal douches with Dobell's solution. Internally, give tonics.

What parasites attack the throat in solipeds? Give symptoms, prevention and treatment in each case.

Homopis sanguisuga (horse leech) attaches itself to the walls of the pharynx and larynx and produces cough, laryngitis, dysphagia and epistaxis. Prevent by avoiding waters harboring the parasite. Treat by throwing salt solution on them and remove with a dry towel or forceps.

Cestrus larve (bots) are sometimes attached to the pharynx and larynx. They produee ehronie irritation, cough and dyspnœa. Prevention depends upon the destruction of the bots and the mature fly, the cestrus equi. Treatment consists of removing the bots with the forceps or hands. Laryngotomy may be necessary.

Give the symptoms and treatment of œdema of the glottis.

Sudden appearance of dyspnœa and an extensive painless, œdematous swelling in the laryngeal region. The temperature is normal; sweating, an anxious expression and paroxysm of eougling are observed.

Treatment: Perform traeleotomy and insert tube. Apply astringent and absorbing agents externally. Burrow's lotion or white lotion could be used on cotton and held in place by a throat bandage.

State the usual causes of inhalation bronchitis and pneumonia.

Faulty methods of drenehing which allows medicine to enter the trachea; dysphagia due to pharyngitis, tetanus, etc. Sometimes 
follows chloroform anæsthesia; inhalation of smoke or irritant gases; regurgitation of food when in a comatose condition as in milk fever. May follow tracheotomy operation.

Give the diagnostic symptoms, prevention and treatment of inhalation pneumonia.

Fever, anorexia, cough, bronchial rales, dyspnœa, fetid odor to the expired air, mucopurulent nasal discharge containing shreds of necrotic tissue; dulness in the lower part of the thorax.

Prevention: Guard against causative factors. Be carefi. in drenching and see that no part of the medicine enters the traclea. Don't drench cows with milk fever, nor horses with tetanus, pharyngitis or other conditions in which there is danger of inhalation of the fluid.

Treatment: Antiseptic inhalations of the vapor or eucalyptus, tar, carbolic acid or turpentine. Intratracheal irrigation with a 1 per cent. solution of hydrogen peroxide in a normal salt solution. Give stimulants and antipyretics.

What domestic animal is most susceptible to bronchial asthma? Give causes, symptoms and treatment for this disease.

The dog is most subject to bronchial asthma.

Causes: Nervous origin, reflexly from pneumogastric irritation due to digestive disorders. The muscle fibres of the bronchi contract and narrow the lumen, thus bringing on paroxysms of coughing.

Symptoms: Obesity, sluggishness, paroxysmal cough and dyspnoa. Usually have digestive disorders.

Treatment: Antispasmodies per rectum or subcutem; cathartics; dietary restrictions to lessen obesity.

What animals suffer from strongylus rufescens? Name the disease produced and the symptoms.

The sheep and goat.

The disease is variously known as verminous bronchitis, bronchial strongylosis, hoose, husk and paper skin disease.

Symptoms: Occurs enzoötically; loss of appetite, unthriftiness, emaciation, fever, dyspnœa, fits of coughing, convulsions, anæmia and emaciation.

What is the treatment for verminous bronchitis in calves?

Inhalations of oil of eucalyptus and turpentine, in a vapor of steam. Intratracheal injection of 15 to 20 c.c. of a 5 per cent. solution of creolin in olive oil. Give stimulants and nourishing food. 
Give cause, symptoms and treatment of gapes in fowls.

Cause: This disease is due to the presence of the parasite, syngamus trachealis, in the trachea.

Symptoms: The bird gapes, sneezes, coughs and discharges mucus, which often contains the worm, from the mouth; dulness, drooping of wings, inappetency. Worms may be seen in the trachea.

Treatment: Remove the worm with forceps or a loop of horse hair.

S: tate the immediate and the remote causes of acute pulmonary congestion. Give the treatment.

The immediate cause is a rush of blood to the lungs. Remote causes are: fat, plethoric condition; sudden chilling; infectious diseases; overfeeding; hot weather; heart diseases and venous stasis.

Treatment: Venesection, counter-irritation over thorax and friction to extremities; heart stimulants, plenty of fresh air. Usually terminates in pneumonia or recovery in 24 hours.

Give the distinctive symptoms of bronchitis, pneumonia and pleurisy, respectively, in the early and fully developed stages.

Early stages: Bronchitis, dry hard cough, normal percussion sound, bilateral, sibilant râles and dyspnœa. Pneumonia (pulmonary congestion), restrained cough, increased resonance on percussion, unilateral crepitant râles, dyspnœa more marked. Pleurisy, painful cough, tenderness to percussion, bilateral friction sounds, pleuritic ridge, high temperature.

Fully developed stages: Bronchitis, resonanee on percussion, mucous râles, temperature high. Pneumonia, dulness on percussion, absence of vesicular murmur, temperature high throughout the attack. Pleurisy, temperature lower, flatness on percussion bounded by a horizontal line, inereased resonance above. 'Tenderness on percussion.

\section{Give the symptoms of gangrene of the lungs.}

Rapid respiration, moist râles, purulent nasal diseharge eontaining slreds of neerotic tissue, fetid odor to breath, high fever, rapid weak pulse and great prostration.

Give the symptoms, course and treatment of acute diffused pleuritis. Chill, fever, hard pulse; rapid, shallow breathing, patient remains standing, pleuritic ridge, suppressed cough, tenderness in the intercostal region, groaning when turned sharply, friction sounds. Later, there appears a horizontal line of dulness, splashing 
metallic tinkling, œdemas. Course may run from a few days to several weeks, depending upon the continuance of the hydrothorax.

Treatment: In early stages, venesection, counter-irritants on chest, such as mustard plasters, oil of mustard and oil silk jacket; apply friction to legs and bandage them warmly. Give a laxative diet. Later, thoracentesis may be advisable to remove the exudate. Give diuretics and stimulants.

Describe a case of pleurisy in the dog.

About the same as previously mentioned in the horse. Dogs sit on haunches and pant. In case of effusion, the horizontal line of dulness changes with the different attitudes the dog may assume.

Give the cause, symptoms and treatment of hydrothorax.

Caused by pleurisy, venous stasis, heart disease, kidney disease, anæmia, parasites, etc.

Symptoms: Dyspnœa, horizontal line of dulness in lower part of thorax, no fever; general dropsy, if from heart and kidney diseases.

Treatment: Diuretics, derivatives, thoracentesis, laxative diet and tonics. Usually incurable.

Describe the symptoms of pulmonary emphysema. Outline treatment.

Double expiratory movement, husky, wheezing cough, dilated nostrils, dyspnœa easily produced by exercise, muggy weather or a full stomach. Digestive troubles often accompany heaves. Occasionally there will be seen a glairy nasal discharge. Cardiac weakness.

Treatment: Dietetic measures such as a laxative diet, concentrated foods and a restricted amount of hay or straw. Give arsenic in graduated doses. Belladonna is useful to suppress the cough.

How would you guard against fraudulent attempts to conceal the symptoms of heaves?

Keep the horse under observation for 48 hours. Give plenty of hay and water and exercise. The dilated nostrils are hard to conceal. Adrenalin chloride aggravates respiration and may be an aid to diagnosis.

\section{Diseases of the Digestive Organs}

Define glossitis and give causes for same.

Glossitis is an inflammation of the mucous membrane and substance of the tongue. It may be due to mechanical, thermal and chemical agents. Infection should be reckoned with, especially specific infections, as in foot and mouth disease, lip and leg ulceration of sheep, etc. 
What animals and what organs are infested by linguatula tænoides? Give diagnosis and treatment, both therapeutic and preventive.

This parasite infests the nasal chambers, turbinated bones, frontal sinuses and pharynx of the dog and occasionally the horse.

The diagnosis is based upon sneezing, coughing, rubbing nose, dyspnœa, epistaxis, convulsions and finding the parasite in the discharge.

Treatment: Nasal douche of benzene 5 parts, and olive oil 100 parts. Prevent dogs from eating the raw offal of sheep. Destroy the heads and carcasses of dead sheep containing the larvie.

How does vomiting in cattle differ from regurgitation? Where does the ejected food come from? How is vomiting diagnosed and treated?

In vomition, there is a greater effort made and the quantity is so great that it runs from the mouth, whereas, in regurgitation, no effort is required and the amount is so small that it is retained in the mouth. The ejected material comes from the rumen. Vomiting is diagnosed by the uneasiness, straining and peculiar smell of the ejected material. Treatment is seldom called for as the act relieves the patient and removes the cause. If too prolonged, give sedatives, such as bromides and chloral and empty the bowels with liberal doses of Epsom salts.

What parasites affect the gullet of cattle? State other habitats of any of these parasites.

Spiroptera scutata and the larvæ of the cestrus (hypoderma) bovis are also found in the stomach of cattle and the gullet of the horse. Psorospermia oviforme (coccidia) inhabit the mucous membrane of the gullet and various other organs, including the liver, intestines, etc., of sheep, goats, pigs, rabbits and man. Sarcosporidia invade the muscles of the ox, pig, sheep and horse.

Describe the symptoms of a case that on post-mortem examination reveals a ruptured stomach.

The abdomen enormously distended with gas on the left side under the ribs. Colicky pains, dyspncea, belching of gas, retching and regurgitation of stomach contents. Sudden paleness of mucous membranes, syneope and death.

Give causes, symptoms and treatment of tympanites in cattle.

Also called "hoove," "hoven," and bloating.

Caused by gascous fermentation of the contents of the rumen. Overfeeding on green foods, especially clover when wet with dew. 
Paresis of the rumen may cause or follow tympanites. Poisons, spoiled foods and foreign bodies are also causative factors.

Symptoms: Abnormal distention of the left side of the abdomen. Drum-like sound on percussion, crepitation heard due to gas bubbles. Suspension of rumination, belching, rapid breathing, frothy foam from mouth, protrusion of anus and sometimes bloody fæces. Death in 15 to 30 minutes.

Treatment: Puncture the rumen with trocar. Pass stomach tube and siphon off the contents of the rumen. Administer through the tube, aromatic spirits of ammonia, oil of turpentine or peppermint. Follow with a large dose of Epsom salts when the tympany subsides. Any treatment must be prompt and energetic.

\section{Describe the symptoms of jaundice. Name causes.}

Icterus or jaundice is characterized by a yellow discoloration of the visible mucous membranes and skin, and the presence of bile pigment in the urine; fæces are pale and dry and the patient shows dulness and loss of appetite.

Causes are numerous, viz., catarrh of duodenum and bile duct, gall-stones, compression of bile duct by tumors and overloaded stomach; acute and chronic hepatitis, rupture of gall-bladder (no gall-bladder in the horse), poisons, parasites, icterus neonatorum, severe infectious diseases, etc.

State the relative gravity of jaundice in the horse and in the dog.

Generally ends in recovery in the horse. In the dog, it is more serious and usually ends in death.

Give the causes and symptoms of acute gastric indigestion.

Overloading, spoiled foods, fermentiscible foods, ice-water, especially after feeding, previous disease, overwork, defective teeth and parasites.

Symptoms: Violent colic, bloating of abdomen and under the ribs on the left side; suppression of peristalsis and passage of fæces; attempts to eructate and vomit; hurried breathing.

In acute tympanitic gastric indigestion, what is the usual reaction of the contents of the viscus? What measures, mechanical, chemical and medicinal, would be especially indicated?

Reaction acid.

Treatment: Pass stomach tube; lavage; puncture the stomach with a trocar passed through the twelfth or thirteenth intercostal space on the left side; give 6 or 8 ounces of sodium hyposulphite in solution. Aromatic spirits of ammonia, turpentine, carbolic acid 13 
and other antiferments may be useful. After the acute symptoms subside, give a full dose of aloes.

Give the diagnostic symptoms of (a) crapulous colic, (b) purely nervous colic. Give treatment of each.

(a) Crapulous or engorgement colic is manifested by an overdistended abdomen, dull percussion sound, continuous dull pain and a "saw-horse" attitude. Rectal examination reveals the solid ingesta.

(b) Purely nervous or spasmodic colic is diagnosed by the remittent pain, intervals of ease; uneasiness, kicking of abdomen, getting up and down, inereased peristalsis; more or less freces passed.

Treatment: In crapulous form, give an aloes ball or one quart of linseed oil or both. Quick-acting cathartics, sucl as arecoline in one-fourth grain doses, repeated every twenty minutes. Quiet the pain with chloral hydrate. Spasmodic colic should be treated with antispasmodies, such as chloral hydrate and cannabis indica. Empty the bowels with an aloes ball, salts or oil.

State the cause of diarrhœa in the new-born and prescribe preventive treatment.

See "white scours," page 294. This disease may be simple or contagious. Among the many causes are improper food, bacteria, navel infection, unelean feeding utensils, cold and weakness. Prevention: Dietary measures; scald feeding utensils; intestinal antisepties, such as, bismuth subnitrate, phenol, etc. Sanitary measures as prescribed under "white scours."

What is intussusception? Give symptoms, prognosis and treatment.

Invagination or telescoping of one portion of intestine into another.

Symptoms: Obstruction, vomiting, no frees passed; continuous colicky pains; later, fever appears, weak pulse, sweating and death. 'Tubular seetions of intestines may be passed. Obstruction may be felt in the dog.

Prognosis: Usually fatal.

Treatment: Laparotomy and replacement of intestine is the only available measure. Iinseed oil and antispasmodics may relieve.

What genera (equine, bovine, porcine, canine) are most liable to intestinal invagination? Why?

More common in bovine; less common in canines and very rare in the equine and porcine.

The spiral arrangement of the intestines and the looser disposition of the mesentery may account for the more frequent appear- 
ance of this condition in bovines. In the equine, the voluminous crecum may receive the ileum and the spacions colon, the cxcum. The intestines of the dog and hog are comparatively simple.

Give the symptoms and treatment for lead poisoning in cattle.

Emaciation, shortness of breath, paralysis of extremities, blue line on the gums and abortion are seen in the chronic form. The acute form shows blindness, stupor, coma, convulsions or delirious excitement, torpor of bowels, gastro-enteritis, vomiting, salivation, suppression of milk and urine and museular eramps.

Treatment: Sulphate of magnesia or other forms of sulphates which form insoluble sulphates of lead. Chronic form: give potassium iodide and tonies.

Mention two intestinal parasites of the horse. Write a prescription for worms in the horse.

Ascaris megalocephala and oxyuris curvula.

$\mathrm{R}$

Antimonii et Potassii tartras ............ 3iij

Div. pulv. No. iv.

Sig.-Give one powder in drinking water every six hours and follow with

R

Sodii sulphatis $\ldots \ldots \ldots \ldots \ldots \ldots \ldots \ldots \ldots \ldots \ldots \ldots \ldots \ldots \ldots$

Sig.-Dissolve in water and give as a drench.

State the factors that produce gall-stones. Give prophylactic and therapeutic treatment.

Precipitation of biliary solids, bacterial infection, concentration of the bile due to idleness, and dry feeding; presence of colloid material as mucus, pus, blood and epithelial cells due to inflammation.

Prophylaxis: Avoid dry feeds; give plenty of water and exercise and keep bowels active.

Treatment: Give narcotics to lessen pain; eathartics such as calomel or olive oil; salicylate of soda or salicylic acid as an intestinal antiseptic. Operative removal of stones.

What tapeworms infest solipeds and what is known of their larval forms?

Tænia perfoliata, tænia mamillana and tænia plicata. Nothing known of their larval forms.

What symptoms indicate ascaridæ and what sclerostomata in the bowels of the horse? How does the prognosis differ in the two cases?

Ascaridæ = slight, recurrent colics, ravenous appetite, unthrifti- 
ness, gastro-intestinal catarrh, passing of worms 6 to 12 inches long.

Sclerostomata $=$ violent colic, frequent defecation, followed by arrest, eyes sunken, cold sweating, paralysis of bowels, death. These symptoms are not due to the presence of the worm in the bowel but to its embryonic form which lodges in the anterior mesenteric artery, causing a thrombus and emboli to form. The latter being carried to the peripheral arteries of the intestinal walls produce the fatal results. Otherwise, the mere presence of the mature worm in the bowels, unless in large numbers, may pass unnoticed. If abundant the symptoms are similar to those of ascariasis and, in addition, marked anæmia and emaciation.

Prognosis: Good in aseariasis; very bad in case of obstruction of the mesenteric arteries by selerostomata ("thrombo-embolic colic").

How may the following be distinguished: sclerostoma equinum, sclerostoma tetracanthum, oxyuris curvula and oxyuris mastigodes? State the relative gravity of infestation by each, giving reasons.

The sclerostoma equinum is larger than the sclerostoma tetraeanthum, and its head terminates bluntly, whereas the selerostoma tetracanthum has a tapering anterior extremity. Oxyuris curvula and oxyuris mastigodes are nearly identical except that the female of the latter is 3 to 4 inches long and of the former only 1 to $11 / 4$ inches.

Sclerostoma tetracanthum is comparatively harmless; it sucks blood and may injure the mueous membrane, produeing unthriftiness.

Selerostoma equinum is very harmful; its embryonic form enters the circulation and produces thrombo-embolic colic which ends in death.

The oxyuridx lodge in the rectum and cause nneasiness and unthriftiness.

What conditions favor the propagation of strongylus (sclerostoma) equinum and tetracanthum and what measures will prevent their production?

Fecal contamination of water and feed favors the development of these worms. As preventive measures, clear the intestinal tract of the worms and destroy the frecs containing the parasites and eggs of same. Prevent contamination of water with fxees. 
What domestic animals are liable to be attacked by the hookworm (uncinaria, anchylostoma)? How do such worms enter the body and what symptoms do they produce? Give treatment.

Ox, sheep, cat and more commonly the dog. The worms enter the intestinal tract through the drinking water which contains the larve.

Symptoms: Digestive derangements, dulness and indifference; whining, tympanites, diarrhoea, loss of appetite, nervous disorders, nausea, anæmia and emaciation.

Treatment: Thymol, 2 to 15 grain doses. Separate the sick from the well to prevent reinfection. Thoroughly clean and disinfect kennels. Supply pure drinking water.

What are coccidia? Name the domestic animals infested by coccidia, mentioning in each case the organs infested. Give diagnosis, prevention and treatment in each case.

Coccidia are a genera of sporozoa, single-celled microörganisms provided with a protoplasmic-celled body in which is found a nucleus.

Cattle, sheep, rabbits, fowls and, occasionally, dogs and pigs are infested. The intestines are more commonly affected in cattle, sheep and fowls, whereas the liver is usually the seat of disease in rabbits, dogs and pigs. Both organs may be affected in all animals. There are a few cases of diseases of the air passages reported in cattle, dogs and rabbits, due to coccidia.

Diagnosis: Fetid, hemorrhagic diarrhœa, fever, loss of appetite, weakness, death, jaundice, when liver is affected; coccidia may be found in the fæces by microscopic examination.

Prevention: Provide pure water; disinfect fxees with 3 per cent. watery solution of sulphuric acid; destroy carcasses and thoroughly disinfect.

Treatment: Remove from pastures; give dry foods and intestinal astringents and antiseptics. Useless to treat the hepatic form.

Describe all the symptoms produced by constipation in the dog.

Small, hard, glazed stools, straining, no stools passed; hot, tender, swollen, bulging anus; colicky pains, tenderness of abdomen, vomiting, fever, icterus, etc.

What are the symptoms of intestinal parasites in the dog other than the passage of worms by the mouth or rectum?

Diarrhœa, vomiting, emaciation, nervousness, convulsions, anæmia, pot-bellied, easily fatigued, whining. 
Describe the symptoms of acute parenchymatous hepatitis in the dog and give treatment.

Tenderness to pressure over the liver, pain during defecation, jaundice, fever, constipation and vomiting.

As treatment, give mild laxatives such as olive or castor oil. Calomel is very good. Intestinal antisepties such as salol, sulphocarbolates, etc., are useful. Restriet the diet, avoiding fats.

Give the causes, symptoms and treatment of peritonitis.

Causes: Infection, traumatic injuries, operative wounds in the abdomen, eastration, laparotomy, perforating ulcer of the intestines, rupture of the stomach or intestine, perforation of a parturient womb, rupture of abseesses in the peritoneal cavity, metastasis.

Symptoms: Presence of a wound with spreading swelling, œdema and tenderness of the abdomen, tucked up abdomen, high fever, quick, wiry pulse, careful decubitus and rising, short, catchy respiratory movements, straddling gait, short steps, constipation, effusion may cause fluctuation and enlargement of the abdomen.

Treatment: Local antiseptics, drainage of wounds, irrigation of the peritoneal eavity with sterile water; saline laxatives, intestinal antiseptics; stimulants; apply mustard over abdomen.

\section{What is ascites? Give causes of ascites.}

Ascites is an accumulation of a serous fluid in the peritoneal cavity. It is caused by chronic peritonitis, venous stasis due to obstruction of the portal vein by tumors, indurative hepatitis, ete. Valvular disease of the heart, kidney diseases, hydremia, tubereulosis and heaves are also etiological factor's.

Mention the different forms of ergotism in cattle. Give the symptoms of each form mentioned.

Acute: Gastro-enteritis, ptyalism, vomiting, colicky pains, diarrhœa, ulcerous stomatitis, labor pains, abortion, prolapsus uteri, insensibility to pain, paralyses, dilatation of the pupils, museular cramps.

Chronic: Neerosis of extremities such as the ears, tail, teats, claws and lower leg; abortion and sterility.

Give causes, symptoms and treatment of distomiasis (liver rot) in sheep.

Caused by the presence of the liver-fluke parasite, distoma hepatieum, in the bile ducts.

Symptoms: During the period of invasion of the parasite, lasting 2 to 3 months, the sheep gain in flesh ; later, dropsy, emaciation, diarrhœa alternating with constipation; variable temperature, icterus, 
presence of the ova in the fices, usually terminates in death. Some recover to be reinfected the following year and then succumb.

Treatment: Prevention; drain soils, avoid low, damp, infected pastures, give common salt in feed, feed well and fortify the system; tonics, vermifuges. Treatment is unsatisfactory.

State the effects of overfeeding cattle and swine with cotton-seed meal.

May produce garget and mammitis in cattle. Will destroy the life of swine with symptoms of scurvy and grave constitutional disorders. In both animals, it may produce diarrhœa, lachrymation, abscess formation, ulceration of the cornea, staphyloma, fever, œdema of the legs, congestion of the liver and spleen, and high-colored urine.

\section{Disenses of the Nervous System}

What is loco poisoning? Where and when is it enzootic and how can it be prevented?

Loco poisoning is a disease of animals, manifested by cerebral disturbances, caused by eating a certain variety of leguminous plants. After once eating these plants, a desire for more becomes a veritable craze or neurosis and the patient becomes unmanageable, vicious and loses flesh.

It is enzoötic in the summer and fall of the year in the Rocky Mountain states and Pacific coast region. To prevent the disease, do not pasture animals on fields where the plant is present, nor feed hay and grasses from such fields.

Describe immobility. Give its causes, symptoms, diagnosis and treatment.

Immobility, chronic hydrocephalus, is a chronic disease of the brain.

Causes: Heredity, congestion of the brain, traumas, venous obstruction, tumors, insolation, hepatic, gastric and pulmonary disorders.

Symptoms: Stupid expression, sluggish movements, dulled reflexes, slow mastication, failure to respond to commands, standing with legs crossed or in other abnormal positions for long periods of time, incoördinate movements.

Diagnosis: Easy in well-marked cases. The above symptoms, together with a normal temperature, are almost conclusive.

Treatment: Derivatives, nux vomica, purgatives, potassium iodide and other drugs may relieve, but the disease is incurable.

Describe abdominal vertigo. Give causes, symptoms, prevention and treatment.

Abdominal vertigo, stomach staggers, is a complication of gastric 
and hepatic disorder associated with giddiness and unsteady movements, caused by overloading the stomach, worms and gastrointestinal catarrh.

Symptoms: Gastric irritation, colicky pains, eructation of gas, delirium followed by a comatose condition.

Prevention: Reduce rations and exercise regularly.

Treatment: Give intestinal evacuants; venesection or derivatives such as arecoline and pilocarpine; laxative diet; chloral hydrate during the violence of the attack.

Give the symptoms of inflammation of the meninges of the brain.

Phrenitis, encephalitis, pachymeningitis or inflammation of the brain proper and leptomeningitis, inflammation of the coverings of the brain usually coexist and are indistinguishable, symptomatically; they are shown by hyperæsthesia, delirium, pawing, plunging, and violent convulsions, followed by dulness, stupor, somnolence, muscular weakness, anæsthesia, paralysis and coma.

\section{Give the causes and symptoms of gid in sheep.}

Caused by the presence of the cystic form of the tconia cœmurus (ccenurus cerebralis) in the brain.

Symptoms: Timidity, nervousness, dulness, dilated pupils, drooping lids, circular movements, pivoting on one foot, plunging ahead, hemiplegia and paraplegia.

\section{Give causes, symptoms and treatment of chorea in the dog.}

Causes: Weakness, previous disease, microbian toxic matters in the blood, hence it usually follows distemper.

Symptoms: Local twitching of one or both fore limbs, neck, head, maxilla, eyelids, hind limbs, or the whole body may participate; movements are rhythmical, are less active when recumbent, and may or may not be absent during sleep.

Treatment: Hygienic measures, fresh air and sunshine, nerve tonies, such as arsenic and strychnine; nerve sedatives may be indicated if too restless, such as belladonna, chloral hydrate, bromides and morphine. Usually incurable.

What symptoms would tend to distinguish cerebral anæmia from cerebral hyperæmia?

Cerebral Ancomia.

Loss of consciousness.

Stumbling.

Vomiting in dogs.

Paleness of mueous membranes.

Respiratory movements shallow and slow.
Cercbral Hyperamia.

Cerebral exeitement.

Delirium.

Mucous membranes injected.

Respiratory movements accelerated. 
Give the symptoms of cerebrospinal meningitis.

Often occurs enzoötically. First stages: Sudden attack, fever, hypersensitiveness, delirium. Later, paralysis of various parts, as the pharynx, shown by inability to swallow, loss of appetite, unequal dilatation of pupils, loss of reflexes, decubitus, spasms of various groups of muscles, opisthotonus. The symptoms vary in different individuals and no two appear exactly the same.

\section{Describe a case of sunstroke and give treatment.}

Insolation or sunstroke comes on suddenly; shown by cessation of perspiration, dyspnœa, staggering and falling down, weak pulse, high temperature $\left(104^{\circ}-110^{\circ} \mathrm{F}\right.$.), cerebral excitement and loss of reflexes.

Treatment: Remove to a cool place; apply ice-bags on the head and give cold water enemas; quiet with chloral liydrate; give heart stimulants such as ammonium carbonate, camphor, digitalis, etc.

\section{Diseases of the Organs of Locomotion}

\section{Mention causes, symptoms and treatment of articular rheumatism.}

Causes: Infection, retained after-birth, cold and dampness. Often seen in connection with endocarditis.

Symptoms: Shifting lameness; heat, swelling and tenderness of one or more joints; decubitus, joints semiflexed, fever, loss of appetite.

Treatment: Antirheumatics such as salicylic acid or salicylate of soda in three-drachm doses every six hours; aspirin, antipyrin and salol are also useful. Locally, apply linimentum saponis, artificial oil of wintergreen, and heat. Slaughter meat animals.

\section{Give causes, symptoms and treatment of muscular rheumatism.}

Causes: Infection, cold, dampness, predisposition. Usually occurs in well-fed and nourished animals.

Symptoms: Shifting, recurrent lameness; muscular soreness; symptoms vary, depending upon the muscles involved; thus we may observe lameness in the shoulder, posterior limbs or neck, difficult mastication, breathing, etc. Fever is usually absent, although there may be a slight rise in severe cases. Appetite remains good. Dogs cry out when handled.

Treatment: Provide warm, dry quarters, warm blankets and administer antirheumatics, such as salicylates, quinine, salol, etc. Give a laxative diet and occasional doses of saline cathartics. A Turkish bath may benefit dogs. 
What domestic animals suffer most from trichinosis? Give usual channels of infection, diagnosis and prevention.

This disease occurs most commonly in swine, rarely in dogs and cats. The infection enters through the digestive tract by eating meat containing the parasite, trichina spiralis.

Diagnosis: Rheumatoid symptoms; harpoon muscle and obtain specimens for microscopical examination; examine the freces for the adult worm. Hogs often show diarrhea, and during the migration of the embryos into the muscles, rubbing, scratching, difficult mastication, and painful breathing.

Prevention: Destroy carcasses of trichinous animals. Destroy rats and mice around slaughter houses as they are frequent hosts of the parasite.

\section{Describe a case of spasm of the muscles of the hind leg and its treat- ment.}

Usually seen in the femoral region, due to a nervous affection of the anterior crural muscles. Appears suddenly after standing; leg held stiffly ; appears longer than its fellow ; knuckling at the fetlock, resting on the toe; difficulty in moving forward or baekward, dragging of the extremity; anterior muscles rigid

Treatment: Rub stimulating liniment over the stifle; rest the patient and give a laxative diet.

\section{DISEASES OF THE SKIN}

\section{Give the symptoms and treatment of acne.}

Acne is an inflammatory disease of the sebaeeous glands, characterized by tenderness of the skin, swellings the size of a pea, vesicles, pustules, exudation, loss of hair, scars and sometimes enlargement of the submaxillary lymph-glands; absence of fever. Treatment consists of the application of astringent and antiseptic washes, such as a 2 per cent. solution of aluminum aeetate or acetate of lead.

Describe the symptoms and give the treatment of favus (ringworm).

Charaeterized by the presence of numerous red spots in the skin, which gradually enlarge and become covered with a thin, grayish seale under which is serum; the hair breaks off, the circumference of the diseased area becomes reddened, the centre, gray-colored and cupped shape; there is great itching present and the disease tends to spread over various parts of the body.

Treatment: Scrape or curette deeply; paint with tincture of iodine or use mereurial ointments. 
Give the symptoms, course and treatment of gangrenous dermatitis.

This disease is generally preceded by swelling, redness and sensitiveness. Then follows discoloration, insensitiveness, putrid odor; a dry or moist portion of the skin is east off, revealing a raw, ulcerative surface.

Course: Progressive, unless properly attended to. May extend deep into the tendons and ligaments or produce fatal septicæmia.

Treatment: Remove dead parts; apply dry dressings of iodoform, boric acid or lead preparations.

Give the cause, symptoms and treatment of urticaria.

Urticaria is an inflammatory affection of the skin, characterized by a sudden development of a serous infiltration of the papillary bodies and of the malpighian layer of the skin. It often disappears completely after a short time.

Causes: Digestive derangements, plethora, rich grain feeding, hot weather, intestinal poisons, bites of insects, individual idiosyncrasy, poisonous plants as poison ivy, etc.

Symptoms: Sudden eruption; in a few hours a healthy skin becomes covered with a uniform eruption of nodules, or blotches, some of which may coalesce and form large areas. Itching may or may not be present; individual nodules subside to be followed by others.

Treatment: Saline cathartics, aloes, alkaline diureties; allay itching by bathing with solutions of sodium bicarbonate, phenol or menthol.

Name the different forms of parasitic skin disease, mentioning the parasite for each form named.

Sarcoptic mange, due to sarcoptes scabei.

Psoroptic mange, due to psoroptes communis.

Symbiotic mange, due to symbiotes communis.

Demodectic mange, due to demodex folliculorum.

Ringworm, due to trycophyton tonsurans.

Ox warble, due to larva of hypoderma lineata.

Cutaneous coccidiosis, due to coccidia oviforme.

Fleas, lice and ticks occasionally burrow under the skin and produce irritation.

What parasites are known to produce cutaneous epizootics?

All those mentioned above but more especially the sarcoptidæ and demodecidæ.

Give the cause of poultry acariasis in the horse. Give treatment.

Housing chickens, infested with the chicken mite (dermanyssus gallinæ), in or near the stable. The mites become temporary para- 
sites of the horse, causing pruritus, scratching, rubbing and a rough coat.

Treatment: Wash with a 2 per cent. solution of creolin, or dissolve four ounces of staphisagria in one gallon of boiling water and use as a wash when cool. Clean the stable thoroughly and use a whitewash containing carbolic acid.

What are the causes, dietetic, climatic, chemical and traumatic, of erythema? Give prevention and treatment of each form of erythema.

Primary erythema is due to external irritants, blows, bites, scalding, burning, sun's rays, vesicants such as mustard, cantharides, acids, lye, insect stings, etc.

Secondary erythema is due to infectious diseases, as swine plague and hog cholera, dog distemper, foot and mouth disease; also follows the ingestion of certain foods as buckwheat, clover and distillers' grains.

Prevention depends upon the avoidance of the above enumerated causes. Treatment: Cold, astringent applications such as Burrow's lotion, Goulard's extract, etc. Give a laxative diet.

Mention one of the parasites that causes mange in the dog.

Demodex folliculorum causes demodectic or follicular mange, which is practically incurable.

What animals and what regions of the body harbor demodex folliculorum? 'Give symptoms and treatment.

The dog and pig. The breast, legs, axillary and facial regions are usually first affected, later the entire surface of the body and legs may be involved.

Symptoms: The skin becomes red and thickened; loss of the hair; extreme pruritus; pustules give the skin a papillated appear. ance.

Treatment: Unsuccessful; a mixture of gasoline, oil of tar and oil of cade has given more or less satisfaction; sulphur and lye is used by some, but the great majority of cases show no improvement and gradually grow worse, become emaciated and die. Some few improve and seem to be cured, only to have the disease break out anew.

Mention the parasites causing scabies in sheep. State the habits of these parasites.

Sarcoptes scabei, rare.

Psoroptes communis, common scab parasite of sheep. 
The psoroptes live on the surface of the skin, eat wool, irritate and cause the animal to bite and pull out the wool.

The sarcuptes burrow under the skin and produce itching and scabs.

Give the prevention and treatment of acariasis.

Quarantine regulations; separation of well from affected; thorough disinfection; dipping and isolation of newly-purchased animals until known to be free from scabies.

Treatment: Lime and sulphur dips, and a tobacco and sulphur dip are recommended by the B.A. I., Dept. of Agriculture. Coaltar products such as creolin, creosote, etc., have given good results.

Give the causes, symptoms and treatment of the disease commonly termed "hunger mange."

This is another name for chronic squamous eczema.

Causes: Insufficient nourishment, faulty skin hygiene, tender skin, nervous temperament, chronic wasting diseases, may follow acute eczema. Long administration of iodides is sometimes followed by this condition.

Symptoms: Poor condition, dry lustreless hair which contains bran-like scales of epidermis; falling out of the hair; itching; skin becomes thickened and occasionally papules and vesicles are seen.

Treatment: Correct the internal disorders; give tonics, arsenic ; careful grooming, and bathing with non-irritating soap. Feed generously with nourishing foods. 


\section{SURGERY*}

\section{WOUNDS}

\section{Define wounds. Give a classification of wounds.}

A wound is any injury accompanied by a breach in the continuity of an internal or external surface.

According to cause, wounds are classified as follows: incised, lacerated, punctured, contused, stab, gun-shot, bites and caustic.

\section{What is wound infection? Give treatment of wound infection.}

The presence of microörganisms or their toxic products in a wound. Treatment: Drain, irrigate, disinfeet thoroughly, and cover with aseptic gauze and bandage. Repeat dressing daily. If impracticable to bandage, apply a protective covering of dusting powder.

\section{State the general principles of antiseptic wound treatment.}

Remove foreign bodies and necrotic tissue, cleanse wound thoroughly and use a non-irritating antiseptic agent. Cover the wound with antiseptic gauze and bandage. In case of operative wounds, the site of operation is shaved, washed and bathed with an antiseptic agent; if possible an antiseptic pack should be applied for 24 hours prior to operating. The operator's hands, nails and arins should be scrupulously eleansed with soap, water and a stiff brush, then with alcohol or ether to dissolve all oily secretions, and, finally, immersed for ten minutes or longer in the antiseptic agent. The instruments, suture material, dressings, ete., are disinfected by being placed in the antiseptic solution for 10 minutes before using. They should be handled only by the operator's disinfected hands. After operation and at subsequent visits, dressings are carried out as directed above.

State the distinction between antiseptic and aseptic wound treatment.

In antiseptic wound treatment, as described above, there are many ehannels of infection overlooked, as from the air, breath of operator, etc.; furthermore, most antiseptic solutions, if efficient germicides are irritating to the tissues and retard healing.

Aseptic wound treatment may be defined as the preeantion to prevent infection of the surgieal wound, while antiseptic surgery refers to the method by which the former is aceomplished and to

* Unless otherwise stated all questions relate to the horse. 
the treatment of unavoidable infections. So, antiseptic wound treatment is giving way to the aseptic method. 'This latter, as its name implies, aims toward the absolute freedom from septic material. This is accomplished by sterilizing all instruments, dressings, bandages, etc., with steam, hot air, or boiling in a one or two per cent. soda solution. The wound is eleansed with sterile water or sterilized physiologieal salt solution, but no antiseptie solution, and covered with the sterilized dressing. 'The operator's hands are cleansed as in the antiseptic method but are rinsed in sterile water to remove all traces of the antiseptie. Some operators use sterilized rubber gloves. 'The operating table, operating field, operator's clothes, assistants, all utensils and the air of the room must be rendered aseptic. This method is impracticable in veterinary surgery for obvions reasons. The antiseptic method with aseptic precautions is preferred.

\section{Mention and describe the different methods of wound healing.}

1. IIealing by first intention consists of a direct union of the margins of the wound through immediate agglutination and withont suppuration.

2. Healing by second intention is characterized by suppuration and granulation.

3. Healing by third intention consists in the artificial union of wound surfaces that are already gramulating and suppurative. It is effected by disinfecting and suturing the suppurative granulations.

4. Healing under an eschar is a form of primary wound healing. The protective coat may be dried blood or a seab produced by actual cautery, ehemical causties, dusting powders, ete.

5. Healing by abnormal granulation and cicatrization takes place when great loss of substance oecurs, when foreign bodies or necrosed pieces of tissue remain in the wound, or when continued infection or irritation oceurs in fresh or healing wounds.

State the indications for the use of the continuous suture.

In non-infected wounds where healing by first intention is anticipated; in viseeral wounds where perfect closure is imperative; and in cases where temporary retention of dressings in the traumatic cavity is desired.

\section{Mention the indications for the reopening of wounds.}

When infection occurs in the deeper part of a wound as shown by escape of discharges or swelling; when necrosed tissue or other foreign bodies are present in the deeper part of the wound. In wound infection diseases as septicæmia, tetanus, etc. 
Describe the different methods of arresting hemorrhage.

1. Ligation of the bleeding vessel by grasping the end with forceps and tying with a strong thread. The vessel may be ligated at a centripetal point.

2. Compression with tampons and bandages, or by an elastic bandage (Esmarch's bandage) applied between the wound and the heart.

3. Torsion, which consists of twisting the bleeding vessel on its axis.

4. Cauterization of the bleeding parts forms an eschar which acts as an aseptic bandage.

5. Cold contracts the vessels and narrows their lumen.

6. Therapeutic agents as alum, sugar of lead, tannin, etc., applied externally, by their astringent action, and ergot, adrenalin chloride, etc., internally, by their vasoconstrictor action, check hemorrhage.

Give the treatment for lacerated wounds.

Fresh lacerated wounds: arrest hemorrhage, irrigate, disinfect, provide drainage, suture and bandage. If extensive and healing by first intention is impracticable, apply drainage tube and suture as much as possible. Remove drainage tube as soon as practicable and secure healing by granulation. Old lacerated wounds may be scarified, disinfected and sutured (healing by third intention), and if this does not succeed, daily dressing and healing should be followed by granulation and cicatrization.

Give the care and treatment of a deep lacerated wound of the coronet.

See answer to preceding question.

Avoid excessive pressure in bandaging as it favors necrosis in the region of the coronet. If the coronary band is much swollen, the horn should be rasped away over an area corresponding to the swelling. Horn formation should be discouraged until all swelling disappears. Keep horn soft with .5 per cent. caustic potash solution until the inflammatory swelling disappears. Irregular cicatrization should be similarly treated. If abnormal growths of horn occur, they should be rasped down.

Mention the domestic animals in the order of their susceptibility to suppuration.

From most susceptible to the least, as follows: horse, ox, shecp, cat, dog, pig, fowls.

Give the method of arresting hemorrhage after castration in the colt.

Cold irrigation, compression with tampons or ligation may be employed. Generally, the preference is given to compression with 
tampons, which are held in place by heavy tape sutures for 24 hours and then removed.

Define (a) abscess, (b) cold abscess. Give treatment for each.

(a) A localized collection of pus in a cavity formed by the disintegration of tissues. Treatment: incision and antiseptic irrigation.

(b) An abscess of slow development, with little evidence of inflammation. Often have a thick, fibrous, connective-tissue capsule. Treatment: Extirpate the capsule, irrigate with antiseptic solution, suture and drain.

Define (a) septicæmia, (b) pyæmia, (c) phlegmon.

(a) A septic intoxication caused by the presence of bacteria and their toxic products in the blood.

(b) A general wound infection disease characterized by the presence of pyogenic germs in the blood and the formation of suppurative foci of disease in the body. (A septicæmia plus metastatic abscess formation.)

(c) An infectious, serous or suppurative inflammation of the connective tissue and all its parts, viz., the subcutaneous, subfascial, intermuscular, periosteal, tendovaginal and interglandular connective tissue.

What precautions should be taken in case an animal has been bitten by a rabid animal?

Cauterize the wounds; excise the wounded tissue if possible, and use strong disinfectant. (Pasteur treatment and quarantine.)

\section{INFLAMMATion}

Define inflammation.

Inflammation is tissue reaction to injury, characterized by pain, heat, redness and swelling; and, histologically, by hyperæmia, blood stasis, changes in the blood-and vessel-walls, and exudation.

Name the four cardinal symptoms of inflammation.

1 , dolor (pain); 2, calor (heat) ; 3, rubror (redness); 4, tumor (swelling).

Give the causes, symptoms and treatment of inflammation.

Causes: Mechanical, thermic and chemical irritants, and microorganisms.

Symptoms: Heat, redness, swelling, tenderness and disturbed function. 
Treatment: Rest, heat, cold, massage, counter-irritation, astringents, antiseptics and operation (amputation, incision, scarification).

Give a classification of inflammation.

According to the character of the exudate: 1 , serous; 2 , fibrinous, or croupous ; 3 , suppurative ; 4 , diphtheritic ; 5 , hemorrhagic ; 6 , necrotic or gangrenous; 7 , productive or proliferative; 8 , specific (tuberculosis, glanders, actinomycosis, strangles, anthrax, etc.).

Describe the inflammatory appearances of the blood.

The white corpuscles are arranged next to the vessel-wall, while the red blood-corpuscles occupy the centre of the stream. The white cells are seen passing through the walls of the vessels. A transudation of serum also occurs. In purulent inflammation, leucocytosis occurs.

What are the terminations of inflammations?

1, Resolution; 2, new formations in the form of thickenings, indurations and adhesions; 3 , gangrene and septic infection.

Name five antiphlogistic remedies.

Heat, cold, counter-irritants, massage and antisepties.

State the indications for heat and for cold in the treatment of inflammation.

Heat is indicated in all aseptic forms, especially subacute and chronic. It is also used in septic forms to hasten the "ripening" of abscesses.

Cold is indicated in septic, as well as in the first stages of acute and very painful inflammations.

Describe the condition known as "lampas."

A congestion of the hard palate, just posterior to the incisors, often seen in young animals during the eruption of teeth. Rarely occurs in mature animals or requires interference. (Often referred to as "a disease of the stableman's mind.")

\section{Ulcer, Fistula and Gangrene}

Define (a) fistula, (b) ulcer.

(a) A deep, sinuous ulcer, often leading to an internal hollow organ.

(b) An open sore other than a wound, characterized by a loss of substance on a cutaneous or mucous surface and a gradual disintegration and necrosis of the tissues. "A wound that has no tendency to heal." 
Give the causes and treatment of ulcer.

Causes: Continuous inflammatory irritation, foreign bodies, necrosed bone, cartilage and teeth ; constant licking, shaking of ears and tail; specific causes, as tuberculosis, glander's, actinomycosis, etc.; microörganisms.

Treatment: Remove cause; extirpate, curette, fire with hot iron, or use chemical canterizing agents. Internally, potassium iodide is a specific for actinomycosis; glanders ulcers are not treated.

Name ten important fistulæ in domestic animals.

1. Fistula of lateral cartilages (Quittor).

2. Tooth fistula.

3. Bone fistula.

4. Fistula of the spermatic cord following castration.

5. Fistulous withers and poll evil.

6. Milk fistula.

7. Salivary fistula.

8. Ear fistula in the horse (teratomata).

9. Esophageal fistula.

10. Vaginorectal fistula.

Define gangrene. Name the different kinds and give treatment.

Gangrene is defined as the death of tissue, due either to direct destruction of a part by burns, ete., to interference with the circulation, or to insufficient blood-supply.

Kinds: Dry and moist; hot and cold; putrid; circumscribed and progressive; septic and aseptic; emphysematous; coagulationnecrosis.

Treatment: Operative removal of the dead part; amputate a whole organ or part if necessary; thorough disinfection.

\section{TUMORS}

Define tumor. Give a classification of tumors.

A tumor is a mass of new tissue which persists and grows independently of its surrounding structures, and which has no physiological use.

Clinical classification: malignant and non-malignant or benign.

Differentiate malignant tumors and non-malignant tumors.

Malignant tumors develop rapidly with a destruction of neighboring tissues, have a tendency toward ulcerative degenerations, and are especially distinguished for the formation of metastases and the production of cachexia. 
Non-malignant tumors have a central growth, push the tissues aside and are usually encapsulated. They do not spread by metastasis and are only harmful when by reason of size or location they interfere with the body functions.

Give the prognosis and the treatment of epithelioma of the tongue.

Prognosis: Favorable if situated on the anterior extremity. If on the base, it is best to slaughter.

Treatment. Amputate all of the diseased part and treat the wound antiseptically.

\section{CONCREMENTS}

What is a calculus? Name the different varieties of calculi and state where each variety is found.

A calculus is an abnormal concretion occurring within the animal body and usually composed of mineral salts.

1. Urinary: Found in the kidney (renal), in the bladder (cystic), and in the urethra (urethral).

2. Intestinal: Found in the large intestines and rectum.

3. Salivary: Found in Steno's duct.

4. Chondroids, or arthritic calculi : Found in joints and tendonsheaths, mucous bursæ, and in the guttural pouches.

5. Milk: Found in the milk-cisterns and teats.

6. Preputial: Found in the preputial sac of the horse, commonly called "bean."

\section{Hernia and Prolapse}

Define (a) hernia, (b) prolapse.

(a) The passage of viscera from body-cavities witlout an injury to the skin or mucous membrane; the viscera protrude through an abnormal opening.

(b) The free passage of viscera throngh natural or artificial body-openings without a covering of the skin or mucous membrane.

Classify hernia according to (a) condition, (b) situation.

(a) Reducible and irreducible.

(b) Umbilical, inguinal, scrotal, ventral, femoral, perineal, rectal, vaginal, diaphragmatic, and hernia of the flank.

\section{Bones}

Define (a) ostitis, (b) periostitis, (c) osteomyelitis.

(a) Inflammation of a bone, especially of the Haversian spaces, canals, and their branches. 
(b) Inflammation of the covering of a bone.

(c) Inflammation of the bone-marrow or bone and marrow.

Give cause, symptoms and treatment of aseptic periostitis.

Caused by traumatisms acting subcutaneously, such as kicks, blows, treads, and pressure on the interdental space.

Symptoms: Pain on palpation, lameness, swelling and heat.

Treatment: Moist warmth, massage, absorbing agents as camphor, iodine ointment or mercurial ointment.

What is caries?

A liquefaction necrosis of bone or teeth in which they become softened, discolored and porous. There is usually associated with it a chronic inflammation of the periosteum and surrounding tissues, and an abscess formation which burrows through the soft parts until it opens externally by a sinus or fistula.

Define fracture. Give the varieties of fracture.

A fracture is a break or division of the continuity of a bone.

Varieties: Simple and compound; complete and incomplete (fissure and green-stick) ; transverse, oblique and longitudinal; simple . and multiple (comminuted).

Define (a) simple fracture, (b) compound, and (c) comminuted fracture.

(a) A fracture of a bone without injury to the skin.

(b) A fracture of a bone accompanied by a skin wound, so that the bone is exposed and entrance of infection is possible.

(c) A fracture of a bone in which the bone is broken into small fragments.

Describe the modes of union of fractures.

Regeneration of the periosteum and, to a certain extent, of the bone-marrow occurs and a granulation tissue is formed, which subsequently ossifies.

What pathologic conditions render bones liable to fracture?

An abnormal fragility due to senility, rarefying ostitis, osteomalacia, rachitis, caries, sarcoma and tuberculosis of bone. Diseases of the nervous system, as seen following neurotomy (trophoneurotic bone atrophy) ; anchylosis which restricts the mobility of the joints.

Describe a method of applying a plaster-of-Paris dressing for fixation in case of fracture.

After reposition of the broken ends of the bone is effected, the limb is covered with a pad of cotton, over which a flannel bandage 
is applied. Over this, the plaster-of-Paris bandages are placed. These bandages are prepared by dusting with fresh plaster and soaking for a short time in warm water. After a suffieient number of plaster bandages have been applied, the outside may be strengthened by applying some of the plaster made into a paste.

Make a diagram of the various methods of firing.

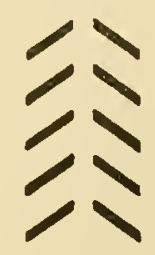

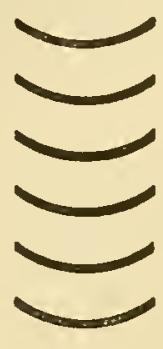

JOINTS

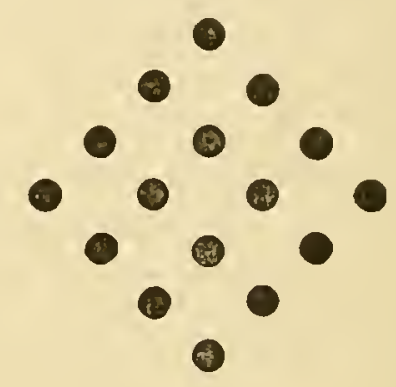

Define arthritis. Name the common varieties of arthritis.

Arthritis is an inflammation of a joint.

1 , serous; 2 , suppurative; 3 , deforming; 4 , tubercular.

Define (a) anchylosis, (b) corpora libra, (c) arthritis, (d) periarthritis, (e) synovitis.

(a) Abnormal immobility and consolidation of a joint.

(b) A free body of organic structure oecurring pathologically in joints.

(c) Inflammation of a joint.

(d) Inflammation of the tissues around a joint.

(e) Inflammation of a synovial membrane.

Give the treatment of an open joint.

In case of a fresh wound, do not probe but irrigate the opening with the mildest non-irritating antiseptie, or physiologic salt solution, suture, and apply iodoform gauze and bandage. Cauterization of punctured openings is often beneficial. Seal with collodion after thoroughly disinfeeting as deseribed above. Suppurating wounds should be drained, irrigated and packed with antiseptie gauze. Such wounds are usually ineurable. The swelling produced by blistering is often employed to close wounds around joints.

Define false joint. At what points is a false joint most likely to occur?

A false joint is a permanent movable union between pieces of bone which oecurs when callus formation fails to produce firm union between the fragments. 
Occurs most commonly between the head of the femur and the os innominata, following fracture of the rim of the cotyloid cavity. Also occurs on the first phalanx, and on the posterior false ribs.

\section{Define luxation. Give causes of luxation.}

Luxation is the displacement of the articular surfaces of one or more bones of a joint from their normal relation to each other.

Causes: Traumatism, pathological changes (alterations of the joint from disease, or paralysis of the surrounding muscles), and congenital malformations.

\section{Tendons and Tendon-SHEATHS}

\section{Give the causes and the treatment of tendinitis.}

Strains, overextensions, and partial ruptures. Predisposing causes: Too long and too weak fetlocks, low heels and long toes, abnormal positions, enforced standing. Occurs secondary to infectious diseases (contagious pleuropneumonia).

Treatment: Rest. In acute conditions, cold irrigation and cold compresses; slight massage and a pressure bandage; shorten the toe and shoe with high heel calks and no toe calk. Chronic cases need warmth, blistering and sometimes firing, in addition to rest and special shoe.

\section{What are the causes of tendon rupture?}

Partial rupture occurs in strains. Complete rupture is caused by traumatisms, overexertion and overstretching, especially when predisposed by suppurative inflammation, necrosis, contagious pleuropneumonia, osteomalacia or continued standing on three feet.

\section{Give causes, symptoms and treatment of tendovaginitis.}

Causes: Traumatisms, infectious diseases (contagious pleuropneumonia, septicæmia, articular rheumatism, contagious abortion, etc.), cold, infection through wounds.

Symptoms: Lameness, more or less pain and local heat; soft, fluctuating or crepitating swelling in the region of affected tendonsheath. In infected forms, abscess formation may appear, accompanied by fever. Chronic cases show thickening and adhesions of the tendon-sheaths.

Treatment: Rest. Moist warmth, pressure bandage. Longstanding cases require mild blisters, or iodine applications. Severe chronic cases may be benefited by firing. Infected cases should be treated with antiseptics. Supply free drainage for pus if present, not hesitating to open the sheath its full length if deemed necessary. 
What are so-called "wind galls"? State their cause.

An accumulation of a serous fluid in a dilated tendon-sheath, non-inflammatory and painless. Oceur most frequently in the region of the fetlock. Caused by chronic serous tendovaginitis, resulting from continued, severe exertions. Occasionally seen following contagious pleuropnemmonia.

Write a prescription for a blister for bowed tendons.

$\mathrm{R}$
Hydrargyri biniodidi $\ldots \ldots \ldots \ldots \ldots \ldots \ldots \ldots \ldots \ldots \ldots \ldots$
Pulv, cantharides $\ldots \ldots \ldots \ldots \ldots \ldots \ldots \ldots \ldots \ldots \ldots$. 3 ij
Ol. adipis $\ldots \ldots \ldots \ldots \ldots \ldots \ldots \ldots \ldots \ldots \ldots \ldots \ldots \ldots \ldots \ldots$
Misce.
Sig.-Apply with friction to affected tendons.

\section{Muscles ANd Nerves}

Define myositis. Give causes and symptoms.

Myositis is an inflammation of a muscle.

Causes: Traumatic, infection, cold and parasites.

Symptoms: Pain, swelling and local heat. Symptoms are localized in most cases, as contrasted with rheumatism which has a tendeney to shift from place to place and has no definite local boundary. Special symptoms, such as lameness, corresponding to the part affected.

Give results of neurotomy when unfavorable.

Fractures, due to neurotrophic atrophy; necrosis of extremity following infected wounds; neuroma forming on end of cut nerve; regeneration and restored function.

Give the differential symptoms of paralysis originating in the brain, cord and periphery.

Brain: Monoplegia or hemiplegia; one or more cranial nerves often involved; more or less loss of consciousncss.

Cord: Paraplegia more common; psychic derangements absent; cranial nerves unaffected; bladder and rectum simultaneonsly paralyzed.

Periphery : Single muscles or groups of museles affected without cerebral or spinal complications.

\section{What is "sweeney"? What treatment is indicated?}

"Sweeney" is the term applied by horsemen to the atrophy of the spinati muscles which follows paralysis of the supraseapular nerve. 
It is frequently incurable. Massage, counter-irritants, subcutaneous injections of veratrin, turpentine and Lugol's solution have been used with more or less beneficial results.

\section{Diseases of BloOd-Vessels}

\section{Define aneurism. Give the varieties of aneurism.}

An aneurism is a sac formed by the dilatation of the walls of an artery and filled with blood.

True aneurism is one in which the sac is formed by the coats of the arterial walls, one of which, at least, is unbroken.

False aneurism is one in which all of the coats of the artery are ruptured and the blood is retained by the surrounding tissues.

Define and give causes of (a) arteritis, (b) phlebitis.

(a) Inflammation of an artery.

(b) Inflammation of a vein.

Causes: Traumatisms, infection, parasites, phlebotomy, emboli and intravenous medication.

Define lymphangitis. Give causes, symptoms and treatment.

Inflammation of lympliatic vessels. Usually follows wound infection, due to the entrance of pus-producing organisms into the open lymphatic vessels. Specific infections, as saccharomyces farciminosis, sporothrix, etc.

Symptoms: Lymph-vessels stand out prominently as cord-like swellings, interrupted by nodules (the valves); lymph-glands in the affected region usually enlarged. Abscess formation along the course of the vessels, at the seat of valves. Chronic eases show great thickening of the skin and subcutaneous connective tissue.

Treatment: Cold irrigation. Open abscesses and give free drainage to wounds. Use antiseptics freely. Hot fomentations may be useful in long-standing cases. Internal administration of potassium iodide in specific infections, sporothricosis, epizoötic lymphangitis.

\section{Eye, Ear and Throat}

Give the causes, symptoms and treatment of acute catarrhal conjunctivitis.

Causes: Cold, traumatisms, foreign bodies, strong gases, smoke, infection, accompanies certain infectious diseases, influenza, dog distemper, etc.

Symptoms: Redness, lachrymation, discharge of mucopurulent, or simply watery, nature. Swelling and closure of the lids which are 
usually covered with crusts and stuck together in the morning. In. protracted cases, ulcers form on the cornea.

Treatment: Remove foreign bodies; a few drops of a 4 per cent. boric acid solution in the eye several times daily, or a 1 per cent. silver nitrate solution may be used. Keep the eye covered with a pad soaked in boric acid solution, which not only serves an antiseptic and astringent purpose but rests the eye by occluding the light.

\section{Describe amaurosis and give its causes and treatment.}

Amaurosis is blindness, especially blindness occurring without any apparent lesion of the eye, and due to disease of the optic nerve, retina, spine or brain.

Causes: Renal disease, diabetes, uræmia, cerebral diseases, reflexly from remote irritation, congenital.

Treatment: Unsatisfactory. May disappear on subsidence of the causative factor. Eliminate the cause if it can be determined.

\section{Give fully the symptoms, prognosis and treatment in a severe case of} periodic ophthalmia.

Symptoms: Local heat and tenderness, lachrymation, photophobia, arborescent appearance of the injected capillaries extending from the sclera down in the cornea, fibrinopurulent exudation in the anterior chamber, iridocyclochoroiditis present. Course, about two weeks. Patient may be blind in one eye and show synechiæ in the other from previous attacks. Atrophy of the globe after two or more attacks.

Prognosis: Unfavorable. Usually recover from one attack but several subsequent attacks, at intervals of one to six months, are inevitable and blindness is sure to result.

Treatment: Rest the eye with atropine. Boric acid, cocaine hydrochlorate and atropine sulphate make a useful combination. Keep patient in darkened room. Cover the eye with a pad soaked in boric acid solution. The use of counter-irritants, blisters and setons, so commonly employed, inflict useless pain. The discase usually runs a two weeks' course in spite of any treatinent.

Define (a) entropion, (b) ectropion, (c) glaucoma, (d) staphyloma.

(a) Inversion of the eyelid. (b) Eversion or turning out of the cyelid. (c) A disease of the eye marked by intense intra-ocular pressure resulting in hardness of the eye, atrophy of the optic disk and blindness. It is due to obstruction of the lymph circulation. (d) A protrusion of the cornea or selcra resulting from inflamsnation. 
What animals suffer from contagious ophthalmia? Give the diagnosis and treatment of contagious ophthalmia.

Seen principally in cattle. Several cattle in the herd show lachrymation, photophobia, mucopurulent discharge, swelling and tenderness of the lids, fibrinopurulent exudate in the anterior chamber. In some mild cases, only a conjunctivitis is seen.

Treatment: Eyewash of boric acid solution ( 4 per cent.) to which may be added 1 per cent. of atropine sulphate. Protect the eyes from all bright light. Segregate affected animals.

Define cataract. Name the different forms of cataract and give the diagnosis.

A cataract is any pathological change in the lens or its capsule which diminishes its transparency.

Varieties: Congenital, senile, soft, hard, incipient, mature, priunary, secondary, capsular, lenticular, stationary, progressive, traumatic, etc.

Diagnosis: History of previous attacks of periodic ophthalmia, or simple ophthalmia; atrophy of the globe; dilate the pupil with atropia and illuminate the depth of the eye with the ophthalmoscope when opacities will be more readily detected. Hold a lighted candle before the eye; in the normal eye, three images are reflected, one from the cornea, one from the anterior capsule of the lens and one from the posterior capsule. Any opacities in the lens will cause the posterior image to become indistinct as it passes over that spot.

\section{What conditions may give rise to cataract?}

Impaired nutrition of lens, inflammation of the iris, choroid, ciliary body and retina, periodic ophthalmia, diabetes, cell proliferation in the lens.

\section{Give the treatment of lachrymal fistula.}

Establish drainage through the lachrymal duct by forcing boric acid solution through it from below upward under slight pressure. Curette the fistulous opening and canterize with silver nitrate.

\section{Describe an operation for enucleation of the eye.}

General anæsthesia is essential. Wash and disinfect the eye and surrounding parts. Retract the lids; make the incision through the conjunctiva around the corneal margin and dissect back the conjunctiva to the insertion of muscles. With small curved scissors cut the muscles near their tendinous insertion. Then with strong curved scissors, cut the optic nerve with one snip. The eye can then be pried out. Check hemorrhage by packing the cavity with aseptic gauze for a few hours. 


\section{Describe otorrhœa of the dog. Give treatment.}

An inflammatory condition of the external auditory meatus. It is characterized by a discharge of a yellowish-brown secretion, usually mixed with pus, pruritus and shaking of the ears.

Treatment: Cleanse with peroxide of hydrogen, probe and cotton. Dry with ether and keep dry by dusting lycopodium over the affected parts. Repeat the treatment daily.

\section{Mention two common causes of deafness in the dog.}

Congenital deafness is occasionally met with; in old age, dogs become more or less deaf; otitis media, inflammation of the middle ear, is generally followed by deafness.

Give the symptoms and the diagnosis of pus in the guttural pouches.

Intermittent, unilateral or bilateral, nasal discharge. Appears in considerable quantity at times and then entirely disappears. The discharge is increased when the head is lowered after being checked up, when eating off the floor, swallowing and when pressure is applied over the pouch. Swelling may or may not be marked. Dyspncea is sometimes produced by the pressure on the larynx. Similarly, difficulty in swallowing may be present. Diagnosis can be confirmed by passing the Eustachian catheter.

\section{Describe the Viborg or the Chabert method of opening the guttural pouch.}

Viborg's method: Secure the patient in lateral decubitus with the head extended. General anæsthesia is advisable. Locate Viborg's triangle (the space between the posterior border of the inferior maxilla, the terminal tendon of the sternomaxillaris muscle and the external maxillary vein). Shave and disinfect this area. Draw the skin tense and make an incision, $5 \mathrm{~cm}$. long, through the skin and skin muscle immediately beneath and parallel to the tendon aforementioned. Force a passage with the finger or blunt instrument through the loose connective tissue to the guttural ponch.

In Chabert's method, the incision (6 cm. long) is made about $1 \mathrm{~cm}$. in front of the lower half of the wing of the atlas and parallel thereto. The parotid gland is drawn forward and an incision is made parallel to and through the fibres of the stylomaxillaris muscle thus exposed. This leads directly into the guttural pouch.

Give the causes, symptoms and treatment of postpharyngeal abscess.

Causes: Injuries to the pharyngeal walls; inflammation of same or neighboring tissues; infection following injury by sharp objects, balling gan, etc. Infection extending from suppurative parotitis to the subparotid lymph-glands. Often seen in strangles. 
Symptoms: Swelling, dyspnœa and dysphagia from pressure; head extended; slight fever.

Treatment: Open through Viborg's triangle as described in preceding answer. In case of subparotid abscess, use a blunt instrument or finger to burrow through the parotid gland. Some operators prefer to make the incision on the median line and dissect through to the abscess along the lateral wall of the larynx. In all eases, good drainage and thorough disinfection are necessary. Use tracheotomy tube to avoid suffocation which may follow the excitement caused by operating.

\section{Give the treatment of pharyngeal polypi.}

Adjust the mouth speculum and attempt grasping and removing the polypi with the hand introduced through the moutl. If this method fails, perform laryngectomy, pass hand or ecraseur through the laryns into the pharynx and remove the growth, preferably by torsion. If this fails, cut the growth away with scissors or scalpel.

\section{Give the treatment for choking.}

Four methods may be employed.

1. Return the foreign body into the pharynx by manipulations over the œsophageal furrow and with the hand in the pharynx, or with extracting instruments; emetics such as apomorphine and veratrine may assist.

2. Reduce the size of the foreign body in situ (soft objects may be crushed by hand).

3. Force the foreign body onward into the stomach with the probang. Great caution should be observed in case of sharp objects as bones, etc. Likewise, a mass of oats may be more firmly impacted.

4. Esophagotomy. This can only be performed on the cervical portion of the cesophagus and is only practised when the other methods fail.

Unless symptoms are alarming, it is best to avoid all treatment in case of impaction of oats, as such cases often remedy themselves in the course of a few days. In all cases, withhold food and water until the condition is relieved to avoid the danger of inhalation pneumonia.

\section{Describe œsophagotomy.}

The animal can be operated upon in the standing or recumbent position. The point of operation is usually determined by the location of the foreign body which necessitates the operation. Shave and disinfect the skin. Make an incision $10 \mathrm{~cm}$. long through the 
skin and skin musele on the left side between the anterior border of the mastoidohumeralis muscle and the jugular vein. Separate the loose connective tissue with the fingers down to the œsophagus which lies between the left sealenus musele, the trachea and the jugular vein. Draw the osophagus ont through the wound and make a longitudinal incision in it, sufficiently large for the removal of the foreign body. The wound in the cesophagus is closed by an intestinal suture, i.e., the external coats are drawn together (Lembert suture). The external wound may be left open, or sutured, and a drainage tube inserted.

\section{Describe the treatment of choking in the cow.}

See answer to the two preceding questions. Choking in cattle is often accompanied by bloating (tympanites). This should be relieved by puncturing the rumen and leaving the eanula in position until relief is obtained, several days if neeessary.

Give the diagnostic symptoms of roaring. Describe an operation for roaring.

Symptoms: Inspiratory dyspnœa, very marked after severe exertion, galloping or heavy pulling without any visible cause. Positive diagnosis is made by examining the larynx with the laryngoscope or by introducing a finger through an opening made in the larynx (laryngotomy). In ease of roaring, the left vocal cord lies motionless in the lumen of the larynx. Sometimes both sides are paralyzed.

Operation: Secure the animal in lateral reeumbeney. Shave a large area in the laryngeal region, disinfect thoroughly. Chloroform anæsthesia is necessary. When anæsthesia is complete, roll the patient upon its back with the head extended. Make a longitudinal incision, $15 \mathrm{~cm}$. long, through the skin, subeutem and museles on the median line directly over the larynx. Continue the ineision through the ericothyroidean ligament and ericoid eartilage. Control hemorrhage with hæmostatic forceps. Insert retraetors and earefully dissect out the mucous lining of the lateral ventricle between the vocal cord and the arytenoid eartilage on the affeeted side. This must be earefully done beeanse any remaining portion of this mucous membrane will seerete mueus and form a mueous eyst. The object is to grow the voeal cord to the wall of the larynx and this is aceomplished by denuding the opposing surfaces of their mucous membrane. The after-treatment consists of daily cleansing of the external wound and eomplete rest for six weeks. The patient should be earefully watehed for the first 48 hours to see that dyspnoea is not provoked by the swelling in the region of the wound. In sueh cases, a tracheotomy tube should be inserted in the opening. 


\section{HEAD AND NECK}

Define (a) gleet, (b) epistaxis.

(a) Chronic nasal catarrh characterized by a thick, purulent discharge, ulcers in the nasal cavity, bulging of the sinuses and eulargement of the submaxillary lymph-glands.

(b) Bleeding from the nose.

Give the causes and the treatment of bleeding from the nose.

Causes: Traumatisms, diseases of the mucous membrane as in glanders, gleet, etc., tumor formation, fracture of nasal bones, severe exertion.

Treatment: Remove cause, irrigate the nasal cavity with cold water to which may be added some astringent agents, as tamin, aluminum sulphate, zine sulphate, etc. Spray the cavity with adrenalin chloride. Plug the nostrils with cotton and keep the head elevated. Slight, and often severe, hemorrhage will often stop without any measures being employed for its control.

What diseases of the facial sinuses require surgical interference?

Empyæmia, diseased teeth, tumors and foreign bodies, necrosis of the bony and cartilaginous walls.

Give the surgical technic of trephining the frontal sinuses.

Operate on the standing animal with the aid of local anæsthesia. Shave and disinfect the region of the frontal bone on a level with the superior border of the orbital cavity and about $1 \mathrm{~cm}$. from the median line of the face. Make a circular incision of the desired size through the skin, subcutem and periosteum, and remove the encircled mass by separating the periosteum from the bone with the scalpel. Place the trephine perpendicular to the bone and drill until the centre bony plate loosens, then pry out the dise of bone.

Give the treatment of pus in the nasal sinuses.

The trephining is carried out in the manner described in the preceding answer. The point of operation may be at any point, immediately against the median line from the level of the upper limit of the superior maxillary sinus to the upper extremity of the false nostril. Great care must be taken to avoid trephining too deeply and injuring the turbinated bones which lie close to the nasal bone. Dilute solutions of hydrogen peroxide can now be injected and followed by a thorough irrigation with sterile water. This irrigation should be repeated daily until suppuration ceases.

Give the symptoms and the treatment of nasal polypus.

Symptoms: Stenosis of the nasal passages, dyspnoa, chronic unilateral catarrh ; in ulcerative degeneration, an ichorous, fetid, occa- 
sionally hemorrhagic, nasal discharge with unilateral swelling of the submaxillary lymph-gland is seen. Polypi may be long enough to protrude or be seen in the nostril.

Treatment: Operative removal with scalpel, scissors or eeraseur.

What are the diseases for which tracheotomy are performed? Describe the operation.

Dyspnœa due to obstructions in the upper air passages from roaring, tumors or other swellings in the nasal passages, larynx, upper part of the trachea, etc., foreign bodies in the trachea, diseases of the larynx, trachea and bronchi which demand intratracheal irrigation or other treatment.

Operation: Shave and disinfect the skin over the trachea in the superior third of the neck. Operate on the standing animal, using twitch. Make an ineision, 6 to $8 \mathrm{~cm}$. long, on the median line, through the skin and between the two sternothyroideus muscles down on to the trachea. Remove a semicircular piece from each of two adjoining rings (avoid complete severance of the rings). In an emergency, requiring great haste, two or three rings may be incised but the former method is to be preferred because of the lesser liability of stenosis following healing.

Give the causes, symptoms and treatment of paralysis of the lips.

Causes: Injury to the facial nerve where it passes over the posterior border of the lower jaw. Tumors, pressing on the nerve, may produce paralysis. Some paralyses are of central origin, i.e., due to cerebral lesions.

Symptoms: Lips are distorted to one side in unilateral paralysis, and hang flaceid in bilateral condition. Diffieulty in prehension of food is noted. The lips and cheeks are injured by the teeth. In paralysis of central origin, the upper eyelid droops and the ear hangs limp.

Treatment: Remove accumulated food from the checks after each meal. Give easily masticated food. A blister may be applied over the point where the nerve emerges on the upper margin of the lower maxilla, but its value is questionable. Most eases of peripheral paralyses recover in 4 to 6 weeks.

Describe caries of the teeth and give treatment.

Caries of the teeth is the term used to deseribe the process whieh results in the gradual destruetion of the cement and dentin, the enamel remaining comparatively intact. Caries is caused by the entrance of mieroörganisms through small openings in the enamel. 
Fermentation occurs and acids are formed which attack the tooth structure.

Treatment: Extraction of the affected tooth. It may be necessary to trephine and punch the tooth out.

Give the causes and the treatment of stomatitis.

Causes: Wounds from sharp teeth, the bit and foreign bodies; infection, chemicals and hot foods.

Treatment: Remove the cause; file off sharp enamel points; use an astringent, antiseptic mouth wash; canterize ulcers with lunar caustic or paint with tincture of iodine. Provide plenty of fresh water; cleanse the mouth after each meal.

Describe the appearance of a horse's mouth at the age of (a) two years, (b) three years, (c) five years.

(a) The inferior dental arch is levelled at the nippers and intermediate milk-teeth. The superior nippers stand out from the gums and behind them is found a moderately sensitive swelling which is due to the pressure of the permanent teeth on the gums of the palatine arch.

(b) The permanent nippers, above and below, are level with the temporary intermediates and corner teeth.

(c) The mouth is complete, "full-mouth," i.e., all the permanent teeth have reached the same level. The anterior borders of the corners are in wear but the posterior borders are not.

Describe the appearance of the mouth of a horse at the age of (a) seven years, (b) eight years, (c) fourteen years.

(a) Notch on the posterior border of the superior corner teeth. The nippers are oval in shape and the intermediates are becoming so. The cups are worn out of the inferior nippers and nearly out of the intermediates.

(b) The intermediates are oval and show a triangular-shaped central enamel. The corners are worn and show their central enamel somewhat concave. The cups are nearly worn out of the inferior corners.

(c) The nippers are becoming triangular. The intermediates and corners remain rounded. The transverse arch of the teeth beeomes narrower.

Describe the appearance of the mouth of the horse at the age of (a) six years, (b) ten years, (c) twelve years, (d) fifteen years.

(a) The nippers are worn and the cups of the inferior pair are worn out. The intermediates are becoming worn and the corners are on a level with them, showing their anterior borders worn down. 
(b) The nippers are rounded, the intermediates are nearly so, while the corners are still oval. The cups are worn out of all the inferiors and the nippers and intermediates of the superior row.

(c) All the teeth are rounded and the central enamel is gone. The superior corners are levelled.

(d) The nippers are triangular, the intermediates are becoming so; the corners are still rounded. The dental star is round in all the lower teeth and is dark and indistinct.

Describe the operation for the repulsion of a diseased upper molar tooth of a horse.

Shave and disinfect the field of operation. Remove a circular piece of skin and trephine through the bone and alveolar plate, immediately over the fang of the tooth. With scalpel and chisel, separate the bone and soft tissues over the entire area of the diseased tooth. Apply a punch against the fang of the tooth and give a few sharp blows with a mallet, directing the force in a line with the long axis of the tooth, driving it into the mouth. If the tooth cannot be dislodged in this manner, comminute it with the chisel and mallet and remove the fragments. Cleanse and disinfect the wound after each meal, or at least once daily.

Give the symptoms and the treatment of paralysis of the muscles of mastication.

Symptoms: Salivation, tongue lolling, inability to close the mouth and take nourishment.

Treatment: (Beware of rabies.) Feed with stomach tube. Apply electric current to the masseter and temporal muscles.

\section{Give the method of "bishoping" a horse.}

"Bishoping" is accomplished by drilling or gouging out a cavity in the tables of incisor teeth and staining the cavity black with silver nitrate or a hot iron. It is a method employed by unserupulous dealers ("gyps") for the purpose of deception in regard to the age of a horse.

Mention four diseases and six accidental conditions, or injuries, that are characterized by a copious discharge of saliva.

Diseases: Pharyngitis, stomatitis, paralysis of lower jaw and dental caries.

Accidents: Wounds of the checks, forcign bodies in the mouth, a severe bit, injuries of the tongue, bags of spices attached to the bit, and choking. 
Give the treatment of salivary calculi.

Operative removal through the buccal cavity to avoid fistulæ, if possible. If the duct must be opened, make a transverse incision which heals more readily than a longitudinal one. Observe strict aseptic precautions and obtain healing by first intention if possible. Withhold food for two days.

Describe causes, symptoms and treatment of salivary fistula.

Causes: Wounds which penetrate the salivary glands or their ducts.

Symptoms: An opening in the gland or duct through which there is a continuous flow of saliva, more marked during eating. The hair is matted or lost and the pigment of the skin is destroyed by the discharge.

Treatment: Fistulæ of the gland sometimes heal without treatment. Cauterize with silver nitrate or actual cautery. See that the opening of the duct into the mouth is free, or provide an artificial opening, and then close the fistula with a purse-string suture. If this fails, ligate the duct above the fistula and produce a destruction of the gland through pressure atrophy. The gland may be destroyed by the injection of irritating fluids into it but this method is very painful and far from surgical.

What are the characteristic symptoms of actinomycosis of the jaw and face in cattle? Give the treatment.

A hard, firm swelling which involves the bone. The teeth become loosened because of a purulent, alveolar periostitis; mastication is painful; the skin becomes thick and adherent; perforation occurs and a thick, yellow pus is exuded in which actinomyces may be found.

Treatment: Mild cases, if treated early, respond to the internal administration of potassium iodide until signs of iodism appear. It is best to dissect away all diseased tissue and, in severe cases, slaughter.

Describe an operation for poll-evil.

Clip the foretop and mane and shave the crest of the neck over the diseased area. Make a longitudinal incision on either side of the median line, and about 2 inches from same, from the top of the head down to the posterior limit of the disease. These incisions should be carried through the skin, subcutem and adipose tissue to the ligamentum nuchæ. Dissect away all necrotic tissue. Pack the wound with antiseptic gauze and hold the packing in place with temporary, retaining sutures. Remove pack in 48 hours and use dry dressings daily. 
Give the prognosis and the treatment of goitre (a) in the dog, (b) in the horse.

(a) Prognosis is not very hopeful if the growth is extensive. Treatment is unsatisfactory; paint with tincture of iodine and give potassium iodide, internally. Thyroid extract, internally, is reputed to give good results. The cystic form of goitre can be tapped with a capillary trocar.

(b) Prognosis favorable; seldom causes any inconvenienee unless very large when dyspnœa may be produced by compression of the throat. Treatment, same as in the dog.

Give treatment of cystic goitre in the dog.

Withdraw the contents of the cyst by use of the capillary trocar and paint the overlying skin with tincture of iodine.

\section{Give the surgical technic of trifacial neurectomy.}

General anæsthesia. Shave and disinfect an area, $10 \mathrm{~cm}$. square, over the infraorbital foramen. Make an incision through the skin, subcutem and the levator labii superioris alaque nasii muscle and expose the nerve. Begin the incision $1 \mathrm{~cm}$. above the foramen and carry it downward directly over the nerve a distance of 5 to $6 \mathrm{~cm}$. Pick up the nerve with an aneurism needle and divide it close to the foramen. Remove about $3 \mathrm{~cm}$. from the distal end. Suture the wound, observing aseptic precautions.

Mention diseases for which phlebotomy of the jugular vein is performed.

Congestion of the brain; diseases which are accompanied by plethora such as azoturia, congestion of the lungs, acute laminitis, etc.; toxæmic diseases such as tetanus.

State the various methods of dehorning cattle.

Dehorning shears; sawing off with ordinary saw ; application of caustic potash on calves at the point where the horn will erupt will prevent the horn from developing.

\section{Disenses of the THORAX}

\section{Describe the operation for the relief of hydrothorax.}

Shave and disinfect an area, $2 \mathrm{~cm}$. square, in the seventh intercostal space on the left side, immediately above the thoracic vein. Draw the skin aside and place the trocar at the anterior border of the rib and, with a sharp thrust, drive it into the thoracic eavity. Withdraw the stilette and allow the fluid to escape. 
Describe symptoms and treatment of a fractured rib.

Symptoms: Hurried breathing; crepitation with each respiratory movement; if the pleura is injured, cough may be present. If the skin is broken (compound fracture), fragments of bone may be seen.

Treatment: Complete rest and quiet. In compound fracture, remove pieces of bone and dress the wound antiseptically.

Give treatment for saddle-galls and collar-galls.

Recent formations may disappear under the application of cold and massage, or by painting with tincture of iodine. Chronic thickenings and necrotic tissue must be removed with the knife.

Describe fistula of the withers and give treatment.

A hot, painful swelling in the region of the withers is seen. There may be a discharge of pus through a small opening and the lymph-vessels in the region stand out as small cords. There is usually necrosis of the skin, subcutem, bursæ, fasciæ, muscles and bones in the affected region.

Treatment: Operative removal of all necrotic tissue. Provide drainage and dress wound daily with antiseptics.

Give the treatment of a case of fistulous withers of three months' standing.

See answer to preceding question. In a case of three months' standing, considerable connective-tissue proliferation will have occurred; this should be removed along with the necrotic tissue.

\section{Diseases of the Abdomen}

Describe a surgical treatment of acute gastric indigestion.

Tapping of the stomach: Shave and disinfect an area $2 \mathrm{~cm}$. square over the point of greatest distention on the left side (usually between the thirteenth and fourteenth ribs, about one hand's breadth from the spinal column). Use a trocar, 8 to 10 inches long, and drive it in a vertical direction downward into the stomach. Allow the gas to escape. The passing of the stomach tube would be a surgical measure to be preferred.

Give the symptoms of rupture of the diaphragm (diaphragmatic hernia).

Asphyxia from compression of the lungs; symptoms of strangulation of the bowels. It is difficult to diagnose. Tapping the intestines through the thoracic walls and the obtaining of ingesta therefrom will aid in the diagnosis. . 
Describe the operation of rumenotomy in the cow.

Shave and disinfect the skin in the left flank. Introduce a bistoury through the skin, muscles and rumen wall at the point.where the rumen is usually punctured and make a quick downward incision, 4 to 6 inches long. The skin incision should be a little longer than that in the wall of the rumen to prevent food from entering the peritoneal sac. A piece of cloth may be placed in the lower angle of the wound for the same purpose. Close the wound in the rumen securely with catgut or silk, using interrupted sutures. Suture the abdominal muscles in a similar way and the skin in the usual way. Some operators draw the skin to one side before making the incision through it so that the openings through the different layers do not overlap.

Give the indications for laparotomy in the cow.

Foreign bodies in the rumen or intestines. Displacement of internal organs. Dystocia, where normal delivery is impossible. Gut-tie in the ox.

Give the symptoms and the treatment of inguinal hernia.

Symptoms: The hind limbs are moved stiffly, dragging the toes. The animal stretches out, shows slight colic and draws up the testicle of the affected side. Strangulation of the incarcerated intestines may produce violent colicky symptoms. In old-standing cases, the testicle is atrophied and flaccid. Rectal examination will aid in the diagnosis.

Treatment: Fast the animal and evacuate the bowels. Place the patient on its back, chloroform and replace the hernial contents. Apply active friction to the cord to produce a swelling which will fill the abdominal ring. (A mild vesicant is often used.) Another method is to perform castration by means of clamps and the covered operation. The latter method is to be preferred because this defect is transmitted to offspring and such animals should not be used for breeding; furthermore, it is a more satisfactory and surer method.

Describe in detail the surgical method of reduction of an inguinal hernia in a stallion without resorting to the castration of the same.

See answer to preceding question.

Give the treatment of an umbilical hernia, the size of a hen's egg, in a colt one year old.

Produce an inflammatory swelling of the hernial ring by inject. ing into it a weak solution of silver nitrate and apply a truss. $A^{\prime}$ 
better method is the radical operation-herniotomy and suturing of the hernial ring. Fast the animal and evacuate the bowels. Chloroform anæsthesia is very desirable and more humane. Place the patient on its back, shave and disinfect the operative field. Make an incision through the skin, suture the hernial ring with silk or chromatized catgut, with or without opening the peritoneal cavity. Close the skin wound and apply an antiseptic dressing holding same in place with a body bandage.

\section{Describe a case of rupture of the prepubian ligament.}

This condition occurs most commonly in pregnant mares. It appears as an immense hernial swelling on the ventral surface of the abdomen, extending from the os pubis forward on the abdomen, giving the animal a much distorted appearance. The mammæ may be drawn anteriorly a distance of 8 to 12 inches from the normal location. The patient is usually quiet unless strangulation occurs.

Give the causes, symptoms and treatment of ascites in the dog.

Causes: Obstruction to the circulation from diffuse induration of the liver, emboli, weak heart, etc., kidney disease, chronic peritonitis and tuberculosis.

Symptoms: An abnormal distention of the abdomen. The swelling is of a fluctuating nature and gives a dull percussion sound which is bounded above by a horizontal line. No matter what attitude is assumed by the animal, this horizontal line remains. The patient has a pot-bellied appearance, appears dull and becomes dyspnœic upon slight exertion. Diagnnsis can be confirmed by passing a trocar into the peritoneal cavity and recovering some of the liquid contents. The prognosis is bad.

Treatment: Remove the cause (heart, liver or kidney diseases). This is usually impossible, so that only temporary relief can be afforded with palliatives. Saline purgatives, diuretics, heart tonics, etc., may be useful. Puncturing is often beneficial in relieving severe dyspnœa.

\section{Give the symptoms of intussusception.}

The symptoms are mainly those of obstruction of the bowels such as continuous colicky pains, passing of a few fecal balls at first but later a cessation of defecation, tympanites, and absence of peristalsis. A manual examination per rectum may aid in making the diagnosis. The pains may subside in about 12 hours to be followed by chills and death. 
Describe in detail the procedure of passing a stomach tube. What are the indications for the use of this tube?

Secure the animal in the standing position and restrain by placing a twitch on the ear. Lubricate the tube with saliva or slippery elm tea. Insert the tube in the floor of the nostril and push it gently until the pharynx is reached. Move the tube slowly in and out until swallowing movements are observed. When the tube passes into the osophagus, force it gently downward into the stomach. By the use of a month speculum or mouth gag, the tube can be passed through the mouth.

Indications for use: Gastric tympany or impaction; poisoning; forced nutrition when the animal cannot swallow, as in tetanus.

Describe enterocentesis and state when indicated.

Shave and disinfect an area $2 \mathrm{~cm}$. square, in the right flank, equidistant from the last rib, the external angle of the ilium and the transverse processes of the lumbar vertebri. Place the trocar perpendicular to the skin and with a sharp blow drive it into the distended cæcum. Withdraw the stilette and allow the gas to escape.

This operation is indicated in cases of intestinal tympany. It is occasionally employed to introduce medicines directly into the cæcum.

Name the tissues involved in puncturing the cæcum.

Skin, abdominal muscle, peritoneum and cxeum.

What are some of the unsatisfactory results that are likely to follow the operation of puncturing the intestines in the horse, and describe the technic you would adopt to guard against them?

1. Peritonitis: Strict antisepsis. Have the stilette in the canula and press the skin firmly against the abdominal muscles when withdrawing the instrument.

2. Abscess at the site of puncture: Same precautionary measures as given in preceding paragraph.

3. Hemorrhage: Operate at the proper point and thus avoid large arteries.

\section{Diseases of the Urinary Organs}

Give the symptoms of urinary calculi in the bladder. What is the method of surgical procedure?

Frequent urination but passing of small amounts. Bloodstained urine after exercise on account of injuries of the mucous membrane by the stone. Examination per rectum will reveal the 
stone as a firm, hard substance. In mares, it can be felt by passing a finger through the urethra.

Perform urethrotomy at the ischial notch. Extract the stone with lithotomy forceps. If the stone is too large to be removed entire, lithotripsy (crushing of the stone within the bladder) must be performed, and if this fails, dilate the neck of the bladder with the lithotome. In mares, the stone can often be removed through the normal urethral opening (cystic calculi are rare in the mare).

Give causes, symptoms and treatment of paralysis of the bladder in the horse and in the dog.

Causes: Retention of urine, due to calculi, causes overdistention and paralysis. Hæmoglobinuria, spinal lesions and enlarged prostates.

Symptoms: Urine discharged in small quantities when the detrusor muscle alone is paralyzed. If the sphincter muscle is paralyzed, an involuntary discharge of urine occurs, especially when the abdominal muscles are contracted as in defecation.

Treatment: Unsatisfactory. Catheterize frequently in case of great distention due to paralysis of the detrusor muscle. Give tonics such as strychnine and arsenic.

Give the treatment of prolapse of the urinary bladder in the mare.

Carefully cleanse, disinfect and replace the viscus. Suture the wound in the vagina if possible. Prevent straining and recurrence by injecting lukewarm water into the replaced bladder (local anæsthetics could be used in the water), and administer sedative.

Give the cause, symptoms and treatment of rupture of the bladder.

Causes: Overdistention, injuries by the catheter, calculi, etc.

Symptoms: Absence of urination; uriniferous odor to the skin, peritonitis and death soon follows.

Treatment: Useless. Might attempt laparotomy and suture the rent in the bladder-wall. Remove the obstruction causing overdistention and rupture.

Describe the operation of passing a catheter in (a) the gelding, (b) the mare, (c) the cow, (d) the steer.

(a) Wash and disinfect the external parts. Grasp the penis firmly and pass a sterilized catheter, lubricated with carbolized raseline, gently upward until an assistant feels it approaching the ischial notch. It is then guided forward into the bladder. If a soft-rubber catheter is used, no assistant will be necessary. 
(b) Wash and disinfect the external genitais. With the fingers of one hand, locate the urethral orifice and with the other hand direct the catheter into it and force it gently into the bladder.

(c) Same as the mare. The urethral orifice is a little more difficult to locate on account of the overlying folds of mucous membrane.

(d) Same as in the gelding. Only the forward end of the urethra as far as the "S" -shaped curve can be catheterized.

\section{Diseases of the Generative Organs}

Describe the operation of castration of the male. What ill effects may follow and how can they be prevented?

The operation may be performed on the standing animal but is safer for the operator if the patient is cast and secured on its back or side. Wash and disinfect the scrotum, grasp the testicle, enclosed in the serotum, and hold firmly. Make an incision, 8 to $10 \mathrm{~cm}$. long, parallel with and about $2 \mathrm{~cm}$. from the median raphe. Carry the incision through the skin, dartos and tunics until the testicle protrudes through the opening. Grasp the testicle and gently pull it out. (By cutting the cremaster muscle, the testicle can be drawn out farther and easier.) Place the emasculator close up to the external ring and sever the cord. Leave the instrument in place for a few minutes to prevent hemorrhage. The wound will usually heal without any attention.

Hemorrhage may occur, but if the emasculator is perfect and is left in place for a sufficient length of time, there is little danger. Blood-clots may form if the external opening is too small. Wound infection can usually be avoided by careful antiseptic preparation. Scirrhous cord may result from leaving the cord too long and exposed.

\section{Give the causes, symptoms and treatment of scirrhous cord.}

Causes: Wound infection following castration. May be due to a faulty method of castration, leaving the cord too long and exposed. Infection leads to a chronic inflammation of the stump of the cord.

Symptoms: A firm, hard, and slightly painful swelling in the region of the scrotum; a fistulous opening, 2 to 4 inches deep, discharging pus. The swelling may extend along the cord into the abdominal cavity.

Treatment: Remove the diseased part, if external to the abdomen. If it extends into the abdomen, nothing surgical can be done. Potassium iodide, internally, may help.

Name three diseases resulting from castration.

Scirrhous cord, hydrocele, peritonitis. 
Mention in order from without inward the tissues cut in the operation of castration of the male.

Skin, dartos, spermatic, cremasteric and infundibuliform fasciæ; the tunica vaginalis and the tunica albuginea.

\section{Describe paraphimosis and give treatment.}

A condition in which the glans penis cannot be retracted into the prepuce, either because the opening is too narrow, or the glans too large. More common in the dog than in the horse, because in the latter the outer folds of the sheath are loosely formed and present a wide opening. But occasionally the preputial folds become greatly swollen and prevent the return of the penis. More often the condition is due to swelling of the penis.

Treatment: Attempt replacement by lubricating with oil and applying pressure on the swollen penis. It may be necessary to incise the preputial ring. Apply astringent packs to combat the inflammation. A suspensory bandage will assist in reducing the œdema.

\section{Describe a method of amputating the penis.}

General anæsthesia. Wash and disinfect the penis and preputial region. Apply a temporary elastic ligature just above the preputial ring. Grasp the penis with one hand and with a circular incision, about $5 \mathrm{~cm}$. in front of the ligature, or immediately in front of the preputial ring, excise the organ. Ligate vessels which may be bleeding. Slit the dorsal wall of the urethra for a distance of about $2 \mathrm{~cm}$; spread it fan-like over the surrounding tissues and suture to the same. A silk ligature can be applied to the corpus cavernosum just above the point of excision and allowed to remain for a few days. Remove the elastic ligature.

Give cause, symptoms and treatment of paralysis of the penis.

Cause: Due to paralysis of the retractor penis muscle. Inability to retract the penis on account of inflammatory swellings of the sheath or penis are erroneously referred to as paralysis.

Symptoms: Inability to retract the penis in the sheath or retain it there when replaced. Insensitiveness of the organ which hangs limply and swings to and fro when the animal walks.

Treatment: Massage the retractor penis muscle between the anus and scrotum. Injections of veratrine or strychnine may assist. Apply a suspensory bandage to prevent injuries and œdema. Amputation may be necessary as a last resort, or better still, the more recent method of removing a band-like piece of skin from the penis (by encircling it with two incisions) equal in width to one-half 
the length of the protruding organ. Suture the edges of the skin. Upon healing, the penis will be drawn back nearly in normal position.

Give the symptoms and the treatment of diseased prostate in the stallion.

Difficulty in defecation and urination. Straining to urinate and passing of a thin stream or only in drops. Rectal examination reveals, close behind the bladder, a soft, painful swelling, in acute conditions, and a hard and painless swelling in chronic inflammation. Abscess formation may fluctuate.

Treatment: Laxatives and enemas lessen the pressure from the rectum. Abscesses may be ruptured into the urethra, or evacuated with a trocar through the rectum. Catheterize regularly until the condition is relieved. Castration has been recommended.

\section{Give causes, symptoms and treatment of orchitis.}

Causes: Traumatisms; extension from the urinary passages; metastatic inflammation is seen in glanders and strangles.

Symptoms: A hot, painful swelling of the testicles. Edema of the scrotum if periorchitis occurs. Infectious orchitis is accompanied by fever. Hemorrhage may produce a hæmatocele which is very readily absorbed.

Treatment: A suspensory bandage; astringent packs such as Burrow's lotion. Paint with tincture of iodine when the inflammation subsides. If pus formation occurs, early castration is imperative to prevent extension and a fatal peritonitis.

Give the symptoms and the treatment of hydrocele.

Marked swelling of the scrotum, rescmbling somewhat an inguinal or scrotal hernia, but is soft, elastic, painless and noninflammatory. Differentiated from hemia, by the fact that the swelling is confined principally to the lower part of the scrotum and tapers away as it approaches the upper part. An cxploratory needle puncture will decide all doubt if necessary.

Treatment: Injections of tincture of iodine into the tunica vaginalis after emptying the same of its watery contents. Castration is usually necessary.

Describe fully ovariotomy in the bitch, including care and after-treatment.

Fast the patient for 24 hours and give a physic before opcration. Use a general anæsthetic. Empty the bladder. Shave and disinfect an area, $6 \mathrm{~cm}$. square, over the linea alba just anterior to the pubie brim. Nake an incision on the median line about $5 \mathrm{~cm}$. 
long, extending anteriorly from the pubis, cutting through the skin, linea alba and peritoneum with one stroke. Hold the wound open with retractors; locate the uterus and grasp it with forceps. By applying slight traction on the uterine cormua, each ovary may be exposed and removed by torsion or ligating and cutting. Draw both cornua, with the ovaries attached, through the opening and rupture them transversely near their bifurcation. The body of the uterus may be ligated with catgut and the horns removed by cutting. Close the skin and muscle wound with interrupted sutures. Paint the wound with collodion and apply a body bandage. Remove the slin sutures in about three days and cauterize any exuberant granulations that may have formed. Feed sparingly for a few days after operation.

\section{Describe vaginal ovariotomy in the mare. Mention the accidents that may occur.}

Fast the patient for 24 hours and give a physic before operation. Secure the patient in the stocks, bandage the tail and draw it aside, cleanse the vulva, clitoris, tail and perineal region by scrubbing with soap and water. After washing thoroughly, disinfect the external parts and for a short distance inside the vulvar lips with a $1: 1000$ aqueous sublimate solution. Rinse away the sublimate solution with a 0.6 per cent. solution of sodium bicarbonate, and fill the vulvovaginal canal with the same. The operator's nails, hands and arms must be scrupulously cleansed and disinfected, and all instruments must be sterilized. "Balloon" the vagina by introducing a tepid sterile water or salt solution into it. When ballooned properly, pass the hand with a sheathed knife and push the blade forward through the vaginal wall and peritoneum, a little above and to one side of the os uteri. Remove the knife, reintroduce the hand, and by careful manipulation push the hand through the incision and Jocate the ovaries. Pass the ecraseur alongside of the arm, carry it to an ovary and place the chain over the same. Tighten the chain and cut the ovary free, removing same with the inserted hand. Repeat the same on the other ovary. Keep the patient quiet for five or six days.

Dangers: Incision in the vaginal wall may be carried into the rectum, iliac arteries, posterior aorta, or uterine cavity. The incision may not penetrate the peritoneum and thus embarrass the operator by forming a large cavity between the vaginal and peritoneal walls. Inexperienced operators have removed a ball of frees in mistake for an ovary. By faulty technic, infection may be carried into the peritoneum and produce fatal peritonitis. 
Give the operative methods of treating inversion of the uterus.

Cleanse and suture any wounds. Give two ounces of chloral hydrate. Elevate the posterior parts and attempt reposition by careful manipulations. Inject lukewarm water to smooth out the folds. Apply a truss or suture the vulva, if neeessary. Keep the hind parts elevated for a few days. It is better to prevent straining by reducing the inflammation than to use sutures, etc. If the prolapsed organ is badly damaged, amputation is the only resort.

Give the treatment of purulent mastitis in cattle.

Apply hot fomentations or poultices. Drain abscesses and disinfect. Irrigate the galactophorous sinuses with a four per cent. solution of borie aeid. It may be necessary to amputate one or both halves of the udder.

Give the symptoms and the treatment of stenosis of the mammary duct in the cow.

Inability to obtain milk when the teat is compressed or the milk may escape in a thin stream only. Milking eauses pain which is resented by the patient. A small lump, "spider," may be felt in the teat.

Treatment: Pass teat sounds of gradually inereasing sizes. If this fails, use a teat slitter (special instrument) and enlarge the duct. It may be necessary to amputate the end of the teat where the obstruetion usually is located.

\section{Diseases of the Spinal Column and Pelvis}

Give the symptoms, prognosis and treatment of fracture of the tuberosity of the ischium.

Symptoms: Swelling of the muscles and crepitation in the region of buttocks. Dragging of the toe. Equal weight is placed on each foot.

Prognosis: Requires months to unite or heal and sometimes results in dragging of the toe.

Treatment: Rest for four to six weeks. Massage the museles to prevent atrophy. It may be necessary to make an incision and remove sequestra of bone.

Give the diagnosis of fracture through the acetabulum of the pelvis.

Severe swinging-leg and supporting-leg lameness. Often aecompanied by groaning. Crepitation when the leg is moved or weight is placed upon it. Sinking of the hip region. Fxamination per rectum will loeate the protruding head of the femur. 
Give the prognosis and treatment of fracture of the external angle of the ilium.

Prognosis is favorable, although a permanent blemish results.

Treatment: Rest the patient for 3 to 4 weeks, and keep in slings to prevent further injuries or displacement of the broken pieces by lying down.

What is the object of caudal myotomy? Describe the operation.

The operation is performed for the correction of curved tail.

Confine the patient in stocks or control with a side line and twitcl. Cleanse and disinfect the tail, and bend it in the opposite direction to the curvature. Locate the longitudinal furrow between the levator and depressor muscles on the convex side, and insert a tenotome at the lower margin of the levator, in the most prominent part of the curvature. Push the knife through the muscle to the vertebræ, turn the cutting edge upward against the lateral muscle and sever it completely. Remove the knife and bandage an antiseptic pad over the wound, leaving the same in place for 24 hours.

Describe an operation for amputation of the tail. When is this operation indicated?

This operation may be performed by clipping the hair over the seat of operation and using the docking shears, controlling hemorrhage by searing the stump with a red-hot iron. The iron also provides a protective scab.

A more strictly surgical procedure is to make two semi-elliptical flaps with the scalpel, by cutting through the skin and muscles in an oblique direction, above and below (over a joint if possible), disarticulate or chisel through the bone and suture the flaps over the end of the stump.

The operation is indicated in malignant or incurable diseases of the tail.

\section{Diseases of the Fore Limb}

Give the diagnostic symptoms of shoulder lameness. What treatment is employed in shoulder lameness.

Suddenly appearing lameness of a supporting and swinging-leg type. The leg is held in abduction and little weight is placed on it. The forward stride is shortened and the toe is dragged. Inflammatory swellings accompanied by increased warmth and pain may appear over the shoulder joint.

Treatment: Rest is imperative. In acute inflammatory conditions, cold applications are indicated. Later, counterirritants 
are best. Subcutaneous injections of Lugol's solution, in several points, over the joint is a good method of applying counterirritation and leaves no unsightly blemish.

Describe cold abscess of the shoulder. Give cause and treatment.

A sharply defined, slightly painful tumor, lying in or below the levator humeri muscle as it passes over the shoulder-joint. The skin is sound and moveable and the thick, hard wall of the tumor may show a point of fluctuation (pus).

Cause: Infection following bruising by an ill-fitting collar on a patient doing heavy draft work.

Treatment: Open the abscess, curette the cavity or cauterize with a white-hot iron. Dress the wound daily with antisepties. If the growth is extensive, it may be necessary to remove some or all of the new-formed tissue.

Give cause, symptoms and treatment of paralysis of the suprascapular nerve.

Cause: Violent backward movements of the shoulder or leg, causing overstretching of the nerve. Bruises to the nerve by blows, collar, ete.

Symptoms: Scapula and humerus are jerked away from the wall of the thorax when weight is placed on the affected leg. Atrophy of the paralyzed muscles occurs later. The atrophy is most marked in the infra- and supraspinati and the two teres muscles. It is noticeable by the apparent increased projection of the scapular spine, and is referred to by laymen as "sweeney."

Treatment: Massage and counterirritants such as subcutaneous injections of Lugol's solution. Usually requires 6 to 8 weeks and often months to effect a cure. Some cases never recover.

\section{Describe dislocation of the scapulohumeral articulation.}

It is caused by excessive movement of the joint, and appears as a sudden lameness and difficulty in moving the joint. Passive movement of the joint is interfered with by the swelling and tenderness. Treatment should be directed to immediate reduction of the luxation. Apply cold compresses and rest the patient as long as lameness exists.

Give the etiology and the treatment of shoe-boil (fibrous growth).

Etiology: Bruises of the elbow in lying and arising. Pressure from the shoe when recumbent is often eited as a cause, but is undoubtedly a minor consideration.

Treatment: Operative removal with the patient under a general anæsthetic. 
Describe the care and the treatment of a shoe-boil of (a) recent origin, (b) long standing.

(a) Cold applications and astringent lotions. If pus be present, incise and disinfect.

(b) There is a fibrous growth present and it must be surgically removed.

Give the symptoms, prognosis and treatment of fracture of the ulna.

Symptoms: Supporting-leg lameness; flexion of all the joints from the elbow downward; displacement of the ulna and severe pain in this region. Crepitation may be detected.

Prognosis: Unfavorable, best to destroy.

Treatment: Useless. Slings may be tried. Impossible to bandage.

What are the diagnostic symptoms of complete radial paralysis? Give method of treatment.

Symptoms: Supporting-leg lameness; the shoulder and elbowjoints extended, while all the other joints are flexed. The anterior wall of the foot may be almost in contact with the ground. Inability to support weight on the leg. The triceps are relaxed and unable to contract; later atrophy of these muscles appears.

Treatment: Nothing direct can be done. Massage the muscles and rest the patient. Electricity and counterirritants are of questionable value.

What are the indications for treatment in a case of "broken knee" with synovitis present?

Very carefully cleanse and disinfect the wound and cover it with an antiseptic dressing. Tie the horse up or use slings to prevent lying down. Suture the wound if practicable, otherwise leave open. Change the dressing daily, irrigating the wound with 1-1000 corrosive sublimate solution. Later, dry dressings such as iodoform and tannic acid are indicated.

Describe the operation of tenotomy as employed in shortening of the flexor tendons.

Secure the animal in lateral recumbency. Extend the affected leg and apply an extension splint on the under side, or have an assistant hold the leg in extreme extension. Shave and disinfect the skin over the tendon of the flexor pedis muscle in the middle of the cannon bone on the inner side. Insert a sharp-pointed tenotome, with the cutting edge toward the foot, through the skin and underlying tissues on the anterior border of the flexor pedis tendon. Push the tenotome through until the point is felt beneath the 16 
skin on the opposite side. Turn the cutting edge against the tendon, which is rendered tense by an assistant, and cut through it. When completely severed, resistance to extension ceases. Remove the Imife and bandage the wound. Healing should oceur by first intention if careful antisepsis is observed. Keep the animal standing and exercise moderately for the first few days following operation.

Give the causes, symptoms and treatment of inflammation of the flexor tendons.

Causes: Strains from slipping, improper shoeing (low heels and long toes), heavy pulling, jumping, continued standing in thoracic diseases or lameness in the opposite leg.

Symptoms: Supporting-leg lameness. The foot is extended forward or held with the heels raised. Shortening of the last phase of movement is noted. Local pain, swelling and warmth. In later stages, there may be shortening of the tendons and continuous volar flexion together with uprightness of the hoof. Weight is now placed on the leg. In shortening of the fiexor pedis perforatus, the obliquity of the pastern joint only is affected, the hoof remaining in a normal position.

Treatment: Rest and cold applications for the first day or two. Then, moist warmth, massage and infrictions with mild blistering agents are used. Old thickenings are best treated by firing. Shoe with a low toe-calk and elevated heel-calks. In chronic cases accompanied by shortening, tenotomy offers the only relief. See preceding question.

Give the causes, symptoms, prognosis and treatment of sprain of the inferior suspensory ligament.

Causes and symptoms are about the same as in tendinitis as described in preceding answer. Lameness is not so marked. Tenderness is detected by pressing in deep close to the bone and anterior to the tendons with the foot raised. Chronic cases, accompanied by shortening, affect only the obliquity of the pastern, the hoof remains in a normal position.

Prognosis: Favorable.

Treatment: Same as for inflamed tendons. Raising the heels, however, does no good in this ease and eutting of the ligament is not generally employed.

\section{What is the etiology of splint?}

Splints are due to a periostitis which develops between the large and the inner small metacarpal bones. Rarely, between the large and outer bone. This periostitis is due to traumatic irritation of 
the interosseous ligament, periosteum and bones. The irritation may be from blows as interfering, or from unequal distribution of pressure in the knee which throws an excessive load on the inner small metacarpus and ruptures the interosseous ligament.

Symptoms: In early stages, lameness is seen which is more marked at the trot. If high, affecting the carpus, the leg is held in abduction and extreme lameness is shown. Slight swelling, increased heat and pain on pressure can be readily detected. When the inflammation subsides, an exostosis remains as a blemish.

Treatment: Rest is important and in most cases is the only treatment needed. If due to striking, correct this fault by proper shoeing. In young horses, splint lameness often disappears spontaneously. Mild blisters and the firing iron may be used in severe cases. The exostosis called the "splint,". if unaccompanied by lameness, should not be interfered with unless, by reason of its size, it is struck by the opposite foot, then its removal may be attempted by chiselling it off.

Give the symptoms and the treatment of fracture of the metacarpus.

Symptoms: Displacement and abnormal mobility of the parts. Inability to place weight on the leg and crepitation may be noted.

Treatment: Place patient in slings. Replace the parts in proper position and apply a plaster-of-Paris bandage. Leave the plaster east in place for six weeks. Some advocate turning the horse in pasture after the cast hardens, but quietude is better.

Give the symptoms and the treatment of fracture of the os suffraginis.

Symptoms: Sudden lameness with volar flexion of the fetlock. Passive rotation of the foot produces crepitation in a complete fracture. In case of fissure, a line of tenderness may be detected on palpation, but no crepitation.

Treatment: Place patient in slings. Replace the parts in proper position and fix firmly with a plaster-of-Paris bandage. After the cast hardens, it may be advisable to provide a soft bed and allow the patient to lie down, thus preventing laminitis or other lameness in the sound foot by reason of its bearing additional weight.

Define ring-bone. Give the symptoms and the treatment of the same.

Ring-bone is a collective term for various chronic aseptic inflammatory processes at the coronary joint, attended with swelling. According to location, we distinguish two forms, viz., articular, involving the joint, and periarticular, in which the joint is not affected. 
Symptoms: Chronic enlargement around the coronet joint. Lameness in which the latter phase of the stride is shortened. In the artieular form, lameness is seen when the patient is turned in short cireles toward the diseased side. Tenderness of the swelling is usually present. The phalanges show volar flexion, that is, the fetlock is upright.

Treatment: Shoe with raised heels and shorten the toe, that is, prepare and shoe the foot so that the pastern lies parallel with the walls of the hoof. Point firing and blisters are beneficial if the animal is rested four to six weeks. This failing to remove the lameness, neurectomy is the last resort, but is of value only when anchylosis has not oceurred. In the latter condition, the lameness is mechanical and may be relieved by the use of a rolling-motion shoe.

\section{Describe neurectomy of the median nerve.}

This operation may be performed under local or general anisthesia. The point of operation is opposite the lower portion of the elbow-joint, immediately behind the upper extremity of the radius, toward the upper point in the depression between the radius and the internal fiexor muscle of the metacarpus. The nerve can be exactly located by palpation. Shave and disinfect the skin and make an ineision $5 \mathrm{~cm}$. long, parallel to and directly over the nerve, through the skin and sterno-aponeuroticus muscle, exposing the antibrachial faseia. Divide the fascia and, if neeessary, remove a small elliptical pieee of the same. Pass an aneurism needle under the nerve and separate it from the neighboring tissues. Excise a section of the nerve $3 \mathrm{~cm}$. long. Disinfect the wound and suture. (Care should be taken to avoid injuring the brachial vein, as hemorrhage from same would be very annoying.)

Mention the diseases in which median neurectomy would be indicated.

Navieular disease, ring-bone, side-bones, chronic sesamoiditis, splints, ehronic earpitis. In the latter three, nlnar neurectomy ought also to be performed. In ehronic synovitis (articular and tendinous) with permanent lameness, median neurectomy may be performed.

Describe the operation of high plantar neurectomy.

Operate on the standing animal, using loeal anasthesia. The point of operation is just above the fetlock in the lower third of the metacarpus, and just in front of the flexor pedis tendon. 'The exact point is determined by feeling the nerve glide beneath the fingers. Shave and disinfeet a small area. Make an ineision 3 to $5 \mathrm{em}$. long, 
parallel to and directly over the nerve, cutting through the skin and connective tissue, exposing the nerve. Scparate the nerve from the adjacent tissues and excise a section 3 to $5 \mathrm{~cm}$. long. Suture the wound and cover with bandage. Healing should occur by first intention. Repeat the operation on the opposite side.

Name three diseases for the relief of which plantar neurectomy is indicated.

Navicular disease, ring-bone and side-bone.

Describe the relations of the artery, vein, nerve and tendon in the region of the ergot at the seat of plantar neurectomy.

From before backward, vein, artery, nerve and tendon. The nerve lies close to the external margin of the tendon.

State your opinion regarding the use of the actual cautery in the relief of equine lameness.

The direct results which are attributed to the use of the actual cautery, e.g., strengthening tendons by the formation of cicatricial tissue, etc., are considerably overrated. The benefits are usually derived, indirectly, from the enforced rest following its use. Nevertheless, the actual cautery is a very valuable therapeutic agent. Puncture-firing augments local nutritive activity, converting chronic into acute processes and thus hastens their termination. Firing operations necessitate protracted rest and cause more or less immobility of the defective organs, both of which are of great benefit in bringing about a cure.

\section{Diseases OF the Hind Limb}

Name the various conditions listed under the category of "hip lameness." Give the diagnostic symptoms and the treatment of hip lameness.

1 , coxitis; 2 , rupture of the ligamentum teres; 3 , disease of the lumbar vertebræ, pelvic bones and femur; 4 , disease of the muscles of the liip region; 5 , disease of the tendon and tendon bursa of the gluteus medius muscle (trochanteric lameness); 6 , inflammation in the structures surrounding the hip-joint; 7 , lameness due to fracture or other disease of the external angle of the ilium is often erroneously referred to as hip lameness.

Symptoms: Swinging-leg lameness; difficulty in advancing the limb; dragging of the toe. In coxitis, there is supporting-leg lameness, not so in the muscular forms. Lameness is marked in turning or backing. Muscular atrophy is noted in cases of long duration. 
Hip lameness is best diagnosed by a process of exclusion and is very difficult at times.

Treatment: Rest is neeessary. Apply counterirritants such as subeutaneous or intramuseular injeetions of dilute Lugol's solution. Setons, blisters and the firing iron are used.

Give the diagnosis and prognosis of fracture of the femur.

Diagnosed by the presence of severe pain, leg abducted when advaneed. Supporting-leg lameness; erepitation. Fraeture of the trochanter is marked by swelling and pronouneed swinging-leg lameness, shortening of the forward stride and abduction of the limb. Weight may be placed on the leg. Fractures into the stifle-joint may show symptoms of gonitis.

Prognosis: Very unfavorable. Best to destroy. Fracture of the trochanter is least dangerous.

\section{Give the symptoms and treatment of stifle lameness.}

The term "stifle lameness" is a eollective one. The following conditions are included under this eaption: 1 , acute and chronic gonitis ; 2 , strains of the patellar ligaments ; 3 , bursitis prepatellaris ; 4 , luxations and fractures of the patella. The term is usually referred to the first named.

Symptoms: Gradually increasing lameness; limb held in a flexed position, or, if both limbs are affected, they are rested alternately. In moving, the limb is earried stiffly, the toe dragging or hitting slight prominenees. In acute conditions, a diffuse swelling is seen and tenderness is very marked. Chronie cases show a distention of the joint eapsule below the patella.

Treatment: Acute conditions call for cold irrigation and compresses. Later, a blister may be of benefit. Chronic eases are usually incurable, although blisters and the firing iron may be tried.

Describe the symptoms and the treatment of displacement of the patella.

Symptoms: Momentary upward (habitual) luxation may be overlooked, or the patella may remain fast for a moment and then suddenly deseend with each step, showing a slight eheck to movement, similar to that seen in string-halt. In stationary upward luxation, the limb is stiffly extended backward and eannot be advanced. Inability to flex the limb, and the patella is fixed on the upper portion of the internal lip of the trochlea. Outward luxation is shown by inability to bear weight on the limb. due to the loss of function of the reetus and vasti museles. The limb can be advaneed but the stride is shortened and lameness is shown when 
weight is placed on the limb; excessive flexion of all the joints of the Jimb occurs.

Treatment: Immediate reduction of the luxation, using great force if necessary, should be effected. In upward displacement, drawing the leg forward with a rope attached to the fetlock region, or starting the animal suddenly with a whip, will often bring about reduction. Teep the patient very quiet in slings. A blister applied over the stifle will help in keeping the limb at rest. If due to general weakness and relaxation of the ligaments from disease, attempt building up the general health. Momentary luxation is said to have been cured by dividing the inner straight ligament (desmotomy).

\section{Describe briefly patellar desmotomy (ligament section).}

The object of this operation is for the relief of habitual luxation of the patella, or patellar string-halt, as it is sometimes called. The operation has been but little tried in this country or elsewhere, and its value is still sub judice.

Secure the patient in lateral recumbency with the affected leg beneath and extended. General anæsthesia should be employed. Locate the internal ligament, running from the patella obliquely to the supero-internal part of the tibia. Shave and disinfect a sufficient area. Make an incision, 2 inches long, through the skin, parallel to and directly over the middle third of the ligament, exposing the fascia. Cut through the fascia, insert a blunt-pointed bistoury beneath the ligament from behind forward and sever the ligament. Suture the skin wound and cover with collodion.

\section{Give the symptoms of ruptured flexor metatarsi tendon.}

Lameness when the limb is carried forward; the stifle is flexed but the hock is excessively extended. The symptoms resemble those of a broken bone but the absence of fracture is shown by the ability to support weight on the limb. The symptoms are more apparent during movement. Swelling and pain may be present over the anterior surface of the tibia.

\section{Describe cunean tenotomy. What is the object of this operation?}

Operate on the standing animal, using local anæsthesia and a sideline on the opposite leg. Locate the cunean tendon by palpation as it passes obliquely downward and backward over the inferior median surface of the hock. Shave and disinfect an area, 5 to $6 \mathrm{~cm}$. square. At a point about $1 \mathrm{~cm}$. below the inferior border of the tendon, midway between the anterior and posterior borders of the hock, insert a narrow-bladed scalpel, flatwise, through the skin and 
upward between the skin and tendon, to the superior border of the latter. Turn the cutting edge against the tendon and by firm pressure cut through the same. A well-marked depression between the cut ends can be detected when the operation is complete. Disinfect the wound and apply an antiseptic bandage. Healing by first intention should follow.

Object: Relief of spavin lameness and as an adjunct to peroneal tenotomy for string-halt.

\section{State the object of peroneal tenotomy. Describe the operation.}

Object: For the relief of string-halt.

Shave and disinfect a small area just below the hock on the outer side, where the peroneal tendon is almost subcutaneous, and about $6 \mathrm{~cm}$. above its point of union with the tendon of the extensor pedis longus muscle. Hold up the opposite hind limb with a sideline and apply a twitch to the nose. Stretch the skin tightly, insert the tenotome through the skin and underlying fascia, push it under the tendon, turn the cutting edge against the same and sever it as well as the fascia through to the skin. An antiseptic bandage should be applied and left in position for eight days. The cutaneous wound should heai by first intention. A rest of one to two weeks is usually demanded, although some operators claim the best results to follow immediate exercise.

\section{Mention the various forms of spavin and give the treatment of each.}

1. Arthritis chronica deformans tarsi (bone spavin).

Produce anchylosis of the joint by prolonged rest for six weeks or longer, in connection with deep point firing and blistering. Cunean tenotomy, as described in preceding answer, is used by some, periosteotomy by others. Whichever method is used, the benefits which follow are due to the anchylosis brought about principally through the enforced rest. As a last resort, anterior and posterior tibial neurectomy may be employed. Shoe with raised heels and shortened toe.

2. Bog-spavin (excessive distention of the capsule of the true hock joint, aue to chronic synovitis).

Recent cases are treated by cold applications and later by blistering. Massage and repeated painting with tincture of iodine may diminish the swelling. Extensive swelling may be reduced by the actual cautery. This condition seldom causes lameness and is best left alone.

3. "Blood-spavin," formerly classified as a variety of spavin, is no longer recognized as such. It is simply a distention of the saphena 
vein as it courses over the hock. Lameness accompanying its presence is usually due to an underlying true spavin (arthritis chronica deformans tarsi) and should be treated accordingly.

Give the pathology of thorough-pin.

Generally due to chronic synovitis brought on by severe exertion. It may follow an acute synovitis, and consists of a distention of the capsule of the tendon in the upper posterior part of the hock-joint. Occasionally this sheath of the flexor pedis tendon communicates with the capsule of the true hock-joint and hence we may see bog-spavin and thorough-pin coexisting. Thorough-pin is seldom accompanied by acute inflammation and hence lameness is rare.

\section{Define curb. Give treatment for curb.}

Curb is a thickening of the metatarsocalcanean ligament, resulting from inflammation. The term curb is often applied to any swelling which causes a deviation from the normal straight line from the tuber calcanei to the fetlock.

Treatment: Acute inflammation calls for antiphlogistic measures such as cold irrigation, Burrow's lotion, etc. Later, blistering, or line firing and blistering with rest, is indicated.

\section{Define "capped hock" and give causes and treatment of same.}

Capped hock refers to any swelling on the point of the os calcis. It may be due to inflammatory swellings or thickenings in the skin and subcutis, gravitation of swellings originating above, hydrops of the subcutaneous bursa of the flexor pedis perforatus tendon, or swelling of this tendon.

Causes: Kicks, violent exertion, slipping and external injuries from various sources.

Treatment: Acute inflammatory conditions demand cold applications. Later, absorbing applications, such as tincture of iodine or mercuric blisters. Extensive swellings may require antiseptic puncturing with a hollow needle and the application of a pressure bandage. Wounds require the usual antiseptic treatment. In swellings of the skin, massage is beneficial.

\section{Describe anterior tibial neurectomy.}

Operate on the standing animal with local anæsthesia but it is better to use general anæsthesia with the animal cast and confined. Locate the furrow between the extensor pedis and the peroneus muscles. Shave and disinfect an area, $6 \mathrm{~cm}$. long by $3 \mathrm{~cm}$. wide, directly over this furrow and extending upward from a point 6 or 7 $\mathrm{cm}$. above the tibio-astragaloid articulation. At a point 8 to $10 \mathrm{~cm}$. 
above the flexure of the hock, opposite the external margin of the extensor pedis muscle, make an incision, 5 to $6 \mathrm{~cm}$. long, through the skin and underlying aponeurosis. Separate this muscle, first from the tendinous, then from the muscular portion of the flexor metatarsi, on the anterior side of the margin of which the anterior tibial nerve is seen. Pass an aneurism needle underneath it and remove a piece, 3 to $4 \mathrm{~cm}$. long. Close the cutaneous wound with interrupted sutures and apply a collodion dressing.

\section{Describe posterior tibial neurectomy.}

Operate on the standing animal with local anæsthesia, side-line and twitch. Operating table with general anæsthesia is better. Shave and disinfect an area, $10 \mathrm{~cm}$. above the top of the os calcis and $2 \mathrm{~cm}$. in front of the tendon Achilles, on the median side. Make an incision about $5 \mathrm{~cm}$. long parallel to the above-mentioned tendon, through the skin. Ascertain, by palpation, the exact location of the nerve and cut through the fascia over it, exposing the nerve. Separate it from the surrounding tissues and remove a piece, $3 \mathrm{~cm}$. long. Suture the cutaneous wound and apply an antiseptic bandage. Healing by first intention should follow.

\section{Diseases OF THE FOOT}

Mention ten diseases of the foot and specify those met with most frequently.

Ring-bone, side-bone, navicular disease, laminitis, pododermatitis (including corns), and quittor are more frequently met with. Less commonly, we see keraphyllocele, contracted sole, quarter crack and canker.

\section{What are the symptoms of fracture of the navicular bone? Give prog-} nosis and treatment.

Symptoms: Foot continually rested and held in excessive volar flexion. Extreme pain is shown when the coronet joint is passively extended. Later, an inflammatory swelling occurs in the hollow of the heel.

Prognosis: Unfavorable. Chronic lameness is very likely to follow.

Treatment: Complete rest is essential. Apply cold compresses. Resection of the flexor pedis perforans and removal of the os naviculare may be attempted. As this operation is oceasionally performed in case of penetrating street-nail, it would seem permissible in this condition. 
Give the symptoms and the treatment of fracture of the os corona.

Symptoms: Sudden severe lameness; volar flexion of the fetlock joint and crepitation in the affected region will make the diagnosis easy. Fissures are harder to detect and require careful examination.

Treatment: Complete fixation in a plaster cast for six weeks. Lameness following may be removed by median neurectomy. Usually unfavorable.

Give the pathology and the treatment of side-bones.

Side-bone is a condition in which the lateral cartilages of the foot are partially or entirely ossified. The causes are excessive concussion by work on hard roads, shoes with high heel-calks which prevent the normal frog-pressure, and traumatisms. There is a congenital predisposition in heavy coarse-bred horses, a large percentage of which are affected.

Treatment: Rest the horse, remove shoes and place the patient in a peat-moss or other soft bed. Thin the wall over the affected cartilage and apply wet swabs to soften the horn. A special shoe is necessary when the outer cartilage is ossified and the corresponding quarter is contracted. After the lameness lessens, or disappears, prepare the foot for the shoe by lowering the outer wall more than the inner. The shoe should be flat, the outer branch broad and well set out, the inner branch closely fitted, thus giving a wider supporting surface on the outside. If both cartilages are affected, a plain open shoe with high calks is best. The bar-shoe is contraindicated, as frog-pressure is undesirable in this condition. As a last resort, perform neurectomy to remove lameness.

Mention the varieties of ring-bone and give treatment of each variety.

1. Articular: Lameness can only be removed by performing neurectomy, and then only in case anchylosis has not occurred.

2. Peri-articular: Level the foot and apply a level shoe or one with the heels raised slightly and the toe shortened. Rest for six weeks may be enforced by, and benefit derived from pointfiring and blistering. These measures failing, neurectomy is the only resort.

3. Traumatic and rachitic forms are sometimes noted. These seldom cause severe lameness. Treat with cold applications or blisters.

Give the symptoms and the treatment of quittor.

Symptoms: The first symptom is a diffuse swelling in the region of the coronet and bulb of the heel. Later, abscess formation occurs 
with a discharge of pus. This may cease and a new abscess form in a different place, and so on until the whole cartilage is more or less necrotic. Lameness is usually slight unless the pedal joint is invaded. In long-standing cases, the wall is thrust outward and ringed.

Treatment: In the early stages, when the pain is slight and the patient is able to work, antiseptic injections may be tried. Caustic agents such as a 10 per cent. solution of zinc chloride or silver nitrate, and corrosive sublimate may benefit. Formalin in a 10 per cent. solution may cause the discharge to cease. Operative removal of the affected cartilage is usually necessary and is best performed early.

\section{Give in detail Bayer's operation for quittor.}

Shave the hair from the coronary region up to the fetlock. Scrub the parts with brush and soap. Apply an antiseptic pack and leave for 24 hours. Use general anæsthesia. Apply a tourniquet above the fetlock. Remove a crescent-shaped piece of horn from the area over the cartilage. Make a corresponding incision through the sensitive structures, about $1 / 4$ inch within the incision through the horn; the ends of the incision are prolonged upward, dividing the coronary band, etc., as high as the upper margin of the lateral cartilage. The flap, thus outlined, is dissected away from the underlying cartilage, and the latter is then removed, either wholly or in part, depending upon the extent of the disease. Freely curette away all necrotic tissue. Disinfect the wound and dust freely with iodoform. Suture the flap, cover the surface with an antiseptic pack and bandage. Leave this dressing in position for ten or twelve days if no great pain is shown and no bad odor or discharge is given off.

\section{Give the symptoms and the treatment of chronic navicular disease.}

Symptoms: Supporting and swinging-leg lameness. Lameness is increased by exercise, decreased by rest. Volar flexion of the phalanges and extension of the foot. Tenderness to pressure over the navicular bone and to forcible dorsal flexion. The use of cocaine will aid in the diagnosis. When both feet are affected, the last phase of movement is shortened and the limbs are carried stiffy and rapidly forward. Sometimes the lameness disappears after exercise but more often it is aggravated. A decrease in lameness follows a long rest. Muscular contraction and hoof contraction follow disuse.

Treatment: In recent cases, a long rest in a box with pcat moss, tan-bark or soft clay, together with the application of wet swabs 
on the feet, may assist repair. Shortening of the toe and raising of the heels of the shoe will often relieve lameness to such an extent that light work can be performed. In most cases, neurectomy is the only measure that will render the horse serviceable.

Describe pumiced sole of the foot, giving cause, prognosis and treatment.

Pumiced sole is that condition in which the horny sole in the neighborhood of the toe readily crumbles away and leaves the sensitive tissues more or less exposed.

Cause: Seen as a complication of laminitis. May follow punctured wounds of the foot or bruises of the sole where exudation from the secreting membrane occurs.

Prognosis: Favorable if due to wounds or bruises with simple exudation and separation of the tissues. If due to laminitis with dropping of the sole, an incurable lameness results.

Treatment: Provide drainage and apply antiseptic dressings to wounds and bruises. Chronic laminitis calls for special shoeing. A wall-bearing shoe with thin heels and thick toes and a protective dressing over the exposed parts are indicated.

\section{What is seedy-toe? Give treatment of seedy-toe.}

Seedy-toe is characterized by the separation of the horny wall from the sensitive laminæ at the toe and an accumulation of imperfect horn or horn debris in the space formed. It follows an injury which destroys the sensitive laminæ. The modified horn is produced by the imperfectly regenerated secreting structures. Also seen as a complication of laminitis.

Treatment: Rasp away the wall over the affected area and remove all imperfect horn tissue. Apply antiseptic packs and later use a tar dressing. A special shoe to protect the exposed toe may be necessary.

\section{Give the pathology and the treatment of corns.}

A corn is the result of an injury to the pododerm in the angle between the quarter and the bar. The laminæ of the bar and quarters and the velvety tissue of the sole may be involved. The primary injury causes hemorrhage between the pododerm and horn. Unless infection enters, the only lesions produced are the blood-stained horn tubules which are exposed by paring away of the horn. This condition is called dry corn. Should infection enter, a suppurating condition is produced and the pus may work its way upward and break out between the wall and the coronary band, causing severe lameness (suppurating corn). 
In chronic corms, the horn is permanently altered, being either soft and moist or dry and crumbled. The inner surface of the horn is covered with horny swellings or nodules and the patient presents well-marked lameness.

Corns are caused by overparing and thus weakening the horn; by contracted heels, by improper balancing, and shoeing of the foot; by neglecting shoeing; by lack of moisture; by direct traumatisms as from stones, bruises, etc. Ossification of the lateral cartilages lessens the elasticity and thus increases the effect of concussion when the foot is brought in contact with the ground. Hence corns and side-bones are often associated in the same foot.

Treatment: Remove the cause; shorten the toe, lower the quarters and remove all dead horn. Avoid too much paring and exposing of the sensitive laminx. Apply a bar-shoe with leather sole and pack the foot with tarred oakum. If side-bones are present, and a bar-shoe is not advisable, a three-quarter shoe may be used until the parts are normally restored. Suppurating corns should be freely drained and disinfected until the part is covered with horn, when a tar dressing and bar-shoe may be applied.

\section{Give the causes, symptoms and the treatment of thrush.}

Causes: Standing in filth (soiled bedding, urine, frees, etc.), excessive paring of the frog, lack of frog-pressure, and hard work on stony ground are exciting causes of thrush. Among the predisposing causes are: navicular disease, contracted heels and scratches.

Symptoms: Increased moisture of the frog, an ill-smelling, darkcolored discharge which may entirely loosen the frog. Lameness may be present in severe cases.

Treatment: Remove the cause; provide clean, dry bedding. Pare away all diseased and ragged portions of the frog. It may be necessary to remove all of the liorny frog. Cleanse and dry the parts and keep dry by dusting with calomel. After healing occurs, apply a bar-shoe and tarred oakum, or otherwise provide for frogpressure to prevent the contraction of the hecls which often follows.

Differentiate thrush and canker. Give prognosis and treatment of each.

See answer to preceding question.

Canker is a chronic inflammation of the secreting structures of the foot, due to the presence of an infection (probably specific), which prevents the growth of healthy horm and produces a greasy discharge, exceedingly offensive to the sense of smell.

Prognosis: In canker, rather unfavorable. Requires long, con- 
tinued, patient endeavors to effect a cure. Relapses are common. Thrush usually responds readily to rational treatment.

Treatment: In canker remove all diseased horn and cauterize; sulphuric acid, nitrate of silver, formalin, zine chloride and tincture of iodine have been used with good results. Daily cleansing is imperative. When healthy horn covers the affected parts, apply a tar dressing.

Give the causes, symptoms and treatment of laminitis.

Causes: Overwork; long-continued rest; sudden cooling of the body after perspiring freely; overfeeding, especially when warm; occurs as a complication of colic, influenza, parturition, and as a sequel of severe purgation.

Symptoms: Acute form appears suddenly with fever, characteristic attitude with fore feet advanced and hind feet thrust forward to relieve weight from the affected members. If all four feet are affected, all movement is exceedingly painful. Strong pulsation is noted in the plantar arteries and the feet are warm and very tender. These symptoms may disappear in from 7 to 10 days, or continue into the chronic form. Sometimes suppuration occurs and is followed by shedding of the hoof.

Chronic form: The soles "drop" and the os pedis is displaced, shown by the depression around the coronet and the convexity of the sole. Seedy-toe often appears. The patient travels with the fore limbs in abnormal dorsal flexion, the heels striking the ground first. Rings form upon the walls of the hoof, showing the disturbed nutrition of the same.

Treatment: Acute form: Remove the shoes and supply a soft bed so that the weight is supported by the soles as well as the walls. Use cold applications during the first 24 hours. Give a quick-acting cathartic such as arecoline and draw 6 or 8 quarts of blood if the patient is plethoric. After 24 hours, use hot applications. Stand the patient in a tub containing sufficient hot water to cover the feet. Give one grain of arecoline daily, in divided doses of $1 / 4$ grain each. Feed a laxative diet. A blister around the coronet may relieve the soreness.

In case of dropped sole (chronic case), proper shoeing is the only measure likely to benefit. An open shoe with a broad web and a wall-bearing surface only is best. A bar-shoe of the same type would be indicated if the wall is weak or broken away. Avoid toeclips and side-clips if their presence produces pain in the sensitive structures beneath. 
State briefly the surgical details in treating a case of penetrating streetnail.

Carefully pare away the sole around the point of entrance of the nail and provide drainage for any diseharges which may form. Dress with antisepties and keep the wound eovered with absorbent gauze or cotton. If the nail has entered the navicular bursa, resection of the perforans tendon will be necessary.

Describe a method of treating contracted hoof.

Apply a bar-shoe, or a flat open shoe and the Chadwiek spring. Keep the horn soft and pliable by frequent moistening.

Hcw would you shoe a horse to overcome forging?

Shorten the toe of the fore foot and roll the toe of the shoe to faeilitate quick "breaking over." The ends of the branches of the shoe should be no longer than neeessary to protect the heels and should be bevelled from the hoof surface of the shoe downward and forward under the foot. The hind foot should be lowered in the quarters and left long at the toe. It should be fitted with a shoe, squared at the toe and well rounded on the lower edge in this region. The shoe should be so fitted that at least three-fourths of an inch of the wall of the toe projeets beyond the shoe. In feet in which the toe is too short, a low toe-calk may be used to cause slow "breaking over."

Describe the treatment of quarter crack in a heavy draft horse. Describe the proper kind of shoe to apply in such a case.

Thin the horn for an ineh on both sides of the erack, direetly over the eoronary band, to prevent any friction between the sides of the eraek. Immobilize the erack by bandaging the hoof with adhesive tape. Apply a bar-shoe, Chadwiek spring and leather sole.

Describe the shoe you would have applied in a case of contracted perforatus and perforans tendons of the hind limb of a draft horse.

An open shoe with low toe-ealk and with heel-calks sufficiently high to give the neeessary support to the heels.

State the uses of a bar-shoe. When is a bar-shoe contra-indicated?

The bar-shoe is used when frog-pressure is desired as in contracted quarters, contracted sole, chronic laminitis, quarter-crack, wry-hoof, and frog atrophy; when it is desirable to relieve a diseased section of wall from pressure as in eorns, ete.

The bar-shoe is contra-indicated when side-bones or navicular disease are present, or when disease of the frog or subjacent tissues renders frog-pressure painful. 
How would you shoe a horse to afford speedy relief from a bruised heel?

Use a shoe with heel-calks and long branches which do not press upon the quarters.

\section{Miethods of Restraint, Casting, Etc.}

Name three common methods of restraint.

Side-line, hobbles and operating table.

Mention three methods of restraint in the standing position and two in the recumbent position.

1. Side-line, stocks and twitch.

2. Hobbles and operating table.

Describe two methods of casting the horse and ox for operation.

Horse: 1. Adjust hobbles on all four feet. Pass a rope or chain through the rings in same and draw the feet together, causing the horse to fall. A soft bed should be provided for the horse to fall upon (English hobbles). 2. A casting harness may be used. A strong girth, provided with large rings, is buckled tightly around the chest close behind the elbows. Hobbles are placed on all four feet and ropes are run from the same to the rings on the sides of the girth. When the ropes are drawn taut, the horse falls and is secured by tying the feet to the girth. A "figure 8 " made with the rope on both hocks will hold the horse more securely.

Ox: 1. Either of the above methods may be used. 2. A long rope (36 feet) is fastened, by one end, to the horns or head and carried backward, making three "half-hitches" around the body, one just anterior to the shoulders, another, just back of the elbows, and the last around the abdomen, anterior to the external angle of the ilium. By pulling firmly on the free end of the rope thus adjusted, the ox will lie down. Hobbles can then be adjusted.

Mention the chief accidents that may occur in casting and securing animals for operation. State how such accidents may be avoided.

1. Fractured vertebræ. Provide a soft bed for the animal to fall upon. Prevent violent movements. Be sure the patient is free from an abnormal fragility of the bones before casting. Don't extend the hind limbs too forcibly, by drawing the feet too far forward and upward.

2. Fracture of the external angle of the ilium. Provide a soft bed. Avoid throwing too suddenly. 
3. Fracture of the pelvic girdle and femur may be due to abnormal fragility of the bones.

4. Facial paralysis. Avoid by using a hood-wink which will protect the facial nerve from injury.

What anæsthetics are commonly employed in major operations and minor operations on (a) the horse, (b) the ox, (c) the dog.

(a) Major: chloroform, chloral hydrate, cannabis indica. Minor: cocaine hydrochlorate, stovaine and alypin.

(b) Major: morphine, chloral hydrate and chloroform. Minor: cocaine hydrochlorate and stovaine.

(c) Major : ether and morphine. Minor: cocaine hydrochlorate and stovaine.

What are the dangers of chloroform anæsthesia? How may these dangers be avoided?

1. Inhalation pneumonia: Keep the head lowered to allow better drainage from the nasal cavities. Fast the patient for 24 hours before administering the anæsthetic to lessen danger of regurgitation of food into the pharynx. Do not prolong the stage of anresthesia unnecessarily.

2. Syncope: Avoid giving the chloroform too fast and with insufficient air or over too long a period of time. Patients witl heaves, valvular disease of the heart, or dyspnœa from any cause should be given chloroform very guardedly or not at all.

How would you anæsthetize a foot for a painful operation?

By injecting one drachm of a 4 per cent. solution of cocaine hydrochlorate over each plantar nerve at the point where high plantar neurectomy is performed. Observe antiseptic precautions in injecting.

Describe briefly a quick and satisfactory method of sterilizing your hands and instruments.

If the hands are cleansed thoroughly with soap, water and a scrubbing brush, then immersed for five minutes in a 4 per cent. solution of potassium permanganate and, finally, in a 10 per cent. solution of oxalic acid until the stain of the permanganate of potash disappears, they will be perfectly sterile. The oxalic acid should be rinsed off with sterile water.

Instruments may be sterilized by placing in boiling water for fifteen minutes. 


\section{OBSTETRICS*}

\section{Obstetrical Anatomy}

Name the soft organs concerned in obstetric anatomy.

Ovaries, uterus, vagina, vulva and mammie.

What is the pelvis? Name the functions of the pelvis. How many centres of ossification appear in its early formation?

The pelvis is a bony framework at the posterior extremity of the trunk, supporting the spinal column and resting upon the posterior extremities. It contains, sustains and protects a portion of the genito-urinary apparatus, as well as the terminal portion of the alimentary canal. It constitutes a most important fulcrum or fixed point in various muscular movements and supplies a passageway for the fœtus during the act of parturition.

Five centres of ossification appear in each half in its early formation; one for each of the three bones and two complementary centres, one for the anterior spinous process and spine of the ileum, the other for the ischial tuberosity.

Make a drawing to show the normal position of the generative organs of the mare. Show also the kidney, the bladder and the rectum. $\dagger$

State how the bones of the pelvis of the mare differ from those of (a) the cow, (b) the sheep, (c) the goat, (d) the bitch, (e) the cat.

(a) The pelvis of the cow is longer and less vertical than in the mare. Because of the greater curvature of the ischiopubic symphysis, the floor is concave. The pelvis of the cow is more cylindrical and less conical than that of the mare.

(b) and (c) The pelvis of the sheep and of the goat is about the same as in the cow, except, of course, in size. The symphysis is nearly rectilinear in its direction, and it ossifies at a very much later period than in the cow or mare.

(d) and (e) The marked angle formed by the sacrum and the lumbar vertebræ diminishes the inlet of the pelvis. The direction of the symphysis is rectilinear and the pelvic cavity is nearly cylindrical.

* Uniess otherwise stated all questions relate to the horse.

†There are no illustrations in this book, but this drawing would seem comparatively simple. 
State the difference between the pelvis of the sheep and that of the cow.

Difference is mainly in size. The coxæ of the sheep are more horizontal and proportionately longer than in the ox.

Give approximately the supero-inferior and the transverse diameters of the bony pelvis of the cow.

$\begin{array}{ll}\text { Supero-inferior } \ldots \ldots \ldots \ldots \ldots & \begin{array}{c}\text { Inlet. } \\ \text { Transverse }\end{array} \ldots \ldots \ldots \ldots \ldots \ldots \\ \text { to } 10 \text { inches. } & 9 \text { inches. }\end{array}$

Name the different articulations of the pelvis.

One sacrolumbar, two sacro-iliac, one ischiopubic symphysis, and one sacrococcygeal.

Name the ligaments connecting the last lumbar vertebræ with the sacrum and the pelvis.

Common inferior vertebral, supradorsolumbar, interspinous, interlamellar, and capsular.

Describe (a) the iliosacral ligaments, (b) the sacrosciatic ligament.

(a) The superior iliosacral ligament is a thick and short cord which arises from the internal angle of the ileum and passes backward to be fixed to the sacral spine where it becomes confounded with the supraspinous, dorsolumbar ligament. The inferior iliosacral ligament is attached by its anterior margin to the upper half of the sciatic border and the internal angle of the ileum. Its inferior margin is inserted into the rugged lip on the lateral border of the sacrum. Its posterior border is united to the aponeurosis covering the coccygeal muscles, and its external face is in contact with the gluteus magnus and long vastus muscles. The internal face lies against the lateral sacrococcygeal muscle.

(b) This is a large membranous ligament situated on the side of the pelvis between the sacrum and the coxa. It is irregularly quadrilateral, having four borders. The superior border is attached to the lateral rugged lateral ridge of the sacrum; the inferior is fixed to the supracotyloid ridge and ischial tuberosity; the anterior aids in forming the great sciatic notch, and the posterior is confounded with the coceygeal aponeurosis. Its internal face is covered with peritoneum. This ligament affords a large area for museular insertion as well as serving a means for enelosing the pelvic cavity.

Where is the ischial notch? What vessels and nerves pass through it?

The ischial noteh lies between and is formed by the posterointernal borders of the two ischii as they join at the symphysis.

The artery of the bulb in the male, the perineal artery and the 
artery of the clitoris in the female, all being branches of the internal pudic artery, pass through the ischial notch, as does the pudic nerve.

\section{Describe the structure of the vulva.}

The vulva lies immediately beneath the anus and opens externally by means of a vertically elongated slit, bounded by two lips (labia vulvie) which meet above and below to form the superior and inferior commissures. It has two groups of muscles which are chiefly circular and are termed anterior and posterior constrictors. The vulva is lined witl mucous membrane, continuous with that of the bladder and vagina. Within the vulvar cavity, about four inches from the exterior and lying on its floor, is the meatus urinarius, the terminal opening of the urethral canal. In the inferior is the clitoris, an erectile organ two or three inches in length, composed chiefly of erectile tissue.

\section{Describe the mucous membrane of the vulva and state what kind of} epithelium covers it.

It is continuous with that of the vagina and bladder and is rosy-red in color. Near the free border of the labia, it often shows black pigment patches. It contains a great number of mucous follicles and sebaceous glands. The epithelium lining the vulva is of stratified pavement type.

\section{Give the anatomy of the uterus.}

The uterus is a musculomembranous sac, situated in the sublumbar and pelvic regions of the abdominal cavity. It is related above to the rectum; below, with the bladder; anteriorly and laterally, with intestines, and behind, with the vagina.

It presents for study a base and two cornua. The base is constricted posteriorly to form the cervix (or neck) and communicates with the vagina through a circular opening, the os. The base is continuous with the two cornua, right and left. The cornua have a superior or convex and an inferior or concave curvature, a base continuous with the uterus, and a summit continuous with the oviducts.

The uterus is supported by two broad ligaments which descend from the sublumbar region to the sides of the uterus and cornua, and envelop the ovaries and their ducts; two rudimentary, round ligaments running from the sides of the uterus to the beginning of the inguinal canal.

The uterus is made up of three coats, an outer serous, derived from the peritoneum; a middle, muscular; and an inner, mucous. 
Blood is supplied to the organ by the utero-ovarian and uterine arteries, and it is innervated by branches from the mesenteric and pelvic plexuses.

\section{Describe the uterus of the bitch.}

The body of the uterus is short, but the cornua are very long and folded, and fioat amongst the intestinal convolutions. Its cervix projects into the vagina. The mucous membrane is very loose and gathered into folds. The museular coat is well developed and is eovered externally with peritoneum.

\section{Give the blood and nerve supply of the uterus.}

Uterine and utero-ovarian arteries. Innervated by branches from the small mesenteric and pelvic plexuses.

\section{Describe the ligaments of the uterus. What are the functions of these ligaments?}

The broad ligaments, two in number, are irregularly triangular in shape, and are more developed before than behind. They descend from the sublumbar region to be attached by their inferior border to the sides of the upper face of the body of the uterus and the small eurvature of the cornua. They sustain the Fallopian tubes and ovaries. These ligaments are close to each other posteriorly in the region of the eervix but separate anteriorly like the branches of the letter $V$. They suspend the uterus in the sublumbar region.

The round ligaments, two in number, outside of the broad ligaments, contain in their folds a small thin musele. These ligaments run from the sides of the uterus to the beginning of the inguinal eanal. Their function is to support and retain the nterus in its proper position.

Describe the glands of the uterus and give their functions.

They are mueous glands and are designated simple and cylindrical. The former, most numerous near the cervix, secrete the peenliar transparent mucous found there. The eylindrieal, uterine or utrieular glands are closely situated and are often twisted in a spiral fashion. They resemble other mucous glands with spheroidal epithelium in the bottom of the tube and columnar cells in their duets.

\section{Describe an ovary.}

A small ovoid body, situated in the sublumbar region, with a deep notch or hilus on its upper surface which receives the oviduct. It is attached by the ovarian ligament to the uterus and supported by the broad ligament. 
It is covered by a serous coat except at the hilus. Underneatl this coat is a strong fibrous coat and beneath this coat is the ovarian tissue proper. The latter is hard and grayish-red and is divided into an external cortical and an internal medullary portion. The cortex is made up of connective tissue and holds large numbers of Graafian vesicles or ovisacs which contain the ova. The medulla is red and spongy and is composed of connective tissue which is richly supplied with blood-vessels. The ovary receives its blood from the utero-ovarian artery and is innervated by a branch from the mesenteric plexus.

State how the ovaries of the mare differ from those of (a) the cow, (b) the sheep, (c) the goat, (d) the pig, (e) the bitch, (f) the cat.

(a) Much smaller than in the mare, but are identical in form and structure. See answer to preceding question.

(b) and (c) Same remark applies here as given in (a).

(d) The ovary is lobulated in the pig.

(e) and (f) Slightly lobulated in aspect.

Describe the mammary gland.

The mammary gland consists of two glandular bodies situated in the posterior and inferior abdominal region. They are hemispherical in shape and terminate below in a small prominence, the teat. Externally, they are covered with skin, beneath which is a fibrous coat which sends prolongations into the interior of the gland. The glandular tissue contains acini which open into lactiferous ducts. These ducts unite and form canals which, in turn, form two, three or four sinuses that open by several canals on the teat. The external pudic artery supplies the gland with blood and innervation is received from the first pair of lumbar nerves.

\section{Describe the mammary glands of the bitch.}

These are ten in number, arranged in two rows of five each, and extend from the inguinal region to below the chest. They have no galactiferous reservoirs and the lactiferous ducts unite directly into a variable number of canals that pass through the teat to pierce its extremity by from five to ten orifices.

Describe the vesiculæ seminales and give their function.

The vesiculæ seminales are two oval pouches, situated above the neck of the bladder, and having a body and an anterior and posterior extremity. The latter is tapering and unites with the vas deferens to form the ejaculatory duct. The anterior extremity forms a rounded cul-de-sac partially covered with peritoneum. The walls 
are composed of three membranes: an internal, mucous; a middle, muscular; and an external, fibrous. The function of these bodies is to store semen for the copulatory act. They also secrete mucus which tends to dilute the semen much the same as the secretion from the prostate and Cowper's glands.

Are the vesiculæ seminales found in all the domestic animals? Explain.

No. They are not found in the dog and cat.

\section{Physiology}

State the four chief functions of the generative system.

Copulation, impregnation, fetation and parturition.

Describe the Fallopian tubes and state their function.

The Fallopian tubes, or oviducts, are two small cylindrical flexuous canals, about ten inches long, one of which is lodged in each broad ligament. They extend in a tortuous manner from the uterine cornua to the ovaries. The calibre of their eanal is very small at the uterine extremity, scareely admitting a hair but it enlarges at the ovarian end where it terminates in a pavilion. The pavilion is fixed to the external side of the ovary and opens into the peritoneal cavity. The function of these tubes is to eonvey the ova from the ovaries to the uterus and spermatozoa to the ovary.

State what takes place in the ovary during the period of menstruation. Give the reason for the pitted appearance of the ovaries in old age.

During menstruation there is an increased blood supply to the ovary. A certain Graafian vesicle, or vesicles, according to the species, becomes more voluminous than the others, raises the enveloping membrane of that body and projects on the surface. Around this vesicle the blood-vessels enlarge, and effusion takes place; the eapsule distends and gives way, allowing the ova to escape.

The pitted appearance of the ovaries in old age is due to repeated rupturing of Graafian vesicles and the shrinkings and eicatrizations of the same.

Define fecundation, abortion, eutocia, dystocia.

Fecundation is the fertilization or impregnation of the ovum, which occurs when it is reached by the spermatozoon.

Abortion is the expulsion of a fotus before it is viable.

Eutocia is a normal parturition.

Dystocia is an abnormal, painful, or slow parturition. 
Define the corpus luteum. Describe the changes in the ovary after fecundation.

The corpus luteum, or "yellow body," is a yellow mass in the ovary in the place of an ovisac which has discharged its ovum. If the ovum has been impregnated, the corpus luteum grows and lasts for several months, usually throughout pregnancy. If impregnation has not taken place, the corpus luteum degenerates and shrinks.

After fecundation of the ovum, segmentation occurs. The ovum divides into halves, each half subdivides, etc., forming a spherical mass known as the morula.

Define (a) a true corpus luteum, (b) a false corpus luteum.

If the ovum has been impregnated, the corpus luteum grows and lasts for several months and is called a "true corpus luteum." If impregnation has not taken place, it degenerates and shrinks and is called a "false corpus luteum."

Describe the corpus luteum in the cow and the sow.

See preceding answers. The ovisac is filled with lymph and blood, projects beyond the ovarian surface, and is deep yellow in color in the cow, and a yellowish-brown color in the sow.

Give the cause of menstruation.

Not definitely known. It is thought to be due to the shedding of the epithelium of the mucous membrane of the uterus. This exposes the tunic of the capillaries, causing them to rupture because of their distended condition.

Is the menstrual flow independent of the influence of the ovaries? Explain.

No. There is a close bond of sympathy between the ovaries and the uterus, which defies explanation. It is well known that, after removal of the ovaries, menstruation ceases to occur.

Define embryology, embryotomy, hydrocephalus.

Embryology is the science which treats of the development of the embryo.

Embryotomy refers to the cutting up of a fœtus to facilitate delivery.

Hydrocephalus is a fluid effusion within the cranium.

Name the female generative organs and state the function of each.

Ovaries: generate ova.

Oviducts: serve to convey the ova from the ovaries to the uterus and spermatozoa to the ovary. 
Uterus: place of nourishment and development of the embryo and fœtus.

Vagina: copulatory organ and passageway for the fotus during parturition.

Vulva: same as the vagina.

Mammæ: supply nourishment to new-born.

Define orgasm.

Orgasm is the crisis of venereal excitement, that is, the time of ejaculation of semen.

State the organic modifications the genital organs undergo after labor.

The uterus reduces in volume and weight by the oxidation, degeneration and absorption of the cells of the muscular fibres. The mucous membrane, which has been enormously thickened, undergoes fatty degeneration and modification until the uterine interior presents the appearance it possessed before impregnation. The cervix contracts, closes and regains its former shape.

Describe the difference between the maternal and the fœtal cotyledons.

The maternal cotyledons are dark-yellow in color and their surface is covered with crypts. The fetal cotyledons are bright-red in color and on their surface is a multitude of long, branched villi which are received into the depressions of the maternal cotyledons.

\section{Are spermatozoa always found in the semen? Explain.}

No. They are usually absent in cases of eryptorchidism, testicular tumors, inflammations and degenerations of the testicles. Hydrocele may prevent the formation of spermatozoa. The following conditions-debilitating diseases, overwork and excessive sexual use, individually or jointly-lessen the abundance of the male fertilizing element and in some cases may lead to a complete absence of same.

Is the vagina strictly a generative organ? Explain.

Yes. Because it serves as an organ of copulation and as a passageway for the foetus only.

Give the meaning of each of the following terms: uniparous, multiparous, primiparous, pluriparous.

Uniparous refers to animals which bring forth but one offspring at birth, as the mare and cow.

MIultiparous refers to animals which bring forth several offspring at one time, as the bitch and cat.

Primiparous: Bearing, or having borne but one offspring.

Pluriparous: Same as multiparous. 
What is the influence of the pregnant uterus on the neighboring organs?

The immense volume of the pregnant uterus occasionally disturbs the neighboring viscera as shown by colic, tympanites, constipation, œdema, coughing and paraplegia. Pressure on the sciatic nerve is shown by cramp of the posterior limbs.

How is the period of menstruation characterized in (a) the cow, (b) the sow, (c) the bitch, and (d) the cat?

(a) By nervous excitement, restlessness, bellowing and mounting other animals of its species. There is an increased secretion of mucus from the vulva and, toward the end of the period, blood-clots or a slight blood-stained discharge. The period lasts about 2 days and reappears every 21 days unless impregnation occurs.

(b) The sow manifests rut by restlessness, rooting, squealing, swelling of the vulva and a sanguinolent discharge therefrom. The appetite is impaired and she seeks the company of the opposite sex. The period lasts from 2 to 5 days and reappears in 15 to 30 days, but usually every month.

(c) By nervous excitement, restlessness, wandering away from home, seeking males, swelling and turgidity of the vulva, frequent urination and a sanguinolent discharge. The appetite is capricious and thirst is increased. The period lasts from 2 to 3 weeks and appears twice a year (spring and autumn, as a rule).

(d) By nervous excitement and an over-affectionate disposition. There is an uncontrollable desire to seek the opposite sex. Restlessness is a notable feature and the movements of rolling and otherwise betray the prevailing desires. The generative organs are more or less turgid and sensitive and the urogenital secretions are increased. This phenomenon appears 3 to 4 times a year.

What is an emmenagogue? Name two of the principal emmenagogues.

An emmenagogue is any agent which stimulates or favors the menstrual discharge. Ergot and rue are well known emmenagogues.

\section{Describe the secretions of the fœtus.}

Mucus is secreted by the glands of the mouth, csophagus and stomach. Bile is secreted by the liver, and emptied into the intestines where it is mixed with the fluid thrown out by the glands there, forming meconium. Urine is secreted by the kidneys, and the thymus, thyroid, spleen and suprarenal glands are said to be active in fetal life. 
Name the secretory glands that are active in fetal life.

See answer to preceding question.

State the duration of pregnancy in (a) the mare, (b) the cow, (c) the sow, (d) the bitch, (e) the ewe.

(a) 330-340 days; (b) 270-280 days; (c) 115-120 days; (d) 58-65 days; (e) 145-155 days.

Trace the journey of the ovum from incipiency to the accomplishment of fertilization.

After rupture of the Graafian vesicle, the ovum escapes and is conveyed into the Fallopian tube by means of the fimbriated extremity of the same. It passes down the tube to the uterus where it is met by the spermatozoa. This meeting may take place in the oviduct but the ovum usually continues to descend to the uterus.

Describe physiologically the impregnation of the ovum.

The spermatozoa pass through the outer layer of the ovum (zona pellucida). The germinal vesicle, or nucleus of the ovum, disappears and a somewhat opaque, embryonal cell (pronueleus) succeeds. With the formation of the pronucleus, the vitellus becomes separated from the zona pellucida and begins to rotate therein. Then a segmentation of the embryonal cell into two portions occurs; each of these two portions divide into two, etc. This division and subdivision continue for a short time ( 2 or 3 days) until the stage of morula is reached. At this stage the mass is still spherical, is surrounded by the vitelline membrane and the zona pellueida, and contains the mass of cells resulting from the repeated divisions before mentioned. After this the mass enlarges, changes shape, and the germinal layers form.

Give the composition of cow's milk.

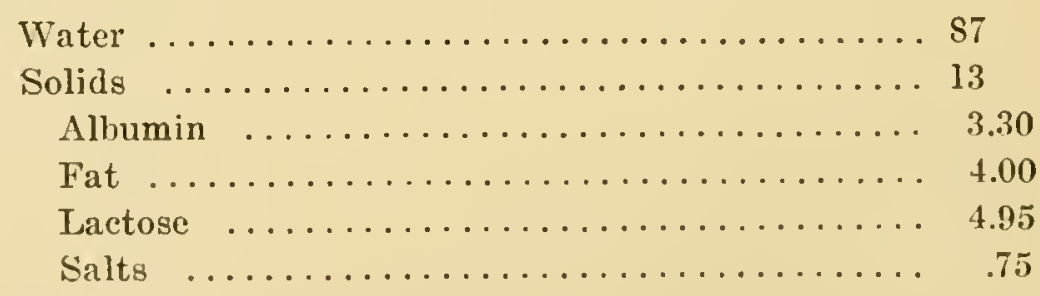

State the difference in the composition of the milk of the mare and that of the cow.

See answer to preceding question.

Mare's milk contains more water and sugar but less fat and albumen than cow's milk. 
Average composition of mare's milk is as follows:

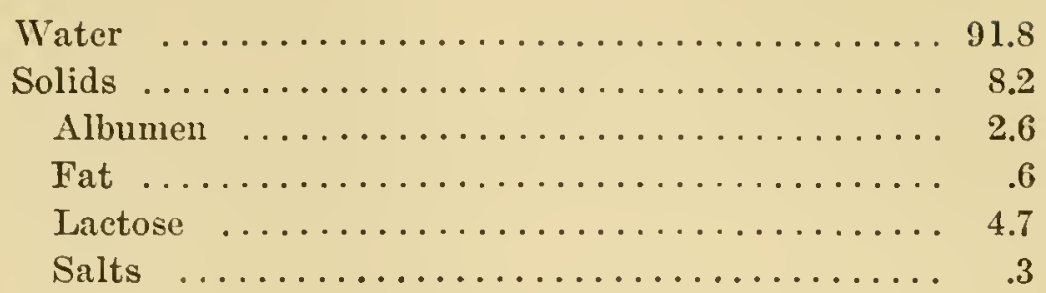

What is colostrum? Give the composition of colostrum.

Colostrum is the first fluid secreted by the mammary gland after delivery. Its average composition is as follows:

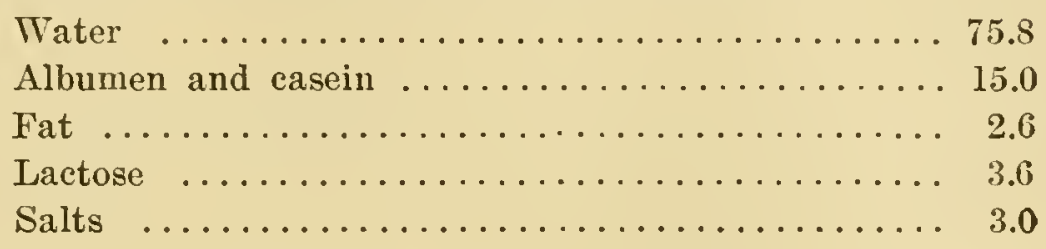

\section{Pregnancy}

Describe the physiologic and anatomic modifications that the uterus undergoes while the fœtus is developing.

The uterus assumes a somewhat oblong or globular form. Its mucosa becomes redder, thicker, more pulpy and vascular. The serous coat also hypertrophies and the fibres of the muscular coat increase in number and volume. The uterus, at this time, is more sensitive to nervous stimuli. The increase in volume and weight causes it to descend and rest upon the abdominal floor. The os uteri is firmly closed by the contraction of the circular muscular fibres of the cervix and is sealed with an albuminoid clot. As parturition time approaches, the os relaxes and, when labor begins, dilates widely.

State what changes take place in the generative organs of the female after conception.

See answer to preceding question.

In addition to the changes in the uterus, a true corpus luteum forms in the ovaries, and the mammary glands become activated.

What precautions should be taken in regard to the care and food of pregnant animals?

They should be regularly exercised and well fed on easily digested nutritive food which does not constipate. Plenty of pure water is essential. They should be well groomed and provided with clean and commodious quarters, especially as parturition 
approaches. Harsh or cruel treatment and surgical operations should be avoided if possible. Avoid, also, strong medicines such as drastic purgatives, powerful narcotics, etc. The milking period of cows should be limited to seven or seven and one-half months, to allow the fotus more nutritive material for its perfect development.

\section{Name the principal signs of pregnancy.}

Absence of estrum, enlargement of abdomen, enlargement of the mammæ, feeling of the fotus per rectum, per vaginam, or through the abdominal wall, auscultation of the fetal heart-beat, and observ. ing the movements of the living fœtus.

Describe (a) ovarian gestation, (b) tubal gestation, (c) abdominal gestation.

(a) Ovarian gestation is rare. Apparently it is due to a failure of the ovum to escape when the ovisac ruptures. The spermatozoa passes up the oviduct and impregnates the ovum which then proceeds to develop, as in normal gestation.

(b) Impregnation occurs in the oviduct. The ovum becomes attached to the walls of the duct and development proceeds. When the fœtus attains a sufficient size, the oviduct ruptures and fatal hemorrhage may ensue, or the fœtus may become attached to or imbedded in the peritoneal surface, and continue to develop.

(c) Abdominal gestation may follow rupture of the gravid uterus or the ovum may fall into the abdominal cavity, following rupture of the ovisac, and become impregnated there. The fœus becomes attached to the abdominal walls or some of the viscera and the fetal membranes closely invest the fetal body.

\section{Describe extra-uterine pregnancy.}

Extra-uterine pregnancy is the existence, for a greater or less period of time, of a living ovum outside of the uterine cavity, but within the abdominal cavity. (See answer to preceding question.)

How are the varieties of extra-uterine pregnancy commonly designated?

Ovarian, tubal and abdominal gestation. (See explanation above.)

\section{What are the effects of indigestion on pregnant animals?}

Tympanites, constipation and diarrhœa usually accompany indigestion. These conditions tend to produce abortion through pressure, straining and reflexly, respectively. Furthermore, indigestion 
causes inanition and thereby prevents the mother from properly nourishing the fœus.

Give the function and describe the early development of the placenta.

The function of the placenta is to establish communication between the mother and fœtus by means of the umbilical cord.

In the mulberry stage (stage of morula), the zona radiata throws out tufts, the primordial chorion, which unite with the uterine mucosa. This zone soon becomes attenuated and disappears while the blastoderm enlarges within it. But this primitive chorion is not permanent, it is replaced by another, similar, but more efficient structure.

From the surface of the outer layer of the blastoderm, tufts or villi grow out to extend into the uterine mucosa. Through these villi, there is an exchange of nutritive material and waste products between mother and fœtus. This is later supplanted by a permanent attachment, formed by the tufts of the allantois which grow out through the amniotic chorion to gain an intimate relation with the blood-vessels of the uterus.

Describe the phenomena of nutrition in the fœtus.

Before the placenta is formed, the ovum is bathed with an albuminoid substance which nourishes it during early development. Later with the development of the placenta, which brings the capillary systems of the mother and fotus into the closest relationship, nourishment passes to the fœtus by osmosis.

Define (a) zonary placenta, (b) diffuse placenta, (c) cotyledonary placenta.

(a) A placenta which is band-like in form. In the bitch and cat, the placenta forms a thick, annular band, or zone, about one and one-half inches wide, passing around the middle of the chorion.

(b) A diffuse placenta is one in which the chorionic villæ are diffused over the entire surface of the chorion. Seen in the mare and sow.

(c) A placenta in which the villi are restricted to certain areas (80 to 100 in number) called cotyledons. Seen in cows and sheep.

Mention the animals in which cotyledons are found.

Cow, sheep and goat.

\section{Describe the umbilical cord and state its function.}

The umbilical cord is a collection of vessels which extends from the placenta to the fetal umbilicus. It is about 35 inelies long in the mare and 15 inches in the cow. It is formed by the allantoic 
stalk, surrounded by the amnion, and includes the remnant of the vitelline duct. For convenience of description, it may be divided into an amniotic and an allantoic portion. The amniotic, the longer, extends from the umbilicus of the fœus, through the amniotic eavity, to open into the cavity of the allantois. It contains the following structures: the amnion, the two umbilical arteries, the two umbilical veins which are sometimes fused into a single vessel, the urachus, and the vestiges of the vitelline duct, besides Whartonian gelatin.

The allantoic portion consists, for the most part, of the mass of umbilical vessels; other structures found in it are the remnants of the vitelline duct, and Whartonian gelatin.

The umbilical cord forms a bond of communication between the fœtus and the placenta.

\section{Describe the position of the fœtus in multiple pregnancy.}

Each fœtus may have its own amnion and chorion, or each may have its own amnion, but the same chorion. Occasionally, in twin pregnancies, one fœtus is more or less enclosed within the body of the other.

In ruminants (cow and ewe) each of the twin fœtuses usually occupies one cornua of the uterus and presents with the head toward the os uteri; although occasionally they present alternately, that is, one anteriorly and the other posteriorly.

What is the liquor amnii? Give its functions in pregnancy and during labor.

The liquor amnii is an albuminous alkaline fluid, found in the amniotic sac, in which the fotus is suspended. It contains about 99 per cent. of water, as well as albumin, sugar, urea, and other urinary products, also meconium. The amount of the fluid in the mare and cow varies from 5 to 6 litres.

During pregnancy, it is useful in: 1 . Preserving an equable temperature for the fœtus. 2. Protecting the skin of the fœtus. 3. Favoring movements of the fœus by equalizing pressure. 4. Preventing injuries of the fœtus from external movements. 5. Protecting the mother from injury by fetal movements.

During labor, it protrudes the membranes and dilates the os uteri, protects the foetus from violent uterine contractions, and lubricates the vagina, thus facilitating passage of the fœtus through it.

Mention the four stages in the process of sexual generation.

Copulation, fecundation, gestation, and parturition. 
Describe the operation of artificial impregnation.

This operation consists of transferring semen from the vagina of a female, with which the male has recently copulated, to the vagina of another female. No special apparatus is necessary, in fact, any ordinary sterile syringe, or the hand will answer the purpose.

Cleanliness must be observed. Allow the male to serve a female and, promptly afterward, withdraw some of the semen into the syringe and inject it into the cervical canal of the second female.

Describe an impregnator and state how impregnation is accomplished by its use.

An impregnator is an instrument designed to keep open the os uteri during copulation and thus insure a direct discharge of the semen into the uterus. It consists of a hollow, soft-rubber tube, 3 to 4 inches in length. It is constricted in the middle portion and flanged at the posterior end to prevent it from falling into the uterus. Those who advocate its use do so with the belief that sterility in most cases is due to occlusion of the os. Intelligent breeders ignore the instrument. Prof. Williams, in his "Veterinary Obstetrics," regards the use of impregnators as "a harmless diversion which ordinarily will not prevent conception."

Mention the changes in position of the neighboring organs during the development of the uterus in pregnancy.

The vagina is drawn forward except in the last stages of gestation, when the fotus protrudes into the pelvic cavity. The stomach is pushed to the left and the intestines and liver are compressed; the diaphragm is pushed forward and the abdomen becomes enlarged, rounded and pendulent.

State the function of the liver in fetal life.

It serves as a blood-forming and blood-purifying organ.

What is the blastoderm? How are its membranes divided?

The blastoderm is the delicate membrane which lines the zona pellucida of the impregnated ovum. Its membranes are divided into hypoblast, mesoblast and epiblast.

\section{What do the different layers of the blastoderm form?}

The hypoblast forms the epithelium of the alimentary canal and of the organs connected with it, and that of the air-passages.

The mesoblast develops into the skin and connective-tissue structures, the bones, muscles, organs of excretion, and internal genitals.

From the epiblast are developed the epidermis and epidermic tissues, such as nails, hair and glands of the skin, the nervous sys18 
tem, the external sense-organs, as ear, eye, etc., and the mucous membrane of the mouth and anus.

\section{What changes take place in the blood of pregnant animals?}

There is said to be an increase in the volume of the blood in the body of a pregnant animal, but a decrease in its corpuscles and solid constituents. Quite recently, investigators have proven the prescnce of a certain substance in the serum of preguant animals which is of value in diagnosing pregnancy.

\section{Name the envelopes surrounding the fœtus and describe each.}

1. Chorion, the outer envelope, is a vast, membranous, closed sac. It being moulded upon the uterine wall, resembles the uterus in form, having a body and two cornua. The cornua are unequal in size, the one in which the fotus lies being the largest. The external surface of the chorion is studded with small, red tubercles, formed by the placental villous tufts which join it to the internal surface of the uterus. The internal surface is lined by the external layer of the allantois, except at the umbilical cord, where there exists a kind of conical infundibulum, occupied by the umbilical vesicle. It is united to the allantois by a layer of mucous connective tissue.

The chorion not only plays a mechanical part in protecting the fotus and supporting the placental blood-vessels, but it holds certain nutritive materials.

2. The amnion, the second sac enveloping the fotus, is a thin, transparent membrane. It floats freely in the interior of the chorion, but is only united to it at one point through the medium of the umbilical cord. It is ovoid in shape and contains the fotus which is attached to its inner face by the vessels of the umbilical cord. In the early embryonic stage, it closely envelops the cmbryo but, later, it is distended with fluid (liquor amnii) and is thus separated from the fotus. The smooth, internal face secretes the liquor amnii which bathes the fotus and serves important functions. The cxternal face is closely adherent to the imner layer of the allantois.

The amnion is made up of three layers: a very thin, connectivetissue membrane that adheres to the allantois; a membrane-proper which is made up of connective tissue and some muscular fibres; and an epithelial layer which lines the latter.

3. The allantois is a thin membrane which lines the inner face of the chorion, and is reflected around the insertion of the umbilical cord to be spread over the outer face of the ammion. By so doing, it transforms the chorionic sac into a kind of serous cavity with the amniotic sac enclosed within it. The allantoic cavity communicates 
with the fetal bladder by means of the urachus. The structure of the allantois is slightly fibrous with an epithelial layer.

Describe the development of the skin of the fœtus.

The skin is developed from the middle and outer layers of the blastoderm (the mesoblast and epiblast). From the mesoblast, the skin-proper, or derma, is formed, and from the epiblast, the epidermis and epidermic tissues, such as the nails, hair, sudoriparous and sebaceous glands are formed. Blood-vessels are apparent in the derma as early as the third month. The horny and mucous layers of the epidermis are distinguished soon after. As the fœtus increases in volume, the epidermis exfoliates and its debris is found in the liquor amnii. Hair is developed in the epidermic laminæ which are prolonged into the substance of the derma. It is seen on the eyebrows, lips and the joints of the limbs early in fetal life, and by the sixth or seventh month covers the body.

\section{Trace the development of the nervous system.}

The first trace of the central nervous system, the neuraxis, is formd in the primitive groove, resulting from an invagination of the thickened ectoderm. The groove deepens and the neural folds which border it increase in prominence until they fuse together above, making a closed canal, lined by ciliated epiblastic cells. This canal persists throughout the animal's life as the central canal in the spinal cord, and as the ventricles of the brain. The deeper epiblastic cells in the walls of the canal develop into the nerve-cells of the cerebrospinal axis. The anterior part of the canal shows three successive dilatations which ultimately become the various divisions of the brain. The spinal motor nerves arise from the cord and the sensory branches appear to be developed from the spinal ganglia which are separately formed.

\section{Describe the situation of the pregnant uterus in the mare and cow.}

The pregnant uterus occupies the floor of the abdominal cavity. In the mare, it is displaced somewhat to the left by the pelvic flexure of the colon and passes beneath the latter to the left of the median line until it reaches the diaphragm. In the cow, the rumen displaces the pregnant uterus, causing it to pass downward and slightly to the right of the median line to reach the diaphragm.

Describe the position of the fœtus in the ninth or tenth month of pregnancy.

The head is directed backward and ventrally in such a manner that the lower jaw is in contact with the throat, and the mouth touches the sternal region. The neck lies against the maternal 
sacrum. The fore limbs are flexed in such a manner that the knees are against the middle of the head and the feet, the umbilicus. The hind limbs are flexed under the body and the pelvic portion of the fotus is in the bottom of the uterus, near the stomach.

\section{Trace the growth of the urinary organs.}

The kidneys arise from the Wolffian bodies. These are glandular bodies which appear very early in embryonic life, one on each side of the vertebræ and extend from the heart to the pelvis. Each empties through a duct into the eloaca. These bodies are perhaps more eoncerned in the development of the sexual organs than the urinary. At any rate, early in embryonic life there appears near the beginning of each Wolffian duct, an outgrowth, or cul-de-sac, which forms the pelvis of the kidney. From the walls of these saes, a number of branehing tubules arise to become the urinary tubules and thus complete the kidney. The posterior part of these saes become the ureters which empty into the eloaea. The bladder is derived from a dilatation of the abdominal portion of the allantois. Posteriorly the allantois is constricted to form the urethra. The extrapelvic portion of the latter is formed by the closing of the genital furrow of the penis.

\section{ABORTION}

What is meant (a) by abortion, (b) by premature birth?

(a) The expulsion of a fœtus from the uterus before it is sufficiently developed to live.

(b) The expulsion of a fœtus from the uterus before the proper time but in a viable condition.

\section{Give the symptoms of abortion.}

In many cases there are no premonitory symptoms and often the first evidence is the presence of the fœtus and its membranes. In other eases, warning is given by the swollen vulva and its mucopurulent discharge together with enlargement of the mammx. Frequently, there is a secretion of milk for days and even weeks before abortion oceurs. The act of abortion is brief and is accompanied by labor pains as in normal birth. For several days following, a mucous discharge, tinged with blood and often containing particles of pus and after-birth, is observed. Unless eomplications ensue, the mother seems to be but little inconvenieneed.

Mention some of the causes of non-contagious abortion.

Mechanieal injuries, severe hemorrhage, eastration, drugs, eer- 
tain infectious diseases, such as foot-and-mouth disease, hog cholera, etc.

Discuss the etiology of infectious abortion in cows. Describe briefly the course and symptoms of infectious abortion.

(There are many conflicting opinions on all phases of this disease.)

Infectious abortion in cows is due to a short bacillus (bacillus of Bang) which is carried from cow to cow by the bull, although other means of transmission are recognized. Entering the uterus, at the time of copulation, or later, it produces a catarrhal endometritis with a fibrinous exudate which causes a separation of the placenta from the uterine wall and abortion follows. Some authorities think the infection enters by way of the digestive tract and udder, and is carried by the blood to the cotyledons. In many cases the infection remains in the system from a previous abortion.

In the majority of cases abortion occurs at about the fourth to sixth month of pregnancy. It may occur much earlier or very near the end of gestation. The fœtus is usually born dead, or, if alive, it very rarely survives. A few days before abortion occurs, a yellow, or reddish-tinged mucopurulent discharge is seen to escape from the vulva. The latter becomes reddened and swollen. The milk secretion lessens and finally, with very little straining or apparent inconvenience, the fœtus is expelled. In a great majority of cases, portions of the after-birth are retained and a mucopurulent, bloodtinged discharge follows for ten days or two weeks. The infection remains in the internal genital organs for several months, so it is quite common for the cow to abort a second time. After the second abortion, the infection seems to disappear, or at least the animal is immune to its effects.

What methods should be employed in the control of an outbreak of infectious abortion in a herd of cows?

Separate the infected from the non-infected. Burn aborted fœtuses, after-births, and soiled bedding. Disinfect stalls and gutters. Irrigate the uterus of each aborting cow with a 1-1000 solution of potassium permanganate. Wash the external genitals of all pregnant cows with the disinfectant. Separate attendants should be assigned to the two divisions of the herd. The sheath of the bull should be disinfected before and after copulation. A separate bull might be used for infected and non-infected cows. Precautions should be observed in introducing new animals into the herd. 


\section{LABOR}

Define (a) presentation, (b) position.

(a) The appearance of some particular part of the fetal body at the pelvie inlet during labor.

(b) The situation of the fotus with respect to the mother at appearance of labor.

Mention the normal presentations of the fœtus in domestic animals.

Anterior and posterior.

Name the different positions of the fœtus during labor.

1. Longitudinal:

A. Anterior presentation:

(a) Dorsosacral position.

(b) Right or left dorso-ilial position.

(e) Dorsopubie position.

B. Posterior presentation:

(a) Dorsosacral position.

(b) Right or left dorso-ilial position.

(c) Dorsopubic position.

2. Transverse.

A. Dorsal presentation:

(a) Right or left eephalo-ilial position.

B. Ventral presentation:

(a) Right or left eephalo-ilial position.

What are the four principal presentations?

Anterior, posterior, dorsal and ventral.

What is the most favorable and most frequent presentation?

Anterior presentation, dorsosacral position, with both forefeet and head presenting.

Define (a) eutocia, (b) version, (c) rotation.

(a) A safe, easy, or natural parturition.

(b) The ehanging of a transverse into a longitudinal presentation.

(e) The turning of a fotus upon its long axis.

Name four of the most difficult presentations.

1. Anterior presentation with both fore limbs retained.

2. Transverse presentation.

3. Breech presentation with eomplete retention of the posterior limbs. 
4. Anterior presentation with forward extension of the hind limbs beneath the fetal body.

Mention two different ways by which the cervix of the uterus may be dilated.

1. Use of drugs, especially injections of cocaine or stovaine.

2. Mechanical, either by manual or instrumental methods.

Mention the signs and the different stages of parturition.

1. Preliminary stage: Enlargement of mamma; swelling of the vulva; relaxation of the broad and sacrosciatic ligament.

2. Dilation of the os uteri: Accompanied by restlessness, laborpains and presentation of "water-bag."

3. Expulsion of fœtus: Pains more severe and frequent; straining, rupture of "water-bag" and expulsion of fotus.

4. Expulsion of the membranes. This may occur at birth or soon after. The uterus contracts and the mass comes away.

Mention some of the causes of dystocia.

Maternal: Pelvic constriction, uterine inertia, torsion of the uterus.

Fetal: Excess in volume, monstrosities, multiparity, diseases, faulty presentation.

Name (a) five maternal causes of dystocia, (b) five fetal causes of dystocia.

(a) Pelvic constriction, uterine inertia, torsion of the uterus, uterine hernia, atresia of the cervix.

(b) Hydrocephalus, wry-neck, emphysema, double monstrosities, faulty presentation.

Name two pathologic conditions of the fœtus that interfere with parturition. State how each of these conditions may be overcome.

1. Hydrocephalus. This consists of a distention of the lateral ventricles of the brain with lymph. In extreme cases, the cranium is distended to two and three times the normal size, and offers a serious obstacle to parturition. Dystocia due to this congenital defect is overcome by puncturing the tumor and breaking down the cranial bones with the chisel.

2. Wry-neck. This deformity of the fœtus is characterized by an abrupt deviation of the head and neck to one side. The cervica] portion of the spinal column is bent and the muscles so contracted that the head is held rigidly in this abnormal position.

To overcome the impediment which this condition offers, ampu- 
tate the head and neck by means of a chain-saw or otherwise, withdraw the severed member, and thell proceed with the remaining por. tion as in normal parturition.

How would you deliver an anterior presentation in a case of hydrocephalus?

See answer to preceding question.

What are the disadvantages under which the veterinary obstetrist labors in case of dystocia?

He is frequently hampered by being called after some unskilled persons have complicated matters or done irreparable injury to the mother and fœtus by their crude tactics. Nany times the quarters in which parturient animals are kept are poorly lighted, improperly ventilated and dirty. Plenty of clean, warm water is not always to be had. Lastly, the severe straining of such large animals as cows and mares is fatiguing to the arm of the operator and impedes his necessary manipulations to a great extent.

Mention four different mechanical means for the extraction of the fœtus.

Cords, hooks, forceps, and halters.

How may strong muscular contractions of the uterus be overcome in case of malpresentation in dystocia?

Many methods have been tried, pressure on the loins, tying a rope tightly round the body, twitching the nose or ear, etc. The most humane and satisfactory way is the administration of a narcotic (opium, chloral hydrate, or, better still, chloroform).

What are the indications for the use of ergot in labor and how should ergot be given?

Ergot is used in case of uterine inertia when there is no malposition of the fœtus or mechanical obstruction to its passage. Very small doses should be given to increase the force of the uterine contractions without producing spasms of the organ or of the cervix.

Under what conditions would you use a repeller for the removal of a calf?

When the foetus, in a faulty position, has become wedged in the pelvic eavity or is approaching the inlet, it may be necessary to return it into the uterus to effect a proper presentation and position. Occasionally, when the foetus is presenting properly and is in a good position, it is advantageous to repel it in order to attach cords to some part of its body. 
Give the method of delivering an anterior presentation (dorsosacral position) with the fore limbs retained.

Repel fotus upward and backward, pass a cord around the radius, slide it down toward the carpus, correct the deviation and complete the delivery. If the head has passed beyond the vulva, decapitation may be advantageous before attempting repulsion. In some cases amputation of one limb and evisceration may be necessary to reduce the size of the fotus and facilitate delivery.

Give a method of delivery of the cephalosacral position of the fœtus.

In this position, the fotus sits on the floor of the abdomen, the head directed forward and the withers toward the sacrolumbar region of the mother. That is, it sits up like a dog. By most authorities, this position is considered impossible because of its unstability. To effect delivery, version must be accomplished. The dorsal presentation must be changed to an anterior or posterior. Version may be effected by intra-uterine injections of emollients such as flaxseed or slippery elm infusions. If this method fails, evisceration and detrumcation of the fotus is the only course to follow.

Describe a method of delivering a right cephalo-ilial position, dorsolumbar presentation.

The dystocia from this position is practically the same as in the cephalosacral position and the method of procedure is the same. (See answer to preceding question.)

Describe the sterno-abdominal position of the fœtus.

This is more accurately termed "ventral transverse presentation." The fœtus presents with all of the feet in, or near, the pelvic inlet and the head retained. It lies upon its side, transverse to the long axis of the body of the mother with the head resting in the flank in the region of one or the other of the maternal ilia. Hence there are two possible positions, right cephalo-ilial and left cephaloilial.

Describe Cesarean section in the mare and name some of the complications that may arise in connection with this operation.

Cesarean section refers to the delivery of a fœtus by means of an incision through the abdominal and uterine walls. The mare should be placed under general anæsthesia. Her forelegs should be drawn forward and the hind legs backward and securely fastened. The field of operation being thoroughly cleansed and disinfected, make an incision in the flank through the skin and muscles, extending from the level of the external angle of the ilium downward about 
ten inches. The peritoneum is then incised and the uterus withdrawn through the opening. It should be laid on sterilized gauze which completely surrounds the wound. Next make an incision into the gravid uterus which will readily permit the extraction of the foetus within its membranes. Free the fœtus from its coverings as soon as extracted; suture the wound in the uterus by means of Lembert's intestinal suture with silk. Close the abdominal wound with interrupted sutures, suturing the muscles and skin separately. Place patient in clean, comfortable quarters to recover from the anæsthesia.

Complications to be feared following Cesarean section are: metritis, peritonitis, abscess at seat of incision, and adhesion of the abdominal organs to this part. Internal hemorrhage and collapse are to be guarded against.

(Records fail to show where the life of a mare has been saved, but a living foetus is often brought forth by this operation.)

\section{Describe the operation of Cesarean section in multiparous animals.}

See answer to preceding question. In the sow, bitch, and cat, the incision can be made in the flank, although most operators prefer the median line. The technic is the same as in the mare. All the fœtuses can be extracted through the one incision into the uterus. A body bandage should be applied after the operation. The prognosis is much more favorable than in the mare and cow.

Describe the method of delivering a posterior presentation (lumbosacral position).

Apply traction upon the two hind limbs and hasten delivery because of the danger of asphyxiation of the fotus from compression of the cord against the pubic brim. This is considered a normal presentation by many authorities. Should the hind limbs be retained, the dystocia is a very difficult one to overcome. Attempt repulsion and correction of the deviation of the limbs. Forced extraction is employed by some obstetrists, but it is a barbarous and unsatisfactory procedure. Embryotomy should be employed, preferably intrafetal amputation of the two posterior limbs. Cesarean section is a last resort.

Describe the method of delivery in deviation of both hind limbs, anterior presentation.

This is one of the most difficult malpositions the obstetrist has to overcome. Repulsion and correction of the deviation should be attempted to increase the working space, but this is seldom successful. Remove one anterior limb and detruncate the fotus. Attach 
cord to and repel the posterior half. Deliver the anterior half first and then the posterior.

Describe method of delivering extreme downward deviation of the head, anterior presentation.

Attempt replacement of the head by seizing the muzzle or nostrils with the hand. If this fails, amputate one anterior limb, which then allows the head to be brought into position. Delivery in the normal way is then easily effected.

\section{What care should be given the dam after labor?}

Clean, comfortable quarters should be provided. Nourishing, succulent food should be freely given to insure an abundant milk secretion. Grass is the best diet for herbivora. The mother should be kept from hard labor for three or four days, and all undue disturbance should be avoided. If the labor is complicated by wounds of the genital organs, or otherwise, proper treatment should be given. Otherwise such interference with nature is contra-indicated. In case the after-birth is not expelled in the usual time allowed, means should be employed to remove same.

\section{Give the symptoms and the treatment of uterine inertia in the mare.}

The fœus presents normally and in a favorable position, but there is a deficiency of the expelling powers. The mother is usually weak, debilitated, and maintains a decubital attitude.

Treatment consists of the administration of stimulants. Ergot is usually chosen. In addition, traction should be applied and delivery effected.

\section{Give the symptoms and treatment of torsion of the uterus.}

Torsion of the uterus is shown by severe expulsive efforts, colicky pains, and extreme uneasiness. If death of the fœtus has occurred, metritis and peritonitis may be present. The diagnosis is confirmed by examination per vaginam when the hand encounters the spiral folds of the vaginal walls and os uteri. The prognosis is grave. Reduction of the twist is very difficult. It may be attempted in case of slight torsion by inserting the hand and arm into the uterus, grasping a limb of the fotus, and exerting force on same. If the torsion is severe, it is impossible to gain entrance into the uterus in this way. In this case, rolling of the mother in the direction of the twist is the logical treatment. With the hand in the vagina, the operator can assist by preventing the uterus from turning when the mother is rolled. These methods failing, laparatomy should be performed and the torsion reduced by the hand placed within the abdomen. As a last resort perform Cesarean section. 
Give the treatment of rigidity of the os uteri.

Inject warm, emollient liquids into the vagina. Some authorities recommend smearing the os uteri with extract of belladonna. Loeal anæsthetics, such as cocaine and stovaine, might be useful. Manual or instrumental dilatation of the os is probably the best method to overcome this condition.

\section{Diseases Incident to Pregnancy and Labor}

Name the most prominent diseases following parturition.

Retention of the after-birth, postpartum hemorrhage, rupture of the uterus, rupture of the vagina, eversion of the uterus, prolapse of the vagina, septic metritis and peritonitis, parturient eclampsia, parturient apoplexy, mammitis and laminitis.

What diseases are incidental to pregnancy?

Osteomalacia, dropsy of the fetal membranes, paraplegia, rupture of the uterus, prolapse of the vagina, metrorrhagia, abortion (sporadic and infections).

Name five diseases following parturition in the cow that may prove serious.

Septic metritis, septic peritonitis, uterine prolapse, parturient paresis, puerperal septicæmia.

\section{Give the diagnosis of dead fœtus in utero.}

The symptoms may vary, depending upon whether mummification or putrid decomposition occurs. In the former condition, no special symptoms are noted; the cow, to all appearances, is in good health, she continues to fatten, the abdomen does not increase in size, the udder fails to develop, and, at the time for delivery, no signs of parturition appear. Examination per rectum will reveal the hard, unyielding mass.

Putrid decomposition of the fœtus may be manifested by expulsion of portions of it through the vagina, an artificial opening in the abdominal wall, or the intestinal tract. The patient is greatly depressed, refuses food, and shows symptoms of septiciemia. Examination of the uterus per rectum or per vaginam will diselose the abnormal condition.

Give the causes and treatment of hydrops uteri.

Hydrops uteri, or hydrometra, is a very rare condition. Two forms are described, viz., œdema of the uterine walls and an accumulation of fluid between the chorion and the uterine walls. 'The cause is not well understood, but may be attributed to eireulatory disturbances. 
Treatment: Evacuate the uterus (removing fœtus if one is present) and irrigate the cavity with mildly astringent antisepties. Build up the general health with tonics.

Give the causes, symptoms and treatment of hydrops amnii.

The causes of this condition are not well understood.

Symptoms: The most important symptom is the enormous rotundity of the abdomen. The walls of the same are tense and give a dull sound on percussion. As the swelling increases, the patient becomes dull, emaciated, and anæmic. Thirst is increased and appetite decreased. The respiratory movements become labored, owing to the pressure on the diaphragm. Rectal examination clinches the diagnosis.

Treatment: Dilate the os, rupture the membranes, and remove the fœtus. Give stimulants and aid involution of the uterus.

Give the causes, prognosis and treatment of antepartum inversion of the vagina.

Causes: Not well known. It has been observed most frequently in cows that have been closely confined and overfed on bulky feeds. These factors depress the general vigor and favor the action of infective agents, especially in the vagina, which responds by becoming inflamed, thus inducing straining and prolapse. A sloping floor is often an accessory, if not a direct, causative factor.

Prognosis: A tendency to recur until parturition is completed makes the prognosis unfavorable; especially is this so when the organ becomes badly excoriated and inflamed. If delivery of the fœtus can be brought about, the condition is more easily overcome.

Treatment: Cleanse thoroughly with warm, non-irritating, antiseptic solutions ( $1 / 2$ per cent. lysol) and effect reposition of the prolapsed organ by gentle manual pressure. The replacement may be more easily accomplished by raising the hind quarters or, in small animals, by liaving an assistant hold the patient by the hind legs. After the organ is returned to its proper position, a snild, antiseptic agent should be injected; iodoform is very useful for this purpose, because it is not only antiseptic but slightly anæsthetic, and therefore lessens irritability and straining. Keep bowels open by administering cathartics. Straining to defecate and distention of the intestines tend to cause a recurrence of the prolapse. If parturition is near, it may be advisable. to empty the uterus. Bandages, sutures, trusses, etc., are of little use unless the cause of straining is eliminated. Sometimes the bladder is carried out within the prolapsed vagina (vesicovaginocele). Urine accumulates 
because of the constriction of the urethra, and must be removed before reposition can be effected.

\section{Give causes, symptoms and treatment of inversion of the uterus.}

Causes: Failure of the os uteri to close after parturition, tardy involution of the uterus, and retained placenta are potent, causative factors. Sloping floors, close confinement, and overfeeding are contributory, if not direct, eauses.

Symptoms: The prolapse may be partial or complete; that is, there may be simply a beginning invagination, or the inversion may be complete with the whole uterus turned inside out and hanging from the vulva. The walls of the prolapsed organ are continuous with the vagina and vulva, and there is more or less displacement of these organs. Occasionally the bladder is carried forward with the floor of the vagina. Intestines may be forced through the pelvic eavity into the inverted uterus. The condition may be further complicated by lacerations, inflammatory degenerations, etc., of the protruding parts.

Treatment: Carefully cleanse and disinfect the prolapsed organ with 0.5 per cent. solution of phenol in normal salt solution. Place the patient in lateral recumbency with the posterior parts elevated. Remove any adherent portions of placenta and replace the organ by careful manual pressure. If the uterus is badly congested it may be very diffieult to do this. The congestion may be overcome by elevating the uterus above the body level and applying a pressure bandage, beginning at the free extremity. After returning the organ, push the cornua back as far as possible with the clinched fist and inject tepid, sterile water to complete the unfolding of the intussusception. If necessary, administer narcotics to prevent expulsive efforts. Should the uterus be badly wounded or necrotic, amputation may be necessary. (See answer to following question.)

\section{What is metrotomy? When is it indicated and how should it be per- formed?}

Metrotomy refers to the incising of the uterus. Metrectomy is the excision, or amputation, of the uterus. (Many persons ineorreetly use these two terms synonymously. Believing that the interrogator refers to amputation of the uterus, the following answer is given.)

Amputation of the uterus is indicated in case of prolapse when reposition of the organ is impossible; when the organ is badly inflamed, necrotic, or wounded. 
The prolapsed organ should be carefully cleansed and disinfected. Make an incision into the uterus to determine whether any viscera extend into the cavity. Tightly apply an elastic ligature around the entire organ near the external os. Completely sever the organ by excising it about three inches from the ligature. Replace the stump of the organ and irrigate the vagina daily for five to ten days, when the necrotic stump should come away. To avoid any danger of the ligature slipping, it is safer to suture the uterus in such a way that the circulation is cut off from the stump. The latter is a more surgical procedure.

State the difference between parturient eclampsia and parturient paresis.

These two diseases usually occur soon after parturition, although they have been observed at, and shortly before, this act. The principal distinction made is the occurrence of tonic and clonic spasms (especially of the diaphragm) in parturient eclampsia, and of a comatose condition in parturient paresis. The former disease is seen most frequently in mares and the latter in cows. It may be noted that tonic and clonic spasms are sometimes seen in the early stages of parturient paresis, but they soon pass away, to be followed by coma.

\section{Give the Schmidt treatment of parturient apoplexy.}

The treatment, as originally introduced by Schmidt in 1897, consisted of the introduction into the udder of a solution of potassium iodide, mixed with atmospheric air. Later investigators found that the injection of air alone sufficed to bring about the same result.

Observing the rules of asepsis, firmly distend the udder by inflating it with air forced in by a suitable instrument. The air should be filtered through sterile cotton or forced through an antiseptic solution to rid it of any impurities. As a rule, a few hours after this treatment the cow regains her feet and appears perfectly normal. If this does not occur after an interval of three to six hours, inflate the gland again. Some practitioners ligate the teat after inflation, but this is seldom necessary, as the sphincter of the teat will prevent the air from escaping.

Give the causes and treatment of puerperal eclampsia in the mare.

The cause of this disease is not known. It is seen following the act of parturition with no premonitory symptoms. Williams mentions the frequent occurrence of the disease in mares which have been suddenly taken from pasture to stable or put in harness, thus 
causing maternal anxiety and a disturbance of the central nervous system.

Treatment:-Keep patient with her foal in quiet, comfortable quarters. Bloodletting is beneficial in early stages. Control spasms by administering large doses of the fluid extract of belladonna and cannabis indica.

\section{Define endometritis. Give causes, symptoms and treatment of acute} endometritis.

Endometritis is an inflammation of the mucous lining of the uterus. It may be acute or chronic.

Causes: Retention of fetal membranes or of a decomposed foetus; infection of wounds occurring during parturition from embryotomy operations or otherwise; introduction of infection through careless manipulations of attendants. The disease very often follows a prolapse of the uterus for obvious reasons. In the case of a mare which recently came under the observation of the writer, the cause was attributed to the repeated attentions forced upon her by a cryptorchid stallion which consorted with her in pasture.

Symptoms: Fever, tenderness of the abdomen, stiffness of the gait due to laminitis, which is usually present, a reddish-gray, flocculent, fœtid discharge from the vulva, a large amount of the same material in the uterus, thickening of the uterine walls, increased frequency of pulse and respiration. The patient may remain in a standing or a recumbent position.

Treatment: Cleanse the uterine eavity by irrigating with warm, sterile water. Be sure to remove all fragments of placenta and accumulated discharges; continue the irrigation until the expelled water is clear. Then inject two or three gallons of a 1-1000 solution of potassium permanganate. Repeat this medication daily until the discharge changes to a healthy mucus, then gradually withdraw treatment. If the condition of the patient requires them, stimulants and antipyretics such as digitalis, quinine, and alcohol may be given.

\section{Give the symptoms and treatment of leucorrhœa.}

The term "leucorrhœa," meaning "white flow," is applied to a whitish, viscid discharge from the vagina and uterine cavity. It is symptomatic of chronie inflammation of these parts (chronic endometritis). The discharge is usually intermittent, occurring during micturition or when straining.

The appetite may be good, but emaciation advances. The mucous membrane of the genital canal is pale or, in some cases, red and roughened by granulations. 
Treatment: Depends upon the cause. In general, the affected parts should be irrigated with warm, sterile water until it flows out clear; then with an astringent, antiseptic solution, such as potassium permanganate, 1-1000, or lysol, 1 per cent. Iodoform is highly efficient in this disease. A gelatine capsule containing two or three drachms of this agent can be carried into the uterine cavity and there opened and the contents scattered over the diseased membrane. Treatment must be persistent and repeated daily until a healthy condition is obtained. General tonies are useful.

How may rupture of the uterus during labor be recognized?

Small ruptures may pass unnoticed for a few days after parturition, when the symptoms of septic peritonitis lead the operator to make a manual exploration and discover the opening. An extensive rupture occurring during labor is often followed by collapse and death from hemorrhage. The escape of the fetal fluids into the peritoneal cavity likewise results in collapse and death. If death is not sudden, the animal ceases straining, the pulse becomes small and imperceptible, and a cold perspiration covers the body.

\section{Give the treatment of laceration of the cervix uteri.}

Small lacerations require little or no attention. Extensive lacerations should be treated antiseptically. Adjust the vaginal speculum and with long dressing forceps, holding pledgets of cotton, remove all discharges. In the same manner swab the edges of the wounds with proper medical agents, such as Tr. iodiné, iodoform, etc.

\section{Define lochia and give its treatment.}

Lochia is the term applied to the uterine discharge occurring for a period of a few hours or a few days following parturition. It consists of blood and fragments of the uterine mucosa or of the placental villi, which must be expelled before the uterus can resume its normal state. It is a purely physiological condition and requires no treatment unless infection occurs, when the condition is no longer normal but pathological.

\section{What is meant by lochia? Is lochia common in domestic animals?}

See answer to preceding question. Lochia is common in all domestic animals, but is more noticeable in some than others. In the mare and cat it is very scant, whereas in the cow, sheep, and bitch it is more abundant. 
Give the treatment of postpartum hemorrhage.

Slight hemorrhage requires little or no attention. Hasten involution of the organ and at the same time check the hemorrhage by the introduction of cold water or ice. Remove coagulated masses of blood and administer ergot or other stimulants to favor involution. Severe hemorrhage should be treated by an intravenous infusion of normal salt solution.

Define and describe (a) vaginismus, (b) vaginitis.

(a) A painful spasm of the vagina due to local hyperæsthesia.

(b) Inflammation of the vagina.

\section{Give the causes, symptoms and treatment of vaginitis.}

Causes: Injuries during the act of parturition and entrance of infection; careless manipulations in assisting dystocia eases; irritant drugs used as vaginal or uterine douches; uterine discharges passing over the vaginal mucous membrane may, and usually do, irritate the same.

Symptoms: Swelling and inflammation of the vaginal mucous membrane and a purulent, leucorrhœal discharge. Defecation and urination are often difficult, owing to the pain in the parts. If long standing, ulceration and necrosis may be present.

Treatment: Irrigate the vagina with warm, mild, antiseptic solutions; 2 per cent. phenol or 1 per cent. lysol is useful. In mild cases use a solution of sodium bicarbonate. In ulceration use silver nitrate or Tr. iodine.

Describe the symptoms and give the treatment of contagious vaginitis.

Granular venereal disease, or infections gramular vaginitis, is a disease of cows which is especially characterized by the formation of small granular elevations in the vulvar and posterior vaginal mucosa. In addition, swelling of the vulvo-vaginal mueosa and a mucopurulent discharge is observed. This disease is said by many good authorities to be the chief cause of the so-called "infectious abortion," and to be very extensively spread in this country. The importance of the disease depends upon its many complications, which are: abortion, retained placenta, septie metritis, septicemia, pyæmia, pyometra, cystic ovaries, persistent corpora lutea, etc.

'Treatment: Separate the well from the diseased; disinfect stables; cleanse vulva and vagina of all discharges and disinfect these parts with a 0.5 per cent. solution of phenol. It would be a wise prophylactic maasure to disinfect the sheath and penis of each bull which has covered affected cows. 
Give the causes, symptoms and the treatment of puerperal septicæmia.

Causes: Septic inflammation of the nterus; retained placenta; retention of a decomposed fotus; infection of wounds occurring during labor.

Symptoms: Four or five days after parturition, we notice fever, rapid pulse and rapid respiration, fetid discharge from vulva, extreme weakness, lessened milk secretion, constipation alternating with diarrhœa, death in a short time ( 24 hours to a few days). In non-fatal cases pyæmic arthritis may supervene.

Treatment: Usually fruitless. Thoroughly cleanse and disinfect the septic genital tract. Quinine, which stands preëminently the best drug in septic fevers, should be administered in large doses (one ounce, twice daily if necessary).

\section{Write a prescription for retained placenta in the cow.}

The handling of retained placenta is principally mechanical, although in cases accompanied by grave constitutional disturbances the following may be useful:

$\mathrm{R}$

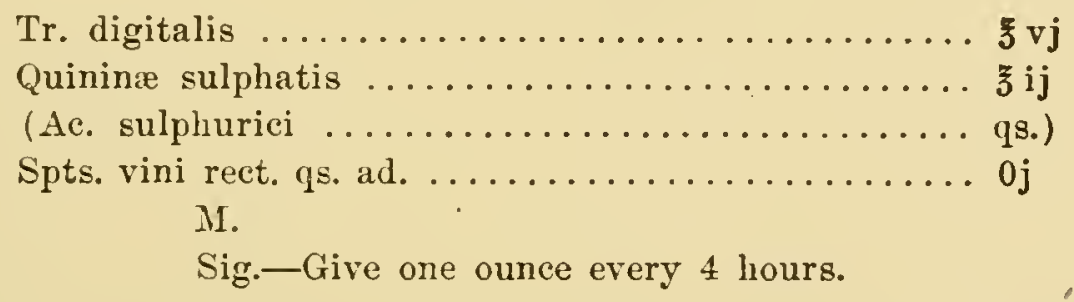

Give the causes, symptoms and treatment of acute mastitis in the cow.

Causes: In practically every case mastitis originates from infection, which gains entrance through the teats, wounds, or by the blood-and lymph-stream. As predisposing or accessory factors the following may be considered: cold, trauma, retained placenta, filthy surroundings, careless and irregular milking, and inflation of the udder in the treatment of milk fever.

Symptoms: One or all four quarters of the udder may be involved. Heat, tenderness, redness, and swelling are marked from the first. There is a suspension of the milk secretion in the affected quarters. The milk which is present in the gland is clumpy and may be streaked with blood. Fever, loss of appetite, constipation, and general depression show the systemic disturbance. Complications that may aggravate the condition are gangrene, abscess formation, pyæmia, septicæmia, atrophy of the gland, and pyæmic arthritis.

Treatment: Hot fomentations and massage increase leucocytosis and are conceded to be the most valuable of all treatments. 
Frequent milking, suspensory bandages, external applieation of disinfectants, intramammary injections of same, and many other measures have their advocates. Increased activity of the alimentary tract should be stimulated by a laxative diet and the use of arecoline, or eserine and pilocarpine. Certain drugs, such as camphor and turpentine, which are eliminated in the milk, are useful because of their disinfectant action, and may be given in full doses. Abseess formation and gangrene call for surgical interference.

What are the causes of colic in pregnant animals? Give treatment.

The etiology of "true" colic oceurring in pregnancy would be little different from that in a non-pregnant animal; likewise the treatment, except that precautions should be taken to avoid drugs whieh might empty the uterus. "False" colic may be observed in torsion of the uterus (q.v.).

Why are rickets and osteomalacia frequently observed in pregnant animals? Give treatment.

These diseases, in any animal, can usually be traced to a defieiency in the quantity or the quality of the food. A lack of lime salts, especially the phosphate of calcium, has long been recognized as a potent etiological factor. Add to this the extra demand made upon the pregnant animal by the developing fotus, as well as a lowered vitality from prolonged lactation, and it is entirely obvious why these diseases are frequently observed in pregnaney.

Treatment: Improve the quality and quantity of the food. The regular administration of calcium phosphate in the food is very benefieial. In addition, nux vomica and potassium iodide may be given with good results.

Mention two causes of hernia of the bladder into the vaginal canal. Give procedure for reducing the hernia.

This very rare condition may occur by reason of a rupture in the floor of the vagina, or the organ may become everted through a relaxed urethral opening when the intra-abdominal pressure is increased by violent expulsive efforts.

In the former eondition replace the organ and suture the rent in the vaginal floor, taking care to bring the peritoneal surfaces of the wound together. In the latter, gentle pressure should be directed toward returning the everted organ. After replacement is effected, allay irritation by irrigating the bladder with war'm, normal salt solution and prevent straining by the use of local or general anastheties. 
Give causes, symptoms and treatment of puerperal laminitis of the mare.

Causes: Occurs in connection with endometritis due to retention of a part of the placenta. Toxins, formed as a result of the bacterial decomposition, are absorbed and laminitis is produced through metastasis.

Symptoms: Same as acute laminitis from other causes, and, in addition, the symptoms of endometritis are observed. (See acute laminitis, p. 255, and acnte endometritis, p. 288.)

Treatment: Remove all placental fragments from the uterine eavity. Irrigate the cavity with mild, antiseptic solutions such as lysol, carbolic acid, and potassium permanganate. Powdered iodoform is useful. (See treatment of acute endometritis, p. 288.)

Name some of the principal causes of sterility in (a) the male, (b) the female.

(a) Cryptorchidism, idleness and overfeeding, masturbation, orchitis and epididymitis, hydrocele, and excessive sexual use.

(b) Cystic ovaries, emaciation, overwork, metritis, occlusion of the os uteri, and senile atrophy of the sexual organs.

What is sterility? Name some causes of sterility and give the treatment.

Sterility is the inability to reproduce young.

Causes: In the male, sterility may be due to cryptorchidism, previous attack of orchitis or epididymitis. No treatment will overcome sterility due to these causes. Idleness and overfeeding often lead to impotency. The treatment for these conditions is suggested by the cause. Onanism may cause sterility. This vice may be corrected by proper feeding and exercise. A shield, so adjusted over the sheath as to cause pain when the penis is protruded, will prohibit erection and thus prevent masturbation.

In the female, sterility is commonly caused by cystic degeneration of the ovaries. These cysts are sometimes crushed by manual pressure, either per rectum or per vaginam, but there is a tendency to recurrence which leads to a fibrous degeneration. Metritis is an etiological factor. Acute metritis usually responds to local treatment (antiseptic irrigation with potassium permanganate, 1-1000), but chronic metritis, pyometra, requires long-continued treatment. The os uteri must be dilated and the uterine cavity irrigated daily with proper antiseptic solutions. The introduction of iodoform powder in a gelatine capsule is useful. Occlusion of the os uteri is 
often advanced as a cause of sterility, but in most cases is overestimated.

Name three pathological conditions of the ovary which may cause sterility.

Tuberculosis, tumors, and cystic degeneration.

\section{Diseases OF THE NEW-BORN}

Name four infectious diseases of the new-born and four non-infectious.

Infectious: Omphalophlebitis, tetanus neonatorum, white scours, septic pleuropneumonia.

Non-infectious: Asphyxia, umbilic hemolrhage, umbilical hernia, retention of meconium.

Name three diseases of the new-born and give the treatment of each. See answers to succeeding questions.

Give method of treatment for the resuscitation of an asphyxiated newborn colt.

Apply traction and relaxation alternately upon the tongue; suspend animal by hind legs to disiodge mucus; induce artificial respiration by alternately compressing and relaxing the chest; alternating electric current may be used if at hand.

Give the causes and the treatment of diarrhœa in the new-born.

Causes: Overfeeding, improper food, milk from overheatad or exhausted mothers, unsanitary feeding utensils, and infection. Infectious diarrhoea ("white scours"), a specific disease, is due to infection of the navel.

Treatment: Allow young to nurse frequently. If artificially fed, sterilize feeding utensils and give food of unquestionable quality as regards bacterial content, etc. Give a mild, soothing cathartic, such as castor oil, and follow, if necessary, with small repeated doses of bismuth subnitrate. Lime water and milk in the proportion of $1: 4$ is an excellent diet for artificially-fed animals. Clean, sanitary quarters should be provided. "White scours," due to navel infection, requires local antiseptic treatment in addition to the above.

Give the causes of umbilic infection.

The cord may be infected in its passage through the vulvovaginal canal, or later the stump of the ruptured cord may come in contact with the earth, soiled bedding, urine, etc. 
Give the causes, symptoms and treatment of umbilic hernia.

Causes: Failure of the umbilic ring in the abdominal floor to close as it normally should. This condition is a congenital defect which seems to be hereditary. Rarely is the defect acquired or accidental.

Symptoms: The presence of a reducible or irreducible, painless tumor in the region of the navel, which may vary in size from that of a hen's egg to a child's head, or larger. It is usually soft and fluctuating and can be pushed through the circular or ellipticalshaped opening in the abdominal floor, but immediately returns when the pressure is released. If strangulation, which rarely occurs, is present, the tumor may be irreducible.

Treatment: Many plans have been tried, such as ligation, bandages, trusses, topical applications, clamps and sutures, but the last named has the preference. Small herniæ often disappear spontaneously before the animal is three or four months old. Best plan of treatment is to secure the patient on its back and give a general anæsthetic; shave and disinfect the skin over the hernia; make an incision through the hernial sac and expose the ring; bring the margins of the ring together with strong, deeply-inserted sutures of silk or catgut; close the skin wound and apply an antiseptic pack over wound, holding it in place with body bandage. Small herniæ may be sutured similarly withont making an incision through the skin, but by passing sutures throngh the whole sac near its base. These sutures may be so arranged that the sac is ligated and sloughed away.

Give the causes, symptoms and treatment of inflammation of the umbilic cord (omphalophlebitis).

Causes: Infection due to contact with soiled litter, fæces, urine, etc. Manipulations of the cord by laymen or others without observing aseptic precautions. Needless or faulty ligation of the cord. Flies also carry infection.

Symptoms: The disease, which occurs a few hours after birth, may remain local (omphalitis) or extend to the umbilical vein (omphalophlebitis) and result in septicopyæmia. If local, swelling and tenderness of the navel region are noted; a thin, watery, or blood-tinged discharge which later contains pus exudes; little or no systemic disturbance is observed. Later, two to ten days, if the inflammation extends to deeper parts, a sudden, severe, general disturbance takes place; this is manifested by fever, inappetency, lameness due to septic arthritis, painful swellings about the articu- 
lations, abscess formation in various parts, such as the liver, kidneys, spleen, lungs, etc. Therefore the symptoms may be many and varied.

Treatment: This disease is more easily prevented than cured. Local disinfection is the best and only measure necessary. Remove all necrotic tissue, thoroughly cleanse and apply dry antiseptic powders to the stump of the cord. If the infection has become generalized, all treatment is practically hopeless, but local disinfection should be energetically effected. The various methods of increasing the opsonic index by injections of antistreptococcic sera, vaccines, etc., may be useful.

Give the causes, symptoms and treatment of foal-lameness.

See answer to preceding question.

\section{Give the treatment of imperforated anus.}

Make an incision through the skin where the anus should be, down upon the mass of meconium in the rectum.

Give the symptoms and the treatment of persistence of the urachus.

Symptoms: All, or part, of the urine, depending upon whether the urethra is open or not, is discharged through the navel. Navel infection with omphalophlebitis may follow.

Treatment: If the urethra is imperforate, attempt opening same, then apply desiccating and astringent antiseptics, such as Tr. iodine, or actual cautery to the navel. If the urethra cannot be opened, the prognosis is bad, as infection will sooner or later enter the navel and produce fatal results.

What is cyanosis in the new-born? Give cause and symptoms.

A blueness of the skin and mucous membranes, due to cardiac malformation causing insufficient oxygenation of the blood.

Cause: Failure of the foramen ovale (a fetal structure, consisting of an opening between the auricles) to elose at birth.

Symptoms: Extreme weakness, rapid respiration, and a bluish coloration of the skin and visible mucous membranes.

Describe the external sexual organs in a case of hermaphrodism.

Varies greatly in different cases. In general, a rudimentary penis or enlarged elitoris projects backward or downward from the lower commissure of a vulva. The mammary gland is moderately developed in its normal position or may resemble a scrotum and contain undeveloped testicles. 


\section{MATERIA MEDICA AND THERAPEUTICS*}

Define (a) materia medica, (b) therapeutics.

(a) Nateria medica treats of the derivation, natural history, physical and chemical properties, physiological actions, doses and tests of purity of drugs.

(b) Therapentics is that branch of knowledge which treats of the application of all means-medicinal or otherwise-to the cure of disease or relief of pain.

By what modes are medicines introduced into the organism?

1. By intravenous injection.

2. By inhalation.

3. By subcutaneous injection.

4. By intratracheal injection.

5. By the mouth (orally).

6. By the rectum.

7. By inunction.

Compare as to size of dose and length of time required for action, the following modes of administering medicine: (a) by mouth, (b) by rectum, (c) by intravenous injection, (d) by hypodermic injection.

(a) One-half the rectal dose, four to six times the intravenous dose, and twice the hypodermic dose. Absorption more rapid than from the rectum and slower than by intravenous and hypodermic methods.

(b) Twice the oral dose. Absorption is slower and more imperfect than by the mouth.

(c) One-half to one-third the hypodermic and one-fourth to onesixth the oral dose. Absorption immediate.

(d) One-half the oral dose. Absorption quicker than all others except the intravenous method.

This comparison is made with alkaloidal drugs, as they are the ones usually given intravenously and subcutaneously.

What is meant by synergistic remedial agents? Describe fully.

Agents which assist or intensify the action of others. Belladonna promotes the action of nux vomica, mercury and the iodides favor

* Unless otherwise stated all questions relate to the horse. 
the action of silver as a waste producer, the alkalies favor the action of sulphur compounds, both chemically and physiologically.

What is meant by (a) the physiological action of a drug, (b) the toxic dose of a drug, (c) the lethal dose of a drug?

(a) The definite and limited action of a drug upon some part of the organism, intended to antagonize or overcome a particular pathological condition.

(b) A dose sufficient to produce poisoning.

(c) A fatal dose.

Into what classes are cathartics divided? Name one cathartic of each class and state how it acts.

1. Laxatives: olive oil acts mechanically and slightly stimulates peristalsis.

2. Simple purgatives: calomel stimulates secretion and peristaltic action.

3. Drastic purgatives: croton oil greatly increases peristaltic action and secretions.

4. Hydragogue purgatives: magnesium sulphate abstracts water from the blood by stimulating secretion.

5. Cholagogue purgatives: sodium phosphate increases the flow of bile, which stimulates peristalsis.

How do sedatives act? What is the danger of the excessive use of sedatives?

Sedatives act by depressing protoplasm and lowering functional activity. They allay nervous irritability by diminishing the conduction of impressions to the brain. Their excessive use may cause the cardiac and respiratory actions to cease. A long-continued use of sedatives may lead to alarming nervous irritability if suddenly discontinued or if the dosage is not increased.

Give the physiological actions and the therapeutic uses of aconite.

Aconite decreases the cardiac rate and force, lowers arterial tension and temperature. The respiratory centre is depressed. It is a diaphoretic and diuretic; depresses the functional activity of the perceptive centres in the brain, the sensory side of the spinal cord, and the peripheral sensory nerves.

It is indicated in all affections characterized by a high resisting pulse and an elevated temperature; is useful in acute pharyngitis, laryngitis, pleurisy, peritonitis, enceplalitis, laminitis, enteritis, and mammitis; also used in acute muscular or articular rheumatism, and as a sedative in cardiac disturbance. 
What are the uses of tincture of aconite? Give the dose of tincture of aconite (a) for the horse, (b) for the dog. How long should maximum doses be given?

See answer to preceding question.

It is given in doses of 15 minims to the horse and 2 minims to the dog, every 15 minutes for two hours, and afterwards 30 minims for the horse and 3 minims for the dog, every hour, until the temperature and pulse-rate are lowered. The drug should be used with cantion and the pulse carefully watched. The maximum dose for the horse, $1 / 2$ to $11 / 2$ drachms, for the dog, 2 to 8 minims, should not be repeated without first examining the pulse and heart.

Give the indications for barium chloride. State the dose according to the method of administration.

Barium chloride is indicated in obstinate constipation of the horse and in colics where a quick-acting cathartic is needed.

Dose: 7 to 15 grains, intravenously; 1 to 3 drachms per os.

Name the drugs that exert the greatest effect on glandular structures.

Pilocarpine, arecoline, belladonna, calomel, potassium iodide, alcohol, ammonia, antimony and potassium tartrate, aloes, apomorphine, ipecac, camphor, opium, spirits nitrous ether, potassium nitrate, etc.

Name the more common preparations of mercury. State the actions, uses and the doses of each.

1. Unguentum hydrargyri: Parasiticide, stimulant, antiseptic, and resolvent. Used externally for mange, lice, ringworm, small exostoses, etc.

2. Hydrargyri iodidum rubrum: Resolvent and pustulant, counterirritant. Used externally for splints, spavius, ringbones, chronic tendinitis, enlarged bursæ, enlarged joints, chronic laryngitis, etc.

3. Hydrargyri chloridum mite: Laxative, cathartic, diuretic, antiseptic, alterative and vermifuge; externally, desiccant, antiparasiticide, and antiseptic. Used in gastritis; icterus due to constipation, catarrh of the duodenum or hepatic congestion; and influenza. Used in combination with santonin for intestinal worms. Externally, it is used in chronic eczema, itching of the skin, and thrush. Dose, $1 / 2$ to $1 \mathrm{drachm}$.

4. Hydrargyri chloridum corrosivum: Corrosive, irritant poison, alterative, antiseptic, and hepatic stimulant. Used externally, in strength varying from $1-500$ to $1-10,000$, as an antiseptic for 
wounds, quittors, fistulous withers, etc. Used as a slonghing agent in fibrous growths. In endometritis, a solution of $1-10,000$ is used as a douche.

\section{Describe the medicinal treatment of pneumonia.}

In the congestive stage, veratrum and aconite in full doses. Counterirritants sueh as mustard on the chest-wall may relieve the patient. Active friction followed with bandages on the legs.

In the stage of hepatization, support the heart with digitalis, aleohol, etc. Reduce the temperature, if exeessive, with aconite, quinine sulphate, etc. Give mild laxatives, such as Glauber's salts, calomel, or linseed oil; alkaline diuretics, as potassium nitrate.

In the stage of resolution, give stimulating expectorants, such as ammonium chloride and ammonium earbonate. The convalescent period is shortened by the use of tonics, such as nux vomica, arsenic, etc.

\section{Give the treatment of tetanus.}

Surgically remove tissue surrounding the point of infection or thoroughly cauterize same and treat daily with strong disinfectants. Phenol is best for this purpose. Keep the patient in a quiet place. The use of antitoxin as a therapeutic agent is still sub judice. By most authorities it is considered valueless in this connection. Attempts to control spasms may be made with potassium bromide, given in four-ounce doses every four hours. Morphine, chloral, or lobelia may assist. Rectal or nasal feeding may help in nourishing the patient. Saline laxatives to secure free elimination.

\section{Describe the treatment of influenza in its simple form.}

A laxative condition of the bowels should be secured by feeding bran-mashes and administering calomel. Stimulants such as liquor aunmonium acetatis or ammonium carbonate are valuable. If the fever is high, quinine, acetanilide and antipyrine are important antipyreties which can be used. In œdema of the extremities, potassium nitrate is indicated. Support a weak heart with digitalis, camphor, or strychnine. Counterirritants on the chest and throat may be nscful. Treat complications symptomatically.

Name four alkalies. Give the action and the uses of alkalies.

Potassium, sodium, lithium, and ammonium.

Actions: The salts of potassium are irritants, caustics, diuretics, antaeids, alteratives, and antipyreties. Potassium nitrate is useful in dropsical effusions. Potassium bromide is a nerve depressant, 
nseful in spasms and kervous excitement. Potassium hydroxide is a eaustic used on warts and tumors and to prevent the growth of horns on eattle. Potassium chlorate is an antiseptic which is nseful in pharyngitis and stomatitis. Potassium iodide is used as au alterative in actinomycosis and other chronic conditions.

The salts of sodum are irritants, caustics, diuretics, eathartics, and alteratives. Sodinm bicarbonate is useful in gastric and intestinal eatarrh. Sodium bromide is used same as potassium bromide. Sodium chloride is nsed intravenously in hemorrhage, anxmia, and collapse, also in gastro-intestinal catarrh. Sodium sulphate is a laxative which is serviceable in gastro-intestinal catarrh, serous exudates, and odemas. Sodinm hyposulphite is used as an antacid and antiseptic in gastric tympany. Sodium hydroxide is used same as potassium hydroxide.

The salts of lithium are diuretics which are used in uric acid ealculi for their solvent action; also used in rheumatism.

The salts of anmonium are stimulants, expectorants, diaphoretics, antipyretics, diuretics, vesicants, irritants, antacids, etc. Ammonium carbonate is nsed as an antacid in colic and tympanites, as a circulatory and respiratory stimulant and a stimulating expectorant in the third stage of pneumonia, in bronehitis, emphysema, and as a heart stimulant in collapse. Ammonium chloride is a stimulant expectorant used in eatarrhal bronchitis and pneumonia. Aqua ammonia is an antacid useful in tympanites and externally in liniments.

\section{What are the general actions of opium? Give the dose of opium for} the horse, the cow and the dog.

Opium is analgesic, hypnotic, diaphoretic, antispasmodic, and narcotic; also cardiac and respiratory depressant, after brief stimulation.

Dose of powdered opium for the horse, 20 to 90 grains; for the cow, 1 to 2 drachms; for the dog, $1 / 4$ to 3 grains.

State the source and the uses of opium.

Opium is obtained in Asia Minor from the unripe capsule of Papaver somniferum, or poppy plant, by incision and spontaneous evaporation of the milky exudate.

It is used as an antispasmodic in peripheral irritation ( cough); checks excessive secretions and suppresses peristalsis in acute inflammatory affections of the bowels (the bowels should be previously cleared of the irritant). Useful in pleurisy to check the develop- 
ment of hydrothorax and in peritonitis to prevent ascites. In catarrhal diseases it lessens the discharge; in cerebrospinal meningitis and muscular spasms to lessen the nervous irritability; to check premature labor pain and prevent straining in eversion of the rectum or uterus.

\section{Give the actions and the uses of ergot.}

Ergot is a powerful vasomotor stimulant, hæmostatic, gastrointestinal irritant, and ecbolic. It stimulates and contracts involuntary muscular fibres, and hence diminishes the blood-stream passing through the arterioles; large doses or small repeated doses produce ergotism, which is characterized by gangrene of the extremities, due to lack of blood supply to the parts.

Ergot is used as an ecbolic to stimulate weak uterine contractions and promote expulsion of the fœtus or fœtal membranes; also used as a vasomotor constrictor in postpartum or other internal hemorrhage.

\section{Give the actions and the uses of the iron salts.}

Iron in general is a hæmatinic, stomachic, styptic, astringent, and hæmostatic. The sulphate is a vermicide. The iodide is alterative and resolvent as well as tonic.

Irou is used in anæmia, diarrhœa, intestinal worms, and as a valuable tonic in convalescence from debilitating diseases. Locally, the ehloride of iron is used to check hemolrhage and as an astringent in chronic pharyngitis and laryngitis. Internally, it is used as a diuretic and tonic in purpura hemorrhagica.

The hydrated sesquioxide of iron is a specific antidote for arsenical poisoning. The phosphate is serviceable in diseases of bone (rachitis, osteoporosis) and nervous exhaustion. The sulphate improves the appetite and abates exhausting discharges in chronic catarrhal rhinitis and endometritis.

\section{Give the actions and the uses of cantharides.}

Externally, cantharides is irritant, rubefacient, vesicant. Internally, it is irritant, and stimulates the genito-urinary tract, diuretic and aphrodisiac.

It is used internally (rarely) to produce sexual excitement; and for incontinence of the urine from paralysis of the bladder. Externally, it is a valuable counterirritant and vesicant. Used in sprains, tendovaginitis, periostitis, exostoses, wind-puffs, chronic laryngitis and plaryngitis, and to stimulate the growth of horn and hair. 
What preparations of arsenic are most used in veterinary medicine?

Arsenous acid, iodide of arsenic, Fowler's solution, and Pearson's solution.

Give the actions and the uses of arsenic.

Arsenic is a gastro-intestinal and respiratory tonic, a stimulant and alterative, acting especially on the digestive and respiratory mucous membrane and the skin. It is an antiperiodic, also antispasmodic in nervous diseases, and is a nervine tonic. It increases the cardiac action, respiratory power, and secretion of the intestines; also has a vermicidal action.

Uses: General tonic after debilitating diseases, especially pneumonia, pleurisy, and bronchitis; intestinal worms, chronic congh (heaves). Used in anæmia, chorea, chronic eczema, and periodically returning fevers.

How should a course of arsenic be administered so as to avoid chronic arsenical poisoning?

Begin with very small amounts and gradually increase the dose until the physiological limit is reached (œdema and itching of the eyelids), then gradually decrease the dose. Do not leave off the administration abruptly. A tolerance for the drug can be acquired so that large doses nay be given with impunity.

Describe the actions of arecoline hydrobromide and give the dose for the horse.

Arecoline hydrobromide increases salivation and intestinal secretions; stimulates peristalsis, slows and softens the pulse. It is used as a quick-acting cathartic in colics and acute laminitis in doses of $1 / 1$ to $1 / 3$ grain subcutaneously, repeated in 20 minutes. A single dose of 1 to $11 / 2$ grains subcutaneously is given by some, but fractional doses are safer.

Name the iodine compounds and give their actions and uses.

Liquor iodi compositus (Lugol's solution), ammonium iodide, sodium iodide, and potassium iodide are given internally; tincture of iodine and iodoform are used externally.

Actions: Externally, stimulant, irritant, and vesicant; if used concentrated, antiseptic, resolvent, parasiticide, deodorizer, and disinfectant. Internally, alterative, resolvent, deobstruent, and expectorant; stimulates glandular activity and promotes tissue changes as well as the absorption and elimination of recently formed tissue and diseased cells. Forms insolnble compounds with lead, mercury, and other metals and hastens their removal in cases of poisoning. 
Uses: Externally for enlarged glands, periosteal inflammation, capped hock, curb, chronic synovitis, pharyngitis, and laryngitis; to stimulate granulations in slow-healing wounds and promote the growth of hair. Useful to disinfect the skin before operations; as a parasitieide in mange, ringworm, and favus; iodoform is used as a dusting powder in suppurative wounds for its bactericidal and stimulating effect. It also has a slight anæsthetic action.

Internally, potassium iodide is most commonly used. It is a specific in actinomycosis; alterative in chronic bronchitis and laryngitis; antidote for chronic lead poisoning; goitre, scirrhous cord, botryomycosis, hydrothorax, ascites, cirrhosis of the liver, and periodic ophthalmia are often improved by the use of potassium iodide internally. Ammonium iodide is useful to hasten the stage of resolution in pneumonia.

What effect has acetanilide on the temperature? Give its action and uses.

Acetanilide has a decided antipyretic effect in fevers, but little effect on a normal temperature. It is mildly diaphoretic, slightly antiseptic, diuretic, and depressant to the heart.

It should be used in very high fevers only, especially thermic fever (sunstroke), in one- to two-drachm doses, repeated not oftener than every six hours.

\section{State the source and the uses of acetanilide.}

Acetanilide is obtained by distilling together glacial acetic acid and aniline and purifying the residue by repeated crystallization. (See answer to preceding question.)

Define the following terms: haustus, collyrium, electuary, decoction, infusion, elixir, emulsion.

Haustus is a draft, or drench, of medicine.

Collyrium is an eye-wash.

Electuary is a medicinal powder, beaten up with sugar, honey, or molasses to the consistency of thick paste. Electuaries are intended to be smeared on the teeth of animals where they melt at body temperature and aet locally on the mouth and throat.

Decoction is an aqueous preparation, obtained by boiling drugs in water.

Infusion is an aqueous solution of a drug, macerated in boiling water withont the aid of ebullition.

Elixir is a swectened, aromatie, alcoholie solution of a drug. 
Emulsion is a milky fluid obtained by mixing an oil or resin with water. The globules of oil or particles of insoluble resin are held in suspension by some gummy substance, usually acacia. Milk is a natural emulsion.

What are stimulants? Name (a) a cardiac stimulant, (b) a hepatic stimulant, (c) a cerebral stimulant, (d) a diffusible, or general, stimulant.

A stimulant is an agent which increases functional activity.

(a) Camphor, (b) podophyllum, (c) opium, (d) alcohol.

Name the ingredients, giving the proportion of each, found in each of the following mixtures: the A.C.E. mixture, the E.C. mixture.

A. C. E. $=$ Alcohol 1 part, chloroform 2 parts, and ether 3 parts.

E. C. $=$ Ether and chloroform, equal parts.

What is meant by (a) chemical incompatibility, (b) physiologic incompatibiiity, (c) pharmaceutical incompatibility? Give an example of each.

(a) Chemical incompatibility occurs when drugs are so mixed that an unsuitable alteration in their chemical composition takes place, e.g., calomel with nitrohydrochloric acid forms corrosive sublimate.

(b) Physiologic incompatibility consists in the union of drugs possessing antagonistic physiological actions;-e.g., atropine and pilocarpine.

(c) Pharmaceutic incompatibility results in the production of an unsightly mixture due to physical change; e.g., resinous tinctures and aqueous solutions cause the resins to separate.

How do tinctures differ from spirits? Give examples.

Tinctures are alcoholic solutions of non-volatile principles (except Tr. iodine), made usually by maceration and percolation of the crude drug. Examples, belladonna tincture, aconite tincture, ete.

Spirits are alcoholic solutions of volatile substances. Example, spirits of camphor.

Describe the preparation of a tincture. Name five official tinctures.

The majority of tinctures are made by percolation. This is accomplished by packing the powdered drug in a suitable vessel and depriving it of its soluble constituents by allowing a menstruum, or 20 
solvent, to descend through it. The menstruum used is alcohol, except in two cases, when aromatic spirits of ammonia is used as a solvent.

Five official tinetures: $\mathrm{Tr}$. aloes, $\mathrm{Tr}$. iodine, $\mathrm{Tr}$. nux vomica, Tr. gentian, and Tr. opium.

Give the actions and the uses of veratrum viride. State the dose for (a) the horse, (b) the dog.

Veratrum viride is a cardiac depressant, febrifuge, spinal paralyzant, emetic, and cathartic. Used about the same as aconite, but is inferior to same. Employed as an emetic in swine, stomachic in cattle in indigestion, and for pneumonia and other respiratory diseases in the horse. Used to lower temperature, relieve pain, and lessen the duration of acute rheumatic fever. Dose for the horse, 5ss-j., for the dog, gr. ${ }^{1} / 10-1$.

Give in the metric system (a) the table of weight, (b) the unit of weight, (c) the unit of measure of liquids.

(a) 10 milligrammes $=1$ centigramme,

10 centigrammes $=1$ decigramme,

10 decigrammes $=1$ gramme,

10 grammes $=1$ decagramme,

10 deeagrammes $=1$ hectogramme,

10 hectogrammes $=1$ kilogramme.

(b) One gramme is the unit of weight; it being the weight of one cubic centimetre of distilled water, at the temperature of $4^{\circ} \mathrm{C}$.

(c) One cubic centimetre is the unit of measure of liquids.

Give the actions and uses of quinine sulphate. State the dose for (a) the horse, (b) the cow, (c) the dog.

Quinine sulphate is a tonie, antiseptie, antiperiodic, antipyretic, antiphlogistic, antimiasmatic, stomachic, and antiferment. Small doses stimulate the heart and brain, large doses depress both. Large doses lower reflex activity of the spinal eord.

It is used as a bitter stomachic and tonie to improve the appetite and stimulate digestion. Cheeks abnormal gastro-intestinal fermentation. Used in anæmia, septiermia, pyæmia, influenza, strangles, purpura hemorrhagica, and other infeetious febrile diseases. It is of great benefit in distemper of dogs, chorea, and rheumatism; also used as an antipyretic and stimulant in pnemmonia and bronchitis.

(a) 2 to 4 drachms, (b) 4 to 6 drachms, (c) 1 to 5 grains. 
State the dose of quinine as an antipyretic and tell how often the dose should be repeated.

Two drachms, repeated every three or fours hours.

What is an anæsthetic? Give the uses of anæsthetics. Mention three examples of each of the two great classes of anæsthetics.

An anæsthetic is an agent which diminishes or abolishes sensation. It is used to prevent pain and struggling during surgical operations, in obstetrical operations, reduction of fractures, dislocation and hernias, to overcome spasms and convulsions resulting from disease or poisons, and finally to destroy aged or sick and useless animals. Local anæsthetics are sometimes used in making diagnoses of lameness.

Local: Cocaine, alypin, and stovaine.

General: Ether, chloroform, and nitrous oxide. (Chloral hydrate is often used as a general anæsthetic.)

Name three local anæsthetics and describe the mode of application of each.

1. Cocaine hydrochloride. Dose for the horse, 2 to 10 grains, hypodermically. Used in 4 to 10 per cent. solution, injected under the skin.

2. Eucaine hydrochlorate. Used same as cocaine.

3. Phenol. Applied to the skin over the line where an incision is to be made.

What is morphine? Describe the actions and uses in medicine of morphine. State the hypodermic dose for (a) the horse, (b) the dog.

Morphine is an alkaloid obtained from opium. It occurs in colorless or white crystals, or as a crystalline powder, odorless and having a bitter taste.

It is hypnotic, anodyne, narcotic, nervous sedative, and antispasmodic.

Used in eclampsia in bitches; useful in painful cough; relieves pain in spasmodic colic, pleurisy, and dyspnœe. Used to prevent straining in eversion of the rectum or uterus; also used in "thumps" (spasms of the diaphragm) and as an anæsthetic for surgical operations on dogs.

(a) 3 to 5 grains, (b) $1 / 16$ to $1 / 4$ grain. For surgical anæsthesia 1 to 2 grains are given hypodermically to dogs. 
Give the composition and the uses of Fowler's solution of arsenic. State the dose for (a) the horse, (b) the dog.

Fowler's solution (liquor potassii arsenitis) is an arsenical preparation of 1 per cent. strength. Its formula is as follows:

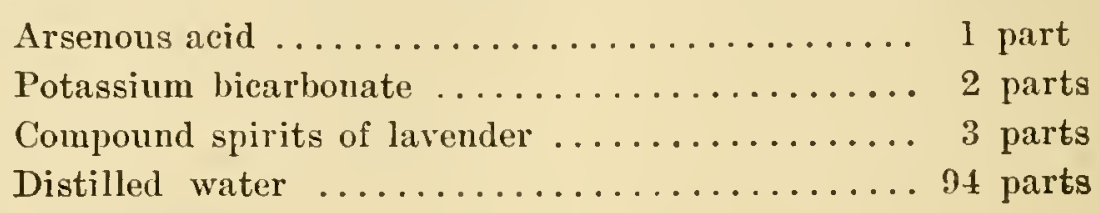

Used as a alterative and tonic in chronic intestinal catarrh, emaciation, chronic dyspnœa (heaves), chorea, chronic skin diseases, anæmia, rachitis, osteomalacia, etc.; as a vermifuge for intestinal worms; used externally to remove warts.

(a) 2 drachms to 1 ounce, (b) 2 to 10 minims.

What is Pearson's solution? How is it prepared? Give its uses and dose.

Liquor sodii arsenatis (Pearson's solution) is a solution of sodium arsenate. It is made the same as Fowler's solution, only sodium arsenate is used in place of potassium arsenite (potassium bicarbonate and arsenous acid). It is used for the same purposes and in the same doses as Fowler's solution, but is less irritating and active. (See answer to preceding question.)

Give the principal use of apomorphine for the dog. State how apomorphine is administered and mention the dose for a 40-pound dog.

Used as a prompt and powerful emetic. Usually given hypodermieally. Dose for a 40 -pound dog, $1 / 15$ grain.

Give the physiologic actions and the uses of belladonna.

Belladonna is a narcotic, mydriatic, antispasmodic, and anodyne. In small doses it is cardiac, respiratory, and spinal stimulant; in large doses, a paralyzer of the seeretory and notor nerve-endings and a stimulator of the entire sympathetic system.

It is used to eheck abnormal secretion in ptyalism, acute catarrhal conditions, and polyuria. Used as an antispasmodic in colie, tetanus, cough, bronchitis, and dyspnoea. It suppresses the symptoms of heaves, relaxes a contracted or rigid os, and allows of parturition. It is useful to relieve congestion in the begimning of aente inflammatory diseases, as laminitis, pneumonia, and pleurisy. Used externally in liniments for museular pain. It is used in ophthalmology 
to dilate the pupil and paralyze accommodation for purposes of refraction; to prevent or break up adhesions of the iris and inflammatory conditions of the cornea. Atropine, the active principle of belladonna, is generally used in this work.

Give the source of atropine and describe its action.

Atropine is an alkaloid obtained from belladonna. It is the chief alkaloid of this drug and represents its action. (See answer to preceding question.)

Name five antiseptics for wounds and give the strength in which each should be used.

Corrosive sublimate, 1-1000 to 1-2000.

Phenol, 3 to 5 per cent. solution.

Creolin, 1 per cent. solution.

Hydrogen peroxide, 50 per cent. solution or undiluted.

Lysol, $1 / 2$ to 2 per cent. solution.

Mention four preparations of iron and state the dose of each for (a) the horse, (b) the dog.

Ferrum reductum, (a) 1 to 3 drachms, (b) 1 to 5 grains.

Ferri sulphas, (a) $1 / 2$ to 1 drachm, (b) $1 / 2$ to 2 grains.

Tr. ferri chloridi, (a) 2 to 8 drachms, (b). 2 to 20 minims.

Ferri hydroxidum cum magnesii oxide, (a) 8 ounces, (b) 4 drachms.

State how benzoated lard is prepared and give its uses.

Adeps benzoinatus is made by melting lard 1000 parts with benzoin 20 parts. The melting is accomplished by means of a waterbath. The temperature should not rise above $60^{\circ} \mathrm{C}$., and should be continued for two hours. After straining, the mixture should be stirred until cool.

It is used as a base for ointments. The benzoin acts as a preservative to prevent the lard from becoming rancid.

What is (a) a hypnotic, (b) a mydriatic, (c) a myotic? Give an example of each.

(a) An agent which produces sleep, without first causing excitement; e.g., potassium bromide.

(b) An agent which causes abnormal dilatation of the pupil; e.g., atropia.

(c) An agent causing abnormal contraction of the pupil; e.g., opium. 
What is strychnine? Describe the actions and the uses of strychnine. State the hypodermic dose of strychnine for (a) the horse, (b) the dog.

Stryehnine is an alkaloid obtained from nux vomica.

It is a nerve tonic, gastric tonic, stimulates respiration, secretion, and digestion; it increases peristalsis, stimulates both the motor and inhibitory apparatus of the heart, and raises arterial tension by stimulating the vasomotor centres, thus contracting the arterioles; full doses relax the arterioles and thus reduce bloodpressure.

Used in paralysis, depression of the nervous system, atonic dyspepsia, heaves, diarrhœa due to relaxation of the bowels from lack of tone, in small doses; convalescence from debilitating diseases, collapse, heart-weakness, chloroform, syncope, narcotic poisoning, constipation, incontinence of the urine, etc.

(a) One-half to one grain, (b) $1 / 250$ to $1 / 60$ grain.

In what diseases of the horse should nux vomica be prescribed? Give the dose of the fluidextract of nux vomica for (a) the horse, (b) the cow, (c) the sheep, (d) the pig, (e) the dog, (f) the cat.

See answer to preceding question, uses of strychnine.

(a) 1 drachm, (b) 2 drachms, (c) 20 minims, (d) 10 minims, (e) 2 minims, (f) 1 minim.

What is Goulard's extract? State how it is prepared and give its uses.

Liquor plumbi subacetatis (Goulard's extract) is an aqueous liquid, containing in solution about 25 per cent. of lead subacetate, prepared by boiling together acetate of lead 180 parts, oxide of lead 110 parts, in 1000 parts of water. It is an active astringent and sedative. Diluted with three parts of water, this agent is used for sprains, bruises, cuts, burns, scratches, grease-heel, skin diseases, eczema, canker of the ear in dogs, ete.

What drugs are used internally and externally to check hemorrhage?

Adrenalin, ergot, digitalis, turpentine, opium, bismutl, lead acetate, and saline infusions are used intermally.

Adrenalin, alum, ferric chloride, ferric sulphate, tannic acid, lead acetate, bismuth, and ether-sprays are used externally.

Mention the methods by which temperature in fever may be reduced. Which method is the most rational and practical?

The temperature in fever may be reduced by lessening the heat production with drugs such as phenacetin, antipyrine, acetanilide, 
quinine sulphate, salicylic acid, aconite, and digitalis, or by increasing the heat loss with alcohol, spiritus atheris nitrosi, cold, and purgatives. The former method is better becanse it strikes more nearly at the somrce or cause, and the latter method stimulates the production of heat.

Give the properties, the uses and the dose of potassium chlorate.

Potassium chlorate occurs in colorless, monoclinic prisms. It casily explodes on trituration with sugar, sulphur, tamnin, and charcoal. It is soluble in 1 to 16 parts of cold and 1 to 2 parts of boiling water; antiseptic, antacid, alterative, sialogogue, diuretic, febrifuge, and cardiac depressant, and is used in laryngitis, pharyngitis, stomatitis, and in febrile conditions of a catarrhal nature. Dose, 2 to 8 drachms.

What is oil of turpentine? How is it obtained? Give its medicinal use.

It is a volatile oil, distilled from turpentine. Turpentine is obtained from the ordinary yellow pine (Pinus palustrus) and other varieties of pine. For uses, see following question.

Give the external use and the internal use of oil of turpentine. State how oil of turpentine should be administered.

Used externally as a counterirritant, rubefacient, or stimulant in sprains, arthritis, pleurisy, peritonitis, spasmodic colic, etc.

Internally, it is used as an antiferment in flatulency, anthelmintic for round- and tapeworms, stimulating and antiseptic expectorant in chronic bronchitis, genito-urinary antiseptic in purulent nephritis, cystitis, and urethritis. Used extensively in internal hemorrhage and purpura hemorrhagica. Injected intratracheally for lung worms in calves and lambs.

It is usually administered in oil or milk. (Its irritating properties are greatly overestimated, however, as it can be given by the mouth undiluted with no inconvenience to the patient.)

\section{What are alkaloids?}

Alkaloids are active nitrogenous principles existing in plants, extracted by chemical art. They are organic bases of alkaline reaction, forming salts with acids, and as salts are very soluble in water.

Mention six alkaloids used in veterinary medicine. State the dose and the mode of administering each.

1. Morphine: Morphine sulphate, 3 grains, hypodermically.

2. Strychnine: Strychnine sulphate, 1 grain, hypodermically. 
3. Quinine: Quinine sulphate, 2 drachms, per os.

4. Cocaine: Cocaine hydrochloride, 5 grains, hypodermically or intramuscularly.

5. Atropine: Atropine sulplate, 1 grain, hypodermically.

6. Arecoline: Arecoline hydrobromide, 1 grain, hypodermically.

Name three alkaloids and state the source of each.

Pilocarpine, obtained from pilocarpus (Jaborandi).

Ergotine, obtained from ergot.

Digitaline, obtained from digitalis.

What are the medicinal uses of gentian root? State the dose for (a) the horse, (b) the ox.

Stomachic in indigestion, debility, and convalescence. Used to relieve acute and chronic flatulence.

(a) 2 drachms to 1 ounce, (b) 1 to 2 ounces.

What are the medicinal uses of ginger root? State the dose for (a) the horse, (b) the ox.

Stomachic and carminative in atonic indigestion of horses and ruminants. Used to aid the action of purgatives and prevent griping.

(a) 2 drachms to 1 ounce, (b) 1 to 4 ounces.

What is eserine? State the dose for (a) the horse, (b) the ox, (c) the dog.

Eserine is the principal alkaloid of physostigma.

(a) 1 to 2 grains, (b) 1 to 3 grains, (c) $1 / 100$ to $1 / 25$ grain (hypodermically).

What are the actions and uses of eserine?

Eserine is a muscular stimulant; it stimulates secretion in general, excites nausea and vomiting, and is a laxative or purgative by stimulating the muscular coat of the intestines as well as the intestinal secretion. It also acts as a myotic and decreases intra-ocular tension.

Used in constipation due to torpor of the bowels, in impaction colic and parturient paresis. Externally, in the eye to decrease intra-ocular pressure and contract the pupil in periodic ophthalmia, where it is sometimes alternated with atropine to prevent adhesions of the iris and diminish pain and congestion.

State the principal alkaloid of the Calabar bean and give its dose and uses.

Eserine (physostigmine) is the principal alkaloid of Calabar bean or physostigma. (See answer to preceding questions.) 
What blistering agents are adapted to the different domestic animals?

Cantharides for the horse, cantharides and red mereuric iodide for bovines, and mustard for dogs and sheep.

What are the indications for the use of counterirritants? Name five counterirritants.

1. To overcome congestion and inflammation in remote parts.

2. To promote absorption of inflammatory products, locally.

3. To relieve pain.

4. To stimulate the heart, respiratory and nervous functions.

Cantharides, iodine, mustard, turpentine, and red mercuric iodide.

What is the best antiferment in gastric flatulence? State the dose of the antiferment and give the method of its administration.

Sodium hyposulphite. Dissolve 4 to 12 ounces in one quart of water and give as a drench.

\section{What is chloral hydrate? How is it prepared?}

Chloral hydrate is a crystalline solid, occurring in colorless, transparent crystals, having an aromatic, penetrating, and slightly acrid odor and a bitterish, caustic taste. It is freely soluble in water, alcohol, ether, and volatile oils.

It is prepared by passing dry chlorine gas into alcohol until the latter is saturated. It is purified by distillation with sulphuric acid, and then with lime.

Give the actions and uses of chloral hydrate. What is the dose for the horse?

It is a local irritant, antiseptic and stimulant. Internally, it has a primary stimulating effect on the circulatory and central nervous systems, but secondarily it depresses both.

The drug is used to lessen irritability and produce sleep. Its principal use is in spasmodic conditions such as colics, coughs, chorea, tetanus, etc. It is one of the best antidotes to strychnine poisoning. Used by some as a general anæsthetic, but is not as reliable as chloroform.

Dose for the horse, 1 to 2 ounces. Four ounces are given for anæsthetic purposes.

Give the principal uses of viburnum prunifolium.

It is used as a tonic, antispasmodic, nerve sedative, and antiabortive. It is principally nsed to prevent habitual abortion. 
Give the treatment of sunstroke.

Remove patient to a cool, shady place; apply ice-bags to the head and neck; cold water enemas are useful. Give antipyretics and heart stimulants, acetanilide, 2 drachms dissolved in 1 ounce of aromatic spirits of ammonia, every two or three hours. Subcutaneous injections of camphor, ether, alcohol, atropine, hyoscyamine, caffeine, veratrine, strychnine, etc., have been employed for their stimulating effect.

Name (a) one powdered diuretic, (b) one liquid diuretic, (c) a blood tonic, (d) a nerve tonic.

(a) Nitrate of potassium, (b) spirits nitrous ether, (c) iron sulphate, (d) nux vomica.

Name (a) two general stimulants, (b) three heart stimulants. State the dose of each.

(a) Alcohol, 2 to 3 ounces; aqua ammonia, 2 to 4 drachms.

(b) F. E. digitalis, 1 drachm; Tr. strophanthus, 1 to 2 crachms; spirit of nitroglycerin, $1 / 2$ to 1 drachm.

Describe the effects of the external applications of bismuth salts. Give the physiological actions of bismuth subnitrate. What is its dose?

No effect on the unbroken skin. They have a protecting, sedative, astringent, and antiseptic action on raw surfaces.

Bismuth subnitrate exerts a sedative, astringent, and antiseptic effect throughout the alimentary canal by reason of its insolubility and coating action on the walls of the same. It is used in vomiting. diarrhœa, and intestinal fermentation. It is comparatively harmless and can be given in relatively large doses. Dose for the horse, 2 drachms.

Mention three iodides and state the dose of each.

Potassium iodide, 2 to 4 drachms.

Sodium iodide, 2 to 4 drachms.

Ammonium iodide, 2 to 4 drachms.

Name two remedies that are used to promote intestinal peristalsis.

Aloes and calomel.

Where are cantharides chiefly obtained? Give the active principles of cantharides.

Cantharides is obtained from the insect Cantharis vesicatoria, or Spanish fly, which is found in the sonthern part of Europe, Germany, and Russia. The active prineiple is cantharidin. 
Give the actions and uses of heroin.

Heroin increases the inspiratory and expiratory force and lessens the number of the respiratory movements. It is a general motor depressant and anodyne and exerts a special sedative influence on the respiratory mucous membranes.

What preparations of copper are used in veterinary medicine and for what purposes?

Arsenite of copper is used in diarrhœa, dysentery, scours, and in relaxation of the muscular wall of the intestines, also in chorea in dogs.

Sulphate of copper used internally as an emetic; antidote for phosphorus, atony of the bowels, diarrhœa, and ascariasis. Externally, it is used as a stimulant and caustic, styptic in foot-rot, granular eyelids, conjunctivitis, etc.

Acetate of copper is an efficient vermifuge in ascariasis in the horse.

Give the properties of pepsin. How is pepsin prepared?

Pepsin occurs as a fine, white or yellowish-white amorphous powder, or pale yellowish, transparent scales or grains, free from offensive odor, having a mildly acidulous and slightly saline taste, followed by a slight bitter taste. It is soluble in about 100 parts water, but more soluble if the water is acidulated with hydrochloric acid. It is used in indigestion in young animals. It is prepared by macerating the mucous membrane of a pig's stomach for several days in a weak aqueous solution of hydrochloric acid. The pepsin is precipitated by adding sodium chloride, and is then removed, pressed, and dried.

Name the active principle of three of the following : aconite, belladonna, ergot, digitalis and opium.

Aconite: Aconitine.

Belladonna: Atropine.

Ergot: Ergotine.

Digitalis: Digitaline, digitoxin, digitalein, digitin, digitonin.

Opium: Morphine and codeine.

Discriminate between the physiological action of chloroform and that of ether. Mention the dangers in anæsthesia. How may these dangers be avoided?

Chloroform is more irritating to the mucous membranes and causes violent gastro-enteritis if administered undiluted; it is less stimulating and more depressing to the heart and circulation; for 
inhalation it requires more air, is less irritating to the respiratory membranes than ether, is more prompt in action, has a shorter preliminary stage of excitement, causes a more profound narcosis, and is less nauseating than ether.

(For dangers in anæsthesia, see p. 258.)

Give the name and the dose of a vermifuge for (a) the horse, (b) the cow, (c) the dog.

(a) Tartar emetic, 5i; (b) ferri sulplas, 5iss; (c) areca nut, 2 grains per pound of body weight.

Name some economic antiseptics for veterinary use, internal and external.

Internal: Phenol, creolin, sodium hyposulplite, salicylic acid.

External: Phenol, creolin, corrosive sublimate, potassium permanganate, and boric acid.

Define laxative, saline purgative, drastic purgative, cholagogue purgative. Give an example of each.

Laxative: A drug which slightly increases intestinal action chiefly by stimulating peristalsis. Example, olive oil.

Saline purgative: A drug which excites peristaltic action by increasing secretions and preventing reabsorption. Example, sodium sulphate.

Drastic purgative: A drug which greatly increases peristalsis and secretion, violently stimulates intestinal contractions, and produces copious, frequent, fluid discharges. Example, croton oil.

Cholagogue purgative: A drug which stimulates the flow of bile, causing green-colored stools. Example, podophyllum.

Mention five emetics and state the dose of each for the dog.

Mustard, 5i-ii; sodium chloride, 5i-iv; zine sulphate, gr. v-xx; apomorphine, gr. ${ }^{1} / \mathrm{s}^{-1 / 5}$ by the mouth, gr. ${ }^{1} /{ }_{20} 0^{1} / 10$ hypodermically; tartar emetic, gr. i-ii.

Mention five different kinds of medicine classified according to their general action and state what the general action is in each case.

Strychnine, stimulant.

Opium, depressant and nareotic.

Arsenic, tonic.

Ether, anæsthetic.

Belladonna, antispasmodic. 
Describe in detail the method by which you would administer a dose of Epsom salts to a cow.

Dissolve the salts in water and put the solution in a long-necked bottle. Raise the cow's head so that the nostrils are on a level with the eyes, but no higher. Gradually pour the solution into the mouth, watching carefully for faulty deglutition.

Give the name and mention the use of each of the following: $\mathrm{Fe}_{3} \mathrm{P}_{2} \mathrm{O}_{8}$, $\mathrm{FeSo}_{4}, \mathrm{Fe}_{2} \mathrm{Cl}_{6}$.

$\mathrm{Fe}_{3} \mathrm{P}_{2} \mathrm{O}_{8}$ (iron sulphate) is used in diseases of bone, diabetes, and nervous exhaustion.

$\mathrm{FeSO}_{4}$ (iron sulphate) is used locally as an astringent and internally as a hæmatinic and tonic in anæmia; also used as a vermifuge and in chronic catarrhal conditions.

$\mathrm{Fe}_{2} \mathrm{Cl}_{6}$ (iron chloride) is used as a tonic in anremia, astringent in chronic pharyngitis and laryngitis, and externally as a styptic.

What is the general action of iodine? State the dose (a) for the horse, (b) for the dog.

Alterative, resolvent, and expectorant, internally; stimulant, irritant, vesicant, and antiseptic, externally.

(a) 15 grains to 1 drachm, (b) $1 / 10$ to 1 grain.

Give the source, general action and the dose of podophyllum.

Obtained from the rhizome and roots of podophyllum pellatum Limne (mandrake or May apple).

General action is a cholagogue cathartic. Dose for horse, $\mathbf{j} \mathbf{i}-\mathrm{ii}$.

Name the different kinds of aloes.

Barbadoes and Socotrine aloes are official.

Cape aloes is non-official.

Name two coal-tar products used to reduce temperature.

Antipyrine and phenacetin.

Give the properties and the uses of lobelia.

Lobelia is obtained from the leaves and tops of Lobelia inflata. Its action depends on its alkaloid, lobeline. It has an acrid, nauseous taste and very umpleasant odor; it is expectorant, diaphoretic, purgative, emetic, antispasmodic, and narcotic. Lobelia is very useful in asthma in dogs, heaves in horses, and dry coughs in general.

Mention a motor excitant of (a) cardiac muscle, (b) intestinal muscle. State in each case the dose for the horse and for the cow.

(a) Digitaline: Horse, $1 / 4$ grain; cow, $1 / 2$ grain.

(b) Pilocarpine: Horse, 3 to 5 grains; cow, 5 to 10 grains. 


\section{State the dose and the general physiological action of cocaine.}

Dose for the horse, 5 to 10 grains. Not much used internally. In small doses it is a cerebral, cardiac, respiratory, and nervous stimulant and dinretic. It is a powerful local anæsthetic, and is used in this connection almost entirely.

Give the source, preparation and uses of adrenalin.

Obtained from the suprarenal glands of the sheep or ox. Prepared by freeing from fat, cleaning, drying, and powdering. Used to arrest hemorrhage from wounds, mucous membranes, and cavities of the body. It is used to render the field of operation bloodless in minor surgery; in inflammatory conditions of the eye and nose. Employed internally to check bleeding from the stomach, intestines, lungs, and uterus.

What is the dose of adrenalin for (a) the horse, (b) the dog.

In solution 1-1000, intravenously, (a) 3i-iv, (b) 10 to 60 minims.

\section{What is tar? Give the uses and the actions of tar.}

Tar is an empyreumatic oleoresin, obtained by the destructive distillation of the wood of varions species of pines, especially that of Pinus palustris.

It is an antiseptic, stimulant expectorant. Externally, antiseptic and parasiticide. Used internally in cough mixtures for chronic bronchitis and heaves. By inhalation (burning on hot coals) it is used for its antiseptic and stimulating effects in bronchitis, distemper, strangles, etc. Externally, it is used with sulphur and linseed oil in eczema and mange in horses and cattle. A common hoof dressing for diseases of the feet in horses.

\section{Name three acid tonics.}

Phosphoric acid, hydrochloric acid, and nitric acid.

Mention six diuretics and state the dose of each for (a) the horse, (b) the cow, (c) the dog.

1. Potassium nitrate, (a) $1 / 2$ ounce, (b) 1 ounce, (c) 10 grains.

2. Spirits nitrous cther, (a) 2 ounces, (b) 3 ounces, (c) $1 / 2$ drachm.

3. F. E. digitalis, (a) 1/2 drachm, (b) 1 drachm, (c) 1/2 drachm.

4. Potassium citrate, (a) 1/2 ounce, (b) 1 ounce, (c) 10 grains.

5. Potassium acetate, (a) $1 / 2$ ounce, (b) 1 onnee, (c) 10 grains.

6. Balsam copaiba, (a) 4 drachms, (b) 1 ounce, (c) $1 / 2$ drachm. 
What is cascara sagrada? Give its uses and state the dose for the dog.

Cascara sagrada is an active cathartic obtained from the bark of Rhamnus purshiana (California buckthorn). It is used in dogs in doses of 5 to 30 grains to overcome chronic constipation and as a stomachic.

What is mustard? State its uses in medicine.

Commercial mustard is a powder obtained from Sinapis alba semina and Sinapis nigra semina, which produce white and black mustard respectively. It is an irritant or counterirritant, rubefacient, vesicant, or suppurant, according to the manner in which it is used. Used internally as an emetic for dogs and pigs. Externally, it is used as a counterirritant in laryngitis, bronchitis, pneumonia, pleurisy, colic, enteritis, peritonitis, etc.

Name (a) a drug that contracts the pupil of the eye, (b) a drug that dilates the pupil of the eye.

(a) Physostigmine, (b) atropine.

What is the effect of massage? When is this treatment advisable?

Massage exerts many of the effects of counterirritants, and, moreover, assists in mechanically relieving overloaded lymph-vessels and veins. It increases metabolism, promotes absorption, stretches adhesions, and relieves pain.

It is advisable in case of cedematous swellings, as in the joints, legs, and udder (mastitis); also useful in overcoming muscular atrophy, following azoturia or from other causes, and to relieve pain in neuralgic attacks.

State the uses, dose and action of nitrate of potash in the treatment of the horse and cow.

Potassium nitrate is used in pneumonia, influenza, mastitis, pharyngitis, laryngitis, dropsical conditions, and many febrile conditions of the horse and cow. Externally, as a refrigerant. It possesses an alterative, febrifuge, diuretic, cardiac sedative, diaphoretic, and feebly laxative action.

Dose for the horse, $1 / 2$ ounce, and for the cow, I ounce.

State the actions, uses and dose of sugar of lead.

Plumbi acetas, acetate of lead, or sugar of lead, is astringent, hæmostatic, styptic, anodyne, local sedative, and desiccant. Used internally to check hemorrhage, diarrhoea, dysentery, and chronic catarrhal bronchitis; externally, to check superficial infiammation, tendonitis, arthritis, eczema, scratches, keratitis, etc. Dose, $1 \mathrm{drachm}$. 
State the physiologic effects, uses and dose of ether.

Ether is anodyne, antispasmodic, diaphoretic, anthelmintic; a cardiac, respiratory, and cerebral stimulant, an anæsthetic and a general diffusible stimnlant.

Used in flatulency, spasmodic colic, intestinal worms, and as a general anæsthetic in surgery. Small doses are stimulant to the heart and nervous system and are useful in collapse, exhaustion, etc.

\section{How are fluidextracts prepared?}

Prepared by extracting (percolation) a vegetable drug with alcohol, or alcohol and water, then concentrating the resulting solution by evaporation until one minim of the fluidextract represents one grain of the original drug.

Give the preparations of ammonia, stating the dose of each.

Aromatic spirits of ammonia, 1 ounce.

Ammonium carbonate, 2 drachms.

Ammonium chloride, 2 drachms.

Give the source of ergot and the dose for the horse and dog.

Obtained from the smut (a fungous growth) on rye. Dose of the fluidextract: For the horse, $1 / 2$ to 1 ounce; for the $\operatorname{dog}, 1 / 2$ to 1 drachm.

Give the treatment of purpura hemorrhagica.

Both general and local treatment are indicated.

General treatment includes the providing of good hygienic surroundings and proper diet; an easily digested and laxative diet is best. Most commonly used drugs are : potassium bichromate, potassium chlorate, digitalis, turpentine, camphor, salicylic acid, quinine sulphate, iron preparations, stryclinine, and ergot.

Local treatment is directed toward swellings which threaten suffocation, and the antiseptic handling of wounds. Tracheotomy may be necessary. The advocates of serum therapy claim excellent results with polyvalent vaccines, antistreptococic sera, etc.

Give the medicinal treatment of rachitis in the dog.

Calcium phosphate, or the syrup of calcium lactophosphate, is especially indicated. Iron in the form of the syrup of the iodide, and cod-liver oil are beneficial.

Define (a) diuretic, (b) diaphoretic, (c) hypnotic, (d) aphrodisiac. Give an example of each.

(a) A drug which increases the secretion of urine, potassium nitrate. 
(b) A drug which increases the secretion of sweat, pilocarpine.

(c) A drug which produces sleep, potassium bromide.

(d) A drug which stimulates sexual appetite and function, cannabis indica.

Name three preparations of zinc and state the uses of each.

1. Zine chloride is used as a caustic in chronic ulcers and fistulæ, and as an astringent in wounds; also used in conjunctivitis and keratitis.

2. Zinc sulphate is used as an emetic for dogs and pigs. Its principal use is externally as an astringent (white lotion).

3. Zinc oxide is used as a dusting powder for wounds and excoriated surfaces. Used in the form of ointment for its desiccating, astringent and protective properties. Occasionally given internally in chorea and diarrhœa.

Describe tannic acid. Give the source and the actions of tannic acid.

Tannic acid is a light, yellowish powder, odorless, or having a faint characteristic odor, and a strongly astringent taste. Soluble in 1 part of water. It is obtained from nut-gall. It is a powerful astringent, styptic, and coagulates albumin.

Compare the action of morphine on the horse with its action on the dog. State the dose in each case.

Morphine often causes cerebral and motor excitement, sweating; and dilatation of the pupil in the horse. In the dog it seldom causes excitement and sweating, but does cause contraction of the pupil, nausea, and cerebral depression.

Hypodermic dose for the horse, 3 to 5 grains; for the dog, $1 / 16$ to $1 / 4$ grain.

What is (a) a tonic, (b) an alterative? Give an example of each.

(a) A tonic is a drug which produces a permanent, though scarcely perceptible, excitement of all the vital functions. Example, iron.

(b) An alterative is a drug which alters the process of nutrition and excretion and restores the normal functions of an organ or of the system; e.g., iodide of potassium.

Give the properties, actions and uses of boric acid.

Occurs in transparent, white, scaly crystals; odorless, faintly bitter taste, permanent in the air, and feebly acid. Soluble in 26 parts cold water, 3 parts of warm water, and in 15 parts alcohol.

It is a non-volatile, unirritating antiseptic, deodorant, and astringent, and is used in all cases where an antiseptic is indicated. 
Particularly useful as a vaginal and uterine douche and to flush the bladder in cystitis. Used in conjunctivitis and keratitis, and is given internally in diarrhœa, dog distemper, and cystic catarrh.

What are expectorants? Name two classes of expectorants and give an example of each class.

Expectorants are agents which modify the secretion of the mucous membrane of the respiratory tract, and promote its expulsion.

Two classes: nauseating (ipeeac) and stimulating (ammonium chloride).

Name three vegetable bitters. State the dose for (a) the horse, (b) the dog.

Gentian, (a) $1 / 2$ to 1 ounce, (b) 5 to 30 grains.

Quassia (fluidextract), (a) 1 to 2 ounces, (b) $1 / 4$ to 1 drachm.

Cascarilla, (a) $1 / 2$ to 1 ounce, (b) 10 to 30 grains.

These bitters are useful in promoting the appetite in atonic indigestion, chronie gastro-intestinal catarrh, anæmia, debility, and during convaleseence from acute diseases, as influenza, pneumonia, etc. They also possess some vermicidal action, espeeially quassia, infusions of which are used as enemas for rectal worms.

They are contra-indicated in acute inflammatory conditions of the digestive tract, as they are mild irritants.

Name three vegetable cathartics. Explain briefly the action of each. State the dose for (a) the horse, (b) the cow, (c) the dog.

1. Aloes. Stimulates peristalsis and the flow of bile. (a) 8 to 10 drachms, (b) 1 to 2 ounces, (c) 20 to 60 grains.

2. Oleum lini. Acts mechanically by lubricating the bowels. (a) $1 / 2$ to 1 pint, (b) 1 to 2 pints, (c) $1 / 2$ to 2 ounces.

3. Oleum ricini. Aets by increasing secretions and mechanically. (a) 1 to 2 pints, (b) 2 to 3 pints, (c) $1 / 4$ to 2 ounces. Seldom used in horses and cows.

Name three drugs that reduce temperature and explain the action of each.

1. Acetanilide: prevents waste and heat production, by increasing radiation and by depressing the activity of the heat centres.

2. Aconite: causes vaseular dilatation, thus increases heat loss by radiation; retards circulation and thus lessens heat production.

3. Quinine: by its antiseptic properties lessens reflex excitability, diminishes oxidation, and depresses the heat centres. 
Describe the treatment of a case of eczema in the dog, explaining fully.

In the erythematous, papular, and vesicular stages zine oxide ointment or zinc oxide and starch dusting powder may be used. In the weeping stage 6 per cent. solution of nitrate of silver or some desiccant powder such as boric acid, lycopodium, or bismuth subgallate is used to check the weeping. Chronic eczema is treated with oil of cade, sulphuretted potash, Peruvian balsam, or creolin in suitable dilutions. Internally, Fowler's solution of arsenic is of great benefit.

In all forms dietetic measures are employed; a laxative diet and occasional doses of sodium sulphate help materially. Cleanliness is important, and in this connection bathing with a non-irritating soap and water is paramount.

\section{Describe a treatment for tapeworms in the dog.}

Fast the dog for 24 hours. Give oleoresin aspidium, 15 to 60 minims, and repeat this dose in three hours. Nine hours later give a purgative dose of castor oil. If the head of the trenia is not expelled, repeat the treatment three to five days later.

What are the actions and the uses of ipecac? State the dose for (a) the horse, (b) the dog.

A nauseating expectorant, emetic, diaphoretic, hæmostatic, sternutatory, stomachic. Used in bronchitis, dysentery, jaundice; also used to induce vomition in dogs and pigs. Dose (a) $1 / 2$ to 2 drachms, (b) as expectorant, $1 / 4$ to 2 grains; as an emetic, 5 to 30 grains.

Discuss venesection. What therapeutic measures may be used in place of venesection?

Venesection, or blood-letting, is employed chiefly to rapidly relieve conditions associated with a high arterial pressure and local engorgement of some organ. It reduces temperature and relieves congestion, dyspnœa, and cyanotic conditions. Venesection is employed in plethoric animals only, in acute pleurisy, pulmonary congestion, acute laminitis, urticaria, acute cerebritis or meningitis, parturient apoplexy in cows, etc. It is also employed in toxæmias to remove the blood and its contained poison. Four to six and often eight quarts are drawn from the horse.

Circulatory depressants as veratrum viride or aconite cause a general reduction of arterial tension and relieve local congestion. Cathartics, diuretics, and diaphoretics abstract fluid from the bloodvessels and thus lower blood-pressure. Notable among these are: arecoline, potassium nitrate, and pilocarpine. 
Compare the action of digitalis with the action of aconite on the heart.

Digitalis slows the heart and increases its force, whereas aconite slows the heart but reduces its force.

Give the action and the uses of chloroform. State the internal dose for the horse and for the dog.

Chloroform is irritant, antiseptic, parasiticide, carminative, antispasmodic, and analgesic. Locally in spray and internally by inhalation, an anæsthetic.

It is used in dystokia to prevent straining; in chronic diarrhœa, tæniasis, spasmodic cough and colic. Externally, in liniments as an anodyne and counterirritant in muscular rheumatism and sprains; by inhalation, a general anæsthetic in surgical operations.

Dose: For the horse, 1 to 2 drachms; for the dog, 2 to 20 minims.

Describe the treatment of a case of mange in the dog.

Bathe with warm water and green soap to remove all dirt and scabs. Clip the hair if it is long. Apply daily for four days a mixture composed of Peruvian balsam 15 parts, creolin 5 parts, and alcohol 80 parts. Bathe again and repeat the application until the skin appears normal.

Mention the chief uses of areca. Name two constituents of areca and give their therapeutic uses.

Areca is astringent in small doses, but large amounts induee catharsis; an effective vermicide for dogs, being destructive to both tape- and round-worms.

Two of its constituents are arecoline and red tannic acid. Arccoline is used as a quick-acting cathartic in colic, acute laminitis, etc.

What is the chief value of aspidium? State the dose for the dog. What precautions must be taken when administering aspidium?

Chief value is its tæniacide action. Dose of oleoresin aspidium (male fern) for the dog is 15 to 60 minims.

It should not be given with oils; they aid its absorption.

Give the actions and the uses of cannabis indica. State the dose for the horse and for the dog.

Cannabis indica is an antispasmodic, anodyuc, and narcotic; a cerebrospinal stimulant and aphrodisiac; increases mental and motor activity, stimulates vasomotor nerves, and depresses sensation.

It is used to relieve pain, spasm, and nervous irritability. Serviceable in colic, tetanus, chorea, and irritable cough. Dose of the 
fluidextract: For the horse, 4 to 6 drachms; for the dog, 2 to 10 minims.

Name three anthelmintics. State the dose of each for (a) the horse, (b) the dog.

Oleoresin aspidium, (a) 3 to 6 drachms, (b) 15 to 60 minims.

Oil of turpentine, (a) 2 to 4 ounces, (b) $1 / 2$ to 4 drachnns.

Santonin, (a) $1 / 2$ ounce, (b) 2 to 20 grains.

Define (a) rubefacient, (b) sedative, (c) mydriatic. Give an example of each.

(a) A drug that produces slight redness of the skin, as mustard.

(b) A drug that lessens functional activity of organs, lowers motility, and diminishes pain, thereby exerting a soothing influence on the whole system, as gelsemium.

(c) An agent which dilates the pupil, as atropine.

What is tartar emetic? Describe the actions and the uses of tartar emetic. State the dose for (a) the horse, (b) the dog.

Tartar emetic (antimonii et potassii tartras) is prepared by mixing cream of tartar, antimony trioxide, and water.

It is a systemic and local emetic, diaphoretic, cardiac, and arterial sedative, gastro-intestinal irritant, expectorant, and vermicide.

Used as an emetic in dogs; in the dry stage of bronchitis and for intestinal worms in horses.

Dose, (a) $1 / 2$ to 2 drachms, (b) emetic 1 to 4 grains, expectorant $1 / 10$ to $1 / 4$ grain.

What is pyoktanin? What are its uses?

"Pyoktanin" is the trade name for methylene blue, an aniline dye. It is antiseptic and astringent, and is used in strength of 1-1000 to 1-100 for ulcerated cornea, conjunctivitis, ulcers, and pus-secreting sores in general. Given internally, it is eliminated chiefly by the kidneys, rendering the urine blue and exerting an antiseptic action on the urinary tract, hence it is serviceable in nephritis, cystitis, urethritis, etc.

Give the source, the actions and the uses of balsam of Peru. State the dose for (a) the horse, (b) the dog.

Balsam of Peru is obtained in Central America from Toluifera pereirce. It is stimulant, antiseptic, and parasiticide externally; stomachic, carminative, and antiseptic internally. Used in chronic eczema, mange, lousiness, ringworm, ulcers, chronic bronchitis, pyelitis, and cystitis.

Dose, (a) 1 ounce, (b) 10 to 30 minims. 
Describe the treatment of a case of mammitis in the cow.

Give a laxative (Epsom salts, 1 to 2 pounds). After purging, give potassium nitrate in one-ounce doses, twice daily. Apply hat fomentations several times daily, and follow each application with a cooling, astringent lotion, such as Burrow's lotion, in the early stages. A suspensory bandage is ser viceable to hold packs and afford relief to the patient. Afterwards, emollients such as camphorated oil and cocoa butter are indicated. The udder should be milked thrice daily. If milking is painful, use a milk catheter and apply ointments containing belladonna extract. If abscesses threaten, apply poultices to hasten their development, open and use antiseptic measures. Gangrene calls for amputation at an early date.

\section{Describe permanganate of potassium. Give its actions and uses.}

Potassium permanganate is prepared by fusing together caustic potash, chlorate of potash, and oxide of manganese. It occurs as needle-shaped crystals of a deep-purple color, disagreeable, astringent taste, soluble in 16 parts of water.

It is a powerful oxidizing agent, hence it is antiseptic and deodorant. Full strength it is caustic; diluted it is astringent.

It is used to deodorize and disinfect foul-smelling wounds, nasal gleet, stomatitis, retained placenta, catarrhal endometritis (1-2000 solution). Used to sterilize hands and instruments. Internally, it is used in flatulency, puerperal fever, septicæmia, and is an antidote for morphine and opium poisoning.

Name four heart stimulants. Give their actions and state the dose of each for (a) the horse, (b) the dog.

1. F. E. digitalis: Slows the heart and increases its force. 1 drachm, (b) 1 to 3 minims.

2. Tr. strophanthus: Same action as digitalis. (a) 1 to 2 drachms, (b) 2 to 10 minims.

3. Spirits of glonoin: Accelerates the heart's action and lower's blood-pressure by dilating the arterioles. (a) $1 / 2$ to 1 drachm, (b) $1 / 2$, to 2 minims.

4. Spts. ammonia aromaticus: Stimulates the vasomotor centres. (a) $1 / 2$ to $1 \frac{1}{2}$ ounces, (b) 5 to 60 minims.

What is an emetic? To what animals should emetics be given? Give examples of emetics, stating the dose in each case.

An emetic is a drug which produces vomiting. Emetics are given to dogs, cats, and pigs. 
Ipecac: Dose for dogs, 5 to 30 grains; swine, 15 to 30 grains ; cats, 5 to 10 grains.

Tartar emetic: Dogs, 1 to 4 grains; swine, 4 to 10 grains; cats, 1 to 2 grains.

Apomorphine hydrochloride: Subcutaneously, dogs, $1 / 30$ to $1 / 10$ grain; swine, $1 / 15$ to $1 / 3$ grain.

What preparations of arsenic are most used in veterinary medicine? Arsenous acid, Fowler's solution, and Pearson's solution.

Discuss the actions and the uses of the salicylic acid preparations.

Actions: Antiseptic, antirheumatic, diaphoretic, cardiac depressant, antiferment, antipyretic, irritant, and astringent.

Used especially in rheumatism and muscular soreness; also used in influenza, strangles, purpura hemorrhagica, and flatulency. Salicylic acid is used externally as an antiseptic in wound dressing, but is too expensive. Salol is used in diarrhœa, cystitis, urethritis, etc.

Give the source, actions and uses of camphor. State the dose for (a) the horse, (b) the dog.

Camphor is obtained from the branches and chipped wood of Cinnamomum camphora, or camphor tree. The wood is exposed to the vapor of boiling water, and the volatilized camphor is condensed and refined by sublimation. It is also obtained by tapping the trees and collecting the exudate.

Actions: Antispasmodic or nerve stimulant, anodyne, antiseptic, diaphoretic, a stimulating expectorant, a cerebral excitant or narcotic, a gastro-intestinal irritant, a rubefacient, a carminative, a respiratory and cardiac stimulant.

Used in cough mixtures (electuaries) for acute bronchitis, pneumonia, antispasmodic in colic, "thumps," chorea, etc. Influenza and dog distemper are benefited by the use of camphor. Given subcutaneously in collapse and exhaustion. Applied externally in liniments and oils for anodyne effect, also to check milk secretion.

Dose, (a) 1 to 3 drachms, (b) 3 to 20 grains.

Give the uses of caffeine in veterinary medicine. State the actions and the dose of caffeine.

Used as an antidote to opium poisoning; dropsical swellings in dogs, heart stimulant in collapse.

Its actions are cerebral and cardiac stimulant and diuretic. It increases blood-pressure. Dose for horse, 7 to 15 grains. 
Give the actions and the uses of strophanthus. State the dose for (a) the horse, (b) the dog.

Strophanthus slows and strengthens the heart, same as digitalis; also has diuretic effect by increasing blood-supply to kidneys and by stimulating the secretory cells of the renal tubules. It is not cumulative like digitalis. Used in valvular disease of the heart, ascites, hydrothorax, chronic interstitial nephritis, and as a substitute for digitalis when the latter is losing its effect from repeated use.

Dose of the tincture, (a) 1 to 2 drachms, (b) 2 to 10 minims.

Give the actions and the uses of podophyllin. State the dose for (a) the horse, (b) the dog.

Cholagogue cathartic, slow and uncertain. Used in constipation associated with jaundice and hepatic disorders.

Dose, (a) 1 to 2 drachms, (b) 1 to 2 grains.

Give the composition and the therapeutic uses of Dover's powder.

Dover's powder, or pulvis ipecachuanhæ et opii, consists of ipecac 10 per cent., powdered opium 10 per cent., sugar of milk 80 per cent.

Used as a diaphoretic and expectorant in colds, early stages of acute bronchitis, and pneumonia.

Discuss pilocarpine with reference to its composition, actions and uses. State the dose.

Pilocarpus contains two alkaloids, pilocarpine and jaborine.

Pilocarpus is a diaphoretic, sialogogue, cardiac depressant, myotic, emetic, expectorant. The alkaloid pilocarpine is used to assist eserine in its action as a quick-acting cathartic in colic, etc. Pilocarpus is used as an expectorant in bronchitis, and as a diaphoretic to stop chills and abort inflammatory diseases such as pneumonia, lymphangitis, laminitis, azoturia, etc.

Dose of the fluidextract for the horse, $1 / 2$ to 1 ounce; pilocarpine, hypodermically, 2 to 5 grains.

Describe croton oil as to derivation, physical properties, action, uses, dose, toxic dose and antidote.

Croton oil is a fixed oil expressed from the seed of Croton tiglium. It is a pale-yellow, viscid liquid, having a slight fatty odor and an oily, burning taste. Externally it is a powerful irritant, and internally it is an intense gastro-intestinal irritant, causing drastic purgation. It is used as a counterirritant (cautiously). Internally it is given for its drastic purgative action to horses and cattle, in obstinate constipation when other remedies fail. 
Dose for the horse, 15 to 30 drops in olive or linseed oil. Toxic dose, over 30 drops, although smaller amounts may produce gastroenteritis with bloody stools and death. Should be given cautiously.

Antidote: Demulcents, opium, and stimulants.

\section{Define cataplasm, counterirritant, fomentation.}

A cataplasm, or poultice, is a preparation for the local application of heat and moisture.

A counterirritant is an irritant used against an existing irritation or inflammation by reflexly causing contraction of the vessels in the congested or inflamed underlying parts.

Fomentation refers to bathing parts with plain or medicated lot water, by means of sponge or cloth.

Define disinfectant, antiseptic, deodorant. Explain the difference in the action of these agents.

A disinfectant is an agent used to destroy microörganisms causing infectious and contagious diseases, fermentation, and putrefaction.

An antiseptic is an agent used to prevent the growth and development of the microörganisms causing fermentation, putrefaction, and disease, more especially the germs producing pus.

A deodorant is an agent which destroys or counteracts a foul odor.

Disinfectants, as a rule, are used on floors, buildings, grounds, etc. Antiseptics are less strongly germicidal and are used on or in the body. Most deodorants are disinfectants and antiseptics.

Give a method of treatment of hæmoglobinuria.

Administer a ten-drachm aloes ball, followed by linseed oil if necessary. Provide plenty of bedding in a warm stable and roll patient over every four hours. If restless and violent, give chloral hydrate by the mouth, or cannabis indica intravenously. Evacuate the bladder and rectum several times daily. Avoid slings unless patient can stand, in which case they are unnecessary. Enforced standing is liable to produce muscle rupture and intramuscular hemorrhage. Feed bran-mashes and supply plenty of fresh water.

Give a method of treatment of lymphangitis.

Give a ten-drachm aloes ball, followed by one pint of linseed oil if necessary to purge. Feed bran-mashes and give plenty of fresh water, but no liay. Cold-water irrigation is indicated during the first 24 hours, afterwards hot fomentations. Apply Burrow's lotion 
after irrigating. Give a diuretic such as potassium nitrate, one-half ounce three times daily. Exercise is beneficial as soon as the patient is able to walk. Treat any wounds antiseptically.

Give the treatment of constipation in a hog weighing about 200 pounds.

Mention three methods of administering the medicine.

Warm soap-water enemas will empty the posterior bowel and stimulate peristalsis. Add one ounce of sodium sulphate to the feed or drinking water or sprinkle upon the tongue. The stomachtube may be used to administer liquid medicines to prevent aspiration of same into the lungs. Three ounces of castor oil may be given in this way. Subeutaneous injections of eserine sulphate in $1 / 5$-grain doses may be useful in removing the impaction.

Give the actions and the uses of resorcin. State the dose (a) for the horse, (b) for the dog.

Resorein is antiseptic externally, and internally possesses a slight local anæsthetic effect. Used externally in skin diseases, psoriasis espeeially. Internally used in gastric fermentation and indigestion, seldom. Dose, (a) 1 to 2 drachms, (b) 2 to 4 grains:

What are the uses of protargol in veterinary medicine? Describe fully.

Protargol is a non-official preparation of silver (8.3 per cent. strength). It is used in acute catarrhal and purulent conjunctivitis in from one-half to ten per cent. aqueous solutions. It has an antiseptic and astringent action and is less irritating than silver nitrate solutions.

Discuss potassium nitrate as to derivation, actions and uses. State the dose for (a) the horse, (b) the cow, (c) the dog.

Potassium nitrate is found in the soils in certain regions and climates (India and Chile). It is made artificially by the putrefaction of animal or vegetable material in the presence of heat, moisture, oxygen, and alkaline or earthy bases.

It is alterative, febrifuge, diuretic, and feebly laxative in action. It is also eardiae depressant, mildly refrigerant and diaphoretic, as well as expectorant.

Used in febrile conditions such as pneumonia, influenza, laminitis, mastitis, etc.; dropsical swellings in general. Externally, it is used for its refrigerant action in local inflammatory conditions.

Dose, (a) 1/2. ounce, (b) 1 ounce, (e) 5 to 20 grains. 
Give the action and the uses of sodium bicarbonate. State the dose for (a) the horse, (b) the dog. Discuss fully.

Sodium bicarbonate is antacid, alterative, and mildly anodyne (locally). It increases the flow of the gastric juice and the fluidity of the bile, and dissolves mucus.

Used in catarrl of the gastro-intestinal tract, gastric indigestion associated with flatulency and acidity. Often combined with calomel for its synergistic action. Dissolves membranes in croupous enteritis. Externally, it is used in solution to allay itching in skin diseases, burns, etc., and as an injection for leucorrhoea and chronic rhinitis.

Dose, (a) 2 drachms to 2 ounces, (b) 10 grains to $1 / 2$ drachm.

What are(a) antiphlogistics, (b) antipyretics? Give an example of each.

(a) Remedies employed to prevent the progress of inflammatory processes, either local or general, as ichthyol.

(b) Agents which reduce high temperature in fever, as phenacetin.

How do acids and alkalies act on the secretions?

Acids lessen the secretion of the gastric juice and increase the secretion of saliva. Alkalies increase the flow of gastric juice and diminish the secretion of saliva.

\section{How are medicines classified?}

A physiological classification of medicines depends upon their action, whether general or local. Drugs having a general action may be subdivided into stimulants, sedatives, tonics, and alteratives. Drugs acting locally may be classified according to the part or parts upon which they act; for instance, cardiac stimulants, cerebral excitants, gastric sedatives, etc.

Name agents that prominently affect the alimentary canal or its contents.

Aloes, calomel, bismuth subnitrate, and opium.

Name agents that prominently affect the respiratory organs.

Lobelia, ipecac, belladonna, veratrum, and ether.

Name agents that prominently affect the follicular or glandular organs. Pilocarpine, belladonna, eserine, and arecoline.

Name agents that prominently affect the nervous system.

Strychnine, opium, chloral, and ether. 
Name agents that prominently affect the organs of reproduction. Ergot, cannabis indica, cantharides, and viburnum prunifolium.

Name agents whose actions are prominently chemical.

Acids, alkalies, and caustics.

Name agents whose actions are prominently mechnical.

Linseed oil, petrolatum, and acacia.

Describe saline infusion, three methods of introduction and three indications for its use.

Saline infusion refers to the introduction of a solution of sodium chloride into the animal's body to replace the normal blood-plasma which has been lost by hemorrhage or has been withdrawn for therapeutic purposes. The solution which is used consists of 0.6 of 1 per cent. sodium chloride in sterile distilled water.

The fluid may be introduced by (1) intravenous injection, (2) injections into subeutaneous tissues (hypodermoclysis), (3) rectal injection (enteroclysis), (4) intraperitoneal injection.

Saline infusions are used in cases of excessive purging where a large amount of fluid is lost; in severe hemorrhage; in certain bloodpoisoning diseases the patient may be bled to rid the body of some of the toxin present, and the fluidity of the blood restored by this method.

\section{Prescription Writing}

Write a prescription for a purgative.

Jan. 2, 1914.

For Mr. Brown's bay horse.

$\mathbf{R}$

Aloes barbadensis ............... $3 x$

Hydrargyri chloridi mitis . . . . . . . . . gr. $x x x$

Pulveris zingiberis $\ldots \ldots \ldots \ldots \ldots \ldots \ldots$ iss

Theriacæ .....................

M. et fiant bolus No. I.

Sig.-For doctor's use.

JoIns Doe, D.V.M.

Write a prescription for a chronic cough.

Jan. 2, 1914.

$\mathrm{R}$

For Mr. Jones's gray gelding.

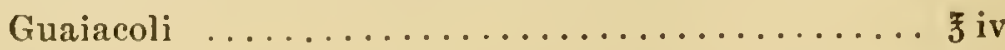

Olei lini ................... O ij

M. Sig.-Give one tablespoonful 3 or 4 times daily.

JoIIN DOE, D.V.M. 
Write a prescription for round worms in the dog. Give full directions.

For Miss Smith's dog. Jan. 2, 1914. $\mathrm{R}$

Santonini.

Hydrargyri chloridi mitis ........... āā grs. iv

Sodium bicarbonatis ............. $3 j$

M. et div. pulv. No. viij.

Sig.-Fast dog 24 hours, then give one powder every hour until all are given.

JoHN DOE, D.V.M.

Write a prescription for a two-weeks-old calf suffering from diarrhœa.

For Mr. Jones's calf. Jan. 2, 1914.

$\mathrm{R}$

Bismuthi subnitratis.

Cretæ præparatæ $\bar{a} \bar{a} 3$ iij

M. et $\mathrm{ft}$. capsulæ No. X.

Sig.-Give one capsule every two hours.

JoHN DoE, D.V.M.

Write a prescription for a horse whose temperature is $105^{\circ}$, respiration 30 and pulse 75 but strong, the medicine to be given in liquid form.

For Mr. Brown's bay mare.

Jan. 2, 1914.

$\mathrm{R}$

Quininæ sulphatis $\ldots \ldots \ldots \ldots \ldots \ldots \ldots \ldots \ldots \ldots \ldots$

(Ac. sulphurici, qs.)

Tr. digitalis $\ldots \ldots \ldots \ldots \ldots \ldots \ldots \ldots \ldots \ldots \ldots \ldots \ldots$

Alcoholis qs. ad. ................... $\mathrm{O}_{\mathrm{j}}$

II. et ft. sol.

Sig.-Give two tablespoonsful every six hours.

JOHN DOE, D.V.M.

Write a prescription for half an ounce of a 5 per cent. solution of cocaine.

$\mathrm{R}$

Cocaine hydrochloratis ............... grs. xij

Aquæ destillatæ .................. 3 iv

Prescribe for a dog suffering from mange.

For Mrs. Smith's dog.

Jan. 2, 1914.

$\mathrm{R}$

Balsami Peruviani .................

Creolini ....................... $3 \mathrm{vj}$

Alcoholis qs. ad. .................. o j

M. et $\mathrm{ft}$. sol.

Sig.-Apply a small amount on affected areas once daily for four days, then bathe and repeat.

John DoE, D.V.M. 
Write a prescription for a purgative for a goo-pound cow.

For Mr. Brown's cow.

Jan. 2, 1914. R

Magnesii sulphatis $\ldots \ldots \ldots \ldots \ldots \ldots \ldots \ldots \ldots \ldots \ldots \ldots \ldots \ldots$

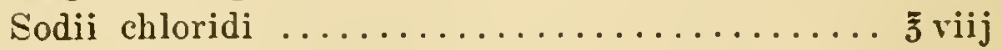

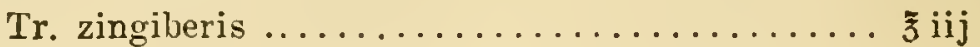

Aquæ .......................... $\mathrm{O}$ iv

M. Sig.-Give at one dose as a drench.

JoHs DoE, D.V.M.

Write a prescription for a horse suffering from spasmodic colic, giving the directions in plain English.

For Mr. Brown's bay mare. Jan. 2, 1914.

B

Spts. ammonii aromatici.

Olei terebinthinæ ..................

Olei lini .........................

M. Sig.-Give at one dose as a drench.

JoHy DoE, D.V.M.

Write a prescription for a tonic for (a) the horse, (b) the cow, (c) the dog.

(a) $\mathrm{R}$

Liquoris potassii arsenitis .............

Tincturæ gentianæ comp. .............

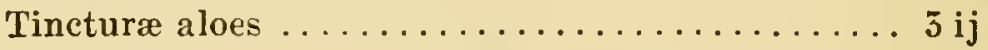

Fluidi extracti nucis vomica ..............

(b) $\mathrm{P}$

M. Sig.-Give one tablespoonful t. i. d. before meals.

Quininæ sulphatis $\ldots \ldots \ldots \ldots \ldots \ldots \ldots \ldots \ldots \ldots \ldots \ldots \ldots \ldots$

Ferri sulphatis . ................ ₹ ij

Pulveris gentinæ radicis $\ldots \ldots \ldots \ldots \ldots \ldots \ldots \ldots \bar{z} \mathrm{vj}$

Pulveris nucis vomice $\ldots \ldots \ldots \ldots \ldots \ldots \ldots \ldots \ldots$ iss

M. et ft. pulv. No. xij.

Sig.-Give one powder on tongue t. i. d.

(c) $\mathrm{R}$

Syrupi ferri, quininæ et strychninæ phosphati..... o iv

Sig.-One teaspoonful t. i. d. before feeding.

Write a prescription for a cough powder for an adult horse.

For Mr. Smith's brown stallion.

Jan. 2, 1914.

$\mathrm{P}_{k}$

Camphoræ.

Potassii chloratis ................ $\bar{a} \overline{\mathrm{a}} \mathrm{j}$

Pulveris glycyrrhizx $\ldots \ldots \ldots \ldots \ldots \ldots \ldots \ldots$ iv

Fl. ext. belladonnæ ................

Theriace qs.

Misce et fiant electuarium.

Sig.-One taljlespoonful on back teetl t. i. d.

Jolis DOE, D.V.M. 
Write a prescription for 15 powders for a tonic containing a simple bitter, a preparation of iron and a nerve tonic, to be given in powder form.

$\mathrm{R}$

For Mr. Black's gray mare. Jan. 2, 1914.

Pulveris gentianæ radicis $\ldots \ldots \ldots \ldots \ldots \ldots \ldots$ ziij

Ferri sulphatis ................... $\xi^{3} \mathrm{ij}$

Strychninie sulphatis .................. grs. xij

M. et ft. pulv. No. xv.

Sig.-Give one powder in feed t. i. d.

JOHN DoE, D.V.M.

Prescribe a treatment for chronic eczema in the dog. $\mathrm{R}$

For Miss Johnson's dog. Jan. 2, 1914.

Sulphuris sublimati $\ldots \ldots \ldots \ldots \ldots \ldots \ldots \ldots \ldots \ldots \ldots \ldots$

Olei cadini $\ldots \ldots \ldots \ldots \ldots \ldots \ldots \ldots \ldots \ldots \ldots \ldots \ldots \ldots \ldots$

Adipis lanæ hydrosi $\ldots \ldots \ldots \ldots \ldots \ldots \ldots \ldots \ldots \xi^{\ddagger} \mathrm{v}$

II. et $\mathrm{ft}$. unguentum.

Sig.-Thoroughly rub in and leave for 48 hours, then wash and repeat.

JoHN Doe, D.V.M.

Write a prescription for a blister, in the form of an ointment. Give directions for applying the blister and state what precautions should be taken after it is applied.

For Mr. Williams's bay mare. Jan. 3, 1914.

$\mathrm{R}$

Hydrargyri biniodidi.

Pulveris cantharis $\ldots \ldots \ldots \ldots \ldots \ldots \ldots \ldots$ a $\bar{a} \bar{z} \mathrm{ij}$

Adipis . . . . . . . . . . . . . .

M. et $\mathrm{ft}$. unguentum.

Sig.-Clip hair over spavin and apply ointment with considerable friction. Three days later, apply vaseline over blistered area. Tie horse short to prevent interference by biting parts.

JoHN DoE, D.V.M.

Write a prescription for a cathartic for a sheep.

For Mr. Black's sheep.

Jan. 3, 1914.

$\mathrm{R}$

Magnesii sulphatis $\ldots \ldots \ldots \ldots \ldots \ldots \ldots \ldots \ldots \ldots, \xi \mathbf{v j}$

Sodii chloridi $\ldots \ldots \ldots \ldots \ldots \ldots \ldots \ldots \ldots \ldots \ldots$ of $\mathrm{ij}$

Misce et ft. pulv. No. I.

Sig.-Dissolve powder in half pint of water and give as a drench. 
Prescribe treatment for a dog whose temperature is $105^{\circ}$, respiration 50 and pulse $\mathrm{I} 20$ but weak, the medicine to be given in liquid form.

For Miss Brown's dog.

Jan. 3, 1?14.

$\mathbf{P}_{k}$

Tincturæ aconiti .................. 3 iss

Spts. æetheris nitrosi .............. 3 iv

Aquæ qs. ad. ....................

Misce et $\mathrm{ft}$. sol.

Sig.-One teaspoonful every 3 hours.

JoHN DoE, D.V.M.

Write a prescription for scratches.

For Mr. Jennings's chestnut mare Jan. 3, 1914.

$\mathrm{R}$

Tincturæ benzoini compositæ.

Glycerini ................... $\overline{\mathrm{a}} \overline{\mathrm{a}} \overline{\mathrm{a}} \mathrm{z}$ viij

Misce et $\mathrm{ft}$. sol.

Sig.-Apply to affected leg t. i. d.

JoHN DoE, D.V.M.

Write a prescription for a liniment.

Liniment.

$\mathrm{B}_{\mathrm{k}}$

Olei terebinthinx.

Aquæ ammonii.

Camphoræ $\ldots \ldots \ldots \ldots \ldots \ldots \ldots \ldots \ldots \ldots \ldots \ldots \ldots \ldots \ldots \ldots$

Olei lini .........................

Misce.

Sig.-Shake well before using.

JoHN DoE, D.V.M.

Write a prescription for a cow suffering from actinomycosis.

For Mr. Black's cow.

Jan. 3, 1914.

$\mathrm{R}$

Potassii iodidi $\ldots \ldots \ldots \ldots \ldots \ldots \ldots \ldots \ldots \ldots \ldots \ldots \ldots \ldots \ldots$

Ft. pulv. No. xvi.

Sig.-One powder in drinking water once daily.

JoIr DoE, D.V.M.

Prescribe for a horse suffering from acute indigestion.

Jan. 3, 1914.

For Mr. White's bay gelding.

R

Sodii hyposulphitis $\ldots \ldots \ldots \ldots \ldots \ldots \ldots \ldots \ldots$ xiv

Ft. pulv. No. II.

Sig.-Dissolve one powder in a pint of water and give as a drench. Repeat in one hour if necessary. JoIn DOE, D.V.M. 
$\mathrm{R}$

Aloes barbadensis ................ $\tilde{z} \mathrm{x}$

Hydrargyri chloridi mitis . ........... gr. $\mathrm{xxr}$

Pulveris zingiberis ............... 3 iss

Theriacx $q s$.

M. et ft. bolus No. I.

Sig.-Give one hour after drenching.

JoHn DoE, D.V.M.

(Evacuation of stomach by means of stomach tube is best treatment.)

Write a prescription for ringworm.

For Miss Brown's dog.

Jan. 3, 1914.

$\mathrm{R}$

Balsami Peruviani $\ldots \ldots \ldots \ldots \ldots \ldots \ldots \ldots \ldots \ldots \ldots \ldots \ldots$

Adipis benzoinati $\ldots \ldots \ldots \ldots \ldots \ldots \ldots \ldots \ldots \ldots \ldots \ldots$

$M$. et ft. unguentum.

Sig.-Apply a small amount to affected parts once daily.

JoIN DOE, D.V.M.

Write a prescription for flatulent colic in the horse.

$\mathbf{R}$

For Mr. Smith's gray mare. Jan. 3, 1914.

Olei terebinthinæ $\ldots \ldots \ldots \ldots \ldots \ldots \ldots \ldots \ldots \ldots \ldots$

Spts. ammonii aromatici $\ldots \ldots \ldots \ldots \ldots \ldots \ldots \ldots \ldots, z_{j} \mathbf{j}$

Olei lini qs. ad. .................. O $\mathrm{ij}$

M. et ft. sol.

Sig.-Give at one time as a drench.

JoHN DOE, D.V.M.

Write a prescription containing at least three drugs for a case of chronic constipation in the dog.

$\mathrm{R}$

For John Smith's dog.

Jan. 3, 1914.

Resinæ jalapæ .................... gr. vj

Extracti belladonnæ.

Extracti physostigmatis ............. āā gr. iij

M. et $\mathrm{ft}$. pilulæ No. xxiv.

Sig.--Give one pill at night.

JoHN DOE, D.V.M.

Write a prescription for a case of chronic cough. Use at least three drugs.

$\mathrm{R}$

For Mr. Brown's bay mare.

Jan. 3, 1914.

Fl. ext. belladonnæ ................

Fl. ext. lobelix $\ldots \ldots \ldots \ldots \ldots \ldots \ldots \ldots \ldots$ zij

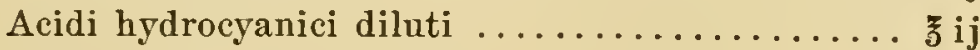

Syrupus simplicis qs. ad. .............. O ij

M.

Sig.-Give one ounce every 3 hours.

JoHx DoE, D.V.M. 


\section{TOXICOLOGY}

Mention three poisons, stating the antidote for each.

1. Corrosive sublimate: Antidote, egg-albumin.

2. Arsenic: Antidote, freshly prepared hydrated oxide of iron.

3. Phosphorus: Antidote, sulphate of copper.

What is the difference between antagonists and antidotes? Give an example of each.

Antagonists are agents which counteract each other in their physiological actions; for example, strychnine antagonizes the depressing effect of chloral hydrate on the heart. In this respect all antagonists are physiological antidotes.

Antidotes are agents which counteract the effects of a poison and render it harmless. They are classified as chemical, mechanical, and physiological, according to their method of action. Chemical antidotes change the composition of the drug, as starch given in poisoning by iodine forms the iodide of starch, which is insoluble and inert. Mechanical antidotes surround the poison and protect the tissues from its action, as egg-albumin protects the tissues from corrosive agents. Physiological antidotes antagonize the action of the poison.

Give the symptoms of arsenic poisoning. Name the best chemical antidote for arsenic poisoning.

Acute arsenical poisoning is shown by retching, vomiting, thirst, purging, bloody stools, colicky pains, gastro-enteritis, rapid weak heart, hæmaturia, subnormal temperature, general œdema, delirium, collapse, coma, and deatli.

Chronic form is characterized by indigestion, thirst, cachexia, enlargement of joints, chronic eczema, and necrosis of bones.

The best chemical antidote for arsenic poisoning is the freshlyprepared hydrated sesquioxide of iron.

Name an antidote for Paris green and tell how it should be administered.

Same as arsenic (the poisonous action of Paris green is due to the arsenic it contains). The antidote should be given every fifteen minutes in doses of 30 ounces to the horse, 40 ounces to eattle, and 1 ounce to dogs, until relief is obtained.

What precautions are necessary in the treatment of skin diseases of smaller animals?

Care should be taken to avoid poisonous drugs or any drugs in large amounts becausc of the danger of absorption and also the danger of the animal licking the medicine off. Coal-tar produets 
often nauseate and cause serious conditions in cats and dogs when applied externally.

\section{What are the symptoms of mercurial poisoning? Give an antidote to mercury.}

The symptoms of merenrialism (hydrargyrism) are: salivation, nlcerous stomatitis, loosening of teeth, blue line along the gums, gastro-enteritis, bloody diarrhœa, cough, nasal discharge, often blood-streaked, weakness, dizziness, trembling, delirium. Acute form lasts from 10 to 14 days. Chronic form may last several weeks or even months, and is accompanied by extreme wasting, chronic eczema, falling hair, and lameness, due to affections of the joints and muscles.

Best antidote is egg-albumin, which forms the insoluble albuminate of mercury. Sulphur or sulphur compounds aiso form insoluble compounds with mereury.

Give the symptoms of lead poisoning in the ox. Prescribe treatment for lead poisoning.

Lead poisoning, also called plumbism and saturnism, occurs in acute and chronic forms. The acute form is rarely seen, and is shown by intense gastro-enteritis, salivation, retching, paralysis, coma, and collapse. The chronic form is characterized by emaciation, dyspnœa, tonic spasms of the flexor muscles and paralysis of the extensors of the fore limbs, blue line along the gums, anæmia, cedema, colic, constipation, convulsions, and death.

Treatment in acute form consists of the administration of large doses of sulphate of magnesia or soda to form the insoluble sulphate of lead and to hasten the emptying of the alimentary tract. Give stimulants and apply warmth to the body.

Chronic form is treated with potassium iodide, after having emptied the alimentary tract. Sulphates may be given in small repeated doses to assist elimination and prevent reabsorption.

Describe the effects of a poisonous dose of aconite.

Muscular weakness, dimness of sight, mydriasis, a slow, small, and weak pulse, dyspnœa, retching, belching, vomiting, salivation, flatulence, and copious sweating. A peculiar clicking sound is often observed, due to the irritation of the throat and constant attempts at swallowing. The temperature falls two or three degrees. Death is preceded by muscular twitching, loss of strength, and falling, and is due to paralysis of the heart and respiration. 


\section{How should a case of poisoning by chloroform be treated?}

Give hypodermic injections of strychnine or spirits of glonoin to stimulate the heart. Inhalations of ammonia or anyl nitrite have the same object in view. Pull the tongue forward to allow free entrance of air. Attempt artificial respiration by rhythmically compressing the chest with the knees, feet, or hands. Allow plenty of fresh air.

\section{How should a case of poisoning by chloral hydrate be treated?}

Use stomach-tube, or emetics in vomiting animals. Give large doses of strychnine and atropine subcutaneously. Enemas of strong, hot coffee and alcoliol are useful. Arouse patient by shouting and whipping. Inhalations of ammonia or amyl nitrite, as in chloroform poisoning, to stimulate the heart.

\section{Give the symptoms of morphine poisoning and state the antidotes.}

In the horse, toxic doses of morphine cause considerable cerebral excitement at first, but later depression, loss of reflexes, coma, cold sweat, slow heart, dilatation of the pupil (not contracted, "pinpoint," as in other animals and man), lessened urinary secretion, and death by suspension of respiration.

Antidotes: Potassium permanganate by the mouth, atropine, and strychnine subcutaneously, artificial respiration ; arouse patient by slapping smartly. Emeties should be given vomiting animals.

\section{Give the symptoms and treatment of atropine poisoning.}

Rapid pulse and respiration, elevated temperature, dryness of mouth, mydriasis, excitement, delirium, muscular twitchings, frequent urination. Later the temperature falls, the urine is retained, convulsions occur, the respiration becomes weak, slow, and irregular, death occurs from eardiac and respiratory failure. A few drops of the urine of the poisoned animal placed in the eye of a healthy animal causes mydriasis and aids in diagnosis.

Treatment: Stomach-pump, emeties, cardiac stimulants. Opium and pilocarpine oppose its physiological action. Tannic aeid should be administered as the chemical antidote. Apply external heat in collapse, and give strychnine if respiration fails.

Give a treatment of strychnine poisoning in the dog.

Apomorphine hydrochlorate, $1 / 20$ to $1 / 5$ grain hypodermically, is the best and surest emetic.

Give potassium bromide 2 to 4 drachms, or chloral hydrate 20 to 40 grains, to control spasms. Tamnic acid is a chemical antidote. 


\section{What is serum therapy?}

\section{Serum Therapy}

Serum therapy is a method of producing passive immunity. It consists in the administration, for preventative or curative purposes, of a blood-serum containing antitoxin (antibodies) or some other substance which is antagonistic to the bacterium or toxin which canses the disease in question.

Define immunity. What is meant by natural and acquired immunity?

Immunity is a state in which an animal's body is resistant or insusceptible to a certain disease. This state may be natural or acquired.

Natural immunity is that enjoyed by the animal from birth, and not a result of any changes during its lifetime. If the immunity is the result of changes during the animal's lifetime, it is spoken of as an acquired immunity.

Acquired immunity may be active,- that is, obtained by an individual by having suffered from an attack of a pathogenic microorganism and having overcome it; or it may be passive,- - that is, a result of the injection of the serum of an animal which has acquired an active immunity against the organism in question.

\section{In what infectious diseases is immunization of value?}

In rabies, tetanus, black-quarter, anthrax, and hog cholera, immunization is unquestionably of great value. Considerable experimental work has been done on immunization in the following diseases: hemorrhagic septicæmia, influenza, dog distemper, Texas fever, infectious abortion, glanders, tuberculosis, and foot-and-mouth disease, but the results have been far from uniform and their valne is still sub judice.

\section{Discuss the antitoxin treatment.}

If gradually increasing doses of the toxins of a pathogenic microorganism are injected into an animal, the animal not only acquires an immunity to the particular toxin, but its blood-serum will antagonize or neutralize the latter if they are brought together. If some of the serum of this immune animal is injected into an animal which is suffering from the disease caused by this toxin, it will antagonize or render inert some or all of the toxin and thus aid in the recovery of the sick animal. The substance contained in the immune sera which combines with and neutralizes the toxin is called an antitoxin.

The treatment of an infectious disease with a specific antiserum is called serum therapy. Diseases treated in this manner are 
tetanus and diphtheria. The antitoxin is also used as a prophylactic agent.

\section{Define amboceptors, lysins, complement.}

Amboceptors are antibodies in serum which possess an affinity for both the complement and the cell to be destroyed (a bacterium or a red blood-corpuscle), and which serves to unite the two, so that lysis or destruction of the cell may be effected. It is also called the immune body.

Lysins are specific antibodies, formed in the blood-serum during bacterial infection, which are destructive to the bacteria of the specific serum. They are probably identical with agglutinins.

Complement is a thermolabile (altered or destroyed by heat) substance in normal serum which is destructive to bacteria and other cells with which it is brought in contact by means of the amboceptor.

(For further details, see Diagnosis of Glanders by Complementfixation Test, p. 167.)

\section{Discuss the serum therapy of hog cholera.}

It has been found that the serum from a hog which has reeovered from an attack of hog cholera possesses immunizing and eurative properties for susceptible hogs. If the hog which has recovered is inoculated with the virus of the disease, its immunizing and curative properties are greatly angmented, although the hog suffers no illness. This is called hyperimmunization. The hyperimmunized hog is bled, the blood defibrinated, and a small amount of a preservative (phenol) is added to insure its keeping qualities.

The use of serum as a curative agent is only of value in the early stages of the disease. The serum is injected subentaneously on the inner side of the thigh in a dose of approximately 40 c.c. per 100 pounds of body weight. In recently infected or non-infected hogs a passive immunity is secured which lasts only a few weeks, but is sufficient to protect against the effects of a transient exposure, as at fairs, travelling, ete.

\section{How is hog cholera serum obtained?}

(See answer to preceding question.)

Where serum is produced on a large scale, instead of utilizing hogs which have survived a natural infection, susceptible logss are used. These are first given an immunizing dose of the serum as a protective measure and later injected with gradually-inereasing doses of virus until they become lyyperimmune (proven by test on hogs). They are bled from the tails at intervals of ten days so long as their serum is potent. They may then be injected with virus and 
brought to the hyperimmune stage again, and so on until, from repeated amputations, their tails become too short for subsequent bleedings.

\section{What is meant by the simultaneous method of immunization against hog cholera?}

The simultaneous method consists of the inoculation of a hog with a protective dose of immune serum and 2 or 3 c.c. of virulent blood at the same time. This method confers an immunity which will last six months and possibly one year. But it is not a practicable method for inexperienced therapeutists, because of the danger of the virus being scattered.

\section{How is tetanus antitoxin obtained? Discuss its use.}

Antitetanic serum is obtained from a horse which has been repeatedly inoculated with gradually-increasing amounts of tetanus toxin, obtained from artificial cultures. Extremely minute doses of the toxin are given at first, but at the end of several months a pint or more produces no ill-effect. When, by test on guinea-pigs, the serum of the horse is of the desired potency, the animal is bled from the jugular at intervals; the serum is drawn off and aseptically preserved.

The antitoxin is measured in units; a unit representing the amount necessary to neutralize a given amount of toxin, as proven on guinea-pigs.

Tetanus antitoxin is a valuable prophylactic or immunizing agent. It should be administered in cases of infected wounds whenever there is a suspicion that tetanus bacilli may be present. If given before the symptoms of tetanus appear, 750 units seem to be sufficient to immunize. This immunity lasts but a few weeks. There is a great diversity of opinion regarding its value as a curative agent. If it is of any value in this connection, it should be given early and in large doses. There is no definite dosage; as much as 5000 , and even 30,000 , units have been given with equally varying results.

\section{VACCINE THERAPY}

\section{What is vaccine therapy?}

Vaccine therapy is a method of producing an active immunity by the injection of bacteria, or the products of bacterial growth, directly into the patient. The virulence of the bacteria is modified by heat or otherwise. As a result of their injection, antitoxins are produced in the body. This is in contradistinction to serum therapy, which produces a passive immunity. (See above.) 
What is (a) a vaccine, (b) a bacterin.

These two terms are being used synonymously of late, although a distinction was formerly, and should now be, made.

$A$ vaccine is the modified and attenuated virus of a disease, incapable of producing a severe infection, but affording protection against the action of the unmodified virus. The term is also applied to emulsions of dead bacteria. Vaccines are designed to antagonize bacterial infection, either in advance of a disease (prophylactic, as in black-leg), or after the advent of the disease (therapeutic, as in the use of vaccines in wound infections).

A bacterin is an emulsion of dead cultures of specific bacteria in water or a saline solution, administered hypodermically to produce an active immunity against the particular bacteria.

\section{What is meant by "autogenous vaccine"?}

A vaccine derived from bacteria taken from the patient infected and intended to be injected into the same individual. It is far superior to the "stock vaccines," which are suspensions of bacteria derived from any convenient source and are intended to be used in the treatment of infections due to the same organism in any individual.

\section{Discuss bacterin therapy.}

Same as vaccine therapy, described above. 


\section{SANITARY SCIENCE-MEAT AND MILK HYGIENE}

Define sanitary science.

Sanitary science deals with all measures designed to promote health and prevent disease.

How can sanitary science be utilized by the veterinarian?

In preventing and controlling outbreaks of infectious diseases by a systematic inspection of buildings and surroundings with regard to ventilation, drainage, construction, etc.

Describe a proper method of drainage for a stable.

Stalls should not slope more than one-half inch toward their centre, and a similar slope from before backward is sufficient. A shallow gutter running back of the stalls should be conducted outside and into a trap which empties into the sewer. All drains within the stable should be on the surface to permit of ready access.

What is the objection to building a stable (a) on a damp northern slope, (b) in a deep, narrow, east and west slope, (c) on a springy, hill-foot or on other wet impervious soil?

(a) There would be insufficient sunlight to evaporate the objectionable moisture.

(b) There would be insufficient sunlight and a tendency to dampness.

(c) It would be difficult to secure proper drainage, and the dampness would be detrimental to health.

Mention some of the ways by which impure water may be purified or made wholesome.

Sand filtration, sedimentation, and boiling.

What precautions should be taken in grain feeding as regards watering in connection with the grain?

Give the water before feeding grain; otherwise, the stomach being comparatively small, considerable grain will be washed through into the intestines in an undigested condition. 
Define proximate principle. Name three proximate principles and mention a common food substance in which each is respectively contained.

A proximate principle is a substance which is capable of being decomposed into simpler principles or parts, as distinguished from ultimate principles which are not capable of further division. For example, $\mathrm{NaCl}$ is a proximate principle and ean be decomposed into $\mathrm{Na}$ and $\mathrm{Cl}$, which, as ultimate principles, cannot be further subdivided.

Starch, protein, and fat are proximate principles which may be decomposed into $\mathrm{C}, \mathrm{O}, \mathrm{H}$, etc. A common food substance which contains these principles is oats.

\section{Air and Ventillation}

What is the average composition of (a) atmospheric air, (b) air that has been breathed?

(a) Oxygen, 20.96; nitrogen, 79.01; carbon dioxide, 0.03 .

(b) Oxygen, 16.02 ; nitrogen, 79.01 ; carbon dioxide, 4.38 .

At what stage of chemical impurity does rebreathed air cause oppression and at what stage does it become irrespirable?

Air becomes oppressive when it contains only 11 per cent. of oxygen, and irrespirable when the oxygen falls to 3 per cent.

State the minimum amount of air space that should be provided in a stable (a) for each horse, (b) for each cow.

This all depends on how often the air of the space is changed. A horse requires 15,000 eubic feet per hour, and cattle slightly less. The average air space given to a horse is 1500 cubic feet, and to a cow 1200 cubic feet. In the case of the horse, the air would need to be changed ten times per hour, and for the cow about twelve times.

Does air space greatly in excess of the required amount render the ventilation of a stable unnecessary? Give reason for your answer.

No. The larger the air space, the smaller number of times the air of that space needs to be changed; but once the impurities are present, they remain and will only be removed by supplying fresh air.

\section{Describe the King system of ventilation.}

Fresh air enters through openings in the outside wall, three or four feet below the ceiling, passes up between the ontside and the 
inside wall and into the building just under the ceiling. These intake flues should be 4 inches in diameter and 6 feet apart on all four sides of the building. Impure air passes out through a large ventilating shaft, situated in the middle of the building, and extending from one foot above the floor upward through the ceiling. One such shaft, two feet square, is sufficient for 30 cows. Its top is usually provided with an elbow-like hood which keeps out rain and swings with the wind. The wind creates a suction which favors the circulation of air upward through this out-take flue. Near the ceiling there is an opening in the shaft provided with a door, which is only opened when the temperature of the interior of the building is too high.

\section{INFECTIOUS DISEASES}

What hygienic measures should be employed to check the spread of infectious abortion in cattle?

Segregation of infected animals. Thoroughly disinfect stables. Wash the external genitals of all pregnant animals daily with a non-irritating antiseptic, and irrigate their vaginas with same. Burn all litter, membranes, and expelled fotuses. Cleanse the penis and sheath of each male which has covered an infected female by irrigating same with a 1 per cent. soda solution, or $1 / 2$ per cent. lysol solution.

Describe the hygienic and sanitary precautions that should be observed in a case of glanders occurring in a large livery in a city.

Apply complement-fixation, agglutination, and ophthalmic tests. Destroy all reactors. Burn all litter and thoroughly disinfect the stable, harness, utensils, etc. The stable should be quarantined until tests have been completed. Any animals failing to react should be kept under suspicion until subsequent tests, applied one month later, prove them to be free from the disease.

Outline a plan for thoroughly disinfecting stable premises that have become infected by the presence of contagious diseases.

Cleanse the stable thoroughly by removing manure and piles of fodder, sweeping the ceilings, walls, and floors, removal of rotten woodwork and loose boards, especially of the floor, removal of dried accumulations about mangers, floors, and drains; burn all the removed material; scrub the mangers, feed-boxes, stalls, partitions, harnesses, utensils, etc., with hot water and strong soap, lye, or washing soda. After cleansing, apply a chemical disinfectant with a brush or, preferably, with a spray pump, which will carry it into every crevice and over every surface. Bichloride of mercury, 
1-1000, is the best disinfeetant. Gutters and drains may be flushed with a saturated solution of sulphate of iron. Dirt floors and barnyards containing infected material should be excavated to a depth of six inches and filled in with new earth. Large fields may be burned over.

Describe in detail your procedure in the treatment of a herd of cattle, a part of which you have discovered to be infected with tuberculosis.

Separate the non-infected from the infected and test them every three months for the first year and thereafter every six months. All reacting or suspicious eases should be promptly removed. Reactors which show elinical symptoms should be destroyed. Others may be kept under the Bang system. Thoroughly disinfect the infeeted premises.

How should all outbreaks of contagious diseases be handled?

By reporting promptly to the local or State authorities handling such affairs. By enforcement of proper quarantine and attention to disinfection.

Describe an effective method of disinfecting a ship that has contained cattle affected with anthrax.

Send the boat out to sea not less than forty miles from land and, beginning at the lowest occupied deck, have all excreta, fodder, fittings, etc., brought up and thrown overboard. Then turn live steam under pressure against every portion of the ship's interior, touching every crevice, nook, and corner. The bilge should be pumped out and disinfected with bichloride of mercury or earbolic acid.

Mention a bacterium that is very resistant to the action of disinfectants. Give a reason for your answer.

Bacterium of anthrax, because it forms spores which are very resistant to the strongest disinfectants. These spores under favorable conditions devclop into virulent bacteria.

Mention five ways in which pathogenic bacteria may be disseminated from diseased to healthy animals.

By common watering and fecding troughs, by attendants, by licking one another, by flies, and by an intermediate host (Texasfever tick).

Mention some of the contributing causes of contagious and zymotic diseases.

Low-resisting powers due to previous disease, fatigne, or lack of nourishment; overcrowding, poor ventilation, wounds. 
State the sanitary police measures necessary to prevent the spread of dourine.

All affected horses should be excluded from brceding again. Castration would be advisable as a safeguard. Stallions showing no symptoms but having covered mares affected with the disease should be similarly dealt with.

Describe the hygienic measures needful for the prevention of cerebrospinal meningitis.

Especial attention should be given to the food and water supply. In case of an outbreak of the disease in a stabie, the food, water, and pasture should be changed immediately. Disinfect stalls, mangers, etc., which have been used by affected animals.

Mention the measures of sanitary police that would be needed if lung plague (contagious pleuropneumonia) were landed on our shores.

Establish quarantine over the infected area. Kill all infected animals and destroy carcasses by burning. Prevent any movements of cattle into or out of the quarantined district for at least three months after the last case appears. Destroy, by burning or plowing under, all contaminated litter, and thoroughly disinfect premises, as well as all boats, cars, etc., used in transporting infected animals.

Describe your method of procedure in case of an outbreak of anthrax in a herd of cattle.

Isolate the sick animals. Kill badly diseased ones, but avoid the shedding of blood. Destroy carcasses by burning, or burying in quicklime at least five feet under the ground. The grave should be in porous soil, far from any pond or river, and it should be fenced off from pastures. Disinfect, by burning, all litter, fodder, manure, urine, etc., and flame or drench with strong formalin solution all stalls, and utensils used about the animals. Keep the remainder of the herd immunized by vaccinating annually until the infection is known to have disappeared from the premises. The sale of meat, milk, hides, or other products from infected animals should be prohibited.

\section{Prophylaxis}

Describe the precautions that should be taken by the national and State governments to prevent the introduction of foot-andmouth disease into this country.

A certificate, declaring the non-exposure of each cloven-hoofed animal imported and a thorongh disinfection of all litter, fodder, 
halters, cars, boats, etc., as well as the clothing and the surface of the bodies of all attendants and animals, should be required in every case of an importation from an infected country. Such animals should be held in quarantine for two weeks.

Describe the Bang method of eradicating tuberculosis from a herd of cattle.

Slanghter all clinical cases. Apply the tuberculin test to the remainder of the herd. Those reacting to the test but showing no clinical symptoms are removed to a separate stable. (Perhaps it would be better to remove the healthy animals to new or non-infected quarters and leave the reactors in the old stable, which, in either case, should be thoroughly disinfected.) Promptly remove the offspring of reactors from the mother and feed them on milk from healthy cows or on sterilized milk of the mother. The non-reacting animals and all offspring should be tuberculin tested every six months and any reacting animals promptly removed and their stalls disinfected. Every avenue of infection of the sound herd must be guarded. Thus a healthy herd may be built up from a diseased one.

Define disinfection. Name two natural and five chemical disinfectants.

Disinfection is the act of destroying microörganisms in or on any substance, or inhibiting their growth and vital activity.

Sunlight and heat are two natural disinfectants.

Phenol, corrosive sublimate, chloride of lime, formaldehyde, and oxalic acid are chemical disinfectants.

What precautions should be taken in feeding a horse that is kept from work two or three days on account of lameness or injury? Why? If such precautions are not observed, what is likely to occur?

The amount of food should be greatly lessened and a laxative diet would be advisable, because the vital activities are lessened and less nourishment is required. Azoturia may follow rest and heavy feeding in plethoric horses.

What factors do you consider important in the prevention of contagious and zymotic diseases?

Isolation, quarantine, disinfeetion, and protective inoculations.

Name five prophylactic serums or vaccines and the disease against which each is employed.

Hog-cholera serum protects against hog cholera.

Tetanus antitoxin protects against tetanus. 
Black-leg vaccine protects against black-leg.

Anthrax vaccine protects against anthrax.

Rabies vaccine protects against rabies.

What precautions are necessary for public safety in an outbreak of rabies?

Rigid quarantine for 100 days, or longer if necessary. Muzzle all dogs over a wide area. All stray and unmuzzled dogs should be shot. All dogs and eats that have been bitten by a rabid animal should be destroyed or shut up in iron cages for six months under veterinary supervision.

\section{Milk and Meat Hygiene}

Mention the diseases of animals that render their flesh unfit for human food.

Unconditional.

Extreme emaciation.

Exhaustion.

Enteritis.

Peritonitis.

Acute nephritis.

Pneumonia.

Pleurisy.

Leukæmia.

Pseudotuberculosis.

Anthrax.

Rabies.

Glanders.

Variola.

Tetanus.

Malignant œedema.

Septicæmia.

Pyæmia.

Black-leg.

Hemorrhagic septicæmia.

Uræmia.

Parturient paresis.

Febrile diseases.
Conditional.

Pregnancy.

Local inflammatory changes.

Tumors.

Hepatitis.

Chronic nephritis.

Mammitis.

Myocarditis.

Endocarditis.

Pericarditis.

Anæmia.

Rachitis.

Osteomalacia.

Parasitic diseases.

Tuberculosis.

Actinomycosis.

Botryomycosis.

Swine erysipelas.

Hog cholera.

Foot-and-mouth disease.

Name ten local disease conditions that do not call for rejection of the meat for human food.

Localized tuberculosis, actinomycosis and botryomycosis; pericarditis, benign tumors, chronic nephritis, dermatitis, mange, hemorrhage, thrombosis.

How is it determined at slaughter whether a tubercular cow is fit or unfit for human consumption?

B. A.I. Order No. 150, Section 13, Paragraph 2, Rule A, reads as follows: "The entire carcass shall be condemned- 
"(a) When there is a tuberculous or other eachexia, as shown by anæmia and emaciation.

"(b) When the lesions of tubereulosis are generalized.

"(c) When the lesions of tuberculosis are found in the muscles or intermusenlar tissue or bones or joints, or in the body lymphatic glands as a result of draining the museles, bones, or joints.

"(d) When the lesions are extensive in one or both body cavities.

"(e) When the lesions are multiple, acute, and actively progressive. (Evidence of active progress consists in signs of acute inflammation about the lesions, liquefaction necrosis, or the presence of young tubercles.)

"Rule B: An organ or a part of a eareass shall be condemned--

"(a) When it contains lesions of tubereulosis.

"(b) When the lesion is immediately adjacent to the flesh, as is the case of tuberculosis of the parietal pleura or peritoneum, not only the membrane or part affected but also the adjacent thoracic or abdominal wall is to be condemned.

"(e) When it has been contaminated by tuberculous material, through contact with the floor, a soiled knife, or otherwise.

"(d) All heads showing lesions of tubereulosis shall be condemned.

"(e) An organ shall be condemned when the corresponding lymplatic gland is tubereulous.

"Rule C: The earcass, if the tubereulous lesions are limited to a single or several parts or organs of the body (except as noted in Rule A), without evidence of reeent invasion of tuberele bacilli into the systemic circulation, shall be passed after the parts containing the localized lesions are removed and condemned in accordance with Rule B.

"Rule D: Careasses which reveal lesions more numerous than those described for carcasses to be passed (Rule C), but not so severe as the lesions described for earcasses to be condemned (Rule A), may be rendered into lard or tallow if the distribution of the lesions is such that all parts containing tubereulous lesions ean be removed. Such eareasses shall be cooked by steam at a temperature not lower than $220^{\circ}$ Fahrenheit for not less than four hours."

What points determine whether a case of tuberculosis is generalized or local?

The term "localized tuberculosis" is applied to cases where there is an infection of a single part of the body with the corresponding lymph-glands, or the infection of several parts of the body withont the eoneurrence of the large eireulatory system. 
"Generalized tuberculosis" is a term applied in cases where a part of the body is affected to which the tubercle bacilli can be taken by the arterial blood only (e.g., spleen, kidneys, suprarenal glands, testicles, ovaries, udder, bones, muscle, body lymph-glands, central nervous system, eyes, etc.). The presence of numerous foci in the lungs positively indicates infection of the blood and therefore is quite indicative of generalized tuberculosis.

What is "bob veal "? How is it detected and is it deleterious to human health?

"Bob veal" is immature veal (veal from calves under three weeks of age). The meat is watery, tender, easily torn, and grayishred in color; shows only slight muscular development, especially in the region of the upper shank. The tissue, which later develops as the fat capsule of the kidneys, is odematous, dirty yellow, or grayishred, and tough. The lumen of the navel vein is wide open and filled with liquid blood. A chemical test will show an abnormal amount of glycogen present in the muscles.

It is generally considered that calves under three weeks of age are unfit for human food, and our Federal regulations provide for their condemnation. Yet, in Germany, calves only three to four days old are frequently slaughtered for food, are considered a delicacy, and apparently are not detrimental to the health of the consumers.

Name ten inflammatory and five non-inflammatory diseases.

Inflammatory: Pneumonia, pleurisy, rhinitis, enteritis, gastritis, peritonitis, hepatitis, nephritis, arthritis, and pericarditis.

Non-inflammatory: Pernicious anæmia, leukæmia, chronic hydrocephalus, nasal polypi, tetanus.

Give the life-cycle of cystercus cellulosæ. What disease does it cause? What disposition should be made of a carcass affected with this parasite?

The mature form of this parasite is the Tænia solium, a tapeworm of man. The ova are passed in the feces and become disseminated through the water or food and are taken in by the intermediate host, the hog In the hog's stomach the ovum hatches into a six-hooked embryo, which finds its way through the stomach and intestinal walls and enters the muscular tissues. There it develops into the larval stage, becomes encysted, and either perishes in time or is eaten by man. If the cyst containing the living larva is eaten by man, the larva becomes liberated and attaches itself, by means of its hooklets, to the intestinal wall and develops into the mature form. 
Pork which contains these cysts is called "measly pork," and if badly affected should be condemned. Careasses showing slight lesions may be passed for lard.

\section{Where and how would you look for "measly pork"?}

With the naked eye the cysts may be seen in the intermuscular tissue of the heart, tongue, larynx, abdomen, diaphragm, Hanks. jaws, neck, sternum, intercostal region, and adductors of the hind legs. In case of doubt, a microscopic examination will help in ascertaining the presence or absence of the larva with its hooked scolex.

\section{Explain the necessity of municipal and State meat inspection.}

To prevent the spread of diseases communicable from animals to man and to safeguard the public from unclean and unlealthy meat. A considerable amount of our local meat supply is slaughtered without inspection. One or more properly-inspected municipal abattoirs should be conducted in or near every city, where all slaughtering of animals should be performed. State meat inspectors should look after the smaller localities.

Mention the principal diseases of domestic animals that are communicable to man.

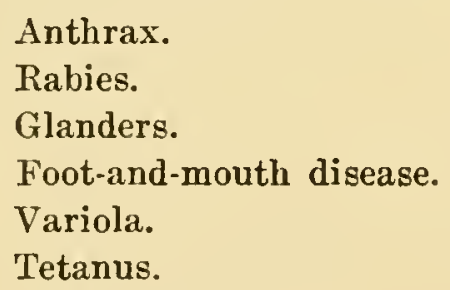

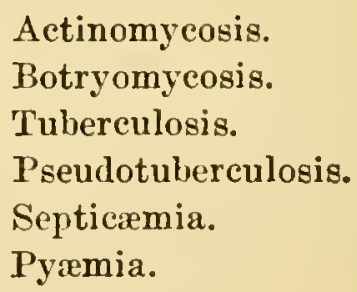

Name four physiological conditions that would render beef unfit for food.

1. Immaturity. 2. Advanced pregnancy. 3. Strong sexual odor. 4. Within ten days after parturition.

Is a carcass affected with mange fit for human food?

Carcasses which show advanced lesions associated with emaciation should be condemned. Mild cases are passed for food.

What is trichinosis? How detected? State the disposition that should be made of a carcass affected with trichinosis.

A disease of hogs (and man) caused by the presence of the larval form of the parasite, Trichina spiralis, in the muscles. (The mature worm infests the intestinal tract and causes intestinal trichinosis.)

A careful mieroscopical examination is necessary in order to detect trichina in pork. 
Badly-infested carcasses should be destroyed. Mild cases should be rendered into lard, smoked, pickled, or salted to destroy the parasite.

\section{What is cold slaughtered beef and how is it detected?}

Cold slaughtered beef is that from a carcass of a dead unslaughtered animal. Fraudulent attempts are made to give the carcass the appearance of a normally slaughtered animal by performing the sticking or cutting on post-mortem. This can be detected by the absence of bloody infiltration of the edges of the wound, improper bleeding, and perhaps evidence of post-mortem decomposition.

\section{What is your opinion about ante-mortem examination of animals used} for food?

It is very desirable, but should not supplant the post-mortem inspection. By it many diseases of animals may be detected and the contamination of slaughter-houses avoided, not to mention the safeguarding of the public health. Certain diseases, such as scabies, rabies, tetanus, etc., which show slight or no lesions on post mortem can be readily diagnosed on ante-mortem examination.

What is the average composition of cow's milk?

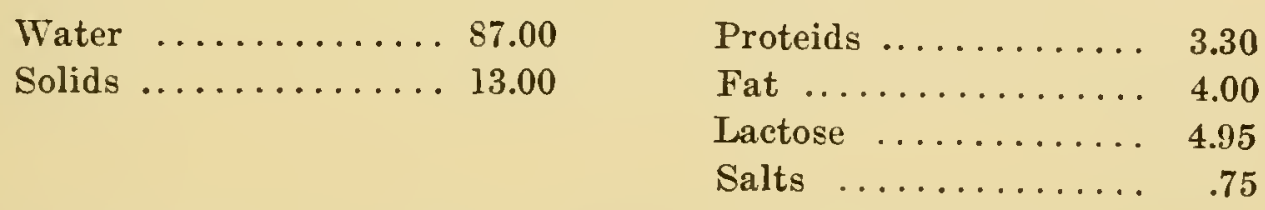

State the hygienic precautions that should be observed in managing a dairy from which milk is sold daily.

"Cleanliness" is the keynote.

Stable: Well drained, ventilated, and lighted.

Cows: Healthy, well fed and cared for, and clean.

Milking: The milkers should be healthy and tidy.

Care of milk: Promptly remove milk from the stable and cool it to $45^{\circ} \mathrm{F}$., and keep it at this temperature.

Utensils: Should be all metal and cleansed daily by washing and sterilizing with steam or boiling water.

Water supply: Should be of unquestioned purity.

What is meant by certified milk? Mention the conditions in the production and care necessary to warrant the certification of the milk from a particular dairy.

Certified milk is that which is produced so as to conform to the requirements of a legal contract between a medical milk commission 
and a dairyman. Although subject to slight variations (principally with regard to the maximum bacterial and minimum buiter-fat eontent), the conditions are as follows: The milk must be clean and wholesome and obtained from healthy cows which are kept in sanitary quarters, fed wholesome feed, and given pure water. It must be drawn from clean cows by clean, healthy attendants into clean receptacles and in a clean atmosphere. It must be handled in a clean manner, cooled quickly, put into sterile receptacles, placed in cold storage, and iced in transportation when neeessary. The bacterial content must not exceed 10,000 per c.c., and the fat-content must equal or exceed 4 per cent.

Name some of the diseases that may be transmitted through the medium of milk.

Typhoid fever, diphtheria, scarlet fever, tubereulosis, foot-andmouth disease, actinomycosis, anthrax, cholera infantum, etc.

Describe the dangers of infection to man through the consumption of cow's milk, covering (a) infection from bovine, (b) infection from germs added to the liquid during or after milking. How may these dangers be guarded against?

(a) Tuberculosis, actinomycosis, foot-and-month disease, and anthrax may be transmitted from the cow to man through the milk. Strict veterinary supervision of the herd should eliminate these dangers.

(b) Diphtheria, tuberculosis, scarlet fever, and typhoid fever may enter the milk during or after milking. To guard against this danger, the milker and milker's family should be free from infectious diseases. All bottles or other receptacles returned from houses holding cases of contagious diseases should be carefully sterilized or, better, destroyed. Dogs and cats carry disease germs, and should be excluded from the stable and dairy-house. The water supply should be pure.

State in what way milk may become a means of transmitting the germs of typhoid fever.

The milk may become infected with the typhoid bacillus through flies, dust, contact with human patients suffering from this disease, cows wading in filth containing bowel and minary discharges of human beings and contaminating the udder with germs of typhoid fever and thus conveying them to the milk; the water supply to the milk-house; bottles returned from houses holding typhoid patients. 
How is milk tested for the presence of (a) boric acid, (b) salicylic acid, and (c) sodium bicarbonate?

(a) Add to a few drops of milk, contained in a white dish, a drop or two of hydrochloric acid, and then several drops of a saturated alcoholic solution of turmeric. Heat the dish gently for a few minutes, and if boric acid or borax is present, a pink or dark-red color will appear. Cool, and add a drop of ammonia, when a darkblue or green color should be seen.

(b) Add two or three drops of sulphuric acid to 20 c.c. of milk and then shake gently with 20 c.c. of a mixture of equal parts of ether and petrolic ether. Then, after standing for several hours, the upper ethereal solution is poured off and the remaining liquid is evaporated in a porcelain evaporating dish. Add to the residue a few drops of water, and if salicylic acid is present a violet or purple color will be produced on adding a drop of a ferric chloride solution.

(c) Add to the suspected milk an equal volume of alcohol and two drops of a 1 per cent. solution of rosalic acid. If sodium bicarboriate is present, a red-rose color will appear.

Classify milk from the stand-point of its number of harmless bacteria.

Class 1. Certified milk: not over 10,000 bacteria per cubic centimetre.

Class 2. Inspected milk: not over 100,000 bacteria per cubic centimetre.

Class 3. Pasteurized milk: none, or a variable low number of bacteria.

\section{What is pasteurized milk?}

Milk which has been heated to a temperature below the boilingpoint but sufficiently high to destroy all pathogenic microörganisms $\left(140^{\circ} \mathrm{F}\right.$., or $46^{\circ} \mathrm{C}$. for 30 minutes ; $150^{\circ} \mathrm{F}$., or $65^{\circ} \mathrm{C}$. for 20 minutes; $160^{\circ} \mathrm{F}$., or $70^{\circ} \mathrm{C}$. for 10 minutes). This should be done as soon as practicable after milking in inclosed vessels, preferably the final containers, and after such heating immediately cooled to a temperature not exceeding $50^{\circ} \mathrm{F}$., or $10^{\circ} \mathrm{C}$.

Give a test to prove that milk has been pasteurized.

Pasteurization cannot be proven unless the milk has been heated to $170^{\circ} \mathrm{F}$., or over, because this temperature is necessary to destroy the ferments upon which the test depends.

Storch's test: Add to 5 c.c. of milk two drops of a freshlyprepared 2 per cent. solution of paraphenylenediamine hydrochlor- 
ide, and then one drop of a 2 per cent. solution of hydrogen dioxide. Unheated milk gives a blue color when thus treated, but milk heated to $170^{\circ} \mathrm{F}$. gives no color.

Arnold's guaiac test: Add, drop by drop, a little tincture of guaiac to a small amount of milk in a test-tube. If the milk has not been heated to $80^{\circ} \mathrm{C} .\left(170^{\circ} \mathrm{F}\right.$.), a blue zone is formed between the two fluids; heated milk gives no reaction, but remains white.

\section{Give a test for formaldehyde in milk.}

Place about 20 c.c. of milk in a small glass vessel, dilnte with an equal volume of water, and add, by pouring slowly down the inside of the vessel, a small amount of 90 per cent. commercial sulphuric acid. If formaldehyde is present, a purple or bluish zone will appear at the junction of the acid and milk. If no formaldehyde is present, a faint, slightly greenish ring forms. This test will detect formaldehyde even if present in as small proportion as 1 in 200,000.

Name the common preservatives used in milk.

Boric acid, salicylic aeid, formalin, benzoic acid, potassinm bichromate.

Give the cause for: (a) ropy milk, (b) bitter milk, (c) blue milk, (d) red milk, (e) suppression of the milk, (f) pus in the milk.

(a) Inflammation of the udder may cause ropy milk, but in the majority of cases it is due to B. lactus viscosus.

(b) Eating of certain foods by cows (lupines, ragweed, cabbages, Swedish turnips); it occurs in old milk due to growth of germs.

(c) Bacillus cyanogenus.

(d) A mixture of blood: B. prodigiosus. Rarely due to eating of pigmented plants.

(e) Mastitis, severe febrile diseases, certain drugs such as belladonna, idodine, eamphor, alum, ete.

(f) Mastitis. (A small number of leucocytes is often found in milk from apparently healthy cows.) Prolonged retention of milk in the udder gives rise to an increased leucocyte content.

Describe briefly: (a) sanitary farm, (b) sanitary barn, (c) sanitary milk-house.

(a) A sanitary farm is one that is located sufficiently high to have good drainage, and that is free from germs of infectious discases.

(b) A sanitary barn is one provided with good drainage, ventilation, and light, and pure water supply; it has the necessary 
amount of air space per auimal, and is clean and free from germs of infectious diseases.

(e) A sanitary milk-house is so constructed that it can be readily disinfected throughout with boiling water or steam. All apparatus used in it should be of metal as far as practicable so as to permit of thorough sterilization. Good drainage, ventilation, and a supply of pure water are essential. It should be well fitted with all apparatus necessary for the proper handling, cooling, and storing of milk.

How is a quantitative bacterial analysis of milk made?

A cubic centimetre of milk is diluted with sterile water and mixed with melted mutrient agar. This mixture is poured in a Petri dish, allowed to cool, and then placed in an incubator for 24 hours. Each bacterium grows and produces one colony. By counting the colonies and multiplying the result by the dilution, the number of bacteria per cubic centimetre is determined.

What is the significance of the presence of streptococci in milk?

This question is subject to great dispute. Most authorities are agreed that any number of streptococei in excess of the ordinary number found in milk calls for an investigation of the dairy supplying the milk, looking particularly for mammitis, and contamination. with dirt, especially manure.

Name the microorganism that causes milk to become sour.

B. lactis acidi.

What is the difference between pasteurized, sterilized and certified milk?

Pasteurized milk has been heated to a temperature below the boiling-point but sufficiently high to destroy nearly all living microorganisms, or at least to check their growth. (Ninety-five to ninetyeight per cent. of all bacteria are destroyed by pasteurization.)

Sterilized milk is free from all bacteria and spores. Sterilization is usually accomplished by heating the milk to the boiling-point. By this process the milk is altered in composition and taste, and therefore it is objectionable as a commercial product.

Certified milk is produced under such cleanly methods as to contain a very low number of non-pathogenic bacteria: not over 10,000 per cubic centimetre. 


\section{ZOOTECHNICS}

What is zootechnics? What subjects are included in the study of zootechnics?

Zoötechnics refers to the breeding, keeping and general management of domesticated animals. It includes a study of breeds, breeding, feeds, feeding, conformation, type, soundness, etc.

Give a definition for the following terms: protein, fat, carbohydrates, balanced ration, crude fibre.

Protein refers to the nitrogen compounds in vegetable and animal foods. About 16 per cent. of protein substances consist of nitrogen.

Fat is an important constituent of foods. Its presence is determined by submitting the feeding-stuff to the action of ether, which dissolves fat. It is often called ether-extract and is found in seeds more than in coarse foods. Cotton-seed and flax-seed are especially oleaginous.

Carbohydrates are compounds that are important constituents of food. They are made up of carbon, hydrogen, and oxygen; the hydrogen and oxygen being in the proportion to form water. They are non-nitrogenous compounds and are present in large proportions in all the common fodders, in the form of starch, sugar, cellulose, etc.

A balanced ration is one which contains the different nutrients in the proper proportions to meet the physiological requirements of the animal, with the least waste of nutrients.

Crude fibre is the tongh or woody part of plants. It consists mainly of cellulose and is especially abundant in hay and straw.

What would constitute a normal day's ration for a I200-pound horse?

The following rations should meet the needs of a 1200-pound horse, doing moderate work:

12

10 pounds hay.

6 pounds corn.

10 pounds hay.

10 pounds oats.

7 pounds wheat bran. 5 pounds wh. bran.
3

10 pounds hay.

6 pounds oats.

6 pounds corn. 
From the following list of hay, grains and concentrates, subdivide those best suited for dairy cattle, beef cattle, horses, sheep and swine: Hay-timothy, common red clover and alfalfa; grains-peas, oats, barley and rye; concentrates-bran, cotton-seed meal, oil cake and gluten meal.

Dairy cattle: Clover hay, alfalfa, barley, bran, cotton-seed meal, oil cake, and gluten.

Beef cattle: Clover hay, rye, bran, cotton-seed meal, and gluten.

Horses: Timothy hay, alfalfa, oats, bran, and barley.

Sheep : Clover hay, alfalfa, bran, cotton-seed meal, gluten, and oil cake.

Swine: Clover hay, peas, barley, and bran.

Define the following terms : hereditary, prepotency, in-breeding, crossbreeding, thoroughbred and grade.

Hereditary refers to diseases or qualities which are derived from ancestry or obtained by inheritance.

Prepotency is a quality possessed by certain individuals, by reason of which they have greater power than the other parent in transmitting inheritable characters to the offspring.

In-breeding is a form of line-breeding which involves the breeding together of sire and offspring or dam and offspring or of brother and sister.

Cross-breeding refers to the combining of ancestral lines of two distinct races, breeds, or varieties.

The term thoroughbred refers to a specific breed of horses (the English race-horse) which are noted for speed and endurance.

The term grade is applied to an offspring resulting from the mating of a common or unimproved parent with one more highly improved, a "pure-bred."

\section{What is atavism? Give an example.}

Atavism is the inheritance of characteristics from remote, but not from the immediate, ancestors. In breeding pure-bred animals we occasionally obtain an offspring which is off-color or off-type and resembles a very remote ancestor. The peculiar color or type may not have been shown in several generations.

Name the various breeds of dairy cattle and wool sheep.

Dairy cattle: Holstein-Friesians, Jerseys, Guernseys, and Ayrshires.

Wool sheep: Merinos, Southdowns, Shropshires, Oxfords, Dorsets, Leicesters, Cotswolds, and Lincolns. 
What points should be especially considered in the selection of animals for breeding purposes?

We should consider the individual and its ancestry, noting particularly that the high standard of the ancestors has been maintained in each individual in the line of parentage. "Like begets like"; therefore, the desirable, as well as the undesirable, points of the selected animal are likely to be transmitted to the offspring.

What influence on the offspring does heredity play and what environment?

Heredity should not be considered from the stand-point of the individuals mated only, but of the race as a whole. Consider the ancestors and the desirable characteristics which they uniformly possessed. From individuals whose ancestry has shown a uniformity of certain characteristics it is reasonable to expect that these points will be transmitted to offspring. Among the characteristics inherited are: conformation, type, color, temperament, milk-production, wool-production, speed, endurance, style, action, etc.

Environment, likewise, deserves general consideration. The effect of environment on the immediate offspring is of little importance. Insufficient food, overwork, and improper care may result in the production of an individual offspring of inferior size and development. But the succeeding generation may lack in neither of these respects. However, if a great number of generations are kept in the same improper environment, there will be a tendency toward retrogression.

\section{What is the value of a pedigree and upon what does it depend?}

A pedigree is a record of ancestry, and its value depends upon the reputation of the ancestors. If the ancestors for five or six generations back have been individuals of a uniformly good character, the pedigree is valuable, and the individual, which it represents, is desirable as a breeding animal. On the contrary, if there has been a lack of uniformity in the previous generations, the pedigree is of little account, and the individual is more or less undesirable as a factor in breeding.

An ideal pedigree would be one which contains definite information regarding the merits and demerits of the individuals recorded.

\section{Name the conditions of the tarsus that cause unsoundness.}

Arthritis chronica deformans, curb, bog-spavin, and thoroughpin. 
What unsoundnesses in horses may be regarded as sufficient cause for disqualification of animals by judges in the show ring?

Some judges disqualify horses which show lameness from any cause whatsoever. But it would seem more logical to disqualify only those in which the lameness is due to structural changes in the limbs, such as ring-bone, navicular bursitis, spavin, curb, splints, quittor, laminitis, teudonitis, shoulder, hip and stifle lameness, etc., and to ignore temporary lameness due to nail-wounds, corns, thrush, etc.

Other recognized unsoundnesses are: roaring, heaves, periodic ophthalmia, blindness, infectious diseases (glanders, influenza, dourine, etc.), osteoporosis, congenital malformations (eryptorchidism, monorchidism, hernix, etc.), chronic hydrocephalus and vicious habits.

What diseases are hereditary in horses? Mention faulty conformations that predispose to unsoundness in horses.

The consensus of opinion would indicate that there are few, if any, hereditary diseases. But there is no doubt about the transmission of defects in conformation. Among the latter should be mentioned:

Curby hocks.

Narrow hocks.

Knee-sprung.

Calf-knees.

Short, upright pasterns.

Base wide.
Base narrow.

Toe wide.

Toe narrow.

Narrow, long-coupled back.

Small, deep-set eves.

Narrow forehead.

These defects predispose to unsoundness.

What are the characteristics of a good milch cow?

Head: Small and clean cut; muzzle large; forehead straight or concave; small horns; eyes bright and prominent.

Neck: Long and thin.

Body: Soft, fine, thick hair; clean, pliable skin; broad loins but not thickly fleshed as in the beef type; frame wedge-shaped, tapering from rump to shoulder; flank high; abdomen well barrelled and roomy.

Udder: Broad, full, extending high up behind and far forward; not loose, pendulent, and fleshy; teats large, evenly placed, and wide apart; large, prominent milk-veins.

Extremities: Fore limbs short and wide apart; long and powerful hind quarters with thin thighs, widely separated; tail long, slim, and loosely jointed.

Temperament: Docile; heavy feeder. 
Describe a properly built stall for a horse. Give its dimensions.

A properly-built stall for a horse should be ten feet long from the manger and six feet wide. The partitions must be strong and high enough, especially in front, to prevent quarrelling. The pillars are romnded and provided with rings, about three feet from the floor, to which a chain can be attached.

The floor is made of concrete or other impervious material and covered with wood. The slope, posteriorly, should be as little as possible to secure drainage. One inch lower behind than in front is sufficient.

Mangers are best made of metal and so constructed as to permit of thorough cleansing. The hay-rack should be low to avoid the danger of dust, chaff, etc., falling into the nostrils and eyes.

Windows should be high overhead to prevent drafts and the glare of light in the eyes.

\section{At what age does the cow, mare, bitch, ewe and cat bear young?}

The age at which the various animals arrive at puberty varies in different species and in individuals of species. Records show that cows have given birth to young as early as 14 months, mares 22 months, bitch 8 months, ewe 13 months, and eat 10 months.

It is undesirable to have a female bring forth young before she has matured because of the dangers to her health and development. Therefore breeders, as a rule, do not mate females until they have reached ages as follows: Cow, 1 to $11 / 2$ years; mare, 4 to 5 years; bitch, 1 year ; ewe, 1 year ; cat, 1 year.

What are some of the principal causes of sterility in domestic animals? How may these conditions be overcome?

(See subject of obstetrics, p. 293.)

\section{Name the several external and internal parasites of sheep.}

External: Melophagus ovinus (sheep-tick), hematopinus stenopsis (sheep-louse), œstrus ovis (sheep gad-fly), sarcoptes scabei (facescab parasite), symbiotes communis (foot-scab parasite), psoroptes communis (common seab parasite).

Internal: Estrus ovis (grub in head), cœnurus cerebralis (gid), strongylus filaria and rufescens (lung worms), strongylus convolutus (stomach worm), cesophagostoma columbiana (nodular disease in intestines), distoma hepaticum (fluke), txuia expansa, alba and fimbriata (tapeworns). 
Give the process of dentition in the equine from birth to the age of five (5) years.

At birth or within two weeks after: The colt shows two temporary nippers, above and below, and the first three temporary grinders.

Four to six weeks: The temporary intermediates appear.

Six to nine months: The temporary corners appear.

Ten to twelve months: The fourth molar erupts.

Two years: The fifth molar erupts.

Two and one-half to three years: The permanent nippers replace the temporary ones and the first two premolars are replaced.

Three and one-half to four years: The intermediates and third premolars are replaced by permanent teeth.

Four and one-half to five years: The permanent cormers, canines, and last molars erupt.

\section{What are the characteristics of a seven-year-old mouth?}

The tables of the nippers and intermediates are levelled (cups gone); the ring of central enamel is wider anteroposteriorly and shorter from side to side; the nippers are oval, the intermediates becoming so. A notch is formed on the posterior surface of the superior corners.

State the advantages and disadvantges of a pair of mules over a pair of horses.

Advantages.

1. Less susceptible to digestive disorders, laminitis, azoturia, glanders, influenza, foot lameness, heat prostration, etc.

2. Require less elaborate stables.

3. Longer period of serviceability.

4. Stand hard usage better.
Practically none.

Disadvantages.

Mans people are prejudiced against the mule for no valid reason.

The mule is not adapted to heavy draft work because of size. 



\section{INDEX}

Abdominal cavity, regions of, 99 organs, pathology, 152

Abducens nerve, 75 functions of, 134

Abomasum, anatomy, 81 conditions of food leaving, 118

Abortion, 264, 276

from ergot, 198

infectious in cows, 182

course and etiology of, 277

methods of control, 277 of diagnosing, 182

symptoms, 277

non-contagious, causes of, 276

symptoms of, 276

Abscess, cold, 209, 240

of shoulder, 240

treatment, 209, 240

defined, 144, 209

postpharyngeal, causes, 220 symptoms and treatment, 220

Absorption, 103, 122

of gas by fluids, 114

Acariasis, poultry, cause of, 203 treatment, 203

prevention and treatment, 205

Accommodation, 103

process of, 137

A. C. E. mixture, 305

Acetanilide, action, 304

effect on temperature, 304

source and uses, 304

Acetates, 35

Acid, 3

acetic, 35,38

action on secretions, 331

arsenious, 33

boric, 31 action, properties and uses of, 321

carbolic, source, 37

dibasic, 4

gallic, 34

hippuric, 127

hydrochloric, 318

preparation of, 26 source of, in gastric juice, 118

lactic, 38,42

mineral, 40

monobasic, 4

nitric, preparation of, and uses, 19

phosphoric, 11, 318

sulphuric, 23

graphic formula of, 11, 24

tannic, 34

preparation of, 23,24

actions and source, 321

tartaric, 38
Acid, tribasic, 4 uric, 127

Acid-fast organisms, 162

Acne, pathology, 156

1. symptoms and treatment, 202

Aconite, dose of tincture, 299

maximum doses, 299

physiological actions, 298

therapeutic úses, 298

Aconitine, 315

Actinobacillosis, 180 animals affected by, 180 diagnosis and treatment, 180.

Actinomycosis, 180 fungus of, 162 prescription for, 336

symptoms and treatment, 180, 227

Adrenalin, dose for dog and horse, 318 preparation, source and uses, 318

Adrenals, anatomy, 96, 98 vascular glands, 112

Aërobic, facultative and obligative, 161 term defined, 161

Age, determination of, 225, 365 of breeding, 364

Agglutinins, 163

Air, 20, 346

changes in inspired, 113,346

composition of breathed, 346 of normal, 115, 346

constituents of, 20

injurious substances added to, in breathing, 20

mixture not a compound, 20

residual, 114

space requirements, 346 tidal, 103, 114

Anatomy, 44

Albuminuria, conditions found in, 186

Alcohols, absolute, 35

ethyl, 35

methyl, 35

preparation and uses of, 35

Aldehyde, 35

Alimentation, 104

Alkalies, 3

actions of, 300

on secretions, 331

caustic, antidote for, 39

uses, 300

Alkaloid, 38, 311

antidote for, 38

Alkaloids, six common, 311

Allantois, 274

Allotropism, 5

Aloes, action of, 322

Barbadoes, 317 
Aloes, Cape, 317

dose for cow, dog, and horse, 322

Socotrine, 317

Alterative, 321

Aluminum, important salts of, 31 sulphate, 31

Alums, 31

Alveolus, 45

Amalgam, 4

Amaurosis, causes, 218

defined, 218

treatment, 218

Amboceptors, 167, 168, 342

bacterial, 168

hæmolytic, 167,168

Ammonia, 19

aqua, 301

aromatic spirits of, dose, 320

sign of danger in drinking water, 19 source and uses of, 19

Ammonium acetate, 35

carbonate, 301

dose, 320

chloride, 19, 301

dose, 320

iodide, 303 dose, 314

nitrate, 20

Amnion, 274

Amorphism, 2

Amphiarthrosis, 52

Amputation of hind limb, 98

of penis, 235

of tail, indications for, 239

of udder, indications, 326

Amylopsin, 116, 121

Anabolism, 40, 126

Anæmia, 182, 141

causes of, 182

cerebral, 200

post-mortem appearance of, 155

infectious, trcatment, 182

Anaërobic, term defined, 161

facultative and obligative, 161

Anresthesia, chloroform, 258, 315 dangers of, 258

of a foot for operation, 258

Anæsthetic, defined, 307 general, local, and uses, 307

Anæsthetics, 258

in major operations, 258

in horse, ox and dog, 258

in minor operations, 258

Analysis, 3

in horse, ox and dog, 258

Anaphylaxis, 143

Anasarca, 144

Anatomy, histological, 99

obstetrical, 259

soft organs concerned in, 259

topographical, 98

Anchylosis, defined, 214

Anchylostoma, 197 animals attacked by, 197
Anchylostoma, symptoms and treatment, 197

Aneurism, 149

causes, 187

defined, 217

false, 217

of coeliac and mesenteric arteries, 149 cause of, 149

symptoms and treatment, 187

true, 217

varieties of, 217

Angioma, 146

Animal heat, 128

conditions infiuencing, 128

how maintained, 128

how regulated, 128

in cold-blooded animals, 128

in warm-blooded animals, 128

Ante-mortem examination of food-animals 355

Anthelmintics, 325

Anthrax, in cattle, 175

bacillus of, 172

course, 175

cutaneous form, 175

differentiaterl from malignant $œ$ dema, 166

disinfecting ships, 348

immunization in, 341

method of procedure in outbreak, 349

post-mortem lesions, $15 \mathrm{~S}$

symptoms, 175

Antibodies, 167, $16 \mathrm{~S}$

Antidotes, chemical, 39

differentiated from antagonists, 338

for poisoning by aconite, 339

by alkaloids, 38

by arsenic, 338

by atropine, 340

by chloral hydrate, 340

by chloroform, 340

by corrosive sublimate, 338

by lead, 339

by mercury, 339

by morphine, 340

by strychnine, 340

mechanical and pliysiological, 39

Antimony, 34

Antiphlogisties, 210, 331

Antipyrine, 310,317

Antiseptic, defined, 161, 329

economic, 316

for wounds, 309

wound treatment, 206

Antiseptics, 24

Antitoxin, 163, 341

tetanus, dose, 343

source, unit, and use, 343

trentment, 341

Anus, imperfor:ted, treatment, 296

Aorta, anterior branches, common, 64 posterior, branches of, 63

Aphrodisiac, 320 
Aphthæ epizoöticæ, 176

Apnoea, 114 symptoms and treatment, 176

Apomorphine, for the dog, $30 \mathrm{~s}$ administration and dose, 308 use, 305,316

hydrochloride, dose, 327

Aponeuroses, 57

Apoplexy, 155 parturient, 287

Aqueous humor, 93, 94

Arachnoid, anatomy; 71 physiology, 133

Areca nut, a vermifuge, dose, 316 use and constituents of, 324

Arecoline hydrobromide, actions, 303

Argyrol, 27 dose, 303,312

Arsenic, 33

actions and administration, 303

antidote for, 39,338

compounds of, used in medicine, 38

Fowler's solution of, 33

Marsh's test for, 33

poisoning by, symptoms, $33 \mathrm{~S}$

preparations used in medicine, 303, 327

trioxide, 33

uses, 303

Arteries, anterior mesenteric, 63

anterior tibial, 65

axillary and brachial, 64

broncho-œsophageal, 63

collateral of cannon, 64

digital, 64

external carotid and iliac, 65

external pudic, 92

femoral, 66

function, 110

gastric, 66

glossofacial, 65

hepatic, 66

histologically described, 99

humeral, 64

iliac, 64

inflammation of, 217

intercostal, 63

internal iliacs, 66

maxillary, 65

pudic, 92

lumbar, 63

middle sacral, 63

perpendicular, 64

phrenic, 63

plantar ungual, 64

popliteal, 65

posterior mesenteric, 63 radial, 64

preplantar ungual, 64

renal, 63

small testicular, 64

spermatic, 63, 92

splenic, 66

superficial temporal, 65
Arteries, umbilical, 67

uterine, 66

vertebral. 65

Arteritis, causes, defined, 217

Arthritis, defined, 148, 214

deforming, 214, 248

lesions of, 148

serous, suppurative, and tubercular, 214

varieties of, 214

Arthrology, 51

Articulations, 51

atlo-axoid, 52

classes, 51

costochondral and costosternal, 53

coxofemoral and femorotibial, 56

humeroradial, 53

interphalangeal, 55

of the tarsus, 56

of the vertebræ, 52

radiocarpal, 54

scapulohumeral, 53

structures entering into, 52

Atrophy, 141, 143

causes of, 143

Ascaris megalocephala, 195

prescription for, 195 symptoms, 195

Ascites, causes, 198

defined, 198

in the dog, causes, symptoms and treatment, 231

Asepsis, defined, 161

Aseptic wound treatment, 206

Asphyxia, 115

in new-born, 294

treatment, 294

stages of, 115

Aspidium, dose, 324, 325

oleoresin, 325

precautions in administering, 324

value of, 324

Asthma, bronchial, 189

animal most susceptible to, 189

causes, symptoms and treatment, 189

Atavism, 361

Atelectasis, 151

Atom, 3

Atomic weight, 5

Atlas, vertebra, 48 articulation of, 52

Atropine, action, 309 poisoning by, symptoms and antidote, 340

source, 309

sulphate, dose of, 312

Auditory nerve, 75

function of, 135, 137

Augmentation, defined, 133

Auscultation, 171

Autogenous vaccine, 344

Auto-intoxication, 142

Automatism, defined, 133

Avogadro's law, 12 
Axis, vertebræ, 48 articulations of, 52

Azoturia, 183

differentiated from spinal meningitis, 169

etiology, 183

pathology of, 154

prevention of, 183

symptoms, 183

treatment, 183,329

Bacillus, 160

Bang's, 161, 277

Johne's, 179

Jioch's, 161

necrophorus, 163

Nicolaier's, 161

of anthrax, tetanus and tuberculosis, 162

paratuberculosis, 163

Bacteria, pathogenic, methods of dissemination, 348

Bacteriaceæ, 160

Bacterin therapy, 344

Bacteriology, 160

Bacteriologic examination, 163 collecting tissues for, 163

Bacterium, 160

lactic acid, 42

method of producing disease, 164

Migula's classification of, 160

resistant to disinfectants, 348

Balanced rations, 127,360

Balsam copaiba, dose, 318

Peru, actions, 325 dose, source, and use, 325

Bang, bacillus of, 161,277

method of eradicating tuberculosis, 350

Barium, 29, 30

chloride, 30

dose, and indications for, 299

Bar-shoe, contra-indicated, 256

in corns, 254

in laminitis, 255

in thrush, 254

Base, 3

uses of, 256

Bayer's operation for quittor, 252

Beef, cold slaughtered, 355 detection of, 355

physiological conditions rendering unfit, 354

Beggiatoa, 160

Beggiatocex, 160

Belladonna, actions and uses, 308

Bell metal, 12

Benzoated lard, 309

preparation of and uses, 309

Bessemer process, 32

Bile, 120

functions of, 120

result of suspended secretion of, 109 salts of, 103
Bile, secretion in cquine and bovine compared, 120

Bishoping, method of, 226

Bismuth, 31

citrate, 31

salts of, action externally, 314

subcarbonate, 31

subgallate, 31

subnitrate, 31 actions and dose, 314

subsalicylate, 31

Bitters, vegetable, 322

Bladder, urinary, anatomy, $\$ 9$ paralysis of, in horse and dog, 233 causes, symptoms and treatment, 233

prolapse of, in mare, treatment, 233 rupture of, causes, symptoms and treatment, 233

Blastoderm, function of, 273 membranes of, 273

Bleaching powder, 8

Blistering agents, 313 for different animals, 313

Bloating, accompanying choke, 222 in cattle, 192

Blood, amount of, in horse, 107 arterial and venous compared, 108 cause of alkalinity, 108 circulation of, in brain, 112 coagulation of, 108

color of, in renal veins, 108 composition of, 101, 106, 107 defined, 106

flow of, in arteries and veins, 111 forces that cause circulation of, 110 function of, in secretion, 104 gases found in, 107 inflammatory appearances of, 210 oxygen, how carried in, 108 pathology of, 146

pressure, 111

factors that decrease and increase, 111

governed, 111

highest and lowest, 111

proteids of, 107

velocity of, 111 greatest and lowest, 111

vessels, 100

diseases of, 217 pathology of, 148

Blood-clot, 147

ante-mortem and post-mortem compared, 147

Blow-pipe, oxyhydrogen, 15

Blue vitriol, 7

Bones, 44

atlas, 48

axis, 48

blood supply of, 66

carpal, 48

cuneiform, $4 \mathrm{~S}$

development of, 44 
Bones, femur, fracture of, 246

frontal of the ox, 45

ilium and ischium, 50

inferior maxillary, 46

inflammation of, 212

lunar, 48

number of, in the horse, 44

of the cranium, 44

of the ear, 137

of the foot, $4 \mathrm{~S}$

of the fore limb, horse and ox, 47

of the head, 44

of the hind limb, 50

of the pelvis, 50

os innominatum, 50

pathology of, 147

pedal, 48

pisiform, 48

properties of, 44, 105

pubis, 50

ribs, 51

sacrum, 50

scaphoid, 48

scapula, 47

superior maxillary, 45

trapezoid, 48

ulna, 47

unciform, 48

Bob-veal, 353

method of detection, 353

relation to health, 353

Body, excreting organs of, 105 inorganic constituents of, 106 secreting organs of, 105 vital organs of, 105

Borax, 31

Boric acid, 31

Boron, 31

Bots, in throat of solipeds, 188

Boyle's law, 1

Brain, anæmia of, pathology, 155 anatomy, 71,72 circulation of blood in, 112 hyperæmia of, 200 membranes of, 71,133 .

Brandy, 35 function of, 133

Brass, 12

Breathing, Cheyne-Stokes, 166

Broken knee, treatment of, 241

Bromine, preparation of, 27 uses in medicine, 27

Bronchitis, inhalation, 188 causes of, 188 symptoms, 189 verminous, treatment in calves, 189

Bronchopneumonia, 188 appearance of lungs in, 151

Bunsen burner, 22

Cæcum, anatomy, 83 capacity of, 83 horse and ox compared, 83 puncturing, tissues involved in, 232
Cæcum, puncturing, unsatisfactory results in, 232

Cæsium, 29

Caffeine, actions, dlose and use of, 327

Calabar bean, alkaloid of, 312

Calcification, 144

Calcium, 29

carbide, 22

hydroxide, 11

hypochlorite, 8

sulphate, 30

Calculus, defined, 212

salivary, treatment, 227

urinary, symptoms and treatment, 223 varieties of, 212

Calomel, 28, 299

preparation and properties of, $2 S$ uses, 299

Calorie, large and small, 129

Camphor, actions, dose, source and uses, 327

Canal, auditory, 95

Haversian, 105

infra-orbital, 46

inguinal, 62

lachrymal, 45

maxillodental, 46

palatine, 45

Cancer, varieties of, 145

Canker, 254

differentiated from thrush, 254

prognosis, 254

symptoms and treatment, 254

Cannabis indica, actions and use, 324 dose for dog and horse, 324

Cantharides, actions and uses, 302 active principles of, 314 source, 314

Capped hock, causes, definition and treatment, 249

Carbohydrates, 34, 41, 360

differentiated from hydrocarbons, 34, 41

Carbolic acid, 37

antidote for, 40

source, 37

Carbon, 20

allotropic forms of, 21

amorphous, 21

dioxide, 11, 21

effect on health, 20

preparation of, 21

test for, 22

weight compared with air, 22

element of proteids, 106

monoxide, 11

reducing agent, 21

Cardiac cycle, 110

hypertrophy, 148

causes and lesions of, 148

Caries, defined, 148, 213

of the teeth, 224

causes of, 148

treatment, 224 
Carpus, structures of, 54

Cartilage, articular, function of, 105 development of bone from, 44 ensiform, 49

lateral, 55 function of, 55,138

of prolongation, 47 xiphoid, 49

Caruncle, 136

Cascara sagrada, 319 dose, source and uses, 319

Cascarilla, actions, dose and use, 322

Casting, accidents in, 257 methods of, in horse and ox, 257

Castor oil, actions and dose, 322

Castration, diseases resulting from, 234 hemorrhage following, 208, 234 in the male, 234 ill effects following, 234 tissues cut in, 235

Casts, urinary, 153 blood, 153

epithelial, 153

fatty, 153

granular, 153

hyaline, 153

in acute parenchymatous nephritis, 153 in chronic interstitial nephritis, 153

in chronic parenchymatous nephritis, 153

varieties, 153

waxy, 153

Catabolism, 40, 126

Cataplasm, 329

Cataract, conditions giving rise to, 219 defined, diagnosis, and forms of, 219

Cathartics, classes of, 298 vegetable, 322

Catheterization, operation of, 233 in cow, gelding, mare and steer, 233

Caudal myotomy, object, 239

Caustic alkali, 3, 39 liquid, 29

lunar, 27

Cautery, actual, 245 value of, 245

Cavity, abdominal, regions of, 99 glenoid, 51

Cell division, 102 direct and indirect, 102 physiology and properties of, 102

Cercbellum, effect of its removal, 133 function of, 133

Cercbral anxmia and hyperæmia, 200

Cerebrospinal meningitis, see Meningitis

Cerebrum, anatomy, 72 function, 133

Cervix uteri, laceration of, 289 treatment, $2 \$ 9$

Cesarean section, in mare, 281 complications of, 281 in multiparous animals, 282

Chabert method of opening guttural pouch, 220
Chemical action, 5

affinity, 3

calculations, 12,13

change, 2

cquations, $8,9,10$

prefixes, $\mathbf{S}$

suffixes, 7

Chemistry, 1, 2

distinguished from physics, 1

inorganic, 2

organic, 34

physiological, 40

Chestnut, anatomy, 95

Cheyne-Stokes breathing, 166

Choke, in the cow, treatment, 222

œsophagotomy in, 221

treatment of, 221

Chordx tendinx, 103

Chorea, in the dog, causes, symptoms and treatment, 200

Chorion, 274

Choroid, anatomy, 93

Chlamydobacteriaceæ, 160

Chloral, 36, 313

hydrate, 36

actions, dose and preparation of, 313

compared with chloroform, 36 uses in medicine, 36, 313

Chlorine, compounds of, 26

preparation and uses of, 26

Chloroform, 36

actions and uses of, 324

action of, compared with ether, 315

compared with chloral, 36

dose for dog and horse, 324

preparation of, 36

test for bile in urine, 42

Chyle, 103

compared witl chyme, 119

Chyme, 119 with !ymph, 120

compared with chyle, 119

Circulation, fetal, 67

of blood in the brain, 112

in the kidncy, 112

pulmonary, 67,110

systemic, 67,110

Circulatory organs, anatomy, 62

Cladothrix, 160

Clipping, arguments for and against, 130

Clitoris, anatomy, 93, 261

Coal-tar products used in medicine, 317

Cocaine, actions and dose, 318 prescription for, 333

Coccacex, 160

Coccidia, 197

animals infested by, 197

diagnosis, prevention and treatment, 197

in the skin, 203

oviforme, 203

Cocliac axis, 66

Cocnurus cerebralis, 200 
Colic, crapulous, symptoms and treatment, 194

engorgement, 194

flatulent, prescription for, 337

in pregnant animals, causes and treatment, 292

nervous, symptoms and treatment, 194

spasmodic, 194

differentiated from enteritis, 170 prescription for, 334

thrombo-embolic, 196

Collar-galls, treatment for, 229

Collargol, 27

Collyrium, defined, 304

Colon, anatomy, 82

double, $\$ 2$

function of, in digestion, 120

floating, S3

Colostrum, composition of, 269

Combustion, 3,17

Complement, 160, 167, 168, 342

Complement-fixation test for glanders, 167

Compounds, 3 for abortion, 182

distinguished from mixtures, 9

inorganic and organic, 7

Concrements, 212

Condyle, 51

Congestion, active, 149

of lungs, 190

causes, 149,190

lesions, 150 symptoms and treatment, 190 passive, 149 difference between active and, 149

Conjunctiva, inflammation of, 217 physiology, 136

Conjunctivitis, acute catarrhal, 217 causes, symptoms and treatment, 217

Connective tissue, anatomy, 101 varieties of, 101

Constipation, in dog, 197

in hog, treatment, 330

prescription for, 337

symptoms, 197

Ccntagious disease, 165, 347

contributing causes of, 348

disinfecting in, 347

important factors in prevention, 350

method of handling, 348

Contagious pleuropneumonia, 175

appearance of lungs in, 151

course of, 175

differentiated from influenza, 170

sanitary police measures, 349

symptoms, termination and treatment of, 175

Contracted hoof, treatment, 256

tendons, 241

operation for, 241

shoe for, 241

Coördination, defined, 133
Copper acetate, 35

uses, 315

arsenite, uses, 315

preparation of, used in medicine, 315

sulphate, 7,24 preparation of, 24

uses of, 315

Cornea, anatomy, 93

Corns, dry, 253

pathology of, 253

side-bones, relation to, 254

suppurating, 253

treatment, 253,254

Corona, fracture of, 251 symptoms and treatment, 251

Coronary cushion, anatomy, 96 function of, $13 \mathrm{~S}$

Corpora libra, 214 nigra, function of, 137

quadrigemina, anatomy, 72

Corpus luteum, 265 false and true, in cow and sow, 265

Corpuscles, Malpighian, 97, 112

red blood-, function, size and shape of, 107

white blood-, function, 107

Corrosive sublimate, 7,28 antidote for, 39

Corti, membrane of, 137

Cotton-seed meal, 199 effects of overfeeding, 199

Cotyledons, animals in which found, 271 fetal and maternal compared, 266

Counterirritants, 313, 339 indications for, 313

Cow, characteristics of a good milch, 363

Cowpox, causes, 173

extinction of, 173

sequelæ of, 173

symptoms and treatment, 173,174

Coxitis, 245

Creatine, 127

Creatinine, 127

Crenothrix, 160

Crith, 5

Cross-breeding, 361

Croton oil, action, 328 antidote for, and derivation of, 328

dose, toxic, 328

properties and uses of, 328

Crude fibre, 360

Cryptorchidism, cause of sterility, 293

Crystalline lens, anatomy, 93

Culture, defined, 161

pure, 161

media, 161

Cuneiform bone, anatomy, 48

Curb, causes of unsoundness, 362

defined, 249

Curd, 42 
Cushion, coronary, 96

elastic, of heel, 95

plantar, 95,96

Cyanosis, age liable to occur, 187 causes of, 187

in new-born, cause and symptoms, 296

Cystic calculi, symptoms and treatment of, 232 ovary, pathology of, 154

Cysticercus cellulosæ, disease caused by, 353 disposition of carcass, 353 life-cycle of, 353

Cystitis, urinary, 141, 185 causes, diagnosis and treatment, 185

Cysts, defined, 146 degeneration, 146 foreign body, 146 parasitic, 146 retention, 146

Dairy cattle, breeds of, 361 hygienic precautions in, 355

Dandruff, $124,150^{\circ}$

Dartos, anatomy, 92

Deafness in the dog, causes of, 220

Death by asphyxia, 115 by lightning, lesions of, 142

Decay, 34

Decidua vera, function of, in cat, 139

Decoction, defined, 304

Decussation, defined, 104

Degeneration, fatty, 143

differentiated from fatty infiltration, 143

Deglutition, organs of, 77,80

Dehorning, methods of, in cattle, 228

Deliquescence, 3

Demodex folliculorum, 203, 204

Dental formula, dog, 78,79

horse, $78,79,115$

ox, $78,79,115$

Dentition, process of, from birth to five years, 365

Deodorant, 24, 329

Dermatitis, gangrenous, 203 course, symptoms and treatment, 203

Descemet's membrane, 94

Desmotomy, patellar, 247 object of, 247

Development, physiology, 139

Diabetes, forms of, 184 insipidus, 184

mellitus, 184

treatment, 184

Diad, 4

Diagnostic inoculation, 171

Diagnosis, general and differential, 165

Dialysis, 2

Diamond, 21, 23

Diaphorctic, 320

Diaphragm, anatomy, 61

of the horse and ox compared, 61 rupture of, symptoms of, 229
Diarrhœa in new-born, causes and treatment, 194 prescription for, 333

Diarthrosis, 52

Diastole, 109

Diet for a dairy cow, 127

for a horse, 127

Diffusion, 6, 41 of gases, 6

Digestion, action of salt in, 122 conditions that retard, 122 of proteids, $11 \mathrm{~S}$ organs of, 77 steps in process of, 115

Digestive organs, anatomy, 77

Digitaline, action of, 317 source of, 312

Digitalis, action of, on heart, 109, 326 compared with aconite, 324 active principles of, 315 fluidextract, dose, $31 \mathrm{~S}$

Diseases, 165 acute general infectious, 172 chronic infectious, 179

communicable to man, 354 contagious, 165 contributing causes of, 348

following parturition, 284

incident to pregnancy and labor, 284 infectious, 165,347 and contagious differentiated, 165 inflammatory, 353

milk transmission of, 356

non-inflammatory, 353

of the abdomen, 229

of the blood and blood-forming organs 182

of blood-vesscls, 217

of circulatory organs, 186

of the digestive organs, 191

of the foot, 250

of the fore limb, 239

of the generative organs, 234

of the bind limb, 245

of the nervous system, 199

of the new-born, 294

of the organs of locomotion, 201

of the respiratory organs, $18 \mathrm{~S}$

of the skin, 202 precautions in treating smaller animals in, $33 \mathrm{~S}$

of the spinal column and pelvis, 238

of the thorax, 228

of urinary organs, 184, 232

rendering meat unfit for food, 351 specific infectious, 178

Disinfectants, 24

chemical, 350

defined, 161, 329

natural, 350

use of formaldehyde as, 25

Disinfection, defined, 141, 350

of ships, 348

of stables, 347 
Distemper in the dog, symptoms, 176

Distillation, 14

Distoma hepaticum, 195

Distomiasis in sheep, 19s

causes, symptoms and treatment,

Diuretic, 320 $19 S$

for cow, dog and horse, 318

liquid and powdered, 314

Dog distemper, symptoms of, 176

Dose, lethal and toxic, 298

Dourine, cause and definition of, 181 sanitary police measures in, 349 symptoms, 181

treatment, 182

Dover's powder, $32 S$ composition and uses, 328

Dropsy of the abdomen, 187 of the limbs, causes, 187

Drugs acting chemically, 332 mechanically, 332

on the alimentary canal, 331

on the glandular structures, 299 , 331

on the nervous system, 331

on the pupil of the eye, 319

on the reproductive organs, 332

Duct, mammary, 91 on the respiratory organs, 331

stenosis of, symptoms and treatment, $23 \mathrm{~S}$

Ductless glands, anatomy, 96

Ductus arteriosus, 68 choledochus, 84 venous, 67

Dummy, see Chronic hydrocephalus

Duodenum, anatomy, 82

Dura mater, anatomy, 71 physiology, 133

Dysentery, chronic bacterial, see Johne's disease

Dyspnca, 114

Dystocia, 264, 279-284

causes of, 279

fetal and maternal, 279

Ear, bones of, 137

diseases of, 217

E. C. mixture, 305

Ectropion, defined, 218

Eczema, chronic squamous, 205

causes, symptoms and treat

stages of, 156 ment, 205

treatment, in dog, 323

Efflorescence, 3

Elastic cushion of heel, 95

Elements, 6

Electricity, 6

Electrolysis, 2

Electrolyte, 2

Electro-plating, 2

Electuary, defined, 304

Elimination, 102, 103
Elimination, four ways of, 103

organs of, 102

Elixir, defined, 304

Embolism, 149

Embryology, 265

Embryotomy, 265

Emetics, 316

animals given to, 326

definition of, 326

Emmenagogue, 267

Emmenagogues, two principal, 267

Emphysema, pulmonary, 191 lesions, 150 symptoms and treatment, 191

in facial sinuses, 223

in frontal sinuses, 223

in guttural pouches, 220 diagnosis and symptoms, 220

in nasal sinuses, treatment, 223

Emulsion, 8, 304

difference from solution, 8

Encephalitis, 200

Endometritis, acute, causes, symptoms and treatment, 288

chronic, symptoms and treatment, 288

Endotoxin, 163

Enteritis, chronica paratuberculosa, see Johne's disease

catarrhal, acute and chronic, 152 intestinal lesions in, 152

Enterocentesis, described, 232

indications for, 232

tissues involved in, 232

unsatisfactory results in, 232

Enterokinase, 116, 119

Enteroliths, description of, 152

Entropion, defined, 218

Environment, influence on offspring, 362

Enzymes, 116, 118, 119

Epiblast, function of, 273

Epididymis, 92

Epididymitis, sterility from, 293

Epistaxis, causes, 188, 223 defined, 188, 223

treatment, 223

Epitheliomata, cylindrical, 145

squamous, 145

Epithelium, columnar, 101

histology, 101

kinds of, 101

modified, 101

specialized, 101

squamous, 101

Epizoötic cellulitis, 175 symptoms and treatment, 175

lymphangitis, 179 symptoms, prognosis and treatment, 179

Epsom salts, 30 administration of, to a cow, 317 . distinguished from zinc sulphate, 31 preparation of, 30 
Equations, 8, 9, 10

Erepsin, 116, 119

Ergot, actions of, 302

anatomy, 95

dose for dog and horse, 320

indications for use in labor, 280

poisoning in cattle, 198

forms of, and symptoms, 198

source, 320

uses of, 302

Ergotine, source of, 312

Ergotism in cattle, 198

forms and symptoms of, 198

Erythema, 204

causes, prevention and treatment, 204

Eserine, actions, 312

dose for dog, horse and $\mathrm{ox}, 312$

source and uses, 312

Esmarch's bandage, 208

Ether, compared with chloroform, 315 dose, 320

effects and uses of, 320

Eupnœa, 114

Eustachian catheter, 220

tube, anatomy, 95 epithelium of, 101 function of, 95,137

Eutocia, 264, 278

Evaporation, 2

Excretion, four ways of, 103 organs of, 102, 103, 105

Expectorants, 322 nauseating and stimulating, 322

Exosmosis, defined, 104

Exotoxin, 163

Exudates, inflammatory, 144

Exudation, difference from secretion, 104

Eye, anatomy, 93, 94

appendages of, 136

diseases of, 217

enucleation of, 219

muscles, 93

pathology, 155

tunics, 93, 94

Eyeball, anatomy, 93

muscles and structures of, 93

tunics of, 93, 94

Eyelashes, 136

Eyelids, 136

Facial nerve, 75

function of, 135

paralysis, 224,258

causes, symptoms and treatment, 224

sinuses, 85

trephining, 223

Fæces, avernge amount of, in horse and cow compared, 126

composition of, 103,120

of herbivora and carnivora compared, 120
Fallopian tubes, function of, 264

Farcy, 180

differentiated from acutc lymphangitis, 169

tissue changes in, 157

Fats, 41,360

palmitin, steapsin, and olein, 41

Fatty degeneration, 143 differentiated from fatty infiltration, 143

infiltration, 143 differentiated from fatty degeneration, 143

Favus, symptoms and treatment, 202

Fecundation, 264

Feeding, precautions as regards rest, 350 watering, 345

Feeling, impressions obtained through, 138

Fehling's solution, use of, 43

Fermentation, 34, 103

Ferments acting on milk, 118 on proteids and starch, 116

defined, 103

digestive, 116

of pancreatic juice, 121

Ferrous chloride, 11, 32, 302 uses of, 317

phosphate, 302 uses of, 317

sulphate, 32,302

dose, 309

preparation of, 32

uses in medicine, 32,317 vermifuge, 316

Fever, caused by infection, 141 by ne-vous disorder, 141 by poison, 141

methods of reduction of, 310

Fibrin, composition of, 108 globulin, 107

Fibrinogen, 101, 107, 108

Filaria immitis, 183 conditions produced by, 183

Filtration, 14 where found, 183

Firing, 245

diagram of, 214

Fistula, bone, 211

defincd, 144, 210

ear, 211

lachrymal, treatment of, 219

milk, 211

of the lateral cartilage, 211,251

of the spermatic cord, 211

of the witliers, 211, 229 treatment, 229

salivary, 227

causes, symptoms and treatment, 227

Fistulax, ten important, 211

Fistulous withers, clironic, 229

Flagclla, 160 
Flatulency, gastric, 193

causes and symptoms, 193

treatment, 193, 313

Fleas, 203 surgical, 229

Fluidextracts, preparation of, 320

Foal-lameness, 296 causes, symptoms and treatment, 296

Fœtus, dead, in utero, diagnosis, 284 envelopes surrounding, 274 extraction of, mechanical means, 280 phenomena of nutrition of, 271 position of, in ninth month, 275 secretions of, 267 skin of, development, 275

Fomentation, 329

Foods, 127 ante-mortem examination of animals for, 355 carbohydrate, 127 conditions of causing paralysis, 155 fat, 127

inorganic matter in, 127

non-nitrogenous, 127 effete materials produced by, 127 proteid, 127 ultimate results of, 127

Foot, diseases affecting, 156, 250 physiology, 138

provisions for preventing concussion in, 138

Foot and mouth disease, 176 pathology, 158 prognosis and symptoms of, 176 sanitary police measures in, 349

Forage poisoning, cryptogamic, 169 differentiated from lead poisoning, 169

hygienic measures in, 349

symptoms of, 201

Foraging overcome by shoeing, 256

Foramen, 51

infra-orbital, 45

magnum, 98

mental, 46

ovale, 68,98

Formaldehyde, use of, in disinfecting, 25

Formalin, used in white scours, 178

Fowler's solution, $30 \mathrm{~S}$ composition and uses, 308

dose for dog and horse, 308

Fracture, comminuted, 213

compound, 213

conditions rendering, bones liable to, 213

defined, 213

modes of union in, 213

of the femur, 246 diagnosis and prognosis, 246

of the ilium, 239,245 prognosis and treatment, 239

of the ischial tuberosity, 238 prognosis, symptoms and treatment, 238
Fracture of the metacarpus, 243 symptoms and treatment, 243

of the navicular bone, 250 prognosis, symptoms and treatment, 250

of the os corona, 251 symptoms and treatment, 251

of the os suffraginis, 243 symptorns and treatment, 243

of the ulna, 241

prognosis, symptoms and treatment, 241

pelvic, 238,239

plaster-of-Paris dressing for, 213

reparative process of, 147

ribs, symptoms and treatment, 229

simple, 213

varieties of, 213

Frog, use of, 138

Frontal bone, anatomy, 45

Fur, compared with hair and wool, 124

Gall-stones, 195

factors producing, 195

prophylaxis and therapeutics, 195

Ganglion, Arnold's, 75

ciliary, 75

Meckel's, 75

ophthalmic, 75

otic, 75

sphenopalatine, 75

sympathetic, 77,136

vertebral, 136

Gangrene, defined, 143, 211

kinds of, 211

of the lungs, 190 post-mortem appearance of, 150 treatment, 211

Gapes, 190

causes, symptoms and treatment, 190

Gas, calculations, 1

laughing, 18

Gastric juice, composition of, 118 source of hydrochloric acid in, 118

Generation, four stages in, 272

physiology, 139

Generative organs, changes in, after conception, 269

female, function of, 265

modifications after labor, 266

system, chief functions of, 264

Genitals of the cow, 92

diseases of, 234

Gentian root, 312

action, 322

dose for dog, horse and ox, 312, 322

uses, 312,322

German silver, 12

Gestation, 269

abdominal, ovarian, and tubal, 270

Gid, in sheep, 200

causes and symptoms, 200 


\section{Glanders, 180}

cause, course and symptons of, 180

chronic, 157

tissue changes in, 157,160

complement-fixation test for, 167

diagnostic tests for, 166-168

differentiated from strangles, 169 from nasal gleet, 169

hygienic and sanitary precautions in, 347

nasal ulcer in, 157

Glands, adrenal, 96, 98

Brünner's, 119

Cowper's, 264

ductless, 96

lachrymal, 94

Lieberkühn's, 119

mammary, 91, 140, 263

pituitary, 97

prostate, 92, 264

disease of, 236

salivary, 80

sebaceous, 95, 124

sudoriparous, 124

sweat, 95,123

thymus, 97,98

thyroid, 97

vascular, 112

Glass, 12

Glauber's salt, 7, 29, 300

Glaucoma, defined, 218

Gleet, defined, 223

Globus major, 92

Glossitis, causes of, 191 definition of, 191

Glossopharyngeal nerve, 75 function of, 135

Glucose in tissues, 127

in urine, 121

relation of pancreas to, 121

Glycerine, preparation of, 38

Glycogen, 121 destination and origin of, 127

Glycosuria, relations of pancreas to, 121

Goitre, cystic, in dog, treatment, 228 prognosis and treatment, 228

Gold, 27 in the dog and horse, 228

test for, 27

Goll's column, 103

Goulard's extract, 310

preparation and uses of, 310

Graafian follicle, 139

development and maturation of. 139

Grade, 361

Gram differential stain, 164 negative and positive, 164

Gramme, defined, 306

Granular venereal disease, in abortion, 182

Graphic formula, 11, 24

Graphite, 21

Gypsum, 30
Guttural pouch, anatomy, $\$ 6$ function of, 86 method of opening, 220

Chabert, 220

Viborg, 220

pus in, 220

diagnosis and symptoms, 220

Hæmatin, 103, 109

Hæmatoidin, 109

Hæmaturia, 153

Hæmoglobin, 107

combination with oxygen, 108

æmoglobinuria, 153, 1S3

differentiated from spinal meningitis, 169

etiology, 183

pathology of, 154

prevention and symptoms of, iS3

treatment, 1S3, 329

Hæmolysis, 108, 167, 168

Hæmophilia, definition of, 1S2

Hæmopis sanguisuga, 188

Hair, 95

compared with fur and wool, 124

precautions to limit injurious growth of, 125

Halogens, 25

Haustus, defined, 304

Haversian canals, 105

Healing of wounds, 207

by first intention, 207

by granulation and cicatrization, 207

by second intention, 207

by third intention, 207

under an eschar, 207

Hearing, mechanism of, 137

Heart, action of digitalis on, 109

anatomy, 62,63

disease, lesions of, 148

hypertrophy, 148

causes and lesions of, 148

muscle, 130

motor excitint of, 317

physiology of, 109

sounds, cause of, 109

Heat, 5

animal, conditions influencing, 125

how maintained and regulated, 128

stroke, 201

differentiated from heat exhaustion, 166

symptoms, 201

treatment, 201, 314

tissues producing greatest amount of, 129

unit of, 129

exhaustion, differentiated from heat stroke, 166

Heaves, symptoms and treatment, 191

lesions, 150

Hematite, 32 
Hemorrhage, 165

drugs checking, 310

following castration, 208, 234

internal, 165

methods of arresting, 208

postpartum, treatment, 290

Hemorrhagic septicæmia, 174 post-mortem lesions of, 159 symptoms of, 174

Hepatitis, acute parenchymatous, in dog, symptoms and treatment, $19 \mathrm{~S}$ chronic interstitial, 152 appearance of liver in, 152

Hepatization, gray, 150 pulmonary, changes in air-cells in, 150 red, 150

Hereditary, 361 diseases, 363

Heredity, influence on offspring, 362

Hermaphrodism, 296 external sexual organs in, 296

Hernia, classification of, 212

defined, 212

diaphragmatic, symptoms, 229

inguinal, symptoms and treatment, 230 irreducible, 212

of bladder into vagina, 292 reduction of, 292

reducible, 212

umbilical, treatment of, 230

Heroin, action and uses of, 315

Histological anatomy, 99

Hobbles, use in casting, 257

Hog, methods of medicating, 330

Hog-cholera, symptoms of, 172 causes of, 163

immunization in, 341

simultaneous method of, 343

lesions of, 160

prophylactic measures in, 173 serum, how obtained, use, 342

Hoof, anatomy, 95 secretion of, 138

Hoose, 189

Hoove, 192

Horns, anatomy, 95

Horse-pox, symptoms and treatment, 173 causes of, and extinction, 173

\section{Hoven, 192}

Humor, aqueous, 93 of the eye, 94 vitreous, 93

Hunger, cause of sensation, 119 mange, see Chronic squamous eczema

Husk, 189

Hydrargyri chloridum mite, 299 actions, dose and uses, 299 chloridum corrosivum, 299 actions, doses and uses, 299 iodidum rubrum, 299 actions, doses and uses, 299

Hydrocarbons, 34, 41 differentiated from carbohydrates, 34 , 41
Hydrocele, sterility from, 293

symptoms and treatment, 236

Hydrocephalus, 265, 279

chronic, causes, symptoms and treatment, 199

pathology of, 155

dystocia from, 279

how overcome, 279

Hydrogen, 13

an element of proteids, 106

compared with oxygen, 17

dioxide, 15,16

sulphide, preparation of, 23

Hydrops uteri, causes and treatment, 284 amnii, 285 causes, symptoms and treatment, 285

Hydrothorax, causes and symptoms, 191 lesions, 151

operations for, 228

treatment, 191, 228

Hygiene, 345 meat and milk, 351

Hyperæmia, 141

cerebral, 200

differentiated from cerebral anæmia, 200

Hyperisotonic, 40

Hyperpnœa, 114

Hypertrophy, causes of, 143

Hypnotic, 309, 320

Hypoblast, function of, 273

Hypoderma lineata, 203

Hypoglossal nerve, anatomy, 76

Hypo-isotonic, 40 function of, 135

Icterus, causes and symptoms, 193

pathology of, 153

relative gravity of, in dog and horse, 193

Ileum, anatomy, 82

Illuminating gas, 22

Immobility, 199 causes, symptoms and treatment, 199

Immune body, 168

Immunity, 141, 164, 341

acquired, 164, 341

active, 164

natural, 164, 341

passive, 164

varieties of, 164

Immunization, 341

in infectious diseases, 341

Imperforate anus, treatment of, 296

Impregnation, artificial, 273

Impregnator, use of, 273

In-breeding, 361

Incompatibility, 6

chemical, 6, 305

pharmaceutical, 6, 305

physical, 6

physiological, 6,305

therapeutic, 6 
Index, opsonic, how determined, 163

Indigestion, acute gastric, 193 causes, 193

prescription for, 336

symptoms, 193

treatment, 193, 313 surgical, 229

Inertia, uterine, 283 symptoms and treatment, 283

Infection, defined, 141 rise in temperature due to, 141

Infectious abortion, causes of, 182 anæmia, causes and characteristics of, 182

disease, 157, 165, 347 agents in development of, 142 disinfection in, 347

Inferior maxilla, anatomy, 46

Infiltration, fatty, 143 differentiated from fatty degeneration, 143

Inflammation, cardinal symptoms of, 144

$$
\text { causes of, } 209
$$

classification of, 210

defined, 144, 209

process of, 144

productive, 144

symptoms and treatment, 209

termination of, 210

tissue changes in, 144

use of cold and heat in, 210

Influenza, causes of, 177

cellulitic form, 175

differentiated from contagious pleuropneumonia, 170

symptoms, 177

treatment, 300 modern forms of, 177

Infusion, defined, 304

saline, indications for, 332 methods of administration, 332

Inguinal canal, anatomy, 62

Inhibition, defined, 133

Inoculation, diagnostic, 171

Insolation, 201 differentiated from heat exhaustion, 166

symptoms, 201

treatment, 201, 314

Insufficiency of cardiac valves, 186 causes and symptoms, 186 treatment, 187

Intestines, anatomy, 82 length of, in horse, cow and dog, 82 small, 82

Intussusception, defined, 194 genera most liable to, 194 prognosis and treatment, 194 symptoms, 194, 231

Invagination, genera most liable to, 194 symptoms, 194, 231 treatment, 194

Invertase, 116,119
Iodine, 25

compounds, actions and uses, 303

dose for dog and horse, 317

gencral actions of, 317

preparation and uses of, 26

test for, 25

tincture, uses of, 304

Iodoform, derivation of, 36

in chronic metritis, 289

uses of, 36,304

Ions, 2

Ipecac, actions and uses of, 323

an expectorant, 322

dose for dog and horse, 323

for cats and swine, 327

in Dover's powder, 328

Iridocyclochoroiditis, 156

Iris, anatomy, 93

function of, 136

innervation of, 136

Iron, 31

carbonate, 32

cast, 32

chloride, 32,302

uses of, 317

compounds of, 32

occurrence in nature, 31

ores of, 32

phosphate of, 302 uses of, 317

preparation of, 309

reduced, 32 dose of, 309

salts of, uses, 302

sesquioxide of, 302 uses of, 39,338

sulphate, 32, 302, 309

preparation of, 32

uses in medicine, 32,317

wrought, 32

Ischæmia, defined, 147

Ischial notch, vessels and nerves passing through, 260

Ischium, 50

fracture of tuberosity of, 238

notch of, 260

Isomerism, 5

Isotonic, 40

Jaborine, 328

Jaundice, 109

causes and symptoms of, 193

pathology of, 153

relative gravity of, in horse and dog, 193

Jejunum, anatomy, 82

Johne's disease, 179 cause, 179,163

genus subject to, 179

Joints, 51, 214 prevention and symptoms, 179

classification of, 51

false, 214

fetlock, 55 
Joints, hip-, horse and ox compared, 56 open, treatment, 214

pathology of, 147

shoulder, 53 muscles that flex, 58 structures entering into, 52

Karyokinesis, 102

Feraphyllocele, 250

Keraphyllous tissue, anatomy, 96

Keratogenous membrane, anatomy, 96 function of, 138

Kidneys, anatomy, 89

blood supply of, 89 compared with liver, 104

capsule of, 125

circulation of blood in, 112

cortical layer of, 125

elimination by, 102

function of, 125

of horse and ox compared, 89

secretion of urine by, 125

structures of, 101, 125

King system of ventilation, 346

Labor, 278

care of dam after, 283

signs and stages of, 279

Lachrymal apparatus, 94, 136

bone and canal, 94

fistula, treatment of, 219

gland in the ox, 94

of horse and ox compared, 94

sac, 94

secretion, function of, 137

Lactase, 116, 119

Lameness, hip, 245

symptoms and treatment, 245 varieties, 245

shoulder, 239 symptoms and treatment, 239

stifle, 246

symptoms and treatment, 246

trochanteric, 245

Laminæ, sensitive, 96

function of, 96, 139

Laminitis, acute, causes, symptoms and treatment, 255 pathology of, 156

chronic, 255 pathology of, 156

puerperal, in mare, causes, symptoms and treatment, 293

Lampas, defined, 210

Lanolin, source, 124

Laparotomy in the cow, 230 indications for, 230

Laryngitis, acute, 171 differentiated from acute pharyngitis, 171

Larynx, anatomy, 85

cartilages of, 86

epithelium of, 104

motor nerve to, 135

effect of division of, 135
Larynx, nerve supply to, 77, 86, 135

sensory nerve of, 135

Lateral cartilages, anatomy, 95 function of, 55,138

Laughing gas, 18

Law, Avogadro's, 12 of constant or definite proportions, 11 of multiple proportions, 11

Laxatives, 298, 316

Lead, 28

acetate of, 35

antidote for, 39

chamber process, 24

poisoning, 169, 195, 339

in cattle, 195, 339 symptoms and treatment, 195,339

sugar of, action, 28

dose, uses, 319

Leech, horse, 188

Lens, crystalline, anatomy, 93

Leptomeningitis, 155, 200

Lesion, primary and secondary, 141

Leucocytes, function, 107

Leucocy thæmia, defined, 146

Leucocytosis, defined, 147

diseases in which occurs, 147

relation of, to phagocytosis, 147

Leucorrhœea, 288

symptoms and treatment of, 288

Leukæmia, definition of, 147, 182

Lice, 203

Ligaments, broad, of liver, 83, 84 of uterus, 85,91

calcaneo-cuboid, 56

iliosacral, 260

of elbow-joint, 53

of femorotibial articulation, 56

of fetlock-joint, 55

of hip-joint, 56

of knee-joint, 54

of liver, 83

of pelvis, 260

of radiocarpal joint, 54

of shoulder-joint, 53

of vertebral articulations, 52

prepubic, rupture of, 231

round, of liver, 84

of uterus, 91

sacrosciatic, 260

suspensory, 55 sprain of, 242

utero-ovarian, 91

Ligamentum nuchæ, 53

Light, 5 elastic fibrous tissue in, 101

Lightning, death by, 142

lesions, 142

Lignieres, coccobacillus of, 177

Lime water, 30

Linguatula tænoides, 192

animals infested by, 192

diagnosis and treatment, 192

Linseed oil, actions and doses, 322 
Liquid, metric unit oł, 306

Liquor amnii, 272,274 functions, 272

plumbi subacetatis, 310 preparation and uses of, 310

potassii arsenitis, 33 sanguinis, 101

Lithium, 29 salts of, uses, 301

Liver, anatomy, 83 blood supply, 66, 84, 120 compared with kidney, 104 cirrhotic, appearance of, 152 fluke, 195

functions, 120

ligaments of, 83,85

nerve supply, 84

rot in sheep, see Distomiasis

Lobelia, properties and uses of, 317

Lochia, 289

common in all animals, 289

treatment, 289

Loco poisoning, prevention, 199 when and where enzoötic, 199

Lugol's solution, 303

Lumbago, 171

distinguished from acute nephritis, 171

Lunar bone, anatomy, 48

caustic, preparation of, 27 uses in medicine, 27

Lungs, anatomy, 87

blood supply, 66,88

congestion of, 190

elimination by, 103

epithelium of, 104

function, 114

number of lobes in dog, horse, ox, pig, and sheep, 87

Luxation, causes of, 215

defined, 215

patellar, 246 symptoms and treatment of, 246

Lymph, appearance, 122

capillaries, 122

described, 122

forces assisting flow of, 123

function of, 122

involved in diseases of connective tissues, 123

source, spaces, and vessels, 122

Lymphagogues, 123

Lymphangioma, 149

Lymphangitis, acute, 169 differentiated from farcy, 169

causes, 217

defined, 217

epizoötic, 158, 179 prognosis and symptoms, 179

infectious, 158, 179

pathology of, 158

symptoms and treatment, 217,329

Lymphatic glands, 70 axillary, 71
Lymphatic glands, bronchial, 70

iliac, 70

inguinal, 71

mesenteric, 71

of the thorax, 70

popliteal, 71

posterior cervical, 70 mediastinal, 70

precrural, 71

Lymphatics, 69

prescapular, 70

Lymphoid tissue, 70

Lysins, 342

Magnesium, 29

carbonate, 30

compounds used in medicine, 30

sulphate, 30

administration of, to cow, 317

distinguished from zinc sulphate, 31

Magnetite, 32 preparation of, 30

Mammary duct, stenosis of, symptoms and treatment, 238

gland, anatomy of, 91, 263

function of, 266

of the bitch, 92, 263

of the cow, 91

of the mare, 140

Mammitis, see Mastitis

Mange, demodectic, 203, 204 symptoms and treatment, 204

disposition of carcass, 354

follicular, 204

hunger, 205

prescription for, 333

psoroptic, 203, 204

sarcoptic, 203, 204

symbiotic, 203

treatment in dog, 324

Malignant œdema, 174 cause and course of, 174

differentiated from anthrax, 166 symptoms, 174

pustule, 175

Mallcin, 162

cutaneous test, 167

intradermal test, 166

ophthalnic test, 167

test for glanders, 166, 167 compared with agglutination, 167 course to be pursued in, 167

Malpighian corpuscles, anatomy, 97, 112

Maltasc, 116, 119

Marsh gas, 22

Marsh's test for arsenic, 33

Missiage, effect of, 319 indication for, 319

Mastitis, $23 \mathrm{~S}$ a sequel of cowpox, 173

acute, in the cow, 291 causes, symptom and treatment, 291,326 
Mastitis, purulent, $25 \mathrm{~s}$

treatment, 23S, 326

Masturbation, cause of sterility, 293 (see Onanism)

Materia medica, defined, 297

Measly pork, 353 method of detecting, 353

Meat and milk, hygiene, 351 inspection, municipal and State, 354

Mediastinum, anatomy, 88

Medicine, classified, 331 theory and practice of, 165

Medicines, kinds according to general action, 316

modes of administration of, 297 comparison of, 297

Medulla oblongata, anatomy, 72 functions of, 133

Meibomian glands, physiology, 136

Melanosarcomata, 145 animals found in, 145 gross appearance of, 145

Melanosis, cause of, 145

Membrana tympani, anatomy, 95 function, 95

granulosa, 139

Membrane, Descemet's, 94

keratogenous, 96

mucous, 100

nictitans, 94, 136

of Corti, 137

of Reissner, $13^{7}$

serous, 100

tympanic, 95

Meningitis, 155

cerebral, symptoms of, 200

cerebrospinal, symptoms of, 201 hygienic measures in, 349 spinal differentiated from azoturia, 169

Menstruation, causes of, 265

in bitch, cat, cow, and sow, 267

notindependent of ovaries, 265

Mercurialism, antidote and symptoms, 339

Mercuric chloride, 7,28 antidotes for, 39 properties of, 28

Mercurous chloride, 11, 28

Mercury, 28 properties of, 28

compounds used in medicine, 28

poisoning, antidote and symptoms, 338

preparations of, 299

Mesoblast, function of, 273

Metabolism, 40, 126

diseases of, 183

of nutrition, 126

Metacarpus, fracture of, 243 symptoms and treatment, 243

Metals, 5

alkaline earth, 29

bell, 12

distinguished from non-metal, 9
Metastasis, defined, 142

Methrmoglobiu, 109

Methylene blue, uses, 325

Metritis, 154 sterility from, 293

Metrotomy, indications and operation of, 286

Micrococeus, 160

Microörganisms, acid-fast, 162 pus-producing, 161

Microspira, 160

Miliary tubercle, 159

Milk, 41

bacterial analysis of, 359

bitter, 358

blue, 358

butter fat in, 42

certified, 355, 359

classification of, 357

cow's, composition of , $41,140,268,355$

dangers of infection in, 356

diseases transmitted through, 356

hygiene, 351

inspected, 357

mare's, compared with cow's, 268 composition of, 140, 269

pasteurized, 357,359

preservatives used in, 358

pus in, 358

red, 358

ropy, $35 \mathrm{~S}$

sour, microörganisms causing, 359

souring of, 42

standards, 42

sterilized, 359

streptococci in, significance of, 359

suppression of, 358

test for boric acid, 357

for formaldehyde, 358

for pasteurization, 357

for salicylic acid, 357

for sodium bicarbonate, 357

typhoid germs in, 356

uterine, 139

Mitosis, 102

Mitral stenosis, changes following, 149

Mixture, distinguished from compound, 9

Molecular repulsion, 4

Molecule, 3 weight, 5

Monad, 4

Morphine, actions and uses, 307

on dog and horse compared, 321 defined, 307

dose for dog and horse, 307

poisoning by, symptoms and treatment, 340

Morula, stage of, 268, 271

Motor oculi nerve, 74

functions, 134

Mucous membrane, 100

compared with serous, 100

location, 100

secreting gastric, 118 
Mules compared with horses, 365

Multiparous, 266

Muscles, anconeus, 58

anterior extensor of the metacarpus, $5 S$

caput magnum, 58

medium, 58

parvum, $5 \mathrm{~S}$

cremaster, 92

diaphragm, 61, 114

expiratory, 114

extensor pedis, 58 suffraginis, 58

external flexor of the metacarpus, 58

flexor brachii, 58

function of, 130

gastrocnemius, 59

gemelli, 59

gluteal, 59

heart, 130

humeralis obliquus, 58

iliopsoas, 59

inspiratory, 114

internal flexor of the metacarpus, 58 obturator, 59

involuntary, 130

kinds of, 130

longissimus dorsi, 60

longus colli, 61

masseter, 57

mastoidohumeralis, 57

oblique extensor of the metacarpus, 58

flexor of the metacarpus, 58

obturator externus, 59

of hogs, parasite in, 155

of respiration, 62,114

of the eye, 57

of the forearm, 58

of the tail, 60

pathology of, 155

panniculus carnosus, 60

pectineus, 59

perforans, 58

perforatus, 58

popliteus, 59

psoas, 59

pterygoid externus and internus, 57

quadratus femoris, 59

sartorius, 59

serratus magnus, 61

small adductor of the thigh, 59

striated, 100

striped, 100

and unstriped compared, 100

subscapulohyoideus, 57

surgery of, 216

temporal, 57

tensor fascia lata, 59

teres externus and internus, 58

triceps, 58

unstriped, 100

vastus externus and internus, 59

voluntary, 100,130
Muscular contraction, 130 chemical changes in, 130 phases of, 130

excitability, conditions enhancing, 131

Mustard, 319 conditions impairing, 131

an emetic, 316

dose for $\operatorname{dog}, 316$

as a blistering agent, 313

Mydriatic, 309

Myocarditis, 149

Myology, 57

Myoma, 146

Myositis, causes, 216

defined, 216

symptoms, 216

Myotic, 309

Myotomy, caudal, object of, 239

Nasal gleet, 169, 188

causes of, 188

differentiated from glanders, 169 symptoms and treatment, 188

Navicular sheath, anatomy, 62

bone fracture of, 250 disease of, 252

symptoms and treatment, 252

Necrobacillosis, cause and forms of, 163

Necrosis, 143

bacillus of, 163

caseation, occurrence, 143

coagulation, 143

liquefaction, 143

Negative phase, 164

Negri bodies, 158

Nephritis, acute, 171 casts found in, 153 causes and treatment of, 185 distinguished from lumbago, 171 from lumbar rheumatism, 171

gross pathology, 154

chronic interstitial, 185

casts found in, 153

gross pathology, 154

Nerves, abducens, 75, 134

afferent, 131

auditory, 75, 135137

ciliary, 93

cranial, $73-76$

deseribed, 99

digital, 76

efferent, 131

facial, 75,134

function of, in secretion, 104

glossopharyngeal, 75, 135

hypoglossal, 76, 135

median, 76

motor, effect of electric stimulation of, 133

motoroculi, 74, 134

olfactory, 73, 134

optic, $74,93,134$ 
Nerves, patheticum, 74, 134

phrenic, function of, 133

plantar, 76

pneumogastric, 75, 135

radial and sciatic, 76

sensory and motor compared, 132

spinal, 73

effect of division of both roots of, 132

of inferior roots of, 132

functions of, 132

number of, 73

spinal accessory, 76, 135

surgery of, 216

trifacial, 74,134

vagus, 75,135

Nervous system, 71, 131

cerebrospinal, 71

development of, in the fœtus, 275

influence on secretion, 134

pathology of, 155

sympathetic, 77 function of, 135

Neurectomy, anterior tibial, 249

high plantar, 244

indications for, 245

relation of artery, vein,

median, indications for, 244 nerve and tendon, 245

structures severed in, 99

posterior tibial, 250

trifacial, technic of, 228

unfavorable results in, 216

Neurilemma, 100

Neurology, 71

Neuroma, 146

Neurotomy, unfarorable results in, 216

Neutralization, 4

New-born, asphyxiated, 294

cyanosis, causes and symptoms, 296 treatment, 294

diarrhœea in, 294 causes and treatment, 294

diseases of, infectious, 294 non-infectious, 294

Nitrate of potash, see Potassium

Nitric acid, preparation and uses of, 19 tonic, 318

oxide, 11,12

Nitrogen, 18

an element of proteids, 106

compared with oxygen, 18

function of, 18

oxides of, 18

preparation of, 18

Non-metal, 9

Nutrition, metabolism of, 126

Nux vomica, dose of fluidextract, 310 uses, 310

Obstetrics, 259

Obstetrist, disadvantage of, 280 veterinary, 280

Ocular sheath, physiology, 136
Oculomotor nerve, 74

Edema, 141, 144

function of, 134

causes, 144

differs from secretion, 104

of the glottis, 188

symptoms and treatment, 188

of the lungs, cause, 149

Esophagotomy, 221

in choke, 221

Esophagus, anatomy, 80

Estrus larva, in throat of solipeds, 188

Oils, castor, action and dose, 322

croton, see Croton oil

essential, 34

fixed, 34

linseed, action and dose, 322

Olein, 41

Olfactory nerve, 73

function of, 134

Oligemia, defined, 182

Oligocythæmia, definition of, 182

Omasum, anatomy, 82

Omphalophlebitis, 295 causes, symptoms and treatment, 295

Onanism, sterility from, 293 correction of, 293

Oöphorectomy, in the bitch, 237 in the mare, accidents, 237

Oöphoritis, 154

Open joint, treatment of, 214

Opium, dose for cow, dog and horse, 301 general actions, source and uses, 301

Ophthalmia, periodic, 155 pathology of, 155 prognosis, 218 symptoms and treatment, 218

contagious, animals affected by, 219 diagnosis and treatment, 219

Opsonic index, 163 how determined, 163

Optic nerve, anatomy, 74, 93 function of, 134 thalami, anatomy, 72

Orchitis, 141, 154 causes, 236 sterility from, 293 symptoms and treatment, 236

Organs, abdominal, pathology, 152 eliminating, 102, 105 genito-urinary, pathology, 153 of secretion, 105 respiratory, pathology, 150 sense, 93 vital. 105

Orgasm, 266

Os innominatum, 50 coxa, 50

Osmosis, 41

Osteology, 44

Osteomalacia, 169 differentiated from osteoporosis, 169 in pregnancy, 284, 292 treatment, 292 
Osteomyelitis, defined, 212

Osteoporosis, 169 course of, 184

differentiated from osteomalacia, 169 pathology of, 147

symptoms and termination of, 183 treatment of, 184

Ostitis, defined, 212

Otorrhœa of dog, treatment, 220

Ovaries, anatomy, 90, 262

changes in, after fecundation, 265

conditions of, causing sterility, 294

cystic, 293

$$
\text { pathology of, } 154
$$

during menstruation, 264

extirpation of, in bitch, 236

$$
\text { in mare, } 237
$$

function of, 265

of cow and mare compared, 90

of mare, cow, sheep, goat, pig, bitch and cat compared, 263

pitted in old age, 264

Ovariotomy, in the bitch, 236

in the mare, accidents, 237

Oviducts, 264

function of, 264, 265

Ovum, impregnation of, 268

journey of, 268

Oxidation, 16,17

rapid and slow, 17

Oxygen, 16

an element of proteids, 106

compared with hydrogen, 17

compared with nitrogen, 18

how carried in blood, 108

preparation of, 16,17

Oxyhæmoglobin, 109

Oxyuris curvula, 195, 196

mastigodes, 196

prescription for, 195

Ozone, 17

Pachymeningitis, 155, 200

Palmitin, 41

Palpation, 171

Pancreas, anatomy, 84

blood and nerve supply of, 84

functions of, 121

relation of, to glucose in urine, 121

relations of, 84

secretion, 121

Paper-skin disease, 189

Patheticum nerve, 74

function of, 134

Paralysis, facial, 224, 258

food conditions causing, 155

of the bladder in horse and $\log$, 233

causes, symptoms and treatment, 233

of the lips, causes, symptoms and treatment, $\$ 224$

of the masticatory muscles, symptoms and treatment, 226
Paralysis of the penis, causes, symptoms and treatment, 235

originating in brain, cord and periphery, differentiated, 216

radial, symptoms and treatment, 241

suprascapular, cause, symptoms and treatment, 240

Paraphimosis, symptoms and treatment, 235

Parasites, affecting gullet of cattle, 192

in intestines of the horse, 195 of the dog, symptoms, 197

in muscles of hogs, 155

in the throat of solipeds, 188 prevention, symptoms and treatment, $18 \mathrm{~s}$

of sheep, 364

of the skin, 203

Paris green, 33 antidote for, 39, 338

Parturient, apoplexy, 2S7 Schmidt treatment of, 287

eclampsia, 287 and parturient paresis differentiated, 287

in the mare, 287 causes and treatment of, 287 paresis, 287

Parturition, 279

diseases following, in cow, 284

fetal conditions interfering with, 279 sign and stages of, 279

Patella, displacement of, symptoms and treatment, 246

Pathogenic, defined, 161

Pathology, defined, 141 special, 141

Pearson's solution, 308 dose, preparation and uses, $30 \mathrm{~S}$

Pedal bone, anatomy, 48

Pedigree, 362 connection of hoof wall with, 96

depends upon, 362

value of, 362

Pelvis, articulations of, 260

bones of, 50

centres of ossification in, 259

defined, 259

diameters of, in cow, 260

discases of, 238

fracture of, 238,239

function of, 259

ligaments of, 260

of horse and ox compared, 50

of mare, cow, sheep, goat, bitch and cat compared, 259

of sheep and cow compared, 260

Penetrating strect nail, treatment, 256

Penis, amputation of, 235

paralysis of, cause, symptoms and treatment, 235

Pentad, 4

Pepsin, 116, 118, 119

preparation and properties of, 315 
Percentage composition, determination of, 11

Periarthritis, defined, $148,2^{\circ}$

Pericarditis, acute, 149

chronic, lesions, 149

in bovines, causes, prevention, symptoms and treatment, 186

Perimysium, 100

Periodic ophthalmia, 155

pathologic changes in, 155

prognosis and symptoms, 218

treatment, 218,312

Periostitis, aseptic, 213 causes, symptoms and treatment, 213

defined, 148, 212

Peristalsis, 119 remedies promoting, 314

Peritoneum, anatomy, $8 t$ part of spermatic cord, 92

Peritonitis, 195 causes, 198, 232

pathology of, 152

pulse in, 165

symptoms and treatment, 198

Perspiration, 124

effect of suppression, 124

Petroleum, uses, 37

Peyer's patches, 70

in catarrhal enteritis, 152

Phagocytes, 146

Phagocytosis, 104, 146 method of stimulating, 147

relation of leucocytosis to, 147

Pharyngitis, acute, differentiated from acute laryngitis, 171

Pharynx, anatomy, 80

Phase, negative and positive, 164

Phenacetin, 310, 317

Phenol, source, 37 antidote, 40

Phlebitis, causes, and defined, 217

Phlebotomy, indications for, 228 (see Venesection)

Phlegmon, 209

Phosphine, 11

Phosphoric acid, 11

Dhosphorus, 25 allotropic forms of, 25

antidotes for, 39

occurrence, 25

physical properties, 25

source and uses of, 25

Phragmidothrix, 160

Phrenitis, 155, 200

Physical change, 2

Physics, 1 distinguished from chemistry, 1

Physiologic action of a drug, 298 salt solution, 40

Physiology, 102 a study of the properties of cells, 102 definition, 102

obstetrical, 264
Physostigmine, 319

Pia mater, anatomy, 71 physiology, 133

Pilocarpine, action of, 317 source of, 312,328

Pilocarpus, actions, 328 active principles of, 328 composition, 328 dose and uses, 328

Pineal bodies, vascular glands, 112

Pisiform bone, anatomy, 48

Pituitary gland, anatomy, 97

Placenta, 139 vascular gland, 112

cotyledonary, 139, 271

development of, 271

diffuse, 139,271

function of, 139, 271

retained, 291 prescription for, 291

zonary, 139,271

Planococcus, 160

Planosarcina, 160

Plasma, 101

Plaster of Paris, 30

Pleura, anatomy, 88

Pleurisy, 190

of the dog, 191

lesions, 151

pulse in, 165

symptoms and treatment, 190

Pleuritis, acute diffused, 190

lesions, 151

symptoms and treatment, 190

Plexus, brachial, anatomy, 76

cardiac, 136

lumbosacral, 76

mesenteric, 136

pelvic, 91

solar, 136

Plumbi acetate, 28

actions, dose and uses, 319

Plumbism, see Lead poisoning

Pluriparous, 266

Pneumogastric nerve, anatomy, 75

function of, 135

influence on heart, 109

Pneumonia, broncho-, appearance of lungs in, 151

gangrenous, 190

post-mortem appearance, 150

symptoms of, 190

inhalation, 188

causes of, 188,258

prevention, 189

symptoms and treatment, 189

medicinal treatment of, 300

post-mortem appearance, 150

symptoms of, 190

Podophyllum, actions and uses, 328

dose, 317,328

general action, 317

source, 317 
Poisoning, ergot, in eattle, 198

lead, 169,195

$$
\text { differentiated from forage poison- }
$$

loco, 199 ing, 169

Poisons, 38

irritant, 38

neurotic, 38

metallic, 39

Poll-evil, operation for, 227

Polycythæmia, defined, 146

Polypi, nasal, 223

symptoms, 223

treatment, 223

pharyngeal, treatment, 221

Polyuria, causes and treatment, 185

Portal circulation, 112

vein, 69

relation to absorption, 120

Position, cephalosacral, 281

obstetrics, 278

right cephalo-ilial, ${ }^{2} 281$

sterno-abdominal, 281

varieties, 279

Positive phase, 164

Post-zygopophyses, 52

Potassium, 300

acetate, 35 dose, 318

alum, 31

bicarbonate of, 29

bromide, 300

chlorate of, 11, 29, 301

dose and properties of, 311 uses, 301, 311

citrate, dose, 318

hydroxide, 29, 301

iodide, preparation of, 26

dose of, 314

uses, 301,304

nitrate, $7,11,29,300$

action, 319,330

dose, 318,330

source, 330

uses, 319,330

permanganate, 11,326 action and uses, 326

sodium tartrate, 7

Precipitation, 14

Prefixes, chemical, 8

Pregnancy, 269

care and food of animals during, 269

changes in blood, 274

diseases incidental to, 284

duration of, in bitch, cow, ewe, mare and sow, 268

effects of indigestion, 270

extra-uterine, varieties of, 270

multiple, position of foetus in, 272

position of neighboring organs during, 273

signs of, 270
Prehension, organs of, 77,80

in horses, cattle and sheep compared, 116

Premature birth, 276

Prepotency, 361

Prescription for actinomycosis, 336

for acute indigestion, 336

for blister, 335

for bowed tendons, 216

for cathartic, sheep, 335

for chronic constipation, dog, 337

for chronic cough, 332, 337

for chronic eczema, dog, 335

for cocaine, 333

for cough powder, 334

for diarrhoea in calves, 333

for fever in horse, 333

for flatulent colic, 337

for intestinal worms, 195

for liniment, 336

for mange, 333

for purgative, 332,334

for ringworm, 337

for round worms in dog, 333

for scratches, 336

for spasmodic colic, 334

for tonic for horse, cow and dog, 334, 335

Presentation, 278

anterior, 281, 282

most difficult, $27 \mathrm{~s}$

most favorable and frequent, 278

normal, 278

posterior, 281

varieties, 278

Prezygopophyses, 52

Primiparous, 266

Process, basilar, 48

condyloid, 46

coronoid, 46

retrossal, 48

spinous, 49,51

Prognosis, 165

Prolapse, defined, 212

Prophylaxis, 349

Prostate gland, 92 diseases of, symptoms and treatment, 236

Protargol, 27 uses, 330

Proteids, elements composing, 106 ferments acting on, 116 important food, 127

Protein, 360

Proximate principles, 346

Pseudomonas, 160

Psoroptes communis, 203

Ptomaines, 39

Ptyalin, 116

Ptyalism, causes, 226 accidental, 226 disease, 226

Puberty, 364 in various domestic animals, 364 
Puerperal laminitis in mare, cause, symptoms and treatment, 293

septicamia, causes, symptoms and treatment, 291

Pulmonary congestion, 190 causes, 149,190

lesions, 150 symptoms and treatment, 190

emphysema, 191

lesions, 150

treatment, 191

œdema, causes of, 149

Pulse, compressible, 165

dicrotic, 165

fast, 165

hard, 165

normal, in horse, ox, dog, sheep and cat, 112

Pupil, anatomy, 93 drugs contracting and dilating, 319

Purgatives, 298, 316

cholagogue, 298, 316

drastic, 298, 316

hydragogue, 298

saline, 316

simple, 298

Purpura hæmorrhagica, causes of, 177

prognosis of, 178

symptoms of, 177

treatment of, 178,320

Pus, microörganisms producing, 161 in guttural pouch, 86 diagnosis and symptoms, 220 in nasal sinuses, treatment of, 223

Putrefaction, 34

Pyæmia, 209 differentiated from septicæmia, 170 treatment for, 170

Pyelitis, diagnosis and treatment, 184 Pyoktanin, uses, 325

Quassia, actions, dose and use, 322

Quinine sulphate, action, 306 dose for cow, dog and horse, 306, 307 uses, 306

Quittor, 251

Bayer's operation for, 252

symptoms and treatment, 251

Rabies, 176

course and symptoms of, 176

diagnosis of, 171

dumb, 176

furious, 176

immunization in, 341

lesions of, 157

period of incubation, 178

precautions taken in bitten animals, 209

sanitary police measures, 351

Rachitis, cause, 184

in pregnancy, treatment, 292

symptoms, 184

treatment, 184, 320
Radial paralysis, 241

symptoms and treatment, 241

Radium, 29

Rations, 127, 360

balanced, 127, 360 nature and value of, 127

for a dairy cow, 127, 361

for a horse, 127, 360, 361

for swine, 361

Receptaculum cliyli, 70

Reduction, 5

Reflex, action defined, 104, 132 experiment illustrating, 132 movements, 134

Reil, island of, 72

Reissner, membrane of, 137

Rennin, 116, 118, 121

Repeller, indications for use, 280

Repulsion, molecular, 4 of a diseased upper molar, 226

Resection, perforans tendon, indications for, 256

Residual air, 114

Resorcin, actions, dose and uses, 330

Respiration, Cheyne-Stokes type of, 166 functions of, 113

muscles of, 62

normal number, 114

relation to pulse-beats, 114

Respiratory organs, anatomy, 85 pathology, 150

Restraint, methods of, 257 in recumbent position, 257 in standing position, 257

Reticulum, anatomy, 82

Retina, anatomy, 93

Rheumatism, articular, causes, symptoms and treatment, 201

muscular, causes, symptoms and treatment, 201

Rhinitis, chronic, causes of, 188

differentiated from glanders, 169

symptoms and treatment, 188

Rhino-adenitis, see Strangles

Ribs, anatomy, 51

asternal, 51

fracture of, 229

symptoms and treatment, 229 sternal, 51

Rigor mortis, 131 changes in muscle in, 131

Ringbone, defined, 243

forms of, 243,251

symptoms of, 243

treatment, 243, 251

Ringworm, cause, 203, 164

prescription for, 337

symptoms and treatment, 202

Roaring, changes in nervous and muscular tissue in, 151

operation for, 222

symptoms of, 222

Rochelle salts, 7

Rotation, obstetrics, 278 
Rubidium, 29

Rumen, anatomy, 81

Rumenotomy, in cow, 230

Rumination, physiology of, 117

Rupture of the bladder, causes, symptoms and treatment, 233

of the diaphragm, symptoms, 229

of the flexor metatarsi, 247

of the ligamentum teres, 245

of prepubian ligament, 231

of tendons, 215

Sacrum, anatomy, 50

Saddle-galls, treatment for, 229

Salicylic acid, preparations of, 327 actions and uses, 327

Saline infusion, 332

-. indications, 332 methods of administration, 332

Saliva, action in stomach, 119

amount in horse and ox, 117

properties and uses of, 116

Salivary calculi, treatment of, 227

fistula, causes, symptoms and treatment, 227

glands, 80

nerve supply of, 77

Salol, 37 ducts of, 80

Salt, 3

actions and uses, 327

acid, 4,12

basic, 12

physiologic solution of, 40 use of, 332

effect of, on growth of wool, 125

Saltpetre, 7

Salvarsan, used in contagious pleuropneumonia, 176 in dourine, 182

Sanitary, barn, farm, and milk-house, 358 science, used by veterinarian, 345

Santonin, dose, 325

Saphrophytic, defined, 161

Sarcina, 160

Sarcolemma, 100

Sarcoma, tissue resembling, 145 types of, 145

Sarcoptes scabci, 203, 204

Saturnism, see Lead poisoning

Scabies, 204

in sheep, 204

Scaphoid bone, anatomy, 48

Scapula, anatomy, 47

Scirrhous cord, causes, symptoms and treatment, 234

Sclerostoma equinum, 196

tetracanthum, 196

Sclerostomata in bowels of horse, 195 symptoms, 195

Seratches, prescription for, 336

Scrotum, anatomy, 92

Sebaceous glands, 124
Sebum, functions of, 124

where and how secreted, 124

Secretion, defined, 104

differs from exudation, 104

from odema, 104

from transudation, 104

function of blood in, 104

function of gland cells in, 104

function of nerves in, 104, 134

influenced by nervous system, 134

lachrymal, function of, 137

organs of, 105

Sedatives, action of, 298

danger of excessive use, 298

Seedy toe, 253

defined, 253

treatment, 253

Selection for breeding, 362

points considered, 362

Sense organs, anatomy, 93 physiology, 136

Senses, physiology, 136

Septicæmia, 209

differentiated from pyæmia, 170

puerperal, 291

causes, 291

symptoms and treatment, 291

trcatment for, 170

Serous membrane, 100

compared with mucous, 100

location, 100

Serum albumin, 101, 107

bactericidal, 163

bacteriolytic, 163

danger in transfer, 108

globulin, 101, 107

prophylactic, 350

therapy, 341

of hog cholera, 342

Sexual organs, anatomy, 90

Sheep, parasites of, 364

wool brecds of, 361

Shoe-boil, etiology, 240

treatment of, 240,241

Shocing, in bruised heel, 257

in canker, 254

in contracted tendons, 256

in contracted hoof, 256

in corns, 253

in laminitis, 255

in navicular disease, 252

in quarter crack, 256

in thrush, 254

physiologic, 139

to overcome forging, 256

Shoulder abscess, cold, 240

joint, 53

cause and treatment, 240

$$
\text { dislocation of, } 239
$$

lameness, 239 symptoms and treatment, 239

Side-lones, pathology, 251

treatment, 251

Siderite, 32 
Silver, 27

compounds used in medicine, 27

Gernuan, 12

nitrate, 11,18

test for, 27

Sinapis alba semina, 319

nigra semina, 319

Sinuses, 51

facial, trephining of, 223

frontal, of horse and ox compared, 85

galactophorus, 92

maxillary, 45

point to trephine, 99

nasal, pus in, treatment, 223

of the head, 85

Skin, appendages of, 95

diseases of, 202

elimination by, 102

function of, 123

glands found in, 123

parasites of, 203

pathology of, 156

Soap, preparation of, 41

Sodium acetate, 35 .

arsenate, 33

bicarbonate, 11, 29, 300

action, 331 dose and uses, 331

borate, 31

bromide, 300

carbonate, 7, 29 preparation of, 29

chloride, 29,300

an emetic, 316

dose for dog, 316

citrate, a lymphagogue, 123

hydrate, 42

hydroxide, 29, 301

hyposulphite, 300,313

iodide, 303

dose, 314

nitrate, 18

phosphate, 29

salts, 29

Solder, 12

sulphate, 7, 29, 300

Sole, pumiced, cause, 253

Solution, 8 prognosis and treatment, 253

difference from emulsion, 8

Fehling's, use of, 43

Fowler's, composition, 308 dose for dog and horse, 308 uses, 308

Pearson's, 308 dose, preparation and use, 308

Solvay process, 29

Soundness, certificate for, 172

mode of examining for, 172

Spasm of diaphragm, and treatment, 307

of muscles of hind leg, and treatment, 202
Spavin, blood, 248

bog, 248,362

forms of, and treatment, 248

lesions of, 148

unsoundness, 362

Specific gravity, determination of, 1 of urine, 43

Spermatic artery, 92

cord, structures of, 92

vein, 92

Spermatozoa not always in semen, 266

Spider in teat, 238

symptoms and treatment, 238

Spinal accessory nerve, 76 function of, 135

Spinal column, diseases of, 238

cord, anatomy, 72

functions of, 131

inferior columns of, 132

function of, compared with superior column, 132

reflex functions of, 132

superior columns of, 132

Spinal meningitis, 169

differentiated from azoturia, 169

Spine, acromian, 47 supermaxillary, 45

Spirillaceæ, 160

Spirillum, 160

Spirits, ammonia aromaticus, action and dose, 326

definition, 305

difference from tinctures, 305

glonoin, action and dose, 326

nitrous ether, dose, 318

Spirochæta, 160

Spirosoma, 160

Spleen, a ductless gland, 96

anatomy, 97

a vascular gland, 113

blood supply of, 66,97

diseases in which enlarged, 153

engorgement of, 97

function of, 113

nerve supply of, 77, 97

of horse and ox compared, 97

Splint, etiology of, 242

symptoms and treatment, 243

Spore, 160

Sporotrichosis, 179

Stable, objectionable locations for, 345 proper drainage for, 345

Staggers, stomach, see Vertigo

Stall, properly built for horse, 364

Stannous chloride, 11

Staphylococcus pyogenes albus, 161 aureus, 161 citreous, 161

Staphyloma, defined, 218

Starch, ferments acting on, 116

Starvation, 126

effect on tissue, 128

on urine, 126

Steapsin, 116, 121 
Stearin, 41

Stenosis, mammary duct, symptoms and treatment, 238

mitral, changes following, 149

Sterile, defined, 161

Sterility, causes and treatment, 293 in female and in male, 293 defined, 293

Sterilization of hands and instruments, method of, 258

Sternum, anatomy, 49 of horse, ox and dog compared, 49

Stimulants, cardiac, 305

cerebral, 305

definition of, 305

diffusible, 305

general, 305, 314

hepatic, 305

Stomach, anatomy, 81

blood supply of, 66,81

epithelium of, 104

function of, 117

nerve supply of, 77,81

number of, in horse, ox, goat and camel, 118

ruptured, symptoms of, 192

staggers, see Vertigo

tube, indications for use, 232 method of passing, 232

Stomatitis, causes and treatment, 225

Strangles, complications occurring in, 178 differentiated from glanders, 169 symptoms of, 178

Streptococcus pyogenes, 161

Streptothrix, 160

Stringhalt, operation for, 248

Strongylosis, bronchial, 189 symptoms, 189

Strongylus equinum, 196 rufescens, 189 disease produced by, 189 symptoms, 189

tetracanthum, 196

Strontium, 29

Strophanthus, action and dose, 326, 328 uses, 328

Strychnine, actions and uses, 310

antidote, 39,340

dose for dog and horse, 310

poisoning in dog, and treatment, 340

Succus entericus, 119

Suffixes, 7

Suffraginis, fracturc of, symptoms and treatment, 243

Sulphur, 23

an element of proteids, 106

cffect of ingestion of, on wool growth, 125

in disinfecting, 23

propertics and uses of, 23

Sunstroke, differentiatcd from exhaustion, 166

symptoms of, 201

treatment, 201, 314
Superior maxilla, anatomy, 45

Suppuration, 208

susceptibility of differcnt animals, 208

Suprascapular paralysis, cause, symptoms, and treatment, 240

Surgery, 206

Surra, causes of, 163

Suspensory ligament, anatomy, 55 sprain of, causes, prognosis, symptoms and treatment, 242

Suture, continuous, uses of, 207

Swamp fever, causes and characteristics of, 182

Sweat-glands, 123, 124

in different genera, 123

Sweeney, defined, 216, 240

treatment, 216, 240

Swine plague, 172 prophylactic measures in extinction of, 173

symptoms, 172

Sylvius, fissure of, 72

Symbiotes communis, 203

Sympathetic nervous system, 77

Synarthrosis, 52

$$
\text { functions of, } 135
$$

Syncope in anxsthesia, 258

Synechia, 156

Synergistic remedial agents, 297

Synovitis, 214

Synthesis, 3, 6

Systole, 109

Tænia cœnuris, 200

mamillana, 195

perfoliata, 195

plicata, 195

solium, 353

Tapeworm in dog, treatment, 323

in solipeds, 195

Tar, actions of, 318

coal, products of, 317

source and uses, 318

Tarsus, conditions causing unsoundness, 362

Tartar emetic, 34,325

actions, 325

dose, $316,325,327$

vermifuge, 316

Taste, nerves of, 134, 135, 137

primary sensations of, 137

Teeth, anatomy, 78

at various ages, 79, 225

canine, 78

composition of, 78

incisor, 77,78

horse and ox compared, 78

modifications in upper and lower molars, 79

molar, 78

repulsion of discased upper, 226

Temperature, body, 128

average normal, for different genera, 128 
Temperature, causes of the variation in, 129 in cold-blooded animals, 128 in warm-blooded animals, 128 factors in regulation of, 129 result of severe exercise on, 129 rise in, due to infection, 141 due to nervous disorders, 141 due to poison, 141

subnormal, diseases with, 171

of a germ, maximum, minimum, optimum, 164

Tendinitis, causes of, 215,242 symptoms, 242 treatment, $215,241,242$

Tendons, bowed, prescription for, 216 flexor, contraction of, treatment, 241 inflammation of, causes, symptoms and treatment, 242 metatarsi, rupture of, 247 rupture of, causes of, 215 surgery, 215

Tendovaginitis, causes, symptoms and treatment, 215

Tenotomy, cunean, object of, 247 peroneal, object of, 248

Termination, defined, 165

Testicles, anatomy, coverings of, 92 function of, 139

Test, agglutination, 166, 167 complement-fixation, 166, 167 for preservatives in milk, 357 mallein, 166, 167 Marsh's, for arsenic, 33 precipitin, 166

Tetanus, accessory cause, 174 bacillus of, 162 cause and prevention, 174 genera most subject to, 174 immunization in, 341 symptoms and treatment, 174,300

Tetrad, 4

Texas fever, causes, 176 post-mortem lesions, 158 symptoms, 176

Therapeutics, defined, 297

Thermic fever, symptoms and treatment of, 201

differentiated from heat exhaustion, 166

Thermometric equivalents, 2

Thiothrix, 160

Thirst, cause of sensation of, 119

Thoracic duct, 69, 123

Thorax, anatomy, 87 receptaculum chyli of, 70 diameters enlarged in inspiration, 113 diseases of, 228 of horse and ox compared, 87 organs contained in, 87

\section{Thoroughbred, 361}

Thorough-pin causes unsoundness, 362 pathology of, 249

Throat, diseases of, 217

Thrombin, 108
'Thrush, causes, prognosis, symptoms and treatment, 254

differentiated from canker, 254

Thumps, treatment for, 307

Thymus gland, 97, 98

$$
\text { a vascular gland, } 112
$$

Thyroid gland, 97

$$
\begin{aligned}
& \text { a vascular gland, } 113 \\
& \text { function, } 113
\end{aligned}
$$

Ticks, 203

Tidal air, 103, 114

Tincture, definition of, 305 difference from spirits, 305 official, 306 preparation of, 305

Tinea tonsurans, disease produced by, 164 Tissue, collecting for bacteriologic examination, 163 connective, 101 elastic fibrous, where found, 101 keraphyllous, 96

Tongue, anatomy, 77, 79

Tonic, 321 acid, 318 blood and nerve, 314

Topographical anatomy, 98

Torsion, arresting hemorrhage by, 208 of uterus, symptoms and treatment, 283

Toxicology, 38, 338

Toxin, 163

Trachea, anatomy, 86

Tracheotomy, indications for, 224 in œedema of glottis, 188 structures severed in, 98

Transudation differs from secretion, 104

Trapezoid bond, anatomy, 48

Triad, 4

Trichina spiralis, 155, 202, 354

Trichinosis, 202, 354 animals affected by, 202 channels of infection, 202 diagnosis and prevention, 202 disposition of carcass, 354 lesions, 155 methods of detection, 354

Trifacial nerve, 74 function of, 134

Trochanter, 51

Trochanteric lameness, 245

Trochlea, 51

Trypanosoma Evansi, 163

Trypsin, 116, 121

Turpentine, oil of, administration of, 311 dose, 325 source and use, 311

Tube, Eustachian, anatomy, 95 epithelium of, 101 function of, 95,137

stomach-, indications for, 232 methods of passing, 232

Tubercle, crude and miliary, 159

Tubercula nates, 72 testes, 72 
Tuberculin, 162

testing with, 170

Tuberculosis, 181 sources of fallacy in, 170

bacillus of, 162

Bang method of eradicating, 350

channels of infection, 162

course of, 1S1

generalized, 352

handling of infected herds, 348

localized, 352

rules for inspection of carcass, 351

symptoms of, 181

tissues most commonly affected, 159

Tuberosity, 51

Tumors, classification of, 145, 211

defined, 211

malignant and non-malignant, 145, 211

Tunica adventitia, 99

intima and media, 99

vaginalis, anatomy, 92

Tympanites accompanying choke, 222 in cattle, 192

ante-mortem and post-mortem, 153

symptoms and treatment, 192

Udder, anatomy, 91

of the cow, 91

diseases affecting, 154

Ulcer, causes and treatment, 211

defined, 144,210

Ulna, anatomy, 47

fracture of, 241

prognosis, symptoms and treatment, 241

Umbilical cord, function, 271

inflammation of, causes, symptoms and treatment, 295

hernia, causes, symptoms and treatment, 295

infection, causes, 294

Unciform bone, anatomy, 48

Uncinaria, 197

animals attacked by, 197

symptoms and treatment, 197

Unguentum hydiagyri, 299

Uniparous, 266

actions, doses and uses, 299

Unit, antitoxin, 343

of measure of liquids, 306

of weight, 306

Unsoundness, conditions of tarsus causing, 362

diseases causing, 363

faulty conformation predisposing to, 363

in horses disqualifying, 363

Trachus, 275

persistence of, 296

symptoms and treatment, 296

Uræmia, symptoms and treatment, 185

Urea, 43,127

sources of, 126
Ureter, anatomy, 89

Urethra, anatomy, 90

of horse and ox compared, 90

of mare, 90

Uric acid, 127

Urinary organs, 89

Urine, 42,125

fetal development of, 276

acidity of, causes, 126

albumin in, 186

test for, 42

average amount of, in horse and cow, 126

bile in, test for, 42

blood in, 186

composition of, 125

examination of, steps in, 185

of herbivora and carnivora compared, 126

reaction of, 126

specific gravity of, 43,126

sugar in, test for, 42

Urticaria, causes, symptoms and treatment, 203

Uterine inertia in mare, 283 symptoms and treatment, 283

Uterus, amputation of, 286

anatomy, 90, 261

blood supply of, 66,262

cervix of, 279

lacerations of, 289 methods of dilating, 279

function of, 266

glands of, functions of, 262

inversion of, 238,286 causes and symptoms, 286 treatment, 238,286

ligaments of, 91 functions of, 262

modifications after labor, 266 during pregnancy, 269

muscular contractions of, 280 methods of overcoming, 280

nerve supply of, 77

of bitch, 262

of cow and bitch compared, 90

pregnant, influence on neighboring organs, 267

situation of, in mare and cow, 275

rigidity of the os, treatment, 284

rupture of, during labor, 289

torsion of, symptoms and treatment, 283

Vaceine, autogenous, 344

prophylactic, 350

therapy, 343

Vagina, anatomy, 91

function of, 91,266

inversion of, antepartum, 285

causes, prognosis and treatment, 285

strictly a generative organ, 266 
Vaginismus, 290

Vaginitis, causes, 290

contagious, symptoms and treatment of, 290

defined, 290

symptoms and treatment of, 290

Vagus nerve, anatomy, 75

function of, 135

influence on heart, 109

Valence, 4

Valves, heart, 62 ileocaccal, 83 of veins, 110

Valvular insufficiency, causes and symptoms, 186 treatment, 187

Vascular glands, 112

Vas deferens, definition of, 92

Vaseline, source of, 37

Vaso-vasorum, 99

Vegetables, green, 127

Veins, anterior cava, 68

described, 99

dorsal, 68

function of, 110

internal thoracic, 68

jugular, 69

portal, 69, 120

pulmonary, 68

spermatic, 92

superior cervical, 68

valves of, 110

vena azygos, 68

vertebral, 68

Venesection, 323

Ventilation, King system of, 346 relation of air space to, 346

Veratrum viride, actions, 306 dose for dog and horse, 306 uses, 306

Vermifuge for cow, dog and horse, 316

Version, obstetrics, 278

Vertebræ, anatomy, 48

cervical, 48

common characteristics of, 49

true, 49

Vertigo, abdominal, 199 causes, prevention, symptoms and treatment, 199

Vesicoraginocele, causes, 292 reduction of, 292

Vesiculæ seminales, 92 absent in dog and cat, 264 function of, 263

Viborg method of opening guttural pouch, 220

triangle, 220,221

Viburnum prunifolium, uses of, 313

Vieussens, ring of, 68

Vinegar, 35

Vitreous humor, 93, 94

Vitriol, blue, 7

Voluntary movements, 134 muscle, 100, 130
Vomition in cattle, diagnosis, 192 differentiated from regurgitation, 192

rare in the horse, reason, 117

Vulva, anatomy, 93

function of, 266

mucous membrane of, 261

structure of, 261 epithelium of, 261

Washing soda, 7

Water, composition of, 14

decomposed, 14

hard, tests for, 15

lime, 30

purifying, 14, 345

soft, 15

tests for chlorides in, 14

for lead in, 14

for nitrates in, 14

Weight, atomic, 5

metric system of, 306

molecular, 5

of animal, supported by hoof, 96 , 139

unit of, 306

Whartonian gelatin, 272

Whey, 42

White scours in calves, 178 causes and treatment, 178

Wind-galls, causes, defined, 216

Wine, 35

Wool compared with fur and hair, 124 conditions favoring growth of, 125 improvement of, 125

effect of ingestion of salt on, 125 of sulphur on, 125

Wounds, classification of, 206

healing of, 207

infection, 206

lacerated, treatment of, 208

of the coronet, treatment, 208

reopening, indications for, 207

treatment of antiseptic and aseptic, 206

Wry-neck, 279

Zinc, 31

acetate, 35

antidote for, 39

chloride, 31 uses of, 321

oxide, 31 uses of, 321

sulphate, 31

an emetic, 316

dose for dog, 316

distinguished from Epsom salts, 31

preparation of, 31

uses of, 321

Zona pellucida, 268

Zone of Zinn, anatomy, 93

Zoötechnics, 360 




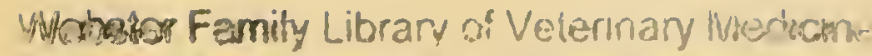

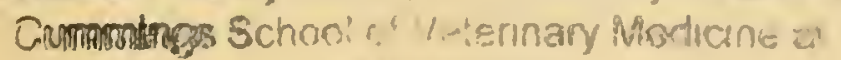
Tutu unmersity 200 Westboro Foad Worth Grafton, MA M165: 



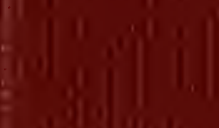

(2) 